\title{
Renewable energy markets in developing countries
}

Martinot, E.; Chaurey, A.; Lew, D.; Moreira, J.R.; Wamukonya, N.

Published in:

Energy technologies for Post Kyoto targets in the medium term. Proceedings

Publication date:

2003

Document Version

Publisher's PDF, also known as Version of record

Link back to DTU Orbit

Citation (APA):

Martinot, E., Chaurey, A., Lew, D., Moreira, J. R., \& Wamukonya, N. (2003). Renewable energy markets in developing countries. In L. Sønderberg Petersen, \& H. Larsen (Eds.), Energy technologies for Post Kyoto targets in the medium term. Proceedings (pp. 42-54). Denmark. Forskningscenter Risoe. Risoe-R No. 1405(EN)

\section{General rights}

Copyright and moral rights for the publications made accessible in the public portal are retained by the authors and/or other copyright owners and it is a condition of accessing publications that users recognise and abide by the legal requirements associated with these rights.

- Users may download and print one copy of any publication from the public portal for the purpose of private study or research.

- You may not further distribute the material or use it for any profit-making activity or commercial gain

- You may freely distribute the URL identifying the publication in the public portal

If you believe that this document breaches copyright please contact us providing details, and we will remove access to the work immediately and investigate your claim 


\section{Energy Technologies for Post Kyoto Targets in the Medium Term}

\section{Proceedings}

Risø International Energy Conference

Risø National Laboratory 19 - 21 May 2003

Edited by Leif Sønderberg Petersen and Hans Larsen

Risø National Laboratory, Roskilde

September 2003 
Abstract The Risø International Energy Conference took place 19 - 21 May 2003 and the aim was to present and discuss new developments and trends in energy technologies which may become main contributors to the energy scene in 15 to 20 years. The conference addressed R\&D related to the individual technologies as well as system integration.

The proceedings are prepared from papers presented at the conference and received with corrections, if any, until the final deadline on 25 June 2003.

ISBN 87-550-3203-6

ISBN 87-550-3205-2 (Internet)

ISSN 0106-2840

Print: Pitney Bowes Management Services Denmark A/S, 2003 


\section{Contents}

Preface 4

Programme committe 5

Opening Session 7

Session 1: Global or Regional Scenarios and Technology Prospects 15

Session 2: Energy and Developing Countries 41

Session 3: Perspectives for Industrialized Countries 83

Session 4A: Wind Energy incl. Economics 103

Session 4B: Wind Energy incl. Economics 125

Session 5: Efficient Fossil Fuel Technology 139

Session 6: Biomass, Small Scale CHP and Waste 147

Session 7: Integrated Systems, Transmission and Storage 173

Session 8: Fuel Cell Technology 203

Session 9: Hydrogen Society 235

Session 10: Biomass in the Transport Sector 267

Session 11: Electricity and Gas Markets and Liberalization 279

Session 12: Solar Energy Technologies, $P V$ and Thermal 327

Session 13: Technology and Policy Options 355

Session 14: Climate Change, Emission Reductions and Permit Trading 385

List of participants 417 


\section{Preface}

The world is facing major challenges in providing energy services to the future needs of the developed world and in particular the growing needs of the developing countries. The challenge is enhanced by the need to provide these energy services with due respect to climate change effects and specifically the emission reduction targets of the Kyoto Protocol and subsequently to the even stricter targets expected to be agreed for the years ahead (post Kyoto targets).

Recent research shows that a sustainable development focus can facilitate a path that both ensures economic development and meets concerns about the environment, but this will require major shifts compared with present policies and finance decisions.

The aim of the Risø International Energy Conference was to present and discuss new developments and trends in energy technologies which may become main contributors to the energy scene in 15 to 20 years. The conference addressed $R \& D$ related to the individual technologies as well as system integration. The conference took place at Risø National Laboratory 19 - 21 May 2003 and attracted wide interest. The 113 participants represented 19 different countries covering international organisations, ministries, universities, research centres and industry. The conference was organised in 17 sessions dealing with: Global or Regional Scenarios and Technology prospects. Energy and Developing Countries. Perspectives for Industrial Countries. Efficient Fossil Technology. Biomass, Small Scale CHP and Waste. Fuel Cell Technology. Hydrogen Society. Wind Energy incl. Economics. Integrated Systems, Transmission and Storage. Wind Energy incl. Economics. Biomass in the Transport Sector. Electricity and Gas Markets and Liberalisation. Technology and Policy Options. Climate Change, Emission Reductions and Permit Trading. Solar Energy Technologies, PV and Thermal.

We would like to take this opportunity to thank all those who contributed to the success of the conference: The authors of the papers, the keynote speakers and the members of the scientific programme committee and the local committee. Not least we would like to thank our secretaries Vivi Nymark and Cecilia Steck for their fine peace of work. Finally, we would like to express our sincere gratitude to the UNEP, Elsam, ENERGI E2, DONG and IEA for sponsoring the conference.

The proceedings are prepared from papers presented at the conference and received with corrections, if any, until the final deadline on 25 June 2003.

\section{Leif Sønderberg Petersen and Hans Larsen}




\section{Programme committe}

\section{Scientific Programme Committee}

Nebojsa Nakicenovic, IIASA, Austria

Hanns-Joachim Neef, IEA, Paris

Jayant A. Sathaye, LBL, University of California, USA

Hans Larsen, Risø National Laboratory, Denmark (Chairman)

Ogunlade R. Davidson, Energy and Development Research Centre, South Africa

Komninos Diamantares, Research Directorate General, CEC

Jos Beurskens, ECN, Holland

Mikko Kara, VTT Energy, Finland

Ulf Hansen, Universität Rostock, Germany

Mark Radka, UNEP, Paris, France

Hans Jørgen Koch, Ministry of Economic and Business Affairs, Denmark

Mogens Arndt, Energi E2, Denmark

Peter Høstgård-Jensen, ELSAM, Denmark

Hans Jørgen Rasmusen, DONG, Denmark

\section{Local Committee}

Leif Sønderberg Petersen

John M. Christensen

Erik Lundtang Petersen

Robert Feidenhans'1

Jens-Peter Lynov

Benny Majborn

Klaus Bechgaard

Jens Kossmann 


\section{Opening Session}

Chairman: Hans Larsen, Risø National Laboratory 


\title{
Energy for Sustainable Development
}

\author{
Dr. Klaus Töpfer \\ Executive Director \\ United Nations Environment Programme
}

Background paper for Keynote Address

\section{Energy Technologies for post Kyoto targets in the medium term}

The theme of this conference is indeed very timely given the expected ratification of the Kyoto Protocol by Russia later this year and the Protocol's likely entry into force in early 2004. The agreed Protocol targets will then be binding for those industrialised countries who have ratified the Kyoto Protocol. Sadly the US, Australia and a few other countries have decided to stay out of the Protocol; we remain optimistic that this situation will change.

Considerations about "post-Kyoto" targets and other ways to achieve the objectives of the Protocol are critical and are taking place in most countries active in the negotiations of the UN Framework Convention on Climate Change (UNFCCC). Scientific evidence presented by the IPCC in its third assessment in 2002 clearly indicates the need not only to implement the Protocol, but agree on further emission reductions in the medium term in order to keep changes in the world's climate at a manageable level.

Energy production and consumption worldwide is the main source of greenhouse gas emissions and it is therefore mandatory to examine how future emissions can be limited in the energy sector. At the same time it is fully accepted that energy plays a key role in development and economic growth so it must be made clear that the issue is not to reduce energy services but to provide these in ways that do not affect the earth's climate.

New energy technologies that are cleaner and more efficient are therefore key to sustainable development. In industrialised countries new and stricter emissions targets can be expected after the Kyoto Protocol's first commitment period, which will require the research, development, and deployment of new energy technologies. In developing countries the focus will generally be on providing access to reliable and affordable energy services for expanding populations and industries, ensuring economic growth that leads to improved living standards. It is very important, however, that this development is based on cleaner and more efficient energy technologies as well. If we fail at this there will be unwelcome environmental impacts, not only on the global environment but also at the local and national levels.

The Plan of Implementation adopted at the World Summit on Sustainable Development in Johannesburg in September 2002 also highlights the need for improved access to reliable and affordable energy services for sustainable development, sufficient to facilitate the achievement of the Millennium Development Goals. The plan specifies the most important areas of intervention as: access to energy, sustainable use of renewable energy, the development of national policies and regulatory frameworks for clean energy, and enhanced international co-operation in the energy area.

With a UN system focus on the so-called WEHAB priority issues (Water-Energy-HealthAgriculture-Biodiversity), the WSSD also for the first time put energy issues high on the intergovernmental agenda. By linking energy with other areas on the development agenda, WSSD helped people who are not energy specialists see clearly the links between energy and other development goals (see figure below). 


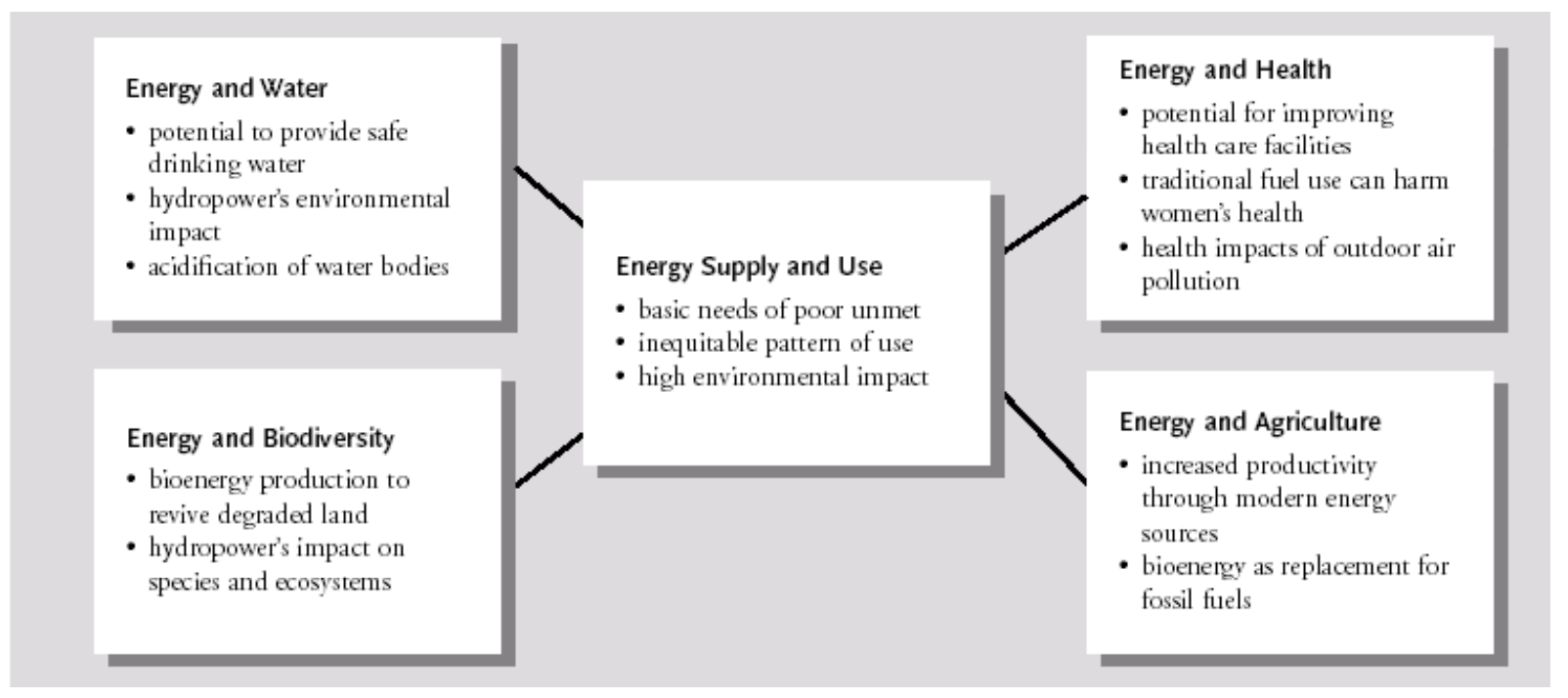

From WEHAB working group paper

Figure. Examples of the Critical Role of Energy in WEHAB Priority Areas

\subsection{Energy for Sustainable Development is therefore the key theme of this address}

The global energy scene is presently characterised by significant changes in the structures of energy markets: institutional and market reforms are taking place in almost all regions. While the general driving force is a desire to increase overall cost-effectiveness and improve the delivery of energy services, there are clear regional differences. The industrialised countries are concentrating on environmental concerns, while developing countries are more concerned with energy for development and access to energy for the poor.

Access to energy services is an important instrument for economic growth and essential for providing the basic living conditions for all human beings. No country has substantially reduced poverty without increasing its use of energy, replacing human and animal labor with more convenient and efficient sources of energy and technology. The stable and efficient provision of energy services is necessary a input to improve productivity at all levels in both rural and urban production. Energy is needed for most income generating activities and to gain access to markets.

These energy needs can be met in different ways, however. In the climate context it is important that developing countries do not blindly follow the high emission development paths of the industrialized countries but rather focus broadly on making their energy development more sustainable. It is a false argument to state that countries need to pollute in order to become wealthy, and that only then can they afford to attend to the consequences of a polluted environment.

The scale of this challenge is huge. In Africa, Asia, and Latin America 1.6 billion people lack access to electricity and cannot light their homes adequately. Almost as many people use fuel wood for cooking, forgoing productive activities during the time they must gather wood and then suffering the health effects of exposure to noxious fumes. Only 15 percent of large cities in developing countries have acceptable air quality, largely due to the way energy is used in homes and industries and for transport. 


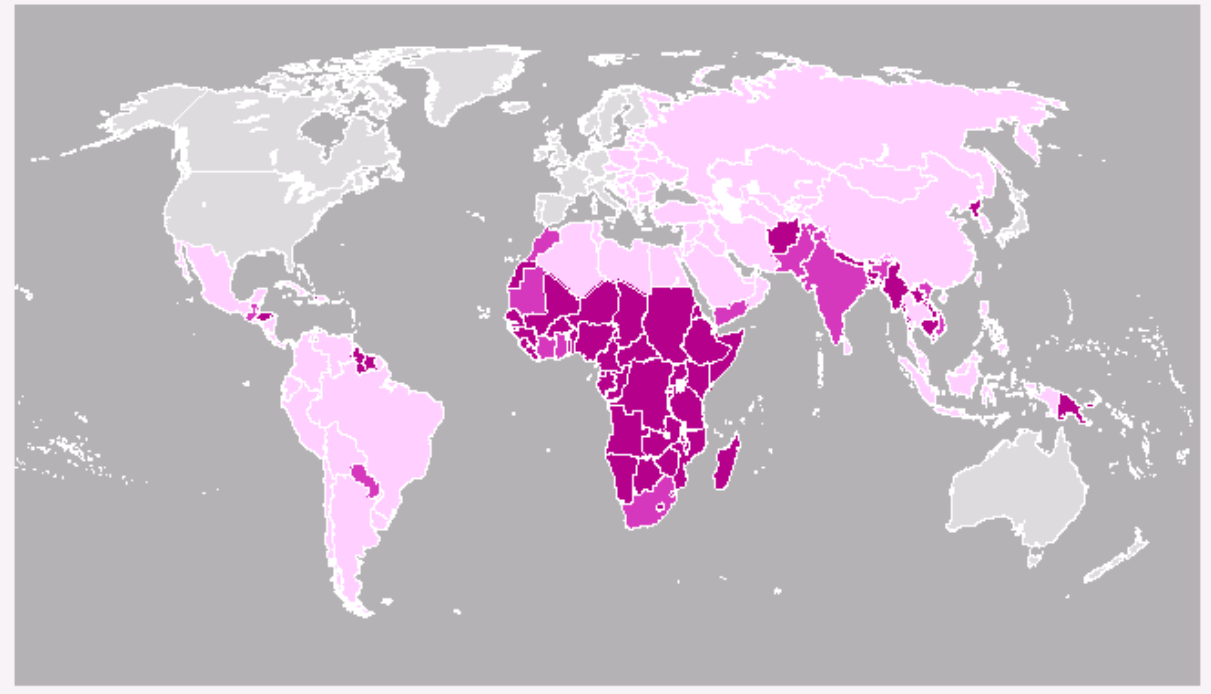

Sourœ: World Bank Group starr estumates

Significant investments are required to ensure access to new energy resources and to deliver energy services, especially to consumers in developing countries. This is a challenge to the international finance community and to industrialised countries in particular

\subsection{Potential of renewable energy technologies}

All these trends relate to technological developments in the short or long term. With conventional fossil-fuel-based energy systems still dominating energy investment, the introduction of new and emerging energy technologies need to be assessed over a longer time scale. Such time scales are consistent with IPCC emission scenarios, which common sense tells us will not occur overnight.

Renewable energy technologies hold great potential to satisfy basic needs and to support poverty alleviation and sustainable development. There is a range of commercially available, field-proven renewable energy technologies, including solar, wind, geothermal, biomass and hydropower, but they are not yet widely enough used in tackling the shortfall in access to energy services.

In its Global Energy Outlook, the International Energy Agency (IEA) states that production of primary energy from renewable sources is expected to grow rapidly, but that the impact of renewables on the global energy mix will remain relatively small in the next two decades. From 2020 onwards this situation is expected to change significantly, driven especially by environmental concerns, but this shift will require governments and industry to act together and to invest heavily in technology and infrastructure.

The modularity and decentralized nature of renewable energy technologies make them particularly well suited for rural energy development and an environmentally sound alternative to grid extension. To speed the introduction and adoption of renewable energy systems, the key issues are expanding access to the technologies and reducing their costs. This can be done through supportive policy measures, market incentives and promotion activities. As the G8 - Renewable Energy Task Force has recognized, expanding markets in industrial countries will be essential for bringing costs down. Costs cannot be reduced through activities in developing countries alone. 
Moreover, developing and industrial countries together will need to work to expand the manufacturing, assembly and service capabilities in developing countries to begin to make inroads in meeting the challenge of increasing access to energy services.

Worth special note are modernized biomass technologies that provide fuels and electricity to meet rural energy needs; these are particularly promising and an area ripe for transfer to developing countries. This will require unique approaches to address technology, financing and capacity development efforts that support biomass generation where the natural resource base is sufficient.

Enhanced regional and international co-operation will be important in identifying the appropriate entry points for supporting the expansion of renewable energy. UNEP's contribution in this regard is described below.

\subsection{Advanced Fossil Fuel Technologies}

For at least the next several decades fossil fuels will continue to be the primary energy supply option worldwide when considered as a proportion of the global supply mix. The challenge is how to use them more efficiently and how to reduce their negative environmental effects.

Fossil fuel resources are still abundant on a global scale. Even taking into account short-term price fluctuations, the trend towards relative price stability is expected to continue for the next 20-30 years.

There are significant regional differences, however, and the uneven geopolitical distribution of resources and demand means that any projections are subject to a high degree of political uncertainty. Security of energy supply has become an increasing concern, first in the USA and now in the European Union.

The transition to cleaner and more advanced fossil fuel technologies is recognized as essential to support sustainable development. This is particularly important in developing countries, where the rising demand for energy services and growing populations will drive the largest demand for new installed capacity for electricity and increased supply of clean fuels.

Efforts should be focused on efficiency improvements in power plants, wider access to existing technologies, and research and development for advanced energy systems and fuels.

In order for developing countries to move to cleaner, more advanced fossil fuel energy systems, collaboration and cooperation at the international and regional levels are necessary. Given that the most rapid advances in these technologies have occurred in industrial countries, technology and information exchange is important for speeding up the transition to improved energy systems in developing countries. This will need to be done so that developing countries can maintain, service and potentially manufacture and assemble the equipment, enhancing their own energy self-sufficiency and security.

Regulatory and financing mechanisms will serve as the foundation to encourage the adoption of clean fossil technologies. Government will need to establish guidelines and norms for regulations that will make this happen in a clean and sustainable manner.

A potential major incentive for stimulating technology transfer will be the Kyoto Protocol mechanisms, including the Clean Development Mechanism. Through this, developing countries can use 'technology leapfrogging' to actively advance their sustainable development objectives while reducing greenhouse gas emissions.

\subsection{What UNEP is doing to promote energy for sustainable de- velopment}

UNEP's Energy Programme addresses the environmental consequences of energy production and use, such as global climate change and local air pollution. We assist decision makers in government and the private sector to make better, more informed energy choices, which fully integrate environmental and social costs.

Since UNEP is not an implementing organisation, its role as facilitator is core, but at the same time the driving principle is that its recommendations have to be practical and based on pilot programmes that have developed and tested the approaches in specific case applications at the national level. 
UNEP has been working closely with the Risø National Laboratory for almost 13 years through the UNEP Collaborating Centre on Energy and Environment, which is located at here at the Laboratory. This collaboration, which also includes the Danish Ministry of Foreign Affairs, plays a key role in implementing the energy and climate programmes in UNEP and has since its inception grown from a staff of 4 to now 25 international economists and scientists who are recognised as an international Centre of Excellence on energy and climate issues.

Most of UNEP's energy activities link to mitigation - the reduction of greenhouse gas emissions but these are generally accompanied by broader objectives related to energy and sustainable development. This includes climate change mitigation, but not as the sole objective since many of our partners in developing countries have more immediate development objectives.

The following sections describe the main programmes in a summary way; more details and activity timelines are available on the relevant websites. Activities generally focus on promoting and overcoming barriers to more widespread application of renewable energy and energy efficiency.

\section{Data and information}

The Solar and Wind Energy Resource Assessment (SWERA) project is providing solar and wind resource data and geographic information assessment tools to public and private sector executives who are involved in energy market development. It's high quality information on solar and wind energy resources helps bring renewable energy projects to developing countries in two ways. First, by showing the overall potential for renewable energy in a country, good resource data can help renewable energy become part of the national energy development plan in areas where it makes good technical and economic sense. Second, reliable site-specific information is required for analyzing the merits of individual projects. UNEP's SWERA effort is compiling such data in 13 developing countries. Eventually this will help bring about investments in solar and wind energy projects.

With a US\$6.7 million investment from the Global Environment Facility (GEF), SWERA is developing new information tools for energy planners and project developers, including regional and national maps of solar and wind energy resources. SWERA is also developing a geographical information system (GIS) interface that will allow easy access to data and thus help the screening and preinvestment evaluation of wind and solar energy-based renewable energy projects. Information about planned activities in 2003 can be found at http://swera.unep.net/. The Risø National Laboratory is one of the partners in this programme through its Wind Energy Department.

\section{Energy efficiency}

A new GEF funded programme aims at promoting industrial energy efficiency through a cleaner production / environmental management system framework. Our objective in this effort is to reduce the emission of greenhouse gases by identifying and carrying out Energy Efficiency (EE) improvements as an integral part of Cleaner Production (CP) assessments in industrial enterprises. Six countries are involved in the project (China, Vietnam, India, Hungary, the Czech Republic, and Slovakia), but they are testing an approach that we believe can be applied by all Cleaner Production Centres.

The project will help participating National Cleaner Production Centres integrate energy efficiency concepts into CP approaches, and to include energy efficiency activities as a comprehensive part of their core programmes. Given their mandate and experience, Cleaner Production Centres are very well positioned to promote energy efficiency in industrial settings.

A parallel programme - EMPRESS - Energy Management and Performance Related Energy Savings Scheme - supports energy efficiency efforts in Eastern and Central Europe. The project, which is now getting underway, will help establish specialised energy service companies (ESCOs) that provide Monitoring and Targeting (M\&T) energy services to industrial and commercial clients. EMPRESS development has been supported by the Global Environment Facility (GEF). An ESCO (Energy Service Company) is a professional company that provides energy end users with energy management services; Monitoring and Targeting $(M \& T)$ is an energy saving technique that helps end users achieve and maintain energy efficiency improvements through the careful analysis of metered energy consumption data. The EMPRESS project will combine these two concepts. 


\section{Renewable energy technologies and finance}

As discussed above renewable energy technologies are receiving more policy attendance, their commercialisation is still too slow, especially from an environmental perspective. In response, UNEP has increased its efforts to 'green the finance sector', particularly focusing on promoting investment opportunities in the renewable energy and energy efficiency sectors. For these sectors, the conservative attitude of financial institutions combined with their difficulty in assessing the risks involved often lead to decisions against extending loans or providing other forms of financial support for otherwise sound projects. In the end, projects that might really be good investments and yield a global environmental benefit, such as reducing greenhouse gas emissions, fail to go forward.

Not being a financial institution UNEP is able to deal with the finance sector in non-competitive ways. It has tried to use this neutrality in testing new approaches to supporting the sustainable energy finance sector, particularly in the application of soft financing 'catalysts' that develop the market without distorting it. UNEP's Energy Group currently oversees various activities in the sustainable energy finance area, including enterprise development (seed finance) programmes, energy efficiency finance activities with the World Bank, concessional loan programmes for solar PV, and advisory support to financiers considering clean energy investments.

With the International Energy Agency, the Italian Government, and other partners UNEP has recently started a multi-year, multi-million Euro effort - the Mediterranean Renewable Energy Programme - to promote the financing of renewable energy projects in the Mediterranean basin, work that builds off recommendations made by the G8 Renewable Energy Task Force. UNEP is also beginning work with the insurance sector, targeting the creation of new insurance products that can offset risks associated with renewable energy projects.

UNEP maintains close links with the finance sector, and each of these efforts are implemented with the involvement of one or several finance partners, both public and private. Involving the UNEP Finance Initiative in UNEP energy projects makes for easy links to finance partners already committed to environmental lending. Helping finance partners take forward clean energy investments has also induced some of them to broaden their environmental focus.

The REED programme - Rural Energy Enterprise Development - seeks to develop new sustainable energy enterprises that use clean, efficient, and renewable energy technologies to meet the energy needs of under-served populations, thereby reducing the environmental and health consequences of existing energy use patterns.

The REED approach offers rural energy entrepreneurs a combination of enterprise development services and start-up financing. This integrated financial and technical support allows entrepreneurs to plan and structure their companies in a manner that prepares them for growth and makes eventual investments by mainstream financial partners less risky.

In Africa the REED initiative has now begun operations in Senegal, Mali, Ghana, Botswana, Zambia and Tanzania. In addition parallel programmes are under implementation in North Eastern Brazil and in Yunnan Province in China. The main funder of these activities is the UN Foundation.

Very recently a four-year $\$ 7.6$ million effort has been launched to help accelerate the market for financing solar home systems in southern India. The project is a partnership between UNEP and two of India's major banking groups - Canara Bank and Syndicate Bank.

The solar photovoltaic manufacturing sector in India grew by a factor of 10 in the 1990s, mostly for export, however the market for solar home systems was slow to develop, in part due to a lack of consumer financing options. The aim of this effort is to help Canara bank and Syndicate bank develop lending portfolios specifically targeted at financing solar home systems (SHS). With the support of the UN Foundation and Shell Foundation, the project provides an interest rate subsidy to lower the cost to customers of SHS financing.

The list of activities is significantly longer but the presentation here is mainly to give an impression of the key programmes and the catalytic and innovative approach adopted.

\section{Policy advice and capacity building}

A major new initiative facilitated by UNEP was the establishment of the Global Network on Energy for Sustainable development (GNESD), which was launched as a Type II partnership at the WSSD. 
The Network has now been operationalised with initially a core group of developing country centres of excellence as the members. This will be further expanded with Centres from industrialised countries in 2003 and a broad partnership with national public and private partners from all regions.

The aim of GNESD is to provide policy guidance and capacity building services to developing country governments based on knowledge and experience mainly coming from existing centres of excellence located in all developing regions and interlinked and strengthened through the GNESD.

The Secretariat for the Network is also located here at Risø National Laboratory next to the Collaborating Centre, and arrangement that takes advantages of synergies between the two units and Risø's long experience in implementing UNEP activities.

The Network's first priority theme is "energy access" and a working group with the involved Centres has been established and analytical work initiated. The focus here is on policy aspects, including national and regional differences, and activities getting underway include information exchange, analytical studies, policy support and capacity building. More information can be found on www.gnesd.org.

\section{Kyoto Mechanisms}

As mentioned above the so-called Kyoto Mechanisms, and in particular the Clean Development Mechanism (CDM), can become an important financing tool for energy for sustainable development; UNEP is actively involved in supporting developing countries make full use of this new mechanism.

The main activity in this area is the programme on Capacity Development for the CDM funded by the Netherlands and implemented by UNEP/Risø for UNEP. This programme started in 2002 and will continue through 2005.

The project helps establish GHG emission reduction projects that are consistent with national sustainable development goals, particularly projects in the energy sector. It is developing national capabilities so that persons in the countries are capable of analysing the technical and financial merits of possible CDM projects and negotiating finance agreements with Annex 1 countries or investors.

The project aims at both generating in participating developing countries a broad understanding of the opportunities offered by the Clean Development Mechanism, and developing the necessary institutional and human capabilities that allows them to formulate and implement projects under the CDM.

Twelve countries, in four developing regions, are a part of the project:

North Africa and Middle East: Sub-Saharan Africa:

Asia:

Latin America:
Egypt, Jordan and Morocco

Côte d'Ivoire, Mozambique and Uganda

Cambodia, The Philippines and Vietnam

Bolivia, Ecuador and Guatemala

This is by no means a complete presentation of UNEP's activities but a snapshot of some key programmes that are directly relevant to the theme of the conference. In addition UNEP has a comprehensive climate programme in addition to our many activities in a wide range of other environmental priority areas.

As a closing remark for my contribution to the conference I would like to quote the G8 energy ministers from their meeting in 2002 saying :

"We believe that continued research, development, demonstration and deployment of a broad array of energy technology options will play an essential role in diversifying the energy mix and reducing the environmental impacts of energy production and use." 


\section{Session 1: Global or Regional Scenarios and Technology Prospects}

Chairman: Jayant A. Sathaye, LBL, University of California, USA 


\title{
Energy Technology And More
}

\author{
Dr. Hanns-Joachim Neef \\ Head, Energy Technology Collaboration Division \\ International Energy Agency, IEA \\ 9 , rue de la Fédération \\ 75739 Paris Cedex 15 \\ neef@,iea.org, info@iea.org
}

\section{Looking to 2030}

To what extent can increased energy technology development and deployment enhance energy security? How can it contribute to meeting economic goals and generate significant cuts in $\mathrm{CO}_{2}$ emissions? Faster, more meaningful progress in technology is expected to play an important, if not crucial, role in achieving a sustainable energy economy in the long term, probably even in the medium term. In the short term, we have to live with the disappointing reality: the energy economy is not on a sustainable pathway. The most obvious underlying fact is that greenhouse gas emissions will inevitably grow before they can be reduced. And they have to be reduced dramatically.

The Reference Case Scenario in the most recent IEA World Energy Outlook (WEO) paints a bleak picture for the future if governments maintain their current policies. Oil will remain the largest individual fuel source (increasing by $60 \%$ from $75 \mathrm{mb} / \mathrm{d}$ in 2000 to $120 \mathrm{mb} / \mathrm{d}$ in 2030). This raises energy security issues. Gas will overtake coal as the second largest fuel source in 2010. For many countries, this would shift dependence on imported oil to dependence on gas. Oil, gas and coal are expected to cover close to $90 \%$ of energy demand in 2030 . As the dominance of fossil fuels grows, so will $\mathrm{CO}_{2}$ emissions from energy use in all regions of the world, averaging a $70 \%$ increase by 2030 . But let me emphasise that the WEO findings are merely projections, based on current policies and behaviour patterns.

The life-time of energy equipment and infrastructure is rather long. Capital stock turnover in the energy economy is slow. Therefore, in the short term -- which I define here as the time-span to 2030 focused in the (WEO) -- we have to look to a broader energy market, one not confined to fossil fuels. This is even more the case for the long term, beyond 2030, to the end of the century.

Regional shares in world primary energy demand and $\mathrm{CO}_{2}$ emissions reflect the growing importance of non-OECD countries. Energy is indispensable for economic development, for social welfare and political stability. Making energy accessible to all is a challenge in its own right. It is an underlying necessity for more balanced world economic development, and even for world wide peace.

If greenhouse gas emissions are to be reduced significantly, low-carbon technologies need to be developed and used in both OECD and non-OECD countries. But each region, each country has its own aspirations, its own approaches to energy security, economic growth and environmental protection; the pursuit of a sustainable energy future must respect those aspirations and approaches.

But supplying low-carbon energy is not the only option. Energy efficiency offers huge potential. Technical progress could lead to substantial improvement in energy security by reducing demand for carbon-bearing fuel, much of which is imported oil, and increasingly gas. Large amounts of greenhouse gas emissions could be eliminated through efficiency gains. Reducing the energy bills of countries, industry and the private consumer liberates funding to enhance economic development.

To protect ourselves from the WEO Reference Case Scenario, we need to re-evaluate where our current path leads and ask whether this is where we really want to go. Current policies and behaviour patterns are not sustainable. Will technology play the expected important role? Do we need more than just technological development? 
The WEO Alternative Case Scenario for the OECD gives grounds for some optimism ${ }^{1}$. This scenario models developments if OECD countries adopted energy and environment policies now under consideration, notably those designed to help meet numerical targets for increased use of renewables. In OECD-Europe, for example, the share of non-hydro renewables in the power generation mix would roughly double over the thirty years in comparison with the Reference Scenario. In the Alternative Case Scenario, OECD $\mathrm{CO}_{2}$ emissions would be reduced to1990 levels by 2030, but they would still not fall to zero.

\subsection{Looking beyond 2030}

What about the period beyond 2030, to 2050 , or even 2100 ? Will action today influence the long term future? It will, and here are two examples:

- A power plant starting operation today in China might still be producing electricity in 2050, independent of whether that power plant is a nuclear plant, or coal or gas fired, or hydro.

- The level and quality of basic science and applied energy technology R\&D carried out today will certainly still have a large impact during the second half of this century. So what we do today will influence the future, even the seemingly distant future.

We should not lose time by failing to act now. In the future, the energy sector will probably have to meet heavier obligations than those laid down in the Kyoto Protocol today. To ensure coherence of global environmental goals with energy security, with market liberalisation and with economic development (especially in non-OECD countries), energy technology and "more" will play a key role.

\subsection{Excerpts from an ongoing review of energy technology, un- der the guidance of the IEA Committee on Energy Research and Technology (CERT)}

Many promising advanced technologies are already available. We have seen appreciable progress in technologies to use energy more efficiently, to exploit alternatives to oil, and to use low-carbon technologies and practices. We are seeing advances in opening up the path to hydrogen production and use, and to separating $\mathrm{CO}_{2}$ from fossil fuels and storing it in geological formations, perhaps even in the deep ocean. Substantial further efforts are needed to make such technologies competitive, even with the pull of market incentives that governments are willing to provide. Success will depend on rapid development and adoption of these technologies. The IEA works to encourage the exploration, development and implementation of cleaner, more efficient technology options. Creating a low-emissions energy system cannot wait, it must start now. For this, a portfolio of new energy technologies is needed, and this applies in most countries. An energy technology review is currently in preparation, under the guidance of the IEA Committee on Energy Research and Technology (CERT). The results will be published later in 2003. Some trends are presented below.

The energy systems of tomorrow will rely on a mix of different advanced, clean, efficient technologies for energy supply and use. No single supply technology can by itself address the "3Es" challenge, that of simultaneously meeting energy-security, economic and environmental goals. Different regions and countries will require different combinations of technology to best serve their needs and best exploit their indigenous resources.

\footnotetext{
${ }^{1}$ Due to limited resources and time, the Alternative Case Scenario in the WEO was limited to the OECD regions.
} 
The aims of the CERT project are to:

- identify the technologies and technology developments that could lead to significant reductions in greenhouse gas emissions from energy, and

- identify gaps in basic and applied R\&D programmes that would need to be filled, and other nearterm actions that could be taken, to help ensure the future availability of these technologies at reasonable cost.

The following summary looks at technology developments for reductions in greenhouse gas emissions, but also all the objectives incorporated in the "3Es".

\section{Renewable Energy}

Renewables contribute unique characteristics to the mix that supports economic productivity, energy security and environmental improvements. They are the fastest growing energy type on a percentage basis.

R\&D goals:

- reduce costs

- increase quality of energy delivered

- increase reliability of supply

- match supply with end-user demand

- reduce costs and losses in energy transport and distribution

- advanced energy storage technologies

- superconducting electricity transmission

- electricity system control technologies and modelling tools tointegrate distributed and intermittent resources into the electricity grid

\section{Switching Among Fossil Fuels}

Switching from more carbon-intensive to less carbon-intensive fossil fuels (particularly natural gas) will play an important role in reducing emissions over the next few decades. But increased reliance on natural gas could exacerbate energy security concerns in several countries.

R\&D goals:

- development of technologies for gas exploration, exploitation and gas-to liquid processes.

\section{More Efficient Fossil-Fuel Combustion Technologies}

More efficient fossil-fuel combustion technologies are valuable in reducing emissions, especially in developing countries. Emissions from a new coal-fired plant can be reduced by between $10 \%$ and $15 \%$ if a commercially available supercritical plant (operating at high temperature and pressure) is chosen rather than a subcritical technology plant.

R\&D goals:

- Materials and component development

- demonstration of next-generation systems

\section{$\mathrm{CO}_{2}$ Capture and Storage}

Although cleaner, less-carbon-intensive fossil fuels and more efficient fossil technologies will slow growth in $\mathrm{CO}_{2}$ emissions, much larger cuts in $\mathrm{CO}_{2}$ emissions will be needed. A key to sustainable continued use of fossil fuels will be $\mathrm{CO}_{2}$ capture and storage. 
R\&D goals:

- capture of $\mathrm{CO}_{2}$

- improved solvents

- new materials and system components

- advanced separation membranes

- increasing $\mathrm{CO}_{2}$ concentrations

- storage of $\mathrm{CO}_{2}$

- storage capacities and techniques

- chemical, physical and ecological impacts of geologic storage

- develop measurement and monitoring technologies

- assess health, safety \& environmental risk

- system integration/optimisation

- turbine development

- advanced power systems and cycles

\section{Nuclear Fission}

The size of nuclear fission's contribution to future energy systems will be determined by relative technology costs, public acceptance and progress in dealing with radioactive wastes.

R\&D goals:

- significantly reducing the lifetime and toxicity of residual radioactive waste material

- fuel recycling to recover its residual energy content and to treat long-lived waste constituents

\section{Fusion Energy}

Nuclear fusion energy could contribute significantly to large-scale electricity production during the second half of the $21^{\text {st }}$ century. Major technical progress has been made in both the physics and the technology of fusion over the past decade.

R\&D goals:

- construction of the International Thermonuclear Experimental Reactor (ITER), to demonstrate the scientific and technical feasibility of fusion power

- Materials research and testing

\section{Buildings}

The built environment of tomorrow can revolutionise efficiency in energy use for services such as heating, cooling and lighting, transforming itself gradually over time through modernisation and new construction.

R\&D goals:

- active and passive solar design

- optimised insulation

- intelligent envelopes and components

- efficient district heating and cooling systems

- use of local renewable resources

- fuel cells and energy storage systems

- surplus electricity to the grid

- advances in materials, "smart" building components, sensors and controls, and information systems 


\section{Transport and new transport fuels}

R\&D goals:

- reduced vehicle fuel use

- hybrid vehicles

- fuel cell vehicles

- low-emissions biofuels (cellulosic ethanol production)

- intelligent transport infrastructure

- greater vehicle automation technologies

- more efficient transport systems, especially for public transport

\section{Industry}

R\&D goals:

- plant-wide optimisation of energy sources and sinks

- on-site generation of electricity with $\mathrm{CO}_{2}$ capture

- greater process efficiency, using nanotechnologies, materials, micro-manufacturing and bioprocessing

- separation technologies

- high-speed and high-capacity computing, robotics-using biological/computer interfaces, artificial intelligence, wireless communications, power electronics and photonics

\section{Hydrogen}

Hydrogen, an energy carrier like electricity, could play an important and widespread role in future energy systems for energy storage and transport, as well as stationary applications as a fuel (power plants, buildings, industry) and transport (vehicles, public transport, air transport).

R\&D goals:

- production of hydrogen using low/zero-carbon emitting processes from fossil fuels, with $\mathrm{CO}_{2}$ capture and storage, and from renewable resources and nuclear power

- hydrogen production from water and sunlight by direct photobiological, photochemical and photoelectrochemical processes

- development of enabling technologies (fuel cells, hydrogen transport and storage media) needed for a transition to widespread use of hydrogen

- infrastructure development

\subsection{Energy technology policy - from basic research to the market}

Let us have a look to the development chain for clean and efficient energy technologies, from basic research to markets.

Developing advanced energy systems requires not only applied research and technology refinement, but also the innovation that stems from advances in basic science. Knowledge flowing from basic research is what will feed the development of materials, bioprocesses, nanotechnologies and other approaches that could reduce clean technology costs. It could also lead to new, unforeseen technologies and novel approaches to providing energy services. Effective linkages between basic science and applied technology will be important to ensure that these opportunities are opened up. The portfolio for development of energy technologies will be enlarged; choices and new options will be created. Deployment decisions for sustainable energy systems can then be made on a broader basis, reducing the risk of picking the (wrong) winners already in the R\&D stage. 
Current levels of energy R\&D investment are unlikely to be adequate to ensure sustainable development, given the magnitude of the climate challenge. Energy R\&D investments by governments of IEA Member countries peaked in 1980 and declined substantially thereafter. Industrial energy R\&D investments have become increasingly short-term. Greater, more sustained commitment to energy technology R\&D and to demonstration is needed for selected technologies. Major additional efforts will be needed to make new, more reliable low-carbon energy systems more widely available at lower cost. It would be too easy, however, simply to ask for more public money for energy R\&D. Structural changes in all fields of science and technology have been analysed by the OECD, taking into consideration trends in both public and private sectors. Increasing investments in knowledge remain a key driver of economic performance in the OECD area. Science and technology are becoming more internationalised. International co-operation, using and expanding the collaborative frameworks of the IEA, as well as other bilateral and multilateral structures, can help to make R\&D and demonstration more effective.

Progress in science and energy technology development is not enough. As the "IEA Shared Goals" already emphasise, energy technology policies should complement broader energy policies. Additional policy approaches will enable technology to bring greater energy security, world-wide economic growth and deep reductions of energy-sector emissions. Whatever the policy approach, however, major changes will come about only by transforming the global energy system into one that relies extensively on advanced, efficient, low-carbon technologies for all energy sectors. This will not happen overnight. Advanced energy technologies will have to be adopted progressively. But new technologies will only be adopted if they are available, have the necessary supporting infrastructure, and compete well with conventional solutions.

World-wide uptake of advanced energy technologies is imperative, for the long term as well as for today. Further delay will simply undermine our chances of ever securing a sustainable energy future.

Supporting market uptake of a technology before it is competitive with alternatives is a key component in the drive to make cleaner, cheaper technologies available. Once launched on the market, new technologies require time to gain the market experience and production levels that bring cost reductions through "technology learning". A recent IEA study elaborates further on the question of deploying energy technologies. Twenty-two case studies were analysed from different perspectives, and they confirmed the need for a comprehensive set of actions.

But there is another factor to be taken into account. Past experience shows that the public found it difficult to accept several different technologies. Research should therefore take into account public acceptance of new technologies and define a socially acceptable path to a sustainable energy future. But consumer behaviour also demonstrates preferences for certain technologies. Consumers are willing to pay more for commodities which are environmentally friendly or which carry the image of being progressive. Green electricity and low-consumption vehicles are good examples of preferred customer choice.

To bring new energy technologies to the market, policies are necessary that directly monetise the value of key policy goals. Such price signals as regulatory action, voluntary agreements, carbon or pollution taxes, levies and market-based emissions trading are needed. Price signals reinforce technology-oriented measures to encourage investment in clean and efficient energy technologies. The burden of internalising the external costs of new energy systems can be substantially reduced by adequate R\&D investments, effective R\&D programmes, and support for innovation and international cooperation offering benefits for all involved. The art of energy technology policy is to minimise the amount of public money, to phase out subsidies once technologies are competitive, to aim at an open market with competitive elements right from the beginning of any action, and to establish an efficient energy R\&D network with a strong link to basic science.

\subsection{Priorities for action- what can be done?}

How can we secure reinforced commitment to energy technology innovation and adoption? The need for governments to speed the process of getting innovative technologies into use has become urgent.

Action is called for on the part of both individual countries and countries acting in concert. 
On a national basis, investments for basic science and applied energy technology R\&D need to be increased. But this is not sufficient: the linkages between basic science and energy technology development need to be further developed and strengthened by "mining" basic research for outcomes useful for energy, and by acquainting basic researchers with the challenges and bottlenecks facing applied technology developers. Government investment in long-term, applied energy technology R\&D should be increased, taking in the R\&D which is no longer undertaken on a sufficient scale by industry. Governments should not only invest in R\&D but should also encourage $R \& D$ activities through a range of actions encouraging investment by the private sector.

International collaboration is crucial to enhance information flows and reduce the cost of R\&D. Efforts to foster collaboration in energy technology $R \& D$ can facilitate $R \& D$ cost-sharing in general. Jointly using large R\&D facilities and carrying out demonstration projects is of special benefit to all involved. Technology uptake and "technology learning" are additional areas where national efforts can be boosted by international co-operation. What this means is focusing on increased and concerted efforts to foster use of advanced energy supply technologies that are available but not yet cost-effective. The potential outcome, through increased efforts to reduce barriers to use of advanced energy technologies in all sectors, is reduced emissions through the "technology learning" that brings down costs.

Near-Term Actions Specifically, useful near-term action would:

- investigate the utility of expanded international research collaboration in "use-directed" basic science for energy applications;

- increase collaboration on electricity storage technologies for stationary and mobile applications;

- increase collaboration on development of technologies needed to facilitate introduction of a hydrogen-based energy system, also on development and testing of infrastructure for hydrogen-based transport systems;

- increase cross-border collaboration on large-scale technology demonstrations and pilot plants that are beyond the scope of any one country's efforts. Two examples: increased collaboration on large-scale demonstrations of $\mathrm{CO}_{2}$ capture and storage; proceeding with construction of ITER, the first experimental fusion reactor;

- expand co-operative actions to facilitate market uptake of renewable energy technologies;

- given the expected huge expansion in power generation capacity needs by 2030 , particularly in developing countries, increase efforts to foster use of advanced pulverised coal systems wherever pulverised coal capacity is built world-wide.

\subsection{What is the IEA doing?}

Nothing will happen if we don't take action. New life needs to be breathed into the "Shared Goals" of the IEA, at both national and international level. Energy technology is high on the list of priorities embodied in these Shared Goals, which call for continued research, development and market deployment of new and improved energy technologies. Let me touch briefly on some examples of the IEA's energy technology work. This includes some well established energy technology co-operation frameworks, but also addresses some new ideas and concepts emerging from the ongoing interaction of energy technology experts from IEA countries.

\section{The IEA Framework for International Energy Technology Co-operation}

Since its foundation more than 25 years ago, the IEA has facilitated concrete international energy technology collaboration. More than 40 energy technology co-operation projects, called "Implementing Agreements", are actively contributing to the development and deployment of advanced energy technologies world-wide. A number of changes over the past years have made the Implementing Agreements more attractive. On the basis of intensive consultations with all involved in technology 
co-operation, the IEA Governing Board approved, in early April of this year, a Framework which incorporates:

- provision for full integration of non-IEA countries;

- participation of the private sector in the projects;

- clear rules for participation;

- streamlined administrative procedures.

Implementing Agreements cover most energy technologies: fossil fuels, renewables, fusion and enduse, also incorporating information centres and energy technology systems analysis. The focus is still on $\mathrm{R} \& \mathrm{D}$, with more and more activities supporting broader use of clean, energy-efficient technologies world wide.

The Implementing Agreements have created a network of experts from IEA Member countries, which, in partnership with the IEA Committee on Energy Research and Technology (CERT), its Working parties and the IEA Secretariat, is reviewing energy technology pathways that could lead to a sustainable energy future. Achieving major cuts in greenhouse gas emissions is frequently cited as the principal force shaping that future. But maintaining energy security and economic development are key pre-requisites if environmental protection is to be assured, both locally and globally.

\section{Technology Assessment}

Assessing technologies makes it possible to jointly track progress in innovation in key energy systems, guiding towards the right decisions on necessary investments.

How to compare different energy technologies? Should one use a common baseline, a time- dependent baseline? Different countries will make different choices according to their economic and social, sometimes cultural, background. How would we include policy incentives or constraints? We have also seen that different energy systems have different markets, sometimes developing from small niche markets into the mainstream. What comparison makes sense? Shall we produce, for the different systems, another table with investment costs in Euros or Dollars per kW? Or tables with costs in unit of currency per kWh produced? Of course we can do so. But we would add to the numerous tables with such comparisons, showing that $\mathrm{PV}$ in northern Europe is more costly than nuclear power or $\mathrm{CO}_{2}$ capture and storage. We would learn not much through this exercise.

Country-specific (or region-specific) time-dependent comparisons with deeply disaggregated technology representation would make more sense. At the IEA Secretariat we are close to finalising such a tool. We call it the "Energy Technology Perspectives (ETP)" project and it will include the know-how the IEA energy technology network has accumulated (including more than 40 active energy technology Implementing Agreements, mentioned above). The ETP project can help to assess the importance of $R \& D$ and specific technologies in order to achieve specific energy policy targets and will evaluate the contribution of various energy policy strategies.

\section{Science and Energy Technology}

The IEA Secretariat does not itself undertake scientific research. Rather, our role is to assemble expertise worldwide to inform the energy technology policy debate in our member countries. In early April 2003, our Committee on Energy Research and Technologies (CERT) sponsored a Conference on Linking Basic Science and the Development of New Energy Technologies. The conference focussed on nanotechnology, material sciences and biotechnology, and it also examined the institutional challenges associated with bridging the often separate worlds of basic researchers and energy technology experts. There was a general agreement that to really meet the 3Es, more technological breakthroughs are needed. The best and brightest have to be attracted to the laboratories of today, where the technology of tomorrow is under preparation. Governments and international organisations should foster the dialogue between scientists and energy technology experts. Whether we can find an institutional or systematic mechanism to strengthen these links remains to be seen. The IEA Secretariat guided and supported by the CERT, will continue to explore the linkages which will shape a cleaner energy future. 
The IEA is proposing to convene regular global energy technology forums, under the aegis of its Committee on Energy Research and Technology (CERT). Such forums would foster collaboration with other organisations, private-sector stakeholders and developing countries. The main purposes would be to:

- monitor progress in energy technology and infrastructure development;

- assess possible contributions from various technologies to a low-net-emissions energy system on an ongoing basis;

- exchange information on technology development programmes and priorities;

- recommend fruitful areas for new collaboration. 


\section{References}

[IEA-1993] IEA Shared Goals; $\underline{\text { http://www.iea.org/about/sharegoa.htm }}$

[IEA-2000] Energy Technology and Climate Change: A Call to Action, IEA 2000; http://www.iea.org/public/studies/climte.htm

[IEA-2001] Needs for Renewables: Developing a new generation of sustainable Energy technologies, IEA 2001

http://www.iea.org/techno/renew/index.htm

[IEA-2002-a] IEA World Energy Outlook 2002; IEA 2002;

http://www.worldenergyoutlook.org

[IEA-2002-b] Solutions for the $21^{\text {st }}$ Century: Zero Emissions Technologies for Fossil Fuels; Technology Status Report, May 2002; IEA 2002;

http://www.iea.org/impagr/zets/status/TSR layout.pdf

[IEA-2003-a] Conference on Linking Basic Science and the Development of New Energy

Technologies, Paris, 1-2 April 2003; http://library.iea.org/dbtw-

wpd/textbase/work/worksh.htm

[IEA-2003-b] Toward Hydrogen: R\&D Priorities to Create a Hydrogen Infrastructure; IEA Renewable Energy Working Party Seminar, 3 March, 2003;

http://www.iea.org/workshop/2003/hydrogen/agenda.htm

[IEA-2003-c] Creating Markets for Energy Technologies, IEA 2003; http://www.iea.org/public/studies/2003/markets.htm

[IEA-2003-d] Energy Technology: Facing the Climate Challenge (Working Title); IEA, to be published in 2003

[IEA-2003-e] Cool Appliances: Policy Strategies for Energy-Efficient Homes, IEA 2003; http://www.iea.org/public/studies/2003/cool/index.htm

[IEA-web] Link to homepages of IEA Implementing Agreements; http://www.iea.org/impagr/imporg/imagpub/listof.htm

[OECD/IEA-2003] Cedric Philibert: Technology Innovation, Development and Diffusion; OECD/IEA Project for the Annex I Expert Group on the UNFCCC; IEA, to be published in 2003

[OECD-2002] OECD Science, Technology and Industry Outlook 2002; OECD, 2002; http://www.oecd.org/oecd/pages/home/displaygeneral/0,3380,EN-document-0nodirectorate-no-12-35101-0,00.html 


\title{
Global Energy Scenarios, Climate Change and Sustainable Development
}

\author{
Nebojsa Nakicenovic $\ddagger$ \\ International Institute for Applied Systems Analysis (IIASA) \\ and Vienna University of Technology \\ naki@iiasa.ac.at
}

\begin{abstract}
Energy scenarios provide a framework for exploring future energy perspectives, including various combinations of technology options and their implications. Many scenarios in the literature illustrate how energy system developments may affect global change. Examples are the new emissions scenarios by the Intergovernmental Panel on Climate Change (IPCC) and the energy scenarios by the World Energy Assessment (WEA). Some of these scenarios describe energy futures that are compatible with sustainable development goals; such as improved energy efficiencies and the adoption of advanced energy supply technologies. Sustainable development scenarios are also characterized by low environmental impacts (at local, regional and global scales) and equitable allocation of resources and wealth. They can help explore different transitions toward sustainable development paths and alternative energy perspectives in general.

The considerable differences in expected total energy requirements among the scenarios reflect the varying approaches used to address the need for energy services in the future and demonstrate effects of different policy frameworks, changes in human behavior and investments in the future, as well as alternative unfolding of the main scenario driving forces such as demographic transitions, economic development and technological change. Increases in research, development and deployment efforts for new energy technologies are a prerequisite for achieving further social and economic development in the world. Significant technological advances will be required, as well as incremental improvements in conventional energy technologies. In general, significant policy and behavioral changes will be needed during the next few decades to achieve more sustainable development paths and mitigate climate change toward the end of the century.
\end{abstract}

$\ddagger$ Dr. Nebojša Nakićenović is Project Leader at the International Institute for Applied Systems Analysis (IIASA) and Professor of Energy Economics at the Vienna University of Technology. Correspondence should be sent to naki@iiasa.ac.at. This paper is based on three earlier publications by the author: Nakicenovic et al., 1998, 2000a and 2000b. 


\section{Introduction}

The provision of affordable and environmentally sound energy services is a prerequisite for further social and economic development in the world. This is a formidable challenge considering that two billion people today are still without access to adequate energy services in the world. These two billion are the same people who generally live in poverty and do not have access to clean water, sanitation, education, health care or many other modern infrastructures and the same people who suffer environmental degradation, including indoor air pollution. In addition, the global population is expected to increase between one to six billion people by the end of the century. All of these people will require clean and affordable energy services as well.

Climate change mitigation is another important aspect of the sustainability transition. Yet, the climate change challenge is complex and wrought with deep uncertainty. The uncertainty is associated with the anthropogenic driving forces of global warming, from demographic change and economic development to land-use patterns. However, the global energy development paths are the most important single determinant of future emissions of greenhouse gases and thus, of climate change as well. This is further compounded because driving forces such as economic development and technological change are interrelated and mutually dependent. The nature of climate change itself is also uncertain, especially at the local and regional levels. The impacts and vulnerabilities of global warming on people and nature are even more uncertain and much less well known as they depend both on climate change and on the evolution of its (anthropogenic) driving forces.

A transition to the efficient and environmentally benign provision and end-use of energy can advert the potential conflict between development and protection of the environment and climate. Energy scenarios provide a framework for exploring future energy perspectives, including various combinations of technology options and their implications. Many scenarios in the literature illustrate how energy system developments may affect global change from access to energy services by all to climate change. Examples are the emissions scenarios by the Intergovernmental Panel on Climate Change (IPCC, Nakicenovic et al., 2000a) and the energy scenarios by the World Energy Assessment (WEA, Nakicenovic et al., 2000b). Some of these scenarios describe energy futures that are compatible with sustainable development goals; such as improved energy efficiencies and conservation, the adoption of advanced energy technologies, protection of the environment and climate change mitigation.

The role of technology as a determinant of development perspectives and climate change is unique. Technology is one of the main driving forces of economic development and greenhouse gas (GHG) emissions and thus global warming. It also ranks high as a solution, both in mitigating global warming through reductions of GHG emissions and in helping achieve development goals and thus increase the capacity to mitigate and adapt to climate impacts. For example, the IPCC finds that technology is at least as important a driving force of GHG emissions as population and economic growth (Nakicenovic et al., 2000a). Another IPCC finding is that innovative technology is an important driving force for a broad range of GHG atmospheric stabilization levels over the next 100 years or more (Morita et al., 2001). More specifically, the emissions scenarios of IPCC indicate an increase in the mean global temperature of 1.4 to 5.8 degrees Celsius by 2100 (Cubasch et al., 2001). Roughly half of this uncertainty range is due to the fact that it is not known how sensitive climate will be to increasing concentrations of GHGs and the other half is due to the uncertainty of the future emissions paths themselves, which to a large extent will be determined by technology choices.

The considerable differences in expected total energy consumption among the scenarios in the literature reflect the varying approaches used to address the need for energy services in the future. These differences in the development paths of the scenarios also result in a wide range of environmental consequences from local to global scales. Increases in research, development and deployment efforts for new energy technologies are a prerequisite for the achievement of the transitions foreseen in the scenarios across the range from those that have characteristics of sustainable development to those that fall short and represent extensions of current development paths in the future. Significant technological advances will be required in all of them, as well as incremental improvements in conventional energy technologies. In general, the scenarios demonstrate that significant policy and behavioral changes 
will be needed during the next few decades, especially in order to achieve more sustainable development paths toward the end of the century.

The main energy-related technology measures for achieving the goals of the sustainability transitions and reducing GHG emissions are efficiency improvements and conservation, decarbonization of fossil energy, carbon capture and storage, a shift toward less carbon intensive and zero-carbon energy sources, and afforestration. The introduction and market deployment of these new and advanced technologies for reducing emissions will take a long time. For example, the replacement of older by new energy systems and sources is a slow process; it might take on the order of more than 20 years to half a century to replace 80 percent of energy capital stock. Thus, it is necessary to introduce new and advanced energy technologies as soon as possible in order to achieve cost reductions and other technology improvements through learning and positive returns to scale. Most of the new and advanced technologies for reducing GHG emissions are currently costlier than their conventional counterparts in use today. Generally, cost reductions and improvements will be required to assure timely replacement of fossil intensive systems by those with lower or zero emissions,

Technology improvements through learning and positive returns to scale are uncertain. Investments in new and advanced technology will only achieve improvements and cost reductions in some cases. However, the corollary is also true, without such uncertain investments there surely will be no improvements. Thus, experimentation and accumulation of experience are indispensable to achieve technological change, the replacement of old by new systems and in the long term also the sustainability transition.

\subsection{Energy Challenges}

There are a number of energy challenges for the $21^{\text {st }}$ century. First, about one third of the global population, or some two billion people, do not have access to affordable and clean energy services. These are often the same people who do not have access to clean water or sanitation and are, in general, deprived from adequate access to many other essential amenities. In view of the fact that the global population is expected to grow between one and six billion people by the end of the century, the need for energy services is indeed large. It follows that the access to energy services cannot be provided by the traditional ways of converting energy sources into electricity and fuels nor by noncommercial energy gathering and use. The developing parts of the world cannot rely on following the energy, materials and emissions intensive development path that the now industrialized countries took. The second challenge therefore is how developing countries can "leapfrog some rungs of the energy ladder" to adopt the newest practices and technologies. The third challenge is that technology adoption and diffusion is a long process, especially in the case of energy-related infrastructures. Historically, it has taken between 20 years to half a century and more for new technologies to substitute the old ones. In other words, time itself is a limited resource. A further challenge is finding the means to finance the energy investments that are required for achieving these transformations in a world where ODA (official development aid) and FDI (foreign direct investment) are already falling short of the development needs. 


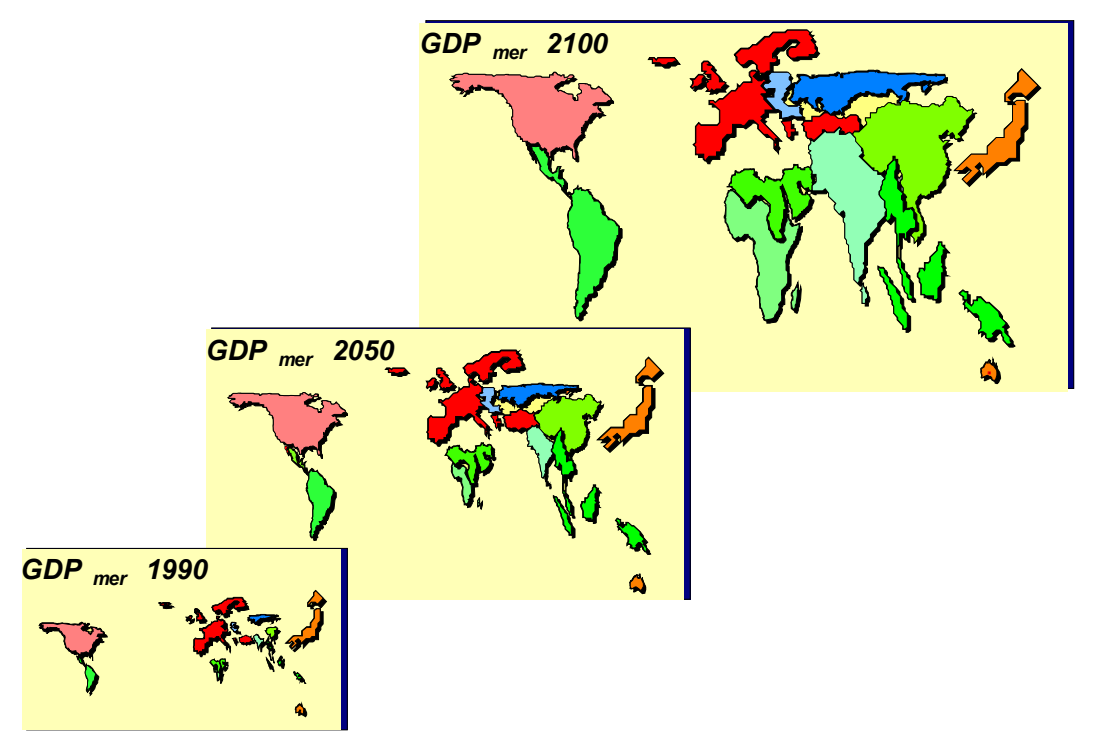

Figure 1. World economic maps show continents proportional to the respective economic activities measured by GDP at market exchange rates, from left to right, for 1990, 2050 and 2100. Source: Based on Nakicenovic et al., 1998

Finally, perhaps the biggest challenge from today's perspective is how to combat the adverse impacts of energy systems across all scales, from local indoor air pollution all the way to climate change. However, to achieve a sustainability transition, all of the above challenges need to be faced and resolved.

Figure 1 illustrates the magnitude of the development challenge and the stark inequities in the world. The graph shows an unconventional economic map of the world. The continents are not shown proportional to their geographic area, but are scaled proportional to economic activity, measured by GDP at market exchange rates. Clearly visible are the highly industrialized parts of the world, while the developing regions are hardly discernable. And yet, 80 percent of the people live in the developing regions while accounting for only 20 percent of the economic activities. This translates into per capita income disparities of factor 16 to one between the "North" and the "South" when measured at market exchange rates or a factor of four to one at purchasing power parities.

In comparison to the 1990 situation, Figure 1 shows two additional economic maps for 2050 and 2100 based on a scenario that illustrates the possibility of a more equitable world in the future. The world map for 2100 looks very familiar, almost like the geographic map of today, indicating that per unit area economic activities would be uniformly distributed. This does not mean of course that every person would be equally well off, but it does imply that the poorest would have access to essential means for existence, including adequate energy services. This development scenario assumes a 10-fold growth in the world economy over this period to some 300 trillion dollars by the end of the century. There are many such scenarios in the literature, including those developed by the IPCC, that have investigated both higher and lower rates of development. What is common to the IPCC scenarios is that in all cases the relative income gap between now developed and developing regions would narrow substantially.

\subsection{Primary Energy Requirements}

A prerequisite for achieving these levels of economic development in the scenarios are adequate levels of affordable energy services. Figure 2 compares future energy requirements with historical development. Since the beginning of the industrial revolution, global primary energy has grown at close to two percent per year. The IPCC scenarios (SRES, Nakicenovic et al., 2000a) indicate a seven-fold increase in primary energy requirements at the high end of the scale and at least almost a two-fold increase at 
the low end. What is interesting to note is that the scenarios in the lower range represent sustainable futures with a transition to very efficient energy use and high degrees of conservation. Generally, these are also the scenarios in which energy sources with low carbon intensity play an important role.

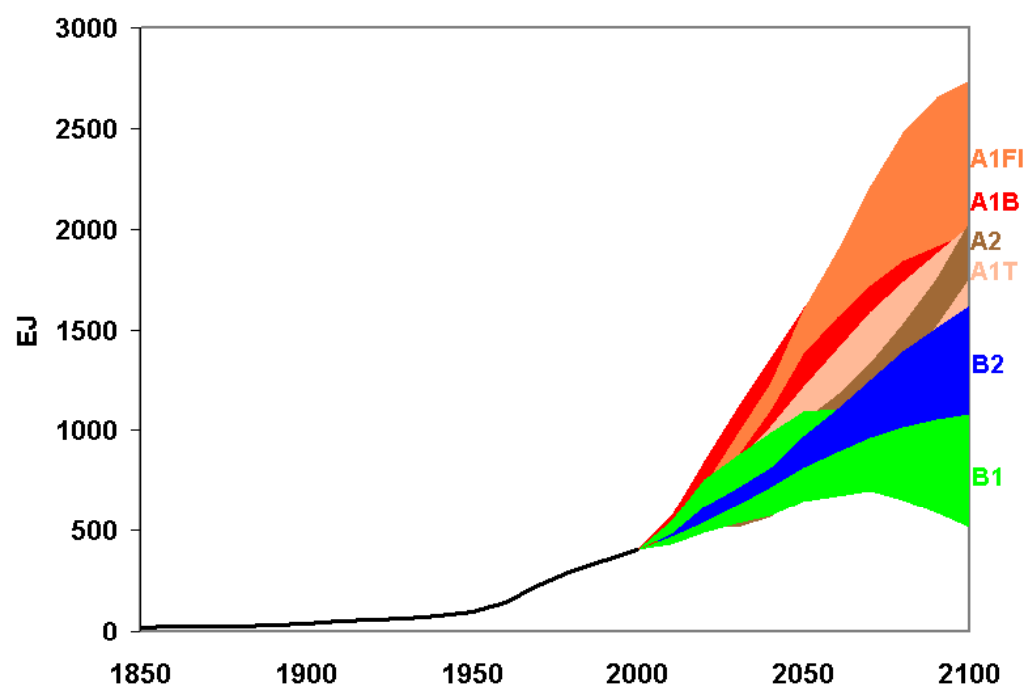

Figure 2. Global primary energy requirements since 1850 and in the range of IPCC SRES scenarios to 2100 in EJ per year. Source: Based on Nakicenovic et al., 2000a

Figure 3 illustrates alternative energy systems structures across the range of IPCC scenarios and historical development since 1850. Relative shares of different energy sources, in percent, show the historical evolution of the global energy supply since the 1850s (Figure 3a). The first transition of the energy system started with the introduction of coal that replaced traditional sources such as fuel wood and working animals. This transition lasted about 70 years until the 1920 s. During that period of time, the share of coal increased from 20 percent in 1850 to more than 60 percent by 1920 . This development phase was characterized by the introduction of the age of steam, steal and railways. The next transition lasted another 70 years and is characterized by the replacement of coal by oil and natural gas. It can further be characterized by the rapid expansion of internal combustion, electricity, petrochemicals and the automobile. By the 1990s, more than 80 percent of global energy was supplied by hydrocarbon sources, that is, coal, oil and natural gas. Zero carbon sources such as hydropower and nuclear play only a limited role today, while traditional renewables supply the rest of the energy needs, especially in the developing countries. 

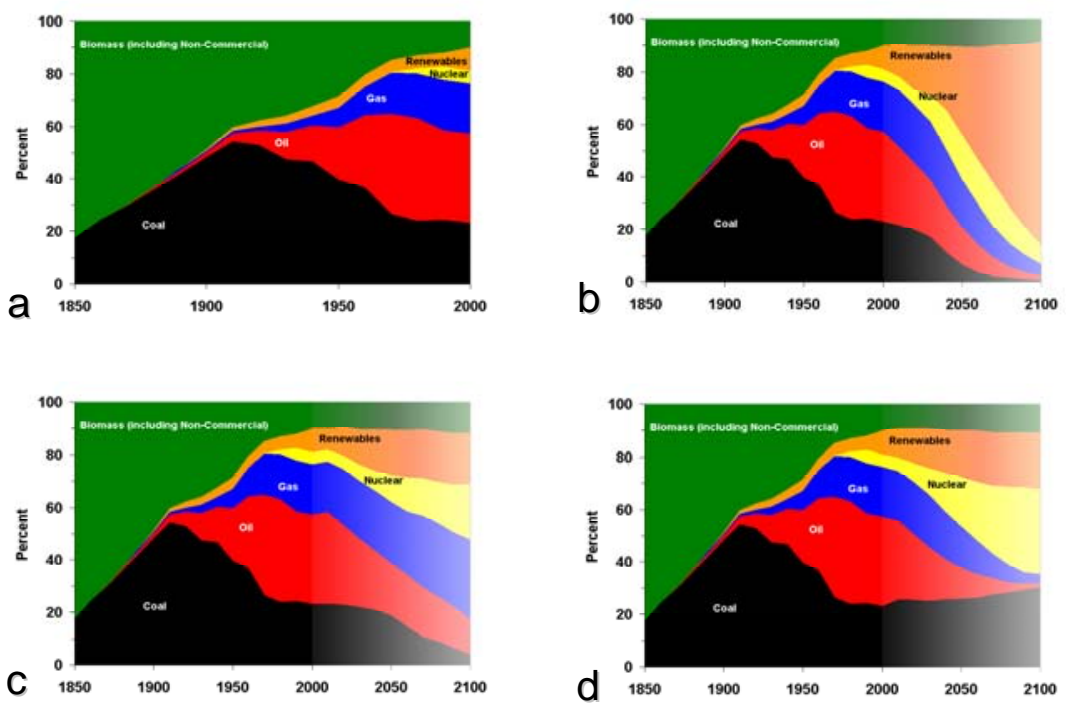

Figure 3. Historical evolution of energy systems structures, as shares of different primary energy sources (a) and future developments in IPCC SRES scenarios developed by MESSAGE model: A1T (b), A1B (c) and A1FI (d) scenarios. Source: Based on IPCC SRES. Source: Based on Nakicenovic et al., $2000 a$

Looking into the future, different possibilities unfold across the scenarios. Some of the scenarios as studied by IPCC, shown in Figure 3, foresee a return to coal (Figure 3d). This is especially important for those regions of the world that have ample coal resources, e.g., India and China. Other scenarios put more emphasis on stronger reliance on oil and gas (Figure 3c), while yet other scenarios foresee a transition toward zero carbon sources with a much stronger role being played by nuclear, solar, modern biomass and other renewable energy sources (Figure $3 b$ ). The scenario shown in Figure $3 b$, in fact, would lead to a dominance of non-carbon energy sources by the end of the $21^{\text {st }}$ century. This transition toward decarbonization of the global energy system would at the same time achieve many goals of sustainable development. These are some of the salient ancillary benefits of decarbonization and deep structural changes in the energy system.

Despite enormous differences across the scenarios they also have common features. For example, in energy area they have the same assumptions about fossil and nuclear energy resources and renewable energy potentials. But their deployment differs across the scenarios, and these differences tend to be amplified after 2020. Because of the long lifetimes of infrastructure, power plants, refineries, and other energy investments, there will not be a sufficiently large turnover of such facilities to reveal large differences in the scenarios before 2020. But the seeds of the post-2020 world will have been sown by then. Figure $3 \mathrm{~b}$ illustrates that the achievement of a more sustainably structured energy system should be seen as a cumulative, evolutionary process: It needs to be initiated early to allow for the long time constants required for fundamental transitions, such as a shift to cleaner fossil fuels, renewables, and possibly nuclear energy.

These deep structural differences across the scenarios indicate that the long-term global energy futures are no longer seen as being geologically preordained. The imminent resource scarcity forecast in the 1970s for the end of the century did not materialize. With continued exploration efforts and technological progress, accessible and affordable reserves have increased, and this trend is likely to continue. After 2020 all scenarios move away from their current reliance on conventional oil and gas, but to a varying degree. In fact, the currently estimated conventional oil and gas reserves do not reach much into the post- 2020 periods in any of the scenarios. This transition progresses relatively slowly in scenarios such as shown in Figure 3c, where oil and gas are plentiful. This is the result of a continuous conversion of abundant (unconventional) resources into economically viable reserves through research and technology development. This faster technological progress also leads to cleaner fossil energy systems in the long run. In the more sustainable scenarios, shown in Figure 3b, structural change away from coal and conventional oil and gas also progresses more rapidly because of faster technological 
progress toward cleaner fossil energy systems, and toward the end of the century toward dominance of renewable energy sources. This is the cumulative result of dedicated energy and environmental policies that favor deployment of renewables.

Most of the divergence across the scenarios after 2020 will depend on technological developments implemented between now and then (Nakicenovic et al., 1998). Which energy sources in 2020 will best match the more flexible, more convenient, cleaner forms of energy desired by consumers? Which firms will have made the investments in research and development that will give them a technological edge? And which will have refocused their operations away from merely providing tons of coal or kilowatt-hours of electricity and toward offering better energy services to consumers? The answers to these questions will be determined between now and 2020 (Nakicenovic et al., 1998). Near-term investment decisions and efforts in technology research and development will determine which of the alternative development paths will dominate the post-2020 period.

\subsection{Global Climate Change}

The alternative developments of the energy systems structure in the future across the scenarios imply developing a whole host of new energy technologies, and have different implications, for example, for climate change. Figure 4 is from the IPCC Third Assessment Report (Cubasch et al., 2001). It shows the changes in the mean global surface temperature for the last 1,000 years and contrasts this with future climate change across SRES scenarios. Clearly, this historical record is highly uncertain as illustrated by the wide error bands (shown in gray). The temperature varied, but what is important is that a clear trend cannot be discerned.

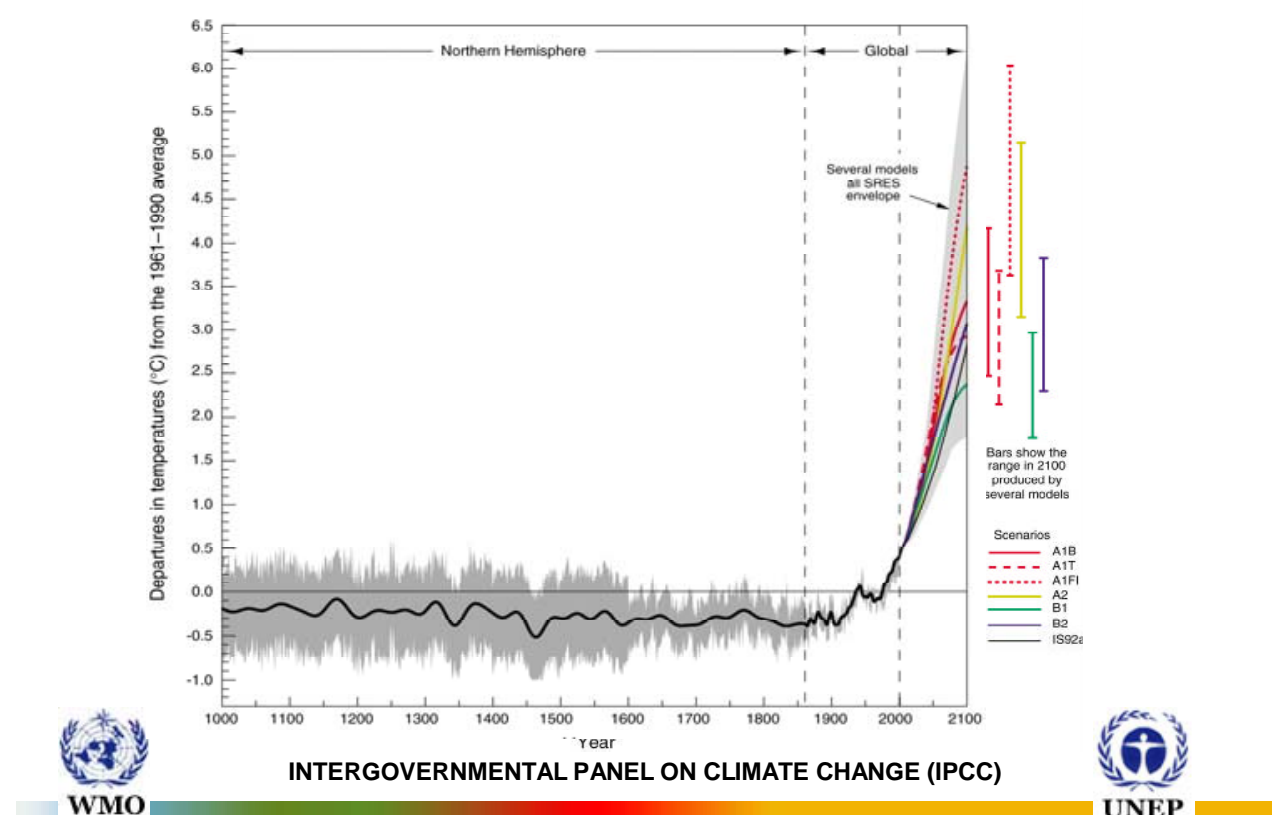

Figure 4. Global mean surface temperature reconstructed for the northern hemisphere for the last 1,000 years, for the globe since 1860 to present and for IPCC SRES scenarios to 2100. Source: Cubasch et al., 2001

A noticeable trend toward higher temperatures starts after the 1850s with the beginning of industrialization and continuous increase of anthropogenic GHG emissions. Compared to this historical development a large funnel of future possibilities opens for the next 100 years, from a minimal increase of 1.4 degrees Celsius to a high of 5.8 degrees. Zooming in on these future possibilities, shows that future temperature increases are based on the whole range of IPCC SRES (Nakicenovic et al., 2000a) emis- 
sions scenarios discussed in the previous section. IPCC used different climate change models to assess the climate change implications of the full range of emissions.

Half of the uncertainty between low and high ranges of temperature change is due to the fact that we do not know today how sensitive climate will be to the future emissions, the other half is due to the fact that we do not know which emissions path humanity will embark on in the future. However, while we do not know exactly how to influence climate sensitivity itself, we can, in principle, decide on the emissions paths as they depend on our present and future actions, which technologies will be deployed, future lifestyles, and so on. Here, we focus on the technological measures and policies assessed by the IPCC that would be required to achieve stabilization of future GHG concentrations in the atmosphere in accordance with Article 2 of the United Nations Framework Convention on Climate Change (Morita et al., 2001). It is the long-term stabilization of atmospheric GHG concentrations that is required to avoid climate change caused by human activities.

Figure 5 shows how much global carbon dioxide emissions would have to be reduced during the next 200 years to achieve atmospheric stabilization. One generic finding that emerges out of the required reductions is that emissions can increase somewhat for a while but must peak during the next decades and decline well below current levels, say down to a quarter or at most a third of current levels. In the very long run, beyond this time horizon of this century, net emissions must slowly cease and approach zero. In other words, achieving total decarbonization of the global energy system is a must, if the concentrations are to be stabilized. This is independent of the stabilization level chosen, be it high or low! For higher stabilization levels there is a bit more time before the peak should be reached: 2065 to 2090 for 1,000 ppmv (parts per million volume) on one end of the scale, but as soon as 2005 to 2015 to achieve stabilization at 450 ppmv. Even for $550 \mathrm{ppmv}$, emissions must peak between 2020 and 2030.

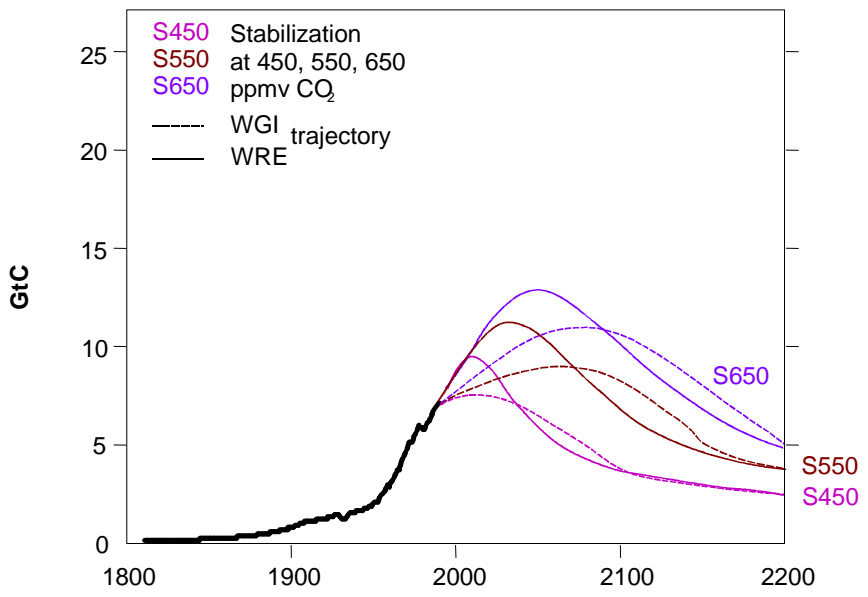

Figure 5. Global carbon dioxide emissions in billion tons of carbon (GtC) per year since 1800 to present and for alternative paths for stabilizing atmospheric concentrations at 450, 550 and 650 ppmv (parts per million volume) for IPCC WGI and WRE stabilization trajectories. Source: Based on Nakicenovic et al., 1998 and Wigley, Richels and Edmonds (WRE), 1996

\subsection{Emissions Scenarios and Response Strategies}

Various mitigation measures and policies need to be invoked in the scenarios to achieve these stabilization levels. Figure 6 shows the carbon dioxide emissions across the IPCC scenarios against the background of the historical increase since 1850. Carbon dioxide emissions grew on average at 1.7 percent per year. Current energy-related carbon dioxide emissions are in excess of 6 billion tons of carbon or Gigatons of carbon (GtC) per year. They increase more than seven-fold in the highest IPCC emissions scenarios, that is, those scenarios envisage the return to coal with high overall energy demand, and decline in the lowest scenarios to less than half the current levels. These are the scenarios 
that describe a more sustainable future with relatively low energy demand and a transition toward less intensive and zero-carbon energy technologies.

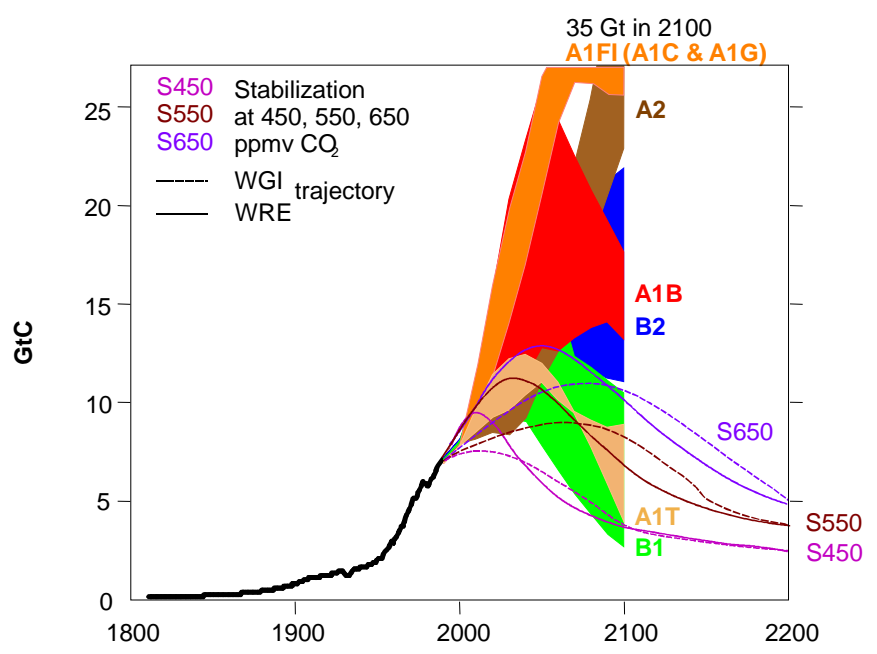

Figure 6. Global carbon dioxide emissions in billion tons of carbon (GtC) per year since 1800 to present, for alternative future paths for stabilization paths (IPCC WGI and WRE) and for IPCC SRES scenarios to 2100. Source: Based on Nakicenovic et al., 1998, Wigley, Richels and Edmonds (WRE), 1996 and Nakicenovic et al., 2000a

IPCC developed a set of stabilization scenarios that were quantified on the basis of the SRES scenarios (Morita et al., 2001). They illustrate how large mitigation measures and policies might be needed to achieve (atmospheric carbon dioxide) concentration stabilization according to Article 2 of the UN Framework Convention on Climate Change (in 150 years from now). The so-called Post-SRES scenarios cover a very wide range of emission trajectories, but the range is clearly below the SRES range. Thus, climate mitigation clearly reduces the uncertainty in the range of future emissions by eliminating the high end. The scenarios jointly illustrate the size of the "gap" between emissions in the baseline scenarios (IPCC SRES) and the stabilization paths (Post-SRES). All scenarios show an increasing $\mathrm{CO}_{2}$ reduction over time. Energy reduction shows a much wider range than $\mathrm{CO}_{2}$ reduction because in many scenarios a decoupling between energy use and carbon emissions takes place as a result of a shift in primary energy sources, carbon capture and storage.

Figure 7 shows the gaps opening between SRES and Post-SRES scenarios for achieving stabilization levels of 750, 650, 550 and 450 ppmv compared with current concentrations of $370 \mathrm{ppmv}$. B2 scenario family portrays emissions reductions gap that falls in-between other scenarios. In case of A1FI (fossilintensive A1 scenario group) the gap attains enormous magnitude toward 2100. In contrast, A1T and B1 scenarios indicate a relatively small gap as many of the carbon mitigation measures are already an integral part of the baseline developments. In other words, the total emissions reduction effort required is significantly smaller as well because of the much lower baseline emissions in the first case. A1T and B1 scenarios illustrate that sustainability transition has the ancillary benefit of relatively low emissions paths even in the baseline developments. In more carbon intensive future, vigorous mitigation measures need to be invoked in addition to those that are included in the baseline if the gap is to be closed. This increases the overall energy-system costs significantly, in some case up to 50 percent compared with the baseline.

In general, the lower the stabilization target and the higher the level of baseline emissions, the larger the $\mathrm{CO}_{2}$ divergence from the baseline that is needed, and the earlier that it must occur. The A1FI, $\mathrm{A} 1 \mathrm{~B}$, and $\mathrm{A} 2$ worlds require a wider range and more strongly implemented technology and/or policy measures than A1T, B1, and B2. The 450 ppmv stabilization case requires very rapid emission reduction over the next 20 to 30 years. 

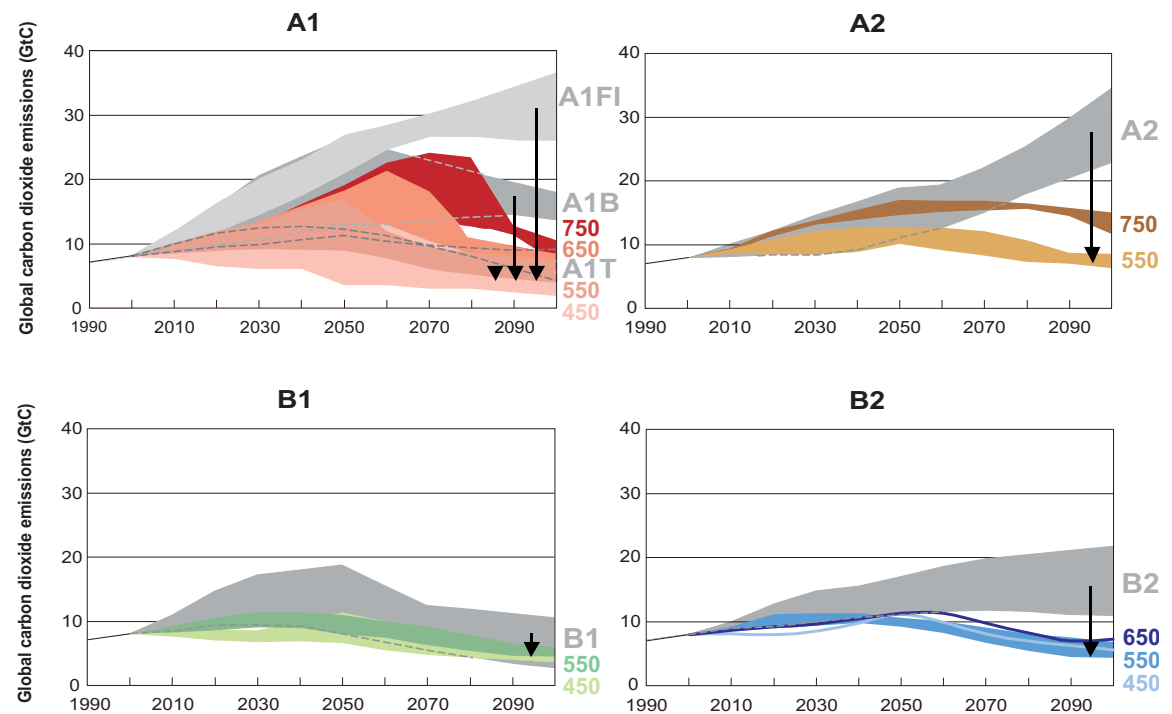

Figure 7. Carbon dioxide gap between SRES baseline scenarios and Post-SRES stabilization cases for 750, 650, 550 and 450 ppmv atmospheric concentrations, shown as differences in carbon dioxide emissions between the baselines and stabilization scenarios. The ranges in future emissions both in baselines and stabilization scenarios are due to different quantifications of the four storylines by nine integrated-assessment models that developed the scenarios. Source: IPCC TAR WGIII (Morita et al., 2001)

\subsection{Emissions Mitigation Technologies}

No single measure will be sufficient for the timely development, adoption and diffusion of mitigation options to stabilize atmospheric GHGs. Instead, a portfolio based on technological change, economic incentives, and institutional frameworks should be adopted. Combined use of a broad array of known technological options has a long-term potential which, in combination with associated socio-economic and institutional changes, is sufficient to achieve stabilization of atmospheric $\mathrm{CO}_{2}$ concentrations in the range of 450 to $550 \mathrm{ppmv}$ or even below.

The extent mitigation options deployment differs among scenarios and is strongly dependent on the model structure. However, common features of mitigation scenarios include large and continuous energy efficiency improvements and afforestation as well as diffusion of zero and low-carbon energy technologies, especially biomass over the next one hundred years and natural gas in the first half of the century. Energy conservation and reforestation are reasonable first steps, but innovative supply-side technologies will eventually be required as well. Possible robust options include using natural gas and combined-cycle technology to bridge the transition to more advanced fossil fuel and zero-carbon technologies, such as hydrogen fuel cells. Solar energy as well as either nuclear energy or carbon capture and storage would become increasingly important, especially in higher emission worlds and in conjunction with lower stabilization targets.

The first class of measures and policies directed at reducing emissions are related to demand reductions and energy savings. This is true across all scenarios, whether they have high or low emissions. The next class of measures includes changes in the structure of the future energy system compared to the baseline, and involves using new technologies to reduce carbon intensity. Primarily, this involves shifting away from coal to fossil energy sources with less carbon such as natural gas and a shift away from fossils in general toward zero-carbon options such as renewables and nuclear. The last class of mitigation measures are technologies for so-called carbon sequestration from fossil energy sources. This involves removing carbon from fuels either before combustion or scrubbing the carbon dioxide from the combustion gases. In either case, this necessitates carbon capture and storage over geological periods of time, that is, hundreds if not thousands of years. Further, it is important that the leakage 
rates of stored carbon are kept well below one percent per year. Given that hundreds of billion tons of carbon would need to be stored in many of the scenarios, higher leakage rates would offset emissions mitigation to the extent that stabilization might not be achievable.

Mitigation efforts vary for different SRES baselines and for different Post-SRES stabilization levels. This indicates that the emission path we choose to embark on will make an enormous difference. For obvious reasons shown here, the mitigation task is more humble and more likely to take place if the reference emissions are lower, if there is a transition toward "leaner" patterns of energy use and toward decarbonization of the energy system for other reasons than climate change. This not only makes the resulting climate change much less threatening, but also makes the task of reducing emissions to a given stabilization level easier to reach and much less costly. This is even more important when one considers the long time required to make structural changes in the energy system. Considering that the two pervious grand transitions in the energy system took on the order of 70 years each; and assuming that the next one lasts as long, it appears that the lower levels of stabilizing atmospheric GHG levels might be rendered impossible with or without carbon sequestration.

New technologies play an important role across all scenarios in the literature and even more so in cases where emissions mitigation is required. To provide for the growing need for energy services, new technologies diffuse in an ever more efficient, less polluting and, also essential, a less costlier manner. Technological change plays an important role in this process along with other important developments such as new institutional arrangements, adequate investments in energy, capacity building and education, or free trade to mention just a few enabling developments. For example, traditional oil and gas power plants are rendered obsolete and decommissioned by the 2020s and 2030s across all emissions scenarios (including SRES baselines and Post-SRES stabilization cases). Traditional coal power plants remain in service only a few more decades at the longest. Natural gas combined cycle (NGCC) power plants are an important source of electricity throughout the century and are already today the cheapest and most efficient plants wherever gas is available. In the mitigation scenarios, coal and gas power plants with carbon removal and disposal are introduced as well, in some of them as early as the 2020s. Fuel cells are another important technology in most of the scenarios and their widespread diffusion is expected to occur during the 2030s. Initially, they would be fueled mostly by natural gas but later, as hydrogen production increases, they would provide a carbon and pollution free source of mobile and stationary electricity. Hydrogen production starts as early as 2020 in some of the scenarios. Finally, in the future, coal conversion to electricity would rely on advanced coal technologies in all scenarios, at the latest by the 2050s. Integrated gasification combined cycle (IGCC) is one such technology that also has the advantage of being suitable for carbon sequestration.

Thus, numerous new and advanced energy technologies will have to be developed and deployed during the next 100 years. This means that large R\&D efforts would be required. What is perhaps more important is that extensive experimentation with those new technologies will also be required, starting with investments in demonstration projects and early deployment. This involves creating niche markets and sometimes requires subsidies because these two phases of technology development are often associated with high costs, and frequently inferior performance of new technologies compared with the old ones. However, dedicated development often, but not always, brings improvements. In economics this is called technological learning or learning by doing. In engineering and business one often refers to so called cost buy-downs along a learning curve. It is only after the costs have been reduced and performance improved that the actual widespread diffusion can take place and old technologies are replaced by new ones. There is a rich literature and practical experience on enormous improvements and cost reductions that could be achieved with accumulated experience and deployment of new technologies eventually resulting in superior performance and lower costs than older competitors. Gas turbines are such an example. It should be mentioned that these stages in the innovation chain are not intended to be linear or sequential, it is an interactive process. R\&D is always required and niche markets for experimentation are needed for advancing even the mature technologies.

Figure 8 shows an impressive example of technological learning from a developing country - ethanol production from sugar cane in Brazil. When the program started in the aftermath of the oil crisis, methanol was about three times more expensive than crude oil at about US\$150 per barrel of oil equivalent (bbl) even though oil was at a historically high price. Over the last 20 years, the costs of alcohol have decreased enormously, at some 30 percent per doubling of accumulated output. This is typical of cost buy-downs for many energy technologies, from photovoltaics, to wind mills and gas 
turbines. Today, ethanol prices appear to be competitive with gasoline in Brazil. In February 2003, the alcohol price was about 1.50 Rials per liter compared with gasoline at about 2.25 Rials per liter. It should be mentioned that gasoline also includes some alcohol and that there is a hefty gasoline tax. This means that the two fuels are roughly competitive. Nevertheless, the future is highly uncertain, it is by no means clear whether alcohol will remain to be competitive. The reason for showing the impressive learning curve in Figure 8 is that the improvements did not occur for free - the accumulated difference between the oil and alcohol prices, the red and the blue curves, shows that Brazil invested at least an estimated US\$2 billion to achieve this competitiveness. To achieve the competitiveness of the other advanced technologies that play important roles in IPCC scenarios will also require large investments world wide, however, their costs would still be relatively low compared to the alternatives of not developing competitive new technologies.

It is however important to be aware of the deep uncertainties surrounding future scenarios. This is not only the case with future climate change scenarios, but also with any attempt to provide a future perspective because of our inherent inability to predict future. In the context of technological change, it should be noted that we do not have any a priori means of distinguishing success from failure. Many technologies will need to be developed but only a few will be successful. However, the converse is certainly true, we will need to invest in new technologies if some of them are to become competitive and lead to lower future emissions as well as better and more affordable energy services for human progress and prosperity. Thus, it is timely to promote the early deployment and market introduction of new energy infrastructures and technologies in order to achieve "cost-buy downs" and technology improvements through experience and learning, recognizing that only a few options are likely to be successful. This is, however, necessary for achieving the widespread diffusion and transfer of new technologies.

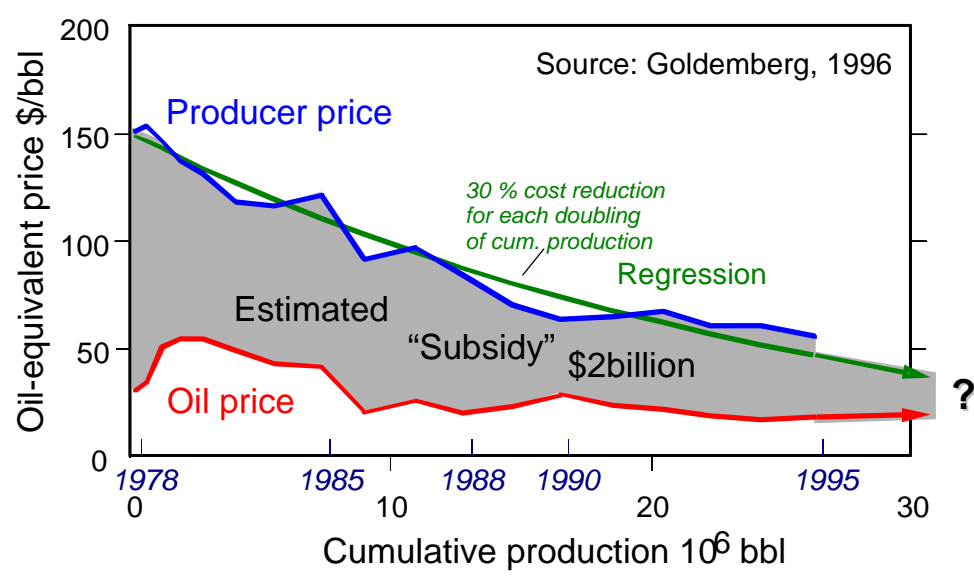

Figure 8. Learning curve for ethanol production from sugar cane expressed in US dollars per barrel of oil (bbl) equivalent as a function of cumulative production since 1978 indicating a 30 percent price reduction per doubling of cumulative production; crude oil price is also shown on the same scale; the cumulative difference between the two curves corresponds to about US\$2 billion investment to bring ethanol prices to competitive levels with crude oil. Source: Grübler, 1998

In conclusion, it should be noted that typical diffusion time constraints for achieving a fundamental transition in the global energy system lasts a very long time, from at least 20 to between 50 and 70 years. Such a transition might involve, say, replacing some 80 percent of energy capital stock. At the same time, it is clear that the premature replacement of energy technologies is too costly. Thus, there is very little time left to waste for initiating extensive early introduction and experimentation with new technologies. As was shown, this is a prerequisite for achieving cost buy-downs through experience and preparing for timely capital replacement.

It is essential, therefore, to put new policies in place and formulate new public-private partnerships, together with science and engineering communities and other stakeholders, directed at providing more sustainable energy services. Here, the developed countries should take a leading role with their gener- 
ally higher capacity and means for developing and introducing more affordable and environmentally benign energy systems.

\section{Conclusion}

Scenarios are an important tool for assessing transitions to sustainable development paths. Sustainable futures often are easier to illustrate when compared with other scenarios that contradict some of the conditions for achieving sustainability. This is one of the reasons why, in recent studies, sustainable scenarios are usually included among alternative futures (Nakicenovic et al., 2000b). The sustainable scenarios can be characterized by low environmental impacts at all scales and more equitable allocation of resources and wealth relative to the current situations and other alternative future energy developments. WEA and IPCC presented a set of global and regional scenarios (Nakicenovic et al., 2000a and 2000b). Each set includes a number of scenarios that describe futures with characteristics of sustainability. Together, they illustrate the measures and policies for the near-term future that would be required to move away from other alternative but unsustainable development paths. Each set includes two classes of scenarios that envisage the sustainability transition.

One class of scenarios that envisage the sustainability transition, such as the IPCC B1 (especially with 450ppm stabilization), can be characterized by low environmental impacts at all scales and more equitable allocation of resources and wealth relative to the current situations and other alternative future energy development paths. Usually, sustainability transitions are embedded in fundamentally different future development paths that share both substantial technological progress and unprecedented international cooperation centered on environmental protection and international equity - they include high degrees of environmental protection at all scales, from eradication of indoor air pollution to low impacts on climate change, sometimes associated with an active redistribution of wealth and usually very high levels of energy efficiency and conservation. Thus, they fulfill most of the criteria for sustainable development - such as increasing both economic and ecological equity among world regions and countries - and lead to a significantly lower impact on the climate than scenarios with higher GHG emissions. These scenarios require a virtually complete transition away from reliance on fossil energy sources toward zero or near-zero emissions energy systems that include carbon capture and storage in association with hydrocarbon sources and stronger reliance on renewable energy sources. All variants of this class of sustainability transition scenarios considered by WEA and IPCC are characterized by a high degree of energy conservation and vigorous efficiency improvements throughout the whole energy system and among end users. Consequently, total energy requirements are relatively low relative to the high levels of affluence and quality of life, especially in today's developing regions. The achievement of such futures is indeed challenging, and ranges from devising new RD\&D and market introduction policies for energy technologies, to imposing energy and carbon taxes as incentives for improving energy efficiency and conservation and increasing the shift away from fossil fuels.

The second class of scenarios that include characteristics of sustainability, such as the IPCC A1T (especially with $450 \mathrm{ppm}$ stabilization), is fundamentally different in nature and quite similar to the reference scenarios as far as most of the driving forces are concerned except for the future structure of the energy system. Thus, environmental protection and higher levels of affluence are achieved less through changes in lifestyles and levels of energy end use and structure, and more through a dedicated decarbonization of the energy system. Again, efficiency improvements are important, and clean fossils such as natural gas are foreseen, as gaining much larger shares of global energy needs, along with renewable sources of energy - all contributing toward decarbonization. Decarbonization is in part also achieved through more sophisticated energy conversion and processing that includes pervasive carbon capture and storage along with zero or close to zero emissions of more conventional pollutants.

Together, these two classes scenarios illustrate different levels of compatibility between future energy systems and goals of sustainable development. However, all sustainable scenarios, including the IPCC scenarios described here, have positive (desirable) and normative (prescriptive) elements. They usually include strong assumptions about desirable futures and prescribe how such futures can be achieved. Common to most is that they show that sustainable futures are not achievable with current 
policies and prevailing development trends. Their achievement often requires a fundamental change or major paradigm shift. Thus, sustainable energy scenarios are often designed to offer policy guidance on managing, for example, an orderly transition from today's energy system, which relies largely on fossil fuels, toward a more sustainable system with more equitable access to resources. More global studies are considering futures with radical policy and behavioral changes to achieve a transition to a sustainable development path during the 21st century (Nakicenovic et al., 2000b).

The great merit of RD\&D policies, diffusion, and the adoption of new technologies associated with market-based instruments for environmental change is that radical developments often proceed gradually from seemingly moderate policies, leading to major improvements over time. However, they require continuity over decades so that the cumulative effects of moderate policies can result in radical change. These are some of the crucial characteristics of the IPCC and WEA scenarios that lead toward sustainable development. Another central feature of these scenarios is that adequate provision of energy services and more equitable allocation of resources are crucial for achieving sustainability. At the same time, energy use is a main cause of environmental degradation at all scales and so can inhibit the achievement of sustainability. Thus, environmental protection - from indoor pollution to climate change - is an essential element of sustainable development in these scenarios (Nakicenovic et al., 2000b). Rapid development and clean, efficient energy are complementary elements of most of the scenarios. The resolution of these future challenges offers a window of opportunity between now and 2020. Because of the long lifetimes of power plants, refineries, and other energy investments, there is no sufficient turnover of such facilities to reveal large differences among the alternative scenarios presented here before 2020, but the seeds of the post-2020 world will have been sown by then. The choice of the world's future energy systems may be wide open now. It will be a lot narrower by 2020 , and certain development opportunities that are forgone now might not be achievable later (Nakicenovic et al., 1998). There may well be environmental irreversibilities, but technical changes may still take place anyway, and it is a question of whether they will be too late rather than whether they will occur at all. Perhaps more important is the question of development initiatives directed at eradicating poverty, disease, and illiteracy in the world, and whether they will be timely and sufficient to offset currently inadequate efforts (Nakicenovic et al., 2000b). The achievement of sustainable development dictates a global perspective, a very long time horizon, and immediate policy measures that take into account the long lead times needed to change the system. 


\section{References}

Cubasch, M. et al., 2001, Projections of Future Climate Change, Chapter 9 in The Scientific Basis, Third Assessment Report, Working Group I of the Intergovernmental Panel on Climate Change (IPCC), Cambridge University Press, Cambridge, UK. (http://www.ipcc.ch)

Grübler, A., 1998, Technology and Global Change, Cambridge University Press, Cambridge, UK.

Morita, T., Robinson, J., Alcamo, J., Nakicenovic, N., Zhou, D. et al., 2001, Socio-economic and Emissions Scenarios, Chapter 2 in Climate Change 2001: Mitigation, Third Assessment Report, Working Group III of the Intergovernmental Panel on Climate Change (IPCC), Cambridge University Press, Cambridge, UK. (http://www.ipcc.ch)

Nakicenovic, N., Grübler, A., and McDonald, A., eds, 1998, Global Energy Perspectives, Cambridge University Press, Cambridge, UK.

Nakicenovic, N. Alcamo, J., Davis, G., de Vries, B., Fenhann, J., Gaffin, S., Gregory, K., Grübler, A. et al., 2000a, Special Report on Emissions Scenarios of the IPCC, Cambridge University Press, Cambridge, UK. (http://www.grida.no/climate/ipcc/emission/index.htm)

Nakicenovic, N., Kram, T., Makarov, A., Sorensen, B., Yokobori, K., Zhou, F. et al., 2000b, Energy Scenarios, Chapter 9 in Energy and the Challenge of Sustainability, World Energy Assessment Report, Goldemberg, J., Anderson, D., Holdren, J.P., Jefferson, M., Jochem, E., Nakicenovic, N., Reddy, A.K.N., Rogner, H.-H. et al., eds, UNDP, UNDESA, WEC, New York, NY, USA. (http://www.undp.org/seed/eap/activities/wea)

Wigley, T.M.L, Richels, R., and Edmonds, J.A., 1996, "Economic and Environmental Choices in the Stabilization of Atmospheric $\mathrm{CO}_{2}$ Concentrations," Nature. 379(6562):240:243. 


\section{Session 2: Energy and Developing Countries}

Chairman: Mark Radka, UNEP, France 


\title{
Renewable Energy Markets in Developing Countries*
}

\author{
Eric Martinot, Global Environment Facility, emartinot@worldbank.org \\ Akanksha Chaurey, Tata Energy Research Institute, akanksha@teri.res.in \\ Debra Lew, National Renewable Energy Laboratory, dlew@nrel.gov \\ José Roberto Moreira, Biomass Users Network, bun@tsp.com.br \\ Njeri Wamukonya, UNEP Collaborating Centre on Energy and Environment, \\ njeri.wamukonya@risoe.dk
}

\section{Introduction}

Developing countries have $80 \%$ of the world's population but consume only $30 \%$ of global commercial energy. As energy consumption rises with increases in population and living standards, awareness is growing about the environmental costs of energy and the need to expand access to energy in new ways. As recognition grows of the contribution renewable energy can make to rural development, lower health costs (linked to air pollution), energy independence, and climate change mitigation, renewable energy is shifting from the fringe to the mainstream of sustainable development. Support for renewable energy has been building among those in government, multilateral organizations, industry, and non-governmental organizations (NGOs) pursuing energy, environment, and development agendas at local, national and global levels. At the same time, commercial markets for renewable energy are expanding, shifting investment patterns away from traditional government and donor sources to greater reliance on private firms and banks.

Changing investment patterns make it more important to think about markets for renewable energy, rather than simply about the technologies themselves and their economic characteristics. The older technology-oriented paradigm focused on technology assessment, economic viability, and technology demonstrations is giving way to a new paradigm focused on market assessment, policy and institutional issues, and demonstrations of business and social models.

"Renewable energy" commonly refers to both traditional biomass (i.e., fuelwood, animal wastes, and crop residues burned in stoves) and modern technologies based on solar, wind, biomass, geothermal and small hydropower. Our definition here, also called "new renewables" by many others, excludes large hydropower because it is already a mature technology and treated well elsewhere. While traditional biomass provides about $7-11 \%$ of global primary energy supply, the modern forms of renewable energy provide about $2 \%$. For developing countries, the traditional biomass share is $30-45 \%$ on average, although some developing countries approach 90\%. Besides traditional biomass, small hydropower in China and transport ethanol in Brazil are among the largest single contributors to renewable energy supplies in developing countries.

We take a market orientation in this paper, providing an aggregate review of past market experience, existing applications, and results of policies and programs, organized by end-use application rather than by technology (Table 1). We then review the emerging lessons suggested by that experience for six key issues.

\footnotetext{
* This paper is excerpted from the full paper of the same title which appeared in Annual Review of Energy and the Environment, Vol. 27 (2002), pp. 309-348. A short selected bibliography has been included. For full sources, readers should consult the original paper, which cites 174 references.
} 


\subsection{From Donor Aid to Sustainable Markets}

In the 1970s and 1980s, many development assistance agencies attempted to promote small-scale renewable-energy technologies like biogas, cooking stoves, wind turbines, and solar heaters in developing countries. From 1980 to 2000, official development assistance for renewable energy totaled about $\$ 3$ billion, most of which went for geothermal, wind and small hydro technologies. Much of this, particularly aid for rural areas, focused on technical demonstrations or on projects that were narrowly self-sustaining but could not be replicated. Many projects were considered failures because of poor technical performance and poor suitability to user needs and local conditions. Projects often did not demonstrate institutional and commercial viability and lacked mechanisms for equipment maintenance, sustainable sources of credit and expertise, and incentive structures for sustained operating performance.

At the same time, however, many developing countries were busy with their own renewable energy programs. Large-scale initiatives by developing country governments included ethanol use for transport in Brazil, household biogas for lighting and cooking in China and India, grid-connected wind power in India, and small hydropower in Nepal. Some success stories, like the market for solar home systems in Kenya, began with donor assistance in the 1980s but then "graduated" to private-sector-led markets in the 1990s. Common to these experiences is the fit between technologies and user needs and practices. For example, the ethanol vehicle fuel program in Brazil was successful partly because using ethanol required little change in consumers' attitudes or behaviors. Many early programs were not successful, however, often because the factors for sustainability and replication were missing.

Table 1. Renewable Energy Markets in Developing Countries.

\begin{tabular}{|l|l|}
\hline Application & Indicators of Existing Installations and Markets (as of 2000) \\
\hline $\begin{array}{l}\text { 1. Rural residential } \\
\text { and community } \\
\text { lighting, TV, radio, } \\
\text { and telephony }\end{array}$ & $\begin{array}{l}\text { Over } 50 \text { million households served by small-hydro village-scale mini-grids. } \\
10 \text { million households get lighting from biogas. } \\
1.1 \text { million households have solar PV home systems or solar lanterns. } \\
10,000 \text { households served by solar/wind/diesel hybrid mini-grids. }\end{array}$ \\
\hline $\begin{array}{l}\text { 2. Rural small indus- } \\
\text { try, agriculture, and } \\
\text { other productive uses }\end{array}$ & $\begin{array}{l}\text { Up to } 1 \text { million water pumps driven by wind turbines and over 20,000 water } \\
\text { pumps powered by solar PV. } \\
\text { Up to } 60,000 \text { small enterprises powered by small-hydro village-scale mini-grids. } \\
\text { Thousands of communities receive drinking water from solar PV-powered puri- } \\
\text { fiers/pumps. }\end{array}$ \\
\hline $\begin{array}{l}\text { 3. Grid-based bulk } \\
\text { power } \\
\text { dro and biomass, with some geothermal and wind). }\end{array}$ \\
\hline $\begin{array}{l}\text { 4. Residential/ com- } \\
\text { mercial cooking and } \\
\text { hot water }\end{array}$ & $\begin{array}{l}220 \text { million more-efficient biomass stoves. } \\
10 \text { million households with solar hot water systems. } \\
800,000 \text { solar cookers. }\end{array}$ \\
\hline $\begin{array}{l}14 \text { billion liters per year ethanol vehicle fuel produced from biomass. } \\
180 \text { million people live in countries mandating mixing of ethanol with gasoline. }\end{array}$ \\
\hline
\end{tabular}


The 1992 UN Conference on Environment and Development, along with the resulting UN Framework on Climate Change, breathed new political life into donor assistance for renewables and led to new forms of multilateral assistance for renewable energy. These have including about $\$ 600$ million in grant assistance by the Global Environment Facility, \$2 billion in loans from the Word Bank, and new initiatives by the UN Development Programme. Many of these programs are designed to promote sustainable technologies and markets by removing key barriers related to skills, financing, institutions, business models, and policies. Project development and implementation progress has been slow, however, and substantial experience from most of these programs is just emerging. These agencies continue to learn and evolve in their approaches.

In the late 1990s, private multinational corporations also began to commit millions of dollars to renewable energy investments, some of which was to go to developing countries. Many domestic firms in developing countries also entered the renewable energy business in the 1990s. But companies have found such investments to be more difficult than they imagined in developing countries, and progress in fulfilling expectations has been slow.

Among bilateral donors, the practice of simple equipment provision continues, although some donor programs have taken more market-oriented approaches that respond to local demand and user needs, promote enterprise development for sustained service, and create financing mechanisms independent of continuing donor aid. Most recently, a task force of the G-8 group of industrialized countries recommended market-oriented approaches and advocated a goal of serving 500 million people in developing countries with renewable energy within a decade. A growing body of experience shows that successful approaches to promoting renewable energy should expand and sustain markets for specific applications that offer the economic and social benefits most needed.

\section{Part 1. Experience with Applications and Markets}

\subsection{Rural Residential and Community Lighting, TV, Radio and Telephony}

Roughly 400 million households, or $40 \%$ of the population of developing countries, do not have access to electricity. Household and community demand for lighting, TV, radio, and wireless telephony in rural areas without electricity has driven markets for "solar home systems," biogas-fueled lighting, small hydro mini-grids, wind or solar "hybrid" mini-grids, and small wind turbines. These technologies are not strictly comparable with each other, however; the level of service that households receive varies considerably by technology and by the specific equipment size used. Regardless of size, surveys and anecdotal evidence suggest that rural households value both electric lighting and television viewing. Growing numbers of individual equipment purchases, beyond government-driven programs, point to growing market demand.

Solar home systems. Solar home systems (typically 15-75 watts) can reduce the need for candles, batteries, and kerosene in rural homes. Typical purchase prices range from \$200-1200. Smaller "solar lanterns" (typically 10-20 watts) provide lighting only. An estimated 1.1 million solar home systems and solar lanterns exist in rural areas of developing countries, and donor approaches and markets have evolved in recent years. Most installations are individual household systems, but some serve public buildings such as schools, health clinics, and community centers - with thousands of such applications in some countries. The largest existing markets for solar home systems are India $(450,000)$, China $(150,000)$, Kenya $(120,000)$, Morocco $(80,000)$, Mexico $(80,000)$, and South Africa $(50,000)$.

Biogas for home lighting and cooking. Biogas digesters convert animal and plant wastes into a fuel usable for lighting, heating, cooking, and electricity generation. Digesters can be household or community scale. Biogas programs have been challenging because a variety of technical options are needed. Community and political issues have also created challenges, along with the need for rural 
service businesses and consumer credit. China, India, and Nepal have conducted the main biogas programs; all three countries now have large manufacturing industries for biogas plants. China leads the world with 7.5 million household biogas digesters, 750 large and medium-scale industrial biogas plants, and a network of rural "biogas service centers" was established to provide the infrastructure necessary to support dissemination, financing and maintenance. India also has had a large program, with about 3 million household plants installed.

Village-scale mini-grids. Village-scale mini-grids can serve tens or hundreds of households in settings where sufficient geographical density allows economical interconnections to a central power generator. Most mini-grids in remote areas have been powered by diesel generators or small hydro. Generation from solar PV, wind, or biomass, often in "hybrid" combinations, can replace or supplement diesel power, but very few such systems exist, perhaps 150 in developing countries. Most village-scale mini-grids have developed in Asia on the basis of small hydro, particularly in China, as well as Nepal, India, Vietnam, and Sri Lanka. In Nepal, most mini-grids have been installed and managed by rural entrepreneurs - a "success story" attributed to several factors, including availability of credit from an agricultural development bank, simplified licensing procedures, unrestricted power tariffs, private financing from commercial banks, and capital cost subsidies.

Household-scale wind power. Household-scale wind power (sized 100-5000 watts) has been piloted in a few countries, with most installations worldwide taking place in Inner Mongolia in China. Public programs were successful in disseminating more than 140,000 small wind turbines for household energy in this region. These programs were driven by local technology promotion agencies, development of local technology manufacturing, subsidies for purchase of locally manufactured wind turbines, and a government revolving credit fund offering repayment tied to the harvest season or future sales of cattle or wool.

\subsection{Rural Small Industry, Agriculture, and Other Productive Uses}

Although electricity provides improvements in the quality of life through lighting, entertainment, and increased conveniences, it is the productive uses of this electricity that increase incomes and provide development benefits to rural areas. As incomes increase, rural populations are better able to afford greater levels of energy service, which can allow even greater use of renewable energy. The major emerging productive uses of renewable energy are for agriculture, small industry, commercial services, and social services like drinking water, education, and health care.

Agricultural water pumping. Wind-driven water pumps for irrigation and livestock historically have played a prominent role in rural areas, but declined in the 1950s and 1960s as rural electrification and diesel-driven pumps took over. A resurgence in interest in wind pumps in the 1970s and 1980s did not lead to new large markets, however, except in Argentina. Up to one million wind-powered water pumps are in use in Argentina, following decades of development of a local manufacturing base. Significant use of wind-powered water pumps is also occurring in South Africa and Namibia, with smaller numbers of installations in Brazil, China, Columbia, India, Peru, and Thailand. Growing interest in solar PV powered water pumps (typically 1-kW) has led to at least 20,000 installed, notably in India, Ethiopia, Thailand, Mali, Philippines, and Morocco. However, many of the pumps are not operating due to poor maintenance.

Small industry. Mini-grid or stand-alone systems can power small industries and provide substantial local income and jobs. In fact, the economic viability of mini-grids often depends on the presence of industry, since household lighting by itself may not provide the revenue to pay for mini-grid investments. Examples of applications exist, but not systematically: on one Philippine island, a wind-solardiesel hybrid provides 24-hour power for seaweed drying, woodworking, and sewing; in West Bengal in India, small local enterprises such as a cycle repair shop, a video cinema, and health clinics receive power from solar and biomass village-scale mini grids; in ten remote fishing villages in Indonesia, wind turbines power ice making to freeze fish, a chick hatching unit, corn grinding, and potable water supplies; in South Africa, women weave mats at night using the light from solar home systems; and in Peru, carpenters and welders work off small hydro power. 
Drinking water. Use of renewable energy to provide clean drinking water is emerging as a potential major market. Applications include both mechanical pumping/filtering and ultraviolet (UV) disinfection. In areas where commercial or piped water is unavailable, villagers may walk several hours each day to obtain drinking water or use hand pumps. Few examples of applications yet exist, however. One example is in the Dominican Republic, where eight PV-powered village water systems provide daily water service to about 1000 people. Users pay for water on a per-gallon basis and prefer the service to existing water supplies.

\subsection{Grid-Based Power Generation}

Total world electric power capacity stood at 3,400,000 MW in 2000, with about 1,500,000 MW (45\%) of this in developing countries (see Table 2). Electricity consumption in developing countries continues to grow rapidly with economic growth, raising concerns about how these countries will expand power generation in coming decades. Small hydro power, biomass power, geothermal power, and wind farms are all competitive and viable technologies for grid-based power generation. Gridconnected installations can range in size from a few kilowatts to hundreds of megawatts:

- Small hydropower harnesses small rivers and streams, typically with plants less than $10 \mathrm{MW}$ size. Small hydropower has been a mainstay of rural energy development for many years in many countries. China alone accounts for $80 \%$ of the small-hydro capacity in developing countries, driven by long-standing government rural electrification programs.

- Biomass power commonly comes from direct combustion of biomass feedstocks to produce power and often cogenerate heat. Other technologies include anaerobic digestion, which produces biogas for use in engines, and gasification, which produces gas for use in combined-cycle gas turbines. In developing countries, most applications are direct combustion and biogas. Most biomass feedstocks come from agricultural and forest industry residues. Sugar cane waste, or "bagasse," is especially common in tropical countries. Brazil and the Philippines are the leading producers of biomass power.

- Wind power, now the fastest growing energy technology in the world, has been slow to emerge in developing countries, with only $10 \%$ of the global total. India, with 1,300 MW of installed capacity, leads the developing world. India's wind power boom during the 1990 s was driven by special tax policies and other regulatory mechanisms. However, these investment-based incentives have not encouraged high operating performance, and declining investment tax credits and changing utility policies moderated growth in the late 1990s.

- Geothermal power is expanding in Indonesia, Philippines, Mexico, Kenya, and Central America.

Table 2. Renewable Grid-Based Electricity Generation Capacity Installed as of 2000 (megawatts).

\begin{tabular}{|l|c|c|}
\hline Technology & All countries & $\begin{array}{c}\text { Developing coun- } \\
\text { tries }\end{array}$ \\
\hline Small hydropower & 43,000 & 25,000 \\
\hline Biomass power & 32,000 & 17,000 \\
\hline Wind power & 18,000 & 1,700 \\
\hline Geothermal power & 8,500 & 3,900 \\
\hline Solar thermal power & 350 & 0 \\
\hline Solar photovoltaic power (grid) & 250 & 0 \\
\hline Total renewable power capacity & 102,000 & 48,000 \\
\hline \hline Large hydropower & 680,000 & 260,000 \\
\hline Total world electric power capacity & $3,400,000$ & $1,500,000$ \\
\hline
\end{tabular}




\subsection{Residential and Commercial Cooking and Hot Water}

Residential and commercial cooking and hot water in rural areas of developing countries are supplied primarily by direct combustion of biomass - in the form of wood, crop wastes, dung, and charcoal. In recent decades, the alarming decline in forest resources in many countries called attention to more efficient household use of biomass, as well as solar cookers. Driven by public programs, household demand, and declining resources, markets for more efficient biomass stoves and solar cookers are primarily in Asia and Africa. In Latin America, resources are more plentiful and these technologies have received less attention.

Since 1980, many donor programs have developed and disseminated new technologies for efficient biomass cookstoves, with close to 220 million stoves disseminated. The largest program, the Chinese Improved Stoves Program, disseminated 180 million improved biomass stoves. This program established local energy offices to provide training, service, installation support, and program monitoring. It also fostered self-sustaining rural energy enterprises that manufactured, installed, and serviced the stoves. A government program in India has resulted in more than 30 million improved stoves by subsidizing half the cost of the stoves. However, surveys suggest that only one-third of the stoves in the India program are still being used, and reveal that many stoves didn't save energy, broke down, and were poorly constructed.

In Africa in the 1990s, over 3 million improved biomass stoves were disseminated. Markets and technology adoption have proven easier for reducing charcoal consumption (as opposed to wood), and for urban markets to save purchased fuel (as opposed to saving collected fuel). Kenya has led this market, with close to one million improved stoves in that country alone. The Kenya ceramic jiko (KCJ) has been the most widely disseminated of all improved biomass stoves. The KCJ success is partly attributed to a "piggyback" strategy used for marketing and distributing stoves through existing sales networks. The KCJ has been replicated in Uganda, Rwanda, Tanzania, Ethiopia, Sudan and Malawi.

Hot water for residential and commercial uses can be provided cost-effectively by solar hot water heaters in many regions. About two-thirds of the 15 million domestic solar hot water collectors worldwide are in developing countries. China's solar hot water industry has mushroomed in the 1990s, with growth rates of $10-20 \%$ and up to 10 million households now served. Other major markets include Egypt, India, and Turkey.

\subsection{Transport Fuels}

Biomass-derived liquid fuels power motor vehicles in Brazil, Kenya, Malawi, and Zimbabwe. Two separate applications exist, one in which ethanol powers specially-designed vehicles that run on pure ethanol and another in which ethanol is mixed with gasoline or diesel fuel to produce "gasohol" for use in ordinary vehicles. Market issues relate to ethanol production efficiency, cost-competitiveness with gasoline, the commercial viability and costs of specially-designed ethanol-only vehicles, fuel distribution infrastructure, and ratios of ethanol to gasoline in gasohol blending. Global annual ethanol production from biomass is estimated at 18 billion liters, $80 \%$ of which is in Brazil.

The commercial viability of converting sugar cane to ethanol for motor vehicles has been demonstrated in the "ProAlcool" program in Brazil. Today, more than 60 percent of Brazil's sugar cane production goes to produce ethanol. Technological advances have continued to improve the economic competitiveness of ethanol and gasohol relative to conventional gasoline, although the price of oil and competitive forces in global automotive technology greatly affect ethanol's prospects. In 2000, over $40 \%$ of automobile fuel consumption and $20 \%$ of total motor vehicle fuel consumption in Brazil was ethanol. According to one estimate, about US\$140 billion would have been added to Brazil's foreign debt if ethanol had not been used as a fuel over the past 25 years.

Brazil's policies mandate the blending of ethanol with all gasoline sold in the country, and also require that all gas stations sell pure ethanol. Initially, in the 1980s, many ethanol-only cars were soldin 1985 virtually all cars sold in the country were ethanol-only. However, by 2000, ethanol-only vehicle sales declined, and most new vehicles were conventional, using gasohol. Early government subsidies for ethanol production declined significantly but were not fully eliminated. Because some ethanol 
production is not competitive with gasoline at lower oil-price levels, the viability of the ethanol market continues to depend on subsidies, further efficiency improvements, and the economic value placed on externalities of fossil-fuel use. Future markets appear to favor use of gasohol rather than pure ethanol.

\section{Part 2: Emerging Lessons}

\subsection{Impacts on Rural Development}

After decades of renewable energy programs and investments in rural areas of developing countries, relatively little is known about the ability of renewables to deliver services that will raise incomes and provide other social benefits. Certainly there are social benefits from lighting, TV, and radio powered by solar home systems, mini-grids, and biogas, and even some economic benefits from reduced kerosene and candle use. Biogas for cooking and improved biomass stoves may also reduce expenditures for fuel wood, either in time or money, as well as create jobs. On balance, however, the literature does not offer a strong case that large rural development benefits have occurred from renewable energy.

Most insight on the economic benefits of rural electricity comes from literature on rural electrification through extension of central power grids. Studies clearly show the benefits and improvements in quality of life through electrification. But where rural electrification took place without other supporting economic infrastructure and skills, as happened in many development projects, productive economic development has often not followed. That is, economic benefits depend not just on the availability of energy, but also on other conditions favoring small business, such as access to markets, finance, communications, and education.

Research results are emerging slowly. In Inner Mongolia, a socio-economic assessment of small household-scale wind turbines found that households bought appliances such as refrigerators, washing machines, rice cookers, irons, and electric heaters to improve living conditions and save time, particularly for women. The study found that television and radio provide language instruction and information on commodity prices, weather, and new farming methods and practices. Electricity also increased income-generating activities.

On balance, it is not clear how welfare and quality of life benefits will drive demand for renewable energy systems beyond the wealthiest rural households. We hypothesize that applications of renewable energy that provide income-generation and social benefits, such as clean drinking water, cottage industry, distance education, and improved agricultural productivity, will appeal to increasing segments of rural populations.

Lessons suggested by experience are that: (a) social benefits and quality of life, rather than income and economic benefits, have driven markets for renewable energy in rural areas; (b) experience with "productive uses" of renewable energy is still in its infancy and deserves much greater attention from donors, development agencies, and governments; (c) economic benefits from renewables are more likely in rural areas that can incorporate the additional energy dimension into existing development activities for water, health, education, agriculture, and entrepreneurship; and (d) published studies of income generation and economic benefits from renewable energy are still limited and call for further research.

\subsection{Affordability, Consumer Credit, and Sales vs. Rentals}

In the rural energy and development literature, much has been made of "affordability" of rural household systems like solar home systems, biogas digesters, and improved biomass stoves. Many argue that households can "afford" to substitute solar home systems for candles and kerosene lighting if the monthly costs for each are comparable. Based on "affordability analyses," some donor programs for solar home systems began by offering large 100-watt sizes. Donors soon found these sizes too expensive for rural households and decreased sizes to 50 watts and below. This "small-size" approach to affordability also has occurred in the private markets in Kenya, Morocco and China, where households 
most often buy very small systems (10-15 watts). Even so, most buyers are among the wealthiest households in rural areas.

Consumer credit is another approach to affordability. A few notable examples of consumer credit for solar home systems have emerged. In Bangladesh, Grameen Shakti has offered 3-year credit. The Vietnam Women's Union offered similar credit terms for systems sold by a private vendor in Vietnam. In Sri Lanka, Sarvodaya, a national microfinance organization, has offered 2- to 5-year credit with 20$25 \%$ downpayment for purchases from any of three private vendors in that market. However, the total number of systems sold for credit is still very small compared to the booming "cash" markets in countries such as Kenya, Morocco, and China. Some have argued that consumer loans do not fit traditional microcredit lending models, and that the prospects for consumer credit are very specific to cultural, legal and financial factors in each country.

Another approach to affordability is the rental model. Typically, an "energy service company" supplies households with solar home systems for a flat monthly fee, sometimes including end-uses like lights. However, rental models are employed on small-scales in only three countries so far: the Dominican Republic, South Africa, and Argentina. The Argentina and South Africa cases are a variation of the rental model using so-called "concessions"-private competitively selected companies with an obligation to serve all customers in a specific geographic region.

Lessons suggested by experience are that: (a) historically, affordability of rural energy has been addressed through government subsidies, donor programs, and private cash sales of small systems; (b) new approaches to affordability are emerging, including vendor-supplied credit, microcredit, and rental models, but are still largely untested; (c) credit risk is a serious concern of both financiers and dealers and makes credit sales challenging; (d) lower income rural households will need long-term credit or rental options; (e) even with credit or rentals, lower incomes groups will only benefit with targeted policies, including subsidy policies, justified by development goals.

\subsection{Equipment Subsidies and Market Distortions}

Subsidies for renewable energy equipment have been driven by three interwoven factors: (i) donors using equipment installation as a visible and politically viable approach to development aid (particularly "tied aid" that requires the equipment to come from the donor country); (ii) the need for subsidies to build market volume on the premise that costs will decline as volume increases, due to economies of scale and learning; and (iii) government goals for addressing poverty and economic development in rural areas. Renewables must often compete against "hidden" subsidies for conventional fuelseverything from subsidized kerosene and coal to government investments in power grid extensions not recovered by electricity rates.

One lesson emerging is that "donations without any cost-recovery destroy markets." Donors are still undermining markets with large capital cost subsidies and donated equipment. The earliest donor projects simply provided equipment and left users on their own. Later came donor projects which still provided free equipment, but also set up sustainable schemes for collecting user fees to pay for ongoing maintenance and spare parts. But without more donor assistance, no more systems can be installed. Some donors have claimed that part of fees charged in some projects are set aside to pay for future capital purchases, but most fees appear adequate only to pay for maintenance and parts. Another problem is that donations can inhibit commercial markets, as consumers come to expect donor aid and will wait rather than pay market prices. Donor projects are still valuable - they can help familiarize governments with technologies and demonstrate market viability. But donors need to better understand existing private activities.

Most recently, the use of "smart subsidies" has been advocated. These subsidies exist only for a limited program duration and are supposed to be self-eliminating. The theory is that subsidized investments and business development eventually lower transaction and technology costs, through learning and economies of scale, to a point where subsidies become unnecessary. Smart subsidies also imply payments based on operational performance, rather than on capital investment. This was the case in the Nepal biogas program, where subsidy payments to individual projects were based on operational milestones over periods of up to three years. The Nepal program also set subsidies inversely related to income. 
Lessons suggested by experience are that: (a) subsidies are unlikely to lead to sustainable markets unless they explicitly create the conditions whereby they are no longer needed (i.e., "smart" subsidies); (b) subsidies can undermine private investments and business in new markets and should be applied with attention to private-sector conditions in a particular market; (c) subsidies can be used effectively to build up initial market volume, local expertise, user awareness, appropriate technology adaptation, quality standards, and entrepreneurial activities; (d) subsidies are more effective when tied to operating performance rather than investment; and (e) continuing subsidies may always be needed for poorer segments of the population.

\subsection{Rural Enterprise Development, Financing, and Business Vi- ability}

Rural entrepreneurship is neglected in much of the literature on rural renewable energy in developing countries. The track record of donor programs in creating and sustaining enterprises is particularly poor. One example is solar home systems in Zimbabwe, where dozens of enterprises entered the market in the mid-1990s in response to a donor program, but then went out of business after the program ended. If businesses are not viable, the sustained provision of after-sales service suffers; many households in Zimbabwe were left without local servicing. Similarly in South Africa, many solar home systems no longer work because maintenance service is not available and original equipment suppliers left the market.

Some have estimated that tens of thousands of rural enterprises offering renewable energy-based products and services would be required to meet the needs of hundreds of millions of households. The number of such enterprises today is in the hundreds. The challenges are large: entrepreneurs often face high costs in rural areas because of long travel distances, poor transport infrastructure, low literacy rates, poor communications, and a lack of trained personnel. Fortunately, promising approaches are emerging that support rural entrepreneurs with training, marketing, feasibility studies, business planning, management, financing, and connections to banks and community organizations. These experiences highlight the importance of marketing, business finance, bundling with existing products, and rural electrification policy.

The lack of rural business financing in particular is often cited as one of the primary factors hindering the development of markets. Credit may be unavailable, too expensive or too limited in time to be usable. Entrepreneurs first face one-time business development costs, such as market surveys, personnel training, establishing sales and service networks, and writing a business plan. They must convince a bank that the business plan is sound-difficult if bankers lack familiarity with renewable energy. Experience also suggests that rural electrification policies and planning have a major influence on market growth and sustainability in specific locations. Unrealistic political promises or plans for rural electric grid extension can be serious barriers to solar-home-system market expansion, as households expect to be "connected" soon.

Lessons suggested by experience are that: (a) a few donor programs have effectively assisted rural renewable energy-based enterprises to build a sustainable and viable business; (b) rural energy enterprises face a high-risk, low-margin business with high transaction costs; (c) commercial banks and financial intermediaries are key decision makers, who must understand the technologies and manage risks; (d) demonstration of viable business models that eventually show sustained profits for the enterprise is key to achieving market sustainability.

\subsection{Policies and Financing for Private Power Producers}

Ongoing power sector restructuring in many developing countries greatly affects the prospects for grid-connected renewable energy. Six key trends occurring are competitive wholesale power markets, self-generation by end-users, smaller-scale generation technologies, privatization and/or commercialization of utilities, "unbundling" of generation from transmission and distribution, and competitive retail sales. With these changes, particularly as utilities become privatized and/or rely on other parties to 
construct generation, utilities increasingly may have little interest in renewable energy themselves. These trends leave a growing share of the power generation field to private power developers.

More than 25 developing countries now have regulatory frameworks that allow "independent power producers" (IPPs) to generate and sell power to utilities under "power purchase agreements." Some countries, including India and Brazil, have additional policies to facilitate grid-connected renewable energy, such as power transmission "wheeling" (selling power to a third party via the utility's transmission lines), "banking" (generating power for later consumption), and direct power sales from producers to end-users. Still, renewable energy power developers in developing countries have faced problems, particularly with financing and with regulatory frameworks that define power purchase tariffs and transmission access.

Developed countries have enacted a number of policies to promote grid-based renewable energy, but most of these policies have yet to be seen in developing countries. So far, India is the only developing country to enact investment tax credits, which spurred a large domestic wind power industry. But these investment-based incentives led to large investments without sufficient regard to long-term operating performance and maintenance. In Brazil, utilities are allowed to purchase renewable power at higher prices than conventional electricity. In addition, IPPs may supply electricity on a competitive basis to any third-party and receive open access to the transmission system based on wheeling fees. Small hydro producers receive $50 \%$ discounts on transmission wheeling fees. Besides India and Brazil, other countries with electric power policies that are leading to greater renewable energy include China, Costa Rica, Morocco, Sri Lanka, and Thailand.

In addition to policy frameworks, availability of financing for renewable power projects is key to market development. Commercial banks must be familiar with and confident in the technology, and must consider power purchase contracts secure enough to guarantee that power developers maintain revenues. But many PPAs with utilities in developing countries can't be "taken to the bank" because of utility contract default risk, revenue risk (tariffs may be subject to annual or short-term adjustment), or currency devaluation risk.

Lessons suggested by experience are that: (a) policies that promote production-based incentives rather than investment-based incentives are more likely to spur industry performance and sustainability; (b) power-sector regulatory policies for renewable energy should support IPP frameworks that provide incentives and long-term stable tariffs for private power producers; (c) regulators need skills to understand the complex array of policy, regulatory, technical, financing, and organizational factors that influence whether renewable energy producers are viable; (d) financing for renewable power projects is crucial but elusive.

\subsection{Market Facilitation Organizations (MFOs)}

Market facilitation organizations (MFOs) are public-private entities that support the growth of particular markets through a variety of means. MFOs may provide networking, partner matching, information dissemination, market research, user education, business-deal identification and facilitation, technical assistance, consulting services, financing, and policy advocacy or advise. Common and historical forms of MFOs are industry associations and government agencies. The highest level government agency serving in this capacity is the Ministry of Non-Conventional Energy Sources of India, which has undertaken many market facilitation programs, in partnership with the India Renewable Energy Development Agency.

In the past decade, a new generation of MFOs has emerged to support renewable energy markets in developing countries - supported by both international donors and domestic sources. These new MFOs operate with a business interest in the industry, but also with a public interest in seeing the technology widespread for public benefits. MFOs, even if initially supported entirely from public funds, usually end up obtaining a share of their funds from private sources in exchange for services. MFOs are usually unable to operate entirely on private revenues, however, since much of the publicinterest aspects of their work cannot be "billed" to private clients. MFOs may be non-profit and nongovernmental - but their purpose is different than traditional NGOs, which have historically focused on public policy advocacy. 
As one example, much of the success of China's dissemination of household-scale renewable energy technologies comes from organizational infrastructure and capacity in rural areas, including MFOs. The Ministry of Agriculture has established rural energy offices at county, district and township levels that provide a variety of services, including information, subsidies, and technical support.

NGOs have often served as MFOs for renewable energy, often with a development motivation, but also accompanied by a private-sector orientation. NGO-led micro-hydro power development in several countries is a good example. In India, the success of rural biogas and improved wood stove programs can be linked to market facilitation efforts by the All India Women's Conference. The five-country network of "renewable energy project support offices" funded through Winrock International act as MFOs. In China, a new renewable energy industry association is facilitating markets, improved capabilities of local firms, financing, and partner matching. In some countries, private power developers have performed a crucial MFO-like role.

Lessons suggested by experience are that: (a) MFOs can be powerful market stimulants but very few exist; (b) public-private MFOs most likely need full public funding to begin, but eventually can become partly self-supporting through private contracts; (c) very few people are thinking about the power of MFOs to stimulate renewable energy market development.

\section{Conclusions}

Based on our examination of renewable energy markets, we conclude that several markets show promise of greatly expanding. Some national programs are poised to expand solar home systems and solar lantern markets for rural residential lighting. For example, India and China have proposed over 10 million additional systems in the next ten years. Programs and future targets for grid-based power production are also expanding. India has proposed that $10 \%$ of new capacity additions through 2012 come from renewable energy, which would mean an additional 10,000 MW. Similarly, China proposes to require $5 \%$ of new power generation from renewables by 2010 , which could mean an added 20,000 MW. Finally, applications for income generation and social benefits are growing markedly but remain underreported; for example, solar PV appears poised to increasingly pump, purify, and distribute drinking water in isolated villages.

The growth of these markets and others will require increased technical know-how in developing countries-including local capabilities to adapt, install, operate and maintain technologies and to build local manufacturing industries. Large renewable energy industries exist in some countries already, notably Argentina, Botswana, Brazil, China, India, Nepal, South Africa, and Thailand. Despite the rhetoric about public "technology transfer," commercially-oriented technical know-how transfer takes place primarily between private entities through licensing, production agreements, joint ventures, or subsidiaries. Public policies must facilitate technical know-how transfer while guarding against "technological imperialism"- - a term used to question the effects of local industry being pushed aside by foreign firms. Some stress the need for "national systems of innovation"-interwoven networks of firms and public institutions.

New sustainable and replicable business models for both consumptive and productive uses of renewable energy in rural areas will also be needed. In addition to new solar home systems business models, other models that promote long-term economic and social benefits show great promise, such as building mini-grids around income-generating microenterprise and incorporating renewable energy into water, agriculture, education, and telecommunications. Insights into successful approaches and models are still far from adequate. Small entrepreneurs and larger firms should be encouraged to take risks and build new businesses.

Even though many donor efforts have not been sustainable or replicable, donor assistance for renewables is still vital for improving environmental conditions and incomes. However, donor projects must avoid an 'equipment demonstration' mentality where the main objective is installation and maintenance of a certain number of systems. By project completion, the amount of hardware installed is much less significant than whether the business, delivery and credit models are viable, sustainable and being replicated, which requires donors to rethink traditional development assistance patterns. 
One must not forget that many renewable energy efforts are directed at improving energy for the poor. Some argue that purely market orientations are going to leave behind large segments of the poorest. Effective policy approaches for reaching them may combine private sector actions with targeted public subsidies linked to development goals and strategies for increasing incomes. Such policies must not lose sight of the real goal - meeting the basic needs of the poor-and must weight the cost and benefits of renewables against all options for water, agriculture, health, education, and transport. For this reason, energy authorities are less relevant to good policy-which is properly the domain of authorities in these other sectors.

Governments need to foster the appropriate conditions for viable rural entrepreneurship and gridbased power investments incorporating renewable energy. Commercial banks, multilateral organizations, and other public lenders need to provide business finance to entrepreneurs, credit to consumers, and project finance to power project developers. National governments and international donors should create and support market facilitation organizations. Finally, research is needed on successful experiences and business models, social and income benefits, technology applications meeting user needs, and lessons from emerging sectoral policy successes and failures-grounded in the specific culture, politics, institutions, and history of each country.

\section{Selected Bibliography}

Anderson D. 1997. Renewable energy technology and policy for development. Annual Review of Energy and the Environment 22:187-215

Barnes D, Floor WM. 1996. Rural energy in developing countries: a challenge for economic development. Annual Review of Energy 21:497-530

Byrne J, Shen B, Wallace W. 1998. The economics of sustainable energy for rural development: a study of renewable energy in rural China. Energy Policy 26(1):45-54

Cabraal A, Cosgrove-Davies M, Schaeffer L. 1998. Accelerating sustainable photovoltaic market development. Progress in Photovoltaics: Research and Applications 6(5):297-306

Cecelski E. 2000. Enabling equitable access to rural electrification: current thinking and major activities in energy, poverty and gender. Proc. Brainstorming on Poverty Alleviation and Women, Jan 26-27, Washington, DC, World Bank. http://www.energia.org.

Chaurey A. 2001. The growing photovoltaic market in India. Progress in Photovoltaics: Research and Applications 9: 235-44

G8 Renewable Energy Task Force. 2001. Final Report, http://www.renewabletaskforce.org

Goldemberg J, Reddy AKN, Smith KR, Williams RH. 2000. Rural energy in developing countries. In World Energy Assessment: Energy and the Challenge of Sustainability, ed. J. Goldemberg et al, pp.367-92. New York: UN Development Programme

Kammen DM. 1999. Bringing power to the people: promoting appropriate energy technologies in the developing world. Environment 41(5):10-15;34-41

Karekezi S. 2001. The potential of renewable energy technologies in Africa. In Renewable Energy Technologies: Potential for Africa. Nairobi: United Nations Environment Programme

Kartha S, Larson ED. 2000. Bioenergy Primer: Modernised Biomass Energy for Sustainable Development. New York: UN Development Programme

Kozloff K. 1998. Electricity Sector Reform in Developing Countries: Implications for Renewable Energy. Renewable Energy Policy Project, Washington, DC

Lew D. 2000. Alternatives to coal and candles: wind power in China. Energy Policy 28: 271-86

Martinot E, Cabraal A, Mathur S. 2001. World Bank/GEF solar home systems projects: experiences and lessons learned 1993-2000. Renewable \& Sustainable Energy Reviews 5(1):39-57

Moreira JR, Goldemberg J. 1999. The alcohol program. Energy Policy 27(4):229-45

Niewenhout FDJ, van Dijk A, van Dijk VAP, Hirsch D, Lasschuit PE, et al. 2000. Monitoring and Evaluation of Solar Home Systems: Experiences with Applications of Solar PV for Households in Developing Countries. Petten, Netherlands: Netherlands Energy Research Foundation ECN 
Posorski R. 1996. Photovoltaic water pumps: an attractive tool for rural drinking water supply. Solar Energy 58(4-6):155-63

Ramana PV, ed. 1997. Rural and Renewable Energy: Perspectives from Developing Countries. New Delhi: Tata Energy Research Institute

Reddy AKN, Williams RH, Johansson TB. 1997. Energy After Rio: Prospects and Challenges. New York: United Nations Development Program

Smith KR, Gu S, Kun H, Qiu D. 1993. 100 million biomass stoves in China: how was it done? World Development 21(6):941-61

van Campen B, Guidi D, Best G. 2000. Solar Photovoltaics for Sustainable Agriculture and Rural Development. Food and Agriculture Organization of the United Nations, Rome. http://www.fao.org/sd/egdirect/egdocuments

Wamukonya N, ed. 2001. Experience with PV Systems in Africa: Summaries of Selected Cases. Nairobi: UN Environment Programme

Williams RH. 2001. Addressing challenges to sustainable development with innovative energy technologies in a competitive electric industry. Energy for Sustainable Development 5(2):48-73

Wilkins, G. 2002. Technology Transfer for Renewable Energy: Overcoming Barriers in Developing Countries. London: Earthscan.

World Bank. 1996. Rural Energy and Development: Improving Energy Supplies for 2 Billion People. Washington, DC 


\title{
Assessment of the Potential of State-of-the-art Biomass Technologies in Contributing to a Sus- tainable SADC Regional Mitigation Energy Scenario
}

\author{
Prof. F. D. Yamba - Director \\ Mr. E. Matsika - Associate \\ Centre for Energy, Environment and Engineering Zambia \\ Private Bag E721 \\ Lusaka \\ Zambia \\ Tel/Fax: 260 - 1 - 240267
}

Email: yamba@eng.unza.zm/ ematsika@eng.unza.zm / ceez@coppernet.zm

\section{Background on Biomass Potential}

\subsection{The Cane Resource}

The sugarcane plant is one of the world's most cost effective and diversified renewable resources, offering many alternatives for production of food, energy, fibre and feed. Owing to climatic factors, sugarcane is found predominantly in the developing world and as sustainable energy resources and new development alternatives. Sugarcane resources support a variety of uses and products based on different resource streams: sugars, molasses/juice, and crop residues, as shown in Figure 1 [1].

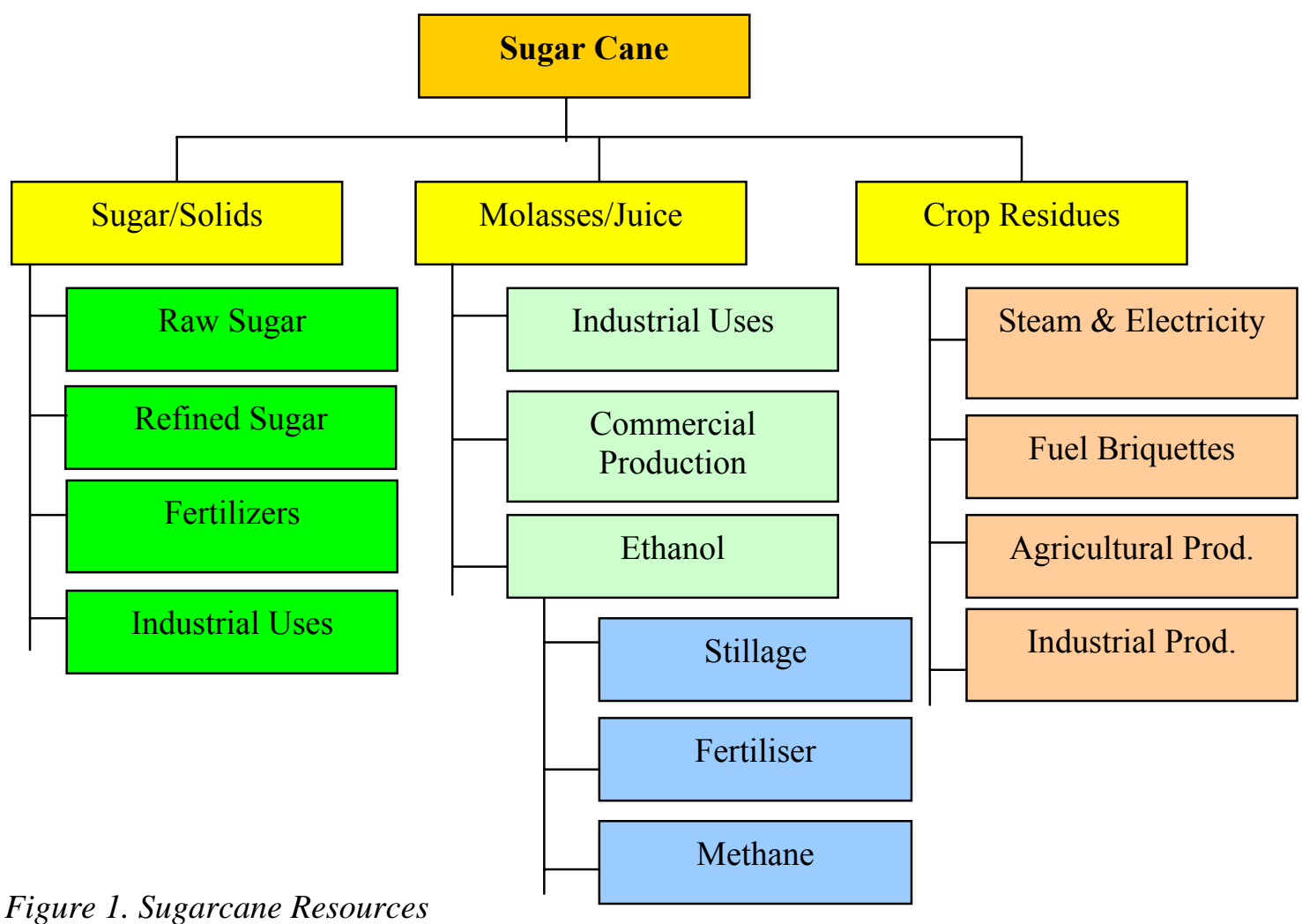


Cogenerated electricity and ethanol are amongst the most important cane co-products in commercial terms, but there are many others as well.

\subsection{Emerging Markets}

The sugar industry has faced increasing competitive pressures in recent years, due to such factors as saturated demand in industrialised countries and competition from other sweeteners, which has resulted in low and/or fluctuating sugar prices. These difficulties have increased economic incentives for sugar producers to diversify their product portfolio by investing in renewable energy applications. Diversification of sugar companies into renewable energy has been slowed by institutional barriers and by continued price supports for sugar production around the world [1].

\subsection{Southern African Potential}

The current cane resource base in Southern African countries is approximately 45.0 million tonnes annually as shown in Table 1 [1].

Table 1. Cane Resource Base in Southern Africa.

\begin{tabular}{|l|c|c|c|c|}
\hline \multirow{2}{*}{ Country } & Production & Area & Avg. Yield & Bagasse Availability \\
\cline { 2 - 5 } & $\mathbf{1 0 0 0}$ tc & $\mathbf{1 0 0 0}$ ha & tc/ha & ('000 tonnes) \\
\hline Angola & 360 & 10 & 38 & 108 \\
\hline DR Congo & 1669 & 36 & 46 & 500.7 \\
\hline Malawi & 2000 & 19 & 105 & 600 \\
\hline Mauritius & 5109 & 73 & 70 & 1532.7 \\
\hline Mozambique & 397 & 27 & 15 & 119.1 \\
\hline South Africa & 23896 & 322 & 74 & 7168.8 \\
\hline Swaziland & 3885 & 37 & 106 & 1165.5 \\
\hline Tanzania & 1355 & 15 & 90 & 406.5 \\
\hline Zambia & 1600 & 15 & 107 & 480 \\
\hline Zimbabwe & 4228 & 43 & 98 & 1268.4 \\
\hline SADC Total & $\mathbf{4 4 4 9 8}$ & $\mathbf{5 9 6}$ & $\mathbf{7 5}$ & 13349.4 \\
\hline World Total & $\mathbf{1 , 2 5 8 , 5 3 1}$ & $\mathbf{1 9 , 1 8 6}$ & $\mathbf{6 6}$ & \\
\hline & $\mathbf{3 . 5 \%}$ & $\mathbf{3 . 1 \%}$ & & \\
\hline
\end{tabular}

Bagasse, fibrous product left over after extraction of sugar from sugarcane has enormous potential as a renewable fuel. Table 1 shows the bagasse available from the SADC sugarcane factories. The figures are derived taking the assumption that bagasse content in the cane averages $30 \%$ in most SADC countries.

If sugar demands have to be met in SADC in the next two or three decades, there is need for existing factories to expand and new factories created to meet this growing demand. The prospect for this expansion does exist in view of adequate available land and infrastructure [2].

Assuming an average per capita consumption of $15 \mathrm{~kg} /$ person per year [2], and a projected growth rate of $2.0 \%$ per annum in sugarcane production, the projected sugarcane production will increase from the present level of 45 million tonnes per annum to 55.1, 67.0, 82.0 and 121.0 million tonnes in 2010, 2020, 2030 and 2050, respectively.

Based on the above assumptions, the projected bagasse resource availability in SADC is given in Table 2. 
Table 2. Bagasse Resource Availability.

\begin{tabular}{|c|c|}
\hline Year & Bagasse Resource available (tonnes) \\
\hline 2000 & 13.5 \\
\hline 2010 & 16.5 \\
\hline 2020 & 20.1 \\
\hline 2030 & 24.5 \\
\hline 20500 & 36.3 \\
\hline
\end{tabular}

\section{Southern Africa Energy Supply Baseline}

\subsection{Southern African Power Pool}

Southern Africa's energy supply is based on power sector collaboration - the Southern African Power Pool (SAPP). SAPP was created in 1995 through an inter-utility memorandum of Understanding among 12 of the SADC utilities including Congo DR.

The aims of SAPP are:

- To increase regional security of supply

口 To smoothen load curves

a To engender economies of scale in the supply base

口 To increase revenue for exporting countries by opening up a ready market

- To share power to meet national shortfalls and to off set temporary deficits in the medium term, and in the long term to adopt and implement power sharing as an operational strategy aimed at maximising financial and environmental benefits

\subsection{Status Quo and Baseline for 2000}

Currently, SAPP has an operational installed capacity of $45,000 \mathrm{MW}$, of which $84 \%$ is thermal, predominantly coal based, which represents $79.0 \%$ of total supply. Hydro stands at $16.0 \%$ of total SAPP interconnected supply, while the contribution from biomass is currently non-existent (Figure 2) [3.4].

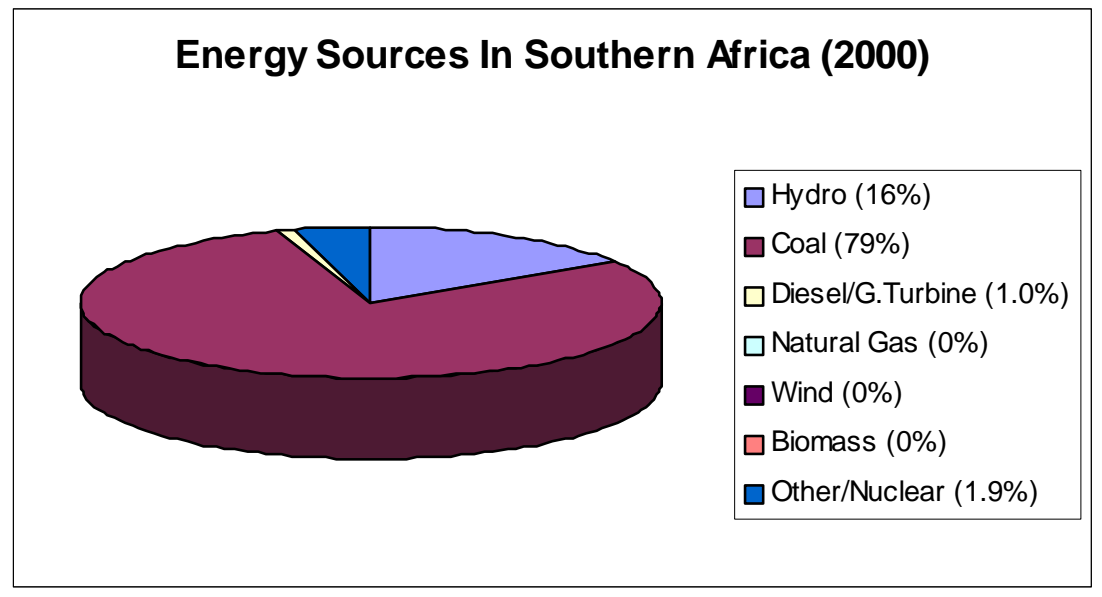

Figure 2. SAPP Installed Electricity Capacity for 2000 (Total Energy 45 GW) 


\subsection{SADC Projected Energy Demand / Supply Scenario}

To come up with the projected demand, the following assumptions were made for electricity growth rates [3],

$\begin{array}{lcc} & \underline{\mathbf{2 0 1 5 - 2 0 2 0}} & \underline{\mathbf{2 0 2 0 - 2 0 5 0}} \\ \text { South Africa } & 2.0 \% & 1.5 \% \\ \text { Rest } 2,5 \% & 3.5 \% & 2.5 \%\end{array}$

The projected energy supply has been arrived at taking into account national utility plans and also experts' assessment on the energy natural resource potential of each SADC country. The results of the supply projections are shown in Figure 3.

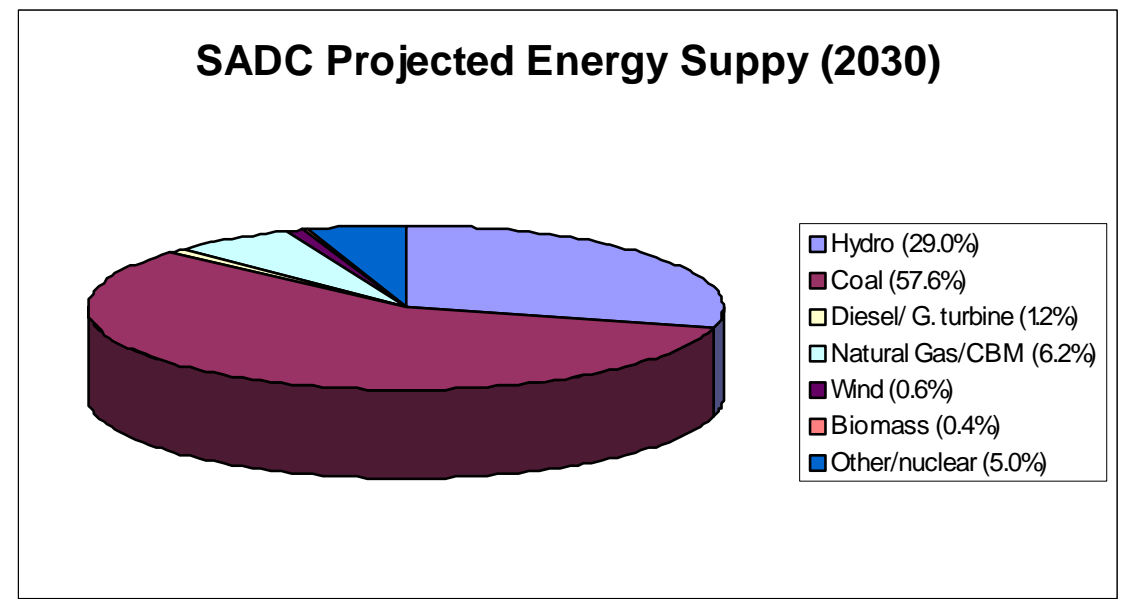

Figure 3 (a). SADC Projected Energy Supply Scenario 2030. (Total Energy 115.2 GW)

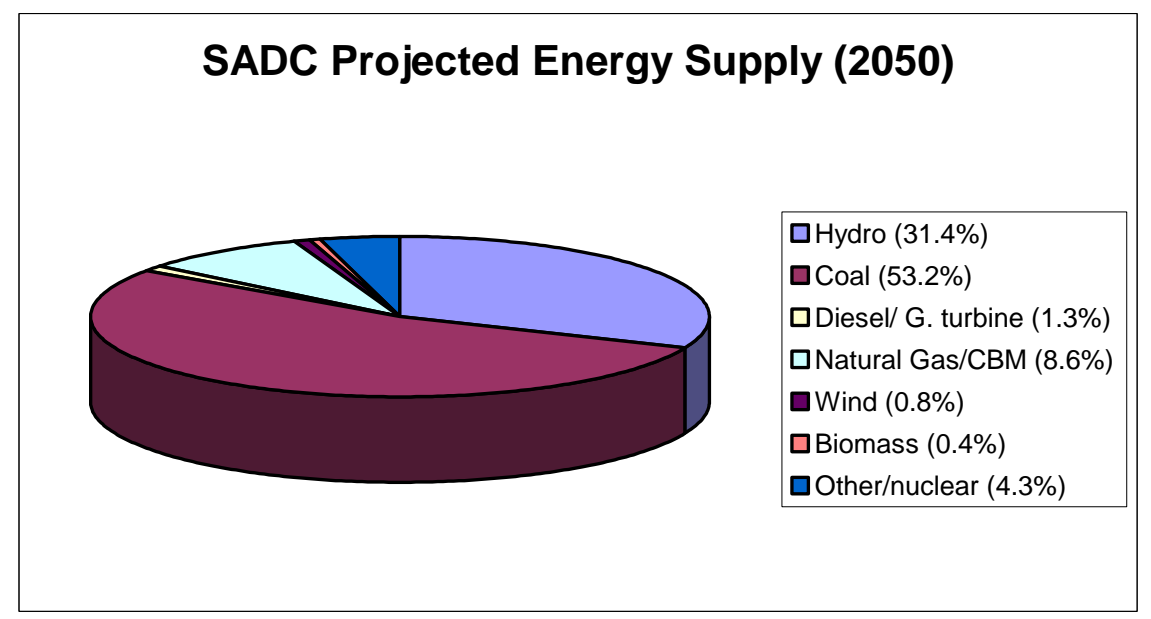

Figure 3 (b). SADC Projected Energy Supply Scenario 2030. (Total Energy 115.6 GW) 


\section{Sustainable Mitigation Scenario which Takes Account of the Role of Bio-Energy}

\subsection{Introduction}

It is Evident from the SAPP's energy supply that the role of bio-energy is negligible amounting to $0.40 \%$ of the total energy supply in 2050 . With the availability of state-of-the-art biomass based technologies, the sugar industry in Southern Africa can significantly alter this picture.

\subsection{State-of-the-art Biomass Based Technologies}

Currently, the sugar industry in Southern Africa uses the traditional approach (conventional back pressure steam boilers) through use of medium pressure ( $15-25$ bars) bagasse -fired boilers/steam turbine systems to co-generate just enough steam to meet the on-site needs. Boilers and steam generators are typically run inefficiently in order to dispose of as much of the bagasse produced from crushing the canes as possible [2].

With the availability of the state-of-the-art technologies. sugar factories can harness the on-site bagasse resource to go beyond meeting their own requirements and produce surplus electricity for sale to the national grid including SAPP interconnected system.

There are three options for selling surplus electricity from sugar production, and they include [2]:

- Improved combustion in traditional boilers

- CEST (Condensing Extraction Steam Turbine)

- $\mathrm{BIG} / \mathrm{CC}$ (Biomass Integrated Gasifier Combined Cycle)

\section{Improved Combustion in Traditional Boilers}

The key to production of surplus electricity in sugar factories is to optimise factory steam generation and utilisation so as to be able to save bagasse through improved combustion $[5,6]$. The approach involves efficient firing of bagasse fuel through maximum use of heat as steam, and control of combustion temperatures, and corresponding air-fuel ratios, and varying loads through use of combustion efficiency monitoring equipment.

\section{Condensing Extraction Steam Turbine (CEST)}

CEST, which uses more efficient steam turbines operating at high pressures, with exhaust at pressures below atmospheric is now available on the market [2], and can significantly increase electricity production at sugar factories.

A typical CEST operates at $40-80$ bars and has a series of expansion turbines. These systems produce enough steam to supply a typical sugar factory, and have surplus electricity to export to the national grid. The key innovation of CEST is that it will yield greater energy production using the same fuel input as traditional boilers. For example, these systems produce enough steam to supply a typical sugar factory and distillery, and export $30-100 \mathrm{kWh}$ of electricity per tonne of cane $(\mathrm{kWh} / \mathrm{tc})$ to the national grid [7].

\section{Biomass Integrated Gasifier Combined Cycle (BIG/CC)}

This system involves gasification of biomass for use in a high efficiency gas turbine. The approach is based on a combination of two technologies [2]. These include a biomass gasifier unit with a gas turbine and the other being steam turbine utilising steam generated from hot exhaust gases from the gas turbine. The combination of the two results in the "Biomass Integrated Gasifier - Combined Cycle (BIG/CC)". These systems produce over twice as much power per tonne of cane as CEST systems. 
However, unlike CEST systems, BIG-CC systems are not yet commercially mature at present. In addition, they have high capital cost.

\subsection{Potential Surplus Electricity Generated From Southern Af- rica's Factories Based on Current and Projected Bagasse Avail- ability}

Based on the current and projected bagasse resource available from Table 2, this section estimates the surplus electricity from Southern Africa based on

- Traditional Boilers with improved Combustion

- CEST

- BIG-CC

(i) Surplus electricity from traditional boilers with improved combustion is estimated using the empirical relation $[6,8]$

$\mathrm{E}_{\mathrm{ex}} / \mathrm{Y}_{\mathrm{c}}=0.278 \times \eta_{\text {elect }} \times\left(17643-203 \times \mathrm{w}_{\mathrm{b}}\right) \times\left[(\mathrm{b} / 100)-1.05 \mathrm{xSC} / \mathrm{r}_{\mathrm{sb}}\right]-\mathrm{E}_{\mathrm{f}}$

Where,

$$
\begin{array}{ll}
\mathrm{E}_{\mathrm{ex}} / \mathrm{Y}_{\mathrm{c}}-\text { surplus electricity potential }(\mathrm{kWh} / \text { tonne cane) } \\
\eta_{\text {elect }} & \text { - electricity yield }(\%) \\
\mathrm{w}_{\mathrm{b}} & \text { - bagasse moisture content }(\%) \\
\mathrm{b} & \text { - bagasse percent in cane }(\%) \\
\mathrm{SSC} & \text { - specific steam consumption }(\mathrm{kg} / \mathrm{kWh}) \\
\mathrm{r}_{\mathrm{sb}} & \text { - steam to bagasse ratio } \\
\mathrm{TCH} & \text { - annual cane crushing capacity (tonnes) } \\
\mathrm{E}_{\mathrm{f}} & \text { - electricity for use in factory }(\mathrm{kWh} / \text { tonne cane) }
\end{array}
$$

Based on experience from typical factories in Eastern and Southern Africa, and Mauritius, the following average figures were used for computation purposes.

Table 4. Typical average Parameters of Sugar Factories.

\begin{tabular}{|c|c|}
\hline Parameter & Value \\
\hline$\eta_{\text {elect }}$ & 0.31 \\
\hline $\mathrm{w}_{\mathrm{b}}$ & $50 \%$ \\
\hline $\mathrm{b}$ & $30 \%$ \\
\hline $\mathrm{SSC}$ & $0.50 \mathrm{~kg} / \mathrm{kWh}$ \\
\hline $\mathrm{r}_{\mathrm{sb}}$ & 2.2 \\
\hline $\mathrm{E}_{\mathrm{f}}$ & $20 \mathrm{kWh} /$ tonne \\
\hline
\end{tabular}

In turn, surplus electricity is obtained with knowledge of total cane crushed per annum in Southern Africa, excluding Mauritius.

(ii) Surplus Electricity from CEST is based on comparison of power output against bagasse utilisation in CEST technologies. Based on the annual bagasse consumption by the system, and electricity generated an index of 9 tonnes of bagasse per $\mathrm{kW}$ produced is adopted $[2,8]$. 
(iii) Surplus electricity from BIG-CC is based on the assumption from design and operational experience of such systems. The index adopted is twice the amount generated from CEST system $[2,8]$.

Based on the assumptions above, and also bagasse resource availability from Table 2, potential surplus electricity from Southern Africa's sugarcane factories is given in Table 5.

Table 5. Potential Surplus Electricity from Southern Africa Factories Excluding Mauritius Based on annual projected bagasse availability.

\begin{tabular}{|l|c|c|c|c|c|}
\hline Year & $\begin{array}{c}\text { Bagasse Re- } \\
\text { source (Million } \\
\text { tonnes) }\end{array}$ & $\begin{array}{c}\text { Traditional } \\
\text { Boiler }\end{array}$ & $\begin{array}{c}\text { Traditional Boiler } \\
\text { with improved } \\
\text { combustion (MW) }\end{array}$ & $\begin{array}{c}\text { CEST } \\
\text { (MW) }\end{array}$ & $\begin{array}{c}\text { BIG-CC } \\
\text { (MW) }\end{array}$ \\
\hline 2000 & 12.0 & Nil & 113 & 1350 & 2700 \\
\hline 2010 & 15.0 & Nil & 135 & 1620 & 3240 \\
\hline 2020 & 18.0 & Nil & 170 & 2010 & 4020 \\
\hline 2030 & 22.0 & Nil & 207 & 2450 & 4900 \\
\hline 2050 & 33.0 & Nil & 306 & 3630 & 7260 \\
\hline
\end{tabular}

Of the three options available, the CEST system is the most promising since it is a proven technology, and has good output which can go a long way in contributing significantly to a sustainable mitigation scenario for SAPP countries as shown in Figure 4.

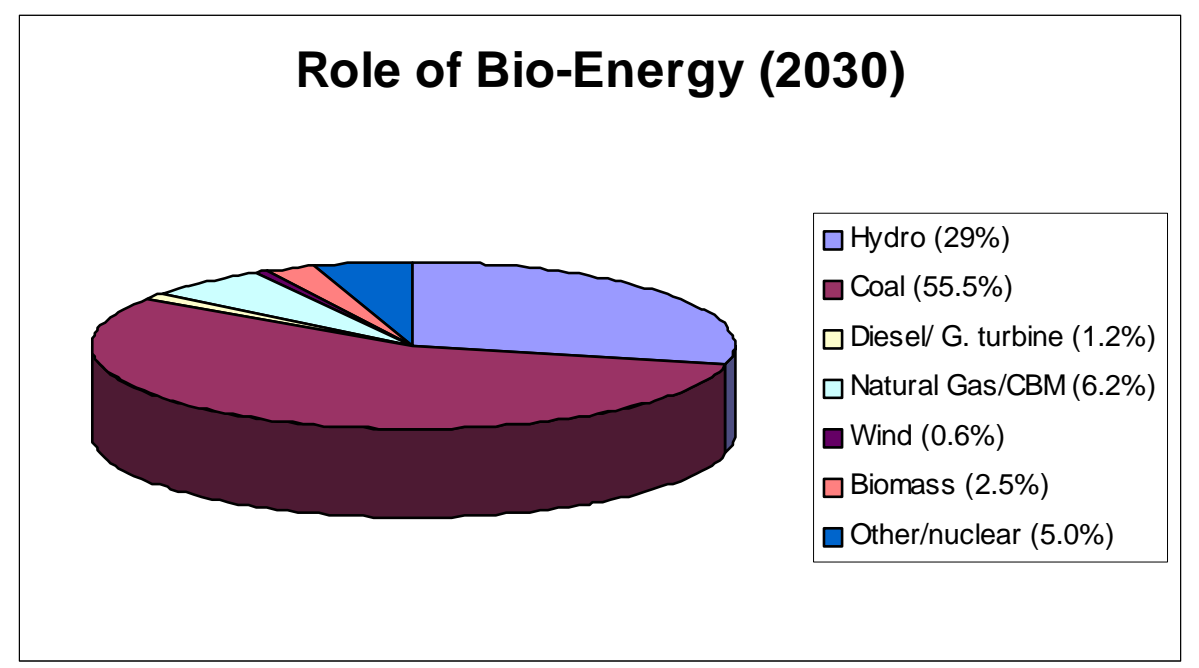

Figure 4 (a). SADC Projected Sustainable Energy Supply Scenario for 2030 (Total Energy 80.2 GW) 


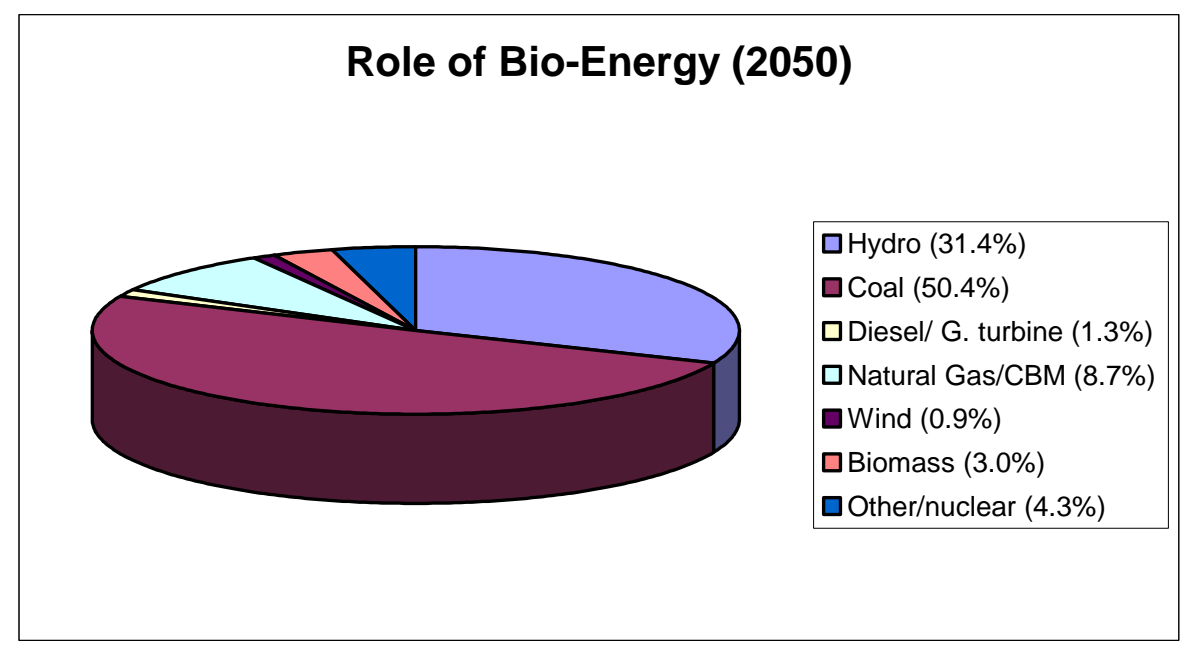

Figure 4 (b). SADC Projected Sustainable Energy Supply Scenario for 2030 (Total Energy 115.2 GW)

\section{$4 \mathrm{CDM}$ as a Driving Force for Investment}

\subsection{Barriers}

Despite concerns from different quarters that Africa will lag behind in terms of size and number of projects under CDM investment, the application of CEST technologies, for example, will go a long way in disregarding this myth. On the other hand, despite existence of such promising environmentally friendly technologies, few countries in Southern Africa have taken advantage of application of such technologies in their business as usual expansion plans. The following barriers have been identified [9] for contributing to such a status quo:

- Decision making process and behaviour

- Lack of adequate financial support

- Relatively low tariff

Due to relatively higher investment requirements for such technologies, most sugar factories in Southern Africa are reluctant to make decisions to invest due to uncertainty and risk in investing in new technologies.

Although the barrier on decision-making can now be overcome through evidence of encouraging results of successful commercial demonstration of such technologies in Mauritius and Re-union, the biggest barrier is that of lack of adequate financial support.

Most traditional banks (both multi-lateral and private) are reluctant to invest in such capitalintensive energy technologies. However, due to the great need to reduce GHGs under Climate Change Convention, the financing mechanisms under the Kyoto Protocol (such as CDM and JI) are bound to act as stimuli towards investment in such environmentally friendly technologies.

\subsection{CDM as a Driving Force for Investment}

Although it is now widely accepted that CDM will only contribute between $1.0 \%$ and $10 \%$ toward internal rate of return (IRR) of most renewable and energy efficiency technologies [10], two main factors that are likely to move such technologies towards investment and implementation are: 
- Coming on stream of green venture capital through existing and new multi-lateral and private banks.

- Benefits of partial advance payments of carbon credits for use as project finance.

\subsection{Environmental and Financial Benefits Through Investment of CEST Technologies in Southern Africa}

\section{Environmental Benefits}

A typical 60 MW CEST technology would cost in the range of US\$ 100 million and would operate for about 10 months using available bagasse on site. If the mitigation scenario adopted in the sector is implemented and taking a penetration rate of $80 \%$, this will result in potential saving GHGs as given in Table 6 .

Table 6. Potential GHG Saved Under Mitigation Scenario.

\begin{tabular}{|c|c|c|c|}
\hline Year & $\mathbf{2 0 1 0}$ & $\mathbf{2 0 3 0}$ & $\mathbf{2 0 5 0}$ \\
\hline GHG Saved (million Tonnes) & 8.0 & 14.0 & 20.0 \\
\hline
\end{tabular}

\section{Financial Benefits}

The financial benefits of investing in such technologies as CDM projects will largely depend on electricity tariff and cost of CERs for the following scenarios:

- Business as usual without sale of carbon credits

- CDM project with normal sale of carbon credits

- CDM project with $33 \%$ advance payments through sale of carbon credits

The results obtaining from such scenarios are given in Figures 5 and 6.

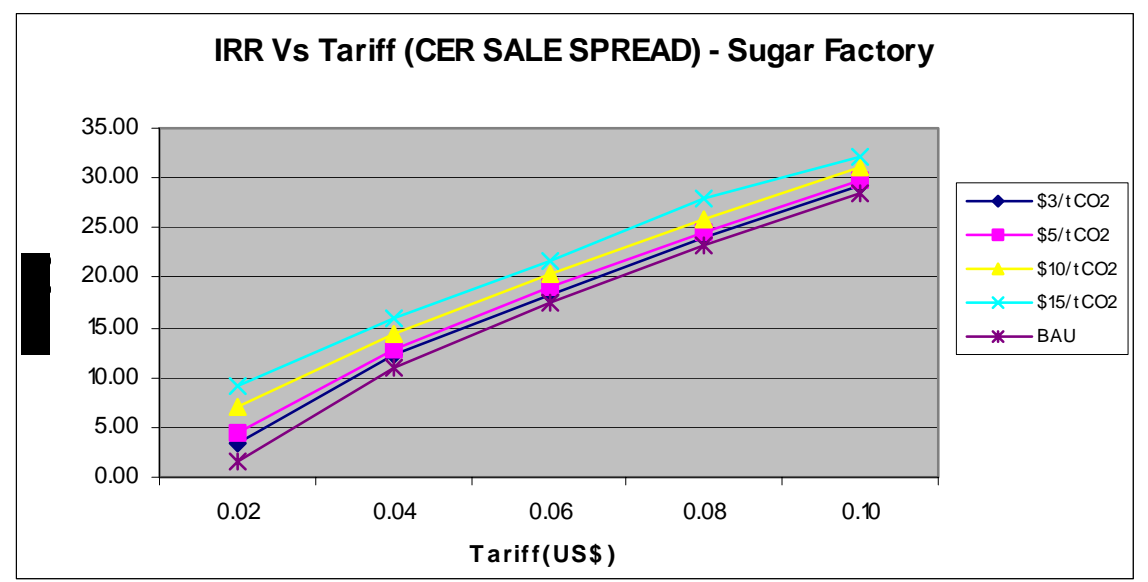

Figure 5. IRR Vs Tariff for different carbon prices (CER sale spread over crediting period) of 21 Years 


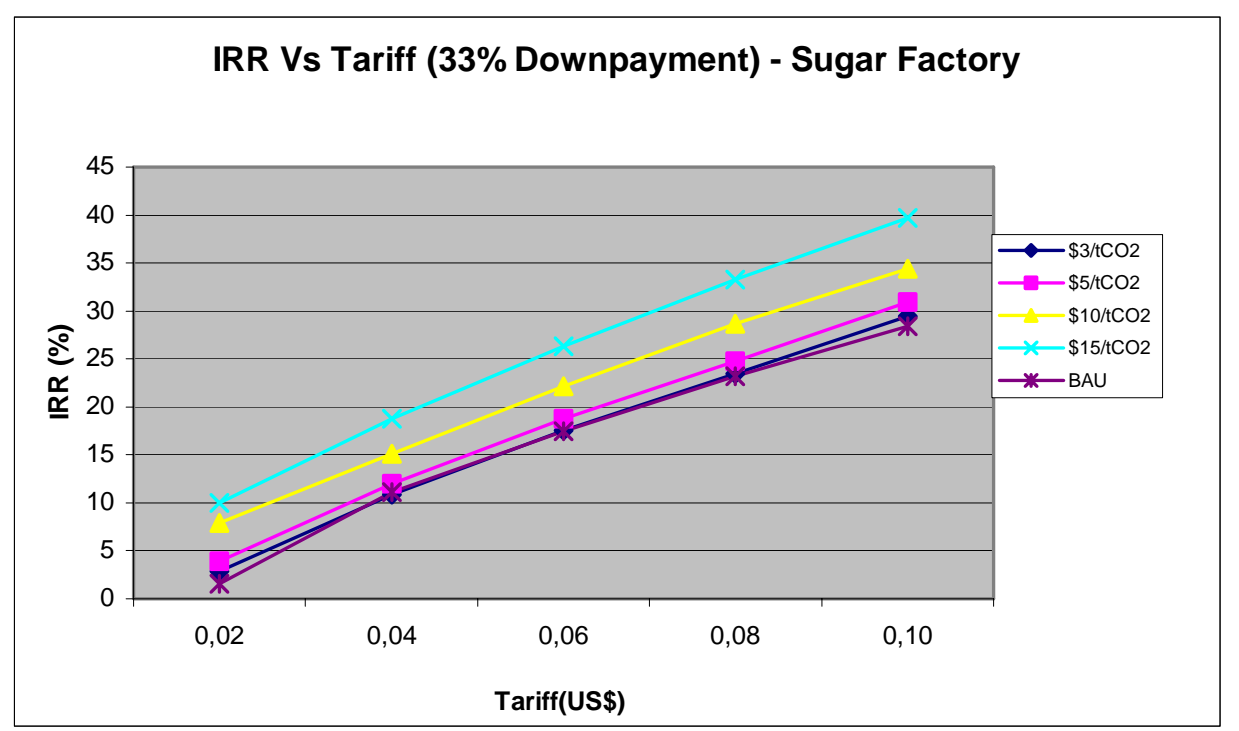

Figure 6: IRR Vs Tariff for different carbon prices (33\% Down payment, the rest spread over crediting period)

Depending on the lending rate, above graphs will greatly assist in investors deciding whether to invest in $\mathrm{CDM}$ or not.

\section{Conclusions}

Application of CEST technologies in Southern Africa on the scale suggested in this paper will modestly contribute towards a sustainable energy supply mitigation scenario. If implemented, the contribution of bio-energy will increase from $0.5 \%$, for the baseline situation, to $2.5 \%$ in 2030 and $3.0 \% 2050$. The scenario will also yield global environmental benefits potential through saving of GHG reductions to 14 million in 2030 and 20 million tonnes of $\mathrm{CO}_{2}$ in 2050.

The paper also produces a monogram which will greatly assist investors in making decisions whether to invest in CDM or not. The factors to be considered in this decision making are electricity tariffs and selling price of CERs. Electricity tariffs vary from country to country in Southern Africa, with the lowest being in South Africa around 2.0 - 2.5 US cents per kWh.

However, in case of Southern Africa, the tariff does not presently take account of externality cost of the environment due to high dependence on coal for electricity generation. Tariffs in the rest of Southern African countries are bound to increase as the utilities become commercialised and need to charge tariffs based on marginal costing.

Successful implementation of the state-of-the-art biomass technologies will largely depend on how policies evolve on the involvement of independent power producers (IPPs), and tariff movements, which in reality should take account of externality costs and viability of utilities based on marginal costing.

The level of investment requirement in the mitigation scenario is estimated at 1.8 billion in 2010, US3.3 billion and US4.8 billion in 2030 and 2050, respectively. If the principle of 33\% down payments is implemented, contribution from CDM for project finance will be around $15.0 \%$ of total investment requirements. 


\section{Acknowledgements}

Results discussed in this paper have been made possible through generation support from the European Commission Fifth Framework Programme for Research through a grant to the study "CARENSA".

\section{References}

1. Morales, M. and Johnson, F: Cane Co-products as a Sustainable Bio-energy Source Portfolio, Stockholm Environment Institute. Paper presented at the LAMNET, CARENSA, SPARKNET Workshop on Bio-energy, $19^{\text {th }}-21^{\text {st }}$ August 2002, Durban, South Africa.

2. Cornland, D, et 'al: Sugarcane Resources for Sustainable Development: A Case Study of Luena, Zambia, 2001, Stockholm Environment Institute, ISBN: 9188714 713, April 2001.

3. Roland, I. H: Climate Change Co-operation in Southrn Africa, ISBN $1-83383-520-$ X

4. Pabot, J. L.: Southern African Power Pool (SAPP), 2001. Pool Plan - Drought Scenario - Paper presented at the SAPP Drought Cycles Scenario, August 2002, Johannesburg, South Africa.

5. Groenewald, J: Bio-energy from Sugarcane Bagasse; PGBI International, South Africa. Paper presented at LAMNET, CARENSA and SPARKNET Workshop, August 2002, Durban South Africa.

6. Southern Centre: Report on Sugar Factories Surplus Bagasse Utilisation for Co-generation for Sugar Industries in Eastern Africa. Project No. CFC/ISO/21FT - Harare, 1999.

7. Williams, R. H. and Larson, E. P.: Advanced Gasification-based Biomass Power Generation: Renewable Energy Sources for Fuels and Electricity (Island Press, Washington D. C., 1993)

8. Beehory, R, Baguant, J.: Electricity from Sugarcane Biomass for Decarbonisation of Energy Supply in Mauritius, the Environmental Professional, Volume 18, pp 61 - 68, 1996.

9. Metz, B. et' al: Climate Change 2001: Mitigation, IPCC, Cambridge University Press, pp 345 398.

10. World Bank: PCF, Publication, 2001. 


\title{
Renewable Energy Barriers and Opportunities; A stakeholders' perspective
}

\author{
Jyoti Prasad Painuly \\ Senior Energy Planner, UNEP Collaborating Centre on Energy and Environment, \\ Risø National Laboratory, Roskilde-4000, Denmark. j.p.painuly@risoe.dk.
}

\begin{abstract}
Developing countries offer tremendous potential for use of renewable energy on account of their current low level of energy usage and predicted high energy growth rates to meet their developmental needs, a part of which could come from renewables. Despite attempts by governments in these countries and by international community, renewable energy usage has yet to reach the levels that the potential justifies due to barriers in their implementation. Remedial measures taken by governments have not been able to address the barriers effectively, and a strong reason for that is neglect of stakeholders in the process. Stakeholders' involvement in identifying barriers and barrier-removal measures can go a long way in designing appropriate strategies and policies for faster dissemination of renewables. A case study of three countries in Africa (Egypt, Ghana and Zimbabwe), that involved various stakeholders such as manufacturers, users, experts, and policy makers in identification of barriers and barrier removal measures, brought out interesting results for policy making. Although several findings were country and technology specific, underlying message could be generalised and used for widespread dissemination of RETs. Thus, economic and information / awareness barriers were found to be the most important barriers across the countries and the RETs. Lack of access to financing also contributed to lack of access to the RETs. Problems related to product quality and maintenance indicated need for capacity building in this area. Finally, lack of institutional structure and an appropriate policy framework to promote RETs were also noted as important barriers by stakeholders for various technologies. Need for a favourable policy regime to address these issues was a clear message given by the stakeholders.
\end{abstract}




\section{Introduction}

The world energy consumption has been increasing and with developing countries accounting for more than half of the world and needing increasing levels of energy to improve life styles, it can be expected to increase further in foreseeable future. The world energy consumption could increase by 60\% between 1999 and 2020, and in particular, energy demand in developing Asia and Central and South America is projected to more than double between 1999 and 2020 (IEA, 2002). World Energy Council (2002) projections also indicate energy consumption increase by 58 to 176 percent between 1990 and 2050, depending on economic growth and energy intensity of the output. The ecological driven scenario, which signifies success in promoting energy efficiency, technology innovation and transfer, and non-fossil fuel development, corresponds to the low energy consumption growth. Since increase in energy use in developing countries is inevitable to meet their development needs, it is important to increase the efficiency of energy use and shift to renewables as much as possible to overcome the threat of climate change. The global environment is already under threat from the greenhouse gases emitted from the use of fossil fuels, which could lead to climate change The renewables thus provide a ray of hope in an otherwise fossil fuel dominated world.

Despite the developments of the past two decades suggesting technical and economic feasibility of using renewable energy, major investments are still directed towards conventional energy technologies. Various estimates suggest that renewable energy sources are capable of meeting a significant part of the energy demand even at the current level of technological development. In developed countries, increase in renewable energy usage has been tried out through various policy measures including some measures that mandated energy suppliers to source a part of their supplies from renewables. In developing countries, most of the measures have been subsidy and incentive based. The fact that renewable energy has not been able to achieve the potential it offers implies presence of barriers in implementation of renewable energy technologies (RETs). These barriers (either financial or non-financial) need to be identified and addressed in order to design innovative policy approaches to help realise the RETs potential. Past approaches in this area, especially in most of the developing countries, have been topdown, where policy makers by and large decide on a policy based on their knowledge and wisdom on these issues. There have hardly been any systematic attempts to involve stakeholders in the process. The perceptions on barriers and barrier removal measures vary across the stakeholders and unless these are harmonised and taken into consideration, policies devised by policy makers based on their perception of the problem may not work. Most of the available work on barriers treats it as a technical and economic issue, sometimes also reflecting perspective of one or a few stakeholders. Involvement of a broad cross section of stakeholders in identifying the barriers and their perspective on barrier removal measures has been missing. This study looks at the barriers that RETs face in three countries in Africa; Egypt, Ghana and Zimbabwe and focuses on involvement of stakeholders in the process of identifying barriers to RETs implementation and barrier-removal measures.

\subsection{Potential for RETs and Barriers}

At the global level, many important studies indicate significant growth-potential for renewables. The International Energy Agency projected an annual growth rate of $7.5 \%$ to $8.5 \%$ in the commercial use of energy from 'new' renewables to 2010 under environmental constraints such as limit on $\mathrm{CO}_{2}$ emissions, World Energy Council estimated that renewables may meet around 21 per cent of the world energy needs by 2020 (from current level of 18 per cent $^{1)}$ in an business as usual scenario, while it could reach 30 per cent in an ecologically driven scenario which includes increased use of renewables (IEA, 1997). In a subsequent work, done jointly with IIASA, the WEC projected renewables use in 2100 between 30 to 82 per cent of the total primary energy use in different scenarios. The 30 per cent share has been projected for the case of a gradual technological development, slower responses to environ-

\footnotetext{
${ }^{1}$ There are different figures in literature on contribution from renewables depending on basket of "renewables" considered by the authors.
} 
mental threats, and coal - intensive global economy, whereas it goes up to 82 per cent in the case where there is success in raising efficiency in energy and widespread use of new renewable energy resources (solar in the longer run), allowing for a gradual phasing out of most fossil fuel use. This scenario also meets the global environmental concern by keeping the atmospheric $\mathrm{CO}_{2}$ concentrations below $450 \mathrm{ppmv}$ (parts per million per volume).

Given the huge potential opportunities in renewables, why there is a lack of entrepreneurs and financing to support the growth of renewables? RETs have to overcome a series of barriers before they can penetrate the market. In the initial stages of development, technical barriers predominate. In order for a technology to become cost-effective, market barriers such as inconsistent pricing structures typically have to be overcome. Then there are institutional, political and legislative barriers, which hinder the market penetration of technologies, including problems arising from a lack of awareness of, and experience with new technologies and lack of a suitable institutional and regulatory structure. Finally, there are social and environmental barriers, which result mainly from a lack of experience with planning regulations, which hinder the public acceptance of a technology. A sound strategy to increase the market penetration of renewables will need to address all these barriers. The barriers have been discussed in detail in the literature on renewables (Martinot and McDoom, 2000; G8 Renewable Energy Task Force, 2001; Wohlgemuth, 2001; Davidson and Turkson, 2001; Painuly, 2001, IPCC, 1996). The GEF experience with renewable energy projects has been summarised by Martinot and McDoom (2000) and they list subsidized or average cost energy prices, lack of information, transaction costs, high front-end capital costs, lack of availability of credit, high user discount rates, perceived technology performance uncertainty and risk, institutional mismatch of energy costs and capital costs, lack of legal framework for cogeneration or independent power production, and lack of technical or commercial skills as major barriers facing renewables. They also emphasize importance of stakeholder participation in renewable energy projects for sustainability and replication.

\section{Methodology}

\subsection{The Framework}

The focus of the broad methodological framework used by country teams was on involvement of various in identification of barriers and barrier removal measures for a few selected RETs of relevance to the country. Briefly, the methodology followed was as follows;

(i) In the first round, RETs were selected and barriers to their diffusion identified by the country teams based on review of national energy policies and plans, reports of existing projects, a number of criteria such as adequacy of resource base, availability of technology and cost, commercial viability etc. This was to ensure that selected RETs were important and relevant for the country concerned.

(ii) Stakeholders were consulted at this stage and their feedback obtained on the selected RETs through individual discussions and / or structured questionnaires, as well as through discussions in a national workshop.

(iii) The list of selected RETs was pruned in some cases based on the stakeholders' feedback and additional information on barriers and barriers removal measures was collected from various sources including stakeholders. Various categories of barriers were analysed in detail using varying approaches such as ranking by stakeholders and calculation of weighted rankings. The categories of barriers analysed are included in Table 1 . 
Table 1. Barriers to RETs diffusion.

\begin{tabular}{|l|l|}
\hline Barrier type & Example \\
\hline Institutional & $\begin{array}{l}\text { Institutional capacity limitations (R \& D, demonstration and imple- } \\
\text { mentation) }\end{array}$ \\
\hline Market & $\begin{array}{l}\text { Small size of the market, limited access to international markets for } \\
\text { modern RETs, limited involvement of the private sector }\end{array}$ \\
\hline Awareness / Information & Lack of awareness / access to information on RETs \\
\hline Financial & $\begin{array}{l}\text { Inadequate financing arrangements (local, national, international) } \\
\text { for RET projects }\end{array}$ \\
\hline Economic & $\begin{array}{l}\text { Unfavourable costs, taxes (local and import), subsidies and energy } \\
\text { prices }\end{array}$ \\
\hline Technical & $\begin{array}{l}\text { Lack of access to the technology, inadequate maintenance facilities, } \\
\text { bad quality of product }\end{array}$ \\
\hline Capacity & Lack of skilled manpower and training facilities \\
\hline Social & Lack of social acceptance and local participation \\
\hline Environmental & $\begin{array}{l}\text { Visual pollution, lack of valuation of social and environmental } \\
\text { benefits }\end{array}$ \\
\hline Policy & $\begin{array}{l}\text { Unfavourable energy sector policies and unwieldy regulatory } \\
\text { mechanisms }\end{array}$ \\
\hline
\end{tabular}

(iv) The information collected from stakeholders also included their views on the barrier removal measures. Each barrier was critically examined and actions identified for its removal. Barrier removal may need actions on several fronts such as policy changes, setting up institutional mechanisms for technology availability and upgrade, capacity building (making available skilled personnel), and financing, changes in laws or designing and implementing a regulatory framework etc. These were provided as options against various barriers and stakeholders asked to rank the importance of each against each category of barrier. It is expected that it would be possible to implement the RETs once the actions so identified are taken.

In the Egypt case study, an attempt was also made to make a qualitative assessment of direct and indirect effects (including environmental impacts) of the RETs implementation. The direct impacts include environmental, social, and other effects, which follow from implementation and operation of RETs, while the indirect impacts are attributable to the barrier removal actions and the necessary assumptions. Such an analysis is important in order to ensure that eventual implementation the projects does not have undesirable side effects.

(v) Finally, specific RETs projects were identified that are expected to lead to implementation of these actions and test their effectiveness. Provided that the actions and conditions for barrier removal identified are fulfilled, these projects would have a high chance of success. Implementation of the projects would test the effectiveness of the barrier removal actions.

A National workshop was held in each country to present the results of the project and the recommendations to promote increased implementation of RETs. The feedback obtained during the workshop was used to refine the analysis and recommendations.

\subsection{Methodological Variation across the Case Studies}

The national teams tailored the methodology to their specific needs within the broad framework. The Egypt national team had an Advisory Committee consisting of experts, relevant governmental institutions / ministries including rural agencies, manufacturers, users, and other stakeholders (NGOs, financiers, etc.), with which the team interacted at various stages of the project. The Ghana team conducted open stakeholder interviews in the first stage, visited some of the specific project sites to discuss various issues with the project operators and owners, and collected additional information on selected RETs through structured questionnaire only during the last phase. The barriers identified for each of 
the technologies were then analysed in detail using a framework that categorised barriers into three main groups - Socio-technical barriers; Economic Barriers; and Cross-Cutting Barriers. Sociotechnical barriers covered resource-based, technological, environmental, and social barriers. Economics barriers included those related to the market, costs and benefits, and finance. Under crosscutting barriers, informational, institutional and policy barriers were considered. In the National workshop, the stakeholders were asked to identify the key barriers to the three selected RETs, then rank the barriers in order of their importance, and recommend how best each of the barriers identified could be removed. In the case of Zimbabwe, barriers were identified through desk study of RET projects and stakeholders were consulted on barrier removal projects. Based on the feedback, four institutions developed the barrier removal projects and discussed with the project advisory committee and stakeholders. The national workshop was utilized to enlarge this consultation and propose projects based on that.

\section{Results and Discussions}

In view of differences across the countries in terms of RETs studied and conclusions drawn for actions needed, we first discuss results of individual country studies, and thereafter present the common message emerging from the study for diffusion of RETs.

\subsection{Egypt Case Study}

At the preliminary stage, the selected RETs included solar water heating systems, PV systems for electrification of remote areas, PV systems for pumping of groundwater, and biomass applications. However, after interaction with stakeholders through structured questionnaires and through a mid project workshop, PV systems for pumping of groundwater was taken out from the list. The barriers for these three were as follows;

Solar water heating systems (SWHS): Most of the SWHS installed in Egypt are small with a capacity of 150 litres/day. The following emerged as major barriers with the first three having no significant difference in their ranking.

- Economic and financial barriers were considered most important barriers (rank 1) by about 26.5\% of the key stakeholders (users, manufacturers and experts). The SWHS were considered high priced compared to conventional water heating systems and subsidised electricity made it further unattractive for the "low bill" electricity consumers. A lack of credit facilities was another obstacle in this category. In case of new houses, low cost LPG and natural gas are fuel choices making the SWHS uncompetitive for this segment.

Financial support including availability of credit facilities with low interest rates, reduction in SWHS prices and providing incentives corresponding to the subsidies given to electricity and natural gas consumers were suggested as remedial measures. Provision of soft loans to entreprenuers, reduction in taxes and duties, and support for product improvement were cited as measures to reduce SHS costs.

- Awareness / information barriers were ranked second with about $24 \%$ of stakeholder indicating these as most important. Presence of SWHS industry can hardly be noticed by consumers. Industry on the other hand offers very limited choices due to a lack of significant market.

Suggestions on remedial measures included a number of media strategies such as awareness and promotion programs through TV and newspapers, participation in various exhibitions held in syndicates, hotels, clubs etc., and setting up demonstration systems in places like city councils, clubs, big factories, conference halls, and stadiums etc. Availability of brochures containing detailed information on systems, selection criteria, maintenance requirements, and information about suppliers and their after sales services to consumers, seminars, presentation and demonstration to targeted users in schools, universities and clubs were other suggestions. 
- Technical barriers were ranked third with about $22 \%$ of the stakeholders indicating these as most important, although there was difference of opinion between manufacturers and others on this issue. The latter attributed it to the lack of knowledge about the system design and operation, and a lack of maintenance by users. Faulty design, malfunctioning pumps, leakage from tanks etc. were experienced with inadequate support from manufacturers to address these problems.

Revision of the standards to include quality control and assurance components and installation requirements were suggested. This included product quality and performance guarantee with a mechanism for their enforceability. Easy availability of spare parts and maintenance centres were considered important.

- Institutional barriers were ranked as fourth, indicating the need for better institutional arrangement and co-ordination between the stakeholders. Setting up a federation, union or society, which can bring representatives of users, companies, financing sources, policy makers and researches on one platform was suggested.

PV systems for electrification of remote areas: The barriers identified were as follows;

There was a consensus that economic and financial barriers are the most important barriers and should be addressed first. These were followed by policy barriers, indicating need for a governmental mechanism to promote PV technology. Market barriers were considered next in importance, indicating small size of the market and limited access to international market. Private sector involvement was limited due to small size of the market. While experts and users considered technical problems and availability of maintenance as an important barrier, PV manufacturers did not consider this as a barrier. A lack of awareness about solar PV systems was also considered an important barrier.

The economic and financial barriers were due to high capital costs of the PV system and a lack of financing mechanism. The high cost, in turn, was due to high taxes and duties on imported components. The subsidized tariff in rural areas also made it difficult for PV systems to compete with grid electricity, even though it may be a remote area. Although there are a number of subsidized PV programmes, they failed to address this issue and ended up killing commercialization of the technology. Transaction costs related to commercial dissemination, installation and after-sales services were high due to dispersed rural dwellings; estimated to be about $30 \%$ of the total costs of PV systems.

The stakeholders' recommendations to address these issues included financial schemes to support buyers and government supported market incentives specially targeted at commercial development and deployment of the PV systems. Availability of manufacturers' support infrastructure near the customers was suggested to address technical problems and generate confidence in the technology. This needs to be supported with periodical awareness campaigns. An interesting suggestion was to integrate PV rural electrification projects with other development programs and experience sharing across various programmes.

Large Biogas Plants (LBP):- The barriers identified in the case of LBP were similar to the other two technologies but with the LBP programme in initial stages, most of the need for action related to designing a sound action plan and setting up a proper institutional mechanism to implement it. The institutional barrier also included a lack of NGOs involvement in the programme. Economic and financial barriers due to high capital costs and subsidy to competing fuels and absence of any financial scheme or national programme were considered very important. Awareness was also an issue in case of LBPs, and technical barriers were also relevant due to skill and quality problems. The need for action was also on similar lines with emphasis on overcoming institutional barrier.

Projects proposed: The Egyptian team proposed three projects; a project to establish and test a financial and technical support mechanism for SWHs dissemination in Egypt, a demonstration project for rural electrification using PV system, and a pilot project for a large-scale (centralized) biogas plant.

\subsection{Ghana Case Study}

Some biomass, solar, and small hydro technologies were selected for preliminary analysis of barriers in Ghana. The preliminary list of RETs studied included biomass fired dryers, sawdust briquetting, sawdust stoves and biogas in the biomass category, solar crop dryers (SCD), solar water heaters (SWHS) and solar water pumps (SWP) in the solar category, and small hydro. Biogas, SWP, and small 
hydro were studied in detail based on their potential contribution to socio-economic development, potential for application, and availability of information on barriers, environmental impacts and benefits.

The barriers have been grouped into three main categories - socio-technical barriers, economic barriers and crosscutting barriers. Socio-technical barriers refer to resource-based, technological, environmental, and social barriers. Economics barriers constitute those related to the market, costs and benefits, and finance. Under crosscutting barriers, informational, institutional and policy barriers were considered.

Solar water pumping technology: The most important barrier identified for SWP was economic barrier; high initial cost with often un-quantified long-term benefits and a general lack of information. This was amplified by a lack financing schemes. Weak and small market was also one of the barriers but it was suggested that market for such RETs should be considered at regional level and not at national level.

The stakeholders suggested that the most effective way of removing these barriers is to start by addressing the information barrier. It was pointed out that information is needed to convince policy makers as well as decision-makers in other sectors of the economy. New and innovative financing mechanisms need to be devised to address financial barrier; for example setting up a fund in a financial institution to administer soft loans, grants and flexible financing schemes to dealers and end-users. Such a fund could be fed by disbursements from the Energy Fund. Other measures include financial incentives like tax waivers and subsidies, and necessary legislation for this purpose. To expand the PV market, it was recommended to use PV systems for rural electrification and also in urban areas where electricity grid is yet to reach.

Biogas technology: There is doubt about adequacy of resources for biogas in Ghana. Inadequate promotion policies, absence of right financing schemes, high cost, and a lack of market and information were other barriers. Experts considered this as the appropriate technology for the poor but regard it's cost as a major barrier. Social barrier reflected in unwillingness of people to use biogas for cooking was also identified.

A combination of environmental regulations requiring proper disposal of waste, information dissemination through workshops, and incentives for biogas programmes were suggested as remedial measures. Resource availability could be addressed by proper site selection. It was suggested to package biogas projects as "sanitation" or "agricultural project" with energy as a spin-off. It was suggested to tap international financing mechanisms such as CDM, and African Rural Energy Enterprise Development (AREED) project to address financing barrier. Awareness programmes and training should also be a component of various programmes.

Hydropower technology: The stakeholders noted that despite identification of 70 sites for hydropower, none had been developed. Absence of a policy framework for the development of SHP was considered to be the most important barrier to harnessing the SHP resources. Other important barriers identified included a lack of information on SHP opportunities to private investors, a lack of financing mechanism to promote SHP development, absence of any specific institutional structure to take up SHP projects, and low electricity tariffs.

The stakeholders emphasised the need to generate information on potential, cost and benefits of the SHP and dissemination among various stakeholders including the government for formulating an appropriate strategy for the development of SHP. For example, SHP could be included in the "Self-Help Electrification Programme" (SHEP) of the government. A couple of sites could also be developed as a pilot or demonstration projects.

Economic barriers were of common concerns for development of RETs and adjustments of electricity tariffs to economic levels was suggested to provide a level playing field to RETs.

Projects proposed: Three projects were proposed; a community biogas plant in a hospital or a school with waste disposal problem, a pilot project for solar water pumping, and a demonstration project for small hydro technology.

\subsection{Zimbabwe Case Study}

The Zimbabwe study focussed on detailed analysis of barriers by the country team and development of project proposals by four other organisations to address the barriers. The stakeholders' inputs were 
used to modify the project proposals. Participants in the workshop said that they were happy that all the stakeholders for the first time had a chance to discuss the barriers together. Building up on an earlier UNDP-GEF study, the approach discusses primary and secondary barriers ${ }^{2}$, the latter's (secondary) existence being due to primary barrier. The stakeholders may see and experience only secondary barriers arising out of the presence of primary barriers. It is important to identify and remove primary barriers but it is equally important to remove "lingering effects" produced by secondary barriers. For example, banks have been reluctant to fund RETs due to poorly developed proposals and rated RETs as poor investment. Therefore, banks may be reluctant to fund RETs even when convincing proposals are made. Inability to develop and present sound project proposals, lack of capacity to assess cost and benefits, ineffective lobbying with the government, lack of information with the government for policy making, poor fiscal support to RETs and a lack of information dissemination on RETs from school level were identified as primary barriers. Developing guidelines for project proposals, setting up financing schemes, capacity building on technology assessment within government and industry, regular stakeholders' interaction with the government, setting up a technology information exchange on RETs, and development of curricular and information programs on RETs for schools were recommended as the measures to overcome the barriers. They also mentioned that clear targets for the numbers of RETs installed in the country in future are needed. Translated to the study framework, the barriers and removal measures were as follows;

Economic and financial barriers: These are reflected in high initial investment costs and price distortions that favour conventional fossil fuels. It was suggested to use fiscal policy instruments to address these issues, and also set up micro finance schemes for the promotion of RETs.

Awareness and information: This is characterised by poor information with stakeholders and weak dissemination strategies, a lack of follow-up of the implemented projects, and no systematic approach to build up awareness. The suggested remedial measures included link between various projects for experience sharing, stakeholders' meetings with policy makers, special programmes for awareness at policy level, dissemination through web site and newsletters, and including RETs in schools' curriculum.

Technical barriers: This includes a lack of skilled manpower, inadequate technological base for manufacture and distribution and weak maintenance infrastructure. The remedial measures included more research and development efforts, technology exchange programmes, and better quality control.

Institutional and policy barriers: These include poor institutional framework and infrastructure, inadequate governmental planning framework for RETs development, and a lack of transparency in project allocation. Macro-economic policies also sometimes are unfavourable to RETs. The remedial measures include policy level commitment to promote RETs, inputs from private sector to policy makers and a mechanism for consultation with stakeholders.

Projects proposed: Several projects were proposed, as follows; "Country strategy on renewable energy technologies", "Entrepreneur business and technical skills development in renewable energy", "Development of house-based solar power generation scheme", "Development of affordable solar cookers for both rural and urban users", "African wind-power for battery charging", and "Identification of desirable stove characteristics and development of prototype stoves for field-testing".

\section{Conclusions}

The basic framework discussed in the methodology section was used by the country teams after tailoring it to their needs of analysis. The basic approach included stakeholders' involvement in identification of barriers to RETs and measures to remove the barriers.

In the Egypt case study, the focus was on PV systems for rural electrification, solar water heaters and large-scale biogas system. High capital costs of the system due to high tariffs and taxes were one

\footnotetext{
${ }^{2}$ The primary barriers are the actual reason why technologies are not implemented and the secondary barriers are often the apparent reason as seen from the stakeholders' perspective.
} 
of the major barriers for PV system. Lack of information and subsidized electricity were other important barriers. High cost, lack of information about technology, technical problems in usage and a lack of institutional structure to promote and support SWHS were identified as main barriers in that order for SWHS. In case of large-scale biogas plants, the barriers in order of importance were; a lack of institutional structure to promote the technology, skills, size of market, cost of technology and awareness. The measures to overcome the barriers recommended by the stakeholders to improve economic viability of these RETs included setting up of new financial schemes, reduction in taxes and duties on imports of RET equipment and components and better designed incentive schemes. Standardization and certification requirements through legislative measures and easy consumer access to the equipment suppliers for fault rectification were recommended measures to address technical barriers. Awareness and promotion campaigns, training courses and seminars for targeted users and educational institutions were recommended to disseminate information on the RETs.

In the Ghana case study, three solar energy technologies (solar water heaters, solar crop drying and solar water pumps), biogas and small hydro were studied. Of the three solar energy technologies, solar water pump was identified as a promising technology with least barriers. High initial costs and a lack of information on technology and its benefits were major barriers to SWP. Although biogas was identified as one of the RETs with promise, resource constraints (for example, minimum dung needed for a household biogas plant) was found to be a major barrier on detailed scrutiny of its potential for largescale application. An interesting finding was the suggestion of the stakeholders to promote biogas projects in Ghana as a sanitation or agricultural project (with fertilizer as output) with energy as a spinoff. In case of small hydro, no development has taken place in Ghana despite some potential. Absence of a coherent energy policy framework was identified the reason for this.

In general, existing renewable energy policy framework in Ghana was found to be inadequate to promote RETs and harness their full potential. The stakeholders identified need for clearly defined targets, investment plans and financing mechanisms in the national framework for renewable energy. It was also suggested to explore international financing mechanisms such as GEF and CDM to address the financing concern. Need for elimination of subsidies to competing fuels (low electricity tariffs) and / or incentives was also indicated to address economic concerns. It was also suggested to devise mechanisms to provide information to stakeholders and to increase awareness.

The Zimbabwe case study focussed on RETs barrier analysis and discussed several projects to remove barriers. The barriers were categorised as primary and secondary barriers. The stakeholders may see and experience only secondary barriers arising out of the presence of primary barriers. It is important to identify and remove primary barriers but it is equally important to remove "lingering effects" produced by secondary barriers. Inability to develop and present sound project proposals, lack of capacity to assess cost and benefits, ineffective lobbying with the government, lack of information with the government for policy making, poor fiscal support to RETs and a lack of information dissemination on RETs from school level were identified as primary barriers. Developing guidelines for project proposals, setting up financing schemes, capacity building on technology assessment within government and industry, regular stakeholders' interaction with the government, setting up a technology information exchange on RETs, and development of curricular and information programs on RETs for schools were recommended as the measures to overcome the barriers.

In general, economic and information / awareness barriers were the most important barriers across the countries and RETs. This points to the low level of awareness and information on RETs among the potential users. Therefore, better ways to raise awareness are required. The economic barrier indicated high cost of the RETs (possibly except for a few selected applications), pointing to the need to bring down the cost of technology. Small size of market, unfavourable policies, and subsidy to competing conventional fuels were other reasons that affected the economics of RETs further. Lack of access to financing also contributed to lack of access to RETs. Problems related to product quality and maintenance indicated need for capacity building in this area. Finally, a lack of institutional structure to promote RETs was also noted as an important barrier by stakeholders for various technologies. Most of the barrier removal measures pointed out by the stakeholders indicated the need for policy intervention by the government to create a favourable environment for RETs to take off. Thus, need for a favourable policy regime to address these issues was a clear message given by the stakeholders. 


\section{References}

Davidson, O. R. and J. Turkson (2001), "Overcoming financial barriers to wider use of renewable energy technology in Africa” International Journal of Global Energy Issues 15(1-2), 117-131.

G8 Renewable Energy Task Force (2001), Final Report July 2001 (available at www.renewabletaskforce.org/report.asp).

IEA (1997), Key Issues in Developing Renewables,

http://www.iea.org/pubs/studies/files/devrenew/devrenew.htm

IEA (2002), World Energy Outlook, http://www.eia.doe.gov/oiaf/ieo/index.html

IPCC (1996), Climate Change 1995: Economic and Social Dimensions of Climate Change, Cambridge Univ. Press.

Ishmael Edjekumhene, Sefa Bonsu Atakora, Rodney Atta-Konadu, and Abeeku Brew-Hammond (2001), "Implementation of Renewable Energy Technologies - Opportunities and Barriers; Ghana Country Study", UNEP Centre, Denmark.

Jefferson, M. (2000), "Long-term-energy scenarios: the approach of The World Energy Council", Int. J. Global Energy Issues, Vol. 13, Nos. 1-3, pp.277-284.

Martinot, E. and O. McDoom (2000), Promoting Energy Efficiency and Renewable Energy: GEF Climate Change Projects and Impacts, Global Environment Facility, Washington, DC.

NREA (2001). "Implementation of Renewable Energy Technologies - Opportunities and Barriers; Egypt Country Study", UNEP Centre, Denmark.

Painuly, J. P. (2001) "Barriers to renewable energy penetration; A framework for analysis" Renewable Energy 24(1), 73-89.

Painuly Jyoti Prasad and Jorgen V. Fenhanan (2002), "Implementation of Renewable Energy Technologies- Opportunities and Barriers; Summary of Country Studies", (Report), UNEP Centre, Denmark.

Southern Centre for Energy and Environment (2001), "Implementation of Renewable Energy Technologies - Opportunities and Barriers; Zimbabwe Country Study", UNEP Centre, Denmark.

World Energy Assessment (2000), UNDP, http://www.undp.org/seed/eap/activities/wea/draftsframe.html

Wohlgemuth, N. (2001) "Directing investment to cleaner energy technologies: the role of financial institutions" in Bouma, J. J., Jeucken, M. and L. Klinkers (eds) Sustainable Banking. The Greening of Finance Greenleaf Publishing, Sheffield, UK, pp 401-411.

World Energy Council (2002), Global Energy Scenarios To 2050 And Beyond, http://www.worldenergy.org/wec-geis/edc/scenario.asp. 


\title{
Policy Options for Developing Asian Countries in the Post-Kyoto World
}

\author{
Toufiq A. Siddiqi \\ Global Environment and Energy in the $21^{\text {st }}$ Century (GEE-21) \\ 1765 Ala Moana Blvd. \# 1189, Honolulu, Hawaii 96815, USA
}

\section{Introduction}

The Kyoto Protocol has now been ratified, accepted, acceded to, or approved by most of the countries of the world (UNFCCC, 2003). The ratification by the Russian Federation, expected later this year, will bring it into legal effect. It is clear that the Protocol represents only a beginning, and additional steps will need to be taken, if emissions of greenhouse gases are to be stabilized, and subsequently reduced, during the $21^{\text {st }}$ century. These additional measures will require the participation of the developing countries, as well as their industrialized counterparts, including the current holdouts such as the United States and Australia.

There are a number of measures that can be taken to reduce greenhouse gas emissions. These have been discussed in detail in a number of excellent reports by the IPCC and others (see, for example, ADB/GEF/UNDP, 1998; Claussen, 2001; Nakicenovic et al., 1994). In this paper, we limit our discussion to some of the infrastructure problems associated with greater use of cleaner energy sources such as natural gas and renewable energy, and policy measures that could be taken to improve the situation.

\section{Climate Change and the Asian Developing Countries}

The developing countries of Asia are amongst the largest contributors to the anthropogenic emissions of the greenhouse gases that are responsible for global climate change, as well as being amongst those most likely to be impacted by global climate change. We shall discuss these two aspects separately in this paper. The principal greenhouse gases include carbon dioxide, methane, nitrous oxide, and halocarbons. A summary of the global annual-mean radiative forcing due to a number of agents from preindustrial times (1750 A.D.) to the end of the last millennium is shown in Figure 1 (IPCC, 2001). 


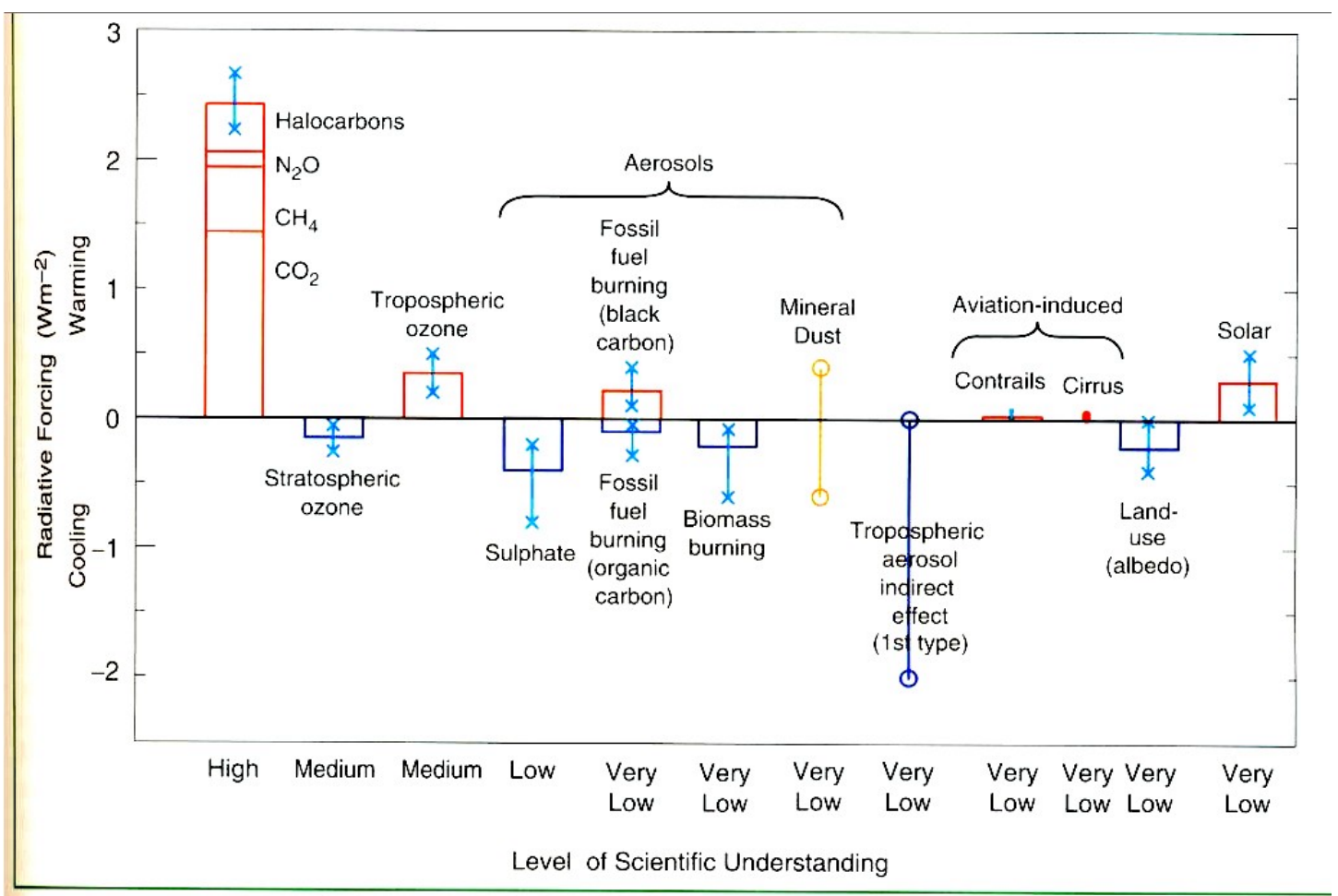

Figure 1.

As seen in Figure 1, carbon dioxide $\left(\mathrm{CO}_{2}\right)$ and methane $\left(\mathrm{CH}_{4}\right)$ are the two largest contributors to radiative forcing from anthropogenic emissions of greenhouse gases. Due to time constraints, we shall focus primarily on these two gases. As far as $\mathrm{CO}_{2}$ emissions are concerned, by far the largest contribution comes from the combustion of fossil fuels. Asia's emissions in this category have exceeded those from any other continent since the early 1990s (Siddiqi, 2000), and their share is increasing in pace with economic development. The share contributed by the different regions of the world is shown in Figure 2. It should be mentioned that Asia in this context is the "Geographical Asia" and includes Japan, the Middle East, and the Central Asian Republics of the former Soviet Union.

\section{Regional Emissions of $\mathrm{CO}_{2}$ from fossil fuels}

\section{(\%)}

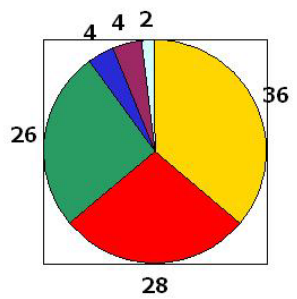

$\square$ Asia

$\square$ N. America

$\square$ Europe

口. \& S. Am.

$\square$ Africa

$\square$ Oceania

Estimates by Toufiq Siddiqi (2003)

Figure 2.

Three (China, India, and Japan) of the five largest $\mathrm{CO}_{2}$ emitting countries from fossil fuels are in Asia. Emissions in other Asian countries are also growing rapidly, and have reached significant levels in a number of countries, including the Republic of Korea, Iran, Saudi Arabia, and Indonesia, as shown in Table 1. 
Table 1. Carbon Dioxide Emissions from fossil fuel consumption in Asian Countries with the largest such emissions.

\section{$\underline{\text { Carbon Dioxide Emissions }}$}

Fossil Fuel Consumption

$\frac{\text { Coul }}{\text { Country/Area }} \quad \underline{\text { Oil }} \frac{\text { Nat. Gas }}{\& \text { Lignite }}$
(million tons oil
equivalent=Mtoe)

$\begin{array}{lrrr}\text { China } & 520.6 & 231.9 & 24.9 \\ \text { India } & 173.5 & 97.1 & 23.7 \\ \text { Indonesia } & 16.7 & 52.3 & 26.7 \\ \text { Iran } & 0.8 & 54.2 & 58.5 \\ \text { Japan } & 103.0 & 247.2 & 71.1 \\ \text { Kazakhstan } & 24.7 & 7.7 & 9.1 \\ \text { Malaysia } & 2.4 & 18.6 & 19.4 \\ \text { Pakistan } & 2.0 & 18.9 & 18.1 \\ \text { Philippines } & 4.5 & 16.5 & 0.1 \\ \text { Saudi Arabia } & 0.0 & 62.7 & 48.3 \\ \text { Singapore } & 0.0 & 36.9 & 2.3 \\ \text { South Korea } & 45.7 & 103.1 & 20.8 \\ \text { Taiwan, China } & 30.9 & 37.7 & 6.8 \\ \text { Thailand } & 8.8 & 33.8 & 19.0 \\ \text { United Arab Em. } & 0.0 & 14.3 & 30.8 \\ \text { Uzbekistan } & 1.1 & 6.5 & 46.0\end{array}$

\begin{tabular}{|c|c|c|c|}
\hline \multicolumn{4}{|c|}{ Carbon Dioxide Emissions } \\
\hline \multicolumn{4}{|c|}{ from fossil fuels ${ }^{*}$} \\
\hline Coal & Oil & Gas & Total \\
\hline \& Lignite & & LNG & \\
\hline \multicolumn{4}{|c|}{$($ million tons carbon $=\mathrm{MtC})$} \\
\hline 568.0 & 203.1 & 15.2 & 786.4 \\
\hline 189.3 & 85.1 & 14.5 & 288.9 \\
\hline 18.2 & 45.8 & 16.3 & 80.4 \\
\hline 0.9 & 47.5 & 35.8 & 84.2 \\
\hline 112.4 & 216.5 & 43.5 & 372.4 \\
\hline 26.9 & 6.7 & 5.6 & 39.3 \\
\hline 2.6 & 16.3 & 11.9 & 30.8 \\
\hline 2.2 & 16.6 & 11.1 & 29.8 \\
\hline 4.9 & 14.5 & 0.1 & 19.4 \\
\hline 0.0 & 54.9 & 29.6 & 84.5 \\
\hline 0.0 & 32.3 & 1.4 & 33.7 \\
\hline 49.9 & 90.3 & 12.7 & 152.9 \\
\hline 33.7 & 33.0 & 4.2 & 70.9 \\
\hline 9.6 & 29.6 & 11.6 & 50.8 \\
\hline 0.0 & 12.5 & 18.8 & 31.4 \\
\hline 1.2 & 5.7 & 28.2 & 35.0 \\
\hline
\end{tabular}

Note: Only countries with emissions exceeding about 20 million tons of carbon during 2001 are included in this Table.

Source: The energy data are from British Petroleum (2002).

${ }^{*}$ The carbon dioxide emissions have been calculated by Toufiq Siddiqi using the following conversion factors :

Coal

Petroleum Prods.

Natural Gas

$\begin{array}{cc}\mathrm{kg}-\mathrm{C} / \mathrm{Gj} & \text { tons-C/toe } \\ 24.8 & 1.091 \\ 19.9 & 0.876 \\ 13.9 & 0.612\end{array}$

Of the countries listed in Table 1, Japan is the only Annex 1 country that has an obligation to reduce its emissions of greenhouse gases. The Republic of Korea and Singapore have per capita GNPs comparable to Western European countries and are no longer classified as "Developing Countries". The ten Asian developing countries with the largest emissions of $\mathrm{CO}_{2}$ from fossil fuel combustion are shown in Figure 3. 


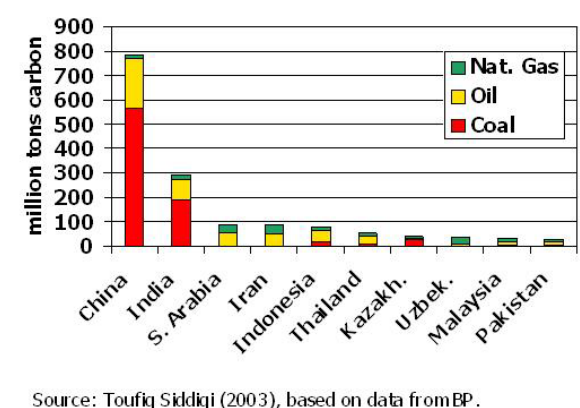

Figure 3.

\section{Policy Options for the Asian Developing Countries}

There are at present no legal requirements for the Asian developing countries to reduce their emissions. Countries could take the "Do nothing" approach and cite the lack of ratification of the Protocol by the United States, Australia, and some other industrialized countries as a basis for inaction. Unfortunately, the medium and long-term impact of global climate change is likely to be proportionately larger for the developing countries than for the industrialized ones, since the latter have the resources to reduce the adverse impacts. Thus it is in the interest of the developing countries, as well as the rest of the world, to have longer-term goals for stabilizing their greenhouse gas emissions, and taking actions during the medium term to achieve these goals. Such measures would also put pressure on the industrialized countries that have not signed the Kyoto Protocol to accede to it or take parallel steps to achieve reductions in their emissions of greenhouse gases.

Asia is a huge and diverse continent where about half of the total population of the world lives. One possible strategy for the developing countries of Asia may be to design differentiated responses for countries with different magnitudes of greenhouse gas emissions. It may be useful to group the countries in three groups:

a) Countries with total $\mathrm{CO}_{2}$ emissions from fossil fuels exceeding $100 \mathrm{MtC}$;

b) Countries with total $\mathrm{CO}_{2}$ emissions between $20 \mathrm{MtC}$ and $100 \mathrm{MtC}$;

c) Countries with total $\mathrm{CO}_{2}$ emissions from fossil fuels below $20 \mathrm{MtC}$.

The initial emphasis could be on actions that could be taken in countries in Group a), since this would have the largest impact on achieving long-term stability in greenhouse gas emissions. At this stage in their development, we are not advocating that China and India reduce their absolute emissions, but only that they take steps to reduce the ratio of emissions to GDP. This is already taking place in China, and to a somewhat lesser extent, in India. The process could be enhanced by some changes in the infrastructure, which are discussed later.

The urgency for action by countries in Group b) is a little less than for those in Group a), since their $\mathrm{CO}_{2}$ emissions from fossil fuels are not as large. However, some of them, such as Indonesia, Malaysia, Pakistan, Philippines, and Thailand could put greater emphasis on reforestation to increase $\mathrm{CO}_{2}$ sinks, better management of water to reduce methane emissions from rice paddies, and other measures to 
reduce emissions of nitrous oxides and "black carbon" (For a discussion of black carbon, see, for example, Streets, 2003). These measures could, of course, also be taken by countries in Group a).

Group c) consists of countries emitting less than $20 \mathrm{MtC}$ from fossil fuel use per year. It includes a substantial number of countries with small emissions, such as Afghanistan, Bangladesh, Cambodia, Maldives, and Nepal. In general, these countries are likely to be affected by global climate change without having contributed much to causing it. Their initial focus could be on adaptation strategies, and on the mitigation measures suggested for group $b$ ).

In the remainder of this section, we discuss briefly the countries in Group a). As mentioned earlier, these are countries with total $\mathrm{CO}_{2}$ emissions from fossil fuels exceeding $100 \mathrm{MtC}$. This group includes only China and India at present. Both countries have populations exceeding 1 billion, so their emissions per capita are only about 0.6 tons of carbon per year (tC/year) and $0.3 \mathrm{tC} /$ year respectively.

China has had the most rapid rate of economic development of the Asian developing countries. GDP growth during the period 1990-95 was $12.5 \%$ per annum, and from 1996-2001 was $8.0 \%$ per annum (World Bank, 2002). The increase in $\mathrm{CO}_{2}$ emissions has been smaller, resulting in a decline in the ratio of energy use to GNP. The average annual decline in energy intensity between 1977 and 1997 was $4.2 \%$ per year (Logan et al., 1999). Further, the absolute amount of primary energy consumption (and corresponding $\mathrm{CO}_{2}$ emissions) actually declined from 1996-99, leading to hope that an early stabilization of the emissions might be achievable. The reasons for the decline include somewhat slower economic growth, more efficient use of energy, particularly in industry (Sinton and Fridley, 2000; Martinot (2001), and the shutting down of many inefficient small-scale coalmines. China's energy use and associated emissions of $\mathrm{CO}_{2}$ increased again during 2000 and 2001, suggesting that additional measures are required in the medium-term for eventual stabilization of greenhouse gas emissions. Some of these are discussed in the next section.

India, in spite of its large total $\mathrm{CO}_{2}$ emissions, has only about half of the per capita emissions from fossil fuels as China. There are several reasons for this, including the absence of a heating requirement in much of India, the greater use of biomass as fuel in the rural parts of the country, and a per capita GNP that is about $60 \%$ of that of China (World Bank, 2002). However, the growth in total primary energy use in India has never been negative in modern times, and may be an indicator of the increased opportunities for achieving higher efficiencies.

\section{Infrastructure Considerations}

A discussion of energy technologies for reducing greenhouse gas emissions per unit of energy supplied in the post-Kyoto world would be incomplete without an analysis of what is required to implement these technologies. This is particularly necessary in a discussion of the situation in the developing countries, where a number of environmentally preferred technologies can still not be used due to a lack of the infrastructure necessary to maintain them. In this section, we discuss some of the infrastructure needs of many of the Asian developing countries, and how these could contribute to reducing the greenhouse gas emissions per unit of GDP.

- Education. Here we are not discussing education regarding specific energy technologies, but basic education in the sense of reading, writing, and arithmetic. The situation varies from country to country, as shown in Table 2, and sometimes from province to province. In parts of South Asia, almost half of the population cannot read or write. Thus even simple instructions for installing or maintaining more efficient appliances such as stoves or pumps are not followed, leading frequently to the discarding of such equipment after a short time. It would not be an exaggeration to say that possibly the most cost-effective investment for addressing global climate change is an investment in basic education in countries where it is still needed. 
Table 2. Asian Developing Countries with Adult Literacy Rates Below 60\%.

\begin{tabular}{lr} 
Country & Adult Literacy \\
\cline { 2 - 2 } & $\underline{1997}$ \\
Bangladesh & 38.9 \\
Bhutan & 44.2 \\
India & 53.5 \\
Lao PDR & 58.6 \\
Nepal & 38.1 \\
Pakistan & 40.9 \\
Yemen & 42.5
\end{tabular}

Source: UNDP, 1999.

- Natural Gas Distribution System. Large numbers of households in many Asian countries continue to use coal or petroleum products or firewood in their homes, even though the countries have natural gas reserves. This is due to the absence of networks to distribute the natural gas. Building such infrastructures requires considerable initial capital, but is quite cost-effective. In addition, there are health benefits and reduced greenhouse gas emissions when compared to firewood, coal, or oil products.

The transportation sector is the fastest growing consumer of energy in most of the developing countries. Replacement of petrol and diesel by compressed natural gas (CNG) would provide health benefits and reduced greenhouse gas emissions. This is already taking place in several major cities of Asia, including Bangkok, Beijing, Karachi and New Delhi. However, inter-city buses and other vehicles are unable to use them, since the infrastructure for supplying CNG outside the major urban areas does not exist.

In several countries, including India and Pakistan, the existing natural gas reserves are already committed. Expansion of the distribution system would require additional discoveries or imports of natural gas. For India and Pakistan, substantial supplies of natural gas could be provided at competitive prices via a pipeline from Central Asia, Iran, or the Gulf States (Siddiqi, 2003). However, the political tensions between the two countries have prevented the implementation of this option, which could result in slowing the rate of increase in greenhouse gas emissions.

- Extension of the Electric Grid. Several of the renewable energy technologies, particularly wind power, would be used more widely if the electricity grid existed in areas where the wind regimes are most favorable. An example of this would be the Indus Delta and the coastal areas of Balochistan. Since relatively few people live in these areas, only a modest electricity network exists. One could envision a system where these areas could become suppliers of wind-based electricity rather than end-users of electricity using fossil fuels. It would require a substantial front-end investment, not only for the wind turbines but for putting in place high-voltage lines to cities such as Karachi and Hyderabad.

There are a number of other infrastructure requirements, such as maintenance centers and consumer loan facilities that are important for the introduction and dissemination of energy technologies in the Asian developing countries. Time limitations prevent us from discussing those in this paper. 


\section{Conclusion}

Even though the Kyoto Protocol does not require developing countries to commit to reducing greenhouse gas emissions, there is likely to be a continuing expectation that they initially reduce the rate of growth of such emissions. Since a reasonable quality of life requires that economic growth continue in these countries for several decades at least, there is a need to reduce the emissions per unit of GDP.

Asia is home to about a half of the world's population, and there is great variation in the levels of industrialization and contribution to greenhouse gas emissions. A differentiated strategy for addressing concerns related to global climate change may be appropriate for the Asian developing countries at this time. Some elements of this strategy have been discussed in this paper.

Developments in energy technology present several attractive options for the developing countries. However, their introduction and successful use depends at least as much on the existence of the necessary infrastructure as on the attractiveness of the technologies themselves. It is suggested that international and bilateral development agencies, as well as the countries themselves, consider the accelerated development of such infrastructure as a major way to contribute to the efforts to address global climate change.

\section{References}

Ambio (1996). Special Issue on "Greenhouse Gas Emissions: Mitigation Strategies in Asia and the Pacific". Volume 25, No. 4.

Asian Development Bank, Global Environment Facility, United Nations Development Programme (1998). Asia Least-Cost Greenhouse Gas Abatement Strategy: Summary Report. Manila: ADB.

British Petroleum (2002). BP Statistical Revue of World Energy June 2002. London: BP p.l.c.

Claussen, Eileen, executive editor (2001). Climate Change: Science, Strategies, and Solutions. Leiden, Boston, Koeln: Brill.

Intergovernmental Panel on Climate Change (2001). Climate Change 2001: The Scientific Basis. Summary for Policymakers. Geneva: IPCC Secretariat, WMO and UNEP.

Logan, Jeffrey, Aaron Frank, Jianwu Feng, and Indu John (1999). Climate Action in the United States and China. Washington, D.C.: Batelle Memorial Institute and Woodrow Wilson International Center for Scholars.

Martinot, Eric (2001). "World Bank Energy Projects in China: influences on environmental protection," Energy Policy, vol.

Nakicenovic, N., W.D. Nordhaus, R. Richels, and F.L. Toth, editors (1994). Integrative Assessment of Mitigation, Impacts, and Adaptation to Climate Change. IIASA Report No. CP-94-9. Laxenburg, Austria: International Institute for Applied Systems Analysis.

Siddiqi, Toufiq A. (2000). "The Asian Financial Crisis: is it good for the global environment?" Global Environmental Change, vol. 10, pp. 1-7.

Siddiqi, Toufiq A. (2003). Enhancing Clean Energy Supplies for Development: A Natural Gas Pipeline for India and Pakistan. Washington, D.C.: BALUSA Inc.

Sinton, Jonathan E., and David G. Fridley (2000). "What goes up: recent trends in China's energy consumption," Energy Policy, vol. 28, pp. 671-687.

Streets, David G. (2003). The Emergence of Black Carbon into the Climate Policy Arena. Discussion Paper 2003/1. Honolulu: Global Environment and Energy in the 21st Century.

United Nations Development Program (1999). Human Development Report 1999. New York and Oxford: Oxford University Press.

United Nations Framework Convention on Climate Change (2003). Kyoto Protocol, Status of Ratification as of 20 March 2003. Bonn: UNFCCC.

World Bank (2002). International Country Tables: China. Washington, D.C.: World Bank. 


\section{Session 3: Perspectives for Industrialized Countries}

Chairman: Hans Jørgen Koch, Ministry of Economic and Business Affairs, Denmark 


\title{
Visions on Energy Production Technologies for Finland up to 2030
}

\author{
Mikko Kara \\ Executive Director, Professor \\ VTT Processes \\ P.O.Box 1604, FIN-02044 VTT
}

\section{Introduction}

The energy sector will face major challenges in the coming decades. Global demand for primary energy is continuously increasing, as are its related environmental effects. On the other hand, the limited resources of especially oil and gas will lead to increasing price instability. Deregulation of energy markets is a challenge for the infrastructure. This deregulation is leading to restructuring of the energy market. States and communities as owners of energy companies and energy policy decision-makers will find difficult to play this double role. Globally big question mark hangs over the developing countries and their energy solutions and related environmental effects.

At European Union level and in Finland the biggest challenge is the attainment of the Kyoto target and then further reduction of greenhouse gas emissions. Renewables, nuclear power and growing imports of natural gas from Russia will play a crucial role in Finland.

In this presentation, my focus is on the development of those energy production technologies which are most important for Finland's energy supply and its energy technology exports. These are combined heat and power generation and bioenergy applications, in all size ranges from large-scale power plants to distributed energy systems. Then I have looked at the development of the energy sector in Finland up to 2030 in three different scenarios: baseline, strong energy savings and ambitious technological development. Transportation sector, transmission and distribution of energy, and energy production and consumption technologies that have not been introduced in this presentation, are included in the scenarios.

\section{Large-scale power production with fossil fuels is replaced by combined heat and power gen- eration}

Large-scale power plants that burn fossil fuels will be the backbone of global electricity production. Technological developments will help to improve the economy and reduce environmental effects of energy production: power production efficiency will be raised, emissions will be eliminated and fuel flexibility will be improved (Fig 1). It seems that renewable and nuclear energy cannot fulfil the longterm electricity needs, and techniques to separate and dispose carbon dioxide will be needed. 


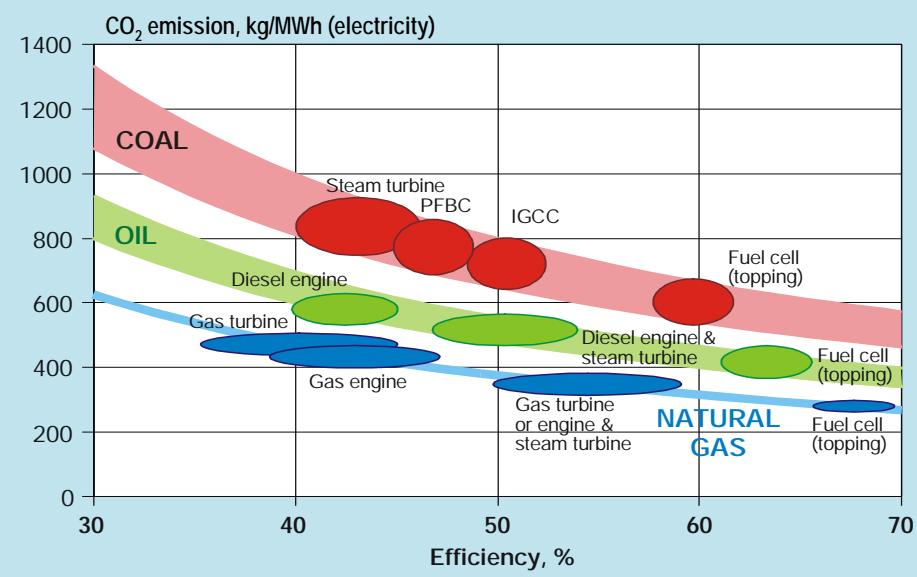

Source: Energy Visions 2030 for Finland

Figure 1. $\mathrm{CO}_{2}$ emissions and electricity production efficiency of condensing power plants based on different technologies and using different fossil fuels

\subsection{Consistent efforts to increase CHP in Finland}

The main option for Finland to increase the efficiency of power generation has been the switch from condensing power plants to combined heat and power production (CHP). CHP plants today produce already over $35 \%$ of the total electricity supply in Finland, but the feasible goal could be about $50 \%$ in 2030 (Fig 2). About $75 \%$ of district heat is provided from cogeneration plants with a typical overall annual efficiency of $85-90 \%$. This is much higher than the $40-45 \%$ efficiency of condensing power plants, which only generates electricity. Separate power and heating plants need about $40 \%$ more fuel than a corresponding CHP plant. 


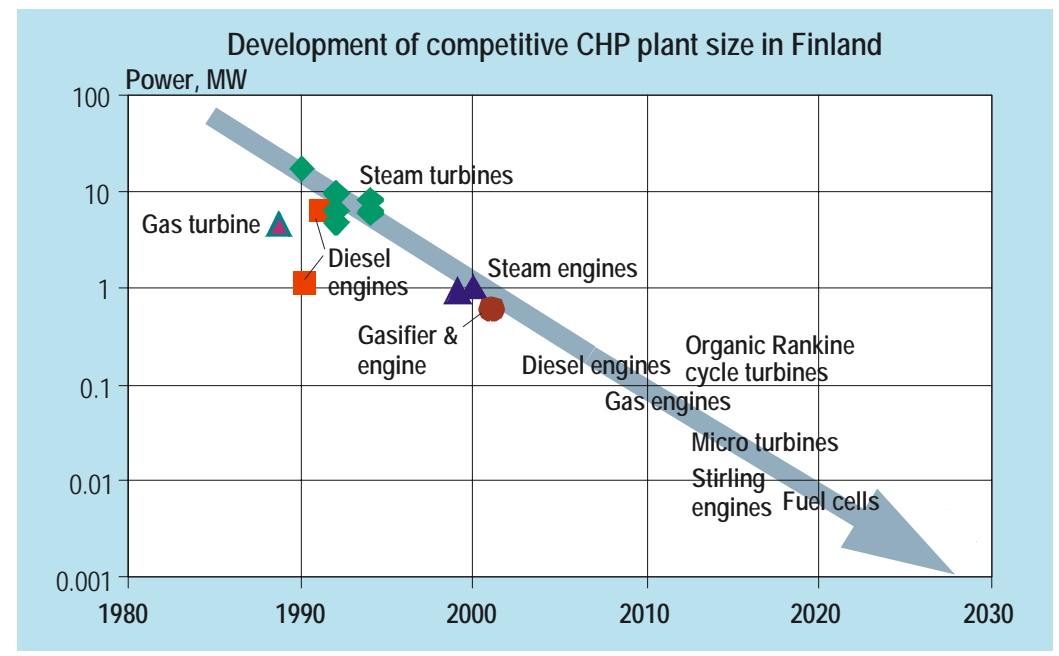

Figure 2. Past and anticipated future development of CHP technology

\subsection{CHP for smaller size ranges}

The future target is CHP plants for ever-smaller heat consumers, because the available large heat loads for district and industrial process heating in Finland are already utilised for combined heat and power consumption (Fig 3.). Diesel and steam engines, and steam and gas turbines are now applied in smallscale CHP of $200 \mathrm{~kW}$ - 3 MW electricity. Microturbines, fuel cells, Organic Rankine Cycle (ORC) and Stirling engines are future options for smaller capacity classes. All these options need standardised concepts and mass or serial production to obtain competitiveness without significant subsidies or other promotion measures. The first small concepts, in $\mathrm{kW}$-size used in private houses, will mostly use natural gas and biogas, but fuel alternatives could be widened to pellets, bio-oils and other biomass derived fuels. 


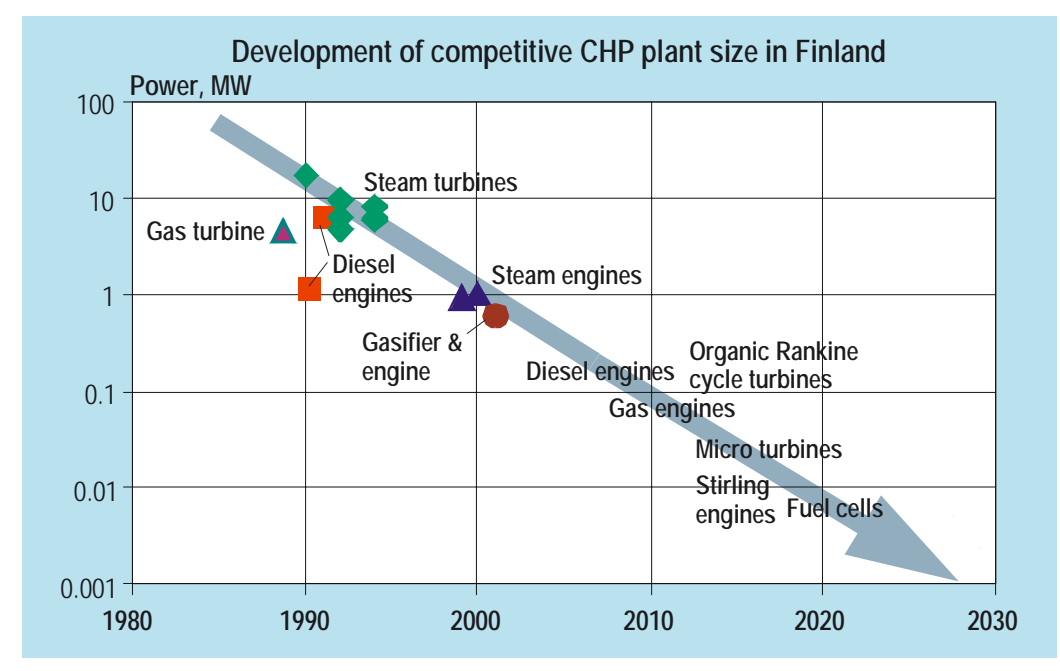

Figure 3. Electricity is generated in ever-smaller units: general trend (line) for the minimum competitive size and actual plants (symbols) built in Finland

\subsection{Higher power-to-heat ratios}

Another trend is to increase power-to-heat ration in combined heat and power production. Backpressure steam cycle plants with varying combustion technologies, depending on fuel and size, are presently dominant for solid fuels. Their power-to-heat ratio is usually $0.35-0.5$ for district heating, and $0.2-0.3$ for processes requiring high steam temperatures. High power-to-heat ratio and suitability for low-grade biomass-based fuels make combined cycle power plants based on pressurised fluidisedbed combustion and gasification attractive for energy production in Finland. The major challenge is the clean-up of hot gas from combustion or gasification before gas turbines. The most promising process alternative for the size range $30-100 \mathrm{MW}$ electricity is a simplified IGCC based on air gasification and subsequent hot gas cleaning. The power-to-heat ratio of this concept is $0.8-1.2$, the power production efficiency $40-45 \%$ and the total efficiency $85-90 \%$ (Fig.4).

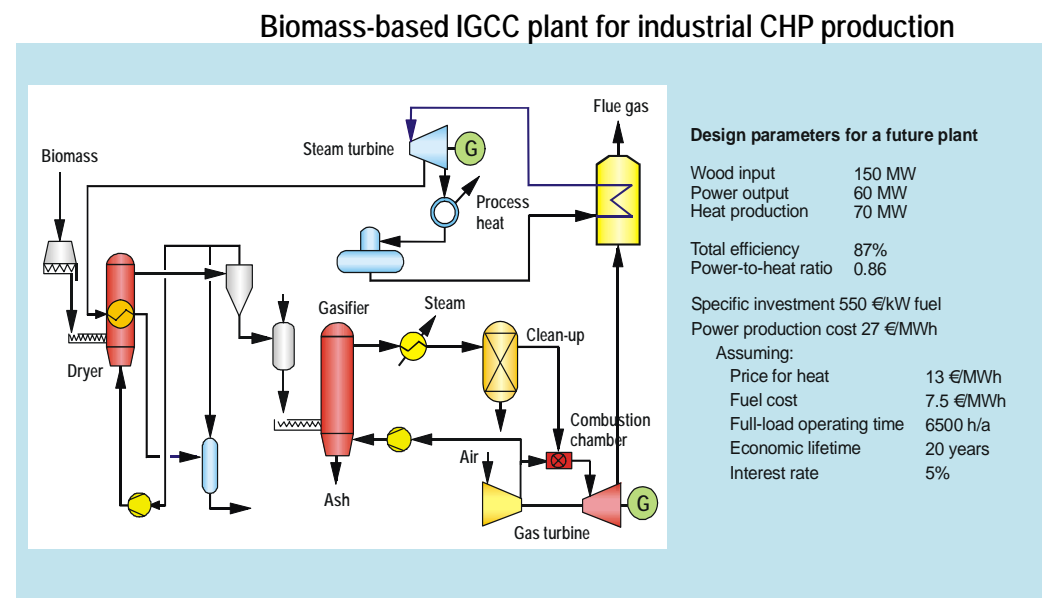

Figure 4. The concept of an Integrated Gasification Combined-Cycle Power Plant (IGCC) for the efficient use of biomass. Indicative design parameters are also shown for a potential application as an industrial CHP plant 
An even higher power-to-heat ratio could be achieved by integrating a high-temperature fuel cell with an IGCC plant (Fig.5). Power production efficiency could be about $60 \%$ with a process based on pressurised gasification of wood fuels.

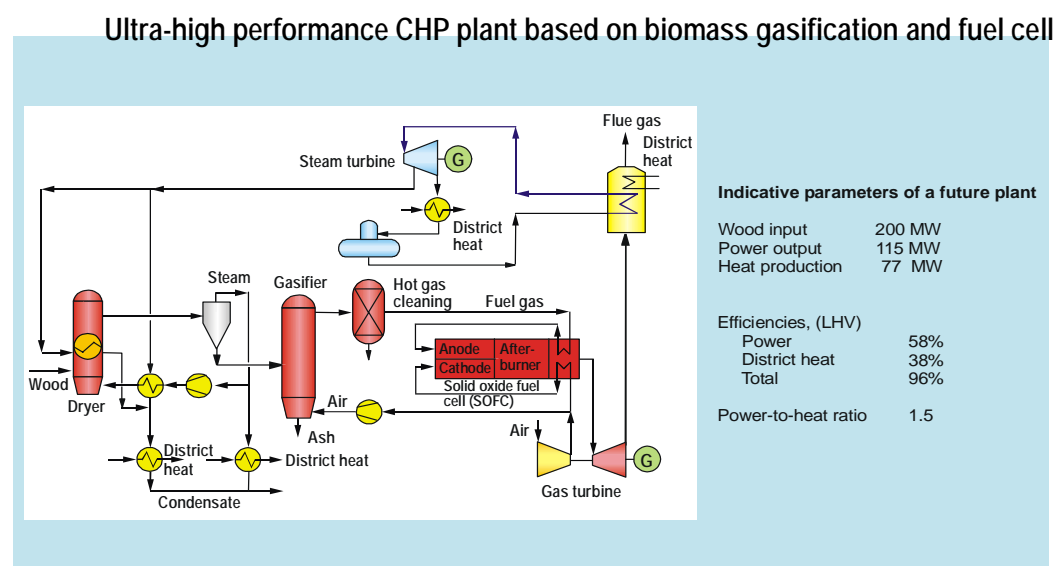

Figure 5. Ultra-high performance CHP plant based on biomass gasification and fuel cell

\section{Replacing coal by biomass}

The increased use of biomass in coal boilers is regarded as a highly promising way to cut greenhouse gas emissions. Coal can be replaced by biomass only to a limited share, typically under $10 \%$, by injecting biomass directly to existing pulverised coal boilers.

\subsection{Fluidised bed replacing pulverised fuel combustion}

The early industrial fluidised-bed combustors were small, atmospheric bubbling fluidised-bed (BFB) boilers. Later in the mid-1970s, atmospheric circulating fluidised (CFB) technology was developed. Nowadays, CFB is the predominant technology in commercial applications with a boiler thermal power greater than $50 \mathrm{MW}$. Further performance improvements for CFB are being sought by introducing a once-through supercritical (OTSC) steam cycle. Foster Wheeler announced a OTSC CFB-boiler for 460 MWe plant in Poland to have a start up in 2006. The potential improvement in efficiency and reduction of $\mathrm{CO}_{2}$ emissions are illustrated in Fig. 6. Supercritical pulverised fuel combustion plants do not appear to be feasible for co-firing coal and biomass. 


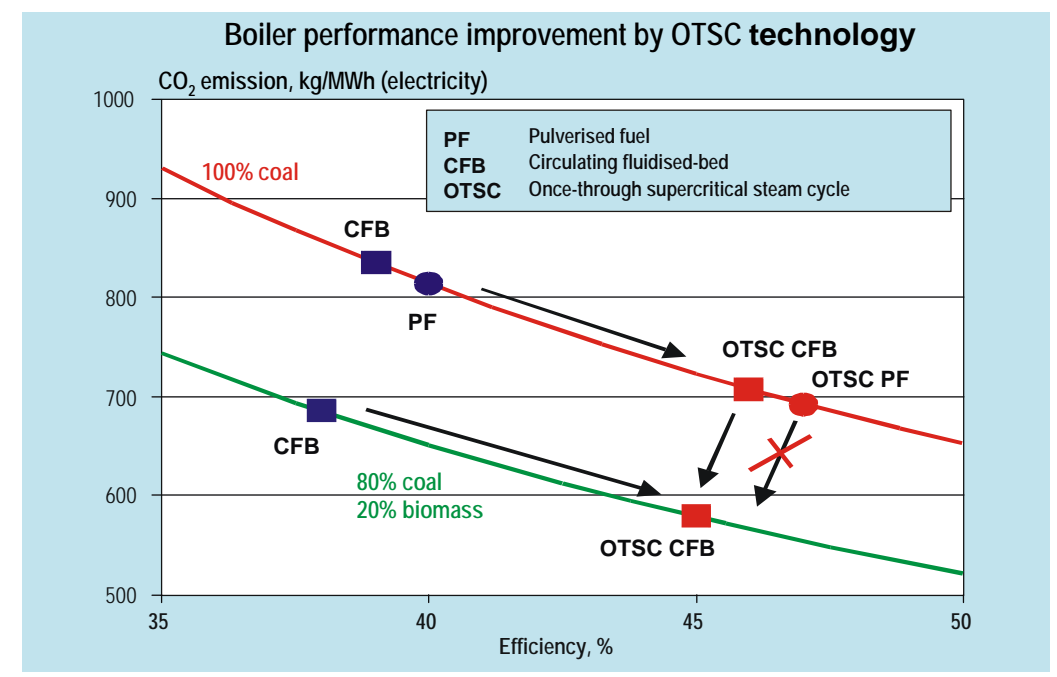

Figure 6. Today's R\&D efforts aim to introduce a once-through supercritical (OTSC) steam cycle to CFB boilers, which would significantly improve efficiency and reduce the specific $\mathrm{CO}_{2}$ release. The concept will first be demonstrated for pure coal in Poland

\subsection{Gasifiers connected to coal boilers and pressurised gasifiers to gas turbines}

Different types of biomass gasifiers have found their suitable size classes and markets in Finland: fixed bed gasifiers are applied for under $20 \mathrm{MW}$ thermal power, bubbling fluidised bed gasifiers 20-60 MW and circulating fluidised bed gasifiers for over $60 \mathrm{MW}$. When fuel is clean, the chlorine content below $0.1 \mathrm{wt}-\%$ and the heavy metal content is low, the gasification product gas can be burned directly in a coal boiler. Since there are no strict demands for the heating value of the hot gas, the fuel can be moist and no drying is needed before gasification.

For fuels containing more alkali metals, chlorine or aluminium, fuel gas cleaning is necessary before delivering the gas to the main boiler (Fig 7). By gas cooling (to $300-400^{\circ} \mathrm{C}$ ) and filtering, the dust can be removed completely from the gas, and most of the heavy metals, alkalis, and chlorine are removed from the gas together with the particulate matter, The removal of chlorine and heavy metals can be further improved up to $90-95 \%$ by injection of calcium-based sorbent and activated carbon. If desired, a wet scrubber can remove ammonia as well as the rest of the impurities. After water scrubbing, the clean and cooled gas is easily transportable and can be burned in the boiler without any risks. 


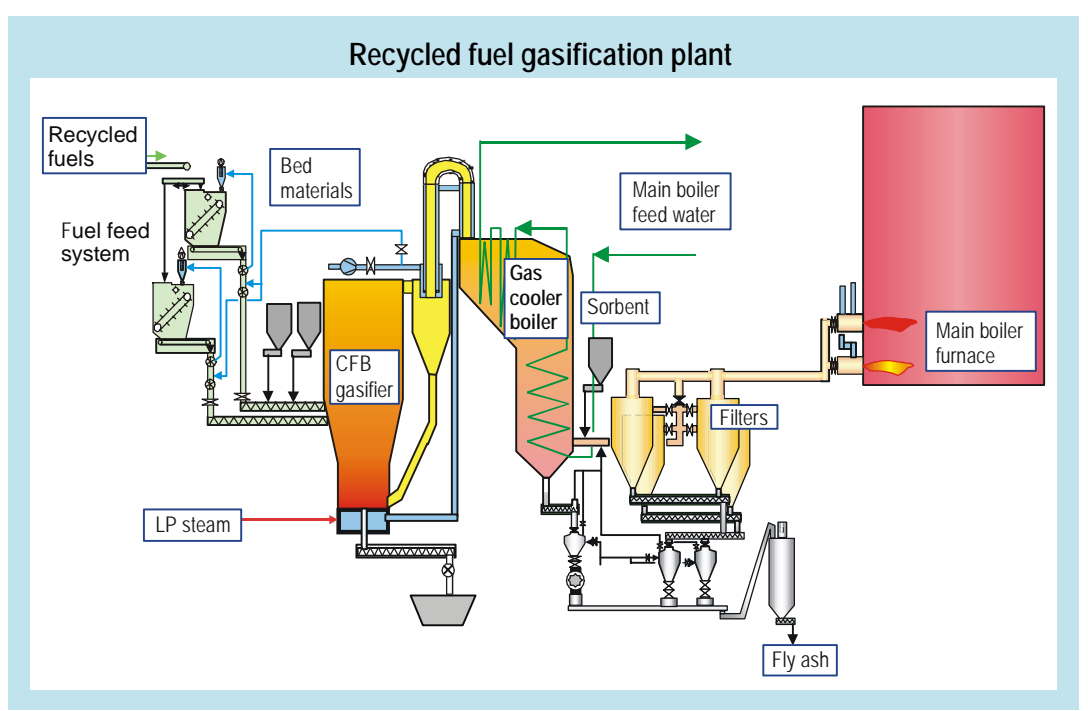

Figure 7. Circulated fluidised-bed gasifier for recycled fuel coupled with a boiler (Foster Wheeler Energia)

In the longer term, pressurised biomass or waste gasifier could also be connected to natural gas combined cycle plants. In this process, the cleaned gas from the gasifier is mixed with natural gas. The fuel has to be quite dry, the moisture content below $25 \mathrm{wt}-\%$ in order to reach a fuel rich gas heating value that is high enough for stable combustion.

\section{Scenarios illustrate future options}

In order to analyse the possible role of various emerging and evolving technologies in the future energy system of Finland, three scenarios were created for a comprehensive energy system model. The model is based on a bottom-up, technology oriented representation of the energy system, including both the supply and end-use sectors. Mathematically, the model is a quasi-dynamic linear optimisation model that simulates the behaviour of energy-economic decision-making by minimising the total present value of all costs and other expenditures in the energy system during the entire time horizon under consideration.

The Kyoto scenario is based on the assumption that the only target for greenhouse gas emissions will be one imposed by the Kyoto protocol (Fig. 8). In the other two scenarios it is assumed that more rigorous emission targets will be set for the subsequent decades up to 2030. In the Save scenario, reduction of the energy demand is considered to be the most effective means of achieving emission reduction, and high energy taxation is selected as the main policy instrument leading to the reduced demand. In Technology scenario, reduction of the carbon intensity of the energy supply is chosen to be the primary means, and intensified R\&D on energy technologies is selected as the main instrument. 


\section{Summary of the main characteristics of the scenarios}

\begin{tabular}{lllll}
\hline Characteristic & Kyoto & Save & Techno & Reference \\
\hline $\begin{array}{l}\text { Energy and } \mathrm{CO}_{2} \\
\text { taxation }\end{array}$ & $\begin{array}{l}\text { Moderate } \\
\text { increase }\end{array}$ & $\begin{array}{l}\text { Large } \\
\text { increase }\end{array}$ & $\begin{array}{l}\text { Small } \\
\text { increase }\end{array}$ & Present \\
$\begin{array}{l}\text { Level of energy } \\
\text { conservation measures }\end{array}$ & Moderate & High & Moderate & Low \\
$\begin{array}{l}\text { Costs and potential of } \\
\text { renewable energy supply }\end{array}$ & $\begin{array}{l}\text { Base } \\
\text { estimates }\end{array}$ & $\begin{array}{l}\text { Base } \\
\text { estimates }\end{array}$ & $\begin{array}{l}\text { Boosted } \\
\text { development }\end{array}$ & $\begin{array}{l}\text { Conservative } \\
\text { estimates }\end{array}$ \\
$\begin{array}{l}\text { Costs and potential of } \\
\text { new technologies }\end{array}$ & $\begin{array}{l}\text { Base } \\
\text { estimates }\end{array}$ & $\begin{array}{l}\text { Base } \\
\text { estimates }\end{array}$ & $\begin{array}{l}\text { Boosted } \\
\text { development }\end{array}$ & $\begin{array}{l}\text { Conservative } \\
\text { estimates }\end{array}$ \\
$\begin{array}{l}\text { Amount of new nuclear } \\
\text { capacity allowed }\end{array}$ & None & $\begin{array}{l}1400 \mathrm{MW} \\
\text { in } 2015\end{array}$ & $\begin{array}{l}3000 \mathrm{MW} \\
\text { by 2030 }\end{array}$ & None \\
\hline $\begin{array}{l}\text { GHG emission reduction } \\
\text { objective }\end{array}$ & $\begin{array}{l}\text { The Kyoto } \\
\text { target }\end{array}$ & $\begin{array}{l}\text {-20\% from } \\
1990 \text { level }\end{array}$ & $\begin{array}{l}\text {-20\% from } \\
1990 \text { level }\end{array}$ & None \\
\hline
\end{tabular}

Figure 8. Summary of the main characteristics of the scenarios

According to the results of the scenario analysis (Fig 9), expanding the utilisation of bioenergy, especially for CHP production (Fig. 10), is in Finland one of the key measures for achieving significant reductions in greenhouse gas emissions. However, the most cost-effective ways of increasing bioenergy utilisation require the introduction of a number of novel technologies both in fuel supply and in the energy production sectors. The use of advanced nuclear power technologies is another key measure. Extensive utilisation of wind power could further increase the percentage of emission-free electricity production by attaining a share of up to $9 \%$ in total energy supply by 2030 .

Furthermore, using new technologies for the integration of the energy sector with waste management offers synergetic advantages leading to significant and cost-effective reductions in emissions.

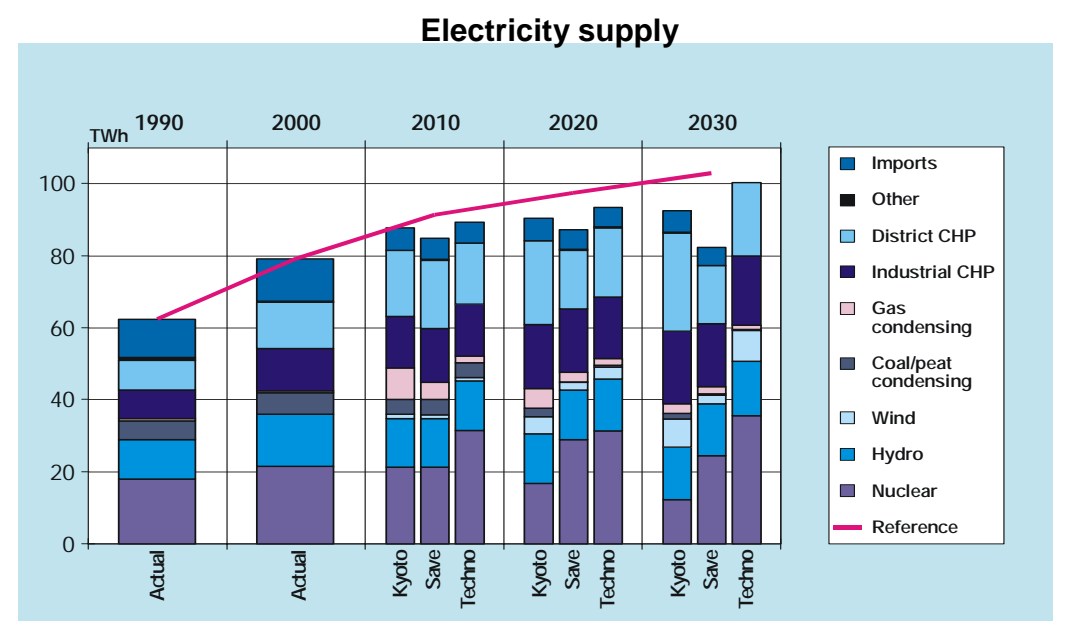

Figure 9. Structure and development of total electricity supply in the three energy futures considered 


\section{Percentage of combined heat and power production}

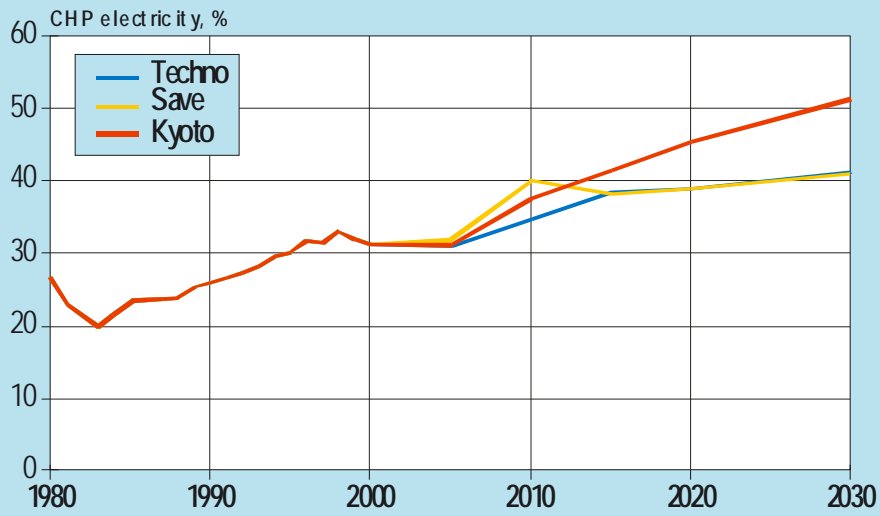

Figure 10. The percentage of CHP of total electricity supply in scenarios

The scenarios appear to be quite different from each other in terms of costs and overall economic impacts. The direct costs of the technical measures that are required to reaching the emission targets are highest in the Kyoto scenario, and by far the lowest in the Technology scenario. Taking into account both costs and taxes, the total increase in the total energy expenses of final consumers is the largest in the Save scenario.

On the whole, with its strong focus on energy-related $R \& D$, the technology scenario appears to offer substantial and wide potential benefits both in terms of overall economic effects (Fig. 11), and with respect to the environmental impacts of energy use.

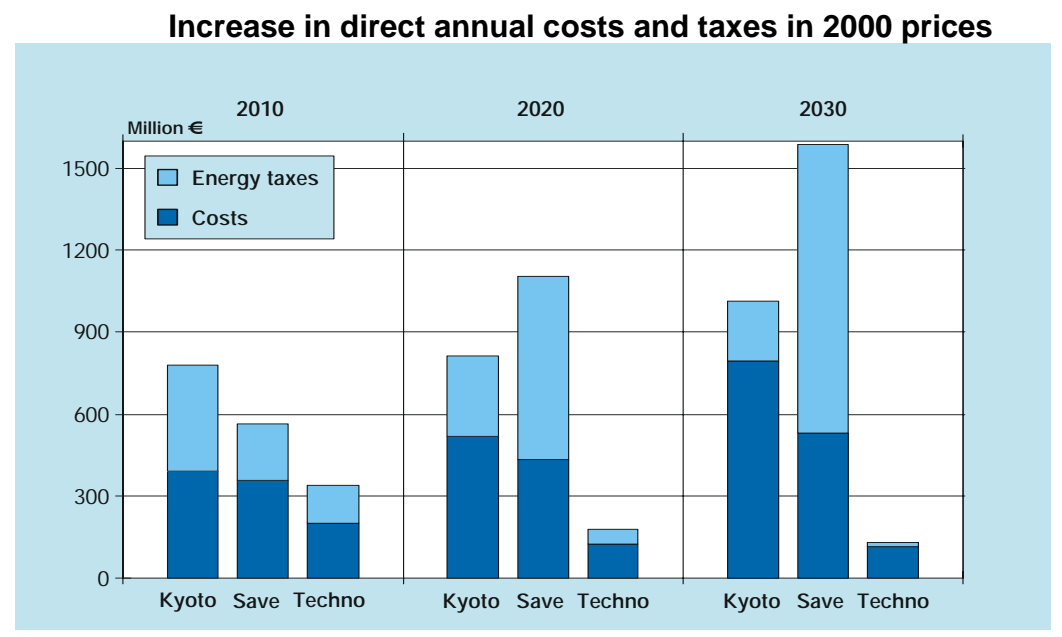

Figure 11. Increase in direct annual costs and energy taxes compared to reference scenario in the scenarios considered 


\section{Conclusions}

Decoupling energy use completely from economic growth can, in general, be considered an almost unattainable target. However, decoupling environmental impacts from economic growth should be an entirely feasible target. Through the development and adoption of new and advanced technologies, the transition leading to a sustainable path of greenhouse gas emissions does not have to be heavy burden onto the economy. It seems to be far more economic for the society to allocate money to technological development than to achieve the same environmental results through higher taxation.

\section{Reference}

Kara, Mikko; Hirvonen, Ritva; Mattila, Lasse; Viinikainen, Seppo; Tuhkanen, Sami (eds.). Energy Visions 2030 for Finland. VTT Energy 2001. 237 p. ISBN 951-37-3596-6. 


\title{
Elaborating SRES Scenarios for Nuclear Energy
}

\author{
Alan McDonald \\ Planning and Economic Studies Section \\ International Atomic Energy Agency (IAEA) \\ Wagramerstrasse 5, P.O. Box 100 \\ A-1400 Vienna, Austria \\ Tel: $+43-1-2600-22650$ \\ Fax: +43-1-2600-29598 \\ E-Mail: a.mcdonald@iaea.org
}

Keywan Riahi

Environmentally Compatible Energy Strategies Project International Institute for Applied Systems Analysis (IIASA)

A-2361 Laxenburg, Austria

Tel: +43-2236-807-491

Fax: +43 $2236807-488$

E-mail: riahi@iiasa.ac.at

Hans-Holger Rogner

Head, Planning and Economic Studies Section

International Atomic Energy Agency (IAEA)

Wagramerstrasse 5, P.O. Box 100

A-1400 Vienna, Austria

Tel: $+43-1-2600-22776$

Fax: +43-1-2600-29598

E-mail: h.h.rogner@iaea.org 


\section{Introduction}

Our eventual objective is mid-century economic targets for nuclear energy. The first step is to describe what the mid-century energy market might look like - the major competitors for nuclear energy, what products are in demand, how much of each, where growth is greatest, and so forth. The mechanism for systematically describing the future market is scenario building. Because we do not know the future precisely, we need several scenarios to reflect our uncertainty.

The starting point is the scenarios in the Special Report on Emissions Scenarios (SRES) of the Intergovernmental Panel on Climate Change (IPCC, 2000). Given their international authorship and comprehensive review by governments and scientific experts, the SRES scenarios are the state of the art in long-term energy scenarios.

SRES developed four narrative storylines, each representing a different coherent set of demographic, social, economic, technological, and environmental developments. For each storyline, several different quantifications, or scenarios, were then developed by six different international modeling teams. The result is 40 scenarios grouped in four "families" (A1, A2, B1, and B2) corresponding to the four narrative storylines. Economic objectives dominate in the "A" storylines, while environmental objectives dominate in the "B" storylines. The " 1 " storylines emphasize globalization, while the " 2 " storylines are better characterized by regionalism. The following summaries are almost verbatim from the SRES report.

- The A1 storyline and scenario family describe a future world of very rapid economic growth, low population growth, and the rapid introduction of new and more efficient technologies. Major underlying themes are convergence among regions, capacity building, and increased cultural and social interactions, with a substantial reduction in regional differences in per capita income.

- The A2 storyline and scenario family describe a very heterogeneous world. The underlying theme is self-reliance and preservation of local identities. Fertility patterns across regions converge very slowly, which results in high population growth. Economic development is primarily regionally oriented and per capita economic growth and technological change are more fragmented and slower than in other storylines.

- The B1 storyline and scenario family describe a convergent world with the same low population growth as in the A1 storyline, but with rapid changes in economic structures toward a service and information economy, with reductions in material intensity, and the introduction of clean and resource-efficient technologies. The emphasis is on global solutions to economic, social, and environmental challenges, including improved equity, but without additional climate initiatives.

- The B2 storyline and scenario family describe a world in which the emphasis is on local solutions to economic, social, and environmental challenges. It is a world with moderate population growth, intermediate levels of economic development, and less rapid and more diverse technological change than in the B1 and A1 storylines. While the storyline is also oriented toward environmental protection and social equity, it focuses on local and regional levels.

For each of the A2, B1, and B2 storylines this paper uses a single "marker" scenario representative of central tendencies within the scenario family. For the A1 storyline, SRES projections showed that greenhouse gas emissions (the principal focus of SRES) vary greatly depending on the technologies assumed to progress most quickly. We have chosen the A1T Scenario, which assumes that advances in non-fossil technologies - renewables, nuclear, and high-efficiency conservation technologies - make them most cost-competitive.

The A1T emission trajectory for carbon is consistent with stabilizing the atmospheric carbon concentration at about 560 parts per million by volume (ppmv), and the emission trajectory for the B1 Scenario is consistent with stabilization at less than 500 ppmv. Thus, although both these scenarios explicitly exclude policies to limit global warming, their resulting carbon emission levels could be consistent with the objectives of the UN Framework Convention on Climate Change (UNFCCC). In contrast, the A2 and B2 Scenarios project higher carbon emissions at levels currently considered inconsistent with the UNFCCC objectives. 


\section{Nuclear Energy in the SRES A1T, A2, B1, and B2 Scenarios}

Figure 1 summarizes the nuclear projections in the SRES quantifications using the MESSAGE model of the International Institute for Applied Systems Analysis. Each quartet of bars shows projected nuclear production in a given year for the four scenarios, with A1T on the left, then A2, then B1, and then B2 on the right. Each bar is divided into four segments corresponding to the four regions into which the SRES analysis divides the world. The dark segments at the bottom include all countries belonging to the OECD as of 1990. The next segments (REF) are countries undergoing economic reform. Next is "Asia," which includes all developing countries in Asia. The top light segments cover the rest of the world (ROW) and include all developing countries in Africa, Latin America, and the Middle East.

Langlois et al. (2002) elaborate on the details underlying the nuclear projections summarized in Figure 1 and identify six key differences in the scenarios' implications for the mid-century market for nuclear energy.

\section{New Products or Old Products}

In the technologically lethargic A2 and B2 Scenarios nuclear energy's market niche remains electricity production. In the technologically aggressive A1T and B1 Scenarios hydrogen production is a substantial contender. Between 2030 and 2050 average annual additions to the world's hydrogen production capacity in the B1 Scenario are more than twice the average capacity additions for electricity. Nuclear energy and renewables compete for this expanding market.

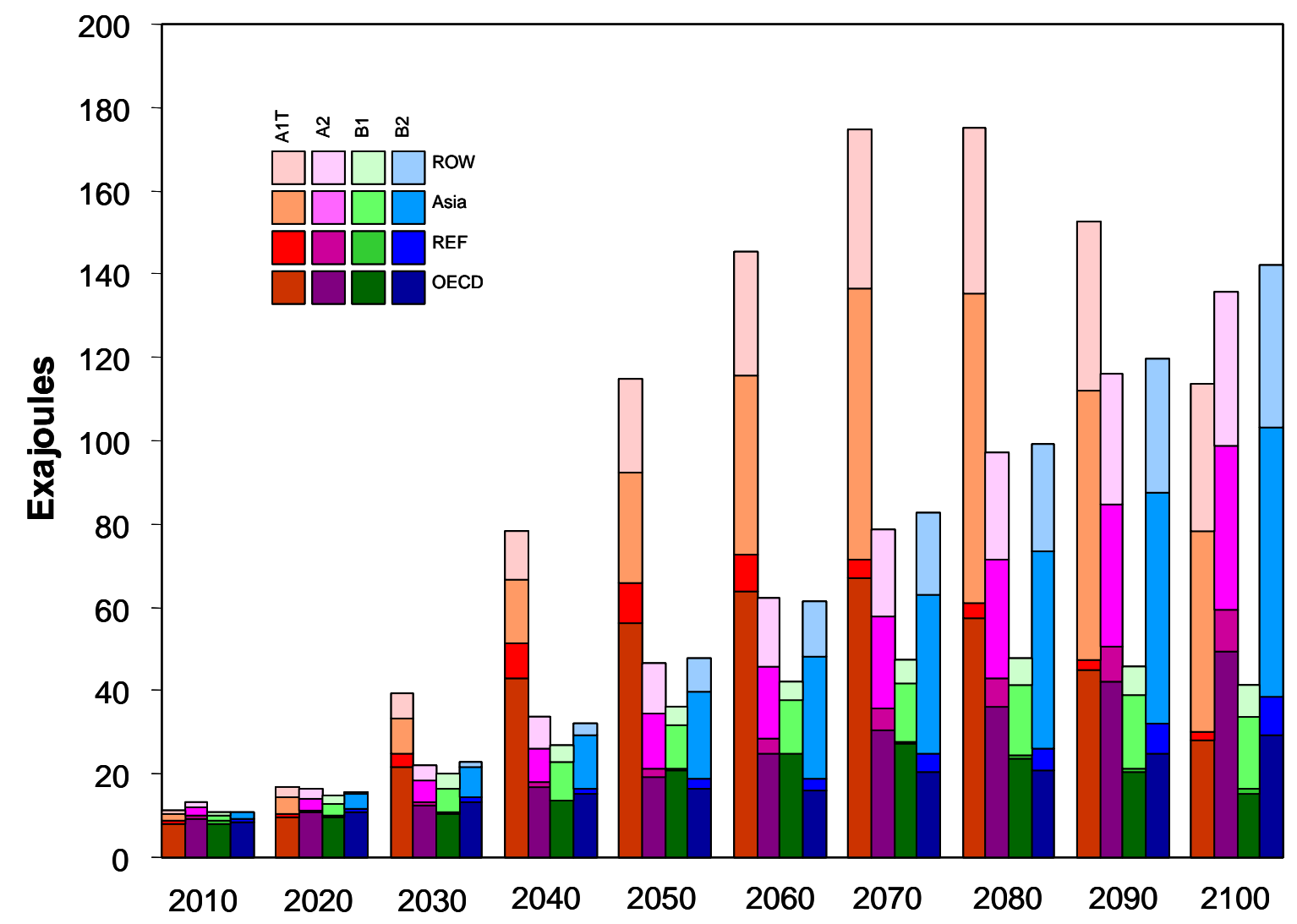

Figure 1. Projected use of nuclear energy in four SRES scenarios 
In the A2 Scenario the global population in 2100 is 15 billion, final energy use is 1300 exajoules (EJ) - compared to 300 EJ in 2000 - and both are still growing. In the B1 Scenario population peaks already in 2050 and final energy use a decade later. By 2100 the population is only seven billion (although they are much richer than their A2 cousins), final energy use is below $500 \mathrm{EJ}$, and both are steadily dropping.

\section{New Customers or Old Customers}

In all scenarios the growth market for new generating capacity shifts to the developing world, but not at the same speed. In the B1 Scenario, for example, average annual additions in developing regions between 2050 and 2070 are nine times those in developed regions. In the B2 Scenario, the ratio is four-to-one, less than half as much.

\section{Globalization or Regionalism}

The globalized, market-oriented A1T world would likely welcome eventual international waste disposal under international standards, recognizing that geology and history have granted some countries a comparative advantage in waste disposal. In the regionalized A2 Scenario, international waste disposal is much less likely.

\section{Old Infrastructures or New}

The key continuing change in the energy system in the A1T Scenario, in all countries and at all levels, is decentralization. In richer countries traditional electric utilities may have essentially disappeared by mid-century. Any move toward decentralization in the A2 Scenario would be much slower and more limited.

\section{Market Security or Resource Security}

In the globalized A1T and B1 Scenarios, energy supply security means access to the most costeffective supplies in the world through a transparent, vibrant, and flexible free global market. In the regionalized A2 and B2 Scenarios it retains much of its current meaning - minimize energy imports, or at least diversify among friendly suppliers.

\section{3 "Aggressive Nuclear" Variations on the SRES Scenarios}

From the perspective of the nuclear industry, the SRES results should be viewed not as tight constraints, but as indications of opportunities. And the important question is how quickly must the industry improve costs and competitiveness to capture future market shares significantly bigger than those based on the cost assumptions of SRES' authors and shown in Figure 1. To develop such cost improvement targets, we start by estimating just how big the potential nuclear market might be beyond what is shown in Figure 1. That is the step reported in this paper. The next task will be to identify improvement rates, and cost targets, consistent with nuclear energy capturing all of the potential markets estimated here. This section therefore presents an "aggressive-nuclear-improvement" variation for each of the four SRES scenarios by assuming reasonable nuclear incursions in the expensive ends of the market shares of key competitors. The resulting aggressive nuclear variations, aggregated to the global level, are shown in Figure 2. 


\section{Electricity}

Any inroads by nuclear energy into the markets held by its competitors (as calculated in SRES) would begin in those parts of competitors' market shares that are most expensive. Consider first competition from coal-fired electricity generation. In the SRES scenarios coal resources are divided into five cost categories. SRES calculates consumption in each category for each region and scenario. In general, consumption early in a scenario concentrates on lower cost categories and, as these are depleted, moves to higher cost categories in later parts of the scenario. In detail, the patterns are more complex, incorporating as they do regional differences in resources and infrastructural inertia - i.e., new plants, mines, transportation systems, and processing facilities do not replace old ones overnight, but are phased in at different rates in different regions.

We assume that even aggressive nuclear improvements would be unlikely to displace electricity produced by coal in the two least expensive coal categories. Electricity from coal in these categories is simply too cheap an option. But the three higher-cost categories are more vulnerable to inroads from nuclear improvements that are faster than those assumed in SRES. We therefore assume that aggressive nuclear improvements would allow nuclear power to capture half of the market share (in each region in each scenario) that corresponds to electricity from coal in these categories.

Taking half of coal use that comes from these three categories, in each SRES scenario and region, gives the numbers in the "coal" column in Table 1. The first, $17 \%$ for Asia in the A1T Scenario, means that our estimated potential nuclear market in that region and scenario adds to what SRES calculated for the nuclear potential (Figure 1) an amount equal to 17\% of SRES's estimate for coal-fired electricity (from all five cost categories of coal). The rest of the column should be interpreted similarly.

Because the market share of oil-fired electricity is currently insignificant and drops quickly to zero in all scenarios, there is nothing for nuclear power to compete with, and the "oil" column in Table 1 is empty.

For natural gas, the assumptions parallel those for coal. The SRES scenarios divide gas resources into eight categories, the first four of which are too cheap for even aggressive nuclear improvements to displace. However, half of unconventional gas consumption from the more expensive categories is assumed to be vulnerable to more accelerated nuclear cost reductions than assumed in the SRES scenarios. The numbers in Table 1's "natural gas" column were calculated, and should be interpreted, in the same way as the numbers in the "coal" column.

Biomass and waste, the electricity sources represented in the next column in Table 1, are not divided into cost categories in SRES like coal and natural gas. But the same principle should hold - even aggressive nuclear improvements would be unlikely to dislodge the cheapest biomass and waste from the electricity market, but should make in-roads at the expensive end of the biomass/waste market share. Since SRES estimates the total potential availability of biomass and waste, we assume that any use that exceeds $60 \%$ of this total potential would fall into the high-cost, vulnerable category. The numbers in Table 1's "biomass/waste" column, thus, show the percentages of SRES's estimates for biomass/waste-fired electricity that we include in Figure 2's estimated nuclear market potentials. 
Table 1. Percentage of SRES-calculated electricity markets that could be captured by nuclear energy in the event of aggressive nuclear improvements.

\begin{tabular}{|l|l|c|c|c|c|c|c|c|c|}
\hline \multicolumn{2}{|l|}{} & & Coal & Oil & Gas & Bio/Waste & Hydro & Solar & Wind/Geo \\
\hline & & & $\%$ & $\%$ & $\%$ & $\%$ & $\%$ & $\%$ & $\%$ \\
\hline A1T & & & & & & & & \\
\hline & Asia & & 17 & na & 30 & 35 & 30 & 25 & 25 \\
\hline & ROW & & 0 & na & 18 & 0 & 20 & 20 & 25 \\
\hline & REF & & 1 & na & 8 & 0 & 15 & 40 & 25 \\
\hline & OECD & & 0 & na & 23 & 31 & 0 & 33 & 25 \\
\hline A2 & & & & & & & & & \\
\hline & Asia & & 36 & na & 27 & 40 & 30 & 33 & 25 \\
\hline & ROW & & 21 & na & 16 & 40 & 25 & 20 & 25 \\
\hline & REF & & 18 & na & 11 & 40 & 15 & 26 & 25 \\
\hline & OECD & & 5 & na & 28 & 40 & 6 & 16 & 25 \\
\hline B1 & & & & & & & & & \\
\hline & Asia & & 11 & na & 27 & 16 & 30 & 34 & 25 \\
\hline & ROW & & 0 & na & 14 & 0 & 20 & 27 & 25 \\
\hline & REF & & 3 & na & 5 & 0 & 15 & 34 & 25 \\
\hline & OECD & & 0 & na & 24 & 26 & 8 & 37 & 25 \\
\hline B2 & & & & & & & & & \\
\hline & Asia & 17 & na & 32 & 40 & 30 & 26 & 25 \\
\hline & ROW & & 0 & na & 18 & 40 & 20 & 20 & 25 \\
\hline & REF & 6 & na & 9 & 40 & 10 & 40 & 25 \\
\hline & OECD & & 0 & na & 30 & 37 & 5 & 28 & 25 \\
\hline
\end{tabular}

SRES divides hydroelectricity into a high-cost category and a low-cost category. Only the high-cost category is considered vulnerable to inroads by nuclear energy. In the OCED and REF regions, we assume that nuclear energy could capture $50 \%$ of the high-cost hydroelectricity calculated by SRES. In the Asia and ROW regions, where nuclear energy faces greater infrastructural challenges even in the event of aggressive improvements, we assume that it could only capture $33 \%$ of the high-cost hydroelectricity calculated by SRES.

Solar electricity is divided in the SRES scenarios into three categories based on whether it is generated by centralized solar thermal plants, centralized photovoltaic plants, or decentralized on-site production (mostly from small photovoltaic systems). Only the two centralized categories are considered vulnerable to displacement by nuclear energy. The numbers in Table 1 assume nuclear energy captures $50 \%$ of their market as calculated by SRES.

For wind and geothermal, SRES includes no cost categories. Based on the expectation that, with aggressive improvements, nuclear energy could displace a share of the more expensive end of the wind/geothermal market share, Table 1 indicates that $25 \%$ (half of half) of the complete wind/geothermal electricity shares calculated by SRES is assumed vulnerable to nuclear inroads.

\section{Hydrogen}

Table 2 quantifies the assumptions underlying Figure 2 for hydrogen production. Hydrogen in the SRES scenarios can be produced in six ways. For the first three, hydrogen is produced directly from carbon fuels - coal, natural gas, and biomass. The fourth option is electrolysis. And the fifth and sixth are thermochemical production from high-temperature nuclear and solar cycles. Of the six, the first three are the cheapest, and are assumed to be less vulnerable to inroads from nuclear energy. Any nu- 
clear inroads into electrolytic hydrogen production we assume are already accounted for in Table 1, where nuclear power displaces the contributions of competitors to the overall electricity mix. Thus the only potential additional hydrogen market share to capture is that from thermochemical solar hydrogen production. Assuming again that the more expensive end of solar's market share is most vulnerable to displacement, Table 2 assumes nuclear hydrogen production displaces any solar hydrogen production in excess of $60 \%$ of the total solar potential estimated by SRES.

Table 2. Percentage of SRES-calculated hydrogen production from solar power that could be displaced by nuclear energy in the event of aggressive nuclear improvements (\%).

\begin{tabular}{|c|l|c|l|l|l|c|}
\hline \multicolumn{2}{|l|}{ A1T } & $\%$ & & A2 & $\%$ \\
\hline & Asia & 40 & & & Asia & 10 \\
\hline & ROW & 40 & & & ROW & 40 \\
\hline & REF & 25 & & & REF & 6 \\
\hline & OECD & 40 & & & OECD & 39 \\
\hline & & & & & & \\
\hline B1 & & & B2 & & \\
\hline & Asia & 0 & & & Asia & 7 \\
\hline & ROW & 40 & & & ROW & 40 \\
\hline & REF & 0 & & & REF & 0 \\
\hline & OECD & 0 & & & OECD & 15 \\
\hline
\end{tabular}

Heat

Additional applications of nuclear energy included in Figure 2 are district heat (i.e., centralized heat generation) and heat for upgrading unconventional oil, for liquefying and gasifying coal, for producing synfuels from coal, and for desalinating seawater to increase freshwater supplies. This section addresses district heat and heat for upgrading oil, for liquefying and gasifying coal, and for producing synfuels from coal. The next section deals with desalination.

District heats supplies are included as a separate category in the SRES calculations, but they are not broken down into different cost categories. Paralleling the logic applied to wind and geothermal electricity generation above - that nuclear energy could displace a share of the more expensive end of the market - we assume in the calculations for Figure 2 that nuclear district heat could capture $25 \%$ (half of half) of the total district heat use calculated by SRES.

Oil resources in SRES, like coal and gas resources, are divided in cost categories. Oil resources in the four highest-cost categories (out of eight) are all unconventional. In SRES the heat needed to upgrade oil in these categories comes from the oil itself, and thus shows up in the calculations as a conversion loss. Similarly, in coal gasification and liquefaction, and in synfuels production from coal, the necessary heat comes from the coal and shows up as a conversion loss. The assumption used for Figure 2 is that aggressive nuclear improvements would allow nuclear energy to supply heat for these purposes equal to $50 \%$ of the conversion losses calculated by SRES.

\section{Desalination}

The SRES scenarios do not elaborate on future water demand and supply. However, recent studies indicate that fresh water demand may well exceed sustainable supply in the near-term future (Falkenmark, 1997; Gleick, 2000; Seckler et. al., 1998; WRI, 1998). Indeed in areas of North Africa, the Middle East, and certain parts of Asia, this is already the case now. For the purposes of Figure 2 we estimated overall water demand based on the demographic developments underlying the SRES scenarios, a daily diet of at least $2700 \mathrm{kcal}$ per person per day, an average water demand of households and industry of $400 \mathrm{~m}^{3}$ per person per year, and rates of productivity in improving water use derived from the SRES storylines. Regional water availability was taken from a variety of sources (Falkenmark, 
1997; Gleick, 2000; Seckler et al., 1998). A sustainable share of 40 percent of total water availability was assumed for all regions, as was a 25 percent potential share of nuclear power in the future water desalination market.

\section{Results}

Figure 2 shows the results at the global level. The bottom three categories in each panel (electricity, hydrogen, and heat) show projected nuclear use in the original four SRES scenarios. Their collective trajectories match those in Figure 1. The top five categories in Figure 2 show the additional nuclear market potential based on the assumptions in Section 3.

As noted at the beginning of the paper, the next step will be to estimate, first, cost improvement rates and targets that nuclear energy should meet by mid-century to capture the nuclear markets projected in the original SRES scenarios and, second, more demanding targets that should be met in order to capture the larger potential nuclear markets in the "aggressive nuclear" scenario variations presented here.

\section{References}

M. Falkenmark, 1997: "Meeting Water Requirements of an Expanding World," Phil. Trans. R. Soc. Lond. B352: 929-36.

Peter H. Gleick, 2000: The World's Water 2000-2001: The Biennial Report on Freshwater Resources. Island Press, Washington, D.C.

IPCC (Intergovernmental Panel on Climate Change), 2000: Special Report on Emission Scenarios. A Special Report of Working Group III of the Intergovernmental Panel on Climate Change. Cambridge University Press, Cambridge, UK, (http://www.grida.no/climate/ipcc/emission/index.htm).

Lucille M. Langlois, Alan McDonald, Hans-Holger Rogner and Ivan Vera, 2002: "Energy System Expectations for Nuclear in the $21^{\text {st }}$ Century: A Plausible Range," $10^{\text {th }}$ International Conference on Nuclear Engineering (ICONE-10), Arlington, VA, USA, April 14-18, 2002.

D. Seckler, U. Amarasinghe, D. Molden, R. de Silva, and R. Barker, 1998: World Water Demand and Supply, 1990 to 2025: Scenarios and Issues. Research Report 19, International Water Management Institute, Colombo, Sri Lanka.

WRI (World Resources Institute), 1998: World Resources 1998-99. Oxford University Press, Oxford, UK. 

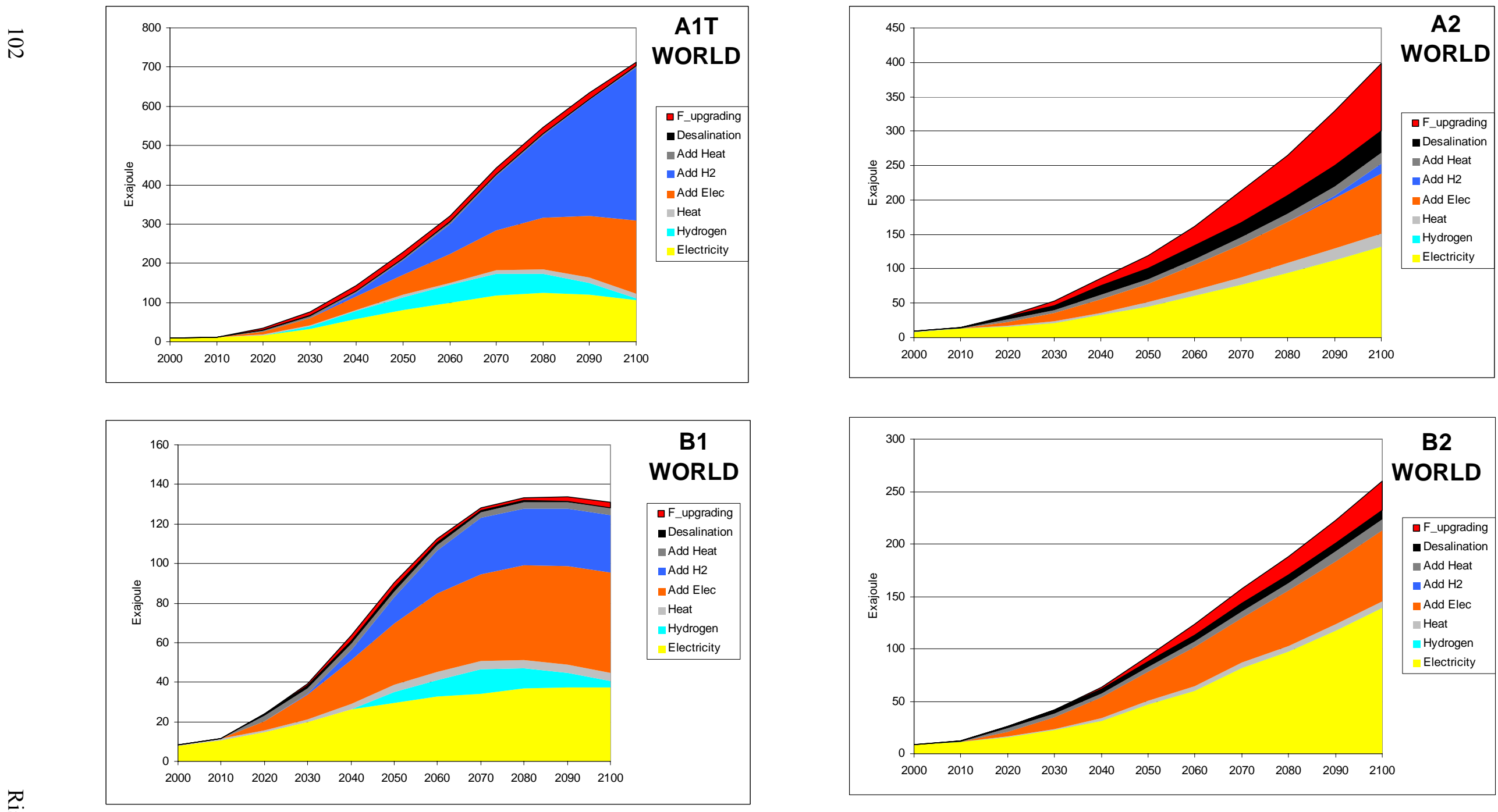

Figure 2. Projected use of nuclear energy in "aggressive nuclear" variations of the four SRES scenarios. The bottom three categories in each panel (electricity, hydrogen, and heat) show projected nuclear use in the original four SRES scenarios. Their collective trajectories match those in Figure 1. The top five categories show the additional nuclear market potential based on the assumptions in Section 3 


\section{Session 4A: Wind Energy incl. Economics}

Chairman: Gijs van Kuik, Delft University of Technology, Holland. 


\title{
Economics of wind power
}

\author{
Senior research specialist P.E . Morthorst \\ Risø National Laboratory, 4000 Roskilde, Denmark \\ Ph. +4546775106, Fax. +4546775199, E-mail P.E.Morthorst@risoe.dk
}

\begin{abstract}
In a European as well as a global perspective wind power is being developed rapidly. Within the past ten years the global installed capacity of wind power has increased from approx. 2.5 GW in 1992 to a little above $32 \mathrm{GW}$ at the end of 2002, an annual growth of almost $30 \%$. However, only at very few sites with high wind speeds wind power is at present economically competitive to conventional power production. This paper treats how the economics of wind power has developed in previous years and how it is expected to develop in the near future. The historical trend towards bigger machines and the impact on the cost of wind generated power is analysed, starting by the old $95 \mathrm{~kW}$ turbines and ranging to modern sizes of $1 \mathrm{MW}$ and more. The structure of onshore turbine investments is analysed and using the experience curve methodology the cost of power production is estimated 5-8 years ahead. The main conclusion is that within this time-horizon wind power is with a high probability fully economically competitive to conventional generated power, especially if the turbines are sited in roughnessclass one areas, i.e. in wind regimes comparable to a coast location. Finally, the paper touches upon the development of offshore turbines with some preliminary calculations of the power production costs of these machines.
\end{abstract}

Keywords: Wind power; Offshore wind; Economics of wind power; Electricity spot market. 


\section{The development of wind power}

Within the last 10 to 15 years wind power has on a global scale developed incredibly fast. In 1990 total installed capacity of wind power in the World amounted to approx. 2.0 MW - by the end of 2002 this capacity has increased to a little above $32 \mathrm{GW}$, equalling an annual growth rate of more than $25 \%$. And the rate of growth is still high - in 2001 global installed capacity increased by $35 \%$ and by $29 \%$ in 2002. But European countries dominate the wind power scene. In 2002 almost $75 \%$ of total installed wind turbine capacity was established in Europe, and the only major contributors outside Europe were the US with a total installed capacity of approx. $4.7 \mathrm{GW}$ and India with $1.7 \mathrm{GW}$ (BTM-consult, 2003).

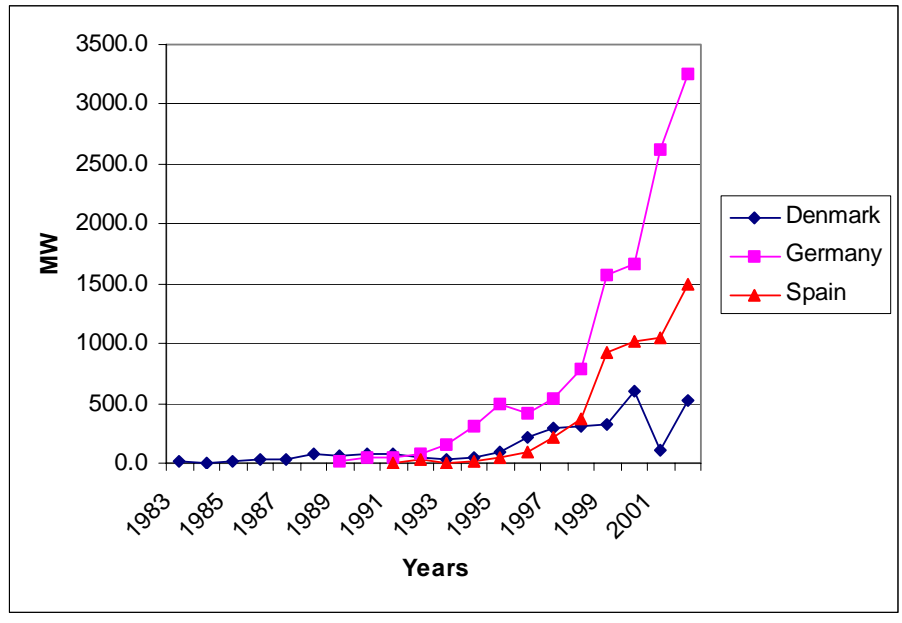

Figure 1. Annual increase of installed wind power capacity in Germany, Spain and Denmark

But even within Europe a few countries are the dominant ones: Germany, Spain and Denmark account for more than $85 \%$ of the growth in European installed wind turbine capacity in 2002, and correspondingly these three countries together have installed almost $85 \%$ of the total accumulated capacity in Europe. Especially Germany has had a rapid development. In 1991 total accumulated capacity in Germany was approx. $100 \mathrm{MW}$; by now the annual capacity increase is approx. $3250 \mathrm{MW}$ and total installed wind power capacity is almost $12 \mathrm{GW}$. Similar developments are found in Denmark and Spain, although not to the same extent. Denmark by now has a total installed capacity of almost 2.9 GW and a net growth rate of approximately $17 \%$ in $2002^{1}$, while Spain in total has installed a little more than $5 \mathrm{GW}$ with a growth rate of more than $40 \%$ in 2002. Other contributors in Europe to be mentioned are the Netherlands $(0.7 \mathrm{GW})$, UK $(0.6 \mathrm{GW})$, Italy $(0.8 \mathrm{GW})$, Greece $(0.5 \mathrm{GW})$ and Sweden $(0.4 \mathrm{GW})$. Of these countries, especially the Netherlands and Greece have experienced rapid growth rates in 2002, 39\% and 29\% respectively (BTM-consult, 2003).

\section{Policy conditions for wind power}

The main reasoning behind the development in these three above-mentioned dominant countries in Europe (i.e. Germany, Spain and Denmark) is a fast improvement of the cost-effectiveness of wind power during the past ten years (Redlinger et.al.,1998), combined with long-term agreements on fixed feed-in tariffs (at fairly high levels), altogether making wind turbines some of the most economically viable renewable energy technologies today. And the national policies of fairly high buy-back rates and substantial subsidies from governments to a certain extent reflect the need for a development of

\footnotetext{
${ }^{1}$ Do to favourable repowering conditions approx. $100 \mathrm{MW}$ of older turbines was decommissioned in Denmark in 2002.
} 
renewable energy technologies to cope with the greenhouse gas effect. According to the Kyoto protocol the European Union has agreed on a common greenhouse gas (GHG) reduction of $8 \%$ by the years 2008-12 compared with 1990. And all the three above-mentioned countries have adopted a policy of GHG-limitations in accordance with the agreed burden sharing in the EU.

That the development of renewable energy resources is expected to play an important role in the implementation of these GHG-targets is reflected in the EU policy as well. In its recent White Paper on a strategy for the development of renewable energy the EU Commission has launched a goal of covering $12 \%$ of the European Union's gross inland energy consumption by the year 2010 by renewable sources, that is mainly by biomass, hydro power, wind energy, and solar energy. Next to biomass wind energy is foreseen to be the main contributor with regard to future importance (European Commission, 1997). Recently the European Commission has agreed on a directive on the promotion of renewable energy technologies, including a proposal on the share of renewables in the individual member states in 2010, based on the percentage of each country's consumption of electricity (European Commission, 2000). Although not binding it seems that these targets by now are accepted by the EU member states. Thus the directive signals the need to include renewable energy technologies as one of the serious options in achieving the targets for GHG-reductions.

In parallel with the implementation of the Kyoto GHG-commitments a number of countries are liberalising their electricity industry. The cornerstone in liberalisation is opening of the electricity markets for trade, within the country and among countries. To generate efficient competition unbundling of the power industry might be necessary: To split existing companies into independent ones for production, transmission and distribution of electricity. Finally, to handle dispatch of electricity an independent systems operator is needed, and establishing a power exchange might facilitate and increase transparency in trading.

This process towards liberalised electricity markets has been going on for some years. The EUdirective on common rules for the internal market in electricity states that each member state has the right of access to the electricity and distribution grids, thus opening the concept of free electricity trade in Europe. A number of countries already have or are in the transition phase of liberalising their electricity industry. Electricity exchange markets are being developed to facilitate electricity trade and now exist in several countries, among these England, Germany, Norway, Sweden, Finland and Denmark. In 1996 Norway and Sweden together established the first inter Nordic electricity exchange market (NordPool). Through collaboration with the existing Finnish electricity exchange, El-Ex, in 1998 Finland was included in the market. In the summer of 1999 the western part of Denmark joined the exchange, while the eastern part became a member in 2000 .

How wind power is to be integrated into the competitive electricity market is still an open question. At present most renewable energy technologies are not economically competitive to conventional power producing plants. Thus it can be expected that if renewables must compete on pure market conditions this will halt the development of new renewable capacity. One model of generating additional payments to renewable technologies is to develop a separate green market. This model will facilitate the integration of renewables into the liberalised market and at the same time make it possible for these technologies partly to be economically compensated for the environmental benefits, that they generate compared to conventional power production.

Holland was the first country to explore the possibilities of the green market. A voluntary green certificate market, called the Green Label, was started in January 1998 with the main objective of increasing the penetration of renewable electricity production into the electricity market by stimulating demand (Voogt et.al., 1999). Green certificates are generated by renewable producers, which receive a certificate for each unit of production sold to the electricity grid. A number of other EU member states has established green certificate markets, among these Italy and England.

In 1999 it was agreed in the Danish Parliament to phase out the existing feed-in tariff system and replace this by a green certificate market (Morthorst, 2000). But uncertainty about how the new certificate system would work stalled the development of wind power in Denmark - in 2001 only 115 MW was established ${ }^{2}$ Thus the Government decided to postponed the certificate market until 2004-5, mainly due to resistance against the green market from Danish wind organisations and wind manufac-

\footnotetext{
${ }^{2}$ This situation was changed in 2002 where turbines with a total rated capacity of approx. 530 MW was installed in Denmark, mainly due to favourable repowering conditions.
} 
turers. If a green certificate system will ever be put in place in Denmark is doubtful, most probably only if a common European-wide system is being established in the future. But at present there are no signs within the EU of developing a common green market for renewables. Germany and France have chosen to continue with the well proven feed-in tariff system.

\section{Economics of on-land sited wind turbines}

Wind power is used in a number of different applications, including both grid-connected and standalone electricity production, as well as water pumping. This section analyses the economics of wind energy, primarily in relation to grid-connected turbines which account for the vast bulk of the market value of installed turbines.

The main parameters governing wind power economics include the following:

- Investment costs, including auxiliary costs for foundation, grid-connection, etc.

- Operation and maintenance costs

- Electricity production / average wind speed

- Turbine lifetime

- Discount rate

Of these, the most important parameters are the turbines' electricity production and their investment costs. As electricity production is highly dependent on wind conditions, choosing the right turbine site is critical to achieving economic viability.

The following sections outline the structure and development of land-based wind turbines' capital costs and efficiency trends. Offshore turbines are gaining an increasingly important role in the overall development of wind power, and thus an overview is given in a separate section.

In general, two trends have dominated grid-connected wind turbine development:

1) The average size of turbines sold on the market has increased substantially

2) The efficiency of production has increased steadily.

Figure 2 shows the average size of wind turbines sold each year using the Danish market as a proxy. As illustrated in Figure 2 (left axis), the average size has increased significantly, from less than $50 \mathrm{~kW}$ in 1985 to almost $1.5 \mathrm{GW}$ in 2002. In 2002 the best-selling turbines had a rated capacity of 750-1500 $\mathrm{kW}$ and a share of the market above $50 \%$. But turbines with capacities of the $1,5 \mathrm{MW}$ and up had a share of $30 \%$ and are increasing their market shares. At the end of 2002 turbines with a capacity of 2 MW and above are getting increasingly important, even for on-land sitings. 


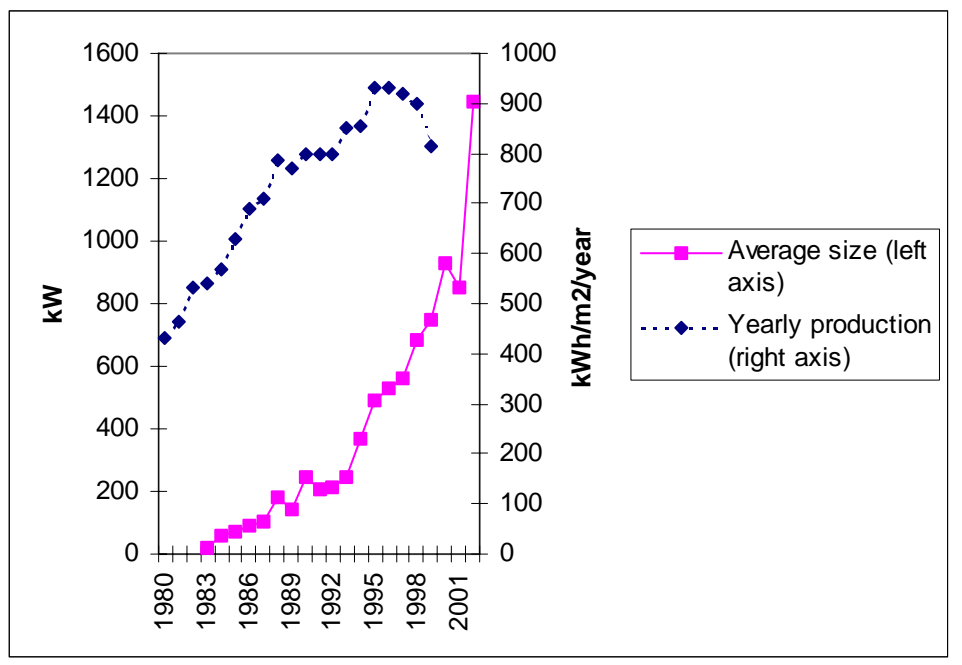

Figure 2. Development of average wind turbine size sold in the Danish market (left axis) and efficiency, measured as $\mathrm{kWh}$ produced per $\mathrm{m}^{2}$ of swept rotor area (right axis)

Comparing to other countries the Danish market is at the upper level for the development of the average size of turbines sold. The average size sold in Denmark in 2002 was $1443 \mathrm{~kW}^{3}$. Germany was a little below with an average size of almost $1400 \mathrm{~kW}$, while the average in the UK was $843 \mathrm{~kW}$ and Sweden was $1112 \mathrm{~kW}$. In Spain the average was $845 \mathrm{~kW}$ and in the US almost $900 \mathrm{~kW}$.

The development of electricity production efficiency is also shown in Figure 2, measured as annual energy production per swept rotor area $\left(\mathrm{kWh} / \mathrm{m}^{2}\right.$ on the right axis). Measured in this way, efficiency has increased by almost 3 percent annually over the last 15 years. This improvement in efficiency is due to a combination of improved equipment efficiency, improved turbine siting, and higher hub height. The decrease in efficiency shown in Figure 2 is due to a lower average wind speed at those sites available for the latest established turbines ${ }^{4}$.

Capital costs of wind energy projects are dominated by the cost of the wind turbine itself (ex works) $)^{5}$. Table 1 shows a typical cost structure for a $1 \mathrm{GW}$ turbine in Denmark. The turbine's share of total cost is approximately 82 percent, while grid-connection accounts for approximately 7 percent and foundation for approximately 5 percent. Other cost components, such as control systems and land, account for only minor shares of total costs.

\footnotetext{
${ }^{3}$ Strongly influenced by the development of offshore wind farms, the most important one being Horns Reef that was put into operation in 2002 equipped with $802 \mathrm{MW}$ machines. In 2001 the average turbine size in Denmark was only $850 \mathrm{~kW}$.

${ }^{4}$ The efficiency measure is based upon Danish turbine statistics and sites available for new turbines are increasingly getting more limited in number.

5 'Ex works' means that no site work, foundation, or grid connection costs are included. Ex works costs include the turbine as provided by the manufacturer, including the turbine itself, blades, tower, and transport to the site.
} 
Table 1. Cost structure for a $1 \mathrm{GW}$ wind turbine (year $2001 €$ ).

\begin{tabular}{|l|c|c|}
\hline & $\begin{array}{c}\text { Investment } \\
(1000 €)\end{array}$ & $\begin{array}{c}\text { Share } \\
(\%)\end{array}$ \\
\hline Turbine (ex works) & 748 & 81.9 \\
Foundation & 44 & 4.8 \\
Electric installation & 10 & 1.1 \\
Grid-connection & 60 & 6.6 \\
Control systems & 2 & 0.2 \\
Consultancy & 8 & 0.9 \\
Land & 27 & 2.9 \\
Financial costs & 8 & 0.9 \\
Road & 7 & 0.7 \\
\hline Total & 914 & 100.0 \\
\hline
\end{tabular}

Note: Based on Danish figures for a $1 \mathrm{GW}$ turbine, using average 2001 exchange rate $1 €=7.45$ DKK.

Figure 3 shows changes in capital costs over the years. The data reflect turbines installed in the particular year shown. All costs at the left axis are calculated per $\mathrm{kW}$ of rated capacity, while those at the right axis are calculated per swept rotor area. All costs are converted to 2001 prices. As shown in the figure, there has been a substantial decline in per-kW costs from 1989 to 1999 . In this period turbine costs per $\mathrm{kW}$ decreased in real terms by approximately 4 percent per annum. At the same time, the share of auxiliary costs as a percentage of total costs has also decreased. In 1987 almost 29 percent of total investment costs were related to costs other than the turbine itself. By 1999 this share had declined to approximately 20 percent. The trend towards lower auxiliary costs continues for the last vintage of turbines shown $(1000 \mathrm{~kW})$, where other costs amount to approximately 18 percent of total costs.

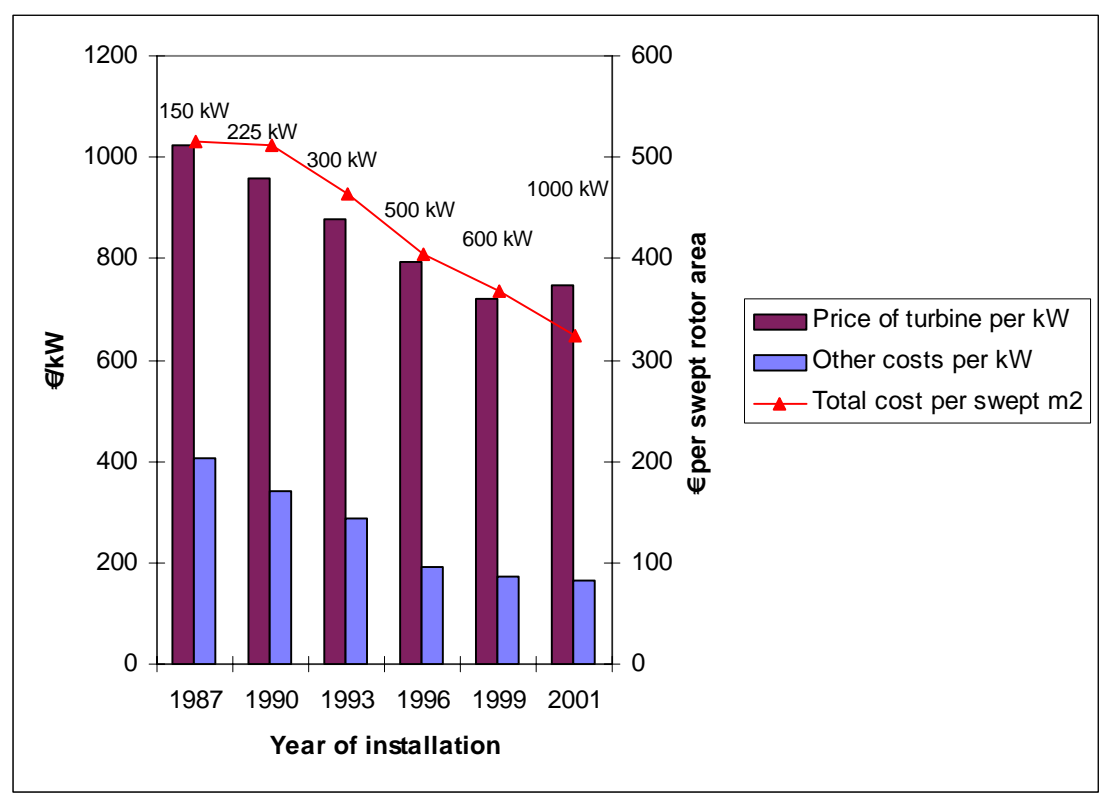

Figure 3. Left axis: Wind turbine capital costs (ex works) and other costs per $k W$ rated power $(€ / k W$ in constant $2001 €)$. Right axis: Investment costs divided by swept rotor area (€/m2 in constant $2001 €)$

A little surprisingly investment costs per $\mathrm{kW}$ have increased for this last-mentioned machine compared to a $600 \mathrm{~kW}$ turbine. The reason has to be found in the dimensioning of the turbine. With higher hub heights and larger rotor diameters the turbine is equipped with a relative smaller generator although it produces more electricity. This is illustrated in Figure 3 at the right axis, where total invest- 
ment costs are divided by the swept rotor area ${ }^{6}$. As shown in this figure the cost per swept rotor area has decreased continuously for all turbines considered. Thus, overall investment costs per swept rotor area have declined by approximately 3 percent per year during the period analysed.

The total cost per produced $\mathrm{kWh}$ (unit cost) is calculated by discounting and levelising investment and O\&M costs over the lifetime of the turbine, divided by the annual electricity production. The unit cost of generation is thus calculated as an average cost over the turbine's lifetime. In reality, actual costs will be lower than the calculated average at the beginning of the turbine's life, due to low O\&M costs, and will increase over the period of turbine use.

Figure 4 shows the calculated unit cost for different sizes of turbines based on the above-mentioned investment and O\&M costs, a 20 year lifetime, and a real discount rate of 5 percent per annum. The turbines' electricity production is estimated for roughness classes one and two, corresponding to an average wind speed of approximately $6.9 \mathrm{~m} / \mathrm{s}$ and $6.3 \mathrm{~m} / \mathrm{s}$, respectively, at a height of 50 meters above ground level.

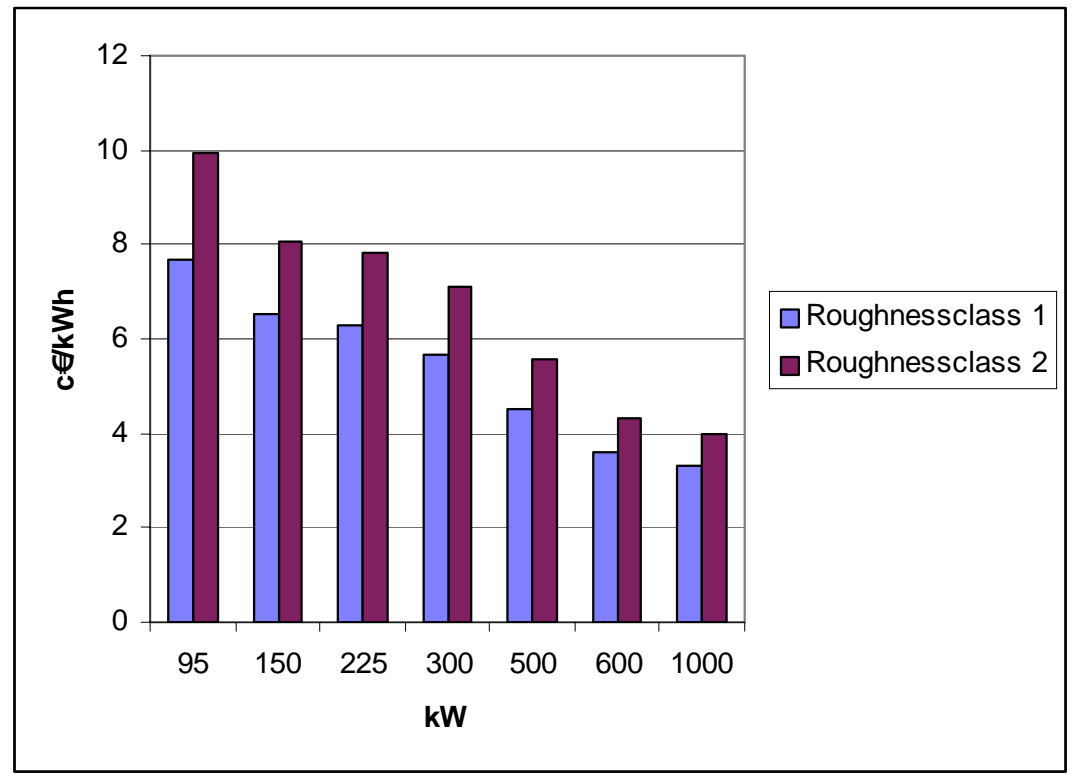

Figure 4. Total wind energy costs per unit of electricity produced, by turbine size. (c€/kWh, constant 2001 prices)

Figure 4 illustrates the trend towards larger turbines and improved cost-effectiveness. For a roughness class one site $(6.9 \mathrm{~m} / \mathrm{s})$, for example, the average cost has decreased from over $7.7 \mathrm{c} € / \mathrm{kWh}$ for the 95 $\mathrm{kW}$ turbine (1985) to under $3.4 \mathrm{c} € / \mathrm{kWh}$ for a new $1000 \mathrm{~kW}$ machine, an improvement of more than 50 percent over a time span of 15 years (constant 2001 prices).

The discount rate has a significant influence on electricity production costs and hence on wind projects' financial viability. For a $1000 \mathrm{~kW}$ turbine, changing the discount rate from 5 to 10 percent per year (in real terms) increases the production cost by a little more than 30 percent.

\section{Future development of the economics of on- land turbines}

In this section the future development of the economics of wind power is illustrated by the use of the experience curve methodology. As is well known the experience curve approach was developed back

\footnotetext{
${ }^{6}$ Swept rotor area is a good proxy for the turbines' power production.
} 
in the 70s of the Boston Consulting Group and the main feature is that it relates the cumulative quantitative development of a product with the development of the specific costs (Johnson, 1984). Thus, if the cumulative sale of a product is doubled, the estimated learning rate tells you the achieved reduction in specific product costs.

The experience curve is not a forecasting tool based on estimated relationships. It is merely pointing out to you, that if the existing trends are going to continue in the future, then we might see the proposed development. It converts the effect of mass production into an effect upon production costs, other casual relationships are not taken into account. Thus changes in market development and/or technological break-throughs within the field might considerably change the picture.

In an ongoing EU-project, EXTOOL, with the participation of Lund University in Sweden, ISET in Germany, and Risø National Laboratory in Denmark the concept of the experience curve has been investigated and applied for wind power. What concerns the use of experience curves the following is essentially based on the results from this project as presented on a workshop in Paris (Extool, 2003).

For Denmark an experience curve using data from the beginning of the 80s until now has been estimated. Using the specific costs of energy as a basis (costs per $\mathrm{kWh}$ produced) progress ratios in the range of 0.83 to 0.87 are found, corresponding to learning rates of 0.17 to 0.13 . That is when total installed capacity of wind power is doubled the costs per produced $\mathrm{kWh}$ for new turbines are reduced between 13 and $17 \%$. In this way both the efficiency improvements and embodied and disembodied cost reductions are taken into account in the analysis.

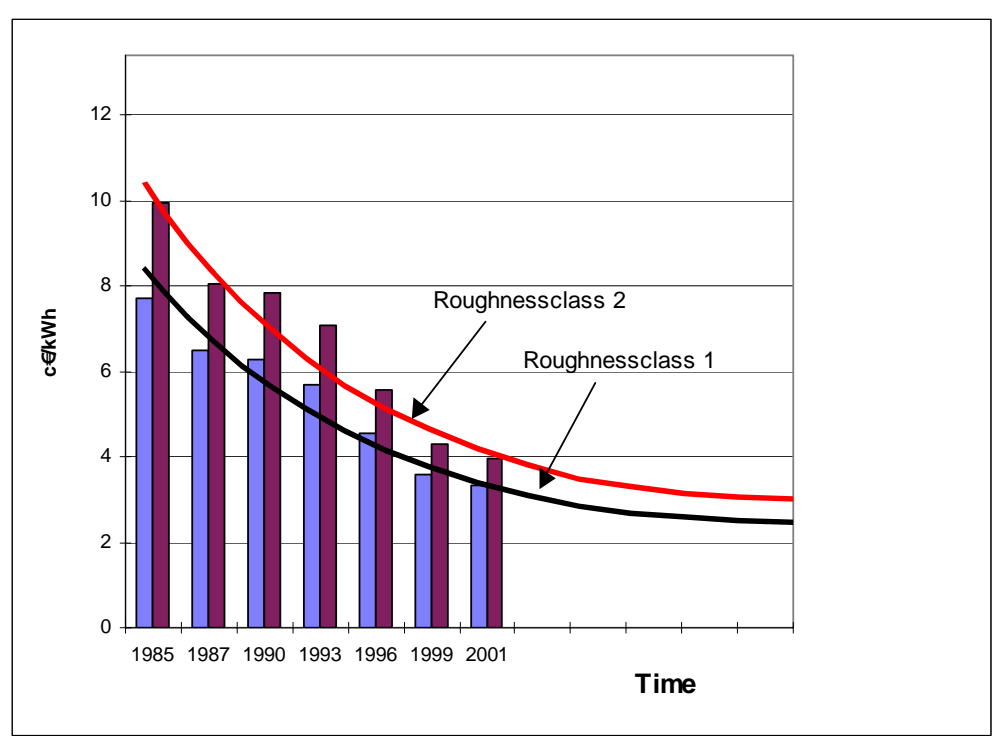

Figure 5. Using experience curves to illustrate the future development of wind turbine economics. Compared with the production costs of a combined cycle plant established in 5-7 years from now

The consequences of applying the above-mentioned results for wind power are illustrated in Figure 5. At present the cumulative installed capacity of wind power world-wide is increasing by approximately $30 \%$ pro annum. Thus, within three years time the total installed capacity is expected to double, and according to the experience curve the costs per $\mathrm{kWh}$ wind produced power could fall by approximately $13-17 \%$ in three years. If growth in installed wind power continues, within 5-7 years the costs of wind produced power should according to the experience curve approach be with in a range of approximately $2.3 \mathrm{c} € / \mathrm{kWh}$ to $3.0 \mathrm{c} € / \mathrm{kWh}$.

What are then the production costs of the competing conventional power producers? Within the last couple of years the price of power at the Nordic power market, NordPool, has averaged approximately $2.5 \mathrm{c} € / \mathrm{kWh}$. (At present the price is approximately $5 \mathrm{c} € / \mathrm{kWh}$ due to draught in Norway and Sweden in the autumn 2002 and the price is expected to come down again in the spring of 2003). However, at the Nordic market no major new investments in power capacity have been undertaken in the time period, where Denmark has taken part in the market. And the Nordic organisation for TSOs, Nordel, expects shortage of power capacity within the next 3-4 years (H.H.Lindboe, 2002). Thus, it is expected that the price will rise to induce new investments in conventional power plants. According to Danish power 
companies the most promising technology to chose is a natural gas fired combined cycle power plants, which will produce at a cost of $3.3 \mathrm{c} € / \mathrm{kWh}$ to $4 \mathrm{c} € / \mathrm{kWh}^{7}$ (ELSAM, 2002).

As shown in Figure 5 above this implies that within 5-7 years wind power should be fully competitive with new conventional produced power, if the existing trends are to continue.

\section{Development of offshore wind turbines}

In a number of countries offshore turbines are getting an increasingly important role in the development of wind power, particularly in the north-western part of Europe. Without doubt the main reasons are that on-land sitings are limited in number and that the utilisation of these sites to a certain extent is exposed to opposition from the local population. This seen in relation to an unexpected high level of energy production from offshore turbines compared to on-land sitings (based on the experiences gained until now), has paved the way for a huge interest in offshore development.

At present a number of offshore wind farms are in operation in the northern part of Europe, the three largest in Danish waters. The Worlds largest offshore wind farm is situated at the West Coast of Denmark, Horns Reef situated approx. $20 \mathrm{~km}$ west of the coast of Jutland was established in 2002 and has a total capacity of $160 \mathrm{MW}$, consisting of $802 \mathrm{MW}$ turbines. Middelgrunden (Denmark) east of Copenhagen was put in operation in 2001. The total capacity is $40 \mathrm{MW}$ consisting of $202 \mathrm{MW}$ turbines (BTM-consult, 2002). Finally, Samsø offshore wind farm (Denmark) situated south of the isle of Samsø was put in operation in 2002 and consists of 10 2,3 MW turbines. Moreover, quite a number of offshore wind power projects are in the planning and implementation phase. In Denmark the Nysted project at Rødsand close to the isle of Lolland is being constructed at present. Nysted has a total capacity of approx. $160 \mathrm{MW}$ and is expected to be finalised in 2003. In Germany approximately 800 MW are expected to be installed within the next 5 years, including a large offshore farm close to Helgoland with a total capacity of $500 \mathrm{MW}$ to be installed by 2005 . Ireland is planning to develop approximately $750 \mathrm{MW}$ before 2005, the Netherlands $340 \mathrm{MW}$, and UK almost $340 \mathrm{MW}$ before 2005 .

An important concern for the Danish government is to ensure that the future offshore development is based on market conditions in an economic efficient way. The Government therefore decided to set up a committee to study the possibilities and conditions of tendering future offshore wind farms in Danish waters. By applying a tendering procedure competition among the bidders will be ensured and the most cost-effective offshore turbine developments will be undertaken. The committee finished its work at the end of 2002 by publishing a report and this paper summarises some of the main findings and recommendations (Danish Energy Authority, 2002). As part of this report a scenario was worked out for the future development of a new offshore wind farm at Horns Rev consisting of $3 \mathrm{Mw}$ turbines compared with the $2 \mathrm{MW}$ turbines, that are utilised at the existing Horns Rev. The economic consequences of this scenario is shortly summarised below:

\footnotetext{
${ }^{7}$ Depending on the number of full load hours the plant is expected to produce. At the high cost an utilisation time of 4000 hours is assumed, while the low costs implies an utilisation time of approximately 6500 .
} 


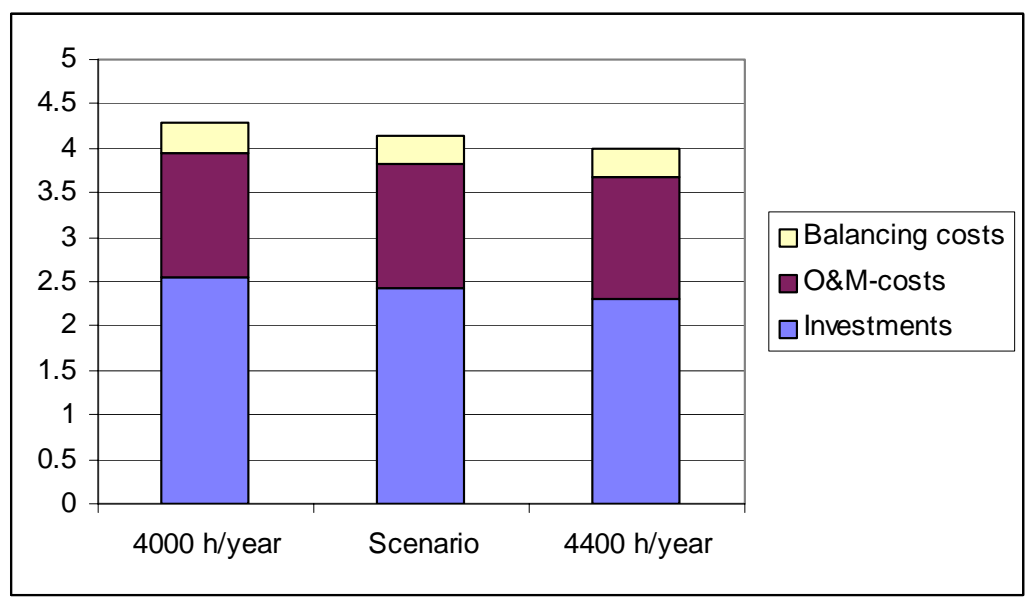

Figure 6. Calculated production costs in scenario 1 based on 3 MW turbines, including sensitivity analyses on numbers of full load hours

In the scenario the number of full load hours is assumed to $4190 \mathrm{~h} /$ year and investment and O\&Mcosts are modified to a $3 \mathrm{MW}$-farm, using cost data from the existing $2 \mathrm{MW}$ farm as a starting point. As shown in Figure 6 in the scenario total production costs are calculated to approx. $4.2 \mathrm{c} € / \mathrm{kWh}$, including $1.4 \mathrm{c} € / \mathrm{kWh}$ as O\&M-costs and $0.3 \mathrm{c} € / \mathrm{kWh}$ for balancing the power production at the market. Not unexpectedly the assumption on full load hours is important. If the assumed utilisation time is reduced to $4000 \mathrm{~h} /$ year costs will increase to $4.3 \mathrm{c} € / \mathrm{kWh}$, while a utilisation time of $4400 \mathrm{~h} /$ year corresponds to a cost of $4.0 \mathrm{c} € / \mathrm{kWh}$, only.

The above costs are calculated as simple national economic ones using a real discount rate of $5 \%$ p.a. and therefore they will not be the costs of a private investor, who will have higher financial costs, require a risk premium and eventually a profit. How much a private investor will add on top of the simple costs will among other things depend on the perceived technological and political risk of establishing the offshore farm and, finally, on the competition in the bidding process for such an offshore farm.

\section{Conclusions}

Wind power is one of the most promising new renewable technologies, undergoing a rapid technological development and possessing environmental characteristics, that makes it well suited to contribute to a future sustainable development. This paper has addressed the market and economic development of wind power and the following issues are highlighted:

- On a global scale wind power is developing rapidly, showing growth rates of installed capacity of almost $30 \%$ annually. Nevertheless the development is vulnerable, because it is dominated by a few countries, Germany, Spain, US and Denmark. A number of EU member states have established green markets, but still there are no signs of a common EU green certificate market.

- The size of the average turbine sold at the market place is continuously increasing. In 2001 the best-selling turbines had a rated capacity of $750-1500 \mathrm{~kW}$ and a market share above $50 \%$. At the end of 2002 turbines with a capacity of $2 \mathrm{MW}$ and above are getting increasingly important, even for on-land sitings.

- Within the last 15 years there has been a continuous trend towards larger and more optimised turbines and thus towards more cost-effective machines. For a coastal location, for example, the average cost has decreased from over $7.7 \mathrm{c} € / \mathrm{kWh}$ for the $95 \mathrm{~kW}$ turbine (1985) to under $3.4 \mathrm{c} €$ $/ \mathrm{kWh}$ for a new $1000 \mathrm{~kW}$ machine (2001), an improvement of more than 50 percent over a time span of 15 years (constant 2001 prices). 
- If growth in installed wind power continues within 5-7 years the costs of wind produced power should according to the experience curve approach be with in a range of approximately 2.3 $\mathrm{c} € / \mathrm{kWh}$ to $3.0 \mathrm{c} € / \mathrm{kWh}$. At the Nordic power market a natural gas fired combined cycle power plants to be constructed and on-stream within 5-6 years will produce at a cost of $3.3 \mathrm{c} € / \mathrm{kWh}$ to 4 $\mathrm{c} € / \mathrm{kWh}$. This implies that with in 5-7 years on-land sited wind turbines should be fully competitive with new conventional produced power, if the existing trends are to continue.

- Offshore wind power is getting an increasingly important role in the development of wind power and a future offshore farm equipped with $3 \mathrm{MW}$ turbines could produce at a cost of approx. 4.2 $\mathrm{c} € / \mathrm{kWh}$, including $1.4 \mathrm{c} € / \mathrm{kWh}$ as $\mathrm{O} \& \mathrm{M}$-costs and $0.3 \mathrm{c} € / \mathrm{kWh}$ for balancing the power production at the market.

\section{References}

BTM-consult, 2003: World market update 2002.

Redlinger, R., P.D. Andersen, P.E. Morthorst, 1998: United Nations, Report of the Secretary General: Report on New and Renewable Sources of Energy: Wind Energy, for UN Committee on New and Renewable Sources of Energy and on Energy for Development.

European Commission, 1997: Energy for the future: Renewable sources of energy. (White Paper, 26/11/97).

European Commission, 2000: Proposal for a directive of the European parliament and of the council on the promotion of electricity from renewable energy sources in the internal electricity market.

Voogt, M.; Boots, M.; Schaeffer, G.J.; Martens, J.W., 1999: Renewable electricity in a liberalised Dutch electricity market - the concept of green certificates. In: Design of Energy markets and Environment, Conference papers, Copenhagen 20-21 May 1999, Nordic Energy Research Program.

Morthorst, P.E., 2000: The development of a green certificate market. Energy Policy, November 2000, vol. 28/15, p. 1085-1094.

Johnson, G. and Scholes, K., 1984: Exploring Corporate Strategy, Prentice Hall, USA, 1984.

Extool, 2003: http://www.iset.uni-kassel.de/extool

H.H.Lindboe, 2002: Presentation given at meeting at ELTRA (Danish TSO), 13 August 2002.

ELSAM, 2002: Personal conversation with ELSAM A/S (Danish power company). 


\title{
Effects of Large-scale distribution of wind energy in and around Europe
}

\author{
Dr. Gregor Giebel \\ Niels Gylling Mortensen \\ Risø National Laboratory \\ P.O. Box 49 \\ DK-4000 Roskilde \\ Gregor.Giebel@,Risoe.DK \\ Tel: +45 46775095 \\ Fax: +45 46775970 \\ Gregor Czisch \\ ISET \\ Universität-Gesamthochschule Kassel \\ D-34119 Kassel \\ GCzisch@iset.uni-kassel.de \\ Tel: +49561 7294359 \\ Fax: +49561729420
}

\begin{abstract}
Europe is the continent with the highest installed capacity of wind energy in the world. At the same time, the installation rates grow at about 30-40\%/year. This paper is to shed some light on the limits of integration.

Using wind power data for one year from 50+ sites in Europe, the apparent smoothing effects within the dataset are shown. The resulting spatially averaged time series is then fed into a scheduling model for the whole European power system. The results are that, under certain assumptions, $20 \%$ of the European demand can be covered by wind energy even without changes to the power system.

Additionally, Reanalysis data has been used to identify areas around Europe with good wind resource. Here, two areas will be shown where local measurements corrobate the quality of the resource: one on the north western shore of Africa, and another one in Egypt, at the south western Gulf of Suez.

It is shown that under the assumptions given, wind energy from southern Morocco can be produced locally for below $3 € \mathrm{c} / \mathrm{kWh}$, and transported to central Europe (Kassel) via HVDC for another 1.5 $€ \mathrm{c} / \mathrm{kWh}$. At the same time, the large-scale build-up of wind energy in Morocco would constitute a substantial transfer of money and other resources to a less-developed country. Were Morocco to provide $10 \%$ of Europe's energy needs, it would see investment worth about two times its current GDP.
\end{abstract}

Keywords: Large-scale integration, dispersed turbine systems, complementary power plant, fossil fuel power generation 


\section{Introduction}

The wind industry had phenomenal success in the last few years, with growth rates of $25 \%$ per year and more. The aim of this paper is to open the eyes to a few future trends and the implications of continued growth.

Usually, the next large step for wind energy is considered to happen offshore. This has different reasons from country to country, but generally in Europe, the best sites in the countries with the best wind power support schemes are already taken. Since wind power installations are strongly correlated with the national climates (more with the political than the wind climate), the huge growth of wind power in Europe in the last few years has happened mainly in three markets: Denmark, Spain, and above all Germany. While there still are windy sites available in Spain, and a new support scheme has brought attention to France, many of the windy counties in Germany and Denmark declared a stop for further increase in installation. In the UK, wind power has been hampered by the planning process, which also favours offshore wind power.

Thyge Weller [1] claims that offshore wind power is "an escape solution aimed at finding new windy sites in countries with financial support systems". He believes "that in the long term, very large terrestrial wind farms are the way to go." Wheeling power over long distances is just a question of price for the consumer - it is not important whether it comes from the local waters or from abroad, as long as it is clean wind power. This paper will look at two places a bit more in detail: north western Africa and a site in Egypt.

Another problem of wind energy is that it is not always available. However, since there is always some wind somewhere, the spreading out of wind turbines over an area as large as Europe (and especially taking into account areas around Europe) smoothes the wind power generation sufficiently to reach higher penetrations in the European grid than without this effect. Our paper will also address this point.

\section{Wind power in Europe}

One year (1990) of wind power data from 50+ sites all over Europe [2] has been used to assess the variability of the resource and the limits of penetration in the grid. Since typical weather patterns over Europe are only ca. $1500 \mathrm{~km}$ wide, there will be in most cases some wind in Europe. Using this data, and using data from the Reanalysis project [3]' it can be shown that at all times some power is produced from wind in Europe.

For a comparison of the generation, three data sets have been produced: Average, Selection and Malin Head. The latter is one site in Ireland, which had the highest production amongst all of the sites investigated (over 3800 equivalent Full Load Hours FLH). The Average data set is the resulting wind power production time series from 50+ stations all over Europe, spatially averaged at each hour. Selection is the same, just for stations with good wind conditions ( $>2000$ full load hours). The noteworthy feature here is that the Average series exhibits much less variation and extremes than the single site data set. Actually, the minimum production in the Average data set is $1.5 \%$ of the installed power, meaning that the assumption of always having some wind power in the grid is true. The reason for this is of course that the wind power time series are uncorrelated over large distances. The correlation actually drops more or less exponentially with a characteristic distance of ca. $700 \mathrm{~km}$. From about 2500 $\mathrm{km}$ distance, the correlation seems random (meaning that there are as many anticorrelated station pairs as there are correlated ones). The highest production was in winter.

The unusual shape of the production probability of Malin Head comes from the fact that often, the wind is either low or full force, with touching the area in between only during the changes. The Average time series is also much less variable: all changes from one hour to the next are smaller than \pm 15 $\%$ of the installed capacity, with a probability of over $95 \%$ that the changes are not larger than $\pm 5 \%$. 
In contrast, the maximum change of the best single site within one hour was $85 \%$ of the installed capacity, with a probability of $5 \%$ that the change is larger than $\pm 18 \%$.

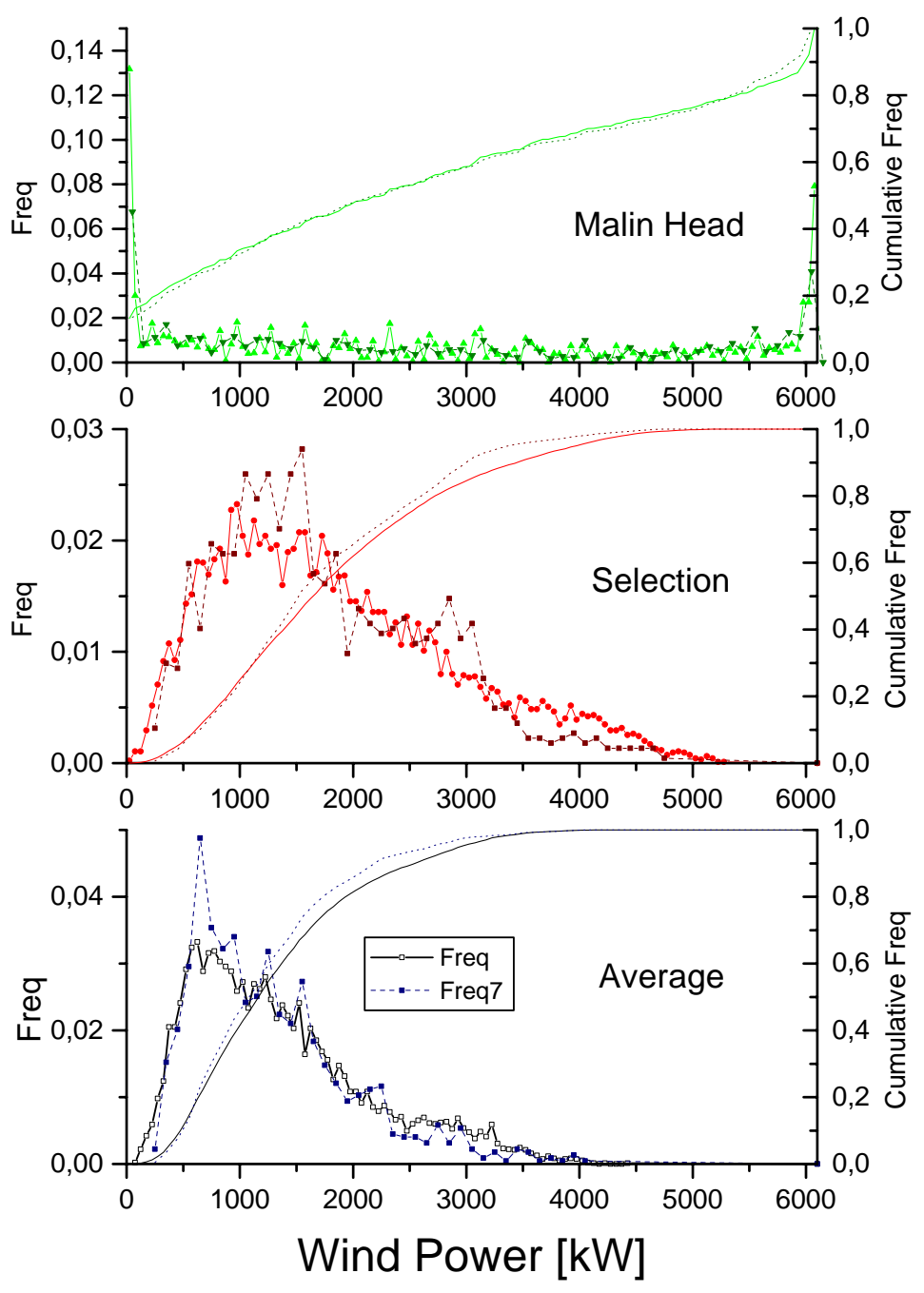

Figure 1. The frequency distributions of wind power generated from all over Europe. The frequency distribution is shown on the left $x$-axis, the cumulative frequency on the right. The results were calculated from a collection of turbines with $6100 \mathrm{~kW}$ installed effect, to simulate a distribution of sizes. The full lines are for the whole year 1991; the dashed lines refer to the 7-week winter period with the highest load. Average, Selection and Malin Head are explained in the text

To assess the influence of the variability on the limits of penetration in the European grid, these time series are fed into a model for the electrical grid of Europe (the National Grid Model of CLRC Rutherford Appleton Laboratories/Reading University was used). It simulates the one-hourly scheduling and dispatch of power plants to meet the demand on a large area network. It can accommodate the effects of wind or photovoltaic power generation. The demand was highest during a 7-week period in winter. The network is herein treated as one node, ie transmission is not an issue. The output of the model is the total cost of fossil fuel to run the electricity system for one year using a number of assumptions. The amount of spinning reserve was optimised for minimal fossil fuel usage, under the constraint that no loss-of-load-event could occur. It was fed with data from 3500 power stations of 12 European countries, plus fossil fuel prices and ramping possibilities of these stations. Wind power forecasting was used, either with perfect or with persistence forecasting.

The results of this optimisation show that forecasting is more important for higher penetrations. This is not very surprising, since for small penetrations, the wind power variations get washed out in the overall variations the utility has to prepare for, like load variations or drop-outs of major power sta- 
tions. The result also shows that wind power can be better integrated into the existing power system without many changes to the power plant composition if the generation profile is less variable. While perfect forecasting allows Malin Head to be integrated up to $10 \%$ of the demand covered (with much higher penetrations possible, but impractical), the Average generation profile can easily contribute more than $20 \%$ of the European electricity demand. Under the assumptions of the scheduling model, this leads to savings of $60 \%$ of the fossil fuel cost, worth about $7 \mathrm{G} €$. This would mean a value of the wind power of $2.2 € \mathrm{c} / \mathrm{kWh}$ just for the fossil fuel saved. Keep in mind that this is dependent on the power plant mix that is assumed. The installed wind power capacity replaces at this stage somewhat more than $10 \%$ of the installed capacity.

\section{Wind Power from around europe}

The smoothing effects can be even higher when wind power from even further away is taken into account. Not only is the distance higher, and thereby the normal smoothing due to the size of the weather patterns, another effect comes in when looking at the northern African countries: they are actually in different climatic zones, and therefore the smoothing effect is even more increased. While most of Europe is having the maximum wind speeds in winter, the trade wind areas south of the Mediterranean have maxima in summer.

Two areas are there in the Maghreb that this paper is shows in detail: the north western African tip near the Atlantic Ocean (southern Morocco, West-Sahara, Mauretania), and the south-western end of the Gulf of Suez, near the Gulf of El-Zayt. These sites are showing much potential: high mean wind speeds, plenty of available land, in part even a good grid connection, cheap labour for the maintenance and building works, and large markets short of electricity locally, with not too much distance to the much larger European market.

\subsection{Western Africa}

One of the main advocates for very large-scale implementation of wind energy on the Atlantic coast of Africa is Saharawind [4]. The resource is very good, since the wind comes from the Atlantic Ocean onto the shore in the area of the trade winds.

The potential size of the installation is tremendous: "With a wind turbine spacing of $2.4 \mathrm{MW} / \mathrm{km}^{2}$ over the 2000 kilometres of coastline from Morocco to Mauritania, a production of more than 1000 TWh per year could be achieved. This would be sufficient to cover almost half of the entire yearly production of the EU (2300 TWh). This very large potential represents several dozen times the electrical requirements of the North African countries, and cannot be utilized locally." The wind resource in southern Morocco or northern Mauretania yields local production cost of below $3 € \mathrm{c} / \mathrm{kWh}$ [5] The transport to Kassel via High-Voltage DC would make a large-scale installation possible, and would drive the cost up to ca $4.5 € \mathrm{c} / \mathrm{kWh}$. This includes the price for the HVDC line, but does not look at the (mostly political) problems involved in planning and constructing that line. 


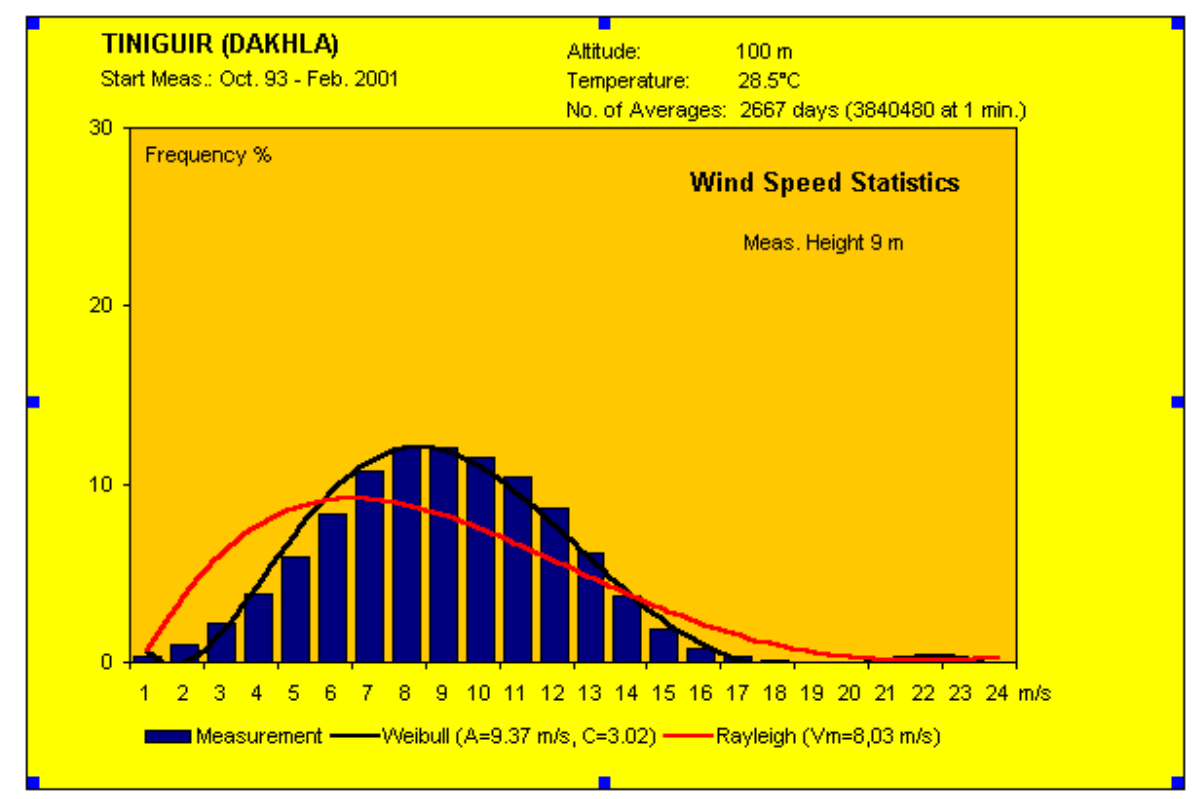

Figure 2. The wind speed distribution for Tiniguir/West Sahara/Morocco. Graphics from saharawind.com

In Figure 2, wind data from a little test station near Dakhla (West Sahara) is shown. One can see that instead of the typical Weibull distributions we are used to from the higher latitudes, the data is nearly Gaussian in shape, neither showing significant portion of low winds or of very high wind speeds (where the turbine would shut down, ie $>25 \mathrm{~m} / \mathrm{s}$ ). The distribution is even more remarkable since it is from only $9 \mathrm{~m}$ above ground level (a.g.l.) results from Reanalysis data for 50 years confirm this picture. The wind data fits in well with the results of the MED2010 project [6], where measurements were presented for a site further up the coast, on Cap Sim near Essaouira, Morocco. There, the mean wind speed in $40 \mathrm{~m}$ a.g.l. was $9.25 \mathrm{~m} / \mathrm{s}$, with an overall maximum at only $24.5 \mathrm{~m} / \mathrm{s}$. A WAsP analysis with $60,1 \mathrm{MW}$ turbines yielded a total production of $316 \mathrm{GWh} / \mathrm{y}$, or an average 5250 full load hours. Another set of data confirming the resource has been measured under the TERNA project of the GTZ (Gesellschaft für Technische Zusammenarbeit, the German development aid agency) [7]. The measurements ran for nearly a year, and yielded mean wind speeds in $40 \mathrm{~m}$ a.g.1. of $7.7 \mathrm{~m} / \mathrm{s}$ (Tarafaya), $8.9 \mathrm{~m} / \mathrm{s}$ (Essaouira) and $9.2 \mathrm{~m} / \mathrm{s}$ (Laâyoune). 


\section{Monthly Mean Electric Production of Wind Power within Selected Favourable Regions at Land Sites and Electric Demand}

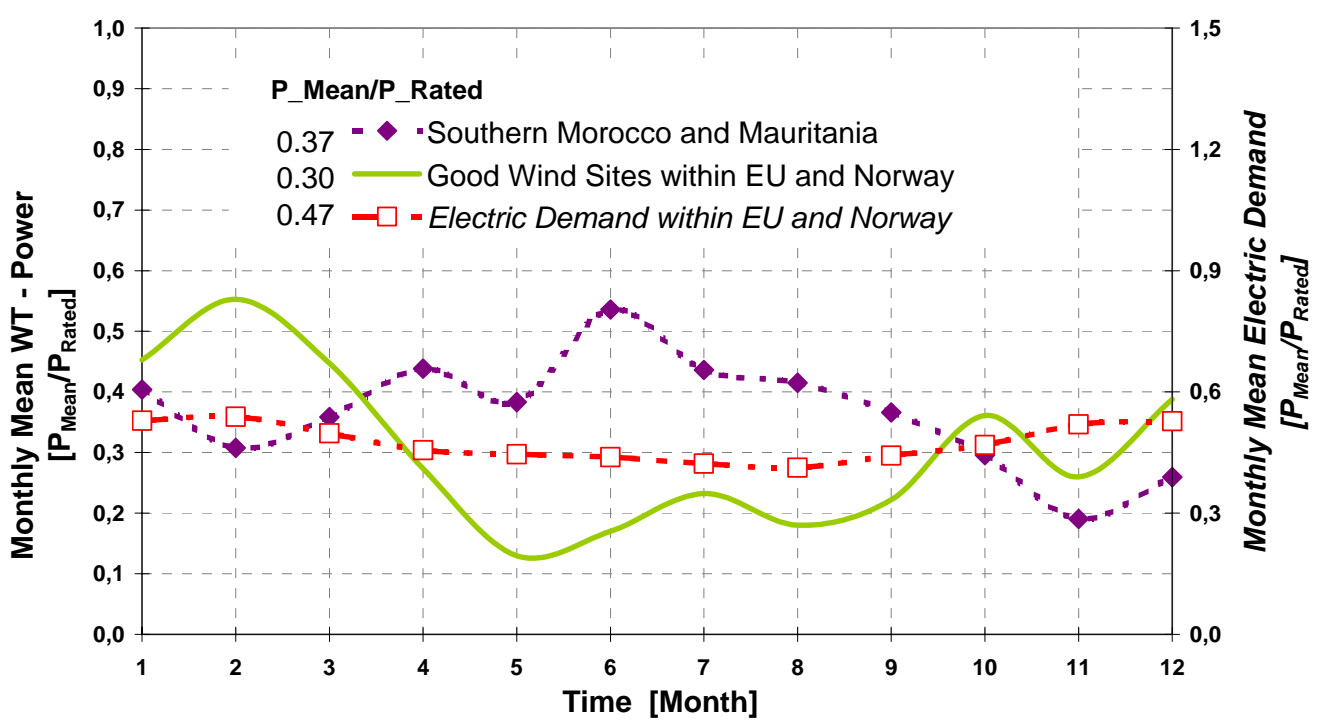

Figure 3. The production profiles of wind power north and south of the Mediterranean. Additionally shown is the electricity demand in Europe, as a percentage of the installed capacity. Also take note that the relative production swings more than the demand. Meteorological data for one year from the ECMWF Reanalysis project [8]

Along with the low price of the resource, another helpful feature comes in: the production profile over the year is anti-correlated with the production in Europe. From Figure 3, it can be seen that the production in Europe has a clear maximum in winter, while the production in north western Africa has a maximum in the summer months. This equalization effect helps to smooth out the variation in the wind power production, and allows wind power to be integrated into the grid with higher penetrations.

A possible strategy for implementation could be to bilaterally extend the German Energy Feed Law or similar other support mechanisms of Spain, France or also Denmark to Morocco. Alternatively, these national regulations could be replaced by a European solution with a clause for Northern African new renewable power. The magnitude should be given by the difference between the local price of electricity and the production price. Since the latter is very low, this incentive would be in the order of $1-2 € \mathrm{c} / \mathrm{kWh}$, and thereby much lower than the corresponding add-on within Europe. The current electricity consumption in Morocco is rather low, therefore already with a total installation below $1 \mathrm{GW}$ one would have to export wind power to Spain. This phase of the build-up would also be over soon, since at the moment, the transport capacity between Spain and Morocco is $350 \mathrm{MW}$, with a doubling to $700 \mathrm{MW}$ being envisaged. However, the bottleneck then could already be within Morocco, where not enough transmission capacity is available from the South to the North. While these stages would be natural, and probably will happen in any case, the large-scale implementation of wind energy for the European market needs dedicated transmission capacity. The Spanish transmission node closest to Morocco has a capacity of ca. $5 \mathrm{GW}$. A HVDC link of ca. $4 \mathrm{GW}$ would increase the price in Spain of the Moroccan wind power by less than $1 € \mathrm{c} / \mathrm{kWh}$. This means that up to ca. $5 \mathrm{GW}$ wind power exports, the technology and investment involved is rather straightforward.

To exploit even larger parts of the potential, dedicated transport systems would have to be built, potentially bypassing the Spanish grid totally and feeding directly to the French, Italian or even German grid. Even including an HVDC line of that length, the resulting price per $\mathrm{kWh}$ would still be about $30 \%$ lower than producing the same amount of wind power in Germany. However, to invite European investors to this kind of involvement, state guaranteed loans would seem necessary. Obviously, this concept is not limited to either wind energy or Morocco. Solar chimneys or solar thermal generation could also be used, partly to smooth out the generation. Alternatively, this kind of support scheme could bring large-scale wind power to Egypt or Kazakhstan, where similarly large potential exists. 


\subsection{Egypt}

Some of the lowest price for wind power is currently being paid for the new (2002) wind farm at Zafarana: $2.89 \mathrm{USc} / \mathrm{kWh}$ is paid by the National Renewable Energy Authority [9]. Due to the high winds (4570 Full Load Hours) and the low-interest loans from both the German and Danish aid banks (3\% over 15 years), the $60 \mathrm{MW}$ wind farm can turn a profit. In that calculation, a moderate contribution from $\mathrm{CO}_{2}$ trade $(\$ 10 /$ ton) is made.

The recently finished Wind Atlas for the Gulf of Suez [10] shows that the site in Zafarana is not even the best site in Egypt: the wind resource is significantly higher in the Gulf of El Zayt, a few hundred kilometres down the coast. Here, the measured mean wind speeds at $25 \mathrm{~m}$ a.g.l. are over $10 \mathrm{~m} / \mathrm{s}$, with highs in the summer months. The Gulf of El Zayt has a winter mean of $8.2 \mathrm{~m} / \mathrm{s}$, and a summer mean of $12.6 \mathrm{~m} / \mathrm{s}$. The daily variations are typically smaller than the seasonal variation, which means that the wind blows much more steady here than in most places in Europe. Wind speeds are highest directly near the shore, with a strong gradient towards the land (can be more than $1 \mathrm{~m} / \mathrm{s}$ over a distance of only $20 \mathrm{~km}$ ). The data at the Gulf of El Zayt translates into ca. 6000 Full Load Hours. The size of the area is enough for ca $20 \mathrm{GW}$ of installed wind power plants. For the initial phase, the transport of the produced electricity is not a problem either, since the main ring transmission line of Egypt runs past this area. In short, using a factor given by the ratio between the Zafarana FLH and the Gulf of El Zayt FLH, a cost price of electricity of just above $2.2 \mathrm{USc} / \mathrm{kWh}$ can be estimated. 


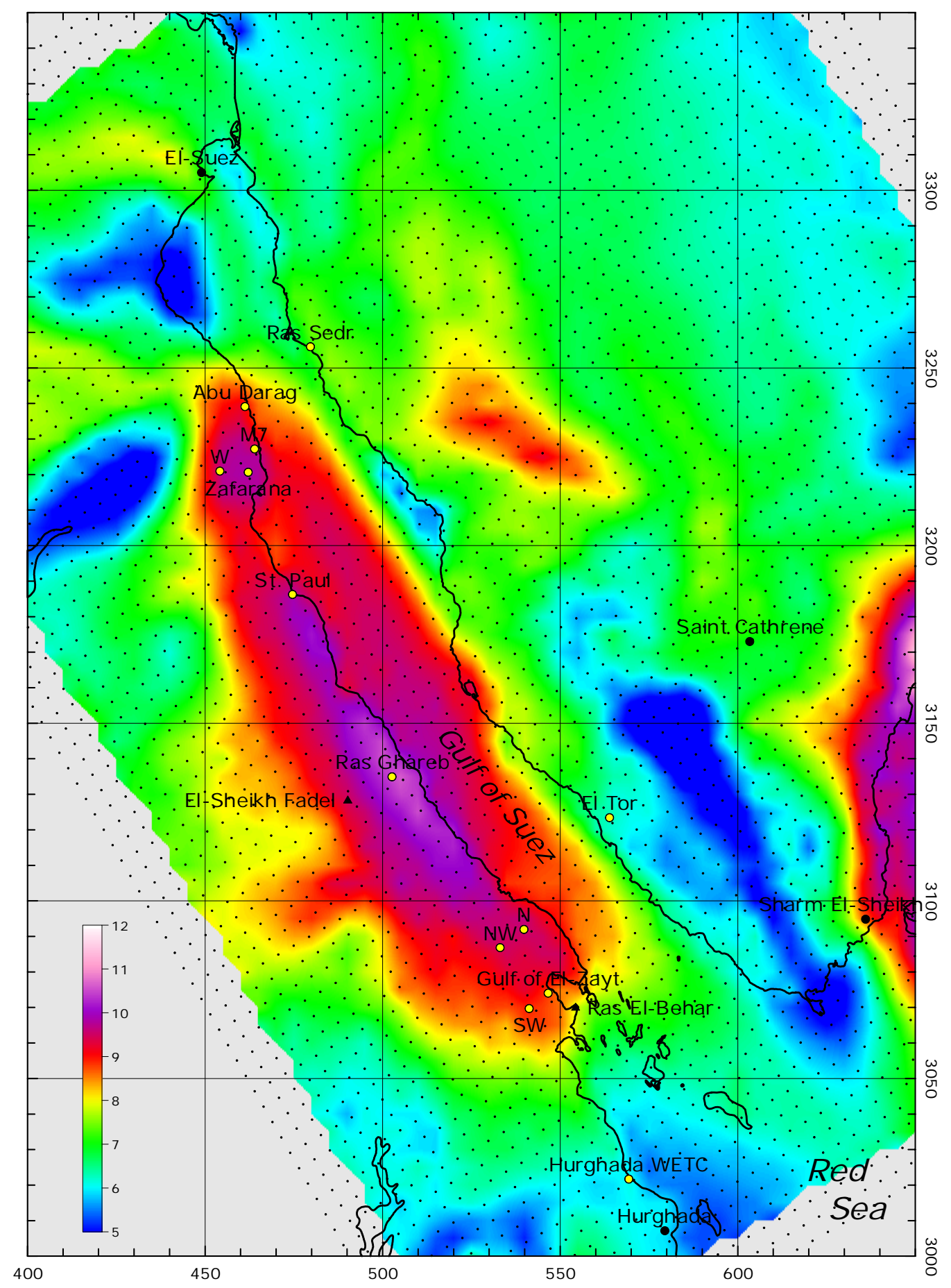

Figure 10. The mean wind speeds in $\mathrm{m} / \mathrm{s}$ at $25 \mathrm{~m}$ a.g.l. over a roughness of $\mathrm{z}_{0}=0.2 \mathrm{~cm}$. in the Gulf of Suez. The co-ordinates are UTM in km. The dots are the grid points of the calculation grid. The Suez Canal is on the upper left

\subsection{Implications of the investments}

The implications for the development of the region are especially noteworthy. Consider the example of Germany and Morocco: Germany yearly spends 40 billion euro for its electricity supply which is about $2 \%$ of its GDP, whereas the total GDP of Morocco lies somewhat above 30 G€. Today's Moroccan electricity consumption is $2.5 \%$ of Germany's 490 TWh. Let us assume Morocco would produce $10 \%$ of the European demand. This would involve a total investment of more than $50 \mathrm{G} €$ for the 
wind power plants erected in Morocco, which is close to twice its GDP. On the other hand, for the European industry this size of development would mean a large opportunity in a time when the stock prices are low and the earnings depend very much on a few politically supported markets. The financial and know-how transfer would probably stretch out over the next decades. To follow such a concept would among other implications mean developing the infrastructure and thus could become a worthy form of development aid based on the needs of both sides.

\section{Discussion}

Wind energy is an electricity generation option that is relatively benign to the environment. The economics of wind energy depend mostly on the wind resource at the site of interest; therefore it makes sense to build wind farms at high-wind sites. The huge success of wind power in Europe (especially Denmark and Germany) is more due to a favourable support scheme than to the wind speeds. Thanks to the Kyoto mechanisms, wind power in third world countries can help developed nations reduce their greenhouse gas emissions, while lowering pollution from fossil fuels in these countries. In the regions with very high wind speeds, the population density is usually rather low, ie large-scale installations are possible. The investment in these regions could be rather large, creating local employment for erection and maintenance, and probably even production of turbines (since it often is cheaper to build a wind turbine production line for a very large farm locally than to transport the large items over many thousand kilometres). Building the farms with a high content of local labour reduces the price for the turbines, which leads to even lower cost per kWh.

These lower cost also translates to lower cost per ton $\mathrm{CO}_{2}$ avoided for the European countries benefiting from the Clean Development Mechanism. In the end, it is all a question of price: whether wind power is cheaper than the local electricity, whether wind power transported from these high-wind regions to Europe is cheaper than locally produced offshore wind, and what the technology development on both technologies will come up with.

\section{Acknowledgements}

Parts of this study were financed with a grant of the Marie-Curie program of the European Commission (JOR3-CT97-5004). The Wind Atlas for the Gulf of Suez was partly financed by the Danish Ministry of Foreign Affairs through Danida. Thanks to Khalid Benhamou for comments. 


\section{References}

[1] Weller, T.: Offshore Only an Interim Step. Letter to the Editor, Windpower Monthly 19(2), pp. 810, February 2003

[2] Landberg, L., S.J. Watson, J. Halliday, J.U. Jørgensen and A. Hilden: Short-term prediction of local wind conditions. Report to the Commission of the European Communities, JOULE programme, JOUR-0091-C(MB), March 1994

[3] http://wesley.wwb.noaa.gov/

[4] http://www.saharawind.com/

[5] Czisch, G., G. Giebel: A comparison of Intra- and Extraeuropean Options for an Energy Supply with Wind Power. Wind Power for the 21st Century, EUWEC Special Topic Conference, Kassel (DE), 25-27 Sept 2000, p. 69-73

[6] Mustapha Enzili, M.: Resultats de l'etude sur les sites de Cap Sim (Essaouira) et Sendouk (Tanger). Talk on the MED2010 Project Conference, 20. Sept 2002, Marrakech (Morocco)

[7] http://www.gtz.de/wind/deutsch/studien_download.htm

[8] ECMWF Re-Analysis (ERA) Project, European Centre for Medium-Range Weather Forecasts, Reading, UK, 1996. See also http://www.ecmwf.int/research/era/

[9] http://uccee.org/WindCDM/index.htm

[10] Mortensen, N.G., U.S. Said, H.P. Frank, L. Georgy, C.B. Hasager, M. Akmal, J.C. Hansen, A.A. Salam: Wind Atlas for the Gulf of Suez. Measurements and Modelling 1991-2001. New \& Renewable Energy Authority, Nasr City, Cairo, Egypt (2003). ISBN 87-550-3195-1 


\section{Session 4B: Wind Energy incl. Economics}

Chairman: Erik Lundtang Petersen, Risø National Laboratory, Denmark 


\title{
Integration of wind energy into electricity supply systems
}

\author{
Per Lundsager \\ Wind Energy Department \\ Risø National Laboratory \\ P.O.Box 49 \\ DK-4000 Roskilde \\ per.lundsager@risoe.dk
}

\author{
Henrik Bindner \\ Wind Energy Department \\ Risø National Laboratory \\ P.O.Box 49 \\ DK-4000 Roskilde \\ henrik.bindner@risoe.dk
}

\begin{abstract}
Wind power has the potential to become the most significant renewable source of zero emission energy, which in a very large scale is a necessary precondition for meeting the global goals of sustainability and security of supply. Wind power is the fastest growing power source in the world, the technology is being developed rapidly, and wind power is supplying significant shares of the energy in large regions. The large scale integration of high proportions of wind power in the power system is therefore now an issue in order to optimise the utilisation of the resource and in order to continue the high rate of installation of generating capacity. There are of course a number of barriers to this development of the wind power from just being a negative load to having power plant like features. The barriers are related to issues such as the connection of wind farms to weak grids, securing power quality, reduction or elimination of power fluctuations, prediction of power output and changes in operating strategies of conventional power plants.

One of the major barriers is the need for large capacities of spinning reserves caused by the power fluctuations and lack of predictability of wind power. The use of controllable optional and/or deferrable loads may contribute significantly to overcoming this barrier by reducing the need for spinning reserve. Such controllable loads include the (reversible) conversion of wind energy into Hydrogen for use as both an energy storage and an energy carrier. The paper will highlight the issues related to this development and their possible solutions, illustrated by examples from finalised and current research work in various time and size scales, and present the current research direction.
\end{abstract}




\section{Introduction}

The power sector is currently undergoing a very fundamental restructuring in many parts of the world including Europe and USA. At the same time the political requirements to the sector are increasing especially in terms of environmental impact and security of supply. However the basic requirement is still that the sector delivers high quality power economically.

During the last 30 years emphasis has been on environmental issues. This trend has been accelerated with the process started at the Rio summit and continued at the Kyoto summit that resulted in firm requirements for emission of green house gases especially $\mathrm{CO}_{2}$. Within the European Union ambitious goals on the share of renewable energy of the power supply have been put forward to reduce the impact on the environment, [1].

One of the keywords in this is integration, taken with at least three meanings:

- Integration of the power, heat and transportation sectors. This is one of the prerequisites to obtain high system efficiency as well as sustainability.

- Integration of the conventional and new technologies for power generation. The renewable energy technologies have characteristics that are very different from conventional ones.

- Actual integration of a particular renewable energy technology in the power system i.e. how can the technology be developed and the system modified to ease the integration

Wind energy has been very successful during the last more than 20 years. The initial development of the technology in the beginning of the 80 'ties soon led to wind turbines that had a high availability at a relatively low cost. The result was a positive track record that encouraged further investment in development and implementation of the technology. Currently wind energy is the fastest growing energy source in the world and in some regions wind energy has a very significant impact on the power system. This has led to interesting development of the technology in order to integrate it economically in the power system.

\section{Current state of implementation}

Wind energy is going through a very rapid phase of implementation. Several countries have very large wind energy programmes and still more countries are initiating such programmes. In Europe the first large market was Denmark. It was succeeded by Germany and later Spain, but also other European countries are much involved in wind energy such as the Netherlands, Greece, Italy and now France.

The total installed capacity worldwide was some $25,000 \mathrm{MW}$ at start of year 2002, up 38\% from year 2001, and this high rate of increase in the installed capacity is also foreseen in the future, [1-4]. The prediction from [2], Figure 1, shows that the predicted installed capacity increases exponentially. Even the lowest estimate for EU year 2010, [1], is more than 10 times the installed capacity by the start of 2002. 


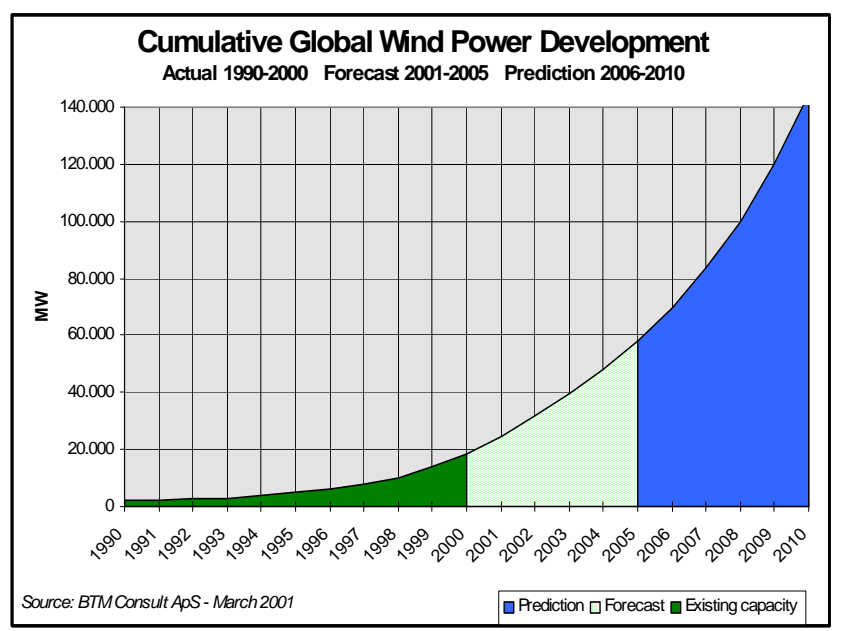

Figure 1. Forecasted and predicted wind power capacity (cumulative). (BTM Consult Aps., World Market Update 2000, March 2001)

The wind turbines are of course concentrated in regions with a good wind resource. This means that there are areas with very significant amounts of wind turbine capacity installed. This is e.g. the case for Western Denmark, Schleswig-Holstein in Germany and Navarra in Spain. In these areas the wind power has a significant impact on the power system.

The wind turbine technology itself is undergoing a rapid development, with wind turbine sizes having increased from 100-200 kW to 1-2(3) MW during the 1990's and still increasing. The electrical system has also undergone changes. Instead of fixed-pitch stall controlled designs with directly grid connected induction generator the large majority of the wind turbines being installed now apply some kind of blade angle control, frequently combined with variable speed drives that include power electronics components.

The wind energy business has changed as well. The typical project size is much larger now than in previous years, frequently more than $100 \mathrm{MW}$, and wind farms are also beginning to be installed offshore in e.g. Denmark, Sweden and UK/Ireland.

The situation in the Western part of Denmark (Eltra area) illustrates many of the above points, [5]. The power system is connected to Germany through a AC-connection (1200MW) and to Norway $(1000 \mathrm{MW})$ and Sweden $(630 \mathrm{MW})$ through HVDC connections. The generation of power comes from conventional coal and natural gas fired power plants, decentralised combined heat and power (CHP) plants and from wind power. The capacity figures and average annual production are shown in Table 1.

Table 1. Eltra area main figures, 2001, annual averages [5]

\begin{tabular}{|c|c|c|}
\hline Type of power plant & $\begin{array}{c}\text { Capacity } \\
{[\mathbf{M W}]}\end{array}$ & $\begin{array}{c}\text { Production } \\
\text { [TWh] }\end{array}$ \\
\hline Central CHP & 3200 & 12,9 \\
\hline Local CHP & 1520 & 6,8 \\
\hline Wind Energy & 1930 & 3,4 \\
\hline
\end{tabular}

Local CHP and wind power are prioritised production which means the system operator is obliged to buy the power from the producer at a given price regardless of time and need due to a public service obligation (PSO). It also means that these to kind of power producers do not participate in the system control.

Figure 2 shows the hourly averages. It is clearly seen that for significant periods supply of wind and CHP exceeds demand and therefore have to exported or dealt with in another way, ref [6]. 


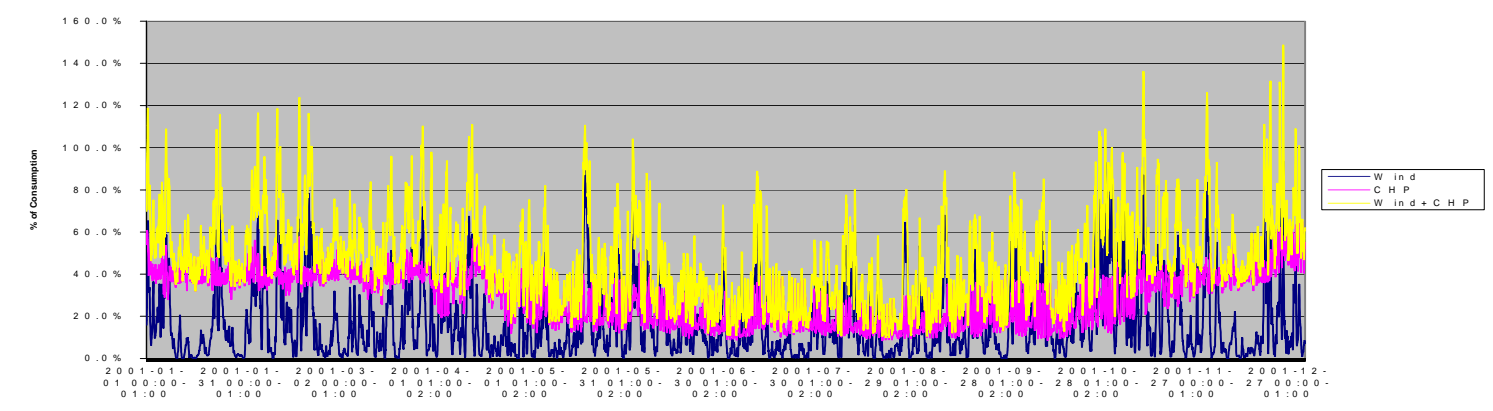

Figure 2. Prioritised production as fraction of consumption during 2001 for Eltra area (Time trace for wind, local CHP and sum)

The wind power capacity has been increased by the installation of the $160 \mathrm{MW}$ offshore wind farm, Horns Rev, which was put in operation by the end of 2002.

It is clear that a system with these properties is greatly influenced by the presence of both wind power and decentralised CHP. This is true at all levels of the system from the low voltage distribution grid over the higher voltage distribution and transmission grid to the operation of the other generating units of the system as well as the interaction with the Nordic Power Pool, NORDPOOL.

It also means that many barriers exist for the optimal integration of e.g. wind power in the power system since many of the grid codes, conventional practices etc. have been developed for optimal performance in systems with conventional power plants without a market. In the following section the many of these barriers are exemplified.

\section{Barriers for continued expansion}

Installation and connection of wind turbines and wind farms meets many barriers from grid companies and system operators. Many of these barriers stem from the inexperience of handling wind energy, which has different characteristics than other types of generation especially the variations, unpredictability and control properties. Below is listed many, but not all, of the barriers with respect to power system integration. Although the list is long many of the barriers can be overcome easily and at low costs as dealt with in the following section. However, it is very important that the barriers are handled seriously if wind energy is to gain confidence at the grid owners and system operators.

The impact of wind power on the power system is at all levels. The main cause for many of the problems resulting in limitations for the integration of wind power is the wind (not very surprising). The problems have several origins. One is the concentration of wind energy in some areas (resource availability) requiring the power is transmitted to the consumers via the transmission grid as noted above. The second problem is the temporal variations of the wind. The problem with the temporal variability is that it imposes increased regulation capabilities on the rest of the generating system. Finally the wind is very difficult to predict. This is true in many time scales from sub second to days (weeks -> years).

For smaller wind farms or single wind turbines the first concern is the grid connection. Usually the distribution company who owns the grid regulates the connection of wind turbines at medium voltage level.

The main concerns are the thermal capacity of the feeder, the voltage level, the reactive power consumption and the power quality mainly in terms of flicker. Each of these can limit the amount of wind power that can be injected into the system at this point of the grid.

The thermal capacity of the grid limits the amount of current that can flow in the conductors without exceeding the thermal limit of the conductors. It means that all other things being equal that there a maximum power that can be transmitted through the line.

Another factor that often limits the amount of wind power capacity that can be installed on a particular feeder is the voltage level. The voltage level at the consumers is regulated by international stan- 
dards e.g. EN50160, [7]. Due to the impedance of the conductors the voltage level will change along the feeder depending on the wind power production and the consumer load. A typical case for a rural medium voltage feeder is shown in Figure 3, [8].

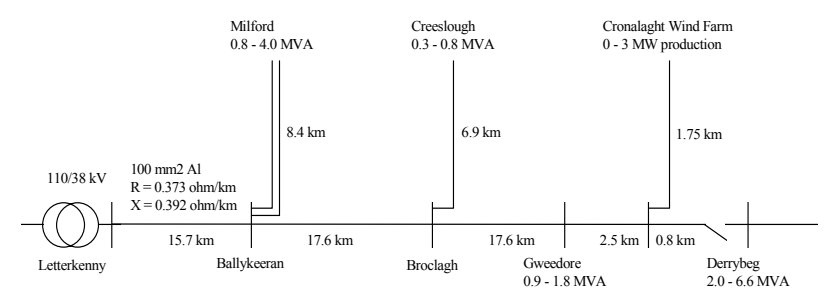

Figure 3. Data for Letterkenny - Derrybeg $38 \mathrm{kV}$ feeder with indication of minimum and maximum loads

The voltage profile for the different load cases are shown in Figure 7

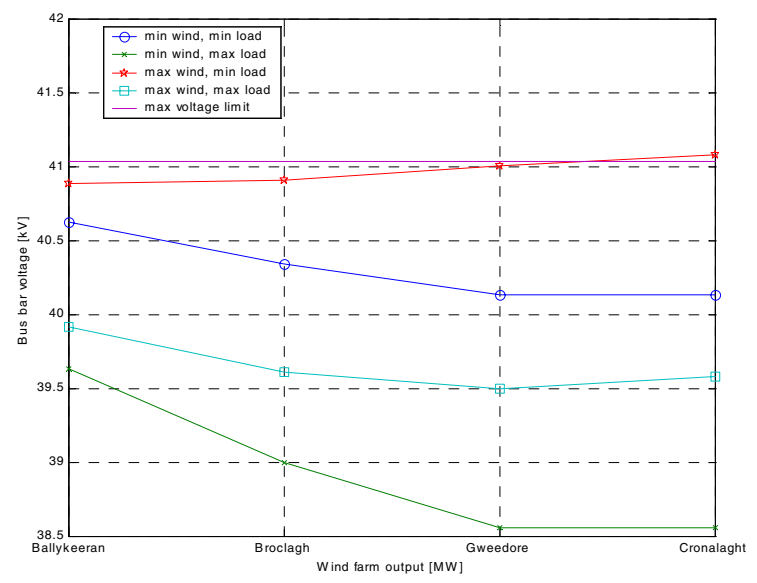

Figure 4. Voltage profile for feeder in different load cases

It is noticed that there is a significant shift in level between the two extreme situations i.e. high load combined with low wind power production and low load and high wind power production. In this particular case the voltage at the bus bar of the substation is regulated to the same level at all conditions (automatic tap changer).

In rural networks voltage instability can occur due to the relatively large network impedances and to the high loading in order to exploit the capacity of the grid. Further, many makes of wind turbines apply induction generators directly connected to the grid and with only no-load reactive power compensation. This will add to the problem since the reactive power consumption is increased, [9].

Other power quality measures also have to be taken into account such as flicker and harmonics when the sizing of the wind farm and the grid connection is done during the design phase. The flicker is a result of the variations in output power due to variations in the wind or due to switching operations (cut-in, cut-out and generator switching). In weak grids this can result in voltage variations at a magnitude and frequency that visibly changes the light emission from light bulbs. If power electronics are applied in the wind turbines the resulting level of harmonics have to be below the limits set in the standards. The power quality from wind turbines and wind farms are calculated on the basis of IEC 61400-21, [10].

Wind turbines are of course mainly installed in places with good wind resources. This can lead to high concentrations of wind power in some regions as described above is the case with the Western 
part of Denmark. This will also in the future be the case in many other places. This means that large amounts of wind power will be generated in regions where the local consumption is low and the excess has to be exported or dealt with in another way, see next section. In order to do that it is necessary to have a strong transmission grid designed for the transmission of wind power. This basically means that it has the right capacity of power transport from the windy regions to the load centres. This of course is a set of problems that has been known in the past when the transmission grid capacity was designed to fit the needs of power transmission from large central (coal, natural gas or nuclear) power plants. The main problem is the rapid implementation of wind power, which means that the reinforcement of the grid has not been planned and that the procedure for determination of the transmission capacity is different due to the stochastic nature of wind energy. When wind power is going to be exploited at high levels it means that large amounts of power has be transmitted over long distances and that in the regions with a high wind power production there will be very little if any conventional production. This also has an impact on how inter-area connections are handled with respect to controllability, security of supply etc. of the areas.

As the level of penetration increases the wind power will have a significant impact not only on the local voltage, but it will also have an impact on the system frequency. This is due to the variations in the wind turbine output, which means that the rest of the system not only has to be able regulate the variations in consumption but also the variations in wind power production. At the same time less conventional capacity will be on-line since the optimal operation (in terms of economy) of the system means that some of the conventional plants have to shut down to save fuel. The ability of the conventional power plants to control power can therefore be limiting the amount of wind power that can be integrated in the system if the system. In some areas this can be even worse since the there can be other limitations on the operation of the system. This is e.g. the case in the Danish system as presented above. Here large amounts of generation is heat bound local CHP (which is participating in the control of the grid) leaving even less capacity for frequency control. Such areas have to rely on power exchange with the neighbouring areas in order to be able to control the system.

The integration of wind power and energy in the market place is also made difficult by the unpredictability of the wind. This is not so much a technical constraint, but a economic constraint. In the Nordpool power pool power on the spot market have to be announced at 12.00 for the next day. This means that a 36 hours prediction horizon is required. In Denmark it is the System Operators that have to make the announcement on the spot market. The prediction of the wind power production therefore covers the System Operators Area. Experience have shown that it is indeed very difficult to predict the production even considering the spatial distribution of the wind turbines that will give some averaging effect, [11].

Therefore one of the major barriers is the need for large capacities of spinning reserves caused by the power fluctuations and lack of predictability of wind power. The nature of the barrier depends strongly on the size and configuration of a given power system. The reaction time of a small gas oil fuelled diesel generator is much smaller than that of a large diesel generator running on heavy fuel, and that again may be much smaller than a coal fired steam turbine generator.

Another barrier in the further implementation of wind power is the planning and operational procedures of the system/grid operators. Grid codes can be very restrictive for wind power since many of the grid codes are based on worst-case analysis without any reflection on the probability of occurrence of the worst case. This can lead to very conservative design of the grid connection, which implies high cost. These costs will usually be born by the wind turbine owner resulting in high-energy costs. Planning and economic dispatch tools also have to be further developed to take the characteristics of wind power into consideration in order to optimise the system operation, [12].

A further complication to the integration of wind power is that the significant impacts of wind power on many, if not all, aspects of the power system is not the only significant change in the power sector. There is also a fast paced development of micro CHP, PV and other generating technologies as well as the ongoing fundamental changes in the structure of the sector towards a market-based system. 


\section{Solutions}

The key to successfully increase the level of wind energy penetration and move towards an energy system that is much more sustainable in terms of exploitation of renewable energy sources is to view the system as a whole and take advantage of the various characteristics that different technologies provide. The keyword is flexibility.

As presented above the main contributor to the barriers of integration of wind energy is the variability combined with the unpredictability of the wind. Many solutions to these barriers exist (available on the market, in development or as changes in the existing practices). In many of these solutions of power electronics and information technology can be used to mitigate the impact and add value.

Power electronics installed as part of the wind turbines is increasingly common. This mainly takes the form of so-called variable speed turbines. The main advantages obtained with this combination is reduction of mechanical loads on the main wind turbine structure, which leads to reduced manufacturing cost, and improved grid connection characteristics, which leads to lower the grid connection costs. The reduced grid connection costs comes from the reduced impact during connection of the generator and from reduction of the power fluctuations in the flicker range. The application of power electronics also adds controllability of the power output both at partial load and at full load. This can successfully be utilised in wind farm control systems where the total output from a wind farm is controlled. Power electronics are used to control reactive power.

Such a concept (although without power electronics) has been installed in Ireland in the Northwestern part (County Donegal), [13]. The grid company was worried that the voltage would exceed the limits specified by the grid company for the operation of their MV-grid. The wind farm owner was presented with to alternatives either to limit the installed capacity of the wind farm to $4 * 600 \mathrm{~kW}$ or to ensure that the voltage would not exceed the specified maximum value by some intelligent wind farm control system. Due to the very good wind resources in the area the wind farm owner opted for the second solution and combined the wind farm $\left(5^{*} 600 \mathrm{~kW}\right)$ with a control system that reduces the wind farm output in case the voltage level get too high, see Figure 5.

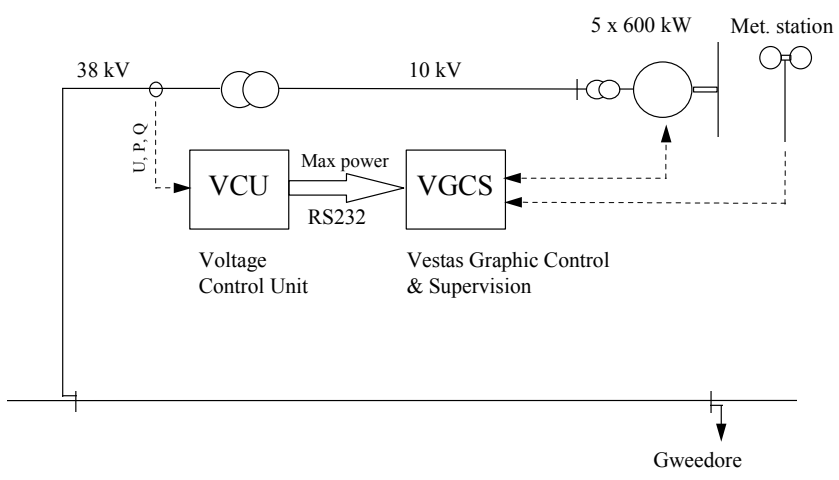

Figure 5. Illustration of wind farm with VCU and VGCS

EU supported the project and during the project period the system did not actively reduce the output from the wind farm. This illustrates another very important point. The analysis and grid connection design method applied by the grid company was based on a worst-case scenario and during the two years of monitoring the worst case did not occur (actually it was not close).

The concept of wind farm control have been further developed in the grid connection requirements set by the Danish System Operators for the connection of large wind farms to the transmission grid, [14]. In these requirements it is specified how the wind farm should behave both during normal operation and during grid faults. In order to increase the ease by which the wind energy can be integrated it is specified that the output from the wind farm should be controllable in such a way that it can be re- 
duced in $2 \mathrm{~s}$ to $20 \%$ of rated output, it should also be able to limit the total output of the wind farm to any value and other similar requirements. The requirements are further exemplified in [15].

On the Swedish island, Gotland, there has been a extensive implementation of wind turbines, especially in the Southern part of the island. The load centre is in the Northern part as is the unidirectional HVDC-connection from the mainland. This has resulted in several problems with the integration of wind power as well as in some interesting solutions. These include the application of HVDC transmission of the power and large converter stations based on voltage source converters using IGBTs, [16]. This system makes it possible to transmit power from the Southern part to the Northern part and due to the power electronics used in the converters it is also possible to control the reactive power. Also in the Southern part of the island (or rather offshore) a small wind farm $(5 * 500 \mathrm{~kW}$ stall controlled wind turbines) has been installed with wind turbines using power converters, [17]. The rating of converters used is one third on the wind turbine rating. This makes it possible to run the machines at variable speed at low wind speeds and produce slightly more power than if the machines were running at fixed speed. When the wind speed increases and the production from the wind turbine exceeds the rating of the power electronics the induction machine is directly connected to the grid and the power electronics is used for power factor correction. Due to the large penetration of the grid in the Southern part of the island several other problems with the grid is also handled by the power electronics. The converters are also used to reduce the impact of the wind turbines on power quality (here taken as flicker and voltage level) by controlling the reactive power and if necessary reducing the active power based on grid parameters.

The combination of wind power and energy storage has also received some attention. The objective have again been several including elimination of local power quality problems (again flicker and voltage level) as well as making the wind power schedulable as conventional power plants. The type of storage depends on the application, but in general the current storage technology is not well suited for these applications. Some special applications are of interest. One of them is utilisation of pumped storage. In areas where natural two-lake systems exist e.g. in County Donegal, Ireland, this option is the least cost option when compared to grid reinforcement, [8]. For smaller system lead-acid batteries are an option. In combination with modern power electronics it is possible to provide a system with significant less power fluctuations, Figure 6, [18].
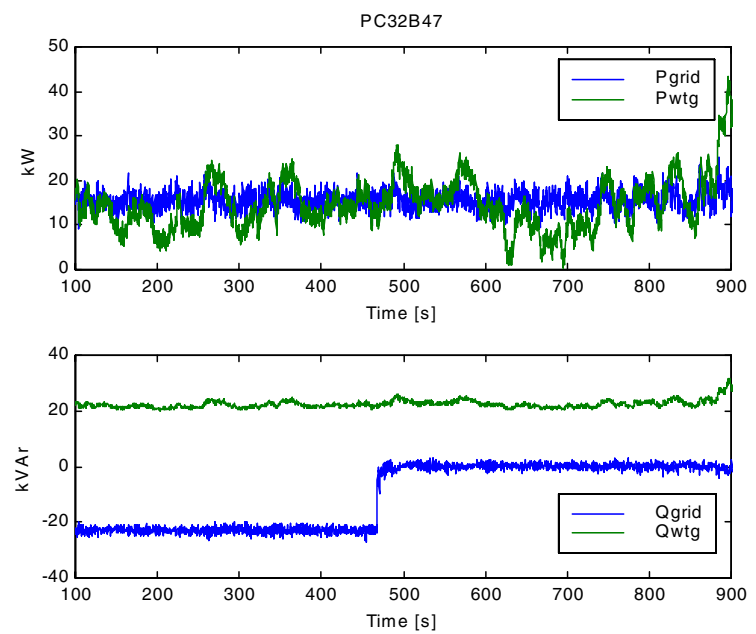

Figure 6. PQ-controller controlling active power and reactive power. Notice the step in reactive power

Other power electronic devices have also been applied in combination with wind farms in order to improve the grid compatibility. In Denmark two advanced Static Var Converters (SVC's) have been installed in the grid connection of wind farms. The newest one was installed at the 24MW wind farm Rejsby Hede, [19]. The objective of the project was to reduce grid losses and improve voltage control. 
As pointed out in the previous section several other technologies are developing at a fast rate. Many of these developments have an impact on the challenges and possible solution in the future energy system.

There has for many decades been worked on storage of electricity for power system applications. During the last few years several new storage technologies have emerged. The most promising of these are based on so-called redox flow technology, [20,21]. They have three very important features. The efficiency is high above, $80 \%$, the lifetime is long more than 10 years (and the charge/discharge regime does not have an impact). The third very important feature is that power rating and energy capacity can be sized independently of each other. The plant consists of two main parts: A cellstack in which the two electrolytes can interact through a membrane and storage tanks for the two electrolytes. The power capacity is determined by the area of the membrane and the energy capacity is determined by the volume of the storage tanks (or rather by the volume of the electrolyte in the system).

Fuel cells will also play a very important role in the future energy system. To begin with because it will be possible to have a very high total efficiency of the energy conversion from fuel to electricity (above 70\%) and heat, [22]. This will make it attractive to uses in houses as well as in office buildings and industry. However, from an integration point of view the real perspective is the ability of some types of fuel cells to work reversibly. In a power system with a high penetration of wind energy there will be long periods with surplus wind energy. This surplus energy can be fed to the fuel cells and hydrogen can be produced. This hydrogen can then later be used for power production is there is a deficit of wind energy, but it can also be used in transportation. In this way renewable energy is used to produce fuel for cars, trucks and tractors enabling a much higher degree of sustainability.

The use of demand side management may contribute significantly to overcoming the need for large capacities of spinning reserves caused by the power fluctuations and lack of predictability of wind power. Demand side management includes the use of controllable optional and/or deferrable loads. Optional loads are loads that need not be served unless there is power available at a given time, an example being water heating. Deferrable loads are loads that must be served within a given time (e.g. once a day), an example being water pumping. Such controllable loads also include the (reversible) conversion of wind energy into Hydrogen or Methane by fuel cells [38] for use as both energy storage and energy carrier. This also opens very promising opportunities for e.g. the transport sector.

The event of widespread application of micro CHP and also PV will result in a power system with a much more distributed nature. This will have to be integrated with wind power that will be concentrated in regions far from the consumption centres. This will have a huge impact on the design and operation of the transmission grid and it will also require new technologies to be developed that can control such a system and further can interact with an energy market. Information technology will be the key technology in this and its application will not be limited to the production side. Many benefits can be gained from including the demand side in the overall system operation in order to increase the flexibility and there by improve the matching of production and consumption, [6, 23].

The value of wind energy can be increased significantly by reorganising the way the power markets operate. Reducing the lead time will also reduce the error in the prediction of the wind power produced. Studies have to made in order to establish a market structure that is fair to all types of generation, [24, 25]. Green certificates have also been investigated as an option, [6], but creating such a market have shown not to be an easy task. These options have also been investigated in order to change from a fixed tariff system to a market based system for renewable energy.

It is evident from the above that no single solution or family of solutions exist that can eliminate or reduce all the barriers. However, it is noticed that integration in the different meanings presented in section I is the key to success. It is also noticed that many of the solutions require significant research effort if the potential is to be realised. 


\title{
5 Current directions of research
}

\author{
The research will work on four fronts
}

- reduction of energy cost as a result of improved performance or reduced manufacturing cost of each RE technology

- improve grid integration of the re technology

- improve flexibility of the energy system for each RE technology

- improve flexibility across the different parts of the energy system

In order to be able to succeed in this it is very important to improve design and analysis tools and through that improve the design codes and practices.

Wind turbine technology is currently undergoing rapid development. This include very detailed understanding of aerodynamics and the interaction with the mechanical structure as well as development of design optimisation tools that concurrently optimises the aerodynamic performance, the mechanical structure and the electrical performance, $[27,28]$. Specially developed power electronics play an important role in this both from a cost point of view as well as from a performance point of view, [29].

Key tools for integration of wind energy have to cover many aspects from sub-second analysis of impacts of faults to the long term planning. In recent years this area have attracted much attention and several tools have been presented.

Tools for analysis of the transient behaviour during and after faults of a complete wind farm connected to a large grid have been developed, $[30,31]$ and have been applied both to evaluate the impact and to device methods for performance improvement. Another area in which advanced tools have been developed is for assessment of power quality from wind farms, [32]. A central point in these models is the modelling of the wind for each individual wind turbine, for the complete wind farm and for all the wind farms included in the analysis, [33]. The majority of the tools are developed within commercially available power system analysis packages such as Digsilent Power factory, [34].

A very important issue is the development of control methods for a distributed system including methods for distributed ancillary services. This could take the form of virtual power plants. A very substantial effort within this field is taking place in the EU-project DISPOWER, [35]. This project covers many aspects of decentralised production, but focuses on the control issue.

The overall performance of the energy system is of course also very important. The analysis of the various energy sources and their interaction is needed for the development of policies and measures to implement the policies. Models that can analyse systems with conventional, CHP and RE production have been developed, [36]. These models are currently undergoing significantly developments in order to include market models. This enables not just analysis of the impact of renewable energy on the existing markets more importantly is makes it possible to investigate the impact of changes in the market structure. An EU-project on that topic is currently being initiated, [37].

Many other power system issues are under investigation such as long distance transmission of power from e.g. Morocco to load centres in EU, large-scale electrical energy storage in combination with wind farms.

A particularly important aspect of the fuel cell development is the development of reversible fuel cells, in effect allowing excess electricity to be stored as fuel for reuse in the power system again or in vehicles. Reversible Solid Oxide Fuel Cells (SOFC) have the ability to produce/absorb both hydrogen $(\mathrm{H} 2)$ and methane $(\mathrm{CH} 4, \mathrm{CH} 3 \mathrm{OH}),[38]$, where methane is more compatible with present day storage/transport technology than hydrogen. The same cells, operated in a different mode, make Solid Oxide Electrolysis Cells (SOEC) with the capability to electrolyse $\mathrm{CO}_{2}$, with very far reaching potential.

A key point and common factor to many of the projects is that they do not only focus on one particular aspect, but also have a system-oriented approach. This reduces the risk for sub-optimisation and is essential if the full potential of wind energy is to be realised. 


\section{Conclusions}

Wind energy is beginning to play an important role in the energy supply in many regions around the world and as the level of penetration increases the integration of the wind energy have to be handled in an increasingly systematic way. Many barriers exist for the economic integration of wind power, however, as described above many solutions to overcoming these barriers do also exist..

In order to reach the goal of a much more sustainable energy supply system a system approach is necessary. It is therefore required to not only develop the different individual renewable energy technologies, but also the technologies that make it possible for these technologies to work together to satisfy the needs for economic and reliable energy supply.

\section{References}

[1] European Commission. Energy for the future, renewable energy sources. White paper for community strategy and action plan. European Commission, Luxembourg, January 1997

[2] BTM Consult. World Market Update 2000. Ringkøbing, 2001

[3] EWEA. revised goals 2000. Wind Directions, Magazine of EWEA. London, 2000

[4] IEA. World energy outlook 2000. Paris 2000

[5] Carl Hilger. Wind powe impacts on system operations. IEEE Meeting, Oslo Norway, June 17 2002

[6] Danish Energy Authority. Report from the task force on combined heat and power (CHP) and RE electricity (in Danish). ISBN 87-7844-239-7. Copenhagen, October 2001

[7] Cenelec. EN50160: Voltage characteristics of electricity supplied by public distribution systems. 1995

[8] H. Bindner, I. Buckley, P. Murphy. Power control for wind turbines in weak grids: Donegal case. Risø-I-1397. Risø, March 1997

[9] P.A.C Rosas, J. Rønne-Hansen, P. Sørensen, H. Bindner, E. Feitosa. Wind energy influences on voltage stability. Proc. EWEC 2001, Copenhagen Denmark, July 2001

[10] IEC. IEC 61400-21: Measurement and assessment of power quality characteristics of grid connected wind turbines. 2001

[11] L. Landberg. Predicting the output from wind farms - an overview. Proc. EWEC 2001, Copenhagen Denmark, July 2001

[12] N. Hatziargyriou et al. Control advice for power systems with large-scale integration of renewable energy sources. CARE-Workshop, Heraklion Crete, July 16-17 1999

[13] H. Bindner. Performance of voltage control unit (vcu) at Cronalaght wind farm, Ireland. Risø-I1484, Risø October 1999

[14] Eltra. Grid connection requirements for wind farms connected to the transmission grid. $2^{\text {nd }}$ edition, April 172000

[15] P. Christiansen. Wind farm controller and dynamic stability. Proc. EWEC 2001, Copenhagen Denmark, July 2001

[16] ABB. Gotland: the first commercial HVDC Light project. http://www.abb.com

[17] Westcontrol. http://www.west-control.dk/

[18] H. Bindner, L.H. Hansen. Combining wind and energy storage to improve grid integration. Proc. NORPIE2000, Aalborg Denmark, June 2000

[19] Eltra. Power quality improvements of wind farms. ISBN 87-90707-05-2. Fredericia Denmark, 1998

[20] Regenesys. http://www.regenesys.com

[21] J.M. Hawkins, T.P. Robbins. A field trial of a vanadium energy storage system. Proc. INTELEC01.

[22] http://europa.eu.int/comm/energy_transport/atlas/htmlu/bfcdmarpos2.html 
[23] A. Gjerde. Innføring av toveiskomminukation i elsektoren. En analyse av konsekvenser og muligheter. (in norwegian) http://siving.hia.no/ikt97/paper/Asbjorn/paper.html

[24] E: Hirst. Integrating wind output with bulk power operations and wholesale electricity markets. Wind Energy 2002;5

[25] P.E. Morthorst. Policy instuments for regulating the development of wind power in a liberated market. Proc EWEC'99, Nice France, March 1999

[26] P.E. Morthorst. The development of a green certificate market. Energy Policy, November 2000, vol 28/15

[27] H. Aagaard Madsen. Forskning i aeroelasticitet - EFP2000 (in Danish). Risø-R-1272, Risø July 2001

[28] P. Fuglsang et al. Site specific design optimisation if wind turbines. Proc. EWEC'99, Nice France, March 1999

[29] L.H. Hansen. Conceptual survey of generator and power electronics for wind turbines. Risø-R1205. Risø Denmark, 2001

[30] V. Akhmatov et al. Short term stability if large-scale wind farms. Proc EWEC'01, Copenhagen Denmark, July 2001

[31] P. Sørensen et al. Models for simulation of transient events in a wind farm. Global Wind Energy Conference, Paris France, March 2002

[32] P. Sørensen et al. Simulation of interaction between wind farm and power system. Risø-R-1281, Risø Denmark, December 2001

[33] P. Sørensen, A.D. Hansen, P.A.C. Rosas. Wind models for prediction of power fluctuations from wind farms. JWE No. 89, Kyoto Japan, October 2001

[34] DIgSILENT PowerFactory. http://www.digsilent.de

[35] DISPOWER project. www.dispower.org

[36] L.H. Nielsen. Simulation of the Egyptian power system. In Pre-feasibility study for a pilot CDM-project for a wind farm in Egypt, N-E. Clausen, Risø Denmark, 2001

[37] WILMAR project description. to be publised

[38] Mogens Mogensen, Carsten Bagger. SOFC: The key to make renewable energy profitable ? 1998 Fuel Cell Seminar, Palm Springs, CA, Nov. 16 -19, 1998. 


\section{Session 5: Efficient Fossil Fuel Technology}

Chairman: Peter Høstgård Jensen, ELSAM, Denmark 


\title{
High-Efficiency Coal-Fired Power Plants Development and Perspectives
}

\author{
Jørgen Bugge and Sven Kjær \\ Tech-wise A/S \\ 7000 Fredericia \\ Denmark \\ Rudolp Blum \\ Elsam A/S \\ 7000 Fredericia \\ Denmark
}

\section{Introduction}

The Danish power stations have a long-standing tradition of building plants with high efficiency. This is a consequence of among other things that all fuel from the beginning had to be imported. Apart from a period from the sixties and up to the first oil crisis coal has always been the preferred fuel due to its low price.

In the early nineties when the trend was that the further development in coal-firing should be PFBC or IGCC, Elsam decided to build two $400 \mathrm{MW}$ units with advanced steam parameters and double reheat. Steam temperatures from the boiler were $3 \times 582^{\circ} \mathrm{C}$ and live steam pressure was 290 bar. This decision was taken after a thorough study of the 3 technologies dealing with efficiency, cost and risk.

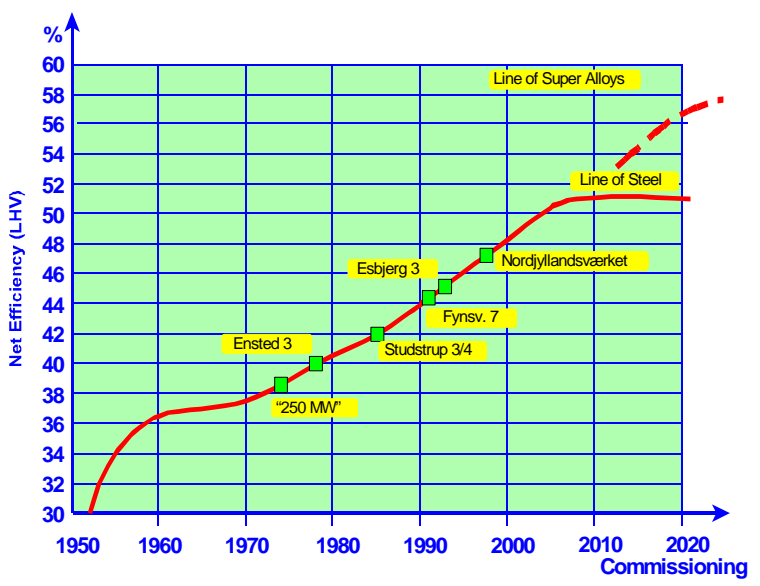

Figure 1. Efficiency in the Elsam System

The USC concept would give the highest efficiency at the lowest cost and risk as Elsam's metallurgists had confidence in the new developed steel P91. 


\section{Nordjylland and Skærbæk}

The units were planned for pulverised coal-firing, but the Danish energy authorities demanded that one of them should be fired by gas, which was to be Skærbæk unit 3. So only Nordjylland 3 is actually coalfired.

The boilers for the two units are identical except that the Skærbæk boiler is not fitted with coal-firing equipment. The turbines are also identical except for minor differences in relation to the district heating systems.

The boilers were built by a consortium of Burmeister and Wain Energy (BWE), Aalborg Industries and Vølund as tower boilers and the turbines were supplied by Alstom. The turbines have 9 cylinders arranged in 5 casings: Very High Pressure, High Pressure and Intermediate Pressure 0, Intermediate Pressure 1 and 2 and two Low Pressure casings.

The coal-fired plant is fitted with flue gas cleaning consisting of high dust $\mathrm{SCR} \mathrm{NO}_{\mathrm{x}}$ removal, electrostatic precipitator and wet scrubbing $\mathrm{SO}_{2}$ removal making the plant a real clean coal plant.

\section{The $600^{\circ} \mathrm{C}$ plants}

Table 1. Recent “ $600^{\circ} \mathrm{C}$ ” Power Plants.

\begin{tabular}{|l|c|l|c|c|c|}
\hline Power station & $\begin{array}{c}\text { Cap. } \\
\text { MW }\end{array}$ & Steam parameters & Fuel & $\begin{array}{c}\text { Year of } \\
\text { Comm. }\end{array}$ & $\begin{array}{c}\text { Eff. } \\
\%\end{array}$ \\
\hline Matsuura 2 & 1000 & $255 \mathrm{bar} / 598^{\circ} \mathrm{C} / 596^{\circ} \mathrm{C}$ & PC & 1997 & \\
\hline Skærbæk 3 & 400 & $290 \mathrm{bar} / 580^{\circ} \mathrm{C} / 580^{\circ} \mathrm{C} / 580^{\circ} \mathrm{C}$ & NG & 1997 & 49 \\
\hline Haramachi 2 & 1000 & $259 \mathrm{bar} / 604^{\circ} \mathrm{C} / 602^{\circ} \mathrm{C}$ & PC & 1998 & \\
\hline Nordjylland 3 & 400 & $290 \mathrm{bar} / 580^{\circ} \mathrm{C} / 580^{\circ} \mathrm{C} / 580^{\circ} \mathrm{C}$ & PC & 1998 & 47 \\
\hline Nanaoota 2 & 700 & $255 \mathrm{bar} / 597^{\circ} \mathrm{C} / 595^{\circ} \mathrm{C}$ & PC & 1998 & \\
\hline Misumi 1 & 1000 & $259 \mathrm{bar} / 604^{\circ} \mathrm{C} / 602^{\circ} \mathrm{C}$ & PC & 1998 & \\
\hline Lippendorf & 934 & $267 \mathrm{bar} / 554^{\circ} \mathrm{C} / 583^{\circ} \mathrm{C}$ & Lignite & 1999 & 42.3 \\
\hline Boxberg & 915 & $267 \mathrm{bar} / 555^{\circ} \mathrm{C} / 578^{\circ} \mathrm{C}$ & Lignite & 2000 & 41.7 \\
\hline Tsuruga 2 & 700 & $255 \mathrm{bar} / 597^{\circ} \mathrm{C} / 595^{\circ} \mathrm{C}$ & PC & 2000 & \\
\hline Tachibanawan 2 & 1050 & $264 \mathrm{bar} / 605^{\circ} \mathrm{C} / 613^{\circ} \mathrm{C}$ & PC & 2001 & \\
\hline Avedøre 2 & 400 & $300 \mathrm{bar} / 580^{\circ} \mathrm{C} / 600^{\circ} \mathrm{C}$ & NG & 2001 & 49.7 \\
\hline Niederaussen & 975 & $265 \mathrm{bar} / 565^{\circ} \mathrm{C} / 600^{\circ} \mathrm{C}$ & Lignite & 2002 & $>43$ \\
\hline Isogo 1 & 600 & $280 \mathrm{bar} / 605^{\circ} \mathrm{C} / 613^{\circ} \mathrm{C}$ & PC & 2002 & \\
\hline
\end{tabular}

Japan was the first to raise the steam parameters but that was on gas-fired units. Elsam's decision to build Nordjylland and Skærbæk represented a turning point in Europe where a number of coal-fired plants with advanced steam parameters has been built since then.

The experiences from the newest USC power plants have already demonstrated satisfactory performance with respect to reliability, flexibility, emission control and economy, table 1 . The plants are based on major use of newly developed boiler and turbine component designs, and wide use of the newly developed high performance materials, but the availability has been as good as less advanced power plants. The additional investment costs have been marginal, and are fully returned by the efficiency increase. Therefore, the overall production costs have shown the expected figures. On this background, it can be concluded that the " $600^{\circ} \mathrm{C}$ generation" of USC power plant will end up as a true success. 


\section{The AD700 project}

It was natural to follow the idea further, but it was clear that for ferritic materials there was a limit just above $600^{\circ} \mathrm{C}$. The new developed Ni-based materials gave hope that they could be used to increase the temperature to $700^{\circ} \mathrm{C}$.

In January 1998 the Advanced $700^{\circ} \mathrm{C}$ Pulverised Coal-fired Power Plant Project was started. It is financed by $40 \%$ by EU and the Swiss and UK governments. It comprised about 40 companies ranging from utilities and manufacturers to research organisations and laboratories. The first phase runs from 1998 to 2003. The second phase, which comprises 35 companies, runs from 2002 to 2005 and is by $50 \%$ financed by EU and the Swiss governments. The project is now called AD700.

The overall technical objective of the complete project is a phased development and demonstration of an economically viable, pulverised coal-fired power plant technology with a net efficiency of more than $50 \%$, the potential for which has already been established during the first phase of the project. An advanced super critical water/steam cycle will boost maximum steam temperatures from the standard 540$560^{\circ} \mathrm{C}$ range to the $700-720^{\circ} \mathrm{C}$ range and main steam pressure from the present 250 bar range to the 350 375 bar range.

The phase 1 results indicate net efficiencies in the range of $50-51 \%$ for a power plant with a single reheat cycle cooled by a wet cooling tower and $53-54 \%$ for a double reheat cycle cooled by sea water. Figure 2 shows the water/steam cycle for an inland location.

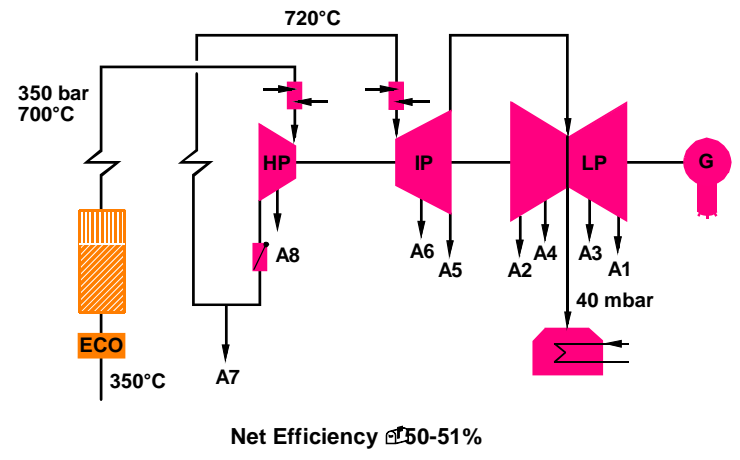

Figure 2. The AD700 cycle

The AD700 technology opens for long-term improvements of the net efficiency of more than 15\%-point from the current $35 \%$ average in European coal-fired capacity to more than 50\%. Even a comparison with today's state of the art super critical plant with steam parameters of $250 \mathrm{bar}$ and $540 / 560^{\circ} \mathrm{C}$ and a net efficiency of $44 \%$ shows that the AD700 technology efficiency is more than 6\%-point better.

A programme for development of materials for the AD700 technology and demonstration of their properties is listed below:

- New Nickel-based superalloys for long-term operation at steam temperatures in the range of 700$720^{\circ} \mathrm{C}$. Superalloys will be developed for thin-walled super and reheater tubes, thick-walled outlet headers and steam piping and castings and forgings for the turbine.

- Fabrication methods of components in super-alloys.

- New austenites for boiler tubes operating in the temperature range $600-700^{\circ} \mathrm{C}$ to minimise the use of expensive superalloys.

- Methods for welding of similar materials and for welding of dissimilar materials.

- Investigation of the corrosion resistance of new alloys operating at $700-750^{\circ} \mathrm{C}$ in an existing boiler fired by coal only or co-fired with biomass. 
Currently, European boiler and turbine manufacturers are in the forefront worldwide and the AD700 technology targets a major step forward to improve the competitiveness of European power technology after a successful demonstration somewhere in Europe shortly after 2010. Therefore, design studies are included in the project to investigate the potential of reductions in the use of expensive super-alloys to make the concept even more economically attractive:

- Steam turbines will be redesigned and revised or new joining methods will be developed to save superalloys.

- New boiler structures will be developed, which will allow steam lines between boiler and turbine to be shortened substantially thereby reducing investment cost.

- Major components outside the boiler and turbine areas like bypasses and safety valves will be redesigned to comply with advanced steam parameters.

Design studies from phase 1 indicate that this will all be accomplished without jeopardising the simplicity, plant economy and high reliability characteristics of the components in a more traditional power station. The AD700 technology will be mature shortly after 2010 and long-term targets after 2020 are net efficiencies above $55 \%$ based on maximum steam temperatures in the range of $800^{\circ} \mathrm{C}$.

Coal-fired plants offer the possibility to co-fire biomass as the coal ash has a benign effect on the corrosive elements in the biomass. Therefore, utility-based efforts to reduce $\mathrm{CO}_{2}$ emissions through the use of biomass will have their economy substantially improved by co-firing biomass and coal in a power plant with a very high net efficiency of more than $50 \%$.

The potential of $\mathrm{CO}_{2}$ reductions through improved generating efficiency is clearly illustrated by figure 3 , which also shows that $20 \%$ biomass being co-fired with coal will bring $\mathrm{CO}_{2}$ emission levels close to those of natural gas burned in gas-fired $\mathrm{CC}$ installations. If the leakage of natural gas from the transmission and distribution lines is being considered this will make the emission levels from the AD700 technology comparable to those from gas-fired CCs.

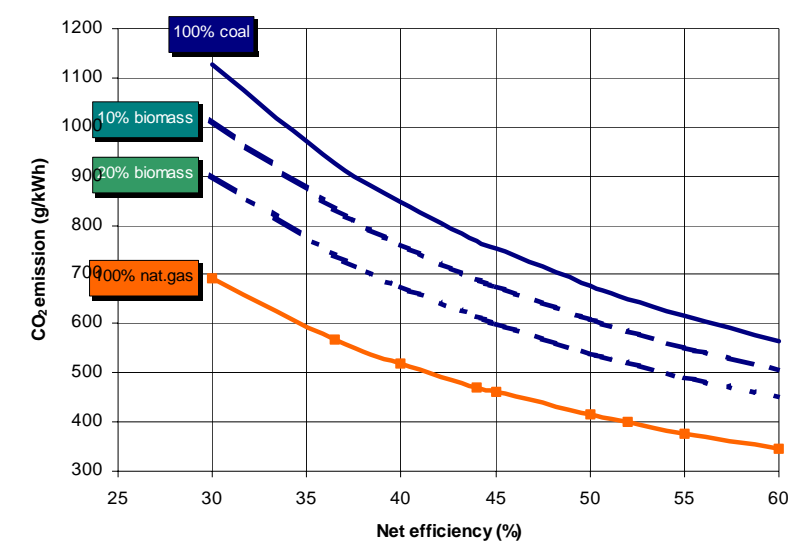

Figure 3. $\mathrm{CO}_{2}$ emissions from coal and gas-fired plants

\section{Materials for AD700}

In order to realise a $700^{\circ} \mathrm{C}$ USC power plant, extensive materials development is necessary including the use of Ni-based superalloys in the most severely exposed components. These developments can be categorised into four groups reflecting the key components of such a power plant i.e.:

- Furnace panels

- Superheaters

- Thick section boiler components and steam lines

- Turbine rotors, casings, valves and bolts 
For furnace panels, steam temperatures above $500^{\circ} \mathrm{C}$ must be foreseen. An interesting candidate material for such conditions might be the $12 \mathrm{Cr}$ steel HCM12. This material has well proven mechanical properties as well as sufficient corrosion and oxidation resistance. The main criterion for proving its applicability in furnace panels is to demonstrate good weldability with no need for post weld heat treatment. Demonstration tests comprising large test panels and one full boiler construction of HCM12 have shown excellent service performance, but they indicate that some work is still needed to develop a welding procedure, which guarantees unproblematic production of gas tight furnace panels. An alternative to HCM12 could be IN617, but this would lead to a very expensive construction.

For superheater tubing the aim is to develop an improved austenitic tube material with sufficient strength and flue gas corrosion resistance to operate at steam temperatures around $650^{\circ} \mathrm{C}$, and to develop a Ni-based superalloy to fill the gap up to $700^{\circ} \mathrm{C}$ steam temperature. Intensive development work is ongoing in the AD700 project to demonstrate a suitable austenitic tube material with 100,000 hour rupture strength of about $100 \mathrm{MPa}$ at $700^{\circ} \mathrm{C}$ and a Ni-based tube material with 100,000 hour rupture strength of $100 \mathrm{MPa}$ at $750^{\circ} \mathrm{C}$. Corrosion and oxidation resistance of both materials have been tested in a laboratory and will later be validated in in-plant test rigs. Results so far have been encouraging, and commercial scale production of both materials is foreseen in the second half of 2002.

For thick section boiler components and steam lines there are two goals for the development. An improved ferritic/martensitic $9-12 \% \mathrm{Cr}$ steel is needed to expand the present temperature range for ferritic steels up to approx. $650^{\circ} \mathrm{C}$. A Ni-based superalloy with a 100,000 hour rupture strength of $150 \mathrm{MPa}$ at $700^{\circ} \mathrm{C}$ is needed to allow construction of outlet headers and main steam lines with acceptable wall thicknesses, figure 4.

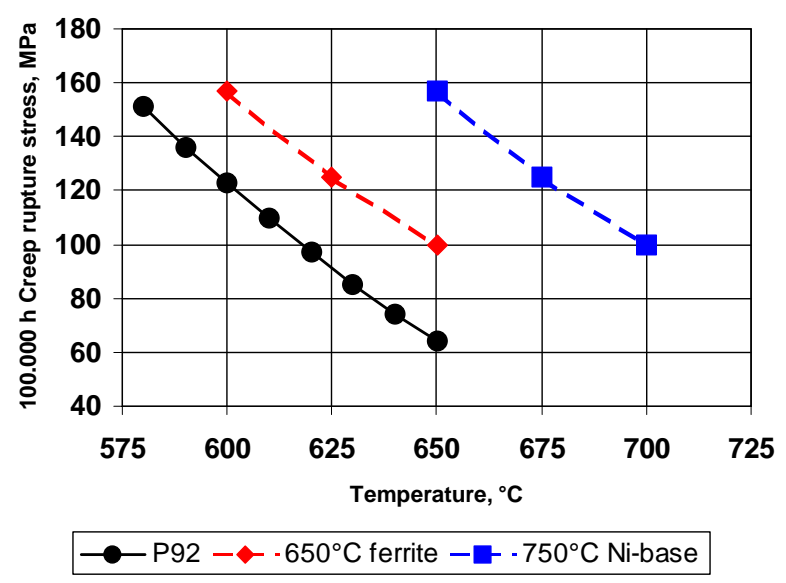

Figure 4. Future prospects for thick walled components

The task to improve the $9-12 \% \mathrm{Cr}$ steels on top of the impressive developments in the last two decades has proven to be very difficult. In the recent five years worldwide research has resulted in a large number of new alloys being announced, and from short-term tests they seemed very promising. However, in longterm tests the strength fall off and so far, no ferritic alloy has demonstrated long-term creep strength better than steel P92. In order to be able to improve the strength, a fine-tuning of the composition is needed based on a thorough understanding of recent developments. Recent advances in microstructure characterisation techniques and thermodynamically based microstructure models may prove to be the only way to go further in the development of improved ferritic steels.

Alloy 263 or an improved version of IN617 may meet the demands for outlet headers and steam lines at $700^{\circ} \mathrm{C}$ steam temperature. Long-term creep data and demonstration of fabricability - pipe production, hot bending and welding - is needed before a $700^{\circ} \mathrm{C}$ power plant can be realised. Alloy 263 is under investigation in the "Advanced ("700 ${ }^{\circ}$ ") PF Power Plant" project and the improved version of IN617 is investigated by the German national project MARCKO DE2. In the second half of 2002 commercial scale production of Alloy 263 and IN617 pipe is foreseen. The products will be used for qualification of the materials.

Recent results of the developments of $9 \mathrm{Cr}$ boron alloyed steels in Europe support the expectations that ferritic turbines can operate up to app. $625^{\circ} \mathrm{C}$ steam temperature. But similar to the ferritic steels for thick 
section boiler components a substantial understanding of the microstructures is needed to fine-tune the chemical composition for optimum strength performance.

For turbine constructions above $625^{\circ} \mathrm{C}$ steam temperature, a suitable Ni-based superalloy is sought amongst existing gas turbine disc materials. Long-term creep data are under development and the fabricability of full-scale turbine components will be demonstrated during the next phases in the "Advanced ("700 C") PF Power Plant"

The start of similar projects in the USA and Japan are important indications of how the AD700 technology is considered to have a great potential and attraction across the globe. In Japan, R\&D work on the use of super-alloys in the $700^{\circ} \mathrm{C}$ range has started headed by the Electric Power Development Company (EPDC) and strongly supported through the Ministry of International Trade and Industry (MITI). In the USA the Department of Energy (DOE) have announced plans in their Vision 21 Strategy to work towards temperatures $>700^{\circ} \mathrm{C}$.

\section{The next steps}

Where phase 1 has been screening, selection and testing of materials together with design and feasibility studies, phase 2 is design and testing of various components and preparation for the final implementation.

Next step, phase 3, will be testing of the critical high temperature part of the cycle preferably in full scale or close to that for a $400 \mathrm{MW}$ plant. That can be done in connection with a " $600^{\circ} \mathrm{C}$ plant" where the existing high pressure turbine is replaced with a new $700^{\circ} \mathrm{C}$ high pressure turbine, and steam from the existing boiler is further superheated up to $700^{\circ} \mathrm{C}$ in a new boiler (superheater). The exhaust steam from the new turbine goes back to the existing boiler and the rest of the cycle is unchanged for the existing plant, Figure 5.

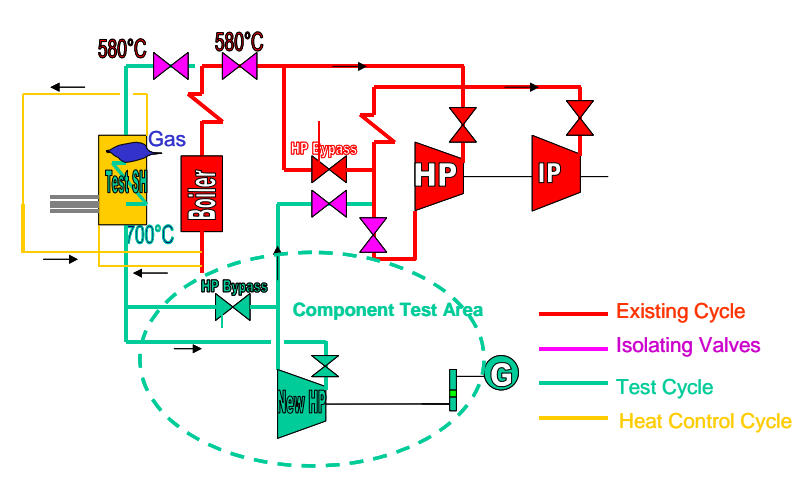

Figure 5. Set-up for a full scale test facility

The design pressure for the AD700 concept will not be reached but the important thing is that full temperature is reached and that load cycling takes place. Heavy load cycling (from full temperature) will in fact represent an "accelerated test of the concept" The full load steady state performance is easier to test in a laboratory. 


\section{The need for high efficiency coal-fired plants}

To assure the electricity supply in the future there is a strong need for coal-fired power plants. In case of the European Union, the Commission published a Green Paper named "Towards a European Strategy for the Security of Energy Supply" in November 2001. The paper shows the severity of the situation by stating that: "if no measures are taken, in the next $20-30$ years, $70 \%$ of the Union's energy requirements, as opposed to the current $50 \%$, will be covered by imported products."

In the long term, as the North Sea resources are being exhausted, natural gas will mainly come from Russia and North Africa and oil from the Middle East, which stresses the importance of coal for European security of supply. Therefore, it is being concluded: "The characteristics of the world coal market (geographical and geopolitical spread of supply and absence of price tensions) are reassuring in view of growing external dependence. In this respect one can speak of a stable economical and physical supply". The situation is the same in many other places around the world.

\section{Conclusions}

Five years of operation experiences with USC power plants have already demonstrated that the " $600^{\circ} \mathrm{C}$ generation" power plants will end up as a true success.

The development of a $700^{\circ} \mathrm{C}$ steam power plant to operate on coal in combination with biomass will enable a reduction of $\mathrm{CO}_{2}$ emission of around $40 \%$ compared with the most advanced USC power plants operating today. This will bring the emissions from a combined coal-biomass fired $700^{\circ} \mathrm{C}$ power plant close to the figures of gas fired combined cycle plants.

The $700^{\circ} \mathrm{C}$ steam power plant offers a flexible technology with minimised $\mathrm{CO}_{2}$-emission based on coal - the most reliable energy source in the world. Further, it gives the demanded production flexibility in order to stabilise a grid with a high amount of unpredictable renewable energy input.

The technical realisation of a $700^{\circ} \mathrm{C}$ steam power plant depends on a successful development and qualification of advanced ferritic, austenitic and $\mathrm{Ni}$ - based alloys. With respect to austenitic and Ni-based alloys promising results have been achieved.

The economic criterion for the realisation of a $700^{\circ} \mathrm{C}$ steam power plant is a realistic budget price. The consumption of large quantities of expensive $\mathrm{Ni}$-based alloys has significant influence in this respect, and a successful development of an improved ferritic steel to be used at temperatures up to $650^{\circ} \mathrm{C}$ would improve the situation. 


\section{Session 6: Biomass, Small Scale CHP and Waste}

Chairman: Jens Kossmann, Risø National Laboratory 


\title{
Biomass a fast growing Energy Resource
}

\author{
Professor Ulf Hansen, \\ Institute for Energy and Environmental Technology \\ Rostock University \\ Albert-Einstein-Strasse 2 \\ 18051 Rostock, Germany \\ Tel. ++49-381-498 3234, Fax Tel. ++49-381-498 3237 \\ E-Mail : ulf.hansen@uni-rostock.de
}

\section{Potentials and Expectations}

The term biomass embraces all forms of matter formed in the photosynthesis process. The global net primary production, NPP, describes the annual growth of biomass on land and in the seas. Our interest is primarily what grows on land and even this is not easy to quantify. A recent estimate for the NPP on the land continents is 120 billion tons of dry matter [Mohr, 2000]. Already, man requests some $40 \%$ or $50 \mathrm{Bt}$ for food production, as raw material, for parks and green fields and as an energy resource. The NPP is not likely to expand in the future, rather the contrary, it is expected that biomass production may fall with some $10 \%$ due to deforestation, desertification and general soil degradation as well as due to an increasing demand on land for urbanisation.

Now how much of the biomass can be used for energy purposes? The potential contribution of wood fuel and energy plants from sustainable production is limited to some $5 \%$ of NPP, i.e. $6 \mathrm{Bt}$ [Mohr, 2000]. With a heating value of $18 \mathrm{GJ}$ per ton of dry matter the energy equivalent is 2,500 million ton of oil. In addition, residues from the food chain and agricultural production can be utilised to supply energy, in the order of 500 Mtoe. From a technical viewpoint the potential worldwide is estimated to $104 \mathrm{EJ}$ or $5.8 \mathrm{Bt}$ of dry matter [Kaltschmitt, 2000], a figure which is compatible with the biological potential mentioned above.

Already, biomass is widely used and makes an important contributions to the world's energy supply. The degree of usage varies and in some regions the stress on the resource goes beyond that of sustainable production e.g. in Asia. Biomass as solid fuel has been the traditional fuel for cooking and heating in many parts of the world and today some 2.4 billion people rely on it as their main energy resource [IEA, 2002]. It is also an important fuel in rural industries for brick making, ceramics, drying and curing of food etc. In all, IEA estimates the contribution of biomass to the world's primary energy supply to 1,076 million ton of oil equivalent in year 2000.

Although being a traditional energy resource biomass is also assigned an expanding role as a new resource in the world's energy balance. The energy policy in many countries designates a fast growing contribution to biomass as well as to other renewable energies. The EU has set a target of doubling the share of renewable energies in the energy mix by 2010 . For biomass the target is even more ambitious. 
Table 1. Biomass in the IEA World Energy Outlook 2002.

\begin{tabular}{|l|r|r|r|r|r|r|r|r|}
\hline \multirow{2}{*}{ Year } & \multicolumn{2}{|c|}{$\mathbf{2 0 0 0}$} & \multicolumn{2}{c|}{$\mathbf{2 0 1 0}$} & \multicolumn{2}{c|}{$\mathbf{2 0 2 0}$} & \multicolumn{2}{c|}{$\mathbf{2 0 3 0}$} \\
\cline { 2 - 9 } & {$[$ Mtoe $]$} & {$[\%]$} & {$[$ Mtoe $]$} & {$[\%]$} & {$[$ Mtoe $]$} & {$[\%]$} & {$[$ Mtoe $]$} & {$[\%]$} \\
\hline $\begin{array}{l}\text { Total Primary Energy Sup- } \\
\text { ply (incl. Biomass) }\end{array}$ & 10,089 & 100 & 12,118 & 100 & 14,190 & 100 & 16,302 & 100 \\
\hline $\begin{array}{l}\text { Biomass Total } \\
\text { - Traditional Uses } \\
\text { (residential in DC) }\end{array}$ & 1,076 & 10.7 & 1,198 & 9.9 & 1,287 & 9.1 & 1,359 & 8.3 \\
$-\quad$ Power Generation & 99 & 7.2 & 778 & 6.4 & 796 & 5.6 & 788 & 4.8 \\
$-\quad$ Other Uses & 254 & 2.5 & 141 & 1.2 & 192 & 1.4 & 261 & 1.6 \\
\hline $\begin{array}{l}\text { Other Renewable Energies } \\
\text { (solar, wind, geothermal) }\end{array}$ & 66 & 0.7 & 124 & 1.0 & 194 & 1.4 & 294 & 1.8 \\
\hline
\end{tabular}

In the latest world energy outlook by the IEA the primary energy demand increases from 10,000 Mtoe in 2000 to more than 16,000 Mtoe in 2030, Table 1 [IEA, 2002]. This business-as-usual scenario is likely to raise questions of energy security and environmental compatibility. But even an alternative policy scenario for the OECD countries with increased emphasis on energy savings and with a higher reliance on renewable energies has no great effect on the use of biomass. The contribution in the reference scenario is forecast to grow by one third from 1.076 to 1,359 Mtoe. In the primary energy balance biomass is far more important than for instance nuclear energy.

In the IEA Energy Outlook biomass is growing in absolute terms but loosing in share of the energy supply. Traditional biomass uses for cooking and lightening in the residential sector is falling in importance and so are other uses like heating and processing in the residential and small business sector. Biomass for power generation is projected to increase, mostly in the OECD countries.

Other Renewable Energies do not figure prominently in the primary energy balance but the role is undervalued due to the statistical method of calculating the primary energy equivalent of electricity from wind and solar. The picture is presented better in Table 2 of the electricity generation. The total production of electricity from renewable energies, excluding hydro, increases from $1.6 \%$ in 2000 to $4.4 \%$ in 2030. Especially the contribution from wind is expanding and at the end of the period reaches almost the electricity production from biomass.

Table 2. Electricity generation by fuel in the IEA Energy Outlook to 2002.

\begin{tabular}{|l|r|r|r|r|r|r|r|r|}
\hline \multirow{2}{*}{ Year } & \multicolumn{2}{|c|}{$\mathbf{2 0 0 0}$} & \multicolumn{2}{c|}{$\mathbf{2 0 1 0}$} & \multicolumn{2}{c|}{$\mathbf{2 0 2 0}$} & \multicolumn{2}{c|}{$\mathbf{2 0 3 0}$} \\
\cline { 2 - 9 } & {$[\mathrm{TWh}]$} & \multicolumn{1}{c|}{$[\%]$} & \multicolumn{1}{c|}{$[\mathrm{TWh}]$} & \multicolumn{1}{c|}{$[\%]$} & {$[\mathrm{TWh}]$} & {$[\%]$} & {$[\mathrm{TWh}]$} & {$[\%]$} \\
\hline Total Electricity & 15,391 & 100 & 20,037 & 100 & 25,578 & 100 & 31,524 & 100 \\
Generation & & & & & & & & \\
\hline Fossil Fuels & 9,906 & 64.4 & 13,438 & 67.1 & 18,157 & 71.0 & 23,189 & 73.6 \\
Nuclear & 2,586 & 16.8 & 2,889 & 14.4 & 2,758 & 10.8 & 2,697 & 8.6 \\
Hydro & 2,650 & 17.2 & 3,188 & 15.9 & 3,800 & 14.9 & 4,259 & 13.5 \\
\hline Renewable Energies & 249 & 1.6 & 521 & 2.6 & 863 & 3.4 & 1,381 & 4.4 \\
Biomass & 167 & 1.1 & 276 & 1.4 & 399 & 1.6 & 568 & 1.8 \\
Wind & 31 & 0.2 & 147 & 0.7 & 307 & 1.2 & 539 & 1.7 \\
Geothermal & 49 & 0.3 & 85 & 0.4 & 126 & 0.5 & 174 & 0.6 \\
Solar incl. & 2 & 0.0 & 12 & 0.1 & 31 & 0.1 & 100 & 0.3 \\
Tide/Wave & & & & & & & & \\
\hline
\end{tabular}

e challenge for biomass utilization lies in improving the technology for traditional usages and expanding the role into other areas like power production and transportation fuel. The principal problem is that biomass and modern technology do not fit well together. Sophisticated, high efficiency engines require a homogeneous, well defined and clean fuel. Either the biomass is upgraded to meet the standard or the 
conversion technology is adapted to accept a lower grade fuel. This leaves a wide field for research and development.

\section{Technologies and Markets}

Traditionally, biomass, in particular wood, has been used for cooking and heating. Whereas wood has more or less disappeared from the kitchens in developed countries, it is the main- and, frequently, the only- fuel in many developing countries. The combustion technology is simple. The primitive "threestone-stove" has a low energy efficiency with only 10 to 15 per cent of the heat transformed into energy for cooking. On the other hand, the simple stove also meets basic demand for heat and lighting. However, the indoor emissions from inefficient and incomplete combustion of wood, residues and dung constitute a large threat to health. The WHO estimate that 2.5 million women and children die prematurely from breathing the fumes from biomass burners. The residential energy supply in rural areas of the developing world is part of a complex problem of poverty and development and shall not be addressed here.

A role for biomass in markets outside the traditional sector demands new technologies.

- Heat either individual or as small scale district heating

- Electricity, mostly decentralised

- Transportation fuel

- Hydrogen for fuel cells

Various technologies are available or under development and in most cases require a fuel processing step. Figure 1 offers an overview of the basic conversion processes. The product then undergoes the conversion to final energy in gas burners, engines etc. The choice of fuel processing and energy conversion is closely linked.

\begin{tabular}{|clll|}
\hline \multicolumn{4}{c|}{ Biomass: Wood, Straw, Bioorganic residues, Dung, etc. } \\
\hline Combustion & Thermo-chemical & Phycical-chemical & Bio-chemical \\
Heat & & Synthesis Gas & Bio-oil \\
& Pyrolysis Oil & Methylated fuel, RME & Biogas \\
& Coke & Gasoline & \\
\hline
\end{tabular}

Figure 1. Principal conversion routes for biomass

\section{Combustion}

Modern wood firing is a fast growing technology in the residential heating sector of many industrialised countries. Traditional boilers for logs and wood chips are built either as stand-alone units or as central heating systems. The output ranges from 15 to $50 \mathrm{~kW}$ suitable for a one family house or a block of flats or a farm. Equipped with a fuel hopper they will burn for half a day or longer and being automatically controlled require little manual effort. The technology improvements over the last ten years are impressing as can be seen from the tests performed in Austria, Table 3. The emissions are reduced by $90 \%$ and the energy efficiency improved from 66 to $86 \%$. Some of the units achieve more than $90 \%$. The costs in 2001 are typically in the range $200-300 € / \mathrm{kW}$ for a heat output of 20 to $30 \mathrm{~kW}$ [Uth, 2001]. 
Table 3. Results from testing log and wood chips fired residential boilers in Austria [Jungmeier, 1999].

\begin{tabular}{|l|c|c|c|}
\hline & $\begin{array}{c}\text { CO } \\
\mathrm{mg} / \mathrm{MJ}\end{array}$ & $\begin{array}{c}\text { Unburnt CH } \\
\mathrm{mg} / \mathrm{MJ}\end{array}$ & $\begin{array}{c}\text { Boiler Efficiency } \\
\%\end{array}$ \\
\hline $\begin{array}{l}\text { Years 1980 - 1989 } \\
\text { (Median of 25 Models) } \\
\text { Mostly over \& under fired boilers }\end{array}$ & 5,043 & 36 & 66 \\
\hline $\begin{array}{l}\text { Years 1996 - 1998 } \\
\text { (Median of 8 models) } \\
\text { Mostly Gasification boilers }\end{array}$ & 170 & 4 & 86 \\
\hline
\end{tabular}

If logs and chips are better suited for rural areas, wood pellets could become a standard fuel in residential and urban areas. The boilers are fully automatic and require very little attention. The progress with this perceived low-tech equipment is impressing and modern technology like lambda sensor to control the optimum air ratio is frequently incorporated. With a heat output as low as $10 \mathrm{~kW}$ they are suited to the requirement in low energy houses and some as high as $60 \mathrm{~kW}$ suitable for larger buildings. The efficiency of pellet fired boilers is generally higher than with logs and chips firing and typically reach $90 \%$. The costs are also higher and in 2001 run to $400-500 € / \mathrm{kW}$ for 15 to $25 \mathrm{~kW}$ units [BIZ, 2002]. Fuel supply logistics similar to heating oil is being built up. To enhance the deployment perspective an "all-in-onehand" logistic and service oriented approach would be needed.

Wood firing has gained large markets in Austria and Finland and is growing in Germany and Switzerland. Small industrial boilers are likewise a promising market for wood and straw firing. Fluidised bed combustion is a preferred technology in larger units of the MW-range. It is a direct route to substitute fossil fuels in the important residential and commercial heating market.

Biomass for higher value conversion to power and electricity calls for a more complex process. Principally, we distinguish between the conversion of the chemical energy to heat and the subsequent utilization of the heat in a thermodynamic cycle. The major process routes discussed in this paper are shown in Figure 2. The heat may be generated directly inside the machine like the internal combustion engine or a gas turbine where the hot gas serves as the working fluid. Alternatively, the combustion takes place outside the machine and the combustion gases serve to raise steam in a boiler for a steam turbine or a steam engine. In the directly fired process the combustion gases must be free of substances that may damage the machine. The indirectly or externally fired process is less demanding in this respect but involves more conversion steps which effect the overall efficiency.

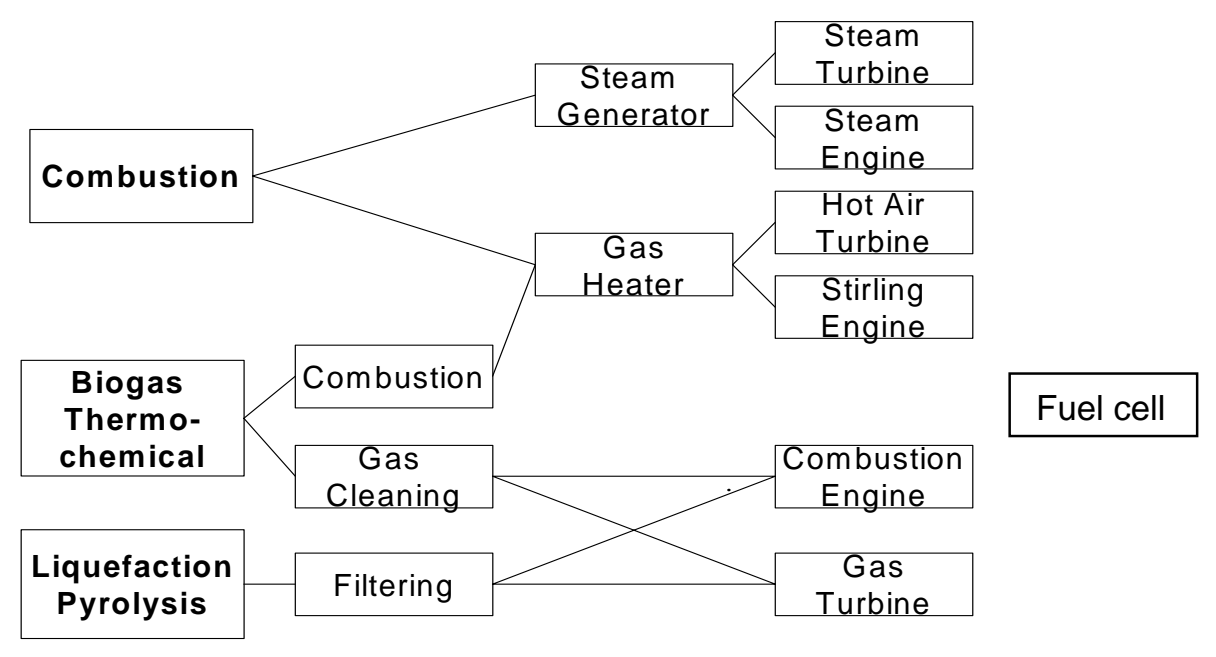

Figure 2. Overview over routes to generate electricity from biomass

The steam cycle is the only technology commercially available today to convert solid biomass into electricity. Wood chips or particles are burnt in a furnace or boiler to raise steam. Depending on the combus- 
tion technology and the size of the boiler 10 to $20 \%$ of the combustion heat is lost. The thermal efficiency of the steam cycle is determined by the quality of the live steam, i.e. temperature and pressure, and the quality of the machinery i.e. turbine, generator, pumps etc. The energy flow in a small wood fired CHP with a steam engine is shown in Figure 3. The boiler efficiency is 0.8 , i.e. of the heat content of the wood fuel $80 \%$ are used to raise steam and $20 \%$ lost to the environment. In the thermodynamic cycle 89 $\%$ of the steam energy are converted to heat and electricity of which $30 \mathrm{~kW}$ or one fifth is needed for various electric auxiliaries. The net conversion of 100 units of fuel energy yields 7 units electricity and 64 units of heat. The technology is well suited for industrial customers with a high demand for process heat like steam.

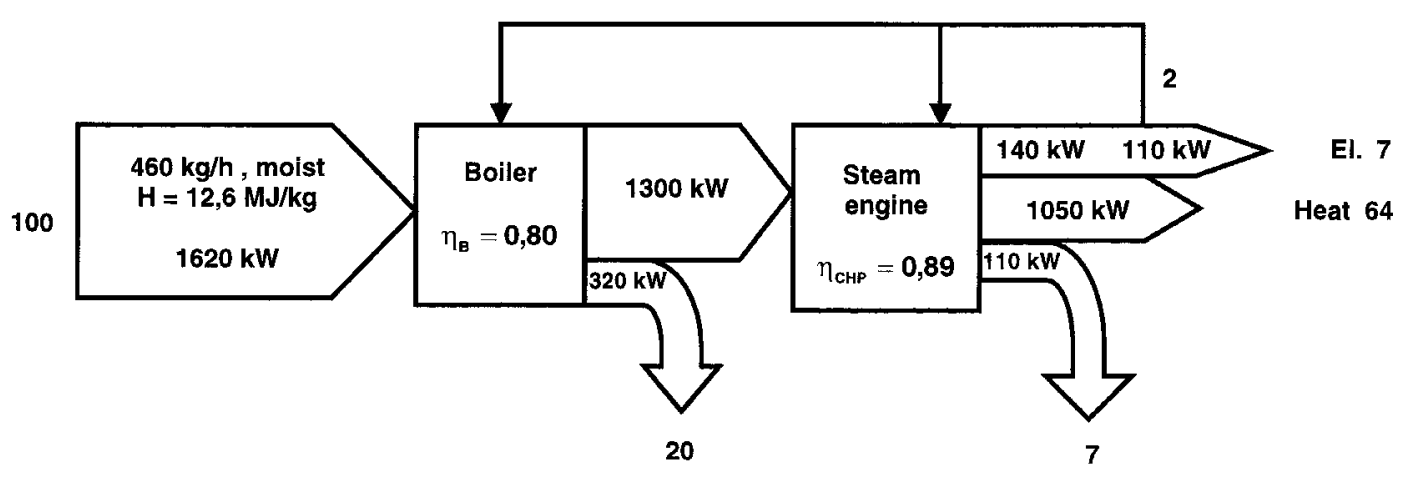

Figure 3. The energy flow in a small steam electric system with a steam engine

Biomass for electricity is utilised generally in small units, mostly less than $20 \mathrm{MW}$-electric. This is the upper limit for a power plant dedicated to burn biomass and would require some 150,000 tons per year. Any larger size would increase the transport distance and costs and complicate the logistics. In larger steam plants the turbine replaces the engine. The net electric efficiency in the power range of 2 to $5 \mathrm{MW}$, however, is not very high 15 to $18 \%$. Also larger units of 25 to $30 \mathrm{MW}$ achieving up to $30 \%$ are far away from large modern coal fired stations reaching 40 to $45 \%$ - not to speak of gas fired combined cycles boasting $55-58 \%$.

Co-firing of biomass in a large coal-fired power station allows to take advantage of the high thermal cycle efficiency. In principle, one unit of heat from biomass replaces one unit of heat from coal in the boiler. There are, however, problems with certain trace substances in the biomass and with the low melting point of ashes which may lead to corrosion in the heat exchanger. Tests have been performed in a number of power stations and with careful selection of type and province of biomass problems can be avoided. In the case of straw a separate boiler may be required, cf. Avedöre 2 [Noppenau, 2003]

In order to use solid biomass directly in an internal combustion machine it must first be converted to either a liquid or a gaseous fuel. The chemical process requires energy inputs and incurs losses. The fuel conversion efficiency need to be accounted for when evaluating the process chain from primary biomass to a final energy like electricity.

\section{Gasification}

The conversion of biomass to gas may either be through an anaerobic process or through a thermo chemical process with oxygen or hydrogen as the gasification medium. Both biogas from fermentation of agricultural residues and thermal gasification of wood and other solid biomass have a long history. Thermo chemical gasification can also draw on experience gained with lignite and hard coal. The produced gas is mostly intended for immediate use and the gasification unit is an integral part of the power generating plant. In consequence, the size of the gasifier and the energy conversion technology must be compatible. The gasifiers fall into three categories:

- Fixed bed gasifiers,

- Fluidised bed gasifiers

- Entrained flow gasifiers 
The fixed bed gasifiers are mostly small scale and come in two types, either down-draft $(<2 \mathrm{MW})$ or updraft $(<10 \mathrm{MW})$. They differ in the direction of gas flow through the biomass in the reactor. In the updraft gasifiers the raw gas exits from the cold end of the reactor and contains important fractions of tar which need to be removed before using the gas. The down-draft reactor enables the cracking of the high hydrocarbon fraction but a drawback is the high gas temperature at the outlet.

The fluidised bed gasifiers, either stationary, SFB, or circulating, CFB, are built in the MW-range. A wide variety of materials can be gasified in the fluidised bed and the product gas contains very little tar. The circulating variety, $\mathrm{CFB}$, requires a size of more than $15 \mathrm{MW}$ to be commercially viable.

Entrained flow gasifiers operate at very high temperatures, 1200 to $2000{ }^{\circ} \mathrm{C}$ and require biomass in dust form, $<1 \mathrm{~mm}$. Again there are a number of different types. A special feature is the utilisation of the high temperature heat in the raw gas which is quenched after leaving the reactor. More advanced gasification schemes are in two steps. In the first process, a pyrolysis unit, the volatile components of the biomass are released, whereas in the second, the thermal gasification of the char takes place, e.g. the Carbo-V process in Freiberg. The advantage being the break-down of higher hydro carbons of the pyrolysis gas in the second process.

In all types of gasifiers, gas cleaning with removal of dust is necessary. Gasifiers based on the fluidised bed technology produce a gas with a very low tar content as the complex components are cracked at the high temperature in the bed. With addition of chalk to the bed material sulphur and chlorides are efficiently captured in the bed ash. In cases where the gas needs to be cooled before entering the gas cleaning sequence, an optimum heat management is mandatory in order to achieve a high overall efficiency. The gas composition and yields from the different technologies vary with a heat value of 4 to $7 \mathrm{MJ} / \mathrm{m}_{\mathrm{N}}^{3}$ and a cold gas efficiency of 50 to $85 \%$. The latter describes the energy content of the product gas in relation to the energy contained in the biomass input. In the gasification of biomass air has become the standard gasifying medium. Pure oxygen or steam are seldom as the complexity of the process scheme is hardly justified.

Optimising the gasification process is a complex task and only justified in very large units where the various energy flows are integrated in the power generating process. The combined cycle, IGCC, offers the highest efficiency potential but need to be in units of $15 \mathrm{MW}$-el or larger, cf. demonstration plant Värnamo, Sweden and commercial units in the paper-\&- pulp industry in Finland.

For the small scale, simple gasifier the cold gas efficiency is typically 70 per cent. Following extensive cleaning the gas can be burnt in an engine or a gas turbine. With a heating value of less than one fifth of natural gas and consisting mainly of $\mathrm{H}_{2}$ and $\mathrm{CO}$ as the burnable components, ignition and combustion pose problems. Fixed bed up-draft gasifiers have been demonstrated to operate successfully [Teisler, 2002], although in the Harboore unit the gas engines had to be derated. Over the years a large number of gasifiers have been built and partly developed to an industrial scale. However, thermal gasification is only justified in the multi-MW range whereas small, decentralised units have not yet reached a commercially viable stage.

The anaerobic fermentation of bioorganic residues yields a gas with a high proportion of methane. The content ranges between 50 to $60 \%$ and the heating value typically corresponds to one half of that of natural gas. The biogas needs cleaning of sulphur compounds and other trace substances contained in the feed material. The gas is utilized in combustion engines for heat and power production. The size is determined by the amount of farm residues and additional biomass is frequently used as co-substrate to enhance the output. Still, the CHP units are small, mostly ranging from 50 to $200 \mathrm{~kW}$ electric. In Germany the number of biogas reactors have doubled within three years from 850 (1999) to 1600 (2002) and have reached a total of $150 \mathrm{MW}$-el. The potential in Europe is significant as the process also enables the mandatory treatment of farm wastes.

The continuous combustion in a gas turbine is less demanding than in a reciprocating engine. However, small gas turbines of standard design are less efficient and need to be beyond $5 \mathrm{MW}$ to reach $30 \%$. However, micro gas turbines with recuperators and gearless permanent magnet generators achieve an electric efficiency of up to $30 \%$ in small the unit size of less than $100 \mathrm{~kW}$. Still at a development and commercialisation stage they offer a promising perspective for utilizing biogas.

The fuel cell offer an even more interesting perspective, although in a more distant future. The synthesis gas from the gasification of biomass contain in the order of $20 \%$ hydrogen. In a chemical process the hydrogen can be separated and cleaned of harmful trace gases before being fed to a fuel cell. The methane in biogas can equally serve as a hydrogen source after passing through a steam reforming process. 


\section{Liquefaction}

Liquid fuels are storable and have the advantage of allowing to separate the fuel production from the utilisation. Also large central units enable economy-of-scale effects. The production of vegetable oils from oil bearing plants and the further treatment to methylated ester, e.g. RME, as well as alcohol from fermentation, e.g. the Brazilian ethanol programme, are well established technologies

Various technologies are under development to convert solid biomass to a liquid fuel. One method is to convert the gas from the gasification in a methanol synthesis process. However, in order to achieve a high efficiency, the gas should contain large fractions of $\mathrm{CO}$ and $\mathrm{H}_{2}$ which is only possible with either steam or oxygen as the gasifying media. The production route from solid biomass to a premium fuel is complex and involves considerable energy inputs and losses. Based on the Carbo-V gasification with subsequent liquefaction $1 \mathrm{t}$ of bone dry wood yields $200 \mathrm{~kg}$ diesel fuel [FAZ, 2003]. The energy conversion efficiency works out at $48 \%$.

A different route, called fast or flash pyrolysis [8], offers a promising perspective for the medium term future. Wood chips and other solid biomass finely grinded to dust or small particles are quickly heated to some $500^{\circ} \mathrm{C}$ in a reactor where the volatile hydro carbon components escape. The gases are subsequently quenched and condense to a mixture of liquid hydro carbons, called pyrolysis oil. The oil also contains 20 to $30 \%$ water and small quantities of solids, mostly coke. The yield calculated on the basis of bone dry biomass is roughly $70 \mathrm{w} . \%$ oil, $15 \mathrm{w} . \%$ non condensing gas and $15 \mathrm{w} . \%$ char. The mass and energy flows are shown in Figure 4. The char is recycled and burned in order to provide heat to the pyrolysis reactor. Auxiliary energy is needed for pre-treating the biomass as well as for the process itself. The ratio of output to input works out to $74:(100+14)=0,65$, i.e. the conversion efficiency is similar to gasification. The oil may then be used in a combustion engine or gas turbine.

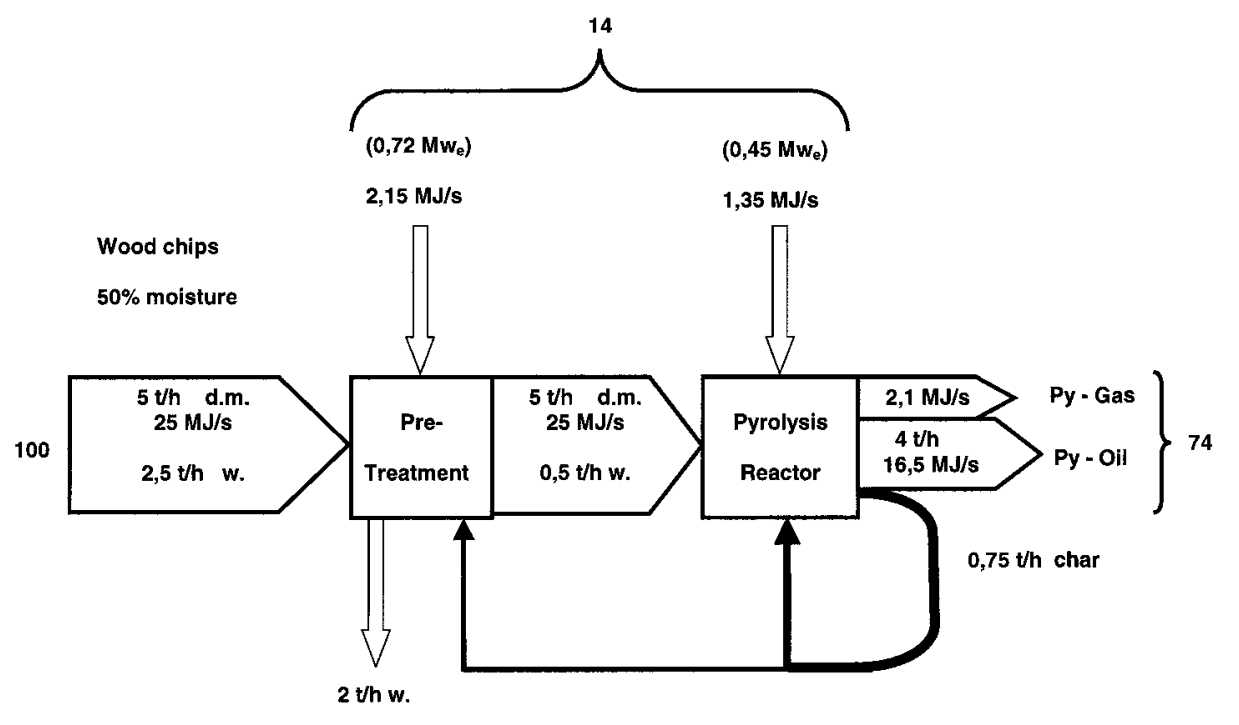

Figure 4. Mass and energy flows in flash pyrolysis based on EU-Project FAIR-CT97-3203

Alternative fuels in the transport sector may either be deployed as a 100 per cent substitute like RME under the brand name "bio-diesel" in Germany or as admixture to standard fuels. Examples of the latter are the 5\% share of RME in diesel in France and $0.8 \%$ ethanol in gasoline in the US. The European Union is preparing a directive to have a $2 \%$ share of bio fuels in motor fuels by 2005 and increasing to $20 \%$ in 2020. This would have a significant impact on the bio fuel market and structure. 


\section{Environmental Impact}

One reason for advocating bio energy is to replace exhaustible fossil fuels and to reduce carbon emissions. The limited availability of biomass allows to substitute fossil fuels only in a few selected areas. The aim must be to select those with the largest benefits, in particular so, as the deployment to a large extent rely on public money. The priorities may be measured by the amount of carbon dioxide savings.

The energy conversion efficiency of the system is an important aspect of the environmental compatibility. Based on a life cycle assessment, LCA, the whole conversion chain from field to final user is analysed. The steps are fuel supply, fuel upgrading, and energy conversion. In Figure 5 an example is given for thermal gasification of wood and the subsequent utilization in a combustion engine supplying heat and power. The energy input to supply wood chips is $3 \%$ and the gasification yield $70 \%$. The efficiency of the CHP unit is $85 \%$. From 100 energy units in biomass 57 units are supplied to the grid as final energy. Taking the electricity output only, the overall efficiency is $24 \%$.

The analysis has been carried out for a number of technologies and conversion routes in Figure 2 and the result is given in Table 4. For small, decentralised units the electric efficiency is in the region of 15 to $25 \%$. A CHP unit based on diesel fuel, similar to the biogas system above, achieves a life cycle efficiency of $34 \%$. The only bio-electric system with an equally high overall efficiency is co-firing in a large steam power plant, taking advantage of the high thermal efficiency modern coal fired units. Typical investment costs for German conditions are also listed. In order to calculate the generation costs, a number of other positions would be needed, especially the cost of biomass, and will not be pursued here.

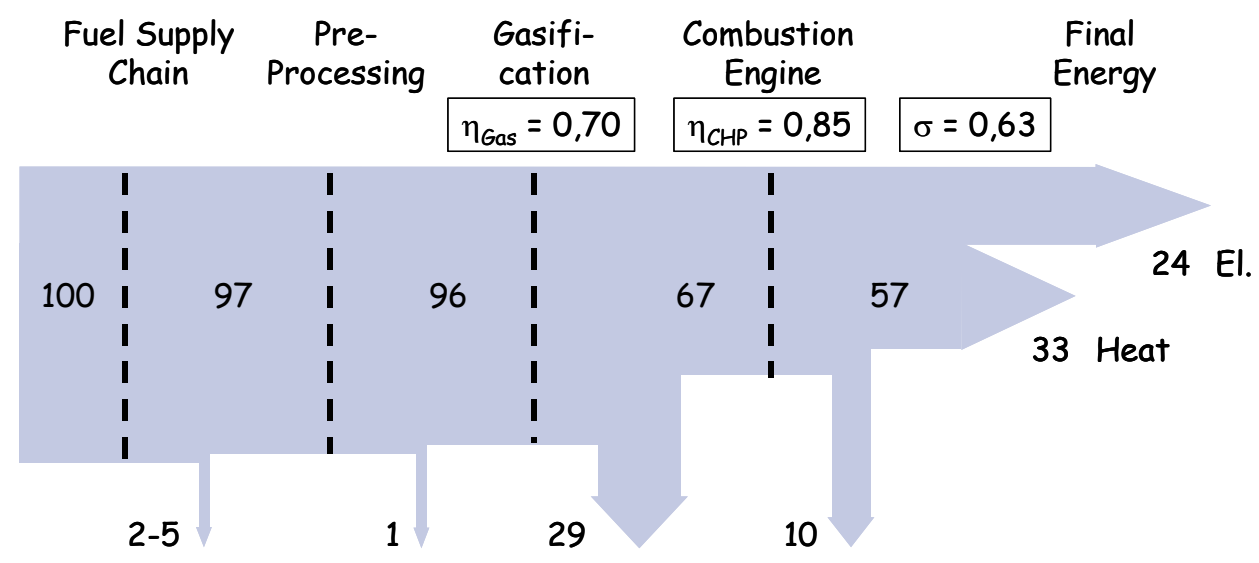

Figure 5. Energy flow and net yield in the production chain biomass-gasification-motor CHP 
Table 4. Life cycle efficiency from primary energy to electricity [Hansen, 2002].

\begin{tabular}{|l|cc|c|c|c|}
\hline Technology & $\begin{array}{r}\text { Genset-Efficiency } \\
\text { Total } \\
{[\%]}\end{array}$ & $\begin{array}{c}\text { Electric } \\
{[\%]}\end{array}$ & $\begin{array}{c}\text { Life Cycle } \\
\text { Efficiency (el.) } \\
{[\%]}\end{array}$ & $\begin{array}{c}\text { Investment costs } \\
{\left[€ / \mathrm{kW}_{\mathrm{el}}\right]}\end{array}$ & Ref. \\
\hline Steam Engine 110 kW & 72 & 7 & 7 & 3,500 & {$[12,7]$} \\
Steam Turbine $2,200 \mathrm{~kW}$ & 83 & 16 & 15 & 2,200 & {$[10]$} \\
Co-Firing 400 MW & - & 40 & 37 & 400 & {$[15]$} \\
Bio-Gas Engine 600 kW & 85 & 36 & 24 & $2600+800^{*}$ & {$[7]$} \\
Bio-Gas Turbine 1,200 kW & 78 & 24 & 17 & $2700+600^{*}$ & {$[7,11]$} \\
Bio-Oil Engine 200 kW & 84 & 38 & 27 & 1,200 & {$[11]$} \\
Py-Oil Micro GT 100 kW & 79 & 29 & 18 & $1000-1,250$ & {$[13]$} \\
Wood-fired EFGT 200 kW & 77 & 28 & 24 & n.a. & {$[8]$} \\
Stirling Engine 5-35 kW & - & $15-30$ & $14-18$ & 1,100 & {$[13,14]$} \\
Diesel CHP Engine 200 kW & 84 & 38 & 34 & & {$[11]$} \\
*) Gasifier plus genset & & & & & \\
\hline
\end{tabular}

The environmental impact of bio energy requires an extensive analysis of all emissions in the production chain and in the provision of auxiliary energy and materials. A first order estimate may be gained from comparing the saving in carbon dioxide emissions from the substituted technology. Based on the figures in Table 4 a one-to-one substitution is assumed and the results are given in Table 5. Clearly, the most efficient saving is in replacing brown coal in a steam-electric unit, due both to the efficiency of the thermal cycle and the high carbon intensity of brown coal. The smallest savings arise from substituting natural gas.

Table 5.: Substitution potential for selected biomass applications [Hansen 2002].

\begin{tabular}{|l|c|c|}
\hline Energy carrier substituted & $\begin{array}{c}\text { 1 GJ biomass } \\
\text { substitutes }\end{array}$ & $\begin{array}{c}\mathbf{C O}_{2} \text { saving } \\
\text { in } \mathbf{~ k g}\end{array}$ \\
\hline Brown coal by co-firing in power plant & $1.0 \mathrm{GJ}$ & 112 \\
Diesel fuel by rape seed oil in engine & $0.8 \mathrm{GJ}$ & 62 \\
Natural gas by gasification in engine & $0,7 \mathrm{GJ}$ & 40 \\
\hline
\end{tabular}

\section{The grand vision}

It might be enlightening to expand today's pedestrian projects to a larger and grander vision in which the chemical elements in the hydrocarbon molecules of biomass are separated and reformed to yield new tailored fuels and form the basis for a new world energy economy [Wolf, 2002]. In a similar vision, once propagated by Häfele [1990], all fossil energy carriers were transformed to hydrogen and carbon dioxide. With biomass, carbon must not necessarily be removed from the cycle as it is recaptured in the photosynthesis process to form new biomass. With coal, crude oil and natural gas, however, the $\mathrm{CO}_{2}$ must be separated and permanently stored in order to approach a sustainable carbon balance in the atmosphere.

The basic processes of the vision are well known and already in place. Thermal gasification is the first step. Synthesis gas consisting of $\mathrm{CO}$ and $\mathrm{H}_{2}$ are further treated to yield hydrogen for fuel cells. Carbon monoxide is either reduced to carbon or oxidized to $\mathrm{CO}_{2}$. Further treatment to methanol and other chemical compounds with a $\mathrm{CH}_{2}$ structure form the basis for a new hydrocarbon economy. The fuel cell is not 
the only target for new fuels. Efforts are on foot to produce a synthetic fuel based on biomass which would be indistinguishable from normal diesel and gasoline. The name "Sunfuel" brings back memories of "Synfuel" based on coal in the 1970ies. Both routes involve extensive physical and chemical processing.

The vision of a new energy system based on fresh and fossilized biomass to be engineered into an environmentally friendly and sustainable fuel is a conceivable technical reality. The economic viability stands to be answered. It would involve a new logistic system and an overall management of material flows. Even if the vision fills the horizon a more immediate and robust bio energy system will contain a wide variety of technologies and move in incremental steps.

\section{Conclusions}

Biomass as an energy resource is as versatile as the bio diversity would expect and features a number of technologies. It also displays a positive environmental balance although it would be exaggerated to maintain it is neutral with respect to the carbon cycle as it needs external energy inputs. The potentials, technologies and markets can be summarized as follows:

- Biomass is a readily available but limited resource and would at most contribute in the order of 3 billion ton of oil equivalent to the world's energy supply. One third of the potential is energy forests and energy plantations which at present are not economic. One third is already used in rural areas as traditional fuel. The remaining third would be available for modern biomass energy conversion. Favourable economic conditions are mostly found locally and in combination with waste and residues.

- From an energy and environmental point of view, the most efficient applications are those where one unit of energy from biomass directly substitutes one unit from a fossil fuel. The immediate market is residential heating. A number of new boilers have been developed which allow an efficient and convenient utilization of biomass as wood chips or pellets. The commercialisation need to be supported by a comprehensive logistics and service system. Similarly, co-firing in large high efficient coal stations is the most promising route to electricity. In the medium term perspective indirect firing with Stirling engines and hot air turbine could become of interest.

- Biomass in the original solid form is not well suited for modern energy conversion technologies and requires upgrading to a liquid or gaseous fuel. Even so, the combustion engines and turbines need to be adapted to the bio fuel specifications. Biogas from fermentation of bioorganic residues is close to commercialisation and besides being an energy resource constitutes an important link in closing the waste management loop in the agricultural industry. Thermal gasification has been successfully demonstrated only in large units whereas in the small scale it is not yet technically mature and commercial. All indirect substitutions involve conversion losses and are less efficient in saving $\mathrm{CO}_{2}$.

- In order to establish biomass in the market technical and political efforts are necessary. A case in point is gasification, where after almost a century of efforts it would seem mandatory to evaluate the multitude of designs and undertake a systematic development to an industrial product.

- The economic viability is a decisive criterion if biomass in the long run is to justify more than a niche role. The present system of subsidizing bio energy in the most hotly competing markets, viz. motor fuels and electricity, is less efficient than in the heat market. One Euro of public money buys more $\mathrm{CO}_{2}$ in residential heating than in a small decentralised electric station.

- Biomass is not yet the big leap forward with one sweeping technology but a strategy of small steps with many technological approaches. A long term perspective of biomass as a chemical resource of carbon and hydrogen to be deliberately separated or synthesized and tailored to "sunfuels" for modern engines and fuel cells is still only the foreshadow of a grand vision. 


\section{References}

1. Mohr, H.(2000) "Energie aus Biomasse - eine oftmals überschätzte Ressource", VDI nachrichten, 18. August 2000

2. IEA ,World Energy Outlook 2002”, OECD/IEA Paris, 2002

3. Kaltschmitt, M. and Hartmann, H. (Eds.) „Energie aus Biomasse- Grundlagen, Techniken und Verfahren“, Springer-Verlag Berlin Heidelberg, 2001

4. Jungmeier, G., Golja, F., Spitzer, J. „Der technologische Fortschritt bei Holzfeuerungen - Ergebnisse einer statistischen Analyse der Prüfstandsmessungen der BLT Wieselburg von 1980-1998, JOANNEUM RESEARCH - Institut für Energieforschung, Bericht-Nr. IEF-B-01/99, Graz 1999

5. BIZ „Pellet-Zentralheizungen Marktübersicht“, Biomasse Info-Zentrum, Universität Stuttgart, 2002

6. Uth, J. ,Scheitelholzvergaserkessel, Scheitholz-Pellet-Kombinationskessel“, FNR, Gülzow, 2001

7. Gailfuß, M. (2001) „Strom aus Holz“, Sonne, Wind \& Wärme, 7 / 2001

8. Hansen, U., R. Strenziok and P. Wickboldt (1999) "Einsatz von Pyrolyseöl als regenerativer Energieträger zur dezentralen Versorgung mit Strom und Wärme“", 5. Int. Fachtagung, Freiberg

9. Ising, M. (2000) „Vergasung fester Biomasse - bereits Stand der Technik“ in Energetische Nutzung von Biomasse durch Kraft-Wärme-Kopplung, FNR, Gülzow 2000

10. Heinrich, P. (2001) „KWK aus festen Biomassen - Entwicklungsstand, Aktivitäten und deren Bewertung“, IE-Tagung „Biomasse in KWK-Anlagen“, Leipzig 2001

11. ASUE (Hrsg.) (2001) „BHKW-Kenndaten 2001“, Verlag Rationelle Erdgasnutzg, Kaiserslauten

12. Spilling „Standardisiertes Biomasse-Kleinkraftwerk“, Spillingwerke AG, www.spilling.de

13. ASUE (Hrsg.) (2002) „Mikro-KWK“, Verlag Rationelle Erdgasnutzg, Kaiserslauten

14. Gailfuß, M. (2001) Sterlingmotoren- eine alternative KWK-Technologie?“, Sonne, Wind \&Wärme, $5 / 2001$

15. Ott, M. (1997) „Biomassemitverbrennung in Heizkraftwerken - eine Möglichkeit der effizienten $\mathrm{CO}_{2}$-Minderung", Elektrizitätswirtschaft Jg. 96 (1997), Heft 24

16. Stahl, K., Neergaard, M. and J. Nieminen, (2000) "Värnamo Demonstration Programme - Final Report", 1. World Conference on Biomass for Energy and Industry, Sevilla, 5-9 June 2000

17. Hansen, U. (2002) “ Biomass; Going up in Smoke?", $25^{\text {th }}$ Annual IAEE International Conference, Aberdeen, 2002

18. Teisler, B. "Wood-Chips Gasifier Combined Heat and Power", VDI-Berichte 1670, Conference Leverkusen 2002.

19. Häfele, W. "Energiesysteme im Übergang", Jülich, 1990

20. Wolf, B. "Wasserstoff aus Biomasse", BWK Bd. 54 (2002) Nr. 12

21. Noppenau, H. „Concept and First Operating Experience with Avedöre 2“, VGB Power Tech 5/2003 


\title{
Technologies for small scale Biomass CHP-Plants - an actual survey
}

\author{
Dr.-Ing. J. Fischer \\ Biomass Information Centre/ \\ Institute for Energy Economics and Rational Use of Energy, IER, University of Stuttgart \\ Hessbrühlstr. 49A., D-70565 Stuttgart, Germany \\ Tel.: ++49-711/7813909, Fax: ++49-711/7806177 \\ e-mail: jf@,biomasse-info.net, Internet: http://www.biomasse-info.net
}

\section{Introduction}

With respect to an increasing energy demand world-wide, concerns about a sustainable energy supply is risen not only in industrial countries but as well in developing countries. Environmental impacts like the well discussed climate change show the drawbacks of a energy system relying mainly on fossil fuels. Political instabilities like the actual situation in the Persian gulf show how vulnerable these energy systems may become.

Therefore big emphasis is set on an accelerated expansion of renewable energies making use of the natural resources of each individual country.

In Europe, political programs of the European community as well as of each member state pay increasing attention to the reinforced expansion of renewable energies in the EU.

According to the white book of the European commission as a basis for the future energy policy, the contribution of renewable energies should be doubled until 2010 on an EU-wide average. In this context, bioenergy must be regarded as the key when it comes to fulfil these ambitious political program, as its share must be tripled in the mean time. Moreover, the European community intends to increase the electricity generation from biomass by a factor of 10 until 2010 compared to the 1995 level.

\section{The role of bioenergy in the European energy market}

If the future contribution of bioenergy should be assessed, first, a closer look at the actual structure of the energy market becomes necessary.

In 2001, total energy consumption in the 15 EU member states (EU-15) summed up to approximately 63.9 EJ.

As Fig.1 illustrates, about 49.9 EJ have been covered by fossil fuels. Nuclear power added some 8.4 EJ, additionally. Renewable energies are still of minor importance. Hydropower and wind energy as the most relevant renewable sources added approx. 3.5 EJ to the primary energy demand. The contribution of bioenergy was about $1.8 \mathrm{EJ}$. 


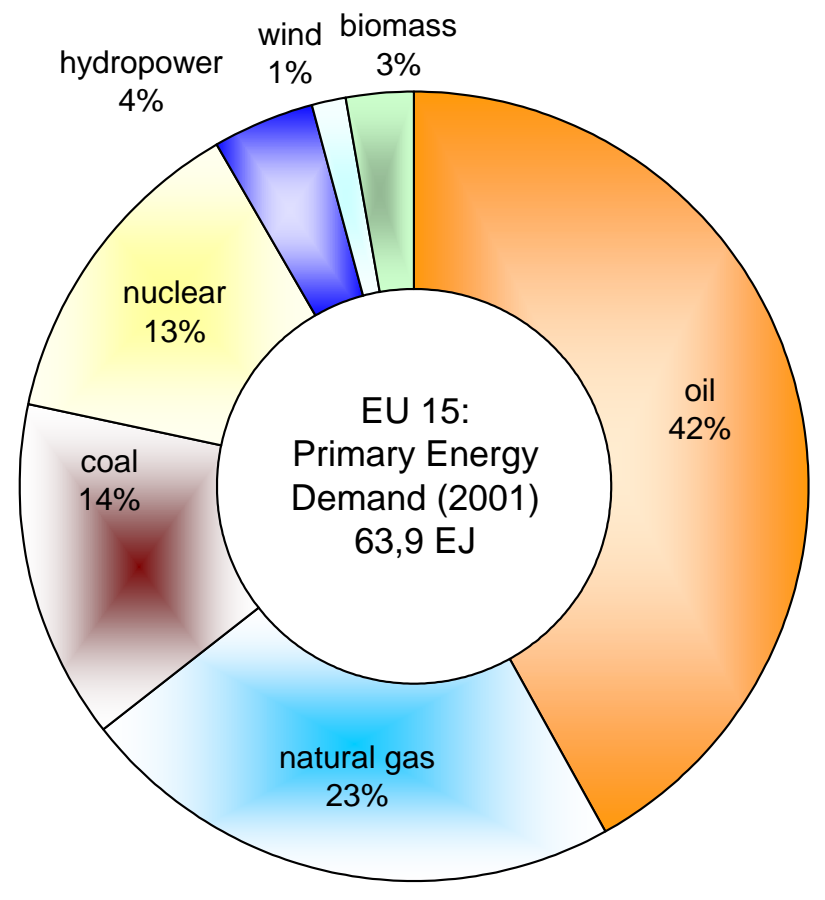

Figure 1. Primary energy demand and energy sources in EU-15 in 2001, Source: BP, EU Commission $/ 1 /, / 2 /$

These figures do not reflect the enormous contribution bioenergy may have in the future, as an increased use of bioenergy is not primarily obstructed by a lack of resources. However, according to different natural resources and demographic constraints, the possible contribution of bioenergy to the national primary energy demand is unevenly distributed in the single member states, as Fig, 2 illustrates. Here the maximal contribution of bioenergy is given in percents of the actual primary energy consumption. On an average level of the EU-15, bioenergy may cover almost $10 \%$ of the actual primary energy demand as actually of the $5.225 \mathrm{PJ} / \mathrm{a}$ available only $1.750 \mathrm{PJ} / \mathrm{a}$ are being used, which means that the full potential of bioenergy in the EU is only tapped to less than $34 \%$. 


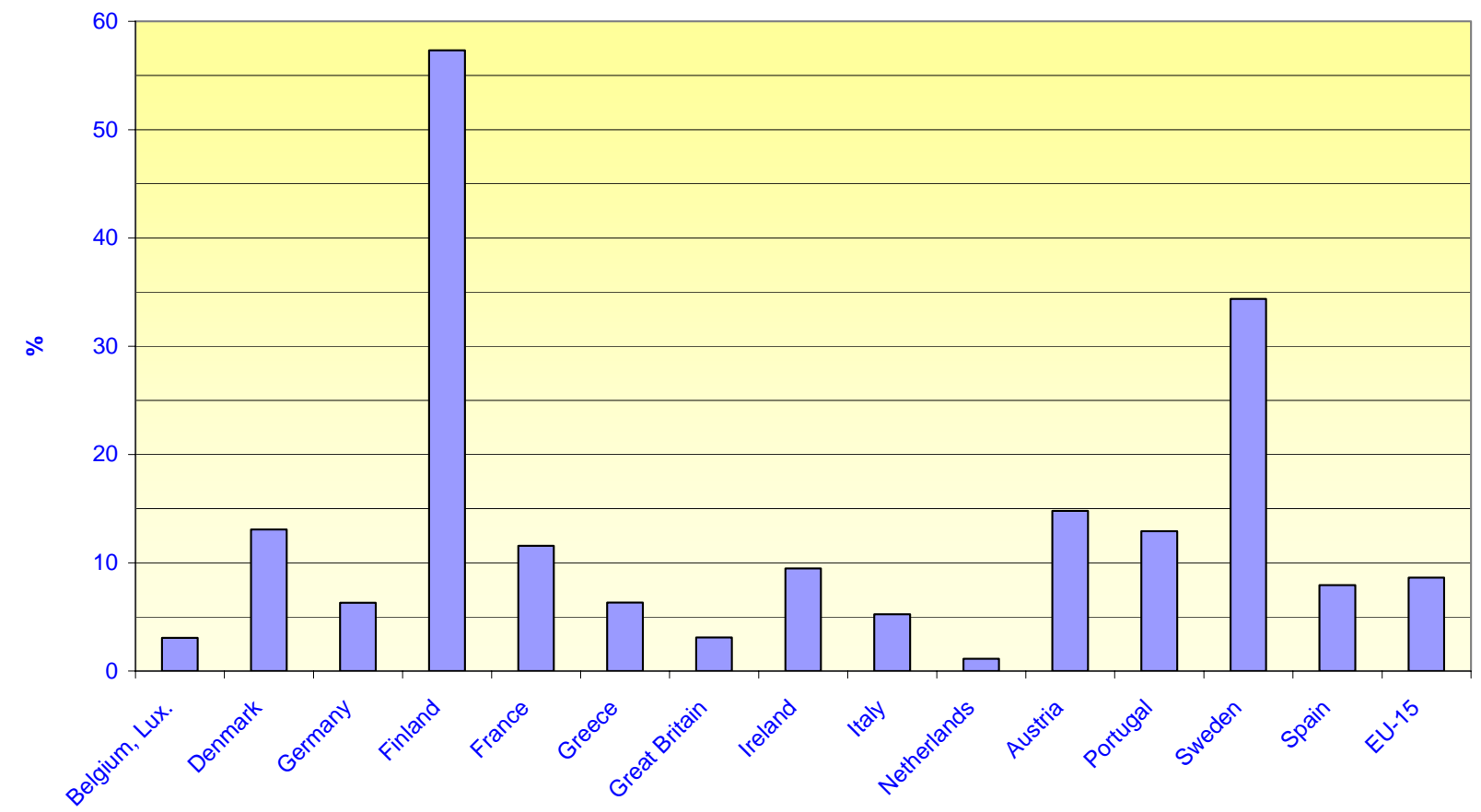

Figure 2. Maximum contribution of bioenergy to the national primary energy demand, based on data from $2001 / 3 /$

\section{Electricy from Biomass - a technological ap- proach}

Today, biomass is mainly used for heat production, mostly in small applications. According to the prospected increase in demand for electricity, co-generation based upon biomass seems to be a very interesting option for the near future.

However, if biomass should be applied successfully in the electricity sector, some specific characteristics of biomass must be taken into account. Biomass is a dispersed form of energy. It originates from various sources in forestry and agriculture, from industry and private households. Due to its lower energy content - compared to fossil fuels, its higher water content and its low bulk density, biomass is a typical local energy source as long distance transports become uneconomic. So today biomass is usually applied in small scale, decentralised plants. In contrast to traditional fuels for electricity generation, co-generation using biofuels will also mainly take place in small scale applications, Fig. 3. 


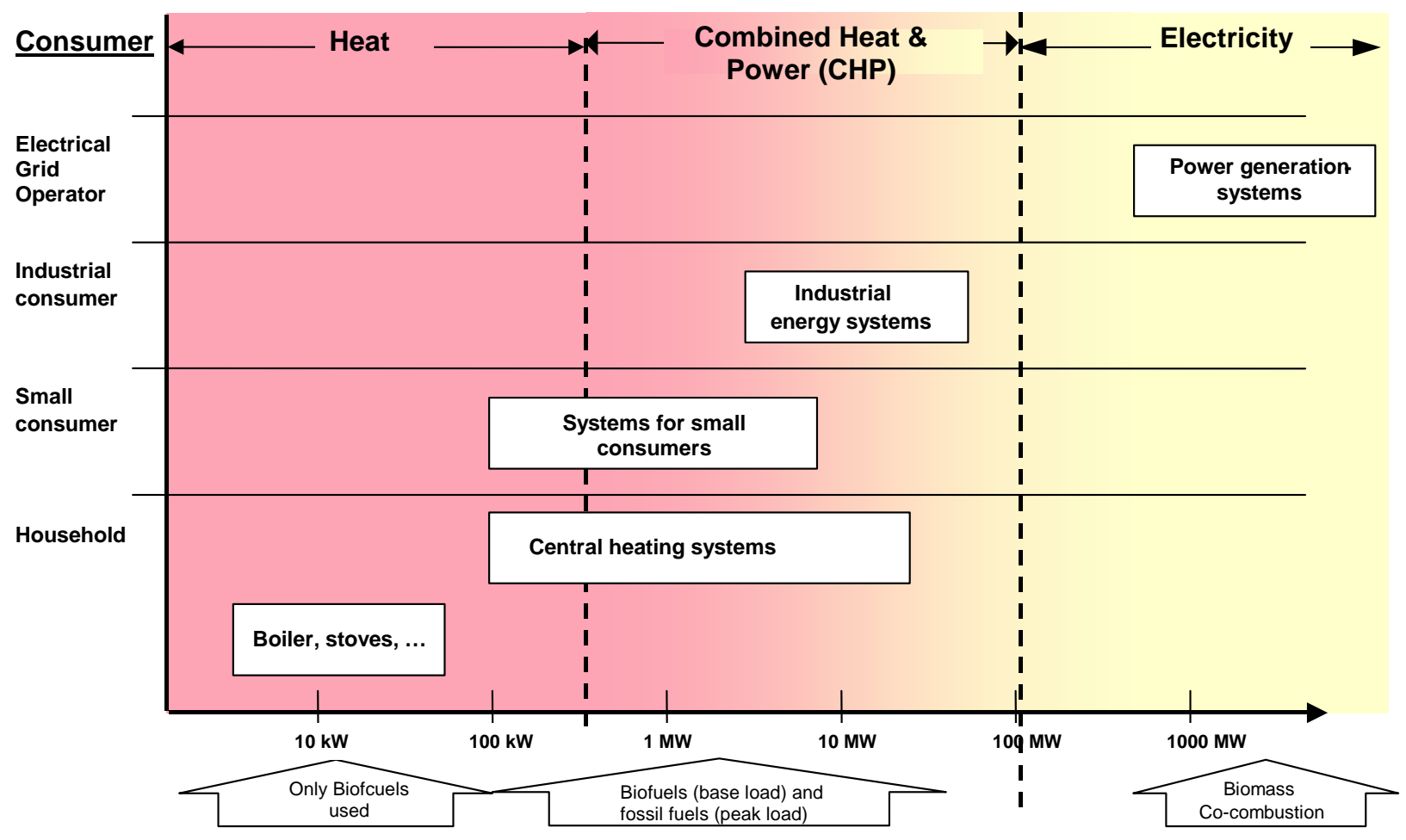

Figure 3. Application of biomass as an energy source, based on /4/

Fig. 3 illustrates the typical range of thermal capacities in which cogeneration is from a today's point of view technically feasible and economically reasonable. So co-generation from biomass can take place in a range of 0.5 to about $1200 \mathrm{MW}$ thermal capacity. In a higher range, co firing will become an option.

According to the different sources of biomass, solid, liquid and gaseous biofuels exist, each of these with very different properties. So concepts for biomass cogeneration have to take the whole chain of biomass production, pre-processing and conversion into account. As a consequence, quite a lot of different options of using bioenergy carriers exist, as Fig. 4 implies. 


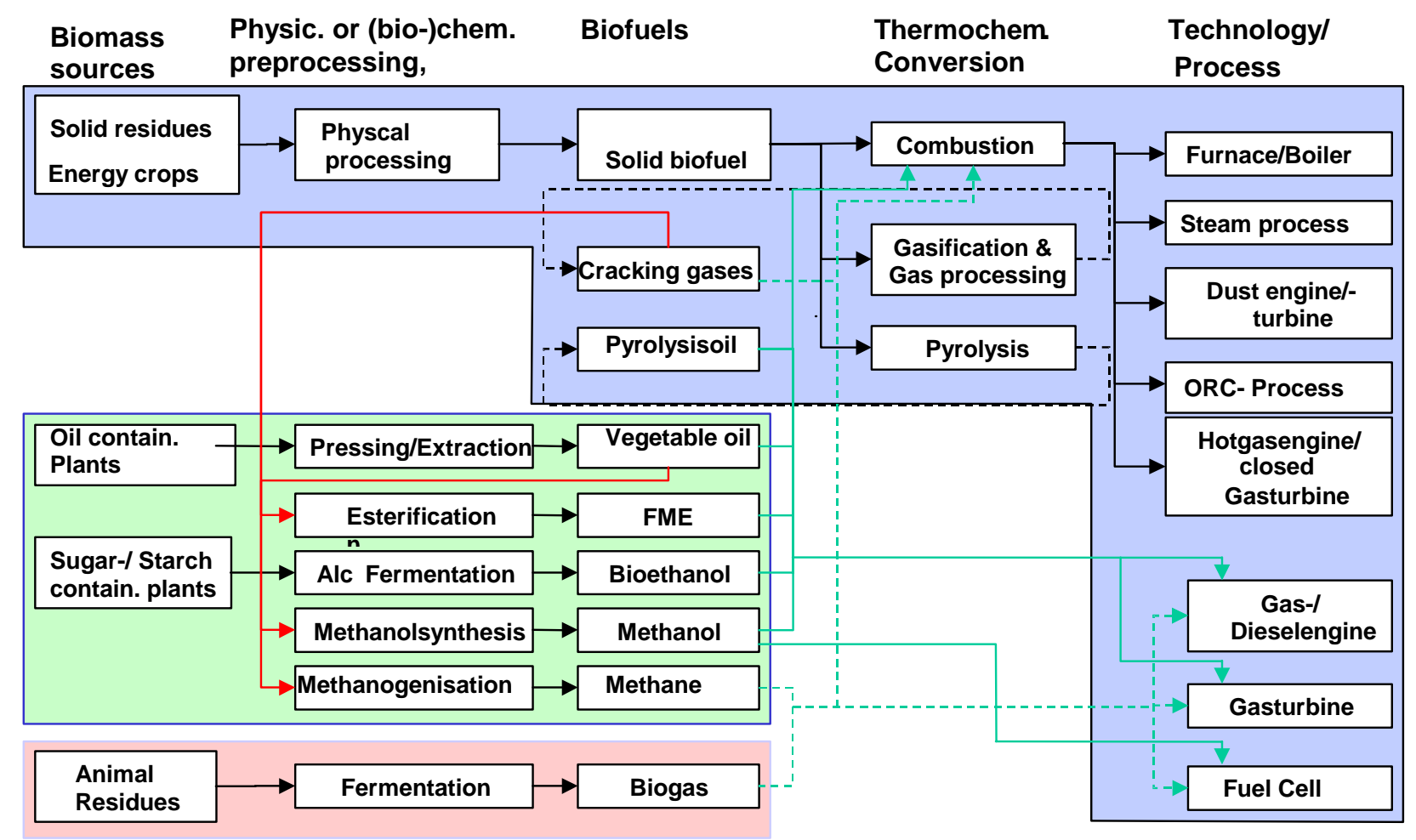

Figure 4. Sources of bioenergy and related technologies for heat and power generation /5/

Obviously, co-generation based upon biofuels can be performed by very different means.

Due to physical and technical constraints none of these technologies can be regarded as suited for all purposes. Fig. 5 summarizes the characteristics of the most important technologies, their power ranges and the electrical efficiencies that can be achieved by today's standards.

\begin{tabular}{|c|c|c|c|}
\hline & Technology & $\begin{array}{l}\text { Power } \\
\text { range, } \\
\left(\mathrm{MW}_{\mathrm{el}}\right)\end{array}$ & $\begin{array}{r}\text { Electr. } \\
\text { efficiency } \\
(\%)\end{array}$ \\
\hline \multirow{5}{*}{$\begin{array}{l}\text { Solid } \\
\text { Biofuels }\end{array}$} & Steam turbine & $0,5->20$ & $12-30$ \\
\hline & Steam engine & $0,2-1,5$ & $10-20$ \\
\hline & Steam screw engine & $0,1-2,5$ & $10-20$ \\
\hline & Stirling engine & $0,01-0,15$ & $8-22$ \\
\hline & ORC - Process & $0,1-3$ & $10-15$ \\
\hline \multirow{4}{*}{$\begin{array}{l}\text { Liqiud } \\
\text { IGasoeus } \\
\text { Biofuels }\end{array}$} & Gas turbine & $>10$ & ca. 25 \\
\hline & Microgas turbine & $0,05-1$ & ca. 20 \\
\hline & Gas engine & $0,05-5$ & ca. 25 \\
\hline & Fuel cell & $0,05-5$ & ca. 30 \\
\hline
\end{tabular}

Figure 5. Characteristic parameters of important power generation technologies 
At a first glance, this broad variety of different options seems to be very promising as it implies that for different power ranges appropriate technologies exist making electricity generation from biomass a profitable option.

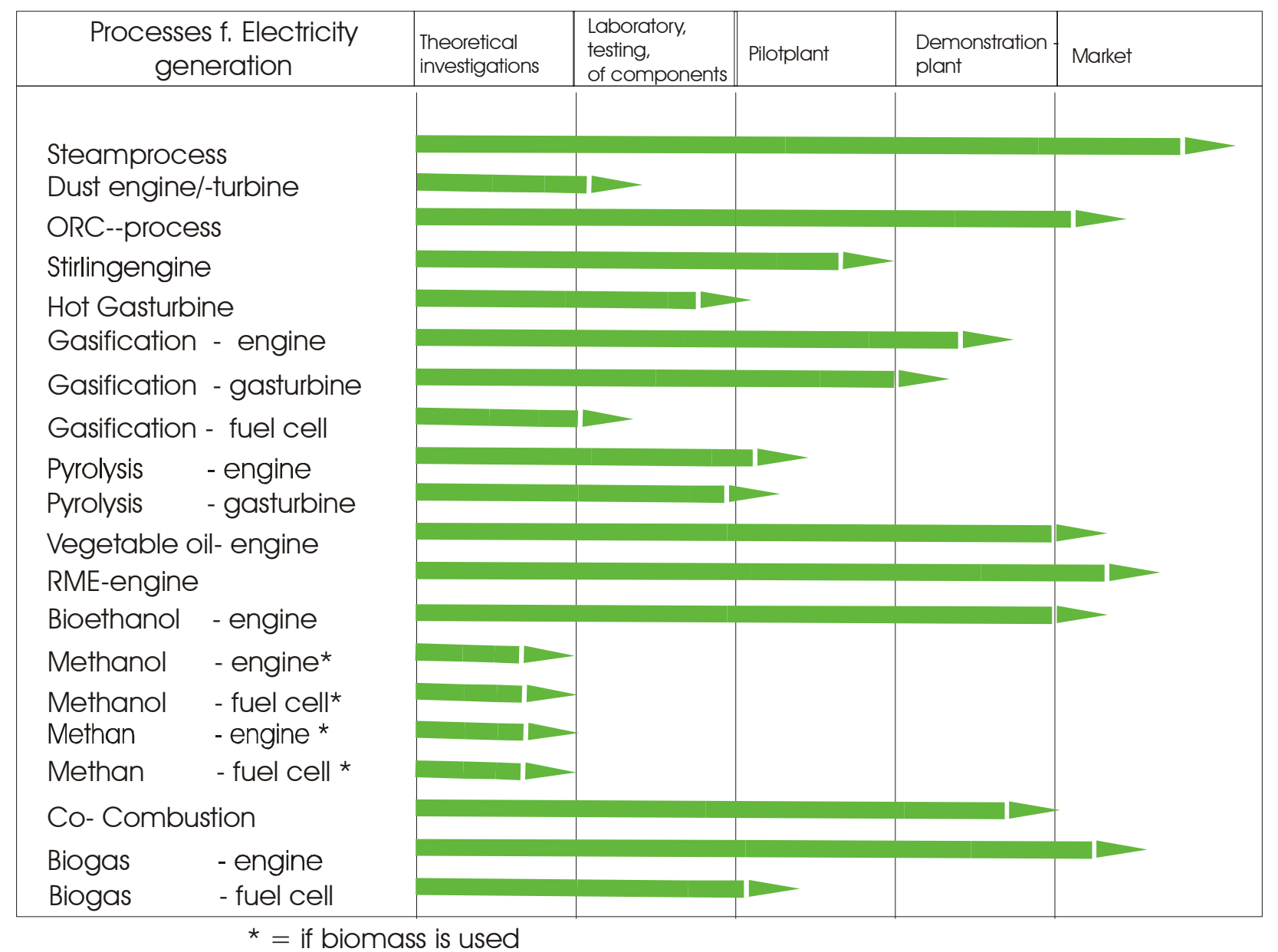

Figure 6. State of development of different biomass CHP technologies, based upon /5/, modified

However, reality looks different. As Fig. 6 shows, only a few technologies can be regarded as ready for the market:

$>$ technologies based upon the steam process as steam turbines and steam engines

$>$ the ORC-process based upon a low temperature Rankine cycle

$>$ internal combustion engines using liquid or gaseous biofuels.

However, the application of these technologies in small scale biomass CHP-plants does not go without problems:

$>$ internal combustion engines, although offering relatively high electrical efficiencies in the range of 25 $-30 \%$, demand for high quality fuels. Increasing environmental standards in the EU demand for a constant technological improvement if these engines with respect to reduced emissions. Thus, highly sophisticated engines have been developed which demand for appropriate high quality fuels fuel. Experiences with applications running on biogas or liquid biofuels show, however, that these quality standards often cannot be achieved. So frequent failures of these systems occur.

$>$ Steam turbines can be regarded as standard equipment in electricity generation. 


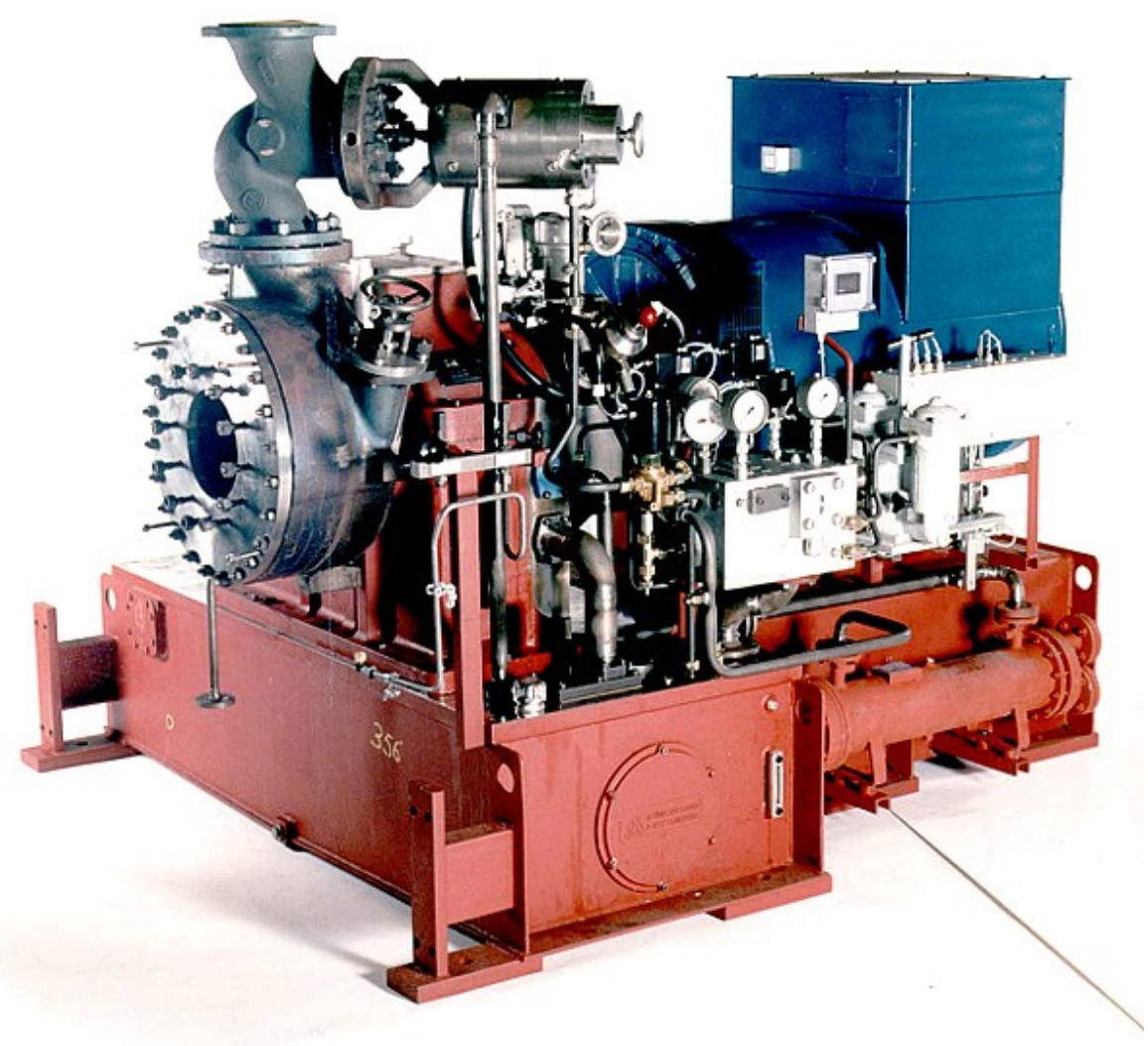

Figure 7. Small Steam turbine for application in palm oil industry; picture courtesy of KKK AG

However these systems have been improved in the last decades mainly for large scale applications in fossil fired power plants. In the power range from $5 \mathrm{MW}_{\mathrm{el}}$ to more than $800 \mathrm{MW}_{\mathrm{el}}$, high efficient condensation turbines can be applied. As the efficiency of a steam turbine depends on the inlet pressure and temperature, higher pressure parameters lead to higher electrical efficiencies. However, due to the chlorine content in biofuels, temperatures are limited. In a modern $20 \mathrm{MW}_{\mathrm{el}}$ biomass power plant, electrical efficiencies of 30 to $33 \%$ can be obtained. Smaller steam turbines in a power range between $0.5 \mathrm{MW}_{\mathrm{el}}$ and 5 $\mathrm{MW}_{\mathrm{el}}$ are usually operated as back-pressure units. As small biomass plants make use of fire tube boilers, the pressures available is limited to $20-30$ bar. So only simple single stage turbines may be used, reducing the electrical efficiency to $8-12 \%$. Additionally, steam turbines are highly sensitive to economies of scale. So a small steam turbine causes relatively high specific investment costs. Therefore, in may cases, the combined heat and power generation using a small steam turbine with an electrical output below 1 MW becomes uneconomical. Table 1 summarizes the main advantages and disadvantages of steam turbines $/ 6 /$. 
Table 1. Advantages and Disadvantages of steam turbines /6/.

\begin{tabular}{|l|l|}
\hline Advantages & Disadvantages \\
\hline$>$ Mature, proven technology & $>\begin{array}{l}\text { Small steam turbines }<1 \mathrm{MW}_{\mathrm{el}} \text { offer only lim- } \\
\text { ited efficiencies }\end{array}$ \\
\hline$>$ Broad power range available & $>$ Low efficiency at partial load \\
\hline$>\begin{array}{l}\text { For large installations: high efficiencies can be } \\
\text { obtained by high steam temperatures and pres- } \\
\text { sures }\end{array}$ & $>\begin{array}{l}\text { High specific investment costs for small tur- } \\
\text { bines }\end{array}$ \\
\hline $\begin{array}{l}\text { Separation between combustion and power gen- } \\
\text { eration enables the use of ash containing fuels }\end{array}$ & $>\begin{array}{l}\text { For biomass application: limited super heater } \\
\text { temperature because of risk of high tempera- } \\
\text { ture corrosion }\end{array}$ \\
\hline & $>$ High quality steam is necessary \\
\hline
\end{tabular}

> Steam engines can fill up the gap towards small scale biomass CHP. Due to their modular structure they are able to cover a power range from 100 to $1.500 \mathrm{~kW}$ electrical capacity. As major advantage compared to steam turbines, steam engines can be operated with low pressure saturated steam, which reduces the investment in an appropriate steam boiler, although, however, the electrical efficiency of the steam engine is also reduced in this case. Another important feature for a biomass CHP application is that steam engines are better suited for part load operation than a steam turbine. As a steam engine reaches up to $90 \%$ of its maximum efficiency in a range between 50 and $100 \%$ of the nominal power, these units are also suitable for varying heat and electrical loads. The development of an oil free steam engine also solves the problem of oil contained in the expanded steam $/ 7 /$. Nevertheless, the technology is expensive and demands for skilled personnel. Additionally, problems related to steam engines are reported quite frequently so constant development and improvement seems necessary.

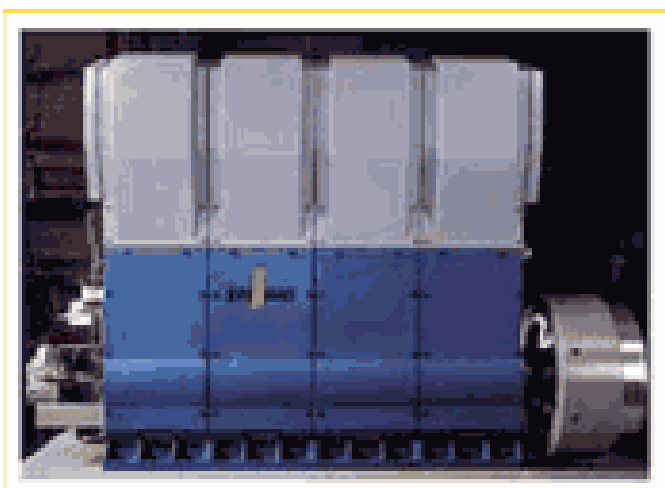

Figure 8. 4-cylinder steam engine, Picture courtesy of Spilling Werke GmbH 
Table 2 shows advantages and disadvantages of steam engines.

Table 2. Advantages and Disadvantages of steam engines /6//8/.

\begin{tabular}{|l|l|}
\hline Advantages & Disadvantages \\
\hline$>$ Suitable for lower power ranges & $>\begin{array}{l}\text { Maximum power output per steam engine is } \\
\text { limited to about } 1.2 \mathrm{MW} \text { el }\end{array}$ \\
\hline$>$ Saturated steam can be used & $>$ High maintenance costs \\
\hline$>$ Very good performance at partial load & $>\begin{array}{l}\text { Electrical efficiency is limited due to low } \\
\text { steam pressures }(<25 \text { bar })\end{array}$ \\
\hline$>\begin{array}{l}\text { Steam extraction at various pressures possible due } \\
\text { to modularity }\end{array}$ & $>$ Heavy vibration and noise production \\
\hline$>\begin{array}{l}\text { Oil free construction avoids steam contamination } \\
\text { and oil separation from steam cycle }\end{array}$ & \\
\hline
\end{tabular}

The ORC-process entered the market for bioenergy CHP recently. Commonly used in other applications, like geothermal energy, its dissemination in the bioenergy sector started with a few demonstration plants in Italy, Switzerland and Austria. Performance of these systems was very encouraging, so that new projects are under realization in Austria and Germany. The technology makes use of an organic oil with a low boiling point instead of water. So ORC plants can be operated at low process temperatures between 70 and $300{ }^{\circ} \mathrm{C}$. As no steam boiler is needed in biomass applications, the investment and maintenance costs are reduced significantly. Similar to steam engines, an ORC plant can be operated in part load between 30 an $100 \%$ of the full load without a significant drop in the electrical efficiency. In a biomass CHP plant, operated with oil temperatures of $300{ }^{\circ} \mathrm{C}$, the electrical efficiency is up to $13 \%$. If a two stage turbine is used, it can be lifted to about $17 \% / 6 /$. The main advantages and disadvantages of the ORC process are summarized in Table 3. /8/

Table 3. Advantages and disadvantages of the ORC-process /8/.

\begin{tabular}{|l|l|}
\hline$>$ Advantages & $>$ Disadvantages \\
\hline$>$ Robust technology & $>$ Relatively high specific investment costs \\
\hline$>\begin{array}{l}\text { Very good controllability and high degree of } \\
\text { automation }\end{array}$ & $>\begin{array}{l}\text { Long term experiences using biomass still } \\
\text { missing }\end{array}$ \\
\hline$>$ Low maintenance required & $>$ Organic thermal oil is inflammable and toxic \\
\hline$>$ Very good performance at partial< load & $>\begin{array}{l}\text { Due to low pressures ( } 10-20 \text { bar) only limited } \\
\text { electrical efficiency temperature corrosion }\end{array}$ \\
\hline $\begin{array}{l}\text { Low temperature waste heat can be used for } \\
\text { power generation }\end{array}$ & $>$ High quality steam is necessary \\
\hline
\end{tabular}

All other technologies mentioned in Fig. 6 must still be regarded as in the stage of research and development.

An interesting option for small scale electricity generation is the Stirling engine. Here, constant research work is performed in Denmark, UK, Austria and Germany.

In Denmark, by example, Stirling engines are operated in combination with a wood boiler. A prototype 4 cylinder Stirling engine with a power output of $30 \mathrm{~kW}_{\mathrm{el}}$ and operated at 4 bar and $620^{\circ} \mathrm{C}$ achieved an electrical efficiency of $18 \%$, with the total efficiency of the CHP process of $87 \%$. Current development are directed at a larger Stirling unit with $150 \mathrm{~kW}_{\text {el }}$ output and improved electrical efficiency of up to $28 \%$. $19 /$ 
Table 4. Advantages and disadvantages of Stirling engines /8/.

\begin{tabular}{|l|l|}
\hline$>$ Advantages & $>$ Disadvantages \\
\hline$>\begin{array}{l}\text { Engine operates independently of type of heat } \\
\text { source }\end{array}$ & $\begin{array}{l}\text { If solid biomass is used, relatively low electri- } \\
\text { cal efficiencies are achieved because of low } \\
\text { flue gas temperatures }\left(<1000{ }^{\circ} \mathrm{C} \text {, ash melting }\right. \\
\text { point })\end{array}$ \\
\hline$>$ Low quality demand with respect to fuel & $>\begin{array}{l}\text { Until today: no reliable solution for sealing } \\
\text { problems, mainly if Helium is used as working } \\
\text { medium }\end{array}$ \\
\hline$>\begin{array}{l}\text { Low maintenance demand because of few mov- } \\
\text { ing parts and "external combustion" }\end{array}$ & $>$ High specific investment costs \\
\hline$>\begin{array}{l}\text { If gaseous fuels, like biogas, are used, forma- } \\
\text { tion of emissions like CO and CH can be } \\
\text { avoided due to external combustion of the gas }\end{array}$ & $>\begin{array}{l}\text { Heat exchanger is exposed to extreme wear } \\
\text { because of high temperature strain }\end{array}$ \\
\hline & $>\begin{array}{l}\text { Risk of high temperature corrosion in ash con- } \\
\text { taining flue gases }\end{array}$ \\
\hline
\end{tabular}

Still lacking is an appropriate technology offering electrical efficiencies in the range of more than $25 \%$ making electricity generation a profitable option for decentralised bioenergy plants. Gasification is since more than decade regarded as a very interesting option for this specific problem. However, disregarding numerous developments of different types of gasifiers this technology still demands for further research work. The production of a high quality synthesis gas free of tar which may be used without problem in a turbine or an internal combustion engine imposes much more problems than expected. Fortunately, some technologies have now reached a high standard so that it seems possible that some companies may offer appropriate, reliable technologies on the market within the next 5 years, Fig. 9.

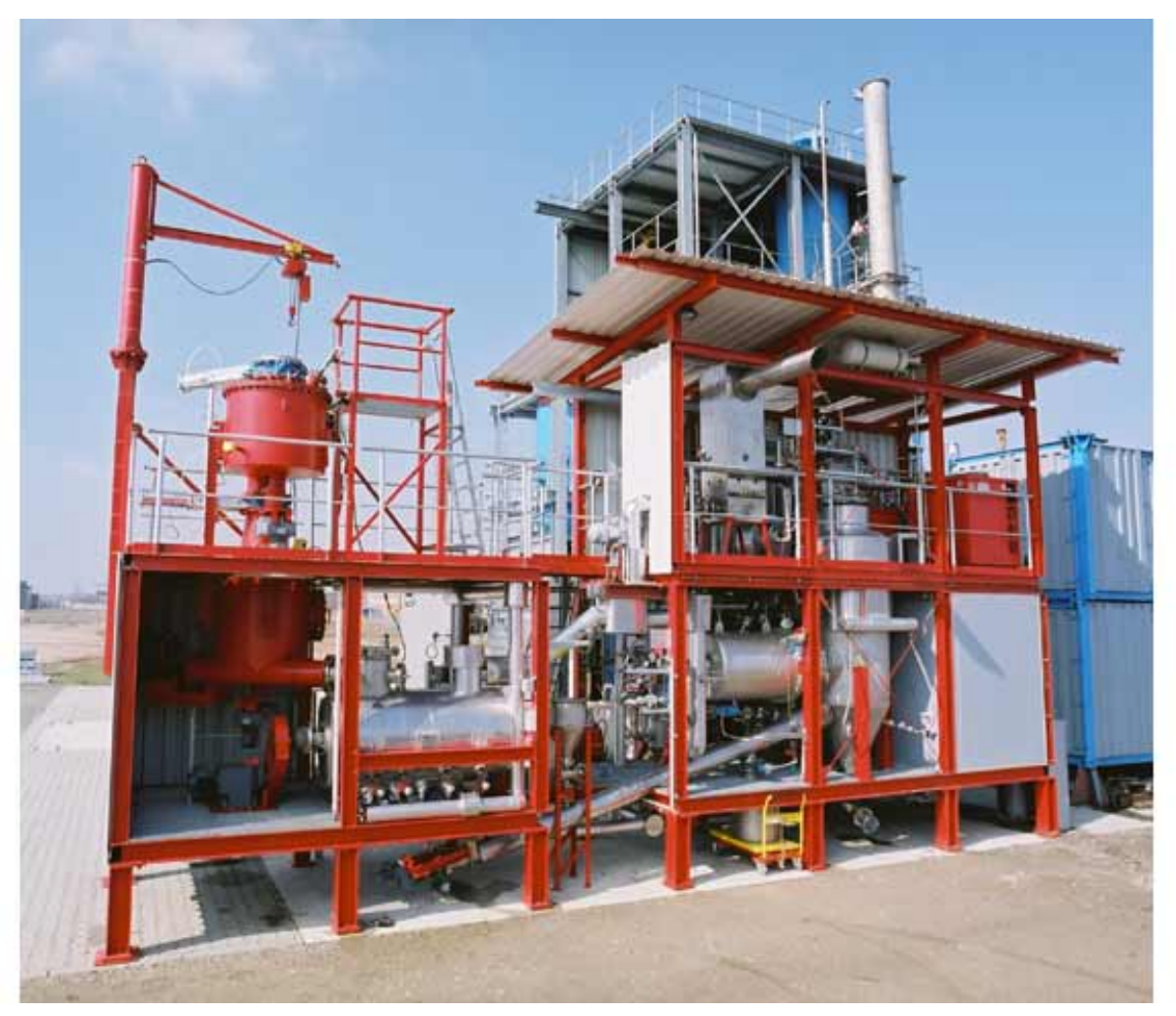

Figure 9. Small scale Gasifier Carbo compact, 150 kWel, Picture courtesy of Technischer Apparatebau Freiberg 
However, due to the considerable costs of these systems, their application may be restricted in the beginning to the use of waste material and to the upper power range of approximately $5 \mathrm{MW}$ electrical capacity.

Once the production of a clean, energy rich synthesis gas will become possible out of various biomass resources, further applications may become feasible, like the use of micro-gas turbines or fuel cells. Although the latter application based on solid biofuels has to be regarded as a long term option, the operation of fuel cells on biogas was already performed successfully /10/. Due to the high costs of either the fuel cells themselves and the necessary equipment for biogas pre-processing, this technology as well must be regarded as being in the stage of development.

\section{Economical Aspects of Biomass CHP}

In Fig. 10 typical values of specific investment costs for different biomass CHP technologies are given. These values are based upon different recent publications $/ 4,6,8,11 /$

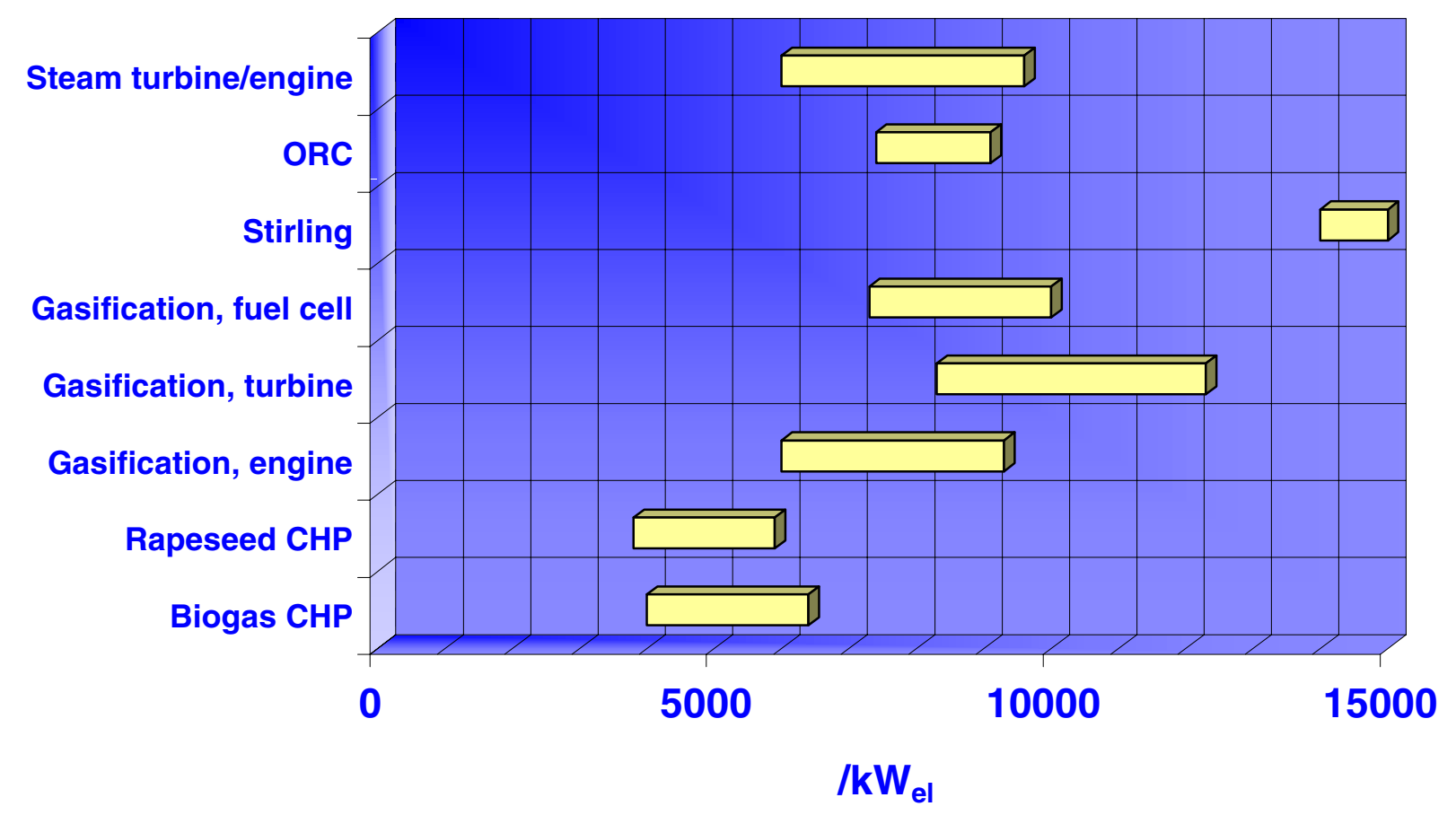

Figure 10. Specific investment costs for different biomass CHP technologies /4,6,8,11/

The lower end of the bandwidth given in Fig 10 represents larger plants with thermal capacities of 10 MW or more, the upper limit represents small scale applications below $1 \mathrm{MW}$ thermal capacity. The specific values include all costs related to an operational plant. Included are as well additional costs for planning, licensing etc. In the case of biogas plants, the costs of the fermenter are included, too.

As part of these costs are very specific to local markets, Fig. 10 can only give a rough survey on the economies of biomass CHP plants. However, it becomes evident that strong differences in specific costs exist among various technologies. This is due to several facts. Firstly, as mentioned before, only some technologies are available on the market. For those in the stage of development, reliable data on costs are not available and assumptions are based on the first pilot plants, only. Secondly, the electrical efficiency 
of the technologies vary broadly. Costly technologies with low electrical efficiency, like the ORC process lead to relatively high specific costs.

Furthermore it must be pointed out that the total economy of a biomass CHP plant is not only determined by investment costs. Fuel costs are at least as important as investment costs. Differences among various sources of biomass can be significant. So a cheaper technology which relies on a high quality fuel (by example rape seed oil used in a combustion engine) may at the end of the day not produce an economical sound result. Careful planning of both electricity and heat demand as well as a secure fuel supply at reliable costs are the key elements for a successful operation of a biomass CHP plant.

\section{Conclusions}

So it becomes obvious that there is in fact a huge demand for appropriate technologies for small scale cogeneration using biomass. Due to the increased political and public intrest in bioenergy the demand for theses systems is actually higher than what is offered on the market. It must be stated that during the last decades, due to a very limited interest in bioenergy, research and development as well as demonstration and testing only took place at a low speed, also due to a lack of money and funding.

Table 5. Current research activities related to biomass CHP technologies, based upon /4/, updated.

\begin{tabular}{|l|l|}
\hline Research and Development activities with respect to Biomass CHP technologies \\
\hline Combustion & Optimisation of plants, standardisation, dust separation, ash utilisation \\
\hline Gasification & $\begin{array}{l}\text { Numerous different activities, different processes entering stage of pilot } \\
\text { plant or demonstration plant }\end{array}$ \\
\hline Pyrolysis & Research and pilot plants using biomass in GB, I, US, D, A \\
\hline Steam process & Only limited activity, optimisation, small turbines \\
\hline Dust engine / - turbine & Only limited activity, mainly in I, A \\
\hline ORC-Process & Demonstration plants operated successfully, market dissemination started \\
\hline Stirling engine & Pilot and demonstration plants mainly in DK, A, D \\
\hline Hot gas turbine & Only limited activity, small scale pilot plants \\
\hline Gas and Diesel engines & Only few activity, optimisation for low caloric biofuels \\
\hline Gas turbine & Only few activity, optimisation \\
\hline Fuel cell & Increasing activity with respect to biogas, pilot plants \\
\hline Vegetable oils, FME (RME) & $\begin{array}{l}\text { Standardisation of fuel quality, long-term stability, optimisation of en- } \\
\text { gines }\end{array}$ \\
\hline Bioethanol & $\begin{array}{l}\text { Large scale demonstration in S, new conversion technologies based upon } \\
\text { cellulose raw material }\end{array}$ \\
\hline Methanol & Increasing activity: methanol production form producer gas in D \\
\hline Methane & No activities \\
\hline Biogas & Process optimisation and controllability, co fermentation \\
\hline
\end{tabular}

Fortunately, the EU commission now pays tribute to the emerging market for electricity from biomass in its specific research programmes. Nevertheless, increased efforts on the level of the individual member states, a closer cooperation among research institutes and industry, including the power producers, and a better information transfer seems to be essential if we want to make use of the enormous potential, which biomass offers as a sustainable energy resource to our societies in the next decades. 


\section{References}

/1/ www.bpamoco.com/downloads

/2/ EU (Ed.): 2001 - Annual Energy Review; European Commission, Directorate-General for Energy and Transport, Bruxelles, 2002

/3/ D. Falkenberg, M. Kaltschmitt, J. Witt: Feste Bioenergieträger in Europa (in German), Institut für Energetik u. Umwelt gGmbH, Leipzig, 2003, to be published

/4/ P. Heinrich, B. Jahraus: Technik und Wirtschaftlichkeit biogener Festbrennstoffe zur Strom- und Wärmeerzeugung, VDI- Tagung „Thermische Nutzung von Biomasse“, Salzburg 16. /17. Mai 2001, VDI Berichte 1588, Düsseldorf 2001

/5/ P. Heinrich: KWK aus festen Biomassen - Entwicklungsstand, Aktivitäten und deren Bewertung, in: Kaltschmitt, Fischer, Langnickel (Eds.): Bioenergieträger in Kraft-Wärme-Kopplungsanlagen, Initiativen zum Umweltschutz, Bd. 47, Erich Schmidt Verlag, Berlin, 2002

/6/ S. van Loo, J. Koppejan (Eds.): Handebook aof Biomass Combustion and Co-Firing, Twente University Press, Enschede, 2002

/7/ T. Augustin: Biomasse-KWK mit standardisierten Dampfmotoren in: Kaltschmitt, Fischer, Langnickel (Eds.): Bioenergieträger in Kraft-Wärme-Kopplungsanlagen, Initiativen zum Umweltschutz, Bd. 47, Erich Schmidt Verlag, Berlin, 2002

/8/ Fachagentur Nachwachsende Rohstoffe e.V ( Ed.): Innovative Verfahren zur Wärme- und Stromerzeugung aus Biomasse, Schriftenreihe „Nachwachsende Rohstoffe“, Bd. 20, Landwirtschaftsverlag Münster, 2002

19/ H. Carlsen: Biomass CHP with Stirling Engines, in: Kaltschmitt, Fischer, Langnickel (Eds.): Bioenergieträger in Kraft-Wärme-Kopplungsanlagen, Initiativen zum Umweltschutz, Bd. 47, Erich Schmidt Verlag, Berlin, 2002

/10/ U. Langnickel: Biogasnutzung in Brennstoffzellen, in: Kaltschmitt, Fischer, Langnickel (Eds.): Bioenergieträger in Kraft-Wärme-Kopplungsanlagen, Initiativen zum Umweltschutz, Bd. 47, Erich Schmidt Verlag, Berlin, 2002

/11/ A. Heinz, R. Hartmann, G. Hitzler, G. Baumbach: Wissenschaftliche Begleitung der Betriebsphase der mit Rapsölmethylester befeuerten Energieversorgungsanlage des Deutschen Bundestages in Berlin, Forschungsbericht Bd. 89, Institut für Energiewirtschaft und Rationelle Energieanwendung, Universität Stuttgart, 2002 


\section{Session 7: Integrated Systems, Transmission and Storage}

Chairman: Mogens Arndt, Energi E2, Denmark 


\title{
Pit Water Storage for Large Scale Thermal Systems
}

\author{
Alfred Heller ${ }^{1}$ \\ Department of Civil Engineering, Technical University of Denmark, \\ Brovej 1, Building 101, DTU, 2800 Kgs. Lyngby, Denmark \\ Carsten Wesenberg ${ }^{2}$ \\ NIRAS consultants, Vestre Havnepromenade 9, 9100 Aalborg,Denmark
}

Keywords: Thermal storage, large-scale, pit storage, floating lid, stainless steel liner.

\begin{abstract}
There are different reasons for applying large scale thermal storage, e.g. balancing of fluctuating heat production, load shaping, and storage of renewable heat. There are various efforts to find cheap and reliable solutions for such thermal storage from well-known steel tank designs to underground storage. In the current paper the technology of pit water storage with floating lid is presented as a solution that indicates lower costs than most competitors. The paper presents the research and development history leading to the final design presented in detail.

The main task of storage method designing is to ensure heat insulation and tightness. Applied materials must not be in contact with hot water. Insulation materials do not meet this criterion and must be covered. Covering materials are either expensive or leading to long-term defects. Different designs are discussed and a first, final and tested solution presented.
\end{abstract}

\footnotetext{
${ }^{1}$ Tel: +45 452518 91; fax: +45 459318 91, E-mail: ajh@byg.dtu.dk (Alfred J. Heller)

${ }^{2}$ Tel: +45 963064 00; fax: +45 933064 74, Email: caw@niras.dk (Carsten Wesenberg)
} 


\section{Introduction}

There are many reasons for developing large scale thermal storage. Within co-generation systems the balancing of heat and electricity production can be balanced to a better degree. The utilisation of fluctuating renewable energy sources can be balanced and peak load shaping/saving, in e.g. Japan, can be made by thermal buffering for e.g. cooling purposes.

There are various technical storage solutions in development and readers may find surveys in e.g. the Special Issue on Large Scale Solar Heating of (Solar Energy [1]) or proceedings from the International Energy Storage Conferences (MEGASTOCK[2]) and (TERRASTOCK[3]).

The application of advanced storage medium may enable a relevant reduction in storage size. However, for large scale solutions, the availability of a harmless and cheap medium is preferred. Due to the good thermal characteristics of water, this medium is preferred in the current presentation. Constructions like steel tanks are well-known and may be pressurised. However such storage in large scale may fill a lot in the landscape and may not be economically competitive with the currently proposed pit water solution. Among others, Swedish efforts are mainly focussed on underground storage (UTES) that are topics of different activities within the International Energy Agency (IEA [4]). UTES are characterised by the fact that the medium is stored at rather low temperatures, typically below $60^{\circ} \mathrm{C}$. Efforts towards a max. medium temperature of near $80^{\circ} \mathrm{C}$ is ongoing. Germany research nominate buried concrete water tanks, manmade aquifer (gravel/water pits) and duct stores and natural aquifer as the most promising techniques. These storage concepts are described by (Lottner and Hahne [5]). Results from the pilot projects are summarised in (Lottner, Schultz and Hahne [6]). The authors state the necessity of applying reinforced concrete wall constructions "for safety reasons in order to fulfil the various technical requirements on the long-term impermeability of the liner to water and vapour, and the high-temperature durability of the materials". In the current work, the same requirements are fulfilled by a much simpler construction. The economic and safety issues of the constructions will be discussed below. Natural aquifer, where natural water-saturated underground is applied for storage purposes, is also a promising and simple technology. Due to geophysical conditions, e.g. high ground water movements, man-made aquifer is a more realistic solution where water flows are controlled. Here a pit is filled with water-saturated gravel as storage material. Similar to Danish experiences, the aquifer in Rostock-Brinckmanshöhe, Germany, showed very high annual heat losses. Other man-made aquifers were demonstrated in Stuttgart, Germany in 1985, Chemnitz, Germany in 1997 and Steinfurt in 2000.

\section{A Survey on Thermal Storage Developments in Denmark}

In Denmark, the development of seasonal storage is closely related to the developments of large scale solar heating, a circumstance that is more historical than technical. The very hard economic competition that solar heating is facing from conventional heating systems, imposes an enormous pressure on the cost side for large scale, thermal storage. In 1990 a goal was set to achieve storage with volume costs of 33 euro/ $\mathrm{m}^{3}$ for a $100,000 \mathrm{~m}^{3}$ storage in 1990 prices. As we shall see, this goal is achieved by the currently presented pit water storage solution. Further price reductions are realistic if especially polymer liners can be employed. A more extensive survey on storage development and the results achieved is given in (Heller J.A. [8]). 


\section{A Floating Lid Testing Facility}

The goal for the current work, was to find a cheap and reliable liner for floating lids that can be applied on pit water storage. Attempts to develop such a lid concept led to an experimental set-up at the Technical University of Denmark. Here a shallow pit of 6 times 16 metres is built as a floating lid test site to be applied for experiments under realistic conditions with the possibility of accelerated testing. The pit can be heated and cooled by the attached energy system, enabling accelerated testing. A monitoring system documents relevant measurements.

Experiments include practical procedures under realistic conditions and in full scale. It is relevant that the procedures that lead to a floating lid are documented improving the reliability of the solutions and scalable to be applied for large scale storage.

The current results are mainly generated at this experimental pit. One important spin-off from the floating lid experimental set up is that stainless steel lining developed for lid lining can also be used for pit lining.

In 2001 a first floating lid with stainless steel lining was built and documented. The results are published by the current author, in Danish only. The first experiment with a thin-sheet steel liner showed problematic weaknesses leading to redesigning. These experiences were although applied on the experimental pit, itself and hereby a complete pit design. The current paper is documentation the final designs, focusing on the lid construction.

\section{The Final Pit Water Storage Design with Stainless Steel Sheet Lining}

Above, a floating lid experiment is discussed where serious problems with the proposed design were uncovered. In the current section a final floating lid design is presented that can be applied to any size of thermal pit water storage.

\subsection{The Overall Installation Procedure}

The earth work is assumed well known technology and is not discussed here. It is assumed that the pit is excavated within small tolerances. The pit lining work is done within the pit itself. The work is done from a mobile work platform from which the liner material is unrolled, prepared and welded. All edges and corner sections are prefabricated of thick material (e.g. $2 \mathrm{~mm}$ stainless steel) with necessary profiles for stabilisation in the horizontal direction. After having tightened the pit, water is filled up to the top edge. Now the lid can be assembled and pulled onto the water in a continuous process. All lid assembly work is done on a work platform that is placed on the side of a pit in full length and at a width of approx. 5 metres. A roof to avoid unnecessary moisture and rainwater to enter the insulation material covers the platform. At the first edge that is assembled a floating pontoon is keeps the lid up and enables bulling the final joint parts of the lid onto the water surface. Once the lid is finished and set in place, the water is lowered to the necessary level and the finish, e.g. water drainage. Insulation across the pit edges, top liner fixation, finalises the enterprise.

\subsection{The Overall Steel Sheet Assembly Procedure}

The single steel stripes are role-welded to a single sheet for each plane. The edges and corners are made of thick stainless steel to avoid problems with deformations and practical procedures as experienced in the experiments at DTU. Joining thin sheets and the edge material is similarly done by role-welding, but minor electrodes or TIC-welding is necessary at the corner-joints. Plates of thick material are fixed to the 
prefabricated parts at these joints supporting the thin material. To avoid very expensive mistakes, the procedures must be drilled at the work hall before executed on the building site.

There is a discussion about using single or double seam welding procedures. Double seam welding gives a possibility of testing for leakage between the two seams. However not all "leakages" lead to water losses and our experience shows good results with single welding procedures controlled by an approved metallurgic institute.

\subsection{The Overall Pit Design}

The pit is a truncated upside down pyramid. In Figure 1 the overall design is sketched. The slope for the pyramid is dependent on the ground material and may be found based on the fact that the pit must not change shape due to erosion. To avoid waste and transport excavated earth may be used as filling material defining a height. For large storage the upper 1-3 metres of the pit are insulated only. The insulation of the pit consists of layers. The upper most insulation layer, shaped as a pyramid, is laid across the pit wall to avoid heat losses at the edges and ensure proper drain-off for rain. Depending on the local conditions and the design a drainage system must be placed around the pit and the covering polymer liner let out to the drainage.

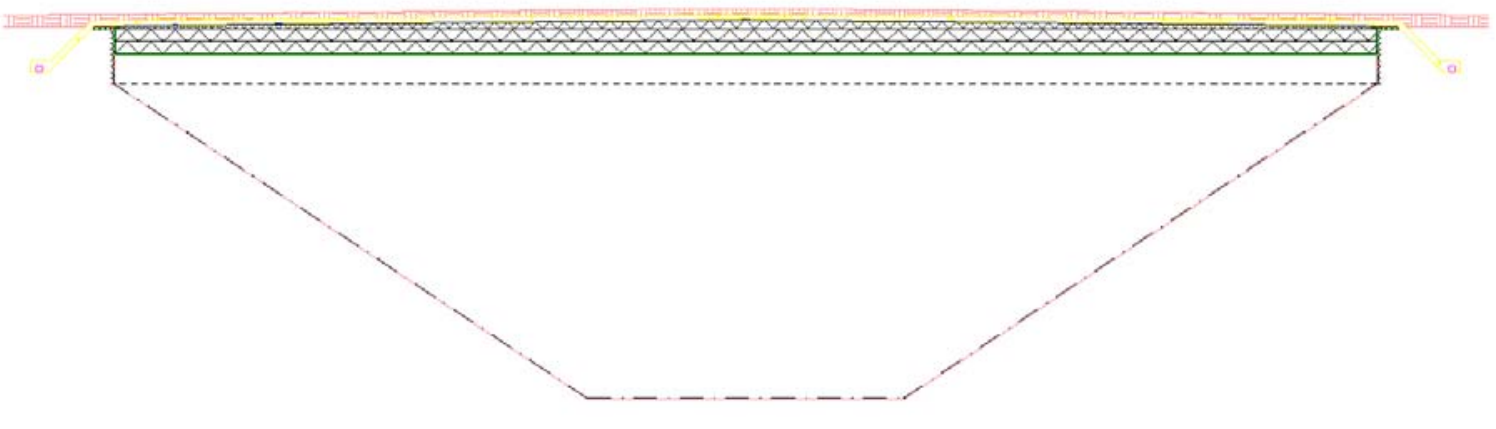

Figure 1. The overall pit design

\subsection{The Lid Design}

The lid can be designed with different multi-layer constructions having various physical purposes. As a minimum it is advised to use a "floating layer" of closed-cell insulation material that, in the case of leakage, would give the constructors time to act and repair a possible leakage. The layers above can be of any insulation material. The uppermost layer is, as mentioned before, a drain off layer that is shaped as pyramid and let across the pit edges.

The insulation material is protected against the pit water by a thin sheet of stainless steel. The whole lid, and insulation material that reaches across the pit edges, are covered by a polymer liner, similar to a roof construction. 


\subsection{Economical Aspects}

The cost breakdown for the current pit storage solution is presented in Table 1.

Table 1. Cost break down for pit water storage with floating lid and stainless steel lining.

\begin{tabular}{|c|c|c|c|c|c|c|c|}
\hline \multicolumn{8}{|c|}{ Price in Euro per $\mathrm{m}^{3}$ storage volume } \\
\hline 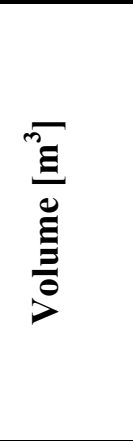 & 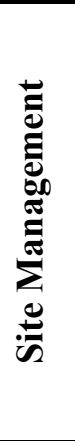 & 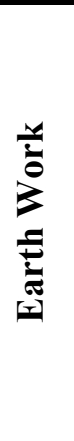 & 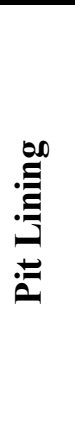 & 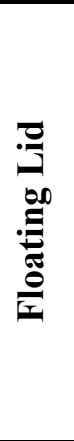 & 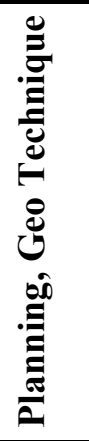 & 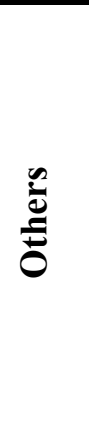 & $\underset{\Xi}{\Xi}$ \\
\hline 10,000 & 12 & 3 & 21 & 31 & 22 & 17 & 105 \\
\hline 15,000 & 9 & 2 & 18 & 26 & 18 & 14 & 87 \\
\hline 20,000 & 7 & 2 & 16 & 23 & 15 & 13 & 77 \\
\hline $\mathbf{5 0 , 0 0 0}$ & 4 & 2 & 12 & 16 & 10 & 9 & 53 \\
\hline 75,000 & 2 & 2 & 10 & 14 & 8 & 8 & 44 \\
\hline 100,000 & 3 & 2 & 9 & 12 & 8 & 8 & 41 \\
\hline
\end{tabular}

The total cost for the pit water storage with floating lid and stainless steel liner (acid proof), including planning costs, excluding VAT, is given in Table 2.

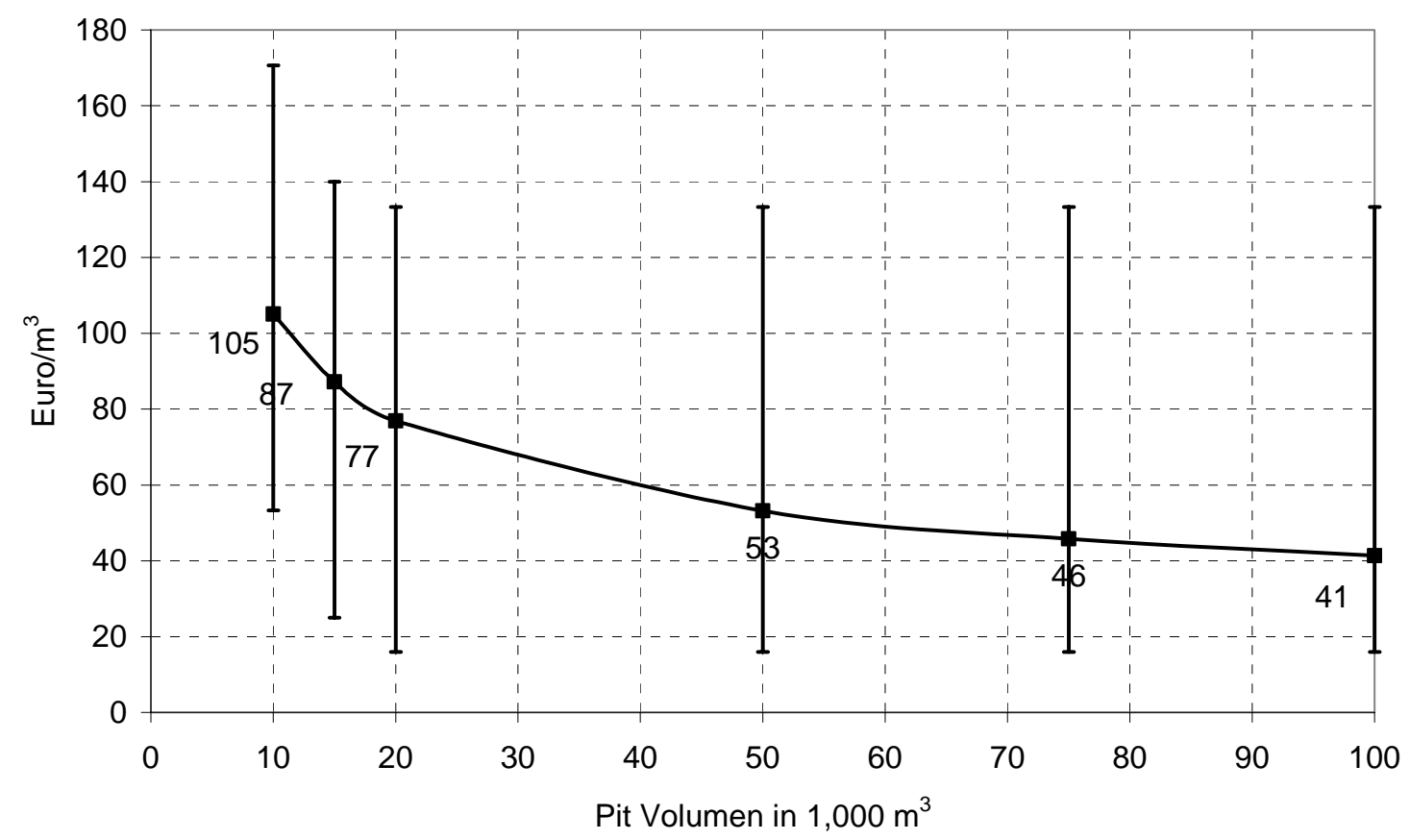

Figure 2. Overall cost for pit water storage with stainless steel liner and floating lid

The error bars represent the boundary for large scale storage that is expected in literature. These boundary values are determined by plotting a wide number of European plants by e.g. Lottner V. Schulz M.E. and Hahne E.[13] and Fisch N., Möws B. and Ziegler J. [14]. We find that the pit storage cost is average for 
volumes below $20,000 \mathrm{~m}^{3}$, however they lie in the lower part for large scale applications. Comparing our results with these curves, we find that the current cost lies in the lower third of the cost bound. Hence a promising technology, especially for large scale.

\section{Reliability Issues}

There are some relevant issues on the safety and reliability of floating lid constructions. Leakages are to be avoided at the time of construction. However, it is advisable to monitor the pit and lid and hereby to uncover possible problems. 1) The pit content changes with temperature, hence content control is necessary by either, controlling the water content or designing the lid as a non-fixed construction. 2) Leakage Sensing, where reasonable well-known products exist by e.g. "Sensor DDS Technology", a grid of wired sensor system that is placed below the bottom liner of the pit. Leakage will lead to increased electrical current by the wires in contact with the sensors. Knowing the position of the wires, the location of the leak can be determined rather precisely. 3) Leakage Plugging: What is possible in case of leakage? While polymer liners cannot be glued or welded under water, steel liners can be repaired. Entrance to the pit is necessary in any case. 4) Lid Traversing and relevant law-topics must be considered, which was no topic in Denmark. Relevant here is to state, that the floating lid can easily be traversed by man and small loads.

\section{Closing}

The pit water storage design described above can be applied for very large storage sizes and for temperatures close to the boiling point for water. The next step will be to demonstrate the technology in a pilot project. There are plans to build a $10,000 \mathrm{~m}^{3}$ pit at Marstal district heating in Denmark in 2004. Others will certainly see the possibilities of this cheap and reliable solution.

The application of synthetic liners instead of stainless steel liners would reduce the cost for pit water storage dramatically. Material cost would be reduced from e.g. 30 euro $/ \mathrm{m}^{2}$ to 3 euro $/ \mathrm{m}^{2}$ for large scale storage and following cost reduction due to simpler handling. At the time of writing, it is not advisable to apply polymer liners for high temperatures. It is shown by (Pedersen S. and Nielsen U. [15]) that the lifetime for polymer liners can be decreased dramatically due to the thermo-physical conditions given at a pit water storage. The hot water on one side and the air-earth boundary on the other side have resulted in a reduction of the lifetime from 20 to 6 years. Investigations on the subject are ongoing in Denmark and Germany at the time of writing. In the Danish investigations two HDPE liners are tested. To be able to evaluate a German solution on the problem where an aluminium foil is protecting the synthetic liner by avoiding oxygen from diffusing through the liner, one of the two HDPE liners from the above tests has been through parallel tests with an oxygen barrier. It is expected that first preliminary results are available at the end of 2002. However, leaks cannot be repaired under water. That must be considered.

As discussed earlier, chlorides and fluorides may lead to pitch oxidation of the stainless steel liners. The problem may be solved by application of more expensive sea waterproof stainless steel. A possibly cheaper alternative could be to combine a polymer liner at the back of the steel liner to avoid the ions diffusing to the steel liner. The method has not yet been tested. 


\section{Acknowledgements}

Most research and development work presented in the current work are supported by the Danish Energy Agency within the programme for the development of renewable energy technologies.

I gratefully acknowledge the excellent work of my colleague Karsten Duer, now working for VELUX. I also express my thanks to Søren Pedersen from the Technological Institute, to the consultants Carsten Wesenberg from NIRAS, Flemming Ulbjerg from RAMBØLL, Per Alex Sørensen from Planenergi, and to the people from the building contractors that helped with practical developments, Marstal VVS (steel lining) and Jacobsen \& Blindekilde A/S (earth work, plumbing and polymer lining).

\section{References}

[1] Solar Energy (2000) Special Issue: Large Scale Solar Heating, Hahne E. and Schulz M.E. (Eds.), Vol.69, No. 6.

[2] MEGASTOCK (1997) $7^{\text {th }}$ International Conference on Thermal Energy Storage, June 18-21, 1997, Sapporo, Japan.

[3] TERRASTOCK (2000) $8^{\text {th }}$ International Conference on Thermal Energy Storage, August 28September $1^{\text {st }}, 2000$, Stuttgart, Germany.

[4] IEA, International Energy Agency, Energy Conservation through Energy Storage Implementing Agreement, Annexes 1-17, http://cevre.cu.edu.tr/eces/.

[5] Lottner V. and Hahne E. (1997) Status of seasonal thermal energy storage in Germany. Proceedings MEGASTOCK'97, $7^{\text {th }}$ International Conference on Thermal Energy Storage, 18-21 June 1997, Sapporo, Japan, Ochifuji K. and Nagano K. (Eds), Vol. 2, pp. 931-936.

[6] Solar-Assisted District Heating Plants: Status of the German Programme Solarthermie-2000 (2000) Solar Energy, Vol. 69, No.6, pp. 449-459.

[7] Heller J. A. 15 years of R\&D in central solar heating in Denmark (2000) Solar Energy, Vol. 69, No.6, pp. 437-447.

[8] Duer K. et. al. (1997) Store Lagre 3, Slutrapport fra projekt borehulslagre til solvarmecentraler (Danish), Thermal Insulation Laboratory, Technical University of Denmark.

[9] Wesenberg C. (1990) Skitseprojekt, Sol til sommerstop i eksisterende halmvarmeværk, forsøgsanlæg. (Danish) Nellemann Rådg. Ingeniører, Denmark.

[10] Kübler R., Fisch N. and Hahne E. (1997) High temperature pit storage projects for seasonal storage of solar heating. Solar Energy, Vol. 61, No.2, pp. 97-105.

[11] Fisch N. and Kübler R. (1997) Solar assisted district heating - Status of the projects in Germany. Int. J. Solar Energy, Vol. 18, No.4, pp. 259-270.

[12] Hirt N. and Benner N. (1997) Pilotvorhaben Erdbecken-Heisswasserwärmespeicher in Rottweil, Abschlussbericht zum BMBF-Projekt FKZ: 0329606 C, 1997, Signatur TIB Hannover F981281+a. (German).

[13] Lottner V., Schulz M.E. and Hahne E. (2000) Solar-assisted district heating plants_ Status of the German Programme SOLARTHERMIE 2000. Solar Energy, Vol. 69, No.6, pp. 449-459.

[14] Fisch N., Möws B. and Ziegler J. (2001) Solarstadt - Konzepte - Technologien - Projekte. (German) Kohlhammer, ISBN 3-17-015418-4.

[15] Pedersen S. and Nielsen U. (2001) Fastlæggelse af levetider for plastliner til sæsonvarmelagre. (Danish) Technological Institute, *Gregersensvej, 2630 Taastrup, Denmark. 


\title{
Superconducting power cables and other super- conducting technologies for the electric power system - status and prospects
}

\author{
Jacob Østergaard \\ DEFU a.m.b.a. \\ Rosenørns Allé 9 \\ 1970 Frederiksberg C \\ tel: +4535300770 \\ e-mail: joe@defu.dk
}

Submitted: April 1st 2003

\begin{abstract}
High voltage power cables, transformers and other components for the electric power system based on high temperature superconductors have been subjected to intensive research and development during the last years. It is expected that the superconducting technology can provide new solutions, which are less expensive, more environmental friendly and have superior technical properties compared to conventional technology.

During the past years several prototype projects have been carried out in the laboratories in order to develop and evaluate the new technology. For the first time, a high temperature superconducting demonstration cable system has been installed in a utility network supplying electricity to about 50,000 consumers. The 30-m long cable is installed in the $30 \mathrm{kV}$ network at a substation in Copenhagen, Denmark. Scale-up in length and further demonstrations are needed, before the first permanent installations will be seen.
\end{abstract}




\section{Introduction}

Superconducting technology is considered to be an emerging futuristic new technology, and important results on the road to commercial applications have been reached during the last years. But superconductivity is not a new technology; the phenomena of materials loosing their resistivity, when they are cooled to some Kelvin above the absolute zero, was discovered in 1911 by the Dutch physicist Kammerlingh Onnes.

During the 20th century several applications based on superconducting materials, mainly $\mathrm{NbTi}$ and $\mathrm{Nb}_{3} \mathrm{Sn}$, was developed. The applications were primarily for research purpose e.g. very strong magnets for particle accelerators and nuclear magnetic resonance (NMR) spectrometers. But also "real-life applications" like magnetic resonance imaging (MRI) widely used on hospitals and industrial superconducting magnetic separation plans has been developed. The applications have been constrained by the need of cooling. The materials is superconducting up to about $20 \mathrm{~K}$ (20 Celsius above absolute zero), and thereby cooling with liquid helium at $4 \mathrm{~K}$ is needed. This is quite complicated and expensive.

Projects on development of applications for the electric power system was carried out in the 1960-70s, but they were terminated due to the cost of cooling and very high break-even with respect to rated power.

In 1986-88 a new group of materials based on oxides was discovered with critical temperatures above liquid nitrogen boiling point, $77 \mathrm{~K}$. This led to a massive research and development on the field of these new so-called high temperature superconductors (HTS).

Today HTS wires are produced in kilometer length. The most common wires are the Bi-2223 and Bi-2212 wires based on $\mathrm{BiSrCaCuO}$. A typically shape of the wire is a flat tape $(4 \mathrm{~mm} \times 0,2 \mathrm{~mm})$ with the superconducting material encapsulated as thin filaments within a silver sheath. Such a wire can today transport $130 \mathrm{~A}$. The price has continuously declined since mid 1990s; at present the price is 200 $\mathrm{USD} / \mathrm{kAm}$, and some manufactures are predicting values of $50 \mathrm{USD} / \mathrm{kAm}$ in 2-3 years time [1]. The potential lower limit is considered to be 10-20 USD/kAm.

A price of $50 \mathrm{USD} / \mathrm{kAm}$ is sufficient for some electric power applications, but it is expected that a broad marked will be available if the price drops to 10-20 USD $/ \mathrm{kAm}$. The price of conventional copper wires is $30 \mathrm{USD} / \mathrm{kAm}$.

In mid 1990s a second generation of HTS wires based on $\mathrm{YBaCuO}$ emerged. This so-called coated conductor is still in the laboratory stage, but offers more significant prospects of cost reduction. Wires in the lengths of 50-100 m has been manufactured, and in US and Japan it is expected that these wires will be available in 2007-10 in kilometer length at price of less than 25-35 USD/kAm [2].

\section{Superconducting technologies for the electric power system}

The new HTS materials can be used for a number of different components in the electric power network. This includes:

- Power transmissions cables

- Power transformers

- Energy storage

- Fault current limiters

- Generators and motors

- Current limiting coils

The prospect is that HTS components can be made more compact, with lower weight, with less loss and with higher rated power than conventional components. Furthermore HTS components can be made with 
new electric, thermal and magnetic properties. This can open a range of new solutions to problems, which is difficult or expensive to solve with conventional technology.

HTS transformers have the typical properties of an HTS component: compact, low weight and low loss. This is expected to lead to less life cycle cost. Furthermore unwanted oil is replaced by nitrogen. By proper design HTS transformers can be made with a remarkable overload capability $(100 \%$ in several days) without lifetime reduction and possibly integrated fault current limitation. Projects with units up to 5 MVA is going on [3], and prototypes have been tested in the grid (see Figure 1). The main challenge for HTS transformers is the AC-properties of the HTS wire in a magnetic field at $77 \mathrm{~K}$. Some projects have been terminated due to this (waiting for better wires), and some projects plan to cool the wire to the $25 \mathrm{~K}$ range.

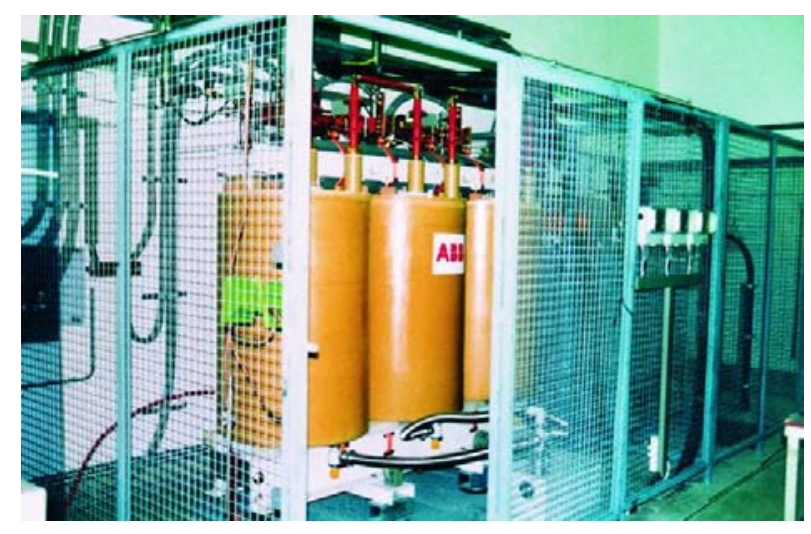

Figure 1. A 1 MW HTS transformer tested in the public network (courtesy of American Superconductor Corp.)

Fault current limiters are a new type of component capable of controlling fault current in strong networks, where this can be a problem. Units up to $15 \mathrm{kV}$ capable of limiting fault currents to $9 \mathrm{kA}$ has been made.

A superconducting magnetic energy storage (SMES) can be made in different scales. Small units (1 MJ, $1 \mathrm{MW}$ ) can be used for local power quality improvement, and thereby postpone network reinforcements. A 3 MW hybrid SMES is commercial available today. Medium units (50 MJ, $100 \mathrm{MW}$ ) under development can be used for stability improvements in the transmission network. Larger units for can be used for load leveling. Large units do not seem economic attractive, and there is no development of such devices.

In Japan 500 MW HTS generators are under development. A $70 \mathrm{MW}$ unit has been developed and tested. In the US the focus is primarily on large motors $(>750 \mathrm{~kW})$. Units up to 3,7 MW is under development [3]. Substantial loss saving is expected by the use of HTS motors.

Often loss savings are considered as a main objective for HTS components. This paradigm can be discussed, because loss saving cannot always be reached. HTS components have to be cooled with liquid nitrogen, which result in losses no matter the load. This is especially the case for long power cables. A certain load therefore has to be present to give a net loss saving compared to conventional components. Because of a high redundancy and thereby a generally low load in the electric power network loss saving is not always possible. Studies indicate that $40-50 \%$ reduction of the losses can be expected for beneficial cable applications [4]. In general it seems that technical benefits rather than the loss issue are the driving force for the future users of the HTS technology.

\section{Power cable development and applications}

Power transmission cables are one of the most near term applications of the HTS technology. Basic R\&D has been carried out, laboratory models have been made, several large demonstration projects (30-100 $\mathrm{m}$ cables) have been established, and presently projects with 200-800 m cables are under way (see Figure 2). 
The first permanent cable applications will probably be seen between 2008 and 2010. An overview of the some important HTS cable development projects worldwide is seen in Table 1.

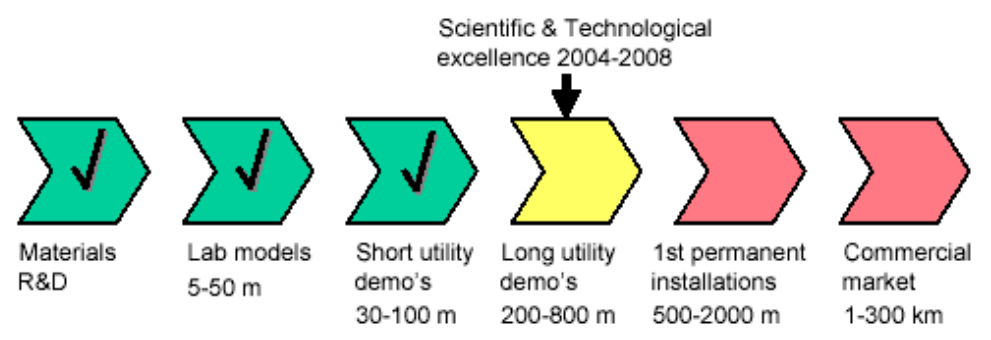

Figure 2. The roadmap for development of HTS power cables. Presently projects with 200-800 m demonstrations has been started

Table 1. Overview of some major HTS cable projects worldwide.

\begin{tabular}{|l|l|l|}
\hline Project & Description & Year \\
\hline Sumitomo/TEPCO (Japan) & $114 \mathrm{MW}, 66 \mathrm{kV}, 100 \mathrm{~m}$, laboratory & 2001 \\
\hline Southwire/DOE (US) & $27 \mathrm{MW}, 12 \mathrm{kV}, 30 \mathrm{~m}$, supply cable factory & 2000 \\
\hline NKT Cables/Eltra/Elkraft (EU) & $104 \mathrm{MW}, 30 \mathrm{kV}, 30 \mathrm{~m}$, utility demo & 2001 \\
\hline Pirelli/Detroit Edision (US) & $100 \mathrm{MW}, 24 \mathrm{kV}, 120 \mathrm{~m}$, utility demo & 2002 (terminated) \\
\hline AMSC/LIPA,N.Y./DOE (US) & $400 \mathrm{~m}$, utility demo & $2003-2005$ \\
\hline Ultera/AEP (US) & $104 \mathrm{MW}, 24 \mathrm{kV}, 300 \mathrm{~m}$, utility demo & $2003-2007$ \\
\hline Furukawa (Japan) & $66 \mathrm{kV}, 500 \mathrm{~m}$, demo & $2003-2007$ \\
\hline LG cable/KERI (Korea) & $30 \mathrm{~m}$, demo & 2003 \\
\hline KEPCO (Korea) & $100 \mathrm{~m}$, demo & 2004 \\
\hline Condumax (Mexico) & $30 \mathrm{~m}$, demo & $2003-2005$ \\
\hline
\end{tabular}

HTS power cables for transmission and subtransmission has different properties than conventional power cables. This can lead to a number of applications where very high cost of a HTS cable system can be accepted because conventional solutions are expensive or impossible. Dependent on the HTS conductor cost, a more or less widespread use of HTS cables will probably be seen.

HTS power cables have advantages such as very high current and power rating, compact cable dimension, low weight, no thermal interaction with surroundings, electromagnetic (EMC) neutrality and low inductance and capacitance.

This provide the possibility of applications such as:

- Network configurations with reduced voltage level

- Connection of remote located renewable energy sources like wind turbines farms with long lowinductance HTS cables

- Undergrounding section of overhead-lines with a single HTS cable with matching power transmission capacity

- Connections between generators and network with build-in fault current limitation

- $\quad$ Retrofit of existing cables in ducts with compact high power HTS cables

- High power DC connections with low voltage and high current

- DC backbones for long length bulk power transmission

- EMC neutral installations

- Thermal neutral installations without interaction with district heating pipes etc.

By using HTS cables with high amperage rating it will be possible to eliminate one or two transformation steps in the transmission and distribution network. This solution could be relevant for high voltage transmission into city centers, where a voltage level and the corresponding voltage transformation can be 
eliminated, as for example by transmission of $200 \mathrm{MVA}$ at 20-60 kV level instead of 120-150 kV level. This will be beneficial with respect to space requirements.

The use of conventional power cables with high current and low voltage in the transmission system has constraints for long length cable systems due to the critical length and the phase shift across the cable. By use of HTS cables with low inductance and capacitance these constrains can be eliminated, and long length cables established.

Projects with large offshore wind turbine farms are in progress around the world. Connecting the farms to the power grid with conventional ac transmission technique is difficult due to non-controllable power flow and voltage stability problems. Very high current capability of HTS dc cables and low cost voltage source commutated (VSC) power electronics for low voltage application can be the key elements in a future transmission concept for grid connection of wind turbine farms in remote locations [5].

HTS cables can be used to connect power plant generators with the grid. At the same time there is a possibility to build in current limiting properties in the cable. Using this technique the short circuit current will be limited at the same time as the grid impedance is low. This is advantageous with respect to voltage regulation and stability.

Retrofitting with higher transmitting power in existing ducts is possible with the HTS technology due to a very compact design with high power. Thereby the installation of high power transmission cable systems in urban areas can be realized without very extensive installation work. This is expected to be on of the first applications of HTS cables.

\section{Cable demonstration project in Copenhagen}

In May 2001 a $30 \mathrm{~m}$ long, $30 \mathrm{kV}, 2,000$ A HTS demonstration cable was installed in the public utility network of Copenhagen Energy [6]. Hereby a HTS cable for the first time is installed in a utility network supplying electricity to customers, and valuable practical experience has been gathered.

The goal of the cable installation has been to demonstrate a superconducting power cable in the electric power network under realistic conditions as well as to collect experience regarding installation and operation of such a system. It is demonstrated whether a complete superconducting cable system consisting of HTS cable, terminations, cooling system etc. can be operated in a realistic environment. This includes varying load, possibilities for short circuit currents, and operation by the utility staff.

The cable is designed as three single-core cables shown in Figure 3. In this design, the superconducting tapes are wound in layers around a former. The HTS tapes are cooled through conduction through the steel former and the bedding material. Thin films with metallic deposited aluminum, are placed between the two steel walls of the thermal insulation. Vacuum together with the reflecting films in all minimize heat radiation, convection and conduction from the surroundings. The heat in-leak is $1.5 \mathrm{~W} / \mathrm{m}$. The outer part of the cable consists of polyethylene (PE) electrical insulation, an electric screen and a mechanical PE protection. These parts are conventional. 


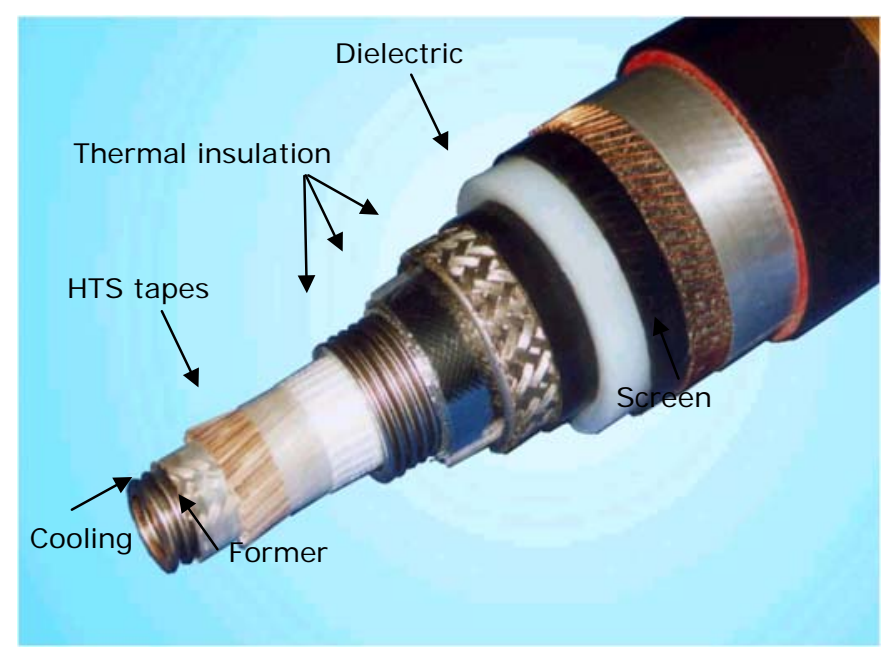

Figure 3. Design of the single-core HTS cable

The electrical and geometrical data for the HTS cable are summarized in Table 2.

Table 2. Electrical and geometrical data for the HTS cable.

\begin{tabular}{|l|l|l||}
\hline Property & Value & Unit \\
\hline \hline Nominal voltage & 36 & $\mathrm{kV}_{\text {eff }}$ \\
\hline System voltage & 30 & $\mathrm{kV}_{\text {eff }}$ \\
\hline Nominal current & 2000 & $\mathrm{~A}_{\text {eff }}$ \\
\hline Rated power & 104 & $\mathrm{MVA}$ \\
\hline Weight & 13 & $\mathrm{~kg} / \mathrm{m}$ \\
\hline Conductor cross section & $\sim 100$ & $\mathrm{~mm}^{2}$ \\
\hline HTS tape fill factor & 25 & $\%$ \\
\hline Cable length & 30 & $\mathrm{~m}$ \\
\hline Former ID/OD & $20 / 30$ & $\mathrm{~mm} / \mathrm{mm}$ \\
\hline Conductor ID/OD & $32 / 36$ & $\mathrm{~mm} / \mathrm{mm}$ \\
\hline Thermal insul. ID/OD & $39 / 66$ & $\mathrm{~mm} / \mathrm{mm}$ \\
\hline Electrical insul. ID/OD & $70 / 90$ & $\mathrm{~mm} / \mathrm{mm}$ \\
\hline Elec. Cu-Screen ID/OD & $90 / 95$ & $\mathrm{~mm} / \mathrm{mm}$ \\
\hline PE-sheath ID/OD & $95 / 105$ & $\mathrm{~mm} / \mathrm{mm}$ \\
\hline
\end{tabular}

A schematic view of the HTS cable cooling system is shown in Figure 4. Liquid nitrogen at $65-80 \mathrm{~K}$ is pumped through the cable. The main cooling system consists of two Stirling-cycle coolers. A passive backup cooling system based on liquid nitrogen boil-off and a liquid nitrogen reservoir automatically takes over if the main cooling system fails. No interruption of the cable operation is necessary. 


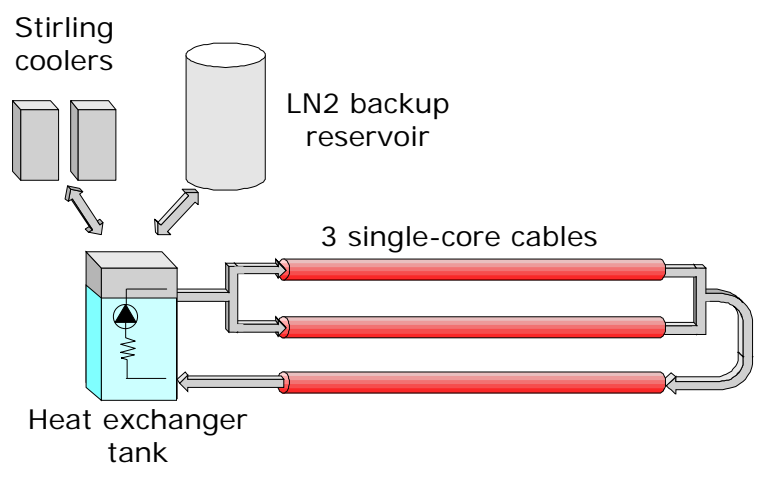

Figure 4. Principle of the cooling circulation system

A monitoring and data collecting system has been established to facilitate the operation and ensure information collection. The system provides the operators at the network operating central of Copenhagen Energy with alarms from the system. A screen dump from the system accessible via www is seen in Figure 5 .

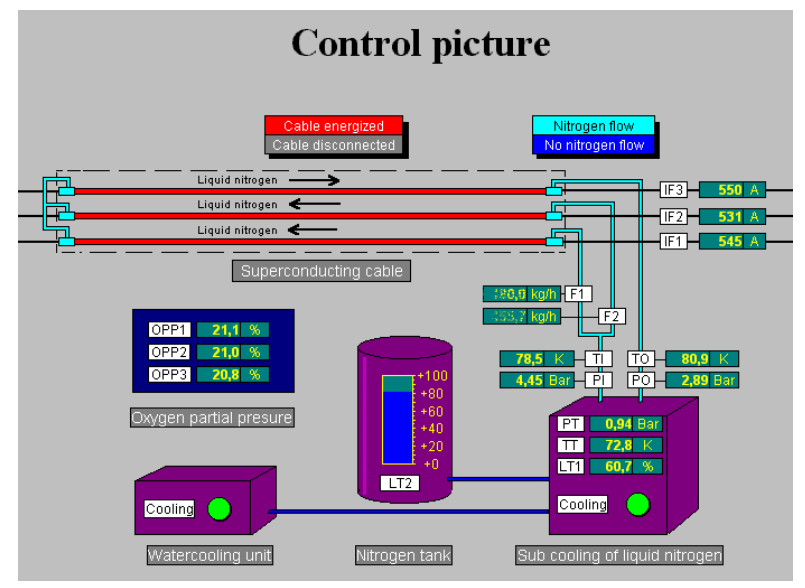

Figure 5. Screen from the cable monitoring and data logging system

The cable is installed internal on a $132 / 30 \mathrm{kV}$ substation (see Figure 6). This provides controllability with respect to load etc. Furthermore, the installation simulates a commercial high current internal connection in a substation. The substation supply approximately 50,000 customers including private households, offices and light industry at the Amager Island, the southern part of Copenhagen. 

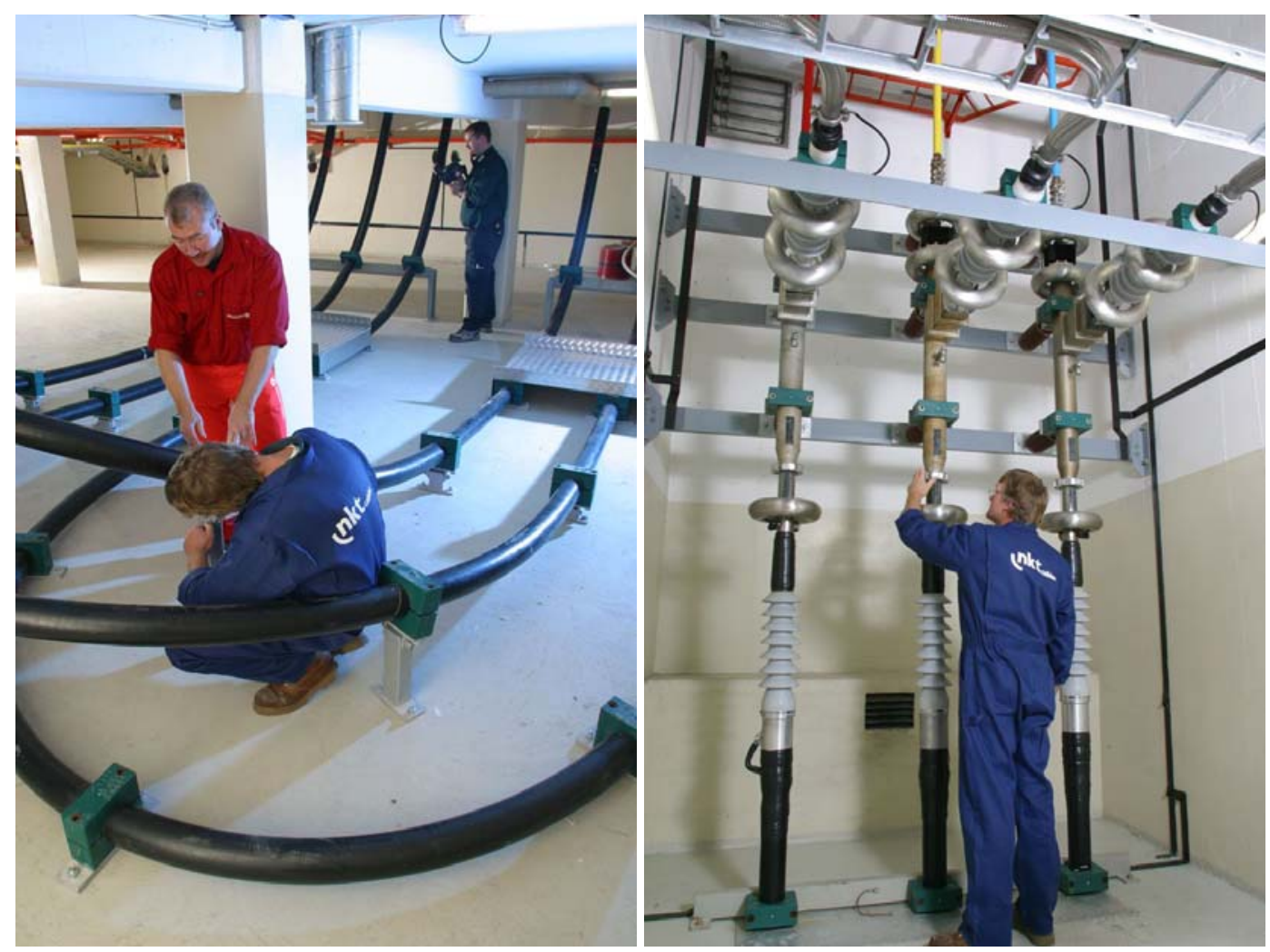

Figure 6. The HTS power cable installed in the basement of the Amager substation and view of the cable termination

The installation was performed with success during 3 months. Due to high flexibility and low weight of the cable the cable installation was unproblematic. The cable was inaugurated in May 2001, and since then it has supplied more than $200 \mathrm{GWh}$ of energy to the customers.

The HTS cable has performed as expected. No degradation of the superconductor or the thermal insulation has been observed. Currents up to $1150 \mathrm{~A}$ have been flowing in the cable. In Figure 7, an example of the load in a one-week period is shown.

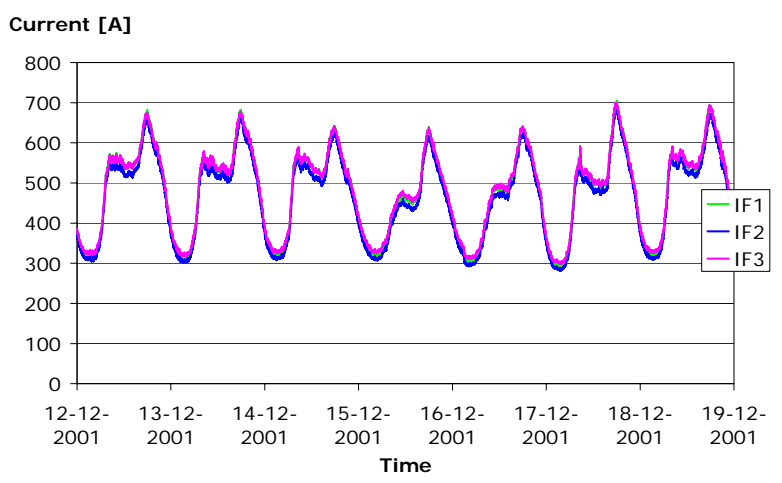

Figure 7. Current flowing in the HTS cable for a 7-day period December 12th-19th, 2001

Due to a failure in the $30 \mathrm{kV}$ network the cable has been exposed to a $6 \mathrm{kA}, 142 \mathrm{~ms}$ short circuit current. No degradation or temperature rise was observed after the short circuit.

The cooling system has provided the necessary cooling of the cable both when it was operated with cooling machine and backup boil-off cooling. As seen in Figure 8, the liquid nitrogen temperature is stable and independent of load etc. The temperature rise in the cable corresponds to loss from primarily the end terminations of the cable. 


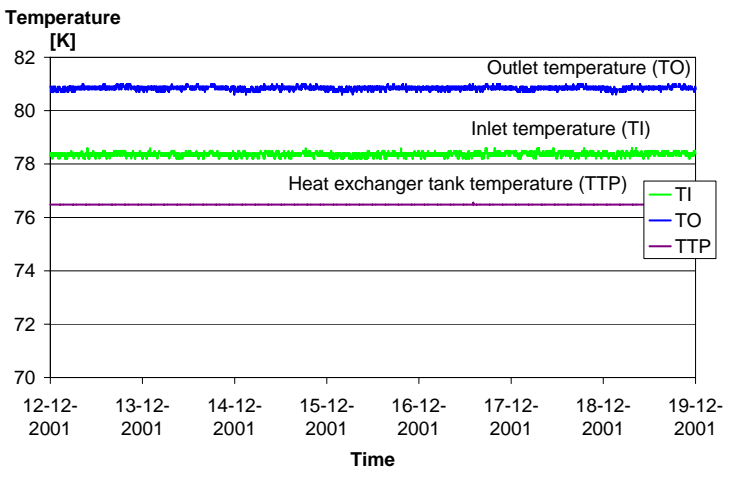

Figure 8. Temperature of liquid nitrogen in heat exchanger tank (TTP), inlet to cable (TI) and outlet from cable (TO) during operation of main cooling system. The small variations in TI and TO are due to resolution and fluctuations in temperature

A problem related to a misaligned liquid nitrogen pump emerged during the initial operation. The pump has been remounted. Furthermore, there have been non-critical problems concerning the conventional water-cooling unit for the cooling machines. Some design changes have been implemented.

Maintenance, adjustments etc. has been needed through the operating phase to keep the cooling machines operate. This point out the need for improved cooling technology and reflects a relatively low focus on the cooling system in the design and development phase of the project.

Cooling is still the Achilles heel of the HTS components. Especially reliability, maintenance and efficiency are of concern. Liquid nitrogen coolers is commercial available, but the requirements with respect to reliability is usually not so high for the present industrial applications. The efficiency of the coolers are limited by the ideal Carnot efficiency of $35 \%$ at $77 \mathrm{~K}$. Present coolers has a efficiency of typically $10 \%$ or less. This means that it requires $10 \mathrm{~W}$ or more to remove $1 \mathrm{~W}$ of heat at $77 \mathrm{~K}$.

To deal with the challenges of coolers dedicated development has to be established on cooler technology along with the HTS technology development. There seems to be potential for the development; for instance the new so-called pulse tube cooling technology is very promising with respect to reliability, maintenance and efficiency.

\section{Conclusion}

Several HTS-based components like cables, transformers, current limiters etc. for the electric power system are under development. HTS components can be more compact, with lower weight, with less loss and with higher rated power than conventional components. Furthermore HTS components can be made with new electric, thermal and magnetic properties. This can open a range of new solutions to problems, which is difficult or expensive to solve with conventional technology.

With respect to power cables a 30-m 3-phase HTS cable system has been designed, developed, manufactured, installed and inaugurated on May 2001 as the world's first HTS cable in a public network. The cable has a nominal rating of $30 \mathrm{kV}$ and $2000 \mathrm{~A}$. The cable has been in operation for nearly 2 years, and the utility staff has operated it. The cable has supplied more than $200 \mathrm{GWh}$ of energy to 50,000 customers. No degradation has been seen with respect to the cable itself. Cooling has been continuously provided by the cooling system, but work has been needed to keep the cooling machines operate.

The demonstration cable has shown the feasibility of the HTS-technology, and future projects will be carried out to scale-up the technology to long lengths. Dedicated development should be established on cooler technology along with the HTS technology development. 


\section{References}

1. J. Van, Next-New-era energy carriers, Chicago Tribune, January 10, 2001.

2. Energetics, Inc. Coated Conductor Technology Development Roadmap, Priority Research \& Development Activities Leading to Economical Commercial Manufacturing, DOE report, August 2001.

3. U.S. DOE, 2001 Annual Peer Review of the U.S. Department of Energy Superconductivity for Electric Systems Program, 2001 Peer Review Report.

4. Østergaard et al., Energy losses of superconducting power transmission cables in the grid, IEEE Transaction on Applied Superconductivity, Vol. 11, No. 1, 2001.

5. Østergaard et al., A new concept for superconducting DC transmission from a wind turbine park, Physica C, 372-376, 2002, p. 1560-1563.

6. Østergaard et al., Design, operation and installation of worlds first high temperature superconducting power cable in a utility network, Cigré Session 2002, 21-205. 


\title{
Active Networks as a tool to integrate large amounts of distributed generation
}

\author{
Bach, P.-F. and Nielsen, J.E., Eltra \\ Hindsberger, $M .^{\ddagger}$ and Varming, S., ECON \\ Gaardestrup, C., Techwise
}

\begin{abstract}
This paper discusses Distributed Generation and the challenges the growth of this impose for the network operators. As case, this paper looks at Western Denmark where already in 2001 about 50\% of the production capacity was connected at lower voltage levels $(60 \mathrm{kV}$ and below). Hence, this part of Denmark can be seen as laboratory for the future electricity grids in Europe. The actions taken here are inspired by the Active Networks vision, which also is presented.
\end{abstract}

Keywords: Distributed generation, active networks, integration.

\footnotetext{
*Corresponding author: magnus.hindsberger@econdenmark.dk
}

The work presented in this paper was prepared as part of the SUSTELNET project, which is supported by the European Commission under the $5^{\text {th }}$ RTD Framework programme under the thematic programme "Energy, Environment, and Sustainable Development", contract No. ENK5-CT2001-00577 


\section{Introduction}

Traditional electricity supply systems are configured with centralized power plants and a grid to distribute the electricity to the final consumers. However, the large central power plants are now challenged by distributed generation (DG) whose growth will certainly have consequences on the power systems. DG in this paper is defined as smaller generation units that are connected to the medium or low voltage network. However, many other definitions could have been used.

While the amount of DG is expected to increase in the future, the future growth rate may vary considerably as it very much depends on the driving forces like economic incentives, legislation, regulation, and environmental obligations. Larger amounts of DG though may create challenges for the Transmission System Operator (TSO) and the Distribution Network Operators (DNO) as it has already happened in Western Denmark (see Jensen, 2002).

This paper discusses Active Networks as a way to handle the increasing amount of DG. First the ongoing change in the generation system is discussed along with the driving forces. Section 3 introduce the challenges DG may impose e.g. in relation to the security of supply which is exemplified in Section 4 using Western Denmark as case. Section 5 presents the Active Networks idea, and finally, in Section 6, the actions taken in Western Denmark to implement Active Networks are described.

\section{A change of paradigm}

For many years the electric power industry has been driven by a paradigm where most of the electricity was generated by large, central power plants, sent to the consumption areas through the transmission lines, and delivered to the consumers through a passive distribution infrastructure at lower voltage levels. In this system, power flows were only in one direction - from higher to lower voltage levels. This is indicated to the left in Figure 1.
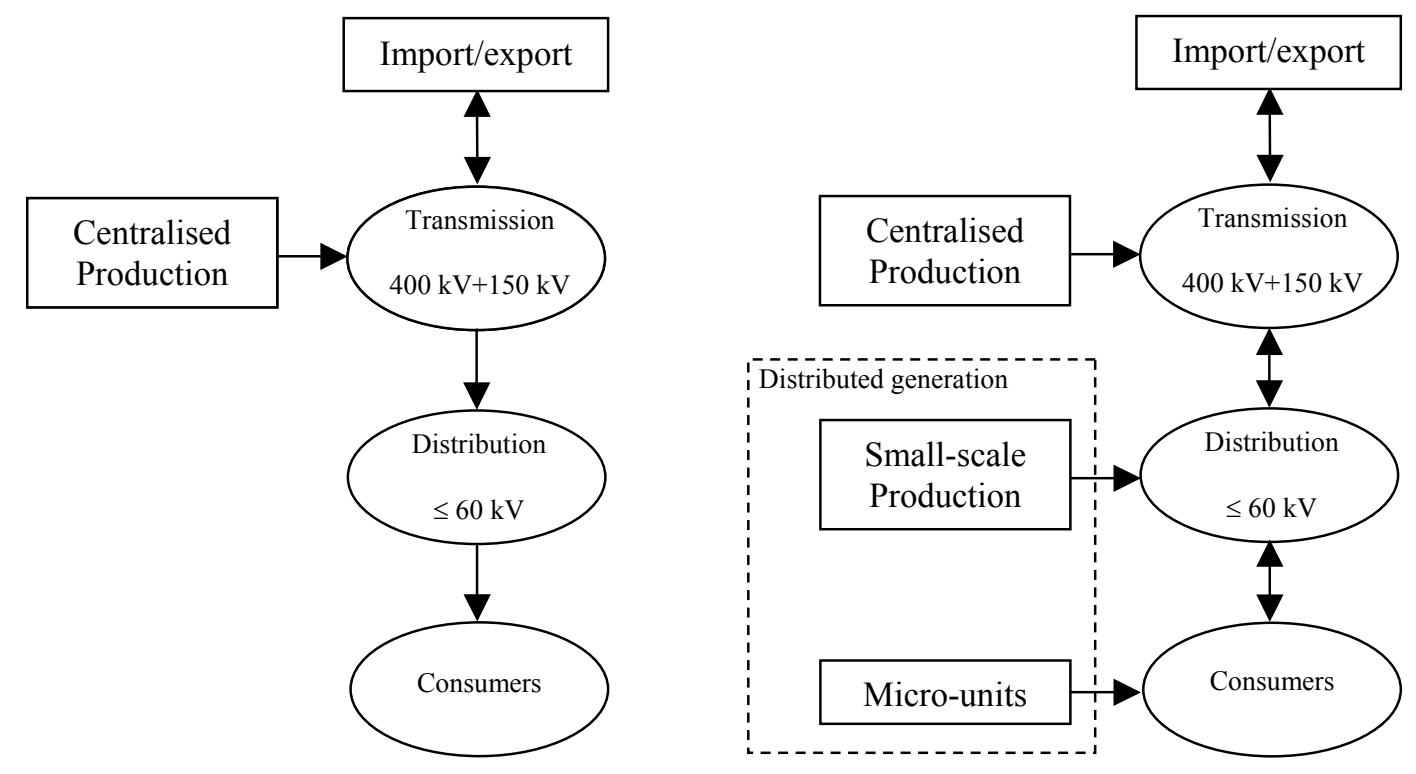

Figure 1. The change from one-directional centrally delivered power generation to bi-directional distributed generation network 
This paradigm is about to change as we might see a large-scale integration of distributed generators (DG) connected to the distribution network or directly at the end consumers. This is sketched to the right in Figure 1.

In some regions this has already happened, e.g. as in Western Denmark, where wind turbines and smallscale combined heat and power plants (CHP) make up 50\% of the total generation capacity. DG is more than this, e.g. small "run-of-river" hydro power stations and photovoltaic systems. Also, new distributed generation technologies like fuel cells and micro-CHP may boost DG growth even more in the future.

Several drivers for the growth in DG can be found. One is the ongoing technological development of DG technologies that make it more and more competitive with the large, central power plants. Also, DG technologies comply well with the EU targets for renewable energy supply penetration, fuel diversification, and greenhouse gas reduction.

\section{Challenges for the traditional DNO}

Several main impacts can be identified in the operation of a distribution system with a large amount of distributed generation:

- Voltage profiles change along the network, depending on the power produced on the consumption levels, leading to a behaviour different from the typical one

- Voltage transients will appear as a result of connection and disconnecting of generators or even as a result of their operation

- Short-circuit levels increase

- Losses changes as a function of the production and load levels

- Congestion in system branches is a function of the production and load levels

- Power quality and reliability may be affected

- Utility protection need to be coordinated with the ones installed in the generator's side

In solving these problems it is important to keep in mind, that the existing network design standards and regulatory framework is based on the old one-directional paradigm.

A power system requires several system services in order to be reliable. Apart from generating power, the central power stations supply are normally used for supplying the following services:

- Power control

- Frequency control

- Load following

- Voltage control

- Power availability 


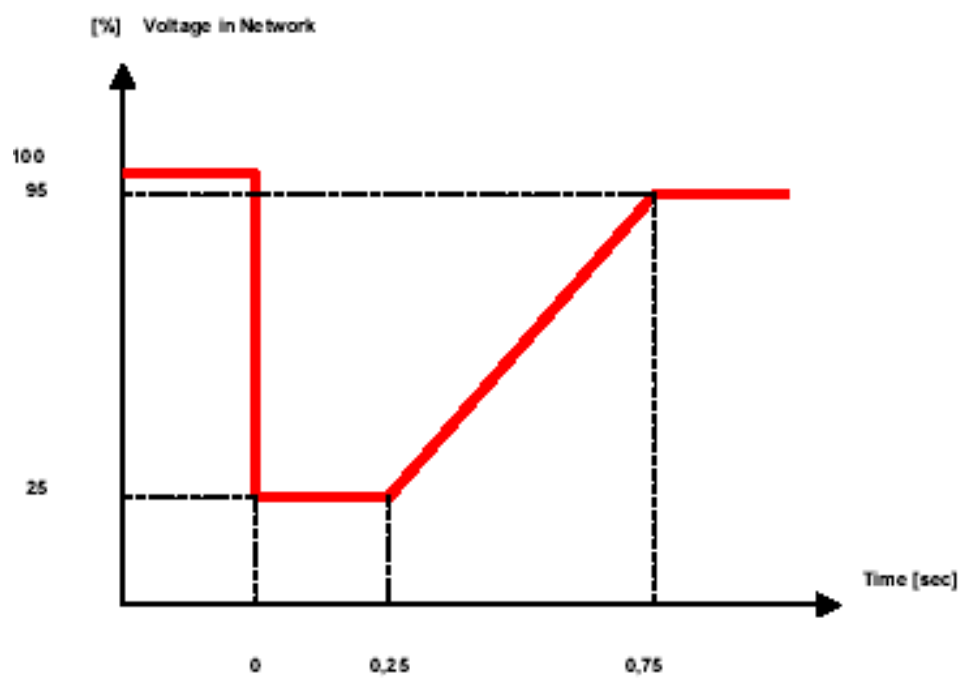

Figure 2 - Dimensioning voltage profile for network fault for central units

An example of performance requirements for central power stations is shown in Figure 2.

In addition, the central units have the following capabilities that make them more reliable:

- Fault current capability

- Fault-ride-through capability

Most DG technologies cannot or can only to a limited degree supply similar services, either due to technological constraints or due to the current regulation of DG production.

\section{The Western Denmark case}

Western Denmark can be seen as a testing ground for implementing large amounts of DG into the distribution network as it has already reached a high percentage of this due to decades of promotion of wind turbines and small-scale CHP in the Danish energy policy.

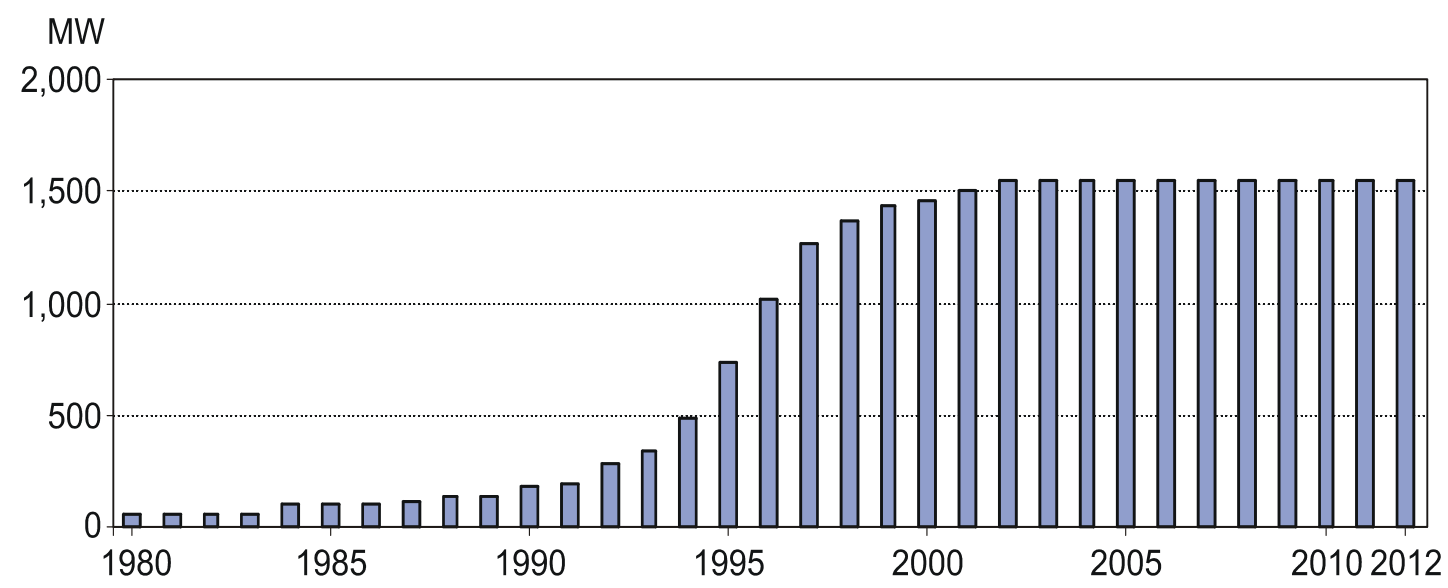

Figure 3. Small-scale CHP capacity in Western Denmark 


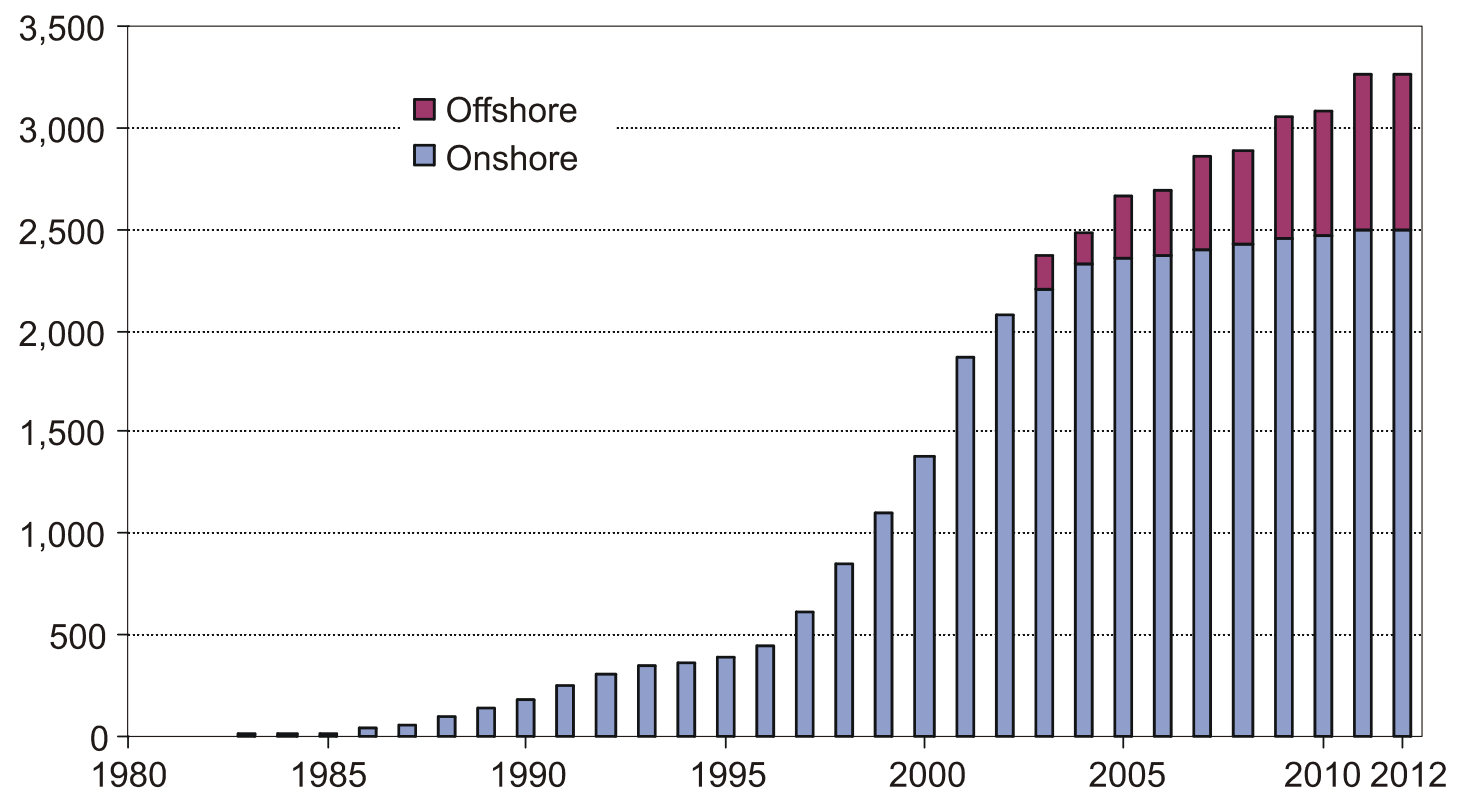

Figure 4. Capacity of wind turbines in Western Denmark

Overall, at the end of 2001 almost half of the production capacity was connected to the distribution network ( $60 \mathrm{kV}$ and below) as seen on Figure 5. This tendency will probably continue though with a smaller growth rate as seen in Figures 3 and 4 . They show that the main future is offshore wind turbines. However, they will typically be clustered and work as a larger, central like power plant with several of the capabilities they usually possess.

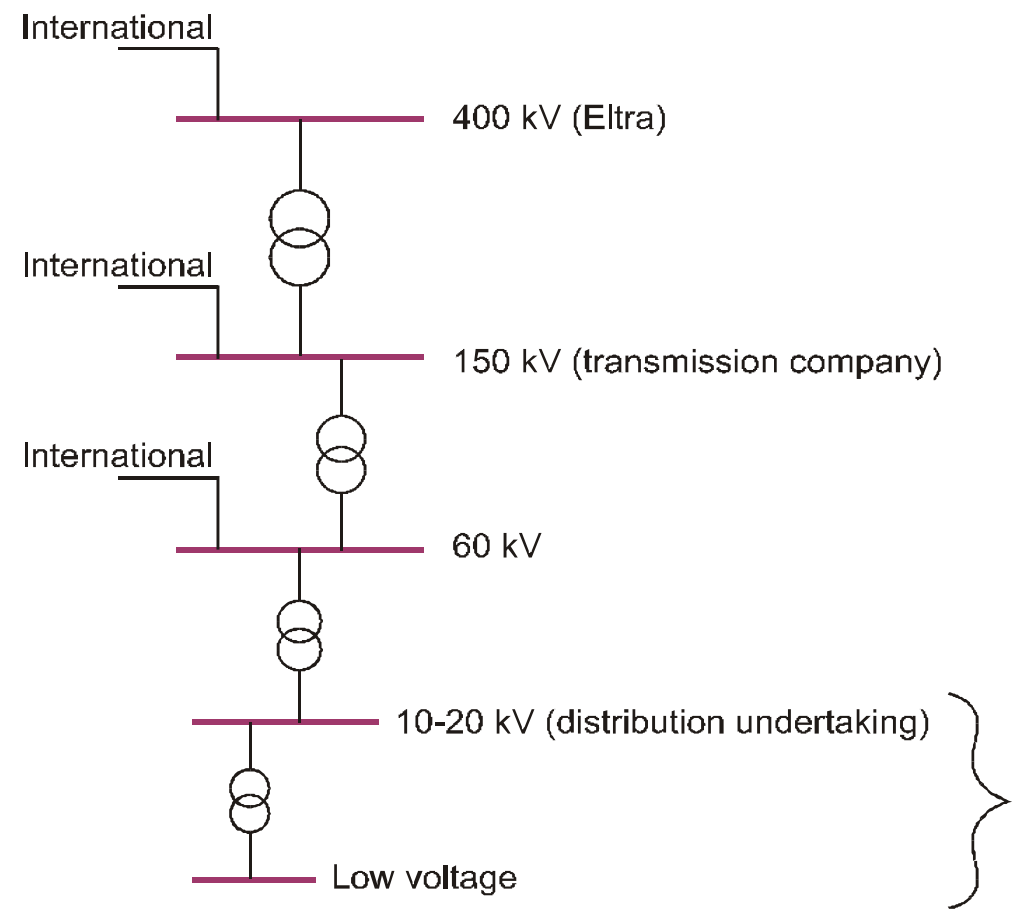

4 primary power stations $(1,488 \mathrm{MW})$

4 primary power stations $(1,619 \mathrm{MW})$

17 local plants (568 MW)

50 wind turbines (32 MW)

711 local plants $(1,053 \mathrm{MW})$

4,938 wind turbines $(1,868 \mathrm{MW})$

Figure 5. Production capacity in Western Denmark at each voltage level (by the end of 2001) 
Compared with the values in Figure 5, the wind capacity has increased further. By the end of 2002 there was a capacity of $2155 \mathrm{MW}$ connected to $60 \mathrm{kV}$ or below (another $160 \mathrm{MW}$, the Horns Reef offshore wind power park, is connected to $150 \mathrm{kV}$ ). Together with the approximately $1500 \mathrm{MW}$ of small-scale CHP, the DG in Western Denmark can produce as much as the peak load of the area, which in 2002 was 3685 MW while the minimum load of 1189 MW often can be supplied by wind turbines alone, see Eltra 2003.

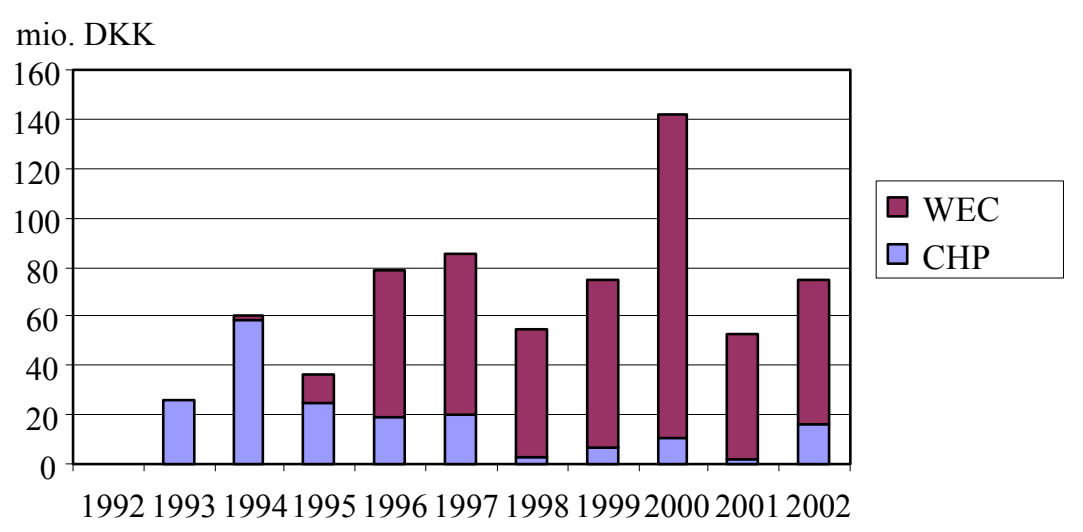

* Year 2002 (Budget)

Figure 6. Eltra network reinforcement costs due to CHP and Wind turbines

The costs of network reinforcement, the so-called deep connection charges, due to connection of CHP plants and wind turbines in the Eltra area, can be seen from Figure 6. In the period from 1992 to 2001 the extra investments made represent more than DKK 630 mio. (of which DKK 400 mio. is due to due wind power). This corresponds to DKK 300,000 per MW for wind power and DKK 500,000 per MW for CHPs. As comparison, the cost of building a wind turbine on land currently is in the order DKK 6-7 mio. per MW.

In general, wind turbines and local CHP plants have displaced central units, which are being decommissioned, as there are no longer any commercial basis for them. It means that the regulating units disappear in areas where the need for regulating capacity is growing. The regulation must then be effected by the local CHP plants and the wind turbines. Eltra is therefore working on getting these services from the DGs through changes in the regulation, the requirements setup for new units, and through support to $R \& D$ in technical solutions.

\section{The Active Networks vision}

The paper "Active Networks as facilitators for embedded generation" by van Overbeeke and Roberts presents a vision for "Active Networks" as facilitators for DG. They foresee that passive distribution networks as we know them, have to evolve gradually into actively managed networks. From their viewpoint this is both technically and economically the best way to facilitate DG in a deregulated electricity market.

The basis for their vision is the recognition: the existing technical and regulatory structure of distribution networks is incapable of supporting the evolution of the power system further. Their theses are:

- The network of the future does not supply power, it supplies connectivity

- The "infinite network" as customers used to know it, no longer exists

The first one is that the network is not, and must not be considered as a power supply system. The network is a highway system that provides connectivity between points of supply and consumption. 
And the second one is that a network interacts with its customers. A network that remains virtually unaffected whatever loads or generators are doing, is a notion of the past. If customers require an infinite network, they have to pay for that service.

Therefore a structural solution is proposed, based on the following concepts:

- Interconnection

- Local control areas ("cells")

- System services are specified attributes of a connection

The first one is interconnection as opposed to dominantly radial networks, i.e. a switch from thinking one-directional to bi-directional flows.

The second one is using automation to support relatively small local control areas. In absence of a standardised nomenclature, we have introduced the concept of "cells" to denote these control areas.

The third concept refers to the way in which system services provided by different units are charged to individual customers.

The basic issue it to create a network analogous to Internet and telephone networks, i.e.:

- There is always more than one path

- Active management of "congestion"

- Prevent propagation of an overload by isolating the "sick" part of the network

The advantage of that approach is that energy transport never is dependent upon a single path. Hence, the vulnerability to component failures is significantly reduced, similarly to telecommunication networks. If some paths are overstressed, power can be re-routed. This calls for some form of active network management, as in purely passive networks Ohm's law would determine the routing of power.

An inherent risk of interconnected networks is the domino-effect: If the system falls over somewhere, the fault could propagate over a very large area. Appropriate protection mechanisms, not too much different from what is being used already, can ensure that the fault is correctly isolated and the rest of the system operates normally.

Apart from the protection systems needed, network design engineers have to address the issues of fault levels which tent to increase in interconnected networks; and automatic reconfiguration actions may lead to a shift from infrequent but long supply interruptions to more frequent but short supply interruptions. 


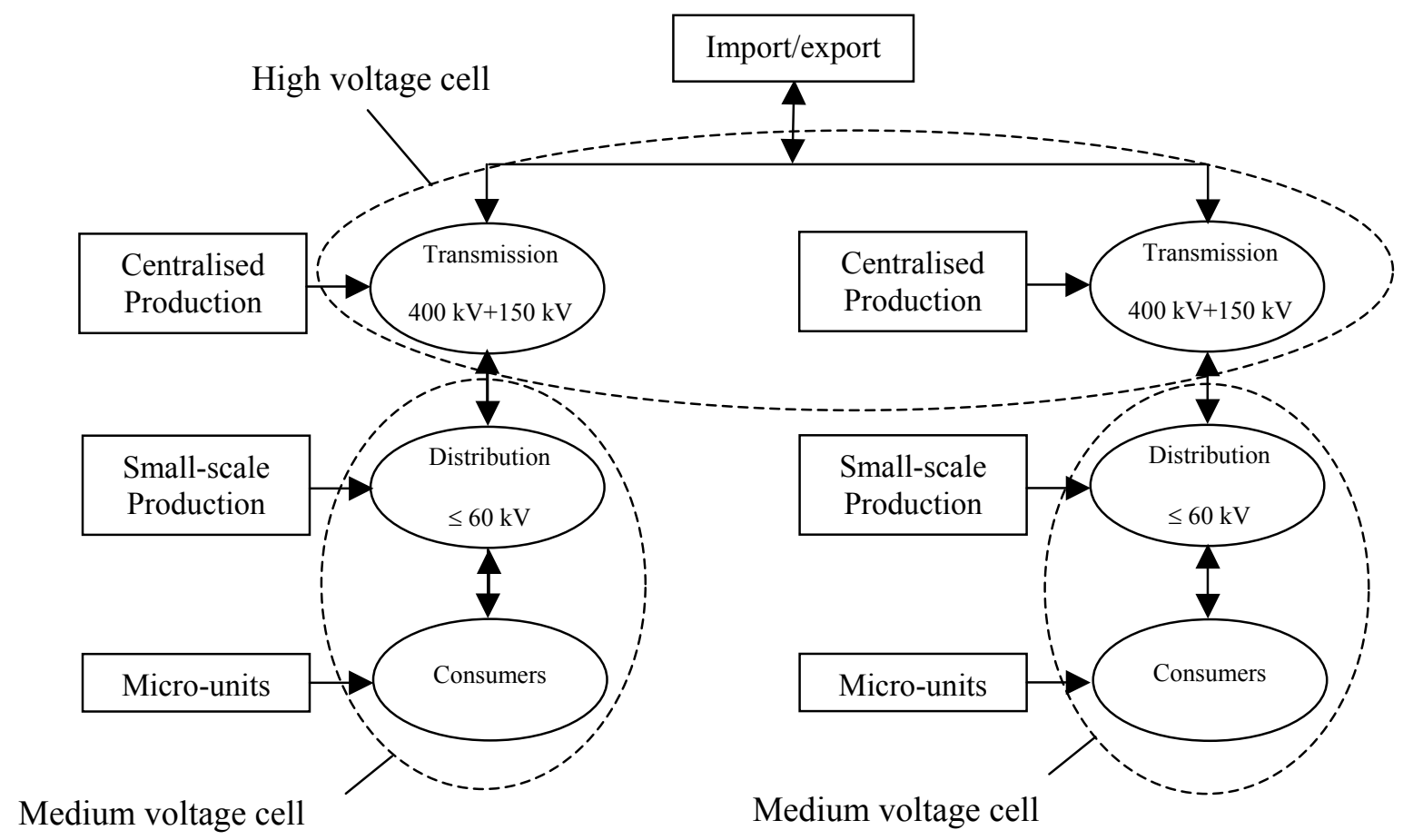

Figure 7. Network subdivided into 'cells' acting as independent islands

The most revolutionary change that is proposed is the introduction of "medium-voltage cells", which are in fact "local control areas" as indicated in Figure 7. The cell concept does not have a large impact on the topology of the power network - at least not as a short-term measure. The difference is mainly in the control hierarchy.

For each cell, the Active Network is to have:

- Local voltage and VAr control

- 'Negotiated' exchange of power with adjacent cells

- Managed operation of connection with adjacent cells

- Faults are managed and isolated within a cell, effect will not propagate to other cells. 'Islanded' operation is available as an emergency condition: If a cell is not capable of importing/ exporting as much power as needed, local generator/loads will be controlled in order to achieve balance

Each cell will eventually have its own power control system, which is essentially computer-based, that manages the flow of power across the cell's boundaries.

\section{System services within the cells}

The proposed system services are:

- Reactive power (supply/absorption)

- Voltage control

- Phase symmetry

- Network impedance within defined range:

- $\quad$ high enough to limit fault level

- $\quad$ low enough to supply starting currents, absorb load variations and secure generator stability

- $\quad$ low enough at harmonic frequencies

- Capability to handle fault currents 
The most obvious system service is the balance of reactive power, and in many cases it is more costeffective to ensure that balance locally. Which means that also DNO provides that as a service.

Ensuring that the system voltage is within agreed limits is also a duty that each network operator needs to fulfil by himself.

Symmetry between phases has never received much attention but may become more of an issue when networks are operated at higher impedance levels.

This brings us immediately at the issue of network impedance. The value of that impedance, with the consequence of regulation on one side of the spectrum and fault level at the other side, is a system service and needs to be quantified accordingly.

The optimal value will be determined by a trade-off between requirements of voltage stability and absorption of flicker phenomena on one hand, and limitations on fault level on the other hand.

Accepting fault level contributions from customers, in particular generators, is considered a service as well and customers may have to choose between paying for that service or limiting the fault contribution on their side of the meter.

And finally the security of supply or connectivity is a system service, where the option of being controlled or even disconnected could result in a discount on your network charges.

\section{Price structure for system services}

As indicated, each system service will have its price and these prices apply to generators as well as to loads. Some examples of this would be:

- Reactive power:

- $\quad$ Standing charge per kVAr for availability

- $\quad$ Charge per kVArh absorbed/generated

- Phase symmetry:

- $\quad$ Standing charge per maximum and average negative-sequence and homopolar currents

- Network impedance:

- Guaranteed network admittance corresponds to $100 *$ rating of connection in kVA

- $\quad$ Higher value can be contracted, if available

- $\quad$ Flicker caused by varying load/generation to be calculated on basis of contracted admittance

- Fault level contribution:

- Standing charge per kVA of fault level contribution from customer into the network

Reactive power could be charged very similar to active power. There is a standing charge for availability plus a certain charge per unit actually exchanged with the system.

In terms of phase symmetry, exceeding certain limits of negative-sequence currents, which is now simply forbidden, could be allowed, at an appropriate price. As the variable cost of compensating these currents will be relatively low, the customer probably pays a standing charge only.

When it comes to network impedance, it is proposed that the DNO guarantees a dynamic impedance of, for example, 100 times the contracted power. The customer can then exercise the option of a lower supply impedance at a cost.

In the same manner, fault level contribution can be charged in the form of a standing charge for each $\mathrm{kVA}$ contributed. These charges are all based on the cost that the DNO has to make either to reduce his own fault level contribution, or to accept a higher fault level by upgrading part of the network.

- Reactive power: Controllable production/absorption of kVAs.

- Reward to be based on availability and the amount actually provided

- Phase symmetry:

- Reward for controllable phase balancing

- Network impedance:

- Reward for increasing (small-signal) admittance without increasing fault level 
- Controllable loads and generators:

- Facilitates operation of a network in (partially) islanded mode if upstream connections have failed. Reward to be based on availability and the amount actually provided.

Because services have a price, a network operator has a basis of purchasing those services from his customers if that is more attractive than producing them within his network.

One example may be a generator providing controllable reactive power production. This may receive a premium dependent upon the degree of controllability. The compensation he receives may be composed of a standing charge for availability and a per unit compensation for the amount actually provided.

Generators using power electronic inverters are perfectly positioned to provide balancing between phases. The network operator would contract the availability of a certain amount of controllable negativesequence current.

When it comes to network impedance, generators with fast-acting voltage controllers could contribute considerably to the dynamic admittance of the network. Again, power electronic controllers have an advantage because they can react rapidly without increasing the fault level.

Finally, any load or generator that can respond to remote control can be contracted by the DNO in order to ensure power balance in case of islanding or restricted availability of external supply.

\section{The economic advantage of this vision}

There has to be an economic case for introducing Active Networks instead of running distribution networks as it always have been done. The most obvious advantage is that the changes proposed ask for virtually no physical reinforcement. Those reinforcements are unavoidable if we are to accommodate larger amounts of DG within a traditional system.

- Only a few lines:

- Reinforcement of existing lines:

- No new transformers:

- More switchgear:

- More control systems:
Basically to provide interconnection between islands

Applicable mostly to tapered circuits where local voltage is uneconomical

Interconnection improves security of supply, existing transformers can be operated to a higher percentage of the rated load.

Increase options for inter- and disconnection; all switches to be remotely operated. Few circuit breakers, many sectionizers

Limit level of investment by phased introduction

\section{Issues for further research}

There are many technical and some regulatory barriers to overcome before the Active Networks vision can be fulfilled. Some issues are:

- More dynamic reliability model

- Efficient planning requires a mature market for DG. How to bridge the present immature phase?

- Tools for voltage control

- Algorithms to (re-)configure networks automatically for optimal power flow and losses

- Concepts for protection

- Cost of system services to be quantified

In relation to the costs of the system services, one should balance the transaction costs of setting a price for a service and the costs of the activity. Sometimes the costs of measuring data and administration may exceed the benefits gained by a pay-per-unit system over a fixed tariff of supplying a service within some requirements.

Finally, the regulatory body should seek to facilitate innovative solutions for tariffs and system service charges. 


\section{Status for Active Networks in Western Den- mark}

In Western Denmark, Eltra has pursuited the Active Networks vision the last year. The first step was to define the cells. These have been defined as the distribution networks connected to the $150 \mathrm{kV}$-stations, of which more than 50 exist.

In theory, those are to be handled using the same methodology as the existing transmission network. This, however, has not been tried, as issues like organisation, responsibility, and data availability have to be sorted out. Hence, as a next step, Eltra plans to specify one or more of these cells to be used as full-scale test sites. The main elements to analyse are:

- System overview

- Organisation

- Planning

- Operation

Overview: Measuring of data within the cells: load, frequency, etc. will be carried out to get the needed data about the capabilities (or lacks of those) of the medium-voltage network cell.

Organisation: It has to be decided how the organisation should be within the cell, which is complicated by the fact that several cells have multiple DNO's operating within in the same. The responsibilities of the actors should also be defined.

Planning: DNO's starting to do day-ahead planning and day-after evaluation of the network including for the system services, as it is done for the main transmission network. This requires that certain data in relation to customers and the network from the TSO and DNO's can be shared.

\section{Operation:}

- How do the medium-voltage cells run controlled island-operation?

- Is new hardware and software needed, and what are the costs?

- How is the power restored in the medium-voltage cells after failures? To analyse this, Eltra has just started a PhD project "Restoration strategies for systems with large-scale distributed generation" at Malmö’s Högskola, where the real-time simulator Aristo is to be used.

As it is now, most small-scale generation units in Western Denmark get a fixed tariff for their production. As it look now, the small-scale CHP plants will go from a fixed tariff structure to payment based on the market price and e.g. of the system services, they offer. How the pricing and regulation should be made, is an issue for discussion in Denmark right now.

Eltra has initiated a project, of which one of the tasks is to get an overview of the capabilities (fail tolerances and system services) of all small-scale production units in the area.

Also, all new generation units will have a set of requirements in terms of system services and fail tolerances equal to those set for central power plants.

So, the basis is set for in the future both to have the units with the right capabilities and the regulation needed to have functioning cells. However, the number of providers of system services (individual generation units) will be high and hard to handle, but the use of clustering may reduce this number.

In Denmark the generation company Energi E2 has started a clustering demonstration project where 5 small CHP plants are to function as one larger unit using remote control and modern information technology, see Energi E2 (2003). Similarly, the 160 MW offshore wind turbine park at Horns Reef can be seen as a clustered unit, which can be regulated as a traditional power plant within the limits of the wind, e.g. the wind speed is high enough for generation, it can contribute to frequency control and voltage control. 


\section{Conclusions}

As it is now, Eltra can manage a system with $50 \%$ of the total capacity being DG, which indicate that large amounts of DG can be handled even in traditional systems. However, inspired by the Active Networks vision, actions have been taken to enhance the system to handle even larger amounts of DG. Cells have been defined and some are to be operated as full-scale test sites to see the necessary actions in investments, $\mathrm{R} \& \mathrm{D}$, and regulation to operate an Active Network nationwide. The experiences will be important for the future penetration of DG in Europe and worldwide.

\section{References}

Creighton, A. (2002); "Evaluation of the issues for distribution networks as they become more actively managed and the possibilities this creates for developing distribution ancillary services", IQPC Conference on Embedded Generation within Distribution Networks", London, January, 2002.

Eltra (2003); "Annual report 2002", Eltra, Denmark.

Energi E2 (2003); “Annual report 2002”, Energi E2, Denmark.

Jensen, J. K. (2002); "Integrating CHP and wind power - how Western Denmark is leading the way", Cogeneration and On-site Power Production, Vol. 3 (6).

Nielsen, J. E. (2002); "Review of the Role of ICT (Information and Communication Technology) in Network Management and Market Operations", Sustelnet report, November 2002 (see www.sustelnet.net).

Nielsen, J. E. (2002); "Review of Technical Options and Constraints for Integration of Distributed Generation in Electricity Networks ", Sustelnet report, December 2002 (see www.sustelnet.net).

Van Overbeeke, F. and Roberts, V. (2002); "Active Networks as facilitators for embedded generation", IQPC Conference on Embedded Generation within Distribution Networks", London, January, 2002 


\section{Session 8: Fuel Cell Technology}

Chairman: Mikko Kara, VTT Energy, Finland 


\title{
High Temperature Electrolysis of Steam and Carbon Dioxide
}

\author{
Søren Højgaard Jensen ${ }^{+, \#, ~ J e n s ~ V . ~ T . ~ H ø g h ~}{ }^{+}$, Rasmus Barfod ${ }^{+}$, Mogens Mogensen $^{+}$ \\ ${ }^{+}$Materials Research Department, Risø National Laboratory, DK-4000 Roskilde, Denmark \\ ${ }^{*}$ H.C.Ørsted Institute, Universitetsparken 5, DK-2100 Copenhagen, Denmark
}

\begin{abstract}
The vision behind this work is establishment of methods for cheap production of hydrogen, $\mathrm{H}_{2}$, and methane, $\mathrm{CH}_{4}$, by electrolysis. $\mathrm{CH}_{4}$ is a particular suitable storage medium for renewable energy. Preliminary electrolysis experiments with a second generation of solid oxide fuel cells developed at Risø show that these cells also have a high potential as solid oxide electrolyser cells. Furthermore, the experiments indicate that production of $\mathrm{CH}_{4}$ by high temperature electrolysis of mixtures of $\mathrm{H}_{2}+\mathrm{CO}_{2}$ is possible using these cell, but very high gas pressure seems necessary to obtain acceptable yields. The results also indicate that much more research and development work is needed in order to make a sufficient durable electrolyser cell.
\end{abstract}




\section{Introduction}

Inefficient conversion technologies as well as improper energy storage systems are major barriers for a wider application of renewable energy such as wind, photo-voltaics and hydropower. [1] Solid Oxide Fuel Cells (SOFC) used in electrolysis mode, called Solid Oxide Electrolyser Cells (SOEC), have the potential to become an efficient and cost effective way to solve the conversion problem. Because the water splitting process is endothermic, the electricity needed for electrolysis, can be significantly reduced, if the formation of hydrogen is taking place at high temperatures $\left(1000^{\circ} \mathrm{C}\right)$. The electric energy need is reduced because the unavoidable joule heat of an electrolysis cell is utilized in the water (steam) splitting process at high temperature. If heat is available from sources such as heat of geothermal (e.g. on Island), solar or nuclear origin, this will further reduce the electric energy necessary to produce a $\mathrm{Nm}^{3}$ (a cubic meter at $0^{\circ} \mathrm{C}$ and $1 \mathrm{~atm}$.) of hydrogen. All heat sources with temperatures above $100^{\circ} \mathrm{C}$ (the boiling point of water) are beneficial as electric energy for steam raising will be saved and the heat dissipation from the high temperature electrolyser will be minimised the more the higher the temperature is of the surrounding gas. The consumption of electricity may be reduced further if steam of a temperature higher than the operation temperature of the electrolyser is available.

Also, the energy losses due to the sluggishness of the electrochemical reactions are in principle the lower, the higher the temperature is. This principle seems to a large degree realised in practise through the significant improvements of the SOFC technology due to the extensive international development efforts. Thus, SOEC is probably more efficient than the already commercialised low temperature electrolysers, and today's SOFC should be tested in the SOEC mode in order to assess the commercial potential of the technology in this application.

Furthermore, the SOEC has the potential of splitting carbon dioxide into carbon monoxide and oxygen. This means that electrolysis of a mixture of steam and carbon dioxide results in a mixture of hydrogen and carbon monoxide, also called synthesis gas or short: syngas. A number of other energy carriers may be produced from syngas. The two simplest are methanol and methane. The latter, $\mathrm{CH}_{4}$, is the main constituent in natural gas.

The infrastructure for natural gas is already widely established with pipelines throughout many countries and with storage facilities such as the artificial caverns in the salt horsts at Ll. Torup and Stenlille in Demark with a total working storage capacity for natural gas of 765 million $\mathrm{Nm}^{3}$.[2] Since methane is much easier to handle compared to hydrogen, and the infrastructure is established, it is also interesting to investigate the possibilities of producing methane from carbon dioxide and steam.

\section{Theoretical background}

The overall reaction of the water electrolysis is:

$$
2 \mathrm{H}_{2} \mathrm{O} \rightarrow 2 \mathrm{H}_{2}+\mathrm{O}_{2}
$$

The reaction at the negative electrode is:

$$
\mathrm{H}_{2} \mathrm{O}+2 \mathrm{e}^{-} \rightarrow \mathrm{H}_{2}+\mathrm{O}^{2-}
$$

and at the positive electrode:

$$
\mathrm{O}^{2-} \rightarrow 1 / 2 \mathrm{O}_{2}+2 \mathrm{e}^{-}
$$

The electric energy supply necessary for the electrolysis process is equal to the change in free energy 
where $\Delta \mathrm{H}$ is the enthalpy change, $\mathrm{T}$ is the temperature in Kelvin and $\Delta \mathrm{S}$ is the entropy change by the reaction. The relation between $\Delta \mathrm{G}$ and the equilibrium potential for the cell is

$$
\Delta \mathrm{G}=\mathrm{nF} \mathcal{E}
$$

$\mathrm{n}$ is the number of electrons involved in the reaction, $\mathrm{F}$ is faradays constant and $\varepsilon$ is the equilibrium voltage, which sometimes is called the electromotive force. The value of $\boldsymbol{\varepsilon}$ is dependent on the actual partial pressures of the reactants as described by the Nernst equation. [3] If equation (2) is inserted in (1) we get

$$
\mathcal{E}=\Delta \mathrm{H} / \mathrm{nF}-\mathrm{T} \Delta \mathrm{S} / \mathrm{nF}
$$

Since both $\Delta \mathrm{H}$ and $\Delta \mathrm{S}$ are positive and approximately independent of $\mathrm{T}$ it is seen that $\boldsymbol{E}$ is decreasing with increasing temperature.

Hydrogen is formed at the negative electrode whenever a potential difference, $\mathrm{V}$, larger than $\varepsilon$ is applied to the electrodes of the cell, and steam supply is sustained to the negative electrode. For this reason the necessary electrical power is reduced when formation of hydrogen is taking place at high temperature. The electric energy demand, given in units of $\mathrm{kWh} / \mathrm{Nm}^{3}$ is illustrated in Fig. 1. The electrical power is determined as -IV, since the current, I, is taken to be negative in electrolysis mode and positive in fuel cell mode.

The passage of current will generate heat inside the cell due to the internal cell resistance in an amount equal to $(\varepsilon-\mathrm{V}) \mathrm{I}$. If a voltage equal to $\Delta \mathrm{H} / \mathrm{nF}$ is applied to the electrodes, the joule heat deposited pr. unit time in the cell is

$$
(\mathcal{E}-\mathrm{V}) \mathrm{I}=(\Delta \mathrm{G} / \mathrm{nF}-\Delta \mathrm{H} / \mathrm{nF}) \mathrm{I}=-(\mathrm{T} \Delta \mathrm{S} / \mathrm{nF}) \mathrm{I}
$$

This is exactly the heat removal pr. unit time by the steam electrolysis process. For this reason $\Delta \mathrm{H} / \mathrm{nF}$ is called thermo neutral voltage.

Considerable Joule heat is unavoidable when electrolysis is done at a practical timescale with overall economy optimised. For this reason SOEC is an interesting technology since the produced joule heat can be utilized in the electrolysis. 


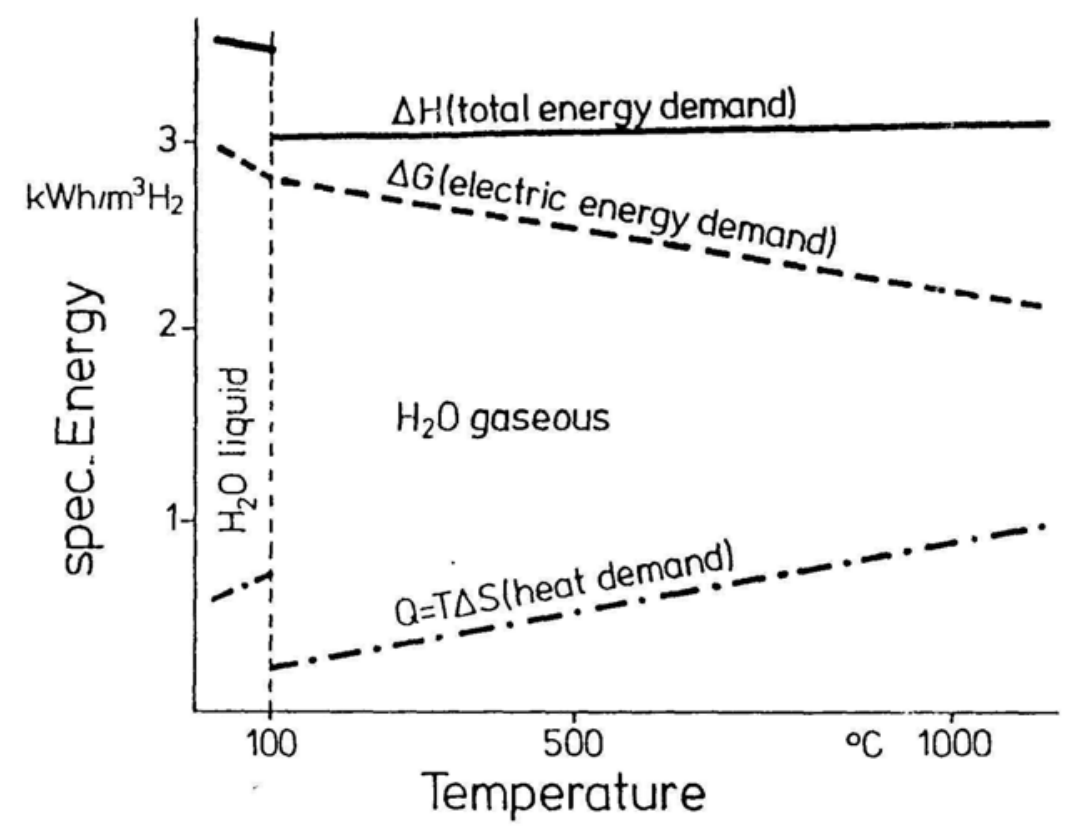

Figure 1. Thermodynamics of $\mathrm{H}_{2} \mathrm{O}$ electrolysis, after ref.[4].

The internal area specific resistance (ASR) for SOEC decreases rapidly with temperature following an Arrhenius expression.[5] Therefore, the Joule heat for a given current density and hydrogen production rate decreases rapidly with temperature. Along with the decreasing $\Delta \mathrm{G}$ the overall efficiency increases significantly with temperature. $\Delta \mathrm{G}$ as function of temperature is illustrated in Fig.1.

The optimal voltage is, in case only electrical energy is supplied, close to the thermo neutral voltage, where $\mathrm{nFV}$ and $\Delta \mathrm{H}$ is equal. Due to heat losses to the surroundings and the necessary evaporation of liquid water, $\mathrm{nFV}$ has to be slightly higher than $\Delta \mathrm{H}$. If excess heat at temperatures above the boiling point of water $\left(100^{\circ} \mathrm{C}\right)$ is available then the operating voltage can be decreased towards the thermo neutral voltage. If heat with a temperature above the cell operation temperature is available the only electrical energy needed is $\Delta \mathrm{G}$ plus the energy to overcome the loss due to the ASR. Thus, if the temperature is high enough the cell operating voltage may approach $\boldsymbol{E}$. The detailed optimisation must take into account the actual circumstances including the thermal loss from the electrolyser to the surroundings, which in turn depends on how well the SOEC system is insulated. In fact the real important optimisation parameters are the investment costs and the cost of electricity.

Electrolysis of a mixture of $\mathrm{CO}_{2}$ and $\mathrm{H}_{2} \mathrm{O}$ forms syngas, a mixture of $\mathrm{CO}$ and $\mathrm{H}_{2}$. At temperatures below about $700^{\circ} \mathrm{C}$ syngas may react to form methane, $\mathrm{CH}_{4}$ :

$$
\mathrm{CO}+3 \mathrm{H}_{2} \rightarrow \mathrm{CH}_{4}+\mathrm{H}_{2} \mathrm{O}
$$

This reaction requires an appropriate catalyst. Dispersed metallic nickel is the catalyst of preference for this. Fortunately, the SOEC negative electrode is usually made of a composite of Ni and YZS (yttria stabilised zirconia), a Ni-YSZ-cermet, and thus, there is in principle a possibility of forming $\mathrm{CH}_{4}$ directly in the SOEC by electrolysis of steam and $\mathrm{CO}_{2}$ mixtures. The possible concentration of methane that can be obtained without producing equilibrium carbon is decreasing with increasing temperature, increasing with pressure, and decreasing with steam to carbon ratio [6] dry gas) can be produced at a negative electrode potential, $\mathrm{V}=-1279 \mathrm{mV}$ vs. air without producing equilibrium carbon. At $150 \mathrm{~atm}$ and $650^{\circ} \mathrm{C}$, a mixture of $85 \%$ methane and $15 \%$ hydrogen dry gas with small concentrations of $\mathrm{CO}$ and $\mathrm{CO}_{2}$ can be produced without producing equilibrium carbon, at $\mathrm{V}=-1081 \mathrm{mV}$ vs. air. It is believed that methane could be produced in SOEC at these pressures, with acceptable costs. The $150 \mathrm{~atm}$ is taken as an example in analogy to the production of ammonium, which is normally synthesised at pressures around $150 \mathrm{~atm}$. [7] 


\section{Experimental}

The cell used was a DK-SOFC 2nd generation cell [8] [9] with a working area of $16 \mathrm{~cm}^{2}$. It had in the fuel cell mode an ASR of $0.20 \Omega \mathrm{cm}^{2}$ at $850^{\circ} \mathrm{C}$ after correction for fuel utilization at $40 \mathrm{~A}$ with $20 \mathrm{l} / \mathrm{h}$ [10] wet hydrogen used as fuel, when tested in fuel cell mode.

The cell test set-up is described elsewhere.[10] A temperature controlled water vaporization bottle was inserted on the hydrogen inlet string in order to increase the water (steam) content in the inlet gas. After characterization in fuel cell mode the cell was tested in electrolyser mode.

$\mathrm{Ni}$ in the Ni/YSZ-electrode of SOFC-cells is reduced from NiO at start up of a new cell. Ni has to stay reduced since cyclic oxidizing and reducing, destroys the cell due to differences in size of the unit cell of $\mathrm{NiO}$ and $\mathrm{Ni}$. When the cell is used as a fuel cell this is done by constantly feeding the cell with a reducing atmosphere as hydrogen. In SOEC it is believed to be possible to reduce the $\mathrm{Ni}$ with hydrogen in a short start-up period, and then keep the Ni reduced solely by keeping up the cell voltage V. The cell was not tested at thermo neutral potential with pure steam as inlet gas because a suitable steam supply was not available, and the maximum current of the cell test set-up is $40 \mathrm{~A}$ at $850^{\circ} \mathrm{C}$.

Also an attempt to produce methane directly by electrolysis of $\mathrm{H}_{2} \mathrm{O}$ and $\mathrm{CO}_{2}$ was made. The presented experiment was carried out at $1 \mathrm{~atm}$, and serves only to test if methane actually can be produced by means of electrolysis. The concentration of produced methane was measured by gas chromatography (GC). 


\section{Results}

Fig. 2 shows an i-V-curve obtained at $1000^{\circ} \mathrm{C}$ with an inlet gas flow $22.1 \mathrm{1} / \mathrm{h}$ steam and $14.3 \mathrm{l} / \mathrm{h} \mathrm{H}$.

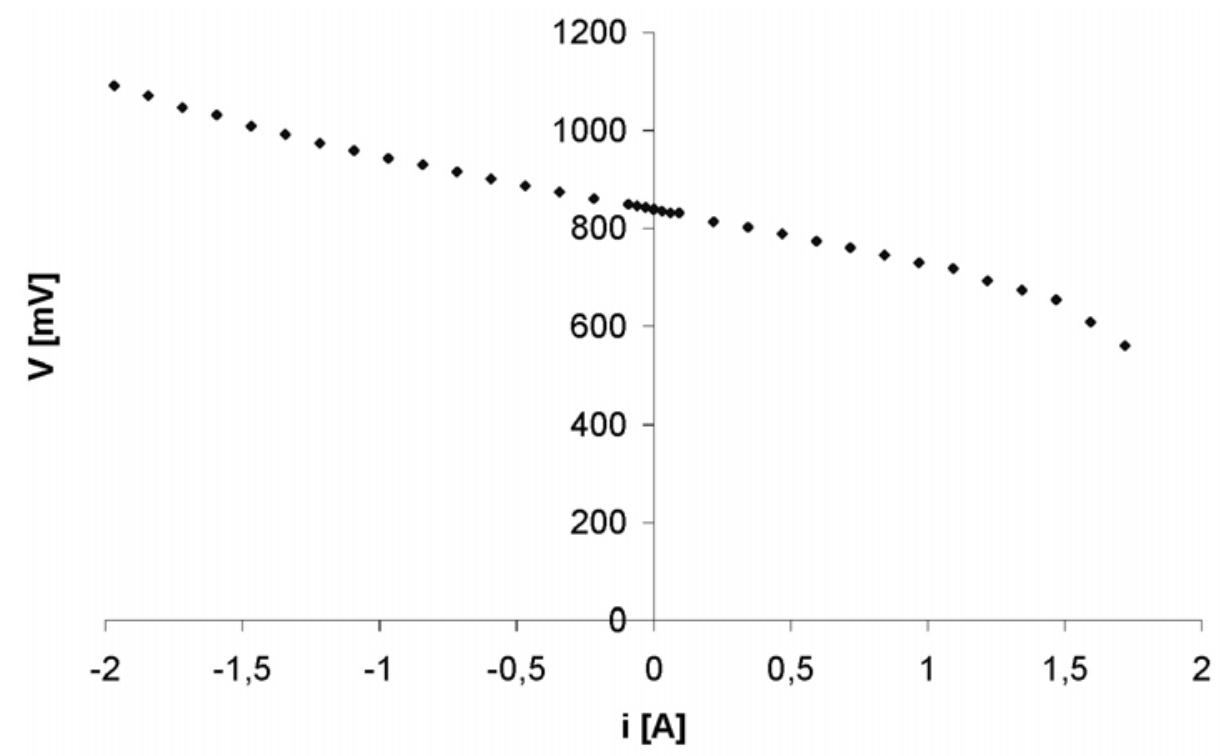

Figure 2. Cell voltage $V$, as a function of current density $i$. The active cell area is $16 \mathrm{~cm}^{2}$. Temperature was $1000^{\circ} \mathrm{C}$. Gas flow: $\mathrm{H}_{2}=14.3 \mathrm{l} / \mathrm{h}, \mathrm{H}_{2} \mathrm{O}=22.1 \mathrm{l} / \mathrm{h} . \mathrm{H}_{2}$ utilization at $1.72 \mathrm{~A} / \mathrm{cm}^{2}$ is $88 \% . \mathrm{H}_{2} \mathrm{O}$ utilization at $-1.97 \mathrm{~A} / \mathrm{cm}^{2}$ is $65 \%$. Negative current density refers to electrolyser mode and positive to fuel cell mode. The voltage drop when the cell is used as fuel cell at high current is due to high fuel utilization

From Fig. 2, the $\mathrm{H}_{2} \mathrm{O}$ conversion corrected area specific resistance (CCASR) of the cell was calculated at various currents. In a computer simulation the cell was divided into 100 strips perpendicular to the direction of the steam flow. $\varepsilon$ was calculated from the Nernst equation for the first strip. A first guess for CCASR was used in order to calculate the current through the first strip. Remembering the cell area was $16 \mathrm{~cm}^{2}$, the current through the first strip $I_{\text {strip }}$ was calculated as

$$
\frac{(\varepsilon-V) 16 \mathrm{~cm}^{2} / 100}{\operatorname{CCASR}}=I_{\text {strip }}
$$

$I_{\text {strip }}$ was then used to calculate the change in gas composition at the negative electrode. The new gas composition was used to calculate $\mathcal{E}$ for the next strip. V was taken to be equal over the whole cell ${ }^{\dagger}$. Using (5) $I_{\text {strip }}$ was calculated for the second strip. This calculation was repeated until the last strip. The sum over all $\mathrm{I}_{\text {strip }}$ is the total current. CCASR was found by iteration as the resistance that resulted in the correct total current for a given $\mathrm{V}$ in Fig. 2. The results are presented in Fig. 3.

\footnotetext{
${ }^{\dagger}$ At $\mathrm{I}=-30 \mathrm{~A}$ the in-plane voltage drop was measured to $-5 \mathrm{mV}$ and $\mathrm{V}$ was measured in the range from 1072 to $1120 \mathrm{mV}$. This gives an error no greater than $5 \mathrm{mV} / 1072 \mathrm{mV}=0.5 \%$.
} 


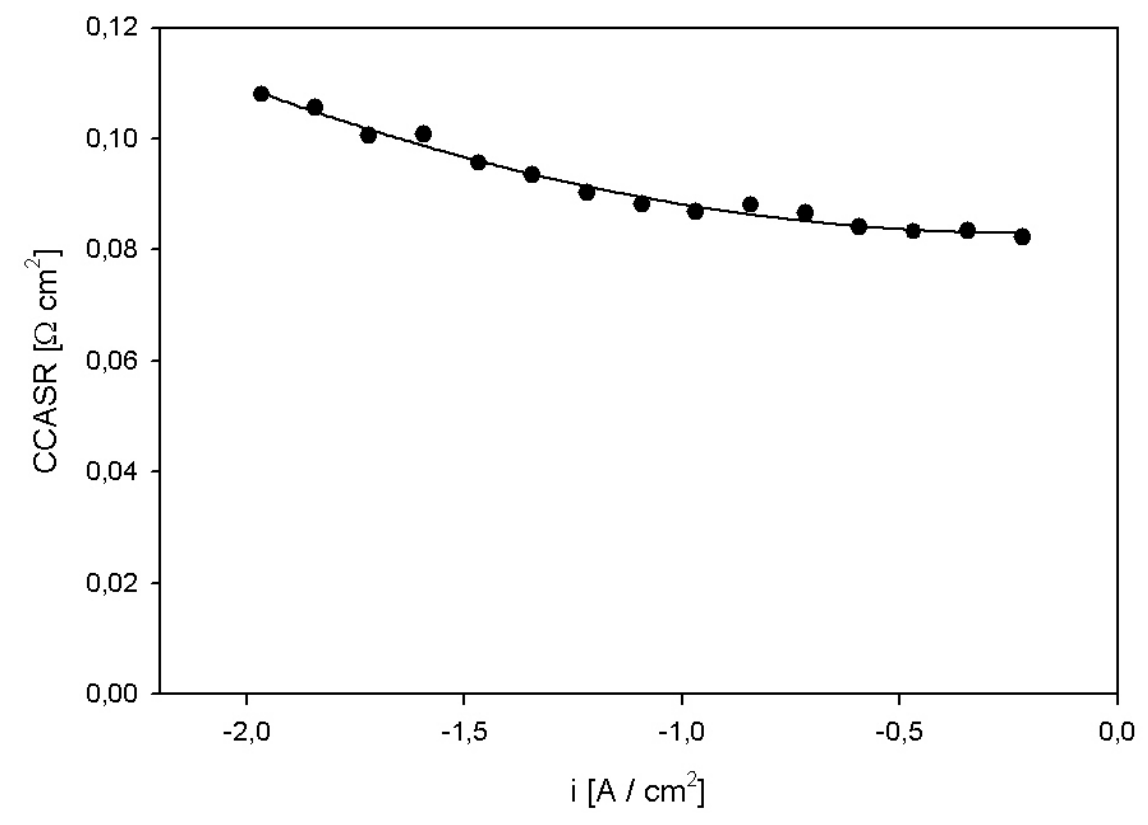

Figure 3. Conversion corrected ASR (CCASR) as function of current density, i. Negative current densities refers to electrolysis mode. CCASR is calculated from values in Fig. 2. The calculation method is described in text. The data was fitted to a 2nd order polynomial in order to calculate (by extrapolation) CCASR at higher currents

CCASR was fitted with 2. order polynomial. The fit (shown in Fig. 3) was then implemented in the above described computer model of the cell in order to calculate a total current at a given inlet gas condition and cell voltage.

The cell was tested for 14 hours. Some degradation of the cell was seen as showed in Fig. 4.

Cell voltage vs. time

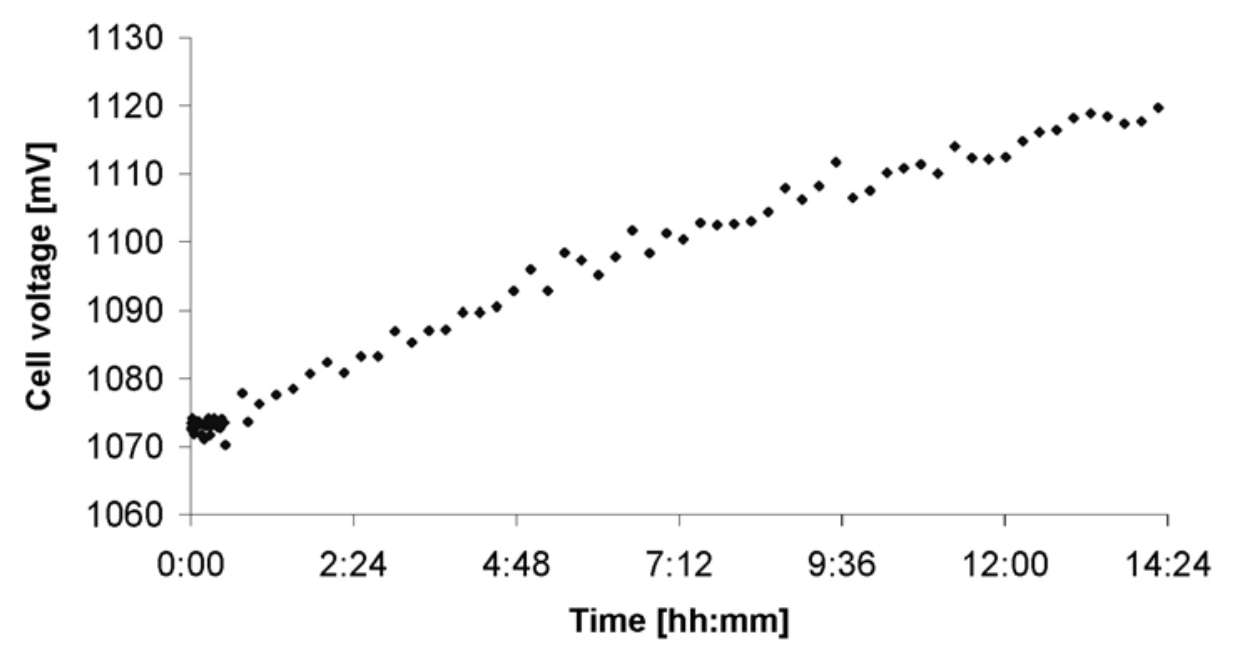

Figure 4. Cell voltage as a function of time. Test conditions were: $i=-1.875 \mathrm{~A} / \mathrm{cm}^{2}$, gas flow rates $23.3 \mathrm{l} / \mathrm{h}$ $\mathrm{H}_{2} \mathrm{O}+14.3 \mathrm{l} / \mathrm{h} \mathrm{H}_{2}$ at negative electrode, $140 \mathrm{l} / \mathrm{h}$ air at positive electrode. The $\mathrm{H}_{2} \mathrm{O}$ utilization was 58.7\%. The oxygen potential of the inlet gas was decreasing $1.5 \mathrm{mV}$ from start to end of test. Testing time was 14 $1 / 4 \mathrm{~h}$. The oxygen potential of outlet gas was decreasing $9 \mathrm{mV}$ from start to end of test. An average voltage increase due to cell degradation of ca. $2.7 \mathrm{mV} / \mathrm{h}$ was observed 
An i-V-curve was obtained just before the test, and another one was obtained just after, with the same test conditions. As a result of the degradation the ASR calculated from the $\mathrm{i}-\mathrm{V}$-curves showed a higher ASR for the cell after the test. The result is shown in Fig. 5.

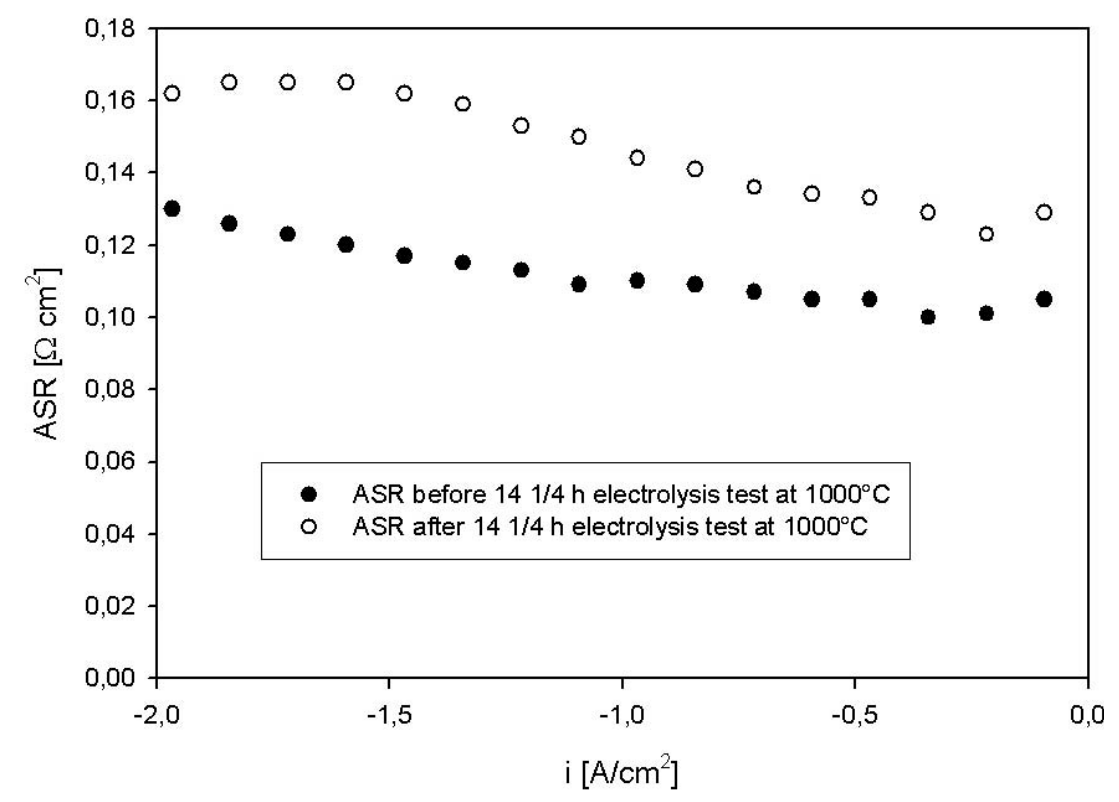

Figure 5. ASR calculated from IV-curves before and after test at $I=-1.875 \mathrm{~A} / \mathrm{cm}^{2}$. The $I V$-curves was obtained at the same conditions. Cell temperature $100{ }^{\circ} \mathrm{C}$, flow rates: $23.3 \mathrm{l} / \mathrm{h} \mathrm{H}_{2} \mathrm{O} / 14.3 \mathrm{l} / \mathrm{h} \mathrm{H}_{2}$ at the negative electrode, $140 \mathrm{l} / \mathrm{h}$ air at the positive electrode. It is seen that ASR has increased due to the electrolysis test

The cell temperature was lowered to $650^{\circ} \mathrm{C}$ and a gas flow to the negative electrode was set to $6.93 \mathrm{l} / \mathrm{h} \mathrm{H}$ $+1.02 \mathrm{l} / \mathrm{h} \mathrm{CO}_{2}+0.32 \mathrm{l} / \mathrm{h} \mathrm{H} \mathrm{H}_{2} \mathrm{O}$.

The oxygen potential at the inlet was measured to $-1110 \mathrm{mV}$ vs. air at $650^{\circ} \mathrm{C}$. The theoretical oxygen potential was calculated to $-1114 \mathrm{mV}$, assuming that no reaction had occurred between the $\mathrm{H}_{2}$ and $\mathrm{CO}_{2}$. The oxygen potential at the outlet was measured to $-1005 \mathrm{mV}$. The equilibrium oxygen potential was calculated to be $-1008 \mathrm{mV}$ indicating that equilibrium was reached. However, a severe air leakage into the negative electrode compartment of the cell was seen. $A \mathrm{~N}_{2}$ content of $67 \pm 16 \%$ was measured with gas chromatograph (GC) for the outlet gas. This means that equilibrium was not reached at the outlet from the cell.

The cell was then used to electrolyse the steam and carbon dioxide. The current density was $i=-0.188$ $\mathrm{A} / \mathrm{cm}^{2}$ at a cell voltage of $1671 \mathrm{mV}$. The calculated and measured concentrations of species are presented in Table 1 .

In order to reduce the relative size of the gas leakage, the inlet gas flow was increased.

The inlet gas was set to $24 \mathrm{l} / \mathrm{h} \mathrm{H}_{2}, 2.03 \mathrm{l} / \mathrm{h} \mathrm{CO}$ and $0.74 \mathrm{l} / \mathrm{h} \mathrm{H}_{2} \mathrm{O}$. A GC measurement was obtained for the inlet gas in order to see if the gas was going to equilibrium before the cell. Result is given in table 2, indicating that no equilibrium reaction has occurred yet.

The outlet gasses were measured by GC with no current, and the current was then set to $\mathrm{i}=$ $0.156 \mathrm{~A} / \mathrm{cm}^{2}$, and the gas were measured by GC once again. The results are presented in Table 2 . 
Table 1. Concentration of species before and after the cell. The second and third column is calculated from the first. The two last columns are measured by GC. Concentrations of species are given in vol \%. Uncertainties are estimated based on the differences to the concentrations in calibration gasses, and relative size. The relatively low uncertainties for $\mathrm{CH}_{4}$, is due to a very little relative change in the calibration constant for various $\mathrm{CH}_{4}$ concentrations for one of the columns of the GC, and because the measured concentration was close to the concentration in one of the reference gases. $\mathrm{H}_{2} \mathrm{O}$ was condensed out before $\mathrm{GC}$ measurement. $650^{\circ} \mathrm{C}$ and $1 \mathrm{~atm}$.

\begin{tabular}{|c|c|c|c|c|c|}
\hline & Cold inlet gas & $\begin{array}{l}\text { Equilibrium com- } \\
\text { position of Inlet } \\
\text { gas at } 650^{\circ} \mathrm{C}, 1 \\
\text { atm. }\end{array}$ & $\begin{array}{l}\text { Equilibrium } \\
\text { composition of } \\
\text { Inlet gas at } \\
650^{\circ} \mathrm{C}, 1 \mathrm{~atm}, \\
\mathrm{H}_{2} \mathrm{O} \text { condensed } \\
\text { out. }\end{array}$ & $\begin{array}{l}\text { GC measured } \\
\text { outlet gas, } \mathrm{i}= \\
0 \mathrm{~A} / \mathrm{cm}^{2}\end{array}$ & $\begin{array}{l}\text { GC measured } \\
\text { outlet gas, } \mathrm{i}=- \\
0.188 \mathrm{~A} / \mathrm{cm}^{2}\end{array}$ \\
\hline $\mathrm{H}_{2}$ & 83.8 & 68.7 & 83.8 & $5 \pm 2$ & $12 \pm 4$ \\
\hline $\mathrm{H}_{2} \mathrm{O}$ & 3.9 & 18.0 & & & \\
\hline $\mathrm{N}_{2}$ & 0 & 0 & 0 & $67 \pm 16$ & $62 \pm 14$ \\
\hline $\mathrm{CO}_{2}$ & 12.3 & 3.3 & 4.0 & $5.0 \pm 0.4$ & $3.3 \pm 0.2$ \\
\hline $\mathrm{CO}$ & 0 & 6.1 & 7.4 & $0.47 \pm 0.2$ & $1.0 \pm 0.2$ \\
\hline $\mathrm{CH}_{4}$ & 0 & 3.9 & 4.8 & $0.044 \pm 0.003$ & $0.160 \pm 0.004$ \\
\hline
\end{tabular}

Table 2. Concentration of species before and after the cell. The second and third column is calculated from the first. The two last columns are measured by GC. Concentrations of species are given in vol \%. The relatively low uncertainties for $\mathrm{CH}_{4}$, is due to a very little relative change in the calibration constant for various $\mathrm{CH}_{4}$ concentrations for one of the columns of the GC, and because the measured concentration was close to the concentration in one of the reference gases. $\mathrm{H}_{2} \mathrm{O}$ was condensed out before $\mathrm{GC}$ measurement. $650^{\circ} \mathrm{C}$ and $1 \mathrm{~atm}$.

\begin{tabular}{|l|l|l|l|l|l|c|}
\cline { 2 - 7 } & $\begin{array}{l}\text { Cold inlet } \\
\text { gas }\end{array}$ & $\begin{array}{l}\text { Equilibrium } \\
\text { composition } \\
\text { of Inlet gas } \\
\text { at } 650^{\circ} \mathrm{C}, 1 \\
\text { atm. }\end{array}$ & $\begin{array}{l}\text { Equilibrium } \\
\text { com- } \\
\text { position of } \\
\text { inlet gas at } \\
650^{\circ} \mathrm{C}, 1 \\
\text { atm, } \mathrm{H}_{2} \mathrm{O} \\
\text { condensed } \\
\text { out. }\end{array}$ & $\begin{array}{l}\text { GC meas- } \\
\text { ured inlet } \\
\text { gas }\end{array}$ & $\begin{array}{l}\text { GC measured } \\
\text { out-let gas, } \mathrm{i}= \\
0 \mathrm{~A} / \mathrm{cm}^{2}\end{array}$ & $\begin{array}{l}\text { GC measured } \\
\text { outlet gas, } \mathrm{i}= \\
-0.188 \mathrm{~A} / \mathrm{cm}^{2}\end{array}$ \\
\hline $\mathrm{H}_{2}$ & 89.3 & 77.7 & 90.5 & $91 \pm 2$ & $60 \pm 13$ & $61 \pm 13$ \\
\hline $\mathrm{H}_{2} \mathrm{O}$ & 3.1 & 14.1 & & & & \\
\hline $\mathrm{N}_{2}$ & 0 & 0 & 0 & $0.15 \pm 0.02$ & $34 \pm 9$ & $34 \pm 9$ \\
\hline $\mathrm{CO}_{2}$ & 7.6 & 1.2 & 1.4 & $5.9 \pm 0.4$ & $3.15 \pm 0.2$ & $2.8 \pm 0.1$ \\
\hline $\mathrm{CO}$ & 0 & 3.2 & 3.7 & 0 & $3.1 \pm 0.4$ & $3.3 \pm 0.4$ \\
\hline $\mathrm{CH}_{4}$ & 0 & 3.8 & 4.4 & 0 & $0.59 \pm 0.02$ & $0.78 \pm 0.03$ \\
\hline
\end{tabular}

An i-V-curve was obtained before and after the electrolysis of $\mathrm{CO}_{2}+\mathrm{H}_{2} \mathrm{O}$ in order to see if the cell had degraded. ASR was calculated and the results are presented in Fig. 6 


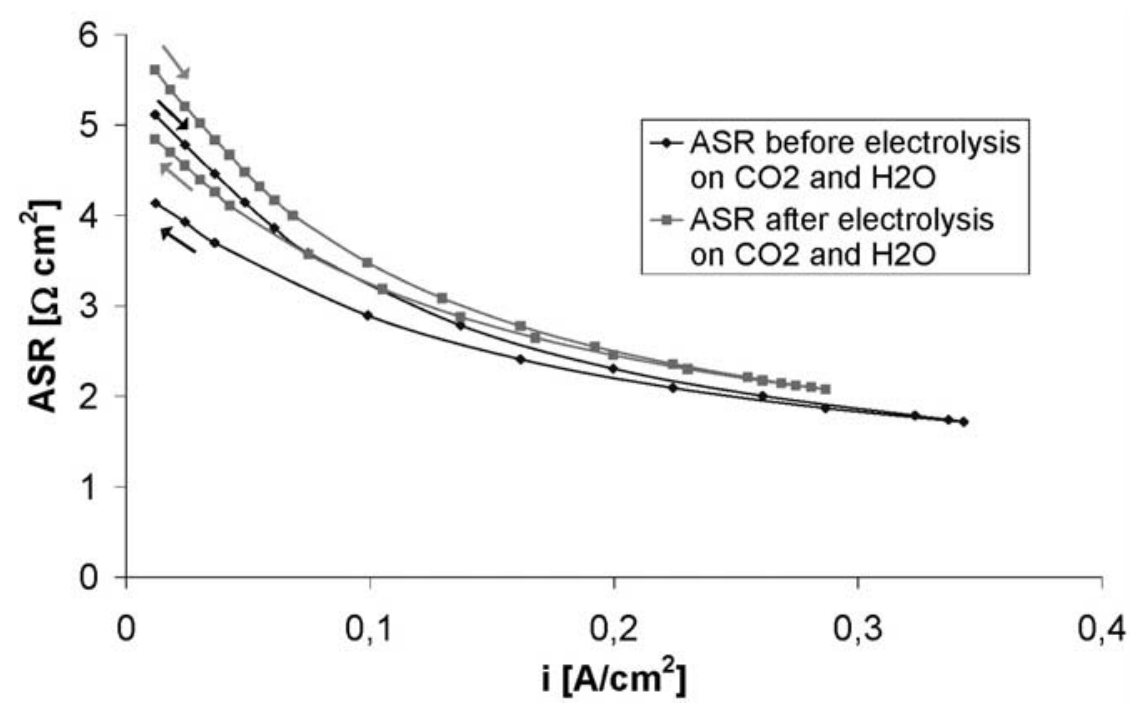

Figure 6. ASRs measured at $650^{\circ} \mathrm{C}$ in fuel cell mode before and after the electrolysis experiments at $650^{\circ} \mathrm{C}$. Gas flow was $24 \mathrm{l} / \mathrm{h} \mathrm{H}$ saturated in $24^{\circ} \mathrm{C}$ and $27^{\circ} \mathrm{C}$ water. Arrows indicate change in current with respect of time. The activation (decrease in resistance with time and current density) is believed to be due to the fuel cell cathode (the positive electrode), which is the most resistive component at $650{ }^{\circ} \mathrm{C}$. Some degradation is seen

\section{Discussion}

It is possible to calculate the size of the oxygen leakage into the negative electrode compartment of the cell from the theoretical oxygen potential (or the oxygen potential of the inlet gas) and the measured oxygen potential of the outlet gas. The $\mathrm{O}_{2}$ leak flow was calculated just before and after the $141 / 4 \mathrm{~h}$ steam electrolysis test at $1000^{\circ} \mathrm{C}$ showing a gas leak of $0.62 \mathrm{l} / \mathrm{h} \mathrm{O}$ before the test and $0.61 \mathrm{l} / \mathrm{h} \mathrm{O}$ after the test. For this reason the increasing cell voltage in the test is believed to be due to cell degradation.

The $\mathrm{O}_{2}$ leakage was calculated to $0.77 \mathrm{1} / \mathrm{h}$ before and $1.48 \mathrm{l} / \mathrm{h} \mathrm{O}_{2}$ after the electrolysis experiments at $650^{\circ} \mathrm{C}$. This means that the observed degradation in Fig. 6 could be due to an increased leakage.

The $\mathrm{pO}_{2}$ monitor $\left(\mathrm{pO}_{2}\right.$ means oxygen partial pressure) measuring the oxygen potential of the outlet gas is not situated at the same place as the outlet tube to the GC. This means that the leak seen by the GC is possibly not the same as the one calculated above.

The leakage to the negative electrode compartment will change the equilibrium composition of the gas towards less methane. This is believed to be the explanation for the low measured concentration of methane. In fact, the high $\mathrm{N}_{2}$ concentrations and low $\mathrm{H}_{2}$ concentrations measured with GC in the outlet gas, corresponds to an air leakage (and thus an $\mathrm{O}_{2}$ leakage) that would change the equilibrium concentration of $\mathrm{CH}_{4}$ to less than the observed $\mathrm{CH}_{4}$ concentration.

Changing to higher gas flow rates gives a relatively smaller leakage. This means that, the amount of $\mathrm{CH}_{4}$ produced at equilibrium is increased. Unfortunately the higher flow rates also gives smaller changes in gas compositions for given electrolysis currents.

If the $\mathrm{Ni}$ in the cell were a really bad catalyst the concentration of produced methane would decrease with increasing flow rate. Since the concentration of $\mathrm{CH}_{4}$ is seen to increase from $0.044 \%$ to $0.59 \%$ when the flow rate was increased, it is believed that the poor relative methane production rates is preferentially caused by a high $\mathrm{H}_{2} \mathrm{O}$ partial pressure due to the leakage of $\mathrm{O}_{2}$, which reacts with the $\mathrm{H}_{2}$ to $\mathrm{H}_{2} \mathrm{O}$.

The economy of this electrolysis process was estimated. To this end a steam flow to the negative electrode $\left(16 \mathrm{~cm}^{2}\right)$ was taken to be $25 \mathrm{l} / \mathrm{h}$ corresponding to $1.11 \mathrm{~mole} / \mathrm{h}_{2} \mathrm{O}$ and the cell voltage $\mathrm{V}=1290$ $\mathrm{mV}$. Using a first guess for CCASR a current was calculated by means of dividing the cell into 100 strips, and calculating the current through each strip, taking in to account the changing in gas composition due to the electrolysis. From the 2.order fit of Fig. 3, CCASR for this current was found. This value for CCASR 
was then used to calculate a new current. This iteration loop was carried out until a stable condition was reached where the calculated CCASR is consistent with the calculated current. With the above given conditions I was found to be $45.7 \mathrm{~A}$. The $\mathrm{H}_{2} \mathrm{O}$ utilization was found to $76.5 \%$. The hydrogen production rate is $19.1 \mathrm{l} / \mathrm{h}$ hydrogen produced.

A fuel cell stack having a cell area of $1429 \mathrm{~cm}^{2}$ is assumed to cost 300 US\$ [11]. When operated as SOEC at thermo neutral potential with an inlet $2230 \mathrm{l} / \mathrm{h}$ steam, it will have a power consumption of 5.3 $\mathrm{kW}$, and it will produce $76 \mathrm{~mol} \mathrm{H}_{2} / \mathrm{h}$.

The investment cost is taken to be 3 times the cost for one fuel cell stack e.g. 900 US\$, the depreciation time to be 10 years and the interest rate $5 \%$ per year. The production price of electricity is taken to be 1.3 US cents per $\mathrm{kWh}$ (this is at least realistic for hydroelectric power and geothermal power e.g. at Iceland) and it is assumed that the system is operated $50 \%$ of the time during the 10 years (low for hydroelectric but high for photovoltaic power plants). With these assumptions the price per $\mathrm{Nm}^{3} \mathrm{H}_{2}$ produced can be found to 5.5 US cents.

It should be noted that the oxygen partial pressure was taken to $1 \mathrm{~atm}$, in the above calculation. This means that pure oxygen was produced at the cathode. If the oxygen is collected and sold, the price per $\mathrm{Nm}^{3} \mathrm{H}_{2}$ may be lowered further.

\section{Conclusion}

The experiments reported here were of a preliminary character because of experimental problems with leakage of air into the $\mathrm{H}_{2} \mathrm{O}$ and $\mathrm{CO}_{2}$ containing gases, which were electrolysed. In spite of this it has been demonstrated that the Risø 2nd generation solid oxide fuel cell can work as an efficient solid oxide electrolyser cell for splitting of steam into hydrogen and oxygen at $1000^{\circ} \mathrm{C}$. The short durability test indicates, however, that much more research and development work is necessary in order to achieve an acceptable lifetime of the cells in electrolysis mode. If an acceptable lifetime of ten years is reached, it is estimated that hydrogen can be produced at a cost of 5.5 US cents per $\mathrm{Nm}^{3} \mathrm{H}_{2}$.

It was further shown that is possible to produce $\mathrm{CH}_{4}$ inside the solid electrolyser cell at $650^{\circ} \mathrm{C}$ from a gas mixture of $\mathrm{H} 2 \mathrm{O}$ and $\mathrm{CO}_{2}$. Both the experimental findings and theoretical considerations show that much higher pressures than one atmosphere and possibly lower temperatures than $650^{\circ} \mathrm{C}$ are necessary in order to obtain $\mathrm{CH}_{4}$ concentrations, which are commercially interesting.

\section{Acknowledgement}

The authors are grateful to the SOFC group at Risø for their support in this work. Especially helpful were the discussion with Dr. Peter Vang Hendriksen. 


\section{References}

[1] M. Mogensen, "Solid oxide fuel cells (SOFC) technology: Status, challenges and visions", in Proceedings of "How far are we from the Hydrogen Society?" Symposium on hydrogen - electrochemistry and energetics, Trondheim (NO), 16-18 Jun 1999. (NTNU, Department of Materials Technology and Electrochemistry, Trondheim, 2000. p. 69-79.

[2] DONG Energi-Service, "Naturgas lagrene i Ll. Torup og Stenlille" ("The natural gas storages in L1. Torup and Stenlille"), DONG Kommunikation, September 2002.

[3] Any decent textbook in physical chemistry or electrochemistry, see e.g. P.W. Atkins, Physical Chemistry, 5th edition, Oxford University Press, 2002. p. 331 - 342.

[4] E. Erdle, J. Gross, V. Meyringer, "Solar thermal central receiver systems", In Proceedings of the Third International Workshop Vol. 2 High temperature and its Applications. June 23-27, 1986, Konstanz, federal Republic of Germany.

[5] P.V. Hendriksen, S. Koch, M. Mogensen, Y. L. Liu and P. H. Larsen, "Break down of losses in thin electrolyte SOFCs", in Proceedings of the 8th International symposium on solid oxide fuel cells (SOFC-VIII), Paris, April 27 -May 2, 2003. Singhal, S.C.; Dokiya, M.; (eds.), (The Electrochemical Society, Pennington, NJ), in press.

[6] J. R. Rostrup, Steam Reforming and Catalysts, Danish technical Press, Copenhagen, Denmark 1975.

[7] C. J. H. Jacobsen, J. Dohrup, I. Schmidt, Katalyse. Introduktion til kemien bag katalytiske processer, (Catalysis. Introduction to the chemistry behind catalytic processes), Gl. Holte bogtryk, Lyngby, Denmark, 1999.

[8] N. Christiansen, S. Kristensen, H.H. Larsen, P.H. Larsen, M. Mogensen, P.V. Hendriksen, S. Linderoth, "Status of SOFC Development at Haldor Topsøe / Risø", in Proc. 5th European SOFC Forum, J. Huijsmans (Eds.) European Fuel Cell Forum, Oberrohrdorf $(\mathrm{CH})$, 2002, p. 34-41.

[9] K Kammer, P.H. Larsen, Y.L. Liu, B. Kindl, M. Mogensen, "Development of ThinElectrolyte Solid Oxide Fuel Cells", in Proc. 5th European SOFC Forum p. 34-41, Roskilde, Denmark, 1-5 July 2002

[10] M. Mogensen, P.V. Hendriksen and K. K. Hansen, "Strategies for testing of SOFC and electrodes", in Proc. 5th European SOFC Forum, J. Huijsmans (Eds.) European Fuel Cell Forum, Oberrohrdorf (CH), 2002,p. 893-902.

[11] M. Mogensen, C. Bagger. "SOFC: The key to make renewable energy profitable?" in Program and abstracts of 1998 Fuel cell seminar, Palm Springs, CA (US), 16 - 19 Nov 1998. Courtesy Associates Inc., Washington, DC, 1998, p. 96-99. 


\title{
Solid Oxide Fuel Cells - Assessment of the Tech- nology from an Industrial Perspective
}

\author{
Jens Pålsson, John Bøgild Hansen, Niels Christiansen, Jens Ulrik Nielsen, Steen Kristensen \\ Haldor Topsøe A/S, Lyngby, Denmark
}

\begin{abstract}
Fuel cells can play a large role in future energy supply as being a clean and efficient power and heat generator. One promising fuel cell type, SOFC, utilises mainly ceramic materials and operates at elevated temperatures. The inherent advantages of high temperature fuel cells, such as internal reforming of methane and waste heat production at high temperatures, lower the demands on the fuel processing system and lead to higher efficiency compared with low temperature fuel cells.

Haldor Topsøe A/S has been active in the fuel cell area for a long time primarily in the fuel processing field. Today, the company has an extended development programme to bring to market SOFC technology. The cell design used is the planar SOFC from Risø National Lab., which is of the anode-supported type.

This paper deals with a thermodynamic analysis of an atmospheric SOFC based CHP system. Using natural gas as feed, an electric efficiency of more than $55 \%$ (88\% total) was predicted. In a comparison made with a PEMFC or solid polymer fuel cell system, the SOFC system comes out superior. An exergy analysis showed relatively small losses of the SOFC system compared with those of the PEMFC system.

In a separate study on flow design for the stack it was found that the preferred flow geometry is counter-current flow, as a more homogeneous temperature profile can be achieved. However, it puts higher demands on the gas manifolding than a cross-flow configuration does. The difference in stack size (power density) was substantial.

Very low NOx emissions can be expected from a SOFC system employing a catalytic combustor for the unspent fuel. Also, carbon dioxide emissions are lower than state of the art gas turbines and diesel engines. Although system performance and emissions are predicted to be extremely good, the road to success depends also on the installation cost. A short to medium term cost goal of $1000 \mathrm{USD} / \mathrm{kW}$ is within reach.
\end{abstract}




\section{Introduction}

Fuel cells, aimed for energy production and vehicle propulsion, have attained a great deal of interest in the last decade. The reasons are many: the prospects for high efficiency, low emissions, low noise, scalability, reliability and finally potentially low cost. The technology is now moving from a research and test phase into an industrial development and demonstration phase. One of the most interesting applications are stationary decentralised power and heat units in the $200+\mathrm{kW}$ range, which are suitable among others in the industrial, commercial and residential sectors.

Exergy analysis is carried out to identify and quantify the losses arising in the systems. Ordinary energy analyses uses the $1^{\text {st }}$ law of thermodynamics, simply counting the Joules and considering them to be of equal value. Energy accounting does not show where and to what extent energy is degraded. If the $2^{\text {nd }}$ law of thermodynamics is also invoked it is possible to use the concept of exergy, which is the ideal work a given stream can perform using reversible processes.

\section{The SOFC project at Haldor Topsøe A/S}

The first generation of SOFCs was based on the electrolyte-supported cell concept with relatively thick electrolytes. In order to obtain a reasonably high electrical performance these cells had to operate within a quite narrow temperature range of $900-1000^{\circ} \mathrm{C}$. The high operation temperature imposes strong demands on the associated fuel processing and air handling system, and the use of cheap standard type steels for interconnects and heat exchangers is excluded. Since the stack cost increases almost linearly with the area-specific resistance, the operation temperature of SOFCs should only be lowered if the Area Specific Resistance can be improved.

At present the anode-supported cell is one of the most promising concepts to reduce the operation temperature of SOFC systems to below $800^{\circ} \mathrm{C}$. Generally, high performance anode-supported cells offer a much higher degree of freedom in the design of the total stack and fuel processing system. The electrolyte thickness is only 10-15 microns compared to ca. 150 microns for electrolyte-supported cells.

A consortium of HTAS and Risø National Lab has established a pilot plant for production of anode supported cells. The pilot plant has now been in operation for more than one year. The production line comprises equipment for large-scale slurry preparation, a 20-m long continuous tape casting machine, automated spray deposition facilities, cell punching equipment and batch sintering furnaces. The manufacturing process allows continuos production of cells in various shapes and sizes up to $20 \mathrm{~cm}$ width, see Fig. 1. Currently, the bottleneck is the size and numbers of the batch-operated furnaces, limiting the production capacity to about $1 \mathrm{MW}$ p.a.

HTAS is carrying out development and test with stacks of $12 \times 12 \mathrm{~cm}^{2}$ cells. In parallel with these activities, other critical material problems are being investigated. The stack material characterisation is focused on high temperature corrosion of ferittic stainless steel interconnects, development of glass seals and contact coatings. For more information on the SOFC development programme, please refer to [1]. 


\section{Anode-supported Cells}

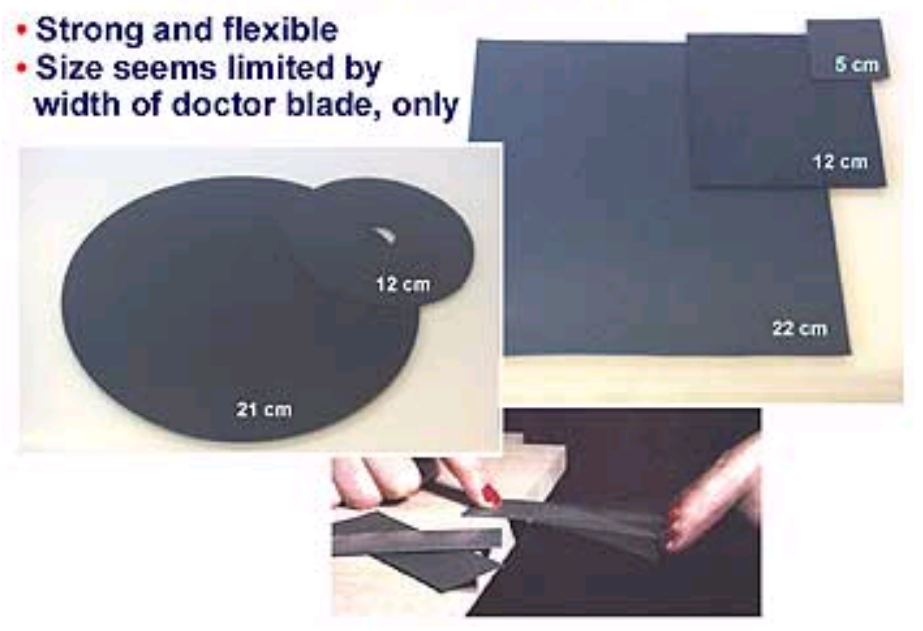

Figure 1. View of anode-supported SOFC cells of various geometry

\section{System Analysis}

\subsection{SOFC Modelling approach}

The principles of a solid oxide fuel cell are described elsewhere, as example in [2]. On the fuel side (anode) a hydrogen rich gas enters reacting with oxygen ions from the electrolyte to form water and at the same time releasing electrons. The electrons pass an external circuit producing power on its way to the air electrode (cathode) where oxygen from the air is reduced to oxygen ions. Individual cells are stacked to yield a sufficient voltage and power output, where an interconnect or bipolar plate connects electrically one cell with another.

The stack model, originally developed at Risø National Lab [3], is based on the method of finite volumes where each repeating element, unit cell, is assumed to have homogenous conditions. Mass and energy balances are formulated and solved for each unit cell resulting in an overall temperature and concentration profile for the stack. In the model the following chemical reactions are considered assuming direct internal reforming in the anode chamber:

(1) Reforming:

$$
\begin{aligned}
& \mathrm{CH}_{4}+\mathrm{H}_{2} \mathrm{O} \rightarrow \mathrm{CO}+3 \mathrm{H}_{2} \\
& \mathrm{CO}+\mathrm{H}_{2} \mathrm{O} \rightarrow \mathrm{CO}_{2}+\mathrm{H}_{2} \\
& \left.\left.\mathrm{O}_{2} \text { (cathode }\right)+2 \mathrm{H}_{2} \text { (anode }\right) \rightarrow 2 \mathrm{H}_{2} \mathrm{O}+\text { heat }
\end{aligned}
$$$$
\text { (3) Oxidation: }
$$

Reaction 1 and 2 take place on the anode side. They are catalysed by the anode structure and effective rate constants can be found. The flow-rate on anode and cathode side together with the rates for the three chemical reactions are used to find the concentration of all species in each unit-cell together with the released heat (from the enthalpy of the reactions). Based on heat transfer via conduction, convection and radiation, the resulting temperature profile for the stack is found.

The results of the model are 3-dimensional tables with concentration profiles of all species, a temperature profile of the complete stack and the voltage of each cell. The current is obtained through Faraday's law and the power output by multiplication of current and voltage. The relative amount of spent fuel, fuel utilisation, is defined as input and the cell voltage as output, however, the reverse can also be the case.

The stack model has been implemented into a general heat and mass balance program, GHEMB, which is an in-house proprietary code with a sequential solver developed and used at HTAS. A number of standard unit operation models are included in its library such as reformer reactors and heat exchangers. The 
stack model, which can consider three-dimensional problems, is simplified to a two-dimensional (crossflow design) or even a one dimensional (counter-flow or co-flow design) problem in the process simulations in order to avoid excessive CPU times.

\subsection{SOFC System Design}

An atmospheric SOFC system for CHP applications is considered with an electrical net output of $250 \mathrm{~kW}$. The stand-alone system is a simpler approach than the hybrid SOFC and gas turbine technology, which has widely been reported achieving high efficiency, as example [4]. However, as a first step towards demonstration and commercialisation the least risky path must be pursued. In addition, thanks to the good anode-supported cell performance, these atmospheric systems are expected to reach electric efficiencies exceeding $50 \%$ as will be shown below.

In the system Danish natural gas, with a composition given in Table 1 , is preheated to $400{ }^{\circ} \mathrm{C}$ and desulfurised. The feed will then, during normal operation, be mixed with recycled anode off-gases to provide steam and heat to an adiabatic pre-reformer, see Fig. 2. Here all heavy hydrocarbons are steam reformed to form a mixture of methane, hydrogen, carbon monoxide and carbon dioxide. A final in/out heat exchanger will increase the inlet fuel gas temperature to around $650^{\circ} \mathrm{C}$. On the cathode side air is compressed in a blower and preheated in an in/out heat exchanger to about the same temperature. The cathode off-gases, consisting of depleted air, are sent partly to a catalytic burner together with anode-off gases. The rest of the cathode off gases together with flue gases will deliver heat to a Heating Ventilation and Air Conditioning (HVAC) system. The burner exhaust gases are also used for steam generation during the start up phase and for fuel preheating.

In the calculations heat loss to surrounding has been neglected. The fuel utilisation of the stack is set to $85 \%$, whereas the total fuel utilisation is somewhat higher thanks to anode recycling. Other assumptions are given in Table 2. The study has been based on fuel cell stacks consisting of $12 \times 12-\mathrm{cm}^{2}$ shaped fuel cells consistent with the stack development programme. In the stack the fuel and air streams are assumed to flow in a counter-current arrangement, however, other flow geometry will also be studied.

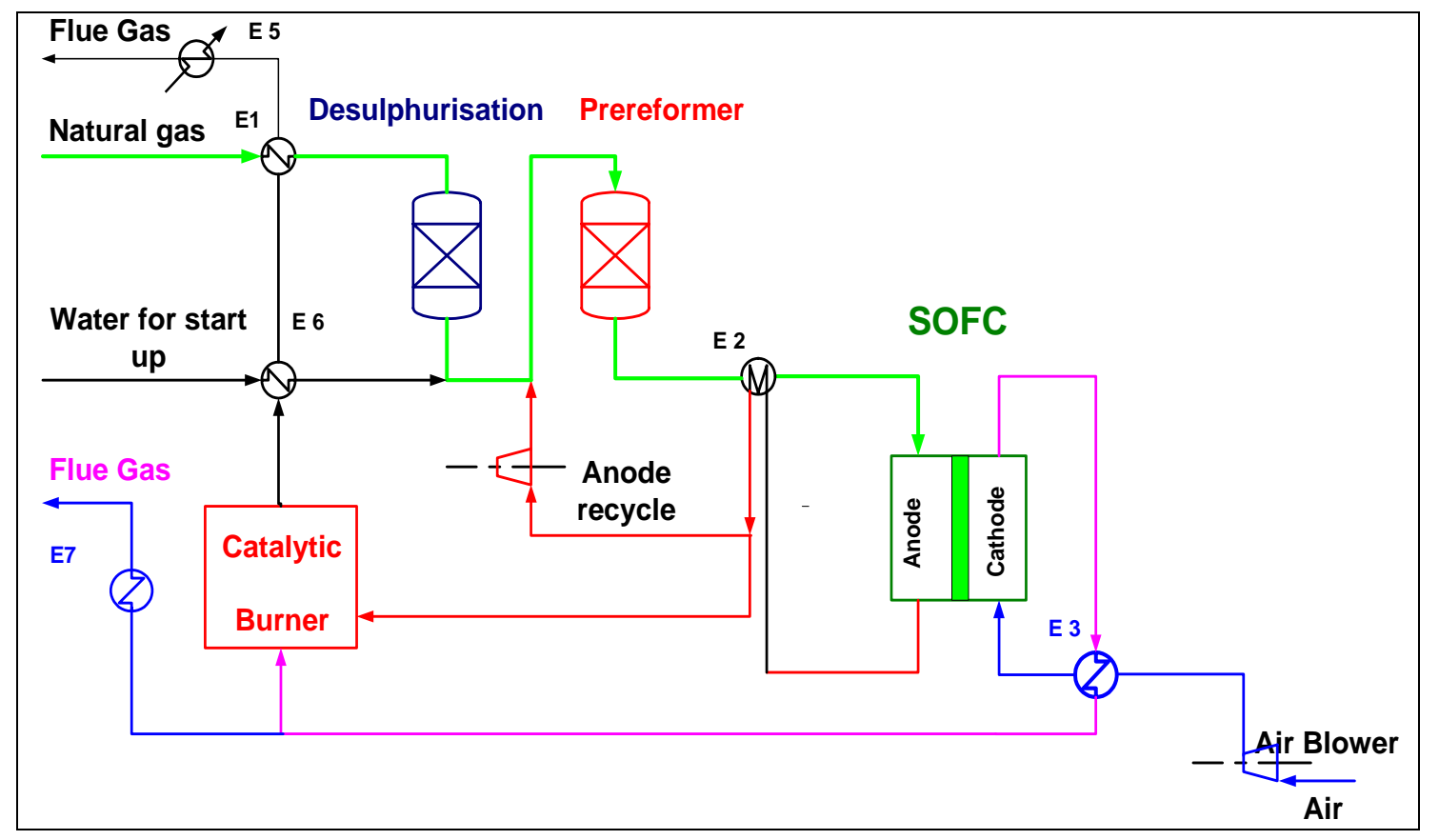

Figure 2. Basic lay-out of the $250 \mathrm{~kW}$ SOFC based CHP system 
Table 1. Composition of fuel used in simulation (Danish natural gas).

\begin{tabular}{|l|l|l|l|l|l|l|l|l|l|}
\hline Component & $\mathrm{CH}_{4}$ & $\mathrm{C}_{2} \mathrm{H}_{6}$ & $\mathrm{C}_{3} \mathrm{H}_{8}$ & $\mathrm{C}_{4} \mathrm{H}_{10}$ & $\mathrm{C}_{5} \mathrm{H}_{12}$ & $\mathrm{C}_{6} \mathrm{H}_{14}$ & $\mathrm{~N}_{2}$ & $\mathrm{CO}_{2}$ & $\mathrm{H}_{2} \mathrm{~S}$ \\
\hline Vol. \% & 88.1 & 6.4 & 2.8 & 1.0 & 0.18 & 0.06 & 0.3 & 1.3 & $10 \mathrm{ppm}$ \\
\hline
\end{tabular}

Table 2. Assumptions for the base case of the system.

\begin{tabular}{|l|c|c|}
\hline Flue gas temperature & ${ }^{\circ} \mathrm{C}$ & 70 \\
\hline Cell voltage & $\mathrm{V}$ & 0.75 \\
\hline Anode recycle ratio & $\%$ & 50 \\
\hline Air compressor efficiency & $\%$ & 72 \\
\hline Anode recycle compressor efficiency & $\%$ & 55 \\
\hline Power electronics (inverter) efficiency & $\%$ & 95 \\
\hline Exhaust temperature from burner & ${ }^{\circ} \mathrm{C}$ & 700 \\
\hline
\end{tabular}

\subsection{PEMFC based system}

The Solid Polymer Fuel Cell or PEMFC has attracted a lot of attention and research efforts in the last decade, especially for mobile applications. The PEMFC has several advantages for mobile applications such as operation close to ambient temperature and fast start-up. The PEMFC will also be the preferred choice for UPS systems, lap top computers and other similar appliances. The disadvantage of the PEMFC is mainly the need for very pure hydrogen as feed. State of the art PEMFC system can not tolerate much more than $50 \mathrm{ppm}$ of $\mathrm{CO}$ in the anode feed without serious deterioration of performance. The water management around the PEMFC is also complicated and waste heat is only available at moderate temperatures.

It is interesting to also consider PEMFC systems for stationary intermediate scale Combined Heat and Power production, because if the PEMFC will be mass produced for mobile applications there is a potential for low cost stacks, despite the significant content of noble metals $(\mathrm{Pt} / \mathrm{Ru})$ in the electrode catalysts. A design of a $250 \mathrm{~kW}$ system, as depicted in Fig. 3, has thus been studied in order to compare with the SOFC system.

The natural gas, with a composition as above, is assumed delivered at around 4 bar, because the optimum operating pressure of a PEMFC has been reported around 3 bar [5]. In the system the feed is preheated and desulfurised before steam is added. Steam reforming is carried out in a heat exchange reformer, where heat is supplied to the reforming catalyst bed both from hot flue gas and by the exit gas from the reforming catalyst bed. The $\mathrm{CO}$ content in the gas is first lowered to a few thousand ppm in a shift section and finally brought down below $50 \mathrm{ppm}$ in a preferential oxidation step (PROX), where CO is selectively oxidised to $\mathrm{CO}_{2}$ with air. 
The exit gas from the PROX is cooled down to $80^{\circ} \mathrm{C}$, delivering heat to an HVAC system, before entering the anode. The PEMFC is cooled by water which also delivers heat to the HVAC system. Unused fuel, $\mathrm{H}_{2}$ and some $\mathrm{CH}_{4}$, is combusted under pressure together with off gas from the cathode after cooling, condensation and separation of water which is reused in the process as boiler feed water. An additional amount of fuel is added to the combustor in the form of desulfurised natural gas.

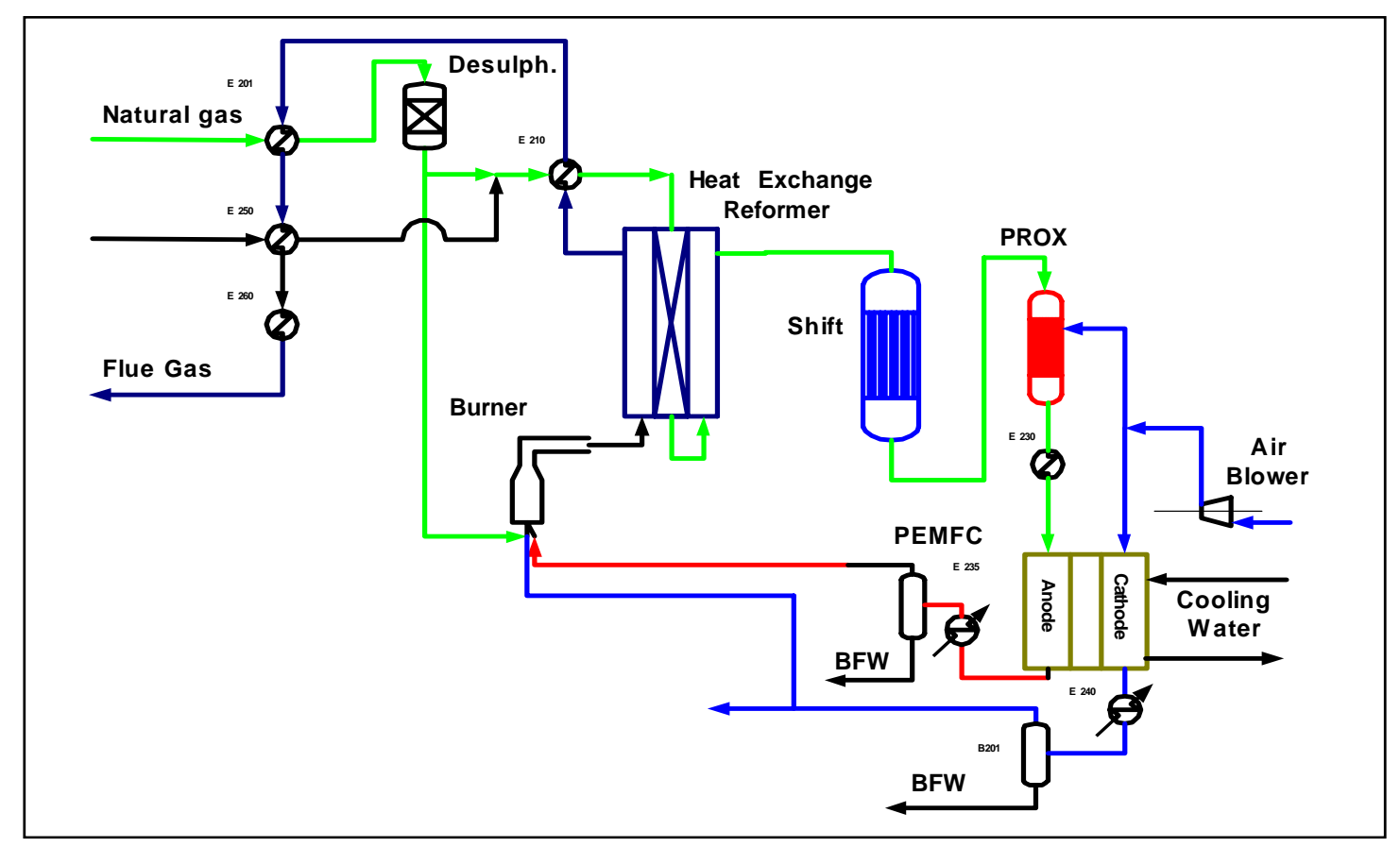

Figure 3. Basic lay-out of a $250 \mathrm{~kW}$ PEMFC based CHP system

The hot flue gas from the burner, which may be of catalytic or thermal type, delivers heat directly to the heat exchange reformer and furthermore provides reformer feed preheat, natural gas prehat and steam generation before excess heat is delivered to the HVAC system.

The assumptions used in the PEMFC study are mainly the same as in the SOFC study, see section 3.2. However oxygen utilisation is set at $50 \%$, because air is not used as stack coolant as in the SOFC system. Also, exhaust gas temperature from the burner is assumed to be $1115{ }^{\circ} \mathrm{C}$ to provide enough heat for the steam reformer.

\section{Results}

\subsection{Stack flow configuration}

The simulation of above described SOFC system yields an electric efficiency of nearly $56 \%$ and a total efficiency of $88 \%$. The airflow has been determined from a maximum solid temperature of the stack of $810{ }^{\circ} \mathrm{C}$ resulting in an oxygen utilisation around $16 \%$. Further, the corresponding temperature increase over the stack is $113^{\circ} \mathrm{C}$. The fuel flow and stack size (number of identical cells) has been determined from a net power output requirement of $250 \mathrm{~kW}$. In this base case calculation the stack produces $297 \mathrm{~kW}$ DC after which inverter losses and auxiliary power losses (compressor work) gives the net power output AC. The estimated performance of this simple cycle SOFC system is higher than what other SOFC developers aim for $[6,7]$. 
Two other cases were investigated using different flow geometry of the stack (cross-flow and co- flow design), see Fig. 4. For gas manifolding the cross flow design is the simplest solution, however, from a cell performance point of view the counter flow design is a better choice as a more homogeneous temperature profile can be achieved. This is due to coinciding location for heat demand (internal reforming reaction) with available heat (heated air). These conclusions have been reported elsewhere as well [8]. By adjusting the number of cells and few operational parameters the same system efficiency could be achieved in the three cases. Further, the same maximum solid temperature has been used. The cell performances are summarised in Table 4, showing an advantage for the counter flow design as discussed above. This is further emphasised by the shape of the temperature profiles, see Fig. 4.

For the cross-flow design the rather steep temperature gradient lowers the average stack temperature and correspondingly more cooling air is required. This would impair the efficiency if not a higher cell voltage were used $(0.77 \mathrm{~V})$, which in turn yields a larger cell stack. The relatively large airflow corresponds to a lower oxygen utilisation number $(13 \%)$ and a smaller stack delta temperature $\left(78{ }^{\circ} \mathrm{C}\right)$. As a consequence, a larger size and thereby cost of heat exchanger E3 will be required. Hot spot (maximum solid temperature) occur at the fuel outlet and air outlet corner.

Calculations with co-flow design revealed that from a performance point of view this case lies between the counter-flow and cross-flow design. Due to the heat absorbing reforming reaction at the fuel cell entrance, however, air inlet temperature was increased to $700{ }^{\circ} \mathrm{C}$. A drawback for this flow design, apart from the gas manifolding, are the high off-gas temperatures from the stack, leading to excessive requirements on the high-temperature heat exchangers. After a moderate drop at the entrance solid temperatures in the stack gradually increase over the length of the channels until maximum is reached just at the outlet. 

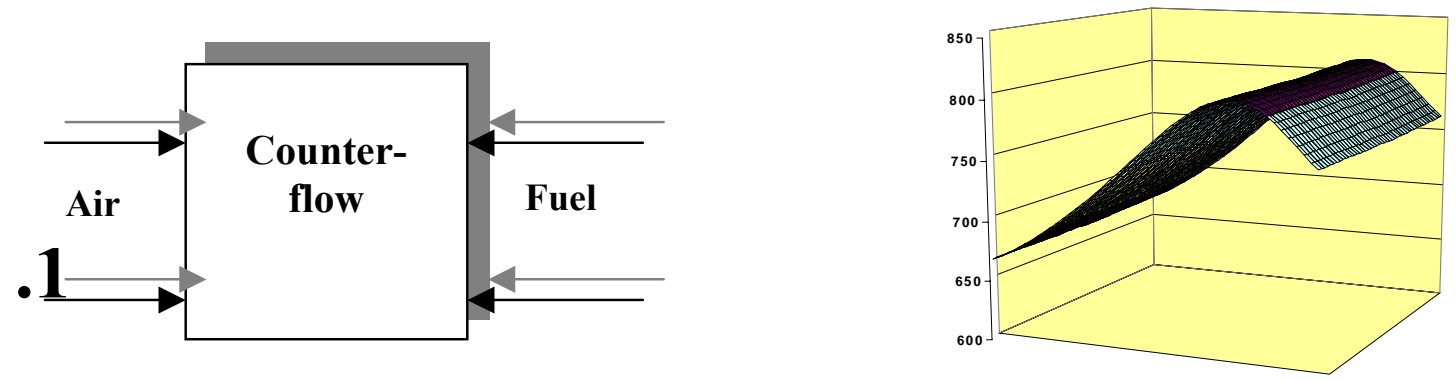

.2
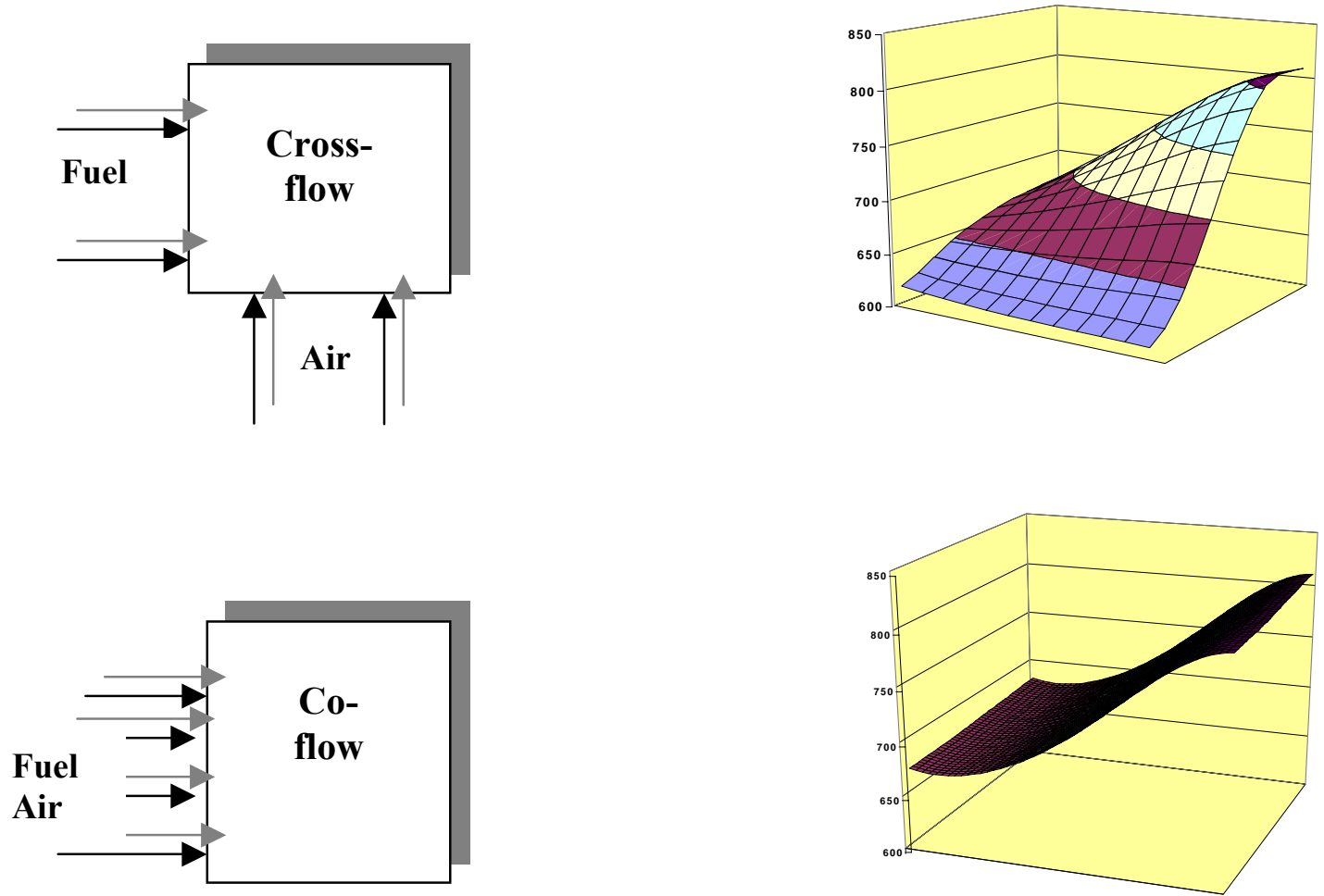

Figure 4. Various flow geometry and their temperature profiles $\left({ }^{\circ} \mathrm{C}\right)$ 
Table 4. Summary of stack results with various flow geometry .

\begin{tabular}{|l|c|c|c|c|c|}
\hline Flow design & $\begin{array}{c}\text { Tgrad } \\
\left({ }^{\circ} \mathrm{C} / \mathrm{m}\right)\end{array}$ & $\begin{array}{c}\text { Tave } \\
\left({ }^{\circ} \mathrm{C}\right)\end{array}$ & $\begin{array}{c}\text { Stack size } \\
(\%)\end{array}$ & $\begin{array}{c}\text { Power } \\
\text { density } \\
\left(\mathrm{W} / \mathrm{cm}^{2}\right)\end{array}$ & $\begin{array}{c}\text { Current den- } \\
\text { sity } \\
\left(\mathrm{mA} / \mathrm{cm}^{2}\right)\end{array}$ \\
\hline Counter-flow & 2610 & 750 & 100 & 0.264 & 353 \\
\hline Cross-flow & 4110 & 692 & 186 & 0.146 & 190 \\
\hline Co-flow & 2360 & 728 & 120 & 0.218 & 291 \\
\hline
\end{tabular}

\subsection{Thermodynamic analysis}

The energy flows of the base case are represented in a Sankey diagram, see Fig. 5, showing the energy contents of the streams in $\mathrm{kW}$ and $\mathrm{kJ} / \mathrm{s}$. When establishing the energy balance, it is necessary to take into account the enthalpy flow of the oxygen passing through the electrolyte. It can be seen that the cathode air in/out heat exchanger, E3, is a major piece of equipment with a transferred duty of 528 $\mathrm{kW}$.

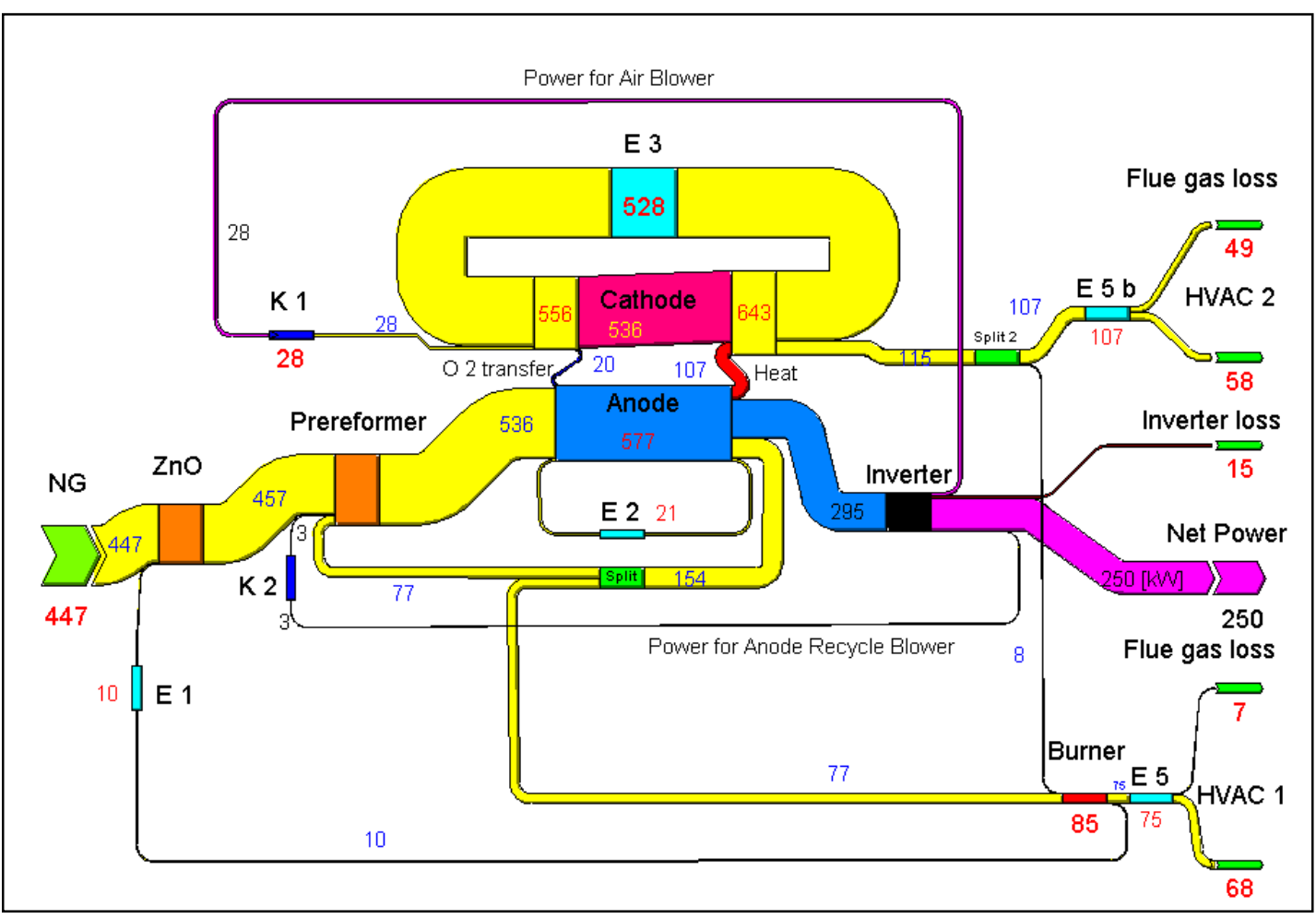

Figure 5. Energy flows in a $250 \mathrm{~kW}$ SOFC CHP system in $\mathrm{kJ} / \mathrm{s}$

Only part of the enthalpy from reaction (3) is available as external work (exergy or Gibbs free energy). The rest is dissipated in the fuel cell as heat and mainly removed with the cathode air through heat exchanger E3. This heat transfer is the main source of exergy losses in the plant.

It was calculated that approximately half of the waste heat from the oxidation reaction, however, is used to drive the internal reforming reaction, where methane in the anode feed is reformed with water to generate hydrogen. This reaction not only reduces the size of the in/out exchanger E3 and reduces the parasitic loss for air compression but also "upgrades" waste heat to chemical energy. This is a major reason for the higher electrical efficiency of the SOFC system compared to the PEMFC system as shown in Table 5. 
Table 5. Summary of energetic efficiencies for the SOFC and PEMFC system.

\begin{tabular}{|l|c|c|}
\hline Efficiency \% & SOFC & PEMFC \\
\hline$\eta_{\text {electrical }}$ & 55.9 & 36.7 \\
\hline$\eta_{\text {thermal }}$ flue gas @ $70^{\circ} \mathrm{C}$ & 32.3 & 45.7 \\
\hline$\eta_{\text {total }}$ & 88.2 & 82.4 \\
\hline$\eta_{\text {exergy }}$ & 56.6 & 39.2 \\
\hline
\end{tabular}

As the price of electricity normally is more than double of that of heat above numbers illustrate the advantages of SOFC versus PEMFC for distributed CHP applications. The more appropriate exergy efficiencies further emphasise this conclusion. The calculated efficiencies for the PEMFC system correspond well to the number reported for a $250 \mathrm{~kW}$ demonstration unit in Berlin [9].

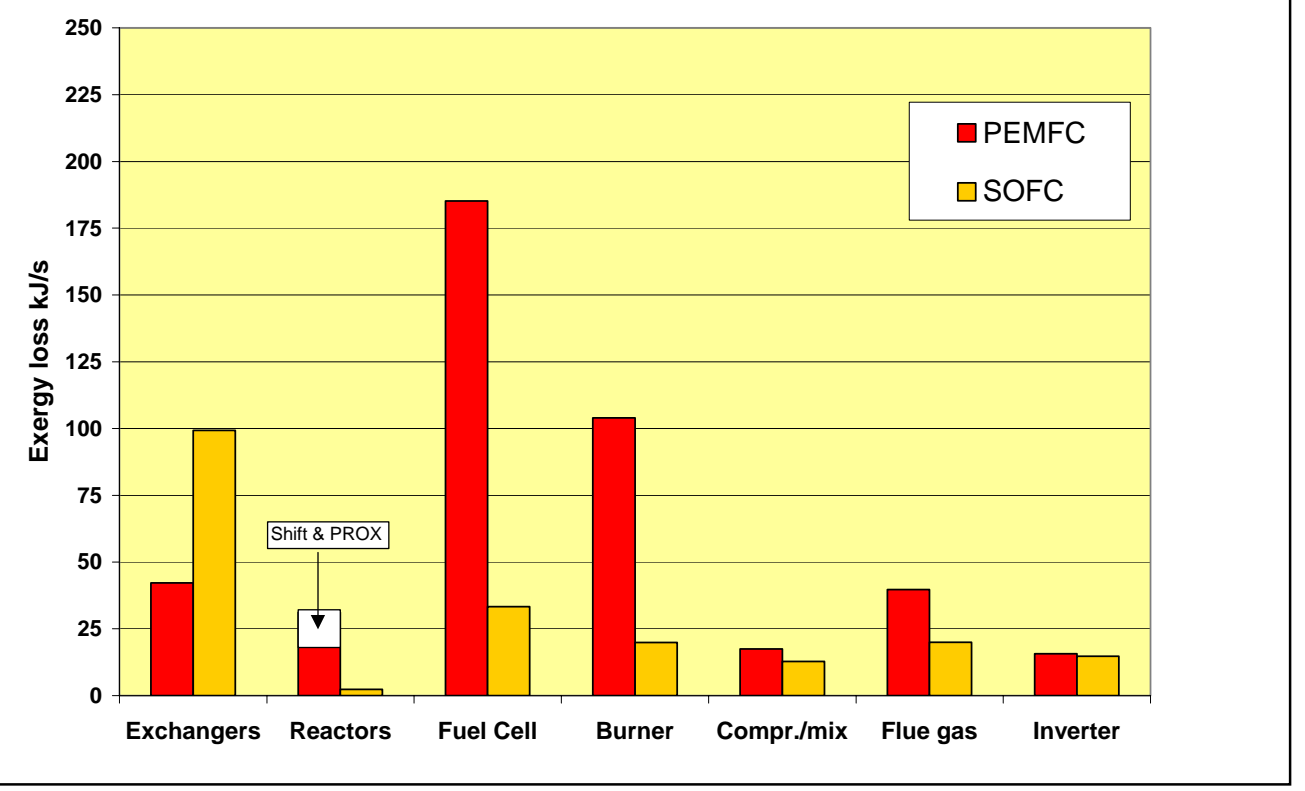

Figure 6. Comparison of exergy losses in PEMFC and SOFC $250 \mathrm{~kW}$ CHP systems

A break down of the exergy losses arising in the PEMFC and SOFC systems is shown in Fig. 6.

The major culprit in the PEMFC system is the fuel cell stack, because waste heat is not recuperated by internal reforming and is in fact degraded directly to the $60{ }^{\circ} \mathrm{C}$ level of the cooling water. Secondly, the need for extensive methane reforming (low methane leakage) dictates a high exit temperature of above $800{ }^{\circ} \mathrm{C}$ from the heat exchange reformer. This fact together with the extra heating duty for the reformer compared with the adiabatic prereformer in the SOFC case makes the use of additional fuel necessary. The exergy loss in the burner unit in the PEMFC system is thus significant. The heat exchange occurring in the reformer, shift and PROX also contributes. The contribution of the Shift and PROX subsystems to the total exergy loss is approximately $3 \%$ only, so even if CO tolerant anodes for PEMFC were developed they would not change the results significantly. The PEMFC system would presumably, however, be simpler and could more easily handle transient operation.

The exergy losses in the heat exchangers in the SOFC system is, however, higher than in the PEMFC system, mainly due to the cathode air in/out exchanger. If the high temperature heat available in the SOFC system were used in a heat engine, e.g. a gas turbine, the advantages of the SOFC would be even more pronounced. 


\subsection{General aspects}

For the balance of plant components following can be said. Desulphurisation and prereforming are well-established technologies and the catalyst consumption will only contribute marginally to the electricity costs. Intricate knowledge about the critical operating conditions and optimised catalysts are, however, a prerequisite for an economic design. The anode recycle blower is not an off the shelf item and the materials for the cathode air in/out exchanger should be carefully chosen.

All items in the system have been cost estimated. The total cost is still above the short to medium term target of approx. $1000 \$ / \mathrm{kWh}$ but not unduly so (long term cost goal is lower around $500 \$ / \mathrm{kW}$ ). It is realistic to achieve the target with some further development and economy of scale. The cost break down of the system shows that the stack represents approximately $1 / 3$ of the cost, but the power electronics and system control accounts for another $1 / 3$ Therefore the major development work needs to be focused on these areas.

Emissions from the investigated system are negligible as sulphur is removed in the fuel treatment and NOx is hardly produced at all in the combustor, which operates at low temperature without an ordinary flame (catalytic type). The emissions predicted are less than $0.2 \mathrm{ppm}$ of NOx and $402 \mathrm{~g} / \mathrm{kWh}$ of carbon dioxide. This represents a significant improvement to even the best state of art systems based on gas turbine or gas compression ignition engines.

The efficiency for above mentioned conventional units, as for the best available unit above $1 \mathrm{MW}$, is in the range of 40 to $45 \%$ net electricity efficiency, defined as net AC power out divided by the lower heating value of the fuel. It should be emphasised that these efficiencies are for operation at full load. The efficiencies of gas turbines and diesel engines decrease at part load, where as the efficiency of the fuel cell based systems will increase at part load, until a point where parasitic losses will decrease the overall efficiency.

\section{Conclusion and Future Work}

An atmospheric SOFC system in the size of $250 \mathrm{~kW}$ based on HTAS/Ris $\varnothing$ cell and stack technology has been analysed. The results are encouraging given the high electrical and total efficiencies as well as the low emissions. Internal reforming of the fuel is one of the reasons the SOFC based system outperforms the PEMFC based system. Further, it was shown that the preferred flow configuration of an SOFC stack would be of counter-current type.

The cost analysis shows that the target values are within reach. Based on the existing development program the road to commercialisation will go through tests of larger stacks, a $5 \mathrm{~kW}$ pilot system, a 50 $\mathrm{kW}$ prototype system and finally a $250 \mathrm{~kW}$ demonstration unit. The goal for commercial products will be the end of this decade. A hybrid system consisting of a solid oxide fuel cell and a heat engine will be investigated and pursued if cost and risk analysis is in favour. 


\section{References}

1. Christiansen, N., Kristensen, S., Holm-Larsen, H., Larsen, P.V, Mogensen, M., Hendriksen, P.V., Linderoth, S., "Status of Stack Development at Haldor Topsøe / Ris $\varnothing$ ", to be presented at the $8^{\text {th }}$ International Symposium on Solid Oxide Fuel Cells (SOFC-VIII), Paris, April 2003.

2. Larmine, J., Dicks, A., "Fuel Cell Systems Explained", John-Wiley \& Sons Ltd, reprint 2001, ISBN 0471490261.

3. Hendriksen, P.V., "Model Studies of Internal Steam Reforming in SOFC Stacks", Proceedings of the fifth international symposium on Solid Oxide Fuel Cells, SOFC-V, The electrochemical society, Aachen, Germany, 1997.

4. Pålsson, J., "Thermodynamic Modelling and Performance of Combined Solid Oxide Fuel Cell and Gas Turbine Systems", Doctoral Dissertation, Lund University, Lund, May, 2002.

5. Wilkinson, D.P., Steck, A.E. "General Progress in the Research of Solid Polymer Technology at Ballard". Proc. Second. Int. Symp. New Materials for Fuel Cells and Modern Battery Systems, Montreal, Quebec, Canada, July 6-10, 1997.

6. George, R., Casanova, A., Veyo, S., "Status of the Siemens-Westinghouse SOFC Program", Proceedings of the 2002 Fuel Cell Seminar, pp. 977-979, Palm Springs, California, USA, Nov, 2002.

7. Godfrey, B., Föger, K., Comer, N., "Ceramic Fuel Cell Ltd's Market Entry Product", Proceedings of the 2002 Fuel Cell Seminar, pp. 964-967, Palm Springs, California, USA, Nov, 2002.

8. Achenbach, E., "Three-dimensional and time-dependent simulation of a planar solid oxide fuel cell stack", Journal of Power Sources, Vol. 49, pp 333-348, 1994.

9. Barisic, Z., "Alstom Ballard PEM Fuel Cell Power Plants - European Field Trial Program, Proceedings of The Business of Fuel Cells for Stationary Applications in Europe, Brussels, Nov., 2001. 


\title{
A Danish micro Combined Heat and Power generator based on PEM Fuel Cells
}

\author{
Laila Grahl-Madsen, Steen Yde-Andersen, Jørgen S. Lundsgaard, Madeleine Odgaard, \\ Jesper Madsen \& Peter Lund \\ IRD Fuel Cells A/S, Kullinggade 31, DK-5700 Svendborg, Denmark \\ E-mail: ird@fuel-cell.dk \\ Url: http://www.ird.dk/
}

\begin{abstract}
IRD Fuel Cells A/S has recently completed a micro-CHP generator based on PEM fuel cells. The micro-CHP is designed to operate in parallel with the existing power grid. The power is sized for an average heat use in a North European single-family house $\left(2 \mathrm{~kW}_{\mathrm{AC}} \& 3 \mathrm{~kW}_{\mathrm{th}}\right)$. The use of fuel cells to generate heat and electricity to single households is only the beginning of the wide future applications of fuel cells. The fuel cell technology is modular and the power output therefore scalable, reflected in the widespread variety of applications, ranging from micro-FCs for mobile telephones to FC systems for cars \& busses as well as in de- and centralised power stations. However, the market for FC systems is yet virtually non-existent. The time for market take-off now depends on the availability of reliable and affordable systems. Manufacturing costs far exceed the prices of competitive products and will fall significantly only when the supply of components and the manufacturing process have been industrialised. The medium to long-term target of EU in FP6 is to reduce the cost of PEM fuel cell systems with a magnitude of 100 times to $100 € / \mathrm{kW}$ for stationary applications having a lifetime of $>30,000$ hours.
\end{abstract}




\section{Introduction to PEM Fuel Cells}

Fuel cells (FC) are electrochemical devices that efficiently convert chemical energy of the fuel directly into electrical energy. They operate like batteries and are similar in components and characteristics, but unlike batteries, their chemical energy is supplied externally. FCs are furthermore environmentally friendly. As long as fuel is supplied to the cell along with an oxidant (typically air), the fuel cell continues to produce electrical energy and heat. The only bi-product of FCs when fuelled with pure hydrogen is water.

Several types of fuel cells exist normally named after the type of electrolyte e.g. Proton Exchangeable Membrane (PEM) fuel cell, Molten Carbonate Fuel Cell (MCFC), and Solid Oxide Fuel Cell (SOFC). The different fuel cell types are at different stages of development. The PEM FC is seen as a system of choice for automotive as well as for smaller stationary applications like micro-CHP (Combined Heat and Power) generation, due to several advantages that the PEM fuel cell offers over the other types. PEM FCs operate at low temperatures $\left(60-80^{\circ} \mathrm{C}\right)$, allowing for fast start-ups and immediate response to changes in the power demand. The PEM FC consists of an anode and a cathode with a proton exchange membrane sandwiched in between (Fig. 1). A single PEM cell in operation delivers a voltage $<1 \mathrm{~V}$. Therefore, to obtain sufficiently high voltages fuel cells are stacked in series (Fig. 2).

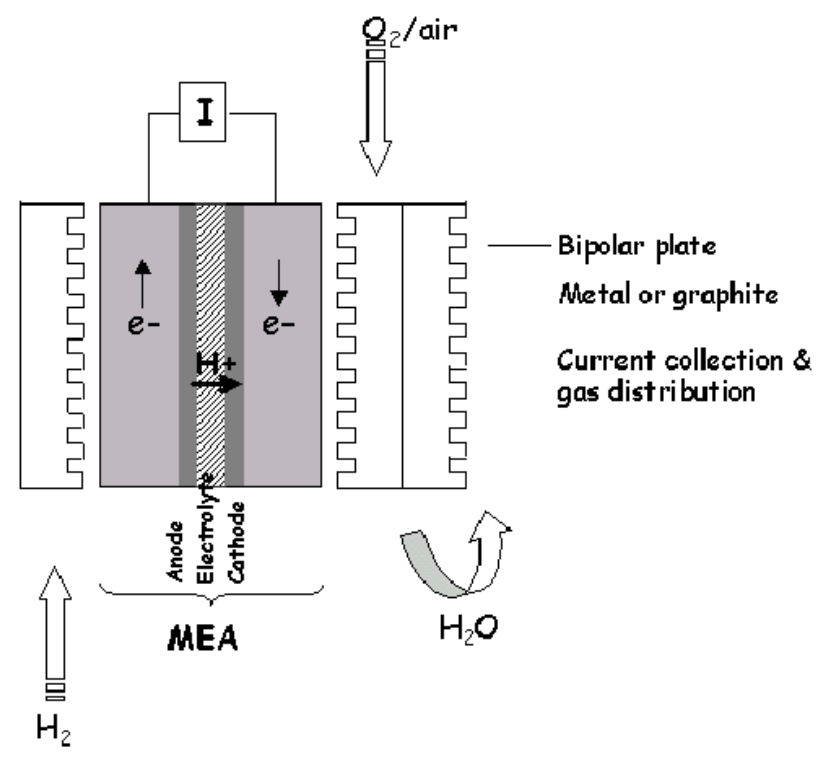

Figure 1. A single PEM fuel cell. The following electrochemical reactions occur within the MEA ( Membrane Electrode Assembly):

Anode: $\quad 2 \mathrm{H}_{2} \rightarrow 4 \mathrm{H}^{+}+4 e^{-}$

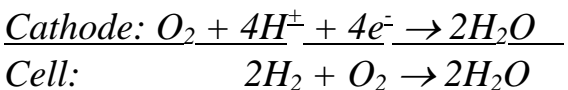

Current collection \&

The use of fuel cells gives several advantages compared to the conventional power generation systems. They offer a source of electrical energy that is continuous (as long as fuel is provided), environmentally safe (discussed below), and always available. Additional benefits include low maintenance, excellent load performance etc. In fuel cells, the chemical energy is directly converted into electricity, i.e. without preliminary conversion to heat. Consequently, this conversion is not limited by the Carnot cycle and $100 \%$ efficiency is theoretical possible. 


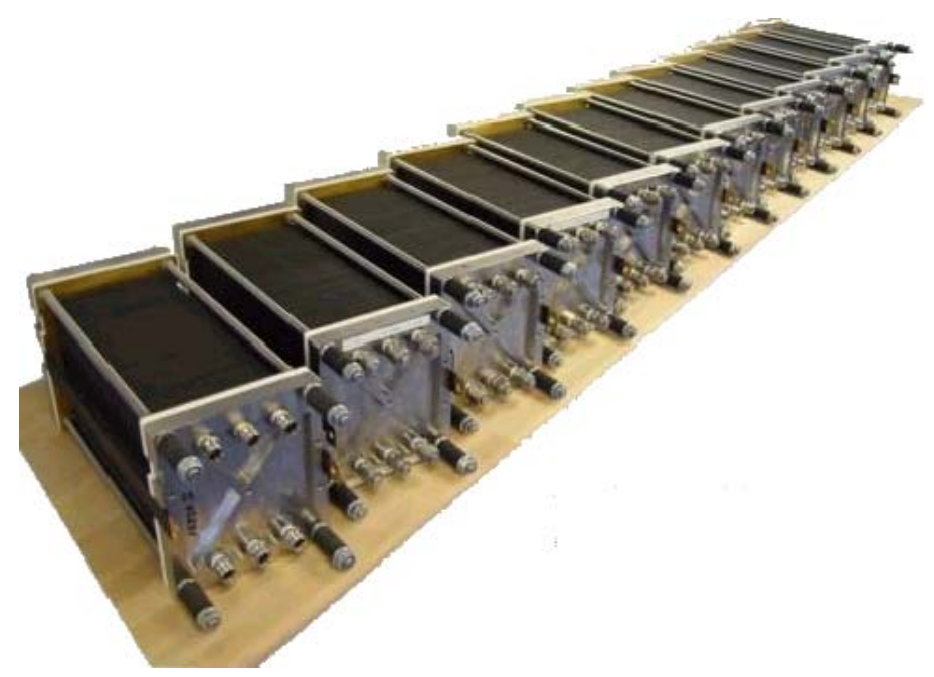

Figure 2. The IRD PEM FC stacks has the following characteristics:

- 70 MEAs per stack

- Fuel/air pressure (abs): 1-3.5 bar Stack power @ 0.5 A/cm²: $p_{\text {air }}=p_{\mathrm{H} 2}=1$ bar (abs): $3.1 \mathrm{~kW}$ $p_{\text {air }}=p_{\mathrm{H} 2}=2.5$ bar (abs): $3.7 \mathrm{~kW}$

- Dimensions: $60 * 19 * 21 \mathrm{~cm}^{3}$ Weigth: $35 \mathrm{~kg}$

An analysis of the current energy consumption and associated emissions in the industrialized countries shows significant contributions from heating and power plants in the form of $\mathrm{CO}_{2}$ and $\mathrm{SO}_{2}$. This provokes the development of not only more advanced heat and power technologies, but also the use of alternative fuel supplies. Advanced technologies will help solve this problem through, for example, the use of excess electricity from renewable energy sources for the production of hydrogen via the hydrolysis of water. A Life Cycle Analysis of hydrogen so produced leads to global-warming emissions, which are a whole order of magnitude less than for fossil-fuel produced hydrogen, even considering the effort needed to produce these systems and to transport the energy produced. However, such an environmentally friendly technology is possible but not yet available. PEM fuel cells today are therefore fuelled by reformed fossil-fuel, which are the present most realistic possibility. Fuel cells have the potential to reduce the fuel consumption. They have a higher efficiency than even the most efficient combustion alternatives, resulting in fuel savings between $15 \%$ and $50 \%$, depending on the application, and a significant reduction in $\mathrm{CO}_{2}$ emission.

\subsection{Micro-Combined Heat and Power generators based on PEM FC}

IRD Fuel Cells A/S has recently completed the first of two-planned micro-CHP generators. The micro-CHP is designed to operate in parallel with the existing power grid. The power is sized for an average heat use in a north European single-family house. The use of fuel cells to generate heat and electricity to single households is only the beginning of the many future applications of fuel cells. The fuel cell technology is modular and the wanted power therefore scalable, which is reflected through the variety of applications; ranging from FCs for mobile telephones to FC systems for cars \& busses as well as in de- and centralised power stations.

The key component in the developed CHP system is the IRD PEM FC-stack (Fig. $2 \& 3$ ). The system specification of the first generation CHP is as follows:

Electric Power, nominal ( $\mathrm{p}=1$ bar(abs))

Output inverter (single phase, $50 \mathrm{~Hz}$ )

Heat supplied from Fuel Cell
$2.0 \mathrm{~kW}_{\mathrm{e}}$

$230 \mathrm{~V}_{\mathrm{AC}}$

$3.0 \mathrm{~kW}_{\text {th }}$ 


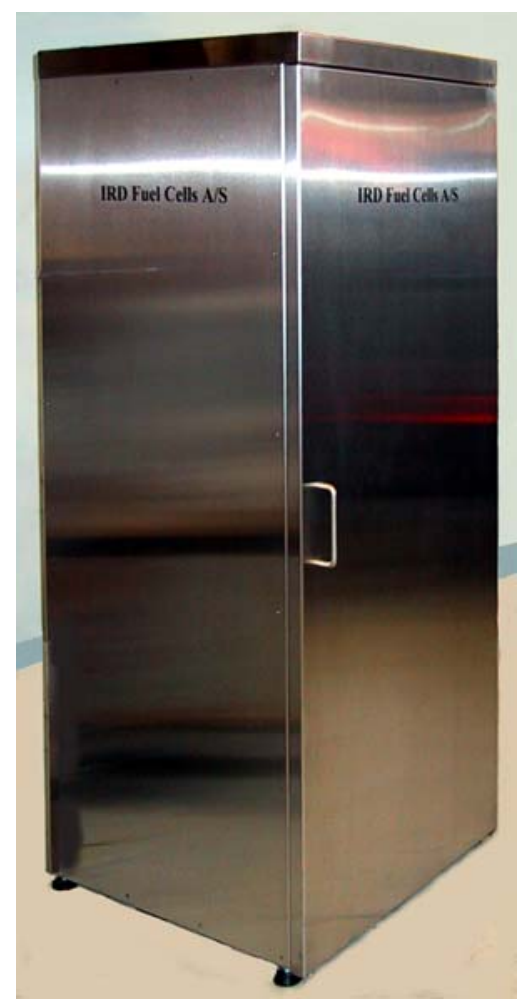

A.

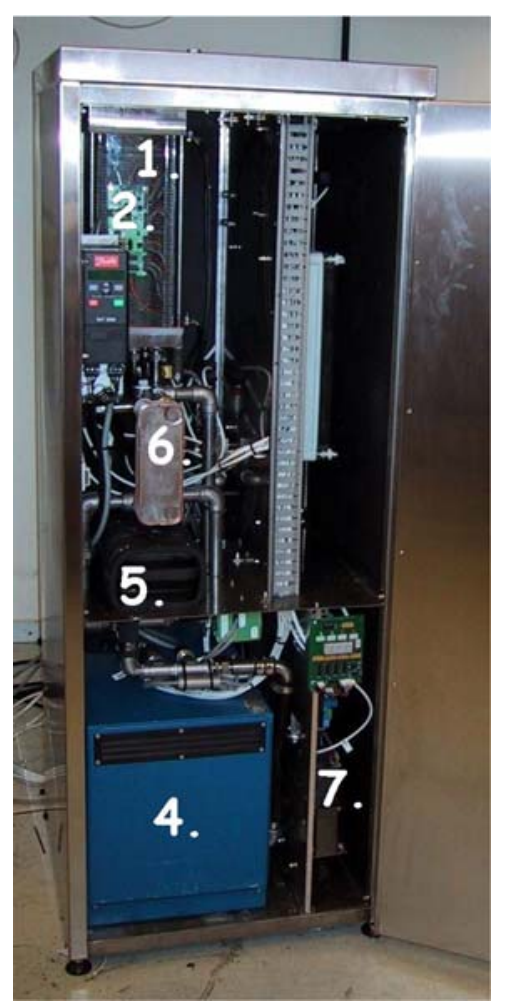

B.

Figure 3. IRD's prototype micro-CHP.

A. Front view of the $60 * 60 * 120 \mathrm{~cm}^{3}$ CHP cabinet.

View into the cabinet. The generator consists of the following components:

1. PEM FC stack

2. Cell voltage monitoring system

3. A fuel supply (not shown)

4. Air supply (compressor)

5. Humidifier

6. FC cooling loop with a heat exchanger

7. A grid connected $D C \rightarrow A C$ inverter

8. An electronic control unit (not shown)

9. An independent hydrogen safety system (not shown)

Fuel

Hydrogen storage

Electrical efficiency, FC Stack $\left(\eta_{\mathrm{el}}\right)$

Electrical Efficiency, system

Total Efficiency, system (el + heat)

System temperature
$\mathrm{H}_{2(\mathrm{~g})} /$ air

200 bar

$45 \%$

$35 \%$

$\approx 70 \%$

$55-75^{\circ} \mathrm{C}$

Larger power output can be obtained by connecting several systems in parallel giving $4 \mathrm{~kW}_{\mathrm{e}}, 6 \mathrm{~kW}_{\mathrm{e}}, 8$ $\mathrm{kW}_{\mathrm{e}}$ etc. The electrical efficiency is approximately 45\%@ nominal load, but can be varied according to the load (Fig. 4). The electrical efficiency for the total system is lower $(\approx 35 \%)$ because power is 
used by the Balance-of-Plant (BoP) components particular the air supply, which uses $\approx 15 \%$ of the generated power.

The first micro-CHP is designed for being fuelled by pure hydrogen only while the secondgeneration system is prepared for being fuelled by reformed Natural Gas (NG). The major difference is the anode catalyst composition, which is $\mathrm{Pt} / \mathrm{C}$ for the pure hydrogen operation and a $\mathrm{Pt} / \mathrm{Ru} / \mathrm{C}$ for the reformat operation. This is necessary, because the pure $\mathrm{Pt} / \mathrm{C}$ anode is extremely sensitive to traces of impurities particular $\mathrm{CO}$ in the ppm-range. The Ru-doped anode has a higher tolerance towards impurities, and no performance loss is associated with up to $10 \mathrm{ppm}$ CO (typically steady-state impurity level of NG-reformat). However, the hydrogen-rich reformat contain other gases that causes small losses in the performance e.g. $\mathrm{CO}_{2}$. To reach the same level of efficiency for the second generation of CHP fuelled with reformat is therefore believed to be ambiguous although a possible goal.

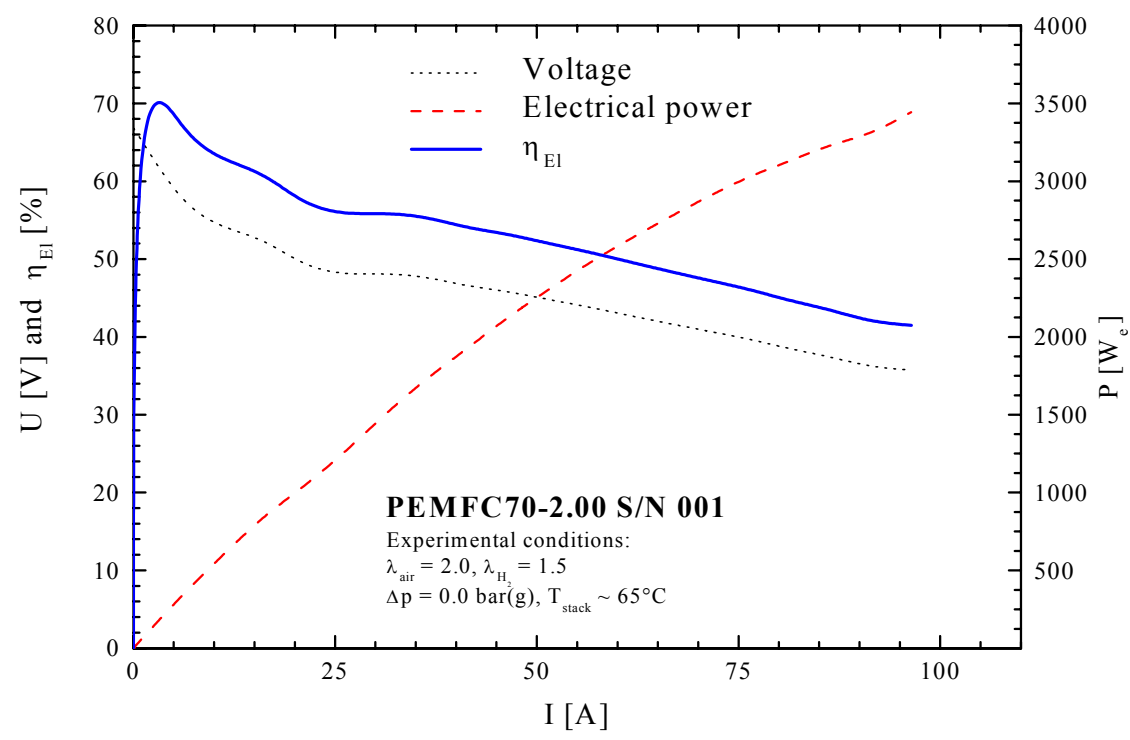

Figure 4. Polarisation curve (I versus V) and electrical efficiency ( $\left.\eta_{e l}\right)$ of IRD's PEM FC-stack

IRDs $1^{\text {st }}$ generation micro-CHP has created a lot of attention. The generator has already been borrowed by several of our partners for demonstration of the simplicity of the system. Pressing one bottom, after connection to hydrogen, cooling water, and the electrical grid, will simply start the system.

\section{The PEM micro-CHP future}

The European market for stationary FC systems is as yet virtually non-existent. The time for market take-off now depends on the availability of reliable and affordable systems. Manufacturing costs far exceed the prices of competitive products and will fall significantly only when the supply of components and the manufacturing process have been industrialised. Stationary FC systems incorporating PEM technology are expected to evolve into the leading technology in this market. Unlike North America, Europe will show the highest demand for FC systems in the segment of micro-CHP. Here, PEM cells are particularly attractive and will gain a lead over the more efficient solid-oxide fuel cell (SOFC) technology, which is expected to dominate the US market. However, the efficiency of PEM cells seems not sufficient for larger-scale base-load applications, which probably will be the domain of SOFC and MCFC technology. PEM technologies are generally believed to cover the lower end of the power output scale where fuel cells are expected to be economically viable.

The potential for micro-CHP systems in Denmark for production of electricity and heat in the NGsupplied areas is estimated to 300,000 single-family houses corresponding to a production capacity of 
$930 \mathrm{MW}_{\mathrm{e}}$ (new systems). Other North European analysis point in the same direction and predict a future yearly need of $\approx 250,000$ CHP-units below $10 \mathrm{~kW}_{\mathrm{e}}$.

However, some issues still exist that limits the commercialisation of the PEM fuel cells. The most important is as follows:

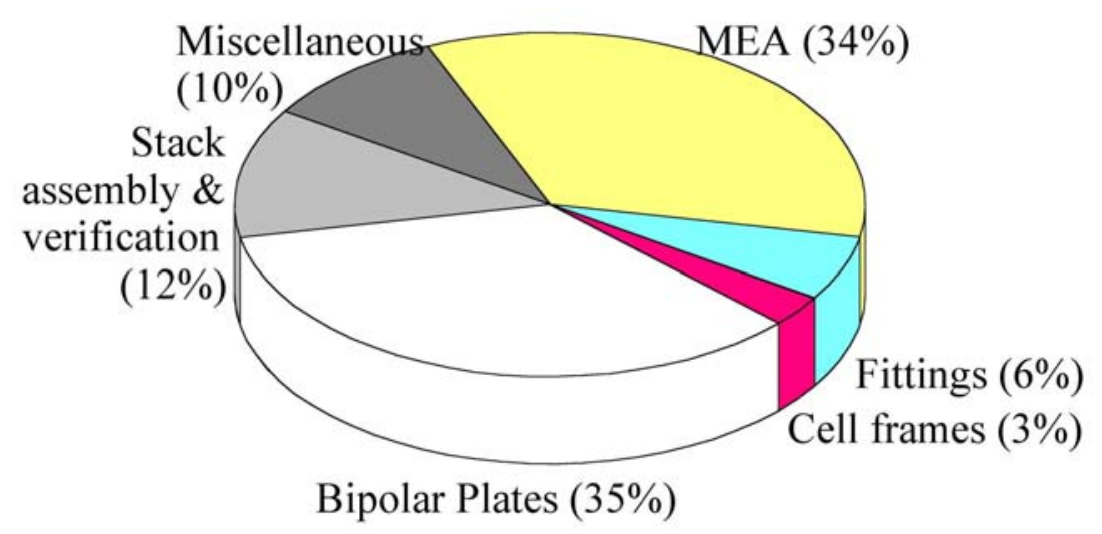

Figure 5.Cost break-down of PEM FC stacks at IRD (2003)

A. Electrocatalyst poisoning by impurities, particular traces of $\mathrm{CO}$ in the fuel

B. Water management and membrane operating temperature limits

C. Cell lifetime

and perhaps the most limiting factor

D. The FC materials and system costs

The biggest challenge for the developers is a substantial reduction of the cost of the cell stack (currently $\approx 10,000 € / \mathrm{kW}_{\mathrm{e}} @ \mathrm{IRD}$, while the medium to long term target price of EU (FP6) for stationary PEM systems is $100 € / \mathrm{kW}_{\mathrm{e}}$ ). The high cost is mainly ascribed to the use of materials such as Nafion membrane and expensive graphite based bipolar plates (Fig. 5) due to by the piece production and the limited numbers of component manufactures. The stringent requirements in terms of compactness, high energy density, performance stability and low cost will change the research direction towards optimising the different aspects of PEM system.

\section{Acknowledgement}

The micro-CHP has been developed with support from the Danish national hydrogen programme through contract no. 1763/00-0035. 


\section{Session 9: Hydrogen Society}

Chairman: Komninos Diamantares, Research Directorate General, CEC, Belgium 


\title{
Hydrogen Storage with Emphasis on Metal Hydrides
}

\author{
Allan Schrøder Pedersen \\ Materials Research Department \\ Risø National Laboratory \\ DK-4000 Roskilde \\ Denmark
}

\begin{abstract}
The present and future needs for suitable energy storage technologies in the energy supply system are discussed on the background of a political aim to cut $\mathrm{CO}_{2}$ emissions and partly also to secure energy supply sources independently of countries outside the industrialised world.

Hydrogen is proposed as an important vector in such a future supply system because of the attractive properties of hydrogen if considered as energy. If electricity from sustainable energy sources is available hydrogen may readily be produced by electrolysis of water, it can be stored and transported in a number of ways suitable for different applications and finally it can be burnt by direct combustion or more effectively in a fuel cell to yield a high chemical to electrical energy conversion efficiency. The special possibility for hydrogen to be stored at low pressure in a solid state as metal hydrides is discussed in more details.
\end{abstract}




\section{Introduction}

A large part of the present emissions of green house gases from the industrialised countries is related to fossil fuel consumption associated with the maintenance and continued development of the modern welfare society. However, it is almost unanimously agreed among the same countries, that the emissions should be reduced and eventually eliminated because of the frightening perspectives of uncontrollable temperature rise in the Earth's surface and atmosphere. Those perspectives may be anticipated to take even more frightening dimensions in the not too far future as energy consumption per capita in densely populated countries like China can be foreseen to increase dramatically as their living standards increase and finally reach the same level as in the Western world.

In addition, an insisting, unstable political situation in the Middle East, which holds by far the largest oil reserves known in the world, has reinforced a growing desire among many people to aim for independence of these oil resources and with it independence of the governments controlling them.

Thus the incentives for leaving utilisation of fossil fuels in the industrialised world are twofold and concern pollution as well as security of energy supply.

Realistically only two alternative energy sources can take over the role of powering the welfare society in the short term. One is nuclear power, either based on fission or fusion. Fission power, however, is disregarded in many countries for political reasons associated with managing risks during power plant operation and with what is widely considered as unsolved problems concerning waste disposal.

Fusion power, on the other hand, does not seem to be within technological reach for several decades and in addition the problem of risk and waste disposal is being questioned.

The only sustainable alternative, which seems to fulfil our requirements and meet our concerns, is solar energy in different forms like wind energy, solar cell electricity or wave energy. This kind of energy source is already being harnessed via a number of techniques and the potential for increased utilisation is certainly present. However, although solar energy is sustainable in terms of pollution and availability, it is certainly not continuously available in amounts sufficient to match our demand. There is an unbalance between energy demand and regional solar energy production and this fact raises a need for storing solar energy

The unbalance may to some extent be levelled by use of administrative and market-related tools. As an example, consumers may be encouraged to place heavy energy consumptions in time periods, where solar energy is abundant and prices are low. Nevertheless, a significant need for energy storage will persist to allow complete levelling and in addition a need for fuel for the transport sector (vehicles, air crafts) will be present if we rely totally on solar energy.

\section{Energy Storage}

The presently used technology for storing energy is basically to store fossil fuels in appropriate and conveniently available amounts. Fossil fuels are in themselves eminent energy stores regarding energy density on both volume and mass basis. Very few man-made energy stores are comparable to fossil fuels in this respect. Table 1 gives an overview of energy densities for a number of energy stores. 
Table 1. Energy Densities for Different Energy Stores. All numbers are based on the upper value of combustion enthalpy and exclude the weight of containers.

\begin{tabular}{|l|r|r|r|r|}
\hline & $\mathrm{w}-\% \mathrm{H}$ & $\mathrm{g} \mathrm{H} / 1$ & $\mathrm{~kJ} / \mathrm{ml}$ & $\mathrm{kJ} / \mathrm{g}$ \\
\hline Hydrogen at 200 bar & 100.0 & 17 & 2.4 & 141.0 \\
\hline Magnesium Hydride & 7.6 & 101 & 14.4 & 10.9 \\
\hline Hydride of Fe-Ti & 1.8 & 96 & 13.7 & 2.7 \\
\hline Hydride of La-Ni & 1.4 & 89 & 12.7 & 1.9 \\
\hline Liquid Hydrogen & 100.0 & 70 & 10.0 & 141.0 \\
\hline Methanol & 12.5 & 99 & 18.0 & 22.7 \\
\hline Gasoline & & & 33.4 & 47.6 \\
\hline Lead/Acid Battery & & & & 0.2 \\
\hline Advanced battery & & & & 0.5 \\
\hline Liquid Methane & 25.0 & 106 & 119.5 & 55.7 \\
\hline Liquid Ammonia & 17.6 & 120 & 32.7 & 25.2 \\
\hline Fly Wheel & & & & 0.5 \\
\hline
\end{tabular}

As can be seen from the table fossil fuels, in this case represented by ordinary gasoline, are outstanding and may only be compared with other organic or organic-like compounds like methanol. An interesting observation from the table is, that the energy density of hydrogen stores are relatively high and much higher than the densities of electrochemical storage devices like traditional lead-acid batteries or even advanced batteries. If we compare with mechanical energy stores (e.g. fly wheels) the picture is the same: energy densities are orders of magnitude lower.

Data like those shown in Table 1 combined with other attractive properties of hydrogen leads to increasing interest in hydrogen as a vector in the future energy supply system.

\section{Hydrogen as an energy vector}

Hydrogen is sometimes called the fuel of the future and hydrogen certainly has a number of inherent attractive features when considered as a fuel for road vehicles.

Hydrogen is by far the most abundant element ( $90 \%$ on number of atoms basis) in the universe and in the Earth's crust it is one of the most abundant elements. On Earth hydrogen is almost exclusively found in chemical compounds whereas free, molecular hydrogen is virtually not seen in nature. A consequence of the latter is, that hydrogen is not a source of energy, but rather a convenient tool for handling energy. In many respects an illustrating parallel may be drawn to electricity, which is also not a source of energy, but instead an appropriate intermediate in energy transport and conversion.

Hydrogen is known in the liquid and in the gaseous states. The solid state, metallic hydrogen, is only possible at extreme conditions, as are believed to exist in the interior of stars and larger planets. The most frequently found state for elemental hydrogen is the gaseous state because this is the stable one at normal temperatures and pressures. The critical temperature and pressure of hydrogen is approx. $33 \mathrm{~K}$ and 13 bar.

Binary, chemical compounds of hydrogen are known for many elements. In particular hydrogen reacts vividly with oxygen to form water. The reaction is strongly exothermic and results in a release of approx. 240 or $286 \mathrm{~kJ} / \mathrm{mole}$, the difference being the heat of evaporation for water. The standard Gibbs function of formation for (liquid) water is approx. $237 \mathrm{~kJ} / \mathrm{mole}$.

The production of industrial hydrogen is currently based mainly on fossil fuels, but to some extent also electricity is used. If considered as an alternative fuel, hydrogen should not be produced from fossils, since that would not lead to decreased emission of greenhouse gas. However, as mentioned, hy- 
drogen can be (and in fact it is) produced from electricity by electrochemical splitting of water. The energy efficiency of the electrolysis process is relatively high, just around $90 \%$, and therefore this production method seems viable, although capital costs for sufficient electrolysation capacity may constitute a serious drawback of the technology.

Various technologies are available for storage and transportation of hydrogen. It should be noted that hydrogen has been handled industrially (and by ordinary consumers) for more than a century, since the well-known "town gas" contains approx. $50 \%$ of hydrogen. In addition, hydrogen has been transported as a chemical for industrial applications via pipelines and in cylinders for considerably more than 50 years. Therefore much experience with widespread use of hydrogen is available, although it is not always recognized.

A lack of feasible technologies for storage of hydrogen is perhaps the major disadvantage of hydrogen as a fuel and therefore this has been subjected to studies over decades. For direct use of hydrogen the following storage technologies may seem most obvious for road vehicle applications:

1. As pressurised gas in cylinders

2. In liquid state

3. As solid or liquid compounds, which easily absorb and desorb hydrogen

As mentioned, option 1 is very well known. The method is widely spread and is probably the one most frequently used for distribution of small amounts of hydrogen. The cylinders are routinely pressurised to approx. 200 bars, but cylinders for much higher pressures are available and will increase the hydrogen (energy) density considerably. Work is going on to develop light weight polymer based composite materials for use as cylinders for pressurised hydrogen up to 600 bars or even higher. Such developments might give valuable contributions to increasing energy densities for cylinder storage of hydrogen both from a weight and from a volume point of view.

The liquid state of hydrogen is already used today for distribution and storage of hydrogen, mainly for larger quantities. Due to an inherent, exothermic ortho-para nuclear spin transition in molecular hydrogen, the liquid hydrogen has a certain boil-off rate (loss from store) and in addition complete heat insulation is not practicably attainable. In consequence liquid hydrogen stores show a loss of gas up to approx. $0.5 \%$ per day. This boil-off is problematic both from storage and safety points of view.

One of the densest ways to store hydrogen is in chemical, hydrogen-rich compounds. Much research has focussed on metal hydrides and for this class of compounds the underlying chemical reaction is:

$$
\mathrm{M}+\mathrm{xH}_{2} \leftrightarrow \mathrm{MH}_{2 \mathrm{x}}+\mathrm{Q}
$$

Most such reactions of practical interest are exothermic, meaning that the formation of hydride is associated with release of heat (as indicated in the above equilibrium (1)). The amount of heat released is usually in the range $10-25 \%$ of the lower combustion heat for the hydrogen stored.

Because of a wish to maximise the hydrogen weight density in metal hydrides, much attention has been paid to the lighter elements particularly of main groups I and II. As an example Mg and its alloys have been studied intensively for several decades and are strong candidates for future use as hydrogen carrier. Efforts are still going on in many laboratories both in Europe and worldwide, to find new effective storage materials.

One reason for the technological interest in hydrogen is, that hydrogen goes very well with fuel cells. Most fuel cells are basically powered by hydrogen, even though the primary fuel is not always pure hydrogen.

Using hydrogen as fuel in the transport sector would require significant changes in distribution and handling infrastructure. Distribution of hydrogen and local fuelling of cars could not be done the same way gasoline is handled today. Therefore the infrastructural problems must be given careful consideration, both concerning economy and safety, in relation to a possible utilisation of hydrogen as an energy carrier. 


\section{Metal hydrides}

Metal hydrides in general store hydrogen in a safe and viable way. The technology is safe because for most systems of practical interest the maximum pressure needed for operation is below 25 bars.

A search for metallic systems showing high hydrogen density in the hydrided state has been going on for many years. In the period 1980-1990 we had a particular interest in the magnesium-hydrogen system at Risø because of the high density (approaching $7.6 \mathrm{wt}-\%$ in the hydride as shown in Table 1) and because of the abundance and low price of magnesium. The work has been concentrated on magnesium in the form of powder with a typical particle size around $80 \mu \mathrm{m}$ diameter. Examples of the obtained absorption and desorption curves are shown in Fig. 1 [ 1]
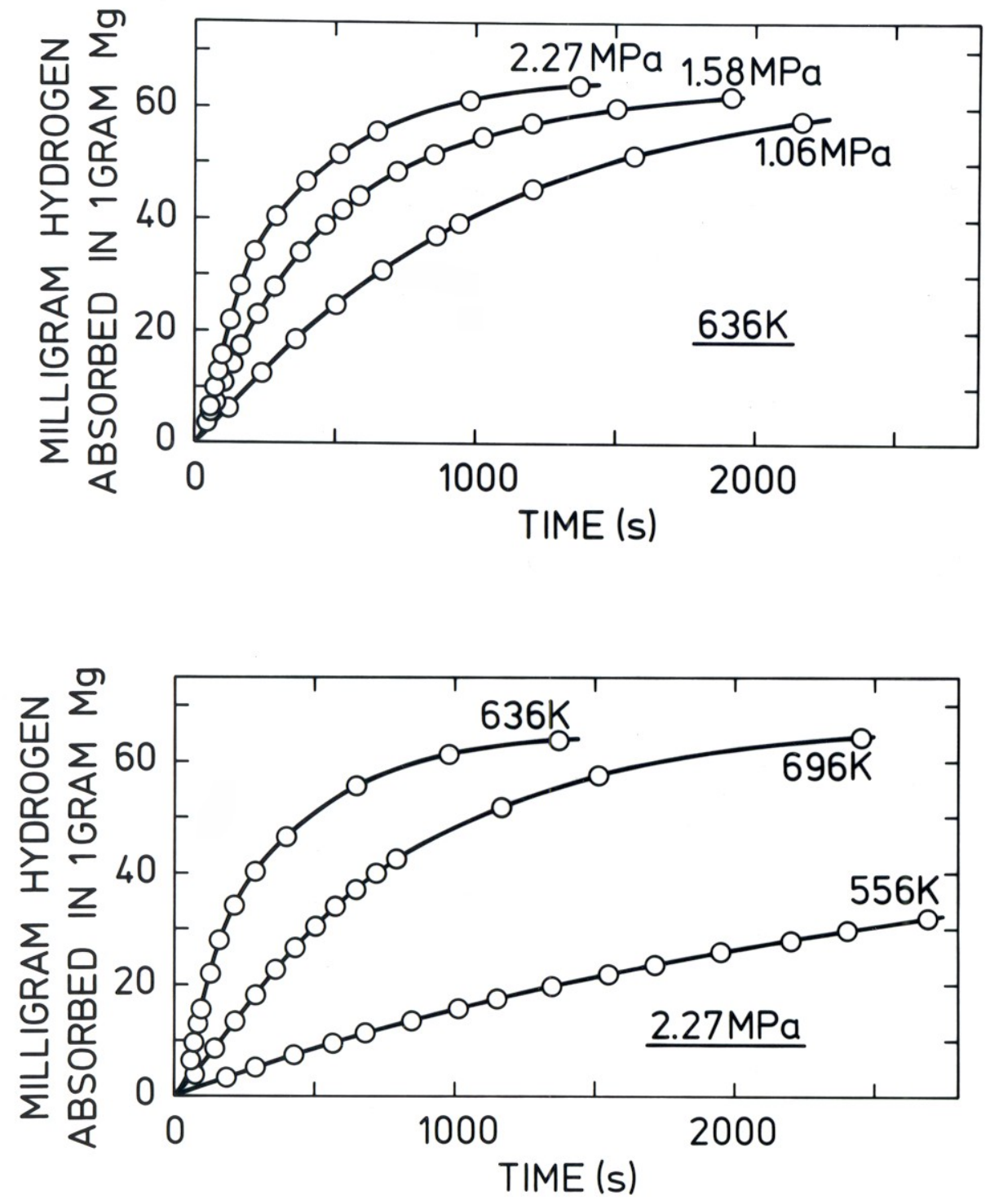

Figure 1. Data illustrating the operation temperature and pressure range of the pure magnesium system

The data in Fig. 1 shows a disadvantage of the magnesium-hydrogen system for storage purposes. The absorption reaction is relatively slow unless the temperature is high, preferably above $350{ }^{\circ} \mathrm{C}$, which is probably due to a rate-limiting step of the absorption process associated with the surface conditions of 
the used magnesium material [2]. This problem has puzzled workers for the last decade and ideas have been brought forward to find solutions to it. Two routes have been proposed and tested with some success. One is to try to decrease the crystallite size of the applied magnesium material and another has been to try to catalyse the process by addition of small amounts of third phases.

Schultz and co-workers [3] has demonstrated the effect of both routes mentioned above. Fig. 2 gives data illustrating the difference obtained by ball milling magnesium (in the hydrided state) and by addition of vanadium, which has a dramatic effect on the reaction properties. Such techniques may open new avenues for identification of metal systems for solid-state hydrogen storage where the optimal compromise between desirable properties like fast reaction rates, low operation temperature and pressure, high hydrogen capacity and low enthalpy of reaction can be reached and lead to feasible, industrial use of hydrogen storage.
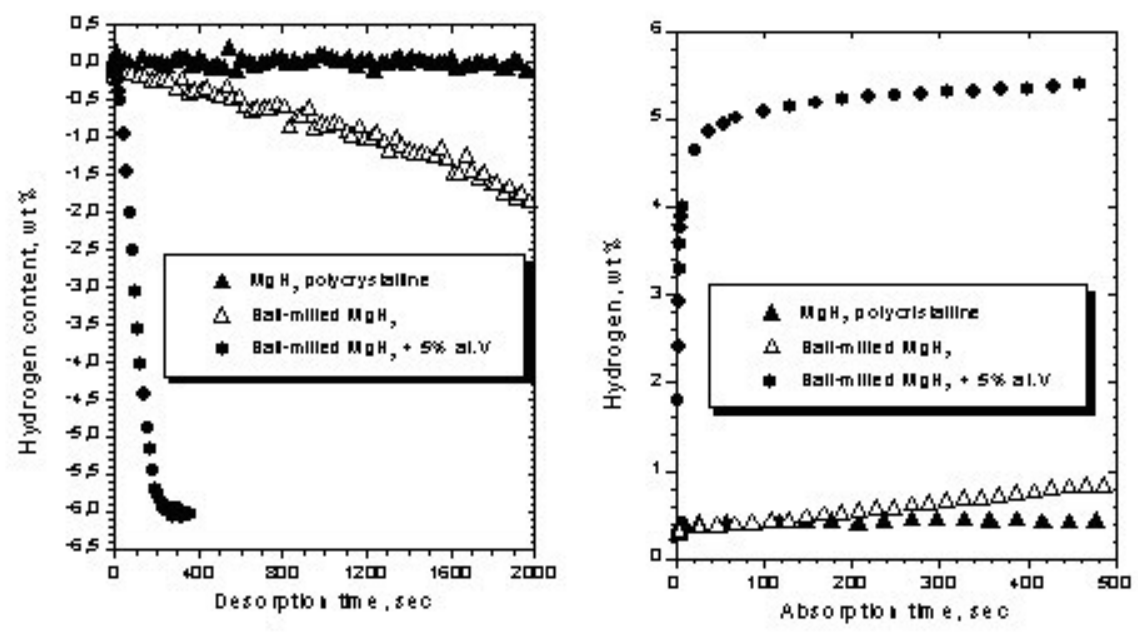

Figure 2. Left: Hydrogen desorption at $573 \mathrm{~K}$ under $0.015 \mathrm{MPa}$ for various Mg hydrides. Right: Hydrogen absorption at $423 \mathrm{~K}$ under 1.0 MPa for various Mg hydrides. (From ref. 3)

In practical use of metals and alloys for hydrogen storage it is important that the metal system is not very sensitive to the type of impurities commonly found in hydrogen produced by standard industrial production techniques. Actually the same elements and alloys, which exhibit a high hydrogen affinity, also seem to show high affinity to oxygen (or oxygen sources like water) and even to nitrogen. In an earlier work [4] we tried to identify the influence of impurities in hydrogen on the storage capacity of pure magnesium as a function of cycle no., i.e. as a function of the number of times the magnesium material has been loaded and de-loaded (cycled). Fig. 3 gives data, which shows this dependence in the case of oxygen and nitrogen respectively. It is seen that both impurities have a significant effect on the storage capacity, but it is also seen that contamination of the metal surface does not lead to an irreversible effect. On the contrary the capacity is recovered if pure hydrogen is applied again after contamination. On the other hand the figure also shows, that a permanent presence of oxygen or nitrogen in a concentration of $0.5 \%$ is not acceptable for the magnesium hydride store and this conclusion stresses the necessity to ensure some purification of the produced hydrogen before storing in a hydride form. 

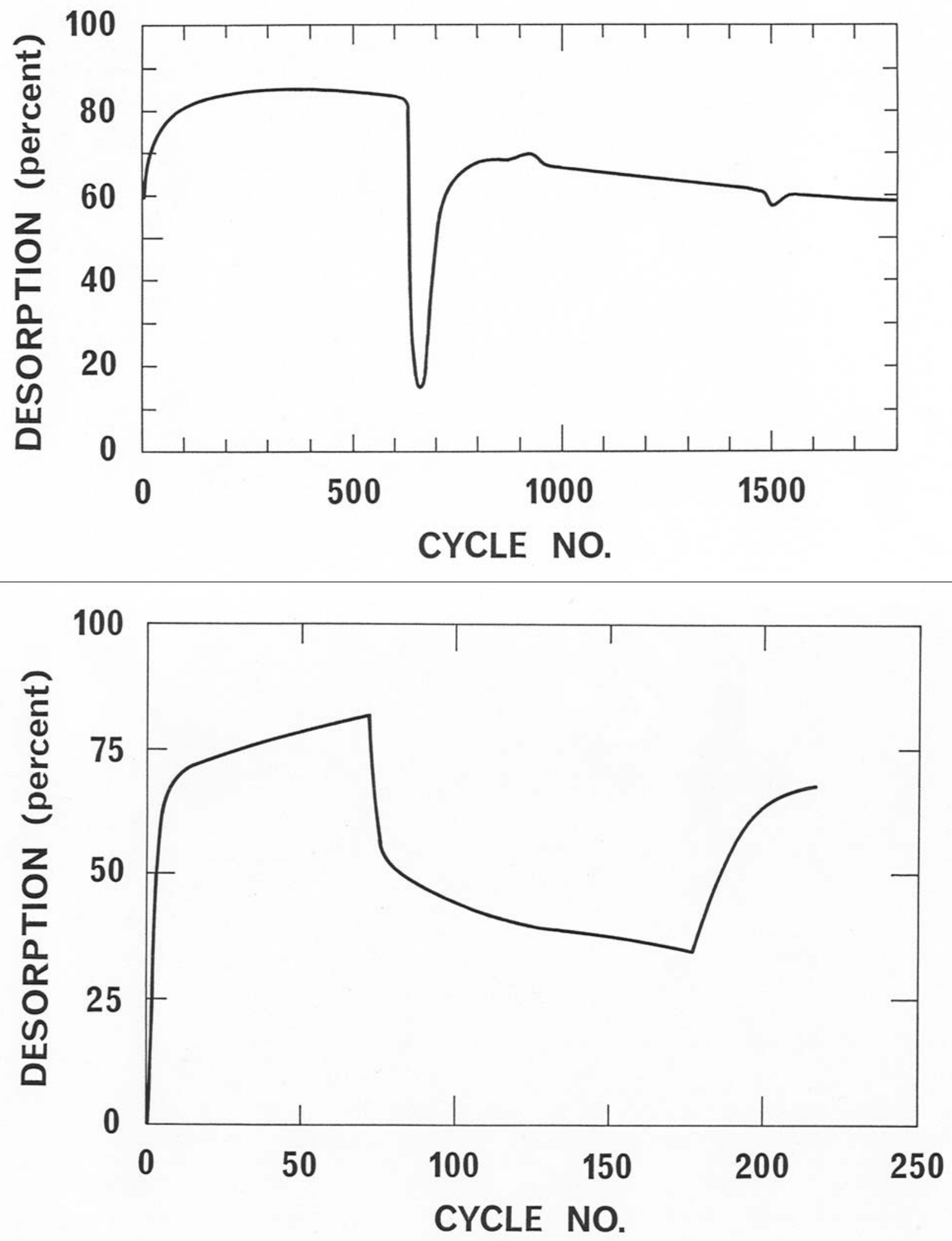

Figure 3. Influence of impurities on storage capacity

a: Cycling capacity as a function of cycle no. Exposure to $\mathrm{H} 57$ followed by $0.5 \% \mathrm{O} 2$ and finally $\mathrm{H} 57$ again. $T=375 \mathrm{C}$

b: Cycling in $\mathrm{H} 57$ followed by exposure to $0.5 \% \mathrm{~N}$ and then again $\mathrm{H} 57$ 


\section{Conclusions}

Needs for shifting our energy sources to new and sustainable ones have been briefly touched upon. The foreseen shift will lead to a subsequent need for feasible technologies for storing energy in small as well as in large quantities.

Hydrogen is proposed as a vector in the new energy system. Hydrogen may meet the requirements inherent in an energy system based on sustainable but unpredictably varying energy sources.

Some important properties of hydrogen, illustrating the feasibility of hydrogen as an energy vector, have been pointed out and metal hydrides have been proposed as a very strong candidate for future hydrogen storage technique.

\section{References}

1. B. Vigeholm, J. Kjøller, B. Larsen and A. Schrøder Pedersen. Formation and Decomposition of Magnesium Hydride. J. Less-Common Metals 89 (1983) 135-144.

2. V.P. Zhdanov, A. Krozer and B. Kasemo, Kinetics of first-order phase transitionsinitiated by diffusion of particles from surface into the bulk. Physi. Rev. B, 47 (1993) 11044

3. R. Schulz, G. Liang and J. Huot, Hydrogen Sorption in Mechanically Alloyed Nanocrystalline and Disordered Materials, Proceedings of the $22^{\text {nd }}$ Risø International Symposium on Materials Science: Science of Metastable and Nanocrystalline Alloys Structure, Properties and Modelling, Editors: A.R. Dinesen M. Eldrup D. Juul Jensen S. Linderoth T.B. Pedersen N.H. Pryds A. Schrøder Pedersen J.A. Wert, Risø National Laboratory, Roskilde, Denmark 2001

4. A. Schrøder Pedersen, B. Vigeholm, J. Kjøller and B. Larsen: The Effect of Cycling in Impure Hydrogen on the Hydrogen Capacity of Magnesium Powder. Int. J. Hydrogen Energy 12 (1987) 765-771. 


\section{New energy, new hazards? The hydrogen scenario}

Lionel PERRETTE, Samira CHELHAOUI

Institut National de l'Environnement Industriel et des Risques

Direction des Risques Accidentels

B.P. 2

F-60550 Verneuil en Halatte

Tel: 33344556339

Fax: 33344556565

Email : $\underline{\text { lionel.perrette@ineris.fr }}$

www.ineris.fr 


\section{Introduction}

For the last ten years and more, INERIS has acquired a practical experience on hydrogen safety. Among others, the following experimental topics have been dealt with :

- confined hydrogen explosion,

- liquid hydrogen leak and subsequent dispersion in air phenomenon,

- hydrogen jet release, dispersion and inflammation,

- measurement of hydrogen concentration in air-hydrogen atmospheres,

- pressurised hydrogen tank testing.

In parallel risk assessment have been carried out on hydrogen-related equipment (reformers, electrolysers ....).

This long lasting experience is now invested in hydrogen technologies. In this field, INERIS is involved in several European and national projects as well as in standardisation working groups focussing on the safe handling of hydrogen

\section{New energy}

\subsection{Hydrogen as a new "energy carrier"?}

Hydrogen based economy and associated energy converters fuel cell systems are said to be a part of the response to increasingly worrying ecological and economical issues embodied by either global warming or the depletion of fossil energy sources.

Indeed, hydrogen shows many benefits in the field of air pollutant as its combustion reduces pollutant and greenhouse gas emissions (carbon dioxide...) ${ }^{1}$. Besides, energy conversion yields seem to be better and finally it allows fossil fuels dependant economy to rely on other energy loops. Hydrogen can virtually be produced from a wide variety of domestic sources. It can also provide a storage medium for intermittent and seasonal peak energy needs.

Hydrogen can be used as an energy carrier for many traditional technologies such as cars (direct combustion engines using hydrogen or hydrogen based mixtures, fuel cell systems), electrical plants, systems to provide heat and electricity for buildings, remote power unit systems, backup systems... .

Hydrogen technologies are under test across Europe (stationary power units, boats, city buses, cars...). Different challenges are being faced : technological, hydrogen production, hydrogen storage,... . Along with public acceptance, authorities agreement for demonstration projects is sometimes difficult to obtain for these new technologies (imported technologies are not CE marked, no straight forward applicable regulation...). Regulation and standardisation will therefore have to make their way to ease hydrogen technologies implementation.

To answer some of potential public fears, this paper will compare hydrogen hazards with more conventional fuels. We will then discuss hazards related to fuel cell systems. All together, we will try to evaluate if there is any new hazard to be expected along with hydrogen technologies development. Finally, we will present existing regulations and standardisation expectations prior to briefly discuss social acceptance aspects.

${ }^{1}$ US Department of Energy, Energy Efficiency and Renewable Energy, http://www.eere.energy.gov 


\subsection{What is a fuel cell ?}

Fuel cells are the core of the hydrogen economy. A fuel cell is an electrochemical energy converter in which hydrogen is combined with oxygen (from air supplied to the system) to produce water and electricity, emitting neither pollutants nor excessive noise. The expected theoretical efficiencies are varying according to the technology used but are higher than those of conventional combustion processes. This means that in the long term, fuel cells will probably be an alternative energy converter.

Any fuel containing an atom of hydrogen (methanol, gasoline, natural gas, biogas, and so on) can be used as fuel in a cell.

Different types of fuel cell have been developed so far. All of them can run with hydrogen. Proton exchange membrane fuel cells (PEMFC) are more than any other technologies expected to be commonly found (cars, home generator..).

Figure 1 gives a schematic view of flows within a fuel cell as well as its working conditions.

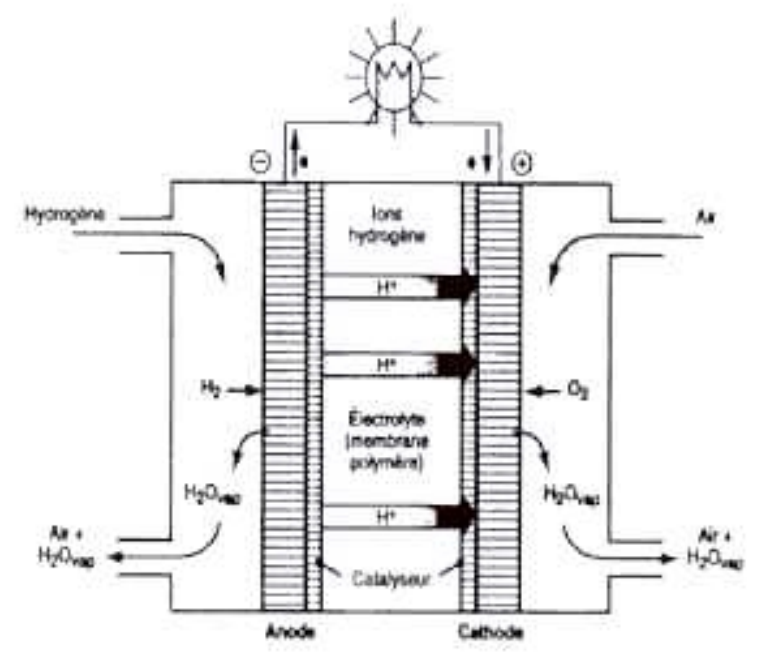

Figure 1. Schematic view of flows and working conditions of a fuel cell ${ }^{2}$.

Hydrogen is supplied either from a storage system where it may be in the form of a cryogenic liquid, hydrides or compressed gas, or from a production system within the installation itself: for example by electrolysis of water, hydrocarbon cracking, vapour reforming of methanol, and so on.

The operating principle is simple: the cell consists of an assembly of elementary units each constituted by a cathode chamber and an anode chamber separated by two electrodes that channel the electrons, with an intermediate electrolyte which may be solid or liquid according to the type of cell. The atom of hydrogen, under the effect of a catalyst, breaks down into a proton and an electron. Protons enter the electrolyte, while the electrons are collected and passed through the external electric circuit before returning to the cathode, where they recombine with protons and oxygen to form a molecule of water. Besides water (by-product of the reaction), electric current and heat are collected at the output, in varying proportions according to the chosen operating point, which is particularly valuable in fixed combined generation applications.

\footnotetext{
${ }^{2}$ Source : R. GALLEY \& C. GATIGNOL, "Les perspectives offertes par la technologie de la pile à combustible", Report of the "Office Parlementaire des choix scientifiques et technologiques", France, p. 30, 2001.
} 


\section{The hydrogen scenario}

We have seen that hydrogen goes along with fuel cells. In the following paragraphs we will try to identify specific safety issues related to its use in a gaseous form.

\section{General considerations}

Gaseous hydrogen is a highly flammable, colourless, odourless and non toxic gas. It is the lightest of all gases.

The following table 1 offers a comparison of hydrogen safety characteristics with the ones of propane, methane and gasoline.

Table 1. Comparison of hydrogen safety characteristics with more conventional fuels ${ }^{3}$..

\begin{tabular}{|l|c|c|c|c|c|}
\hline Property & Unit & Hydrogen & Methane & Propane & Gasoline \\
\hline Molecular weight & $\mathrm{kg} / \mathrm{kmol}$ & 2.016 & 16.043 & 44.10 & \\
\hline Heat of combustion (high) & $\mathrm{kJ} / \mathrm{g}$ & 141.86 & 55.53 & 50.41 & \\
\hline $\begin{array}{l}\text { Limits of flamability in air } \\
\text { (LFL - UFL) Downward } \\
\text { propagating }\end{array}$ & $\mathrm{vol} \%$ & $4.0-75.0$ & $5.3-15.0$ & $2.1-9.5$ & $1-7.8$ \\
\hline $\begin{array}{l}\text { Limits of detonability in air } \\
\text { (LDL - UDL) }\end{array}$ & $\mathrm{vol} \%$ & $18.3-59.0$ & $6.3-13.5$ & $3.1-7^{4}$ & $1.1-3.3$ \\
\hline $\begin{array}{l}\text { Stochiometric composition in } \\
\text { air }\end{array}$ & $\mathrm{vol} \%$ & 29.53 & 9.48 & 4.03 & 1.8 \\
\hline $\begin{array}{l}\text { Minimum Ignition Energy in } \\
\text { air (MIE) }\end{array}$ & $\mathrm{mJ}$ & 0.02 & 0.29 & 0.26 & 0.24 \\
\hline $\begin{array}{l}\text { Maximal Experimental Safety } \\
\text { Gap at NTP (MESG) }\end{array}$ & $\mathrm{cm}$ & 0.008 & 0.12 & $\mathrm{NA}$ & 0.074 \\
\hline Auto-Ignition temperature & ${ }^{\circ} \mathrm{K}$ & 858 & 813 & 760 & $228-471$ \\
\hline Buoyency & $\mathrm{W} / \mathrm{r}$ to air & 0.07 & 0.55 & 1.52 & $3.4-4.0$ \\
\hline $\begin{array}{l}\text { Diffusion coefficient in NTP- } \\
\text { air }\end{array}$ & $\mathrm{cm} / \mathrm{s}$ & 0.61 & 0.16 & 0.12 & 0.12 \\
\hline Diffusion velocity in NTP-air & $\mathrm{cm} / \mathrm{s}$ & $\leq 2.0$ & $\leq 0.51$ & N.A. & \\
\hline Burning velocity in NTP air & $\mathrm{cm} / \mathrm{s}$ & $265-325$ & $37-45$ & N.A. & 0.42 \\
\hline Energy of explosion NTP & $\mathrm{g} \mathrm{TNT/ \textrm {m } ^ { 3 }}$ & 2.02 & 7.03 & 20.3 & 44.22 \\
\hline Toxicity & & $\begin{array}{c}\text { non toxic } \\
\text { (asphyxiant) }\end{array}$ & $\begin{array}{c}\text { non toxic } \\
(\text { asphyxiant) }\end{array}$ & $\begin{array}{c}\text { non toxic } \\
\text { (asphyxiant) }\end{array}$ & toxic \\
\hline
\end{tabular}

We will now discuss these safety characteristics in the light of accidental phenomenon.

\section{Hydrogen dispersion}

In similar release conditions (diameter and pressure), hydrogen is expected to mix with air and disperse more rapidly than other fuels, driving down more quickly its concentration in air in unconfined space. Its low molecular weight drives this property : higher jet speed and higher diffusion coefficient.

\footnotetext{
${ }^{3}$ sources : "Investigation on safety, regulations and acceptability of hydrogen", Euro-Quebec Hydro-Hydrogen Pilot Project (EQHHPP), November 1993.

C.E. Thomas, "Direct Hydrogen fueled proton exchange membrane fuel cell system for transportation applications - Hydrogen Vehicle Safety Report”, Direct Technologies Inc., prepared by Ford Motor Company for DOE, May 1997.

${ }^{4}$ source : J.L. Alcock, "Compilation of existing safety data on hydrogen and comparative fuels", EIHP 2 Project, Shell Global Solutions, May 2001.
} 
On the other hand, its higher leak flow ( 3 times the volumetric one of propane or methane in turbulent conditions) $)^{5}$ its diffusion in air ability (4 times the one of propane or methane) and its buoyancy tends to make hydrogen more hazardous in confined spaces than other fuels.

\section{Flammability}

Lower flammability limit is a key safety factor for vapour and gases knowing how easy it is to ignite an explosive atmosphere. Hydrogen MIE is 10 times lower than conventional fuels $\left(17 \mu \mathrm{J}^{6}\right)$. At stoechiometric conditions the weakest static electricity discharge (brush discharge) is entitled to ignite the mixture. At LFL, MIE of methane is comparable to the one of hydrogen.

\section{Experience shows that hydrogen air-mixture ignites most of the time ${ }^{7}$}

Ability to ignite makes hydrogen very large flammability range less of interest since we would expect it to ignite before reaching high concentration values. Ability to ignite would also tend to minimise explosive atmosphere volume and therefore associated effects. However, if hydrogen accumulates above $L F L$ in a confined space, it is more likely to ignite.

Hydrogen auto-ignition temperature $\left(858^{\circ} \mathrm{K}\right)$ is slightly higher than the one of other fuels. Autoignition is not a usual cause of hydrogen ignition ${ }^{8}$.

\section{Formation of an explosive atmosphere}

We have seen that hydrogen disperses more rapidly in air. This propriety enhances formation of large explosive atmosphere in confined spaces. We will now consider high pressure leaks ${ }^{9}$ in open spaces without obstacle.

The following table 3 compares explosive atmospheres volumes for different gases at different leaking pressure and diameter.

\footnotetext{
${ }^{5}$ See note 3

${ }^{6}$ One has to bear in mind that spark discharges of the human body has an energy level of about $10 \mathrm{~mJ}$.

${ }^{7}$ Reference : C.E. Thomas, "Direct Hydrogen fueled proton exchange membrane fuel cell system for transportation applications - Hydrogen Vehicle Safety Report", Direct Technologies Inc., prepared by Ford Motor Company for DOE, May 1997.

${ }^{8}$ See note 7.

${ }^{9}$ Current hydrogen mobile technologies favour high pressure storage of hydrogen.
} 
Table 3. Comparison of explosive volumes at similar leaking conditions for hydrogen, methane \& propane (Explojet/INERIS software).

\begin{tabular}{|c|c|c|c|c|c|c|c|c|c|c|c|c|c|}
\hline \multirow[b]{3}{*}{ Pressure } & & \multicolumn{4}{|c|}{ Propane } & \multicolumn{4}{|c|}{ Methane } & \multicolumn{4}{|c|}{ Hydrogen } \\
\hline & & \multicolumn{4}{|c|}{ Leak diameter $(\mathrm{mm})$} & \multicolumn{4}{|c|}{ Leak diameter $(\mathrm{mm})$} & \multicolumn{4}{|c|}{ Leak diameter (mm) } \\
\hline & & 1 & 2 & 4 & 10 & 1 & 2 & 4 & 10 & 1 & 2 & 4 & $10^{10}$ \\
\hline \multirow{3}{*}{10 bar } & $\begin{array}{l}\text { Distance to } \\
\text { LFL (m) }\end{array}$ & 0,46 & 0,92 & 1,84 & 4,6 & 0,38 & 0,64 & 1,3 & 3,2 & 1,1 & 2,2 & 4,4 & 11 \\
\hline & $\begin{array}{c}\text { Flammable } \\
\text { mass of fuel }(\mathrm{kg})\end{array}$ & 0,00005 & 0,0004 & 0,003 & 0,046 & 0,00001 & 0,0001 & 0,0008 & 0,012 & 0,000056 & 0,00045 & 0,0036 & 0,056 \\
\hline & $\begin{array}{c}\text { Explosible vol- } \\
\text { ume }\left(\mathbf{m}^{3}\right)^{11}\end{array}$ & 0,0008 & 0,006 & 0,05 & 0,78 & 0,0003 & 0,002 & 0,0017 & 0,26 & 0,011 & 0,09 & 0,72 & 11,2 \\
\hline \multirow{3}{*}{250 bar } & $\begin{array}{l}\text { Distance to } \\
\text { LFL (m) }\end{array}$ & & & & & 1,6 & 3,2 & 6,4 & 16 & 5,5 & 11 & 22 & 54 \\
\hline & $\begin{array}{c}\text { Flammable mass } \\
\text { of fuel (kg) }\end{array}$ & & & & & 0,0015 & 0,012 & 0,1 & 1,5 & 0,007 & 0,056 & 0,46 & 6,79 \\
\hline & $\begin{array}{c}\text { Explosible } \\
\text { volume }\left(\mathbf{m}^{3}\right)\end{array}$ & & & & & 0,033 & 0,26 & 2,1 & 32,5 & 1,4 & 11,2 & 90 & 1360 \\
\hline
\end{tabular}

The following observations can be made:

- at a given pressure, whatever the gaz, distance to LFL doubles when leaking diamater also doubles. At the same time, explosible mass or explosible volume are multiplied about 10 times,

- in any situations, methane leads to smaller explosive atmospheres volumes,

- in any situations, hydrogen leads to much larger explosible volumes,

- whatever the pressure, hydrogen leads to explosible volumes about 40 times higher than the ones with methane,

- at the same leaking pressure, hydrogen and propane lead to the same explosible mass. Explosible volume is somehow very different due to hydrogen low molecular weight.

Table 4. Explosible volumes of hydrogen / air formed for different leaking diameters at 700 bar (Explojet/INERIS software).

\begin{tabular}{|c|c|c|c|c|}
\hline \multirow{2}{*}{$\begin{array}{c}\text { Pressure } \\
\text { (bar) }\end{array}$} & & \multicolumn{3}{|c|}{ Leak diameter $(\mathrm{mm})$} \\
\hline & & 1 & 2 & 4 \\
\hline \multirow{3}{*}{700} & Distance to LFL (m) & 9,1 & 18,2 & 36,4 \\
\hline & Flammable mass of fuel (kg) & 0,0318 & 0,255 & 2,04 \\
\hline & Explosible volume $\left(\mathrm{m}^{3}\right)$ & 6,39 & 51,1 & 409 \\
\hline
\end{tabular}

\section{Combustion regime}

Hydrogen burning velocity is far greater than the one of other fuels. Generally speaking, likelihood to transit from deflagration (DDT) to detonation regime is in relation with this burning velocity.

However, past accidents have shown that few DDT have been observed. In open spaces, deflagration is the combustion regime to be expected unless a very energetic source (explosives) ignites the detonable mixture ${ }^{12}$.

\footnotetext{
${ }^{10}$ For this specific case, figures given by PHAST 6.1 (DNV) are half of those given by Explojet.

${ }^{11}$ Explosible volume is given between LFL and UFL

${ }^{12}$ Reference : L.C. Cadwallader and J.S. Herring , "Safety issues with hydrogen as a vehicle fuel”, Idaho National Engineering and Environmental Laboratory, September 1999.
} 


\section{Pressure effects}

Damageable pressure effects accompany explosion phenomenon. Because of its speed of pressure rise hydrogen explosion induced pressure effects are expected to be more severe than for other gases even though volumetric energy release is lower than the one of other studied fuels.

This quick evaluation shows that hydrogen has a different behaviour than conventional fuels. Hazardous or safe potential of hydrogen is to be revealed by the technology and the context of use.

Therefore, we now propose a risk evaluation overview of a PEMFC.

\section{Risk analysis of Proton Exchange Membrane Fuel Cell systems}

\subsection{Critical events related to the core of the cell}

Whatever technology is used, the core of the cell consists of an assembly of elementary units in which an electrochemical reaction takes place between a fuel (hydrogen) and an oxydant (usually oxygen from the air). The core of the cell remains unchanged over time. In non degraded mode, hydrogen and oxygen never come into direct contact.

\section{Hydrogen leakage and release : formation of an explosive atmosphere}

Leakage (accidental situation) can be distinguished from normal release. Normal release is caused by chronic purging ${ }^{13}$ of the core (PEMFC). Purged hydrogen is then released into air. In confined spaces, one has to pay attention not to progressively enrich the air with hydrogen until it reaches its LFL (high speed release and homogeneous mixing or stratification and further mixing phenomenon). In unconfined spaces no explosive atmosphere is to be expected unless at the point of hydrogen release. The volume of this explosive atmosphere is driven by the flow and the release diameter at operating pressure. Premixing below LFL prior to release is a possible safety solution.

Along with chronic purging, chronic leakage is to be evaluated. Indeed, hydrogen diffusion ability makes it difficult to confine. As a consequence, minor chronic leaks have to be expected.

Hydrogen accidental leakage in PEMFC encompasses a wide range of situations:

- purge malfunction : purging becomes permanent leading to more hydrogen to be released into the outside air,

- membrane puncture can lead to an equivalent situation as well as to form an explosible mixture within the stack. This latest situation is not critical mainly because of reduced volume and the presence of catalyst that would favour moderated hydrogen combustion,

- core, manifold and piping leakage,

- reverse electrolysis of the cells... .

In PEMFC, membrane rupture is a noticeable situation with the potential to lead to large leaks. Membrane rupture can be induced by :

- inappropriate pressure balance between each side of the membrane side,

- excessive local temperature (lack of humidification, inhomogeneous or insufficient cooling ...),

- membrane ageing.

\footnotetext{
${ }^{13}$ Hydrogen purging drives away excessive nitrogen (nitrogen from the air side permeates through the membrane to the hydrogen side) and water on the cathode side.
} 
Any of the above situations can lead to the formation of local (open spaces) and extensive explosive atmosphere (confined spaces).

Severity of the above situations depends on the studied fuel cell. Possible consequences whatever minor or severe the leak is have to be quantified. As such, for each system, one should put figures on :

- the maximum leakage rate and associated maximum explosive volume,

- chronic purge induced explosive atmosphere in open air and ventilated confined space,

- the chronic leakage flow of hydrogen.

\section{Electrical hazards}

Beside hydrogen leaks and associated explosive atmosphere, electrical hazard is a prevalent risk due to the presence of high voltage.

\subsection{Basic safety principles}

\section{General safety principles}

Enforcement of safety principles requires first of all to avoid the hazard (replacement), then to reduce/control its potential and finally to set safety distances with potential targets. Users should also be informed about risks of the equipment.

\section{Control of hydrogen risk}

Above principles apply to fuel cell systems. Control of hydrogen hazards goes through:

- reduction/avoidance of chronic release of hydrogen by appropriate design,

- minimising the size of explosive atmosphere in case of leakage or release (operating pressure, pipe size, maximum hydrogen flow ${ }^{14} \ldots$ ),

- avoidance / limitation of confinement in design and use of the system (open space or controlled ventilation),

- control of ignition sources (appropriate electrical equipment, physical segregation between electrical and hydrogen parts,...),

- early detection of leak and leak interruption before reaching a hazardous situation,

- enforcement of state of the art technical safety principles (redundancy of critical equipment, fail safe system,...)

- regular checks and maintenance,

- end-user information.

Complete control of hydrogen leakage is not realistic. However driving down leakage situation to acceptable level of risk should be the main objective.

Under construction IEC standards (IEC TC 105) suggest among others leaking tests to be undertaken.

This brief evaluation shows that this new technology brings along risks that can be overcome with traditional approaches and safety measures.

\footnotetext{
${ }^{14}$ Maximum hydrogen flow is to be balanced with maximum fuel cell stack hydrogen consumption.
} 


\section{Regulations and standards related to fuel cell systems}

It goes without saying that since fuel cell systems are made up of a variety of equipment, such as compressor, storage tanks, electrical systems,... that many existing regulations and standards can be applied.

Specific regulations and standards are under construction in Europe and at the international level. On legal and standardisation point of view, stationary applications have to be distinguished from mobile applications.

\subsection{Standardisation}

An ISO ${ }^{15}$ technical committee - TC 197 - "Hydrogen Technologies" was set up in 1990 to prepare standards for systems and devices involved in producing, storing, transporting, measuring and using hydrogen. Its $7^{\text {th }}$ working group has prepared a standard on the "Basic requirements for the safety of hydrogen systems"

An IEC ${ }^{16}$ technical committee - TC 105 - "Technologies of fuel cells" was set up in 1996 to prepare standards for fuel cell technologies for both stationary and mobile applications. Its $3^{\text {rd }}$ group focusses on the safety of stationnary fuel cell systems.

In North America, organisations such as the National Hydrogen Association (NHA), the Canadian Hydrogen Association, the National Fire Protection Association (NFPA), the American National Standards Institute (ANSI), and the American Society for Mechanical Engineers (ASME) are working to draw up codes, standards and guides concerning the construction and use of fuel cell systems.

In Europe, there is no specific standard for stationary fuel cell systems. A technical committee has been created within the $\mathrm{CEN}^{17} / \mathrm{CENELEC}^{18}$ and covers residential fuel cells with a power up to 70 $\mathrm{kW}$.

\subsection{Regulations}

In Europe existing directives among others can be applied to stationnary fuel cell systems for CE marking.

Three of these directives appear to be applicable in every cases :

- Machine Directive 98/37/EC ${ }^{19}$

- Low voltage Directive 73/23/EEC

- Electromagnetic Compatibility Directive 89/336/EEC, 92/31/EC, 98/13/EC.

Today, there is no regulation, neither for fuel cell vehicles nor for mobile hydrogen storage.

European Directive 70/156/CE "type-approval of motor vehicles and their trailers" does not include hydrogen vehicle type-approval.

\footnotetext{
${ }^{15}$ ISO: International Standards Organisation

${ }^{16}$ IEC: International Electrotechnical Commission

${ }^{17} \mathrm{CEN}$ : Comité européen de normalisation

${ }^{18}$ CENELEC : Comité européen de normalisation électronique

${ }^{19}$ Its worth indicating that ATEX 94/9/EC is applied as part of the machine directive expectations
} 
To overcome this barrier, $\mathrm{UNECE}^{20}$ rules relative to onboard hydrogen storage are under construction. However, these later rules do not cover the use of a fuel cell in a vehicle.

Meanwhile future dedicated regulations, a manufacturer can apply for a prototype approval of its vehicle.

\section{Social acceptance of hydrogen}

For lay people, the use of hydrogen induces hazardous meanings (explosion).

However, development of hydrogen use will not take off without the public (potential users) onboard.

Social brake is not a dead end. Studies conducted in Germany came to the conclusion that social acceptance of hydrogen can be overcome by raising public awareness ${ }^{21}$.

This communication action could consist in:

1. offering to the public information about hydrogen technologies (through schools and the mass media) ;

2. developing public tests, pilot projects and demonstrations, and these should be accompanied with explanatory measures in order to introduce the information ;

3. advertising upon safety approaches ;

4. stressing environmental advantages of hydrogen.

\section{Conclusion}

Hydrogen economy adresses some of today's environmental issues. As such, it is entitled to become one of tomorrow's new energy carrier. If so, hydrogen is supposed to offer the same services at an equivalent price as today's fuel with equivalent level of safety.

Comparative safety studies require not only to focus on the product itself, but also on supporting technologies as well as on context of use (confined environnement).

It is obvious that hydrogen has different properties than today's fuel. Some of them tend to make it safer (it disperses more rapidly in open space) and some other more hazardous (potentially strong pressure effects) in foreseen context of use. However, it does not bring along risks than can be overcome with traditional approaches and safety measures.

Fuel cell systems do not appear to put public safety at stakes. High pressure storage could be more critical and require special attention from industrial, standardisation and regulatory bodies.

Hydrogen technologies developers seem to have learned from other energy carriers errors in the sense that safety studies are intrinsequely part of the development. On going standardisation work pushes towards an appropriate and homogeneous level of safety in order to avoid any preliminary accident that could geopardise hydrogen future use in everyday life. However, the use of hydrogen will inevitably lead to accidental situation as other fuels would.

Thus, in comparing hydrogen with current energy technologies, one should not be blind on hazards related to the use of gasoline for instance. Gasoline has not the same propension as hydrogen to

\footnotetext{
${ }^{20}$ United Nations Economic Commission for Europe

${ }^{21}$ Ludwig-Bölkow-Systemtechnik GmbH and Ludwig-Maximilians-Universität München, "The acceptance of hydrogen technologies", http://www.hydrogen.org/accepth2/.
} 
explode but it takes fire. Statistics show that gazoline fire sets by car accidents counts for $1 \%$ of fatalities on the road. Would hydrogen be responsible for $1 \%$ fatalities in case of car accidents ? One has to come to turn with the reality of today's fuel in their context of use. Comparative studies should pay attention not to underestimate risks of usual fuels because of their everyday usage and overestimate risks of hydrogen. Hydrogen requires to be better known through experimental / demonstration projects.

Still, acceptance relies on expected users : the public. Pragmatic safety studies are one thing public acceptance is another one. If hydrogen is an appropriate solution, it has to take the public onboard to erase the fear of the unknown.

\footnotetext{
${ }^{22}$ Information given by Laboratoire d'Accidentologie et de Biomécanique PSA Peugeot Citroên Renault - France
} 


\title{
Hydrogen Energy: The Key to a Substainable Development of EU and GCC Countries
}

\author{
AYOUB M. KAZIM \\ United Arab Emirates University \\ Department of Mechanical Engineering \\ P.O. Box 17555 Al-Ain, U.A.E. \\ Fax: +971-3-7623-158 \\ E-mail: akazim@uaeu.ac.ae
}

\begin{abstract}
This paper presents technical, environmental and economical aspects of hydrogen energy and its role to achieve a sustainable development for EU and GCC countries. EU could obtain a clean energy supply of hydrogen to fulfill its future demand and implement the Kyoto- protocol. On the other hand, GCC countries could maintain their share in the energy market by supplying hydrogen energy and achieve a healthy economic growth. In order for the EU countries to fulfill their commitment in the protocol, hydrogen should be supplied at a growth rate of $\mathrm{B}=10 \%$ if their energy demand remained at $\mathrm{A}=1 \%$. Furthermore, The initial photovoltaic cell area required to produce hydrogen energy in GCC countries in 2005 is at least $11,800 \times 10^{3} \mathrm{~m}^{2}$, which is considered to be reasonable and it could be reduced if the efficiencies of the electrolyser and PV cells are increased above $90 \%$ and $18 \%$, respectively.
\end{abstract}




\section{Introduction}

Presently, Gulf Cooperation Council (GCC) countries consisting of Saudi Arabia, United Arab Emirates, Kuwait, Oman, Qatar and Bahrain supply the 15 European union (EU) countries approximately 9,000 million GJ of oil and natural gas, which represent $15 \%$ of EU's annual energy imports [1]. GCC's energy supply to EU is predicted to increase substantially due to future increase in the energy demand along with depletion of the fossil fuel reserves of the non-GCC countries currently supplying EU. Consequently, this would lead them to seek other suppliers like GCC countries, which have approximately $66 \%$ and $35 \%$ of world's proven reserves of oil and natural gas, respectively. However, the environmental and air pollution concerns of EU countries and their determination of implementing the Kyoto-protocol involving reduction of gas emission in the year 2010 by $8 \%$ from the actual levels in 1990 leads them to seek a suitable environment-friendly energy alternative [2]. Besides being pollution-free energy source, this energy alternative should have other characteristics such as availability, storability and sustainability in order for EU countries to rely on for future energy needs without any obstacles. On the other hand, inconsistently oil-dependent economy of GCC countries has led them to serious consequences in the past two decades. Hence, it prompted them to seek suitable and drastic measures such as diversification of their economy and optimum exploitation of their natural resources effectively in order to achieve the desired economical growth and sustainable development.

Hydrogen energy, which possesses significant characteristics such as being environmentally clean, storable, transportable and inexhaustible, could play a key role in fulfilling EU's future energy needs as well as implementing the Kyoto-protocol. Technically, GCC countries have a significant potential of producing hydrogen energy through either steam-methane reformation process using natural gas or by a renewable source namely solar-hydrogen electrolysis process [3]. Through utilization of highly efficient hydrogen fueled fuel cells in power generation, EU could get a clean energy supply to fulfill its future demand and implement the Kyoto-protocol. Moreover, GCC countries could maintain their share in the energy market by supplying a sustainable clean energy source and achieve a healthy economic growth. Thus, the objective of this paper is to present technical, environmental and economical aspects of hydrogen energy and its significant role to a sustainable development for EU and GCC countries.

\section{Future concerns of EU and GCC countries}

\subsection{Energy and Environmental Concerns of EU Countries}

In 1973, oil crisis prompted many energy-related sectors in EU countries to shift towards alternative fuels especially renewable energy such as solar, wind, hydro...etc. to fulfill part of their demand and to have a clean source of energy. Currently, only 6\% of EU's energy needs are fulfilled by renewable resources mainly hydro energy (4\%). In the last decades, exploitation of renewable energy have been disappointing mainly due to their low efficiencies and high capital costs. Nevertheless, EU has set a target of $12 \%$ of its energy needs in 2010 to be powered by its renewable resources. In spite of its environmental concerns, EU's oil import is expected to grow $87 \%$ in 2010 , due to its limited natural resources of conventional energy reserves and additional members, that are also energy importers are set to join EU in 2004 and later. By the same token, EU is expected to increase its dependency on natural gas to reach $60 \%$ in 2010 [1].

Energy-related carbon emissions in the EU countries were estimated to be $14 \%$ of the world total in the year 2000. Under Kyoto protocol, EU countries are obligated to reduce carbon emissions $8 \%$ from the 1990 level by 2008-2012. Thus, their commitment to implement Kyoto protocol dictates them to seek a suitable environment-friendly alternative on the short term [2]. However, it is difficult to make adjustments to the energy system since it requires changes of technology choices, which would take decades to be realized [4]. 


\subsection{Economical Concerns of GCC Countries}

With their huge reserves of oil and natural gas accounting respectively $66 \%$ and $35 \%$ of world's total oil and natural gas reserves, GCC's economy depends heavily if not entirely on the revenues generated from these fossil fuels. For example, oil revenues in Saudi Arabia makes about $90 \%$ of the country's export earnings. Whereas, Kuwait's economy depends on oil revenues of approximately $95 \%$ of total export earnings and two-fifths of gross domestic product GDP [5]. Throughout the years, inconsistency of energy demand, oil pricing along with fluctuations of the \$US Dollars have hindered the economic growth of some GCC countries, causing an economic chaos [11]. In addition, GCC countries are well aware of the commitments made by many developed countries regarding Kyoto protocol; and it would be in their interest to maintain their reputation as world's key suppliers of fossil fuels to gradually initiate supplying the world with a clean form of energy. By supplying the world specially EU countries with both fossil fuels and a clean energy, GCC countries could achieve the desired sustainable continuous economic growth. Table 1 presents energy and economic data of GCC countries and their current role in supplying EU countries with the fossil fuels.

Table 1. Data for GCC countries [5-10].

\begin{tabular}{|l|c|c|c|c|c|}
\hline Country & $\begin{array}{c}\text { Oil Reserves } \\
\text { (Billion bar- } \\
\text { rels) }\end{array}$ & $\begin{array}{c}\text { Natural Gas } \\
\text { Reserves } \\
\text { (Tcf) }\end{array}$ & $\begin{array}{c}\text { \% of Supply } \\
\text { to EU }\end{array}$ & $\begin{array}{c}\text { Population } \\
\text { (Million) }\end{array}$ & $\begin{array}{c}\text { GDP/Capita } \\
\text { (\$/capita) }\end{array}$ \\
\hline Saudi Arabia & 264.2 & 219.5 & $10 \%$ & 21.7 & 8,800 \\
\hline U.A.E. & 97.8 & 212 & Less than $1 \%$ & 2.4 & 26,000 \\
\hline Kuwait & 96.5 & 52.7 & $3 \%$ & 2.0 & 17,550 \\
\hline Qatar & 15.2 & 509 & $1 \%$ & 0.78 & 22,100 \\
\hline Bahrain & 0.125 & 3.2 & - & 0.65 & 13,100 \\
\hline Oman & 5.5 & 29.3 & Less than $1 \%$ & 2.6 & 8,100 \\
\hline
\end{tabular}

\section{Hydrogen energy}

Many scientists, energy economists, and energy policy makers believe that hydrogen energy, which possesses significant characteristics such as being environmentally clean, storable, transportable and inexhaustible, could play a key role in fulfilling the global energy demand. Presently, utilization of hydrogen energy to run fuel cells for a clean power generation has gained worldwide attention. Fuel cells especially proton exchange membrane fuel cells (PEMFC) have been playing a significant role in many industrial, utilities and transportation sectors.

Production of hydrogen can be carried out through either utilizing conventional resources or by renewable resources. Conventional fuels such as oil and natural gas can generate hydrogen by steamreformation, and coal can produce hydrogen by gasification. On the other hand, hydrogen production through renewable resources such as biomass gasification, solar-hydrogen and wind-hydrogen electrolysis process and hydropower electrolysis process, is considered to have a promising future. In the current analysis, I consider hydrogen production by means of natural gas steam-reformation process and by solar-hydrogen energy system, which is ideal for GCC countries that are described to be climatically suitable for solar energy applications.

\subsection{Natural gas steam-reformation}

Globally, around 400 billion cubic meters of hydrogen are produced annually with natural gas steamreformation process, which is considered to be the most common and cost effective hydrogen producing method [12]. About $48 \%$ of worldwide hydrogen production comes from this process, and even experts have recommended the mass production of small-scale natural gas reformers, supplying direct 
hydrogen for stationary fuel cells and at vehicle refueling stations. Natural gas steam-reformation is a two-step process in which four parts hydrogen are produced from one part methane and two parts water at high operating temperatures and pressures and in the presence of a catalyst. It is a relatively efficient and inexpensive process, and can be made still more efficient with the utilization of the waste heat, which could be referred to as cogeneration. This latter feature makes steam-methane particularly attractive for local use. Although the cost of hydrogen produced from steam-reformation process, fluctuates with the fluctuating price of natural gas, it is proved to be more favorable in the near-term than hydrogen produced from renewable methods.

Efficiency of the steam-reforming process is defined as, the ratio of the heating value of the produced hydrogen over the energy input of the raw material, fuel and electricity is about $65-75 \%$ [13]. Since hydrogen production through steam reformation of natural gas is highly exothermic process, the plant generates more steam than it consumes. Thus, energy efficiency of the steam-reformation plant could be drastically increased by at least $10 \%$ if the excess steam generated by the plant is used for another source [14].

\subsection{Solar-Hydrogen energy System}

Solar hydrogen energy could play a key role in the overall GCC's energy supply strategy since it has a great potential of solar energy with an average annual solar insolation exceeding $8.5 \mathrm{GJ} / \mathrm{m}^{2}$. Electricity generated by PV cells could be utilized to power electrolysers to produce hydrogen through electrolysis process. Photovoltaic electrolysis is described to be simple, attains high quality of hydrogen, has less geographical limitations, and easy to couple electrolysers to the PV cells [3]. Several studies have been conducted concerning the above concept for different countries $[15,16,17]$. However, these studies would not be directly applied to GCC countries due to differences in their energy mix and economic situation as compared with the GCC in terms of fossil fuel production/demand, available fuel reserves, and solar energy potentials. From all the GCC countries, it is worth noting that Saudi Arabia has initiated a solar energy program in 1970's called "solar village". This project involved direct conversion of solar energy into electric power with $1000 \mathrm{~kW}$ capacity, which is currently supplying a community of 3,500 people near the capital city of Riyadh [18].

\section{Scenarios of supplying fossil fuel to EU coun- tries}

\subsection{Increase in Energy Demand Scenario}

Currently, GCC supplies EU countries approximately 9,000 million GJ of oil and natural gas, accounting $15 \%$ of EU's energy imports. Each country in GCC has a share of the supply as indicated in table 1. The current average fossil fuel demand growth rate is estimated to be around $A=1 \%$ (business as usual). With the future enlargement of EU countries as a result of addition of new member countries and future expected depletion of their natural resources, the energy demand could drastically increase in the near future. A suggested higher growth rate of $A=3 \%$ is considered in this paper to illustrate the future increase in the energy demand. This demand growth rate could be easily interpolated or extrapolated at any rate other than the above-suggested rate.

\subsection{Rate of Hydrogen Energy Supply Scenario}

Hydrogen energy is proposed to be produced and supply EU in 2005 at an introductory quantity of 5\% of the total amount supplied that year. The rate of increase in the hydrogen supply depends entirely on how seriously GCC and EU countries are welling to supply and consume this energy in the near fu- 
ture, respectively. The suggested growth rates of hydrogen supply considered in this paper are $\mathrm{B}=3 \%$, $\mathrm{B}=5 \%$ and $\mathrm{B}=10 \%$. Definitely the higher the growth rate the less fossil fuel is consumed and hence less environmental pollutions would take place.

\subsection{Hydrogen Energy-Producing Methods Scenario}

For each of the above suggested hydrogen supply growth rate B, two different scenarios are proposed for hydrogen production in GCC countries namely hydrogen production through natural gas steamreformation process and solar-hydrogen energy systems. In the first scenario, a suggested $95 \%$ of hydrogen is produced by natural gas reformation while the rest $5 \%$ is produced through solar-hydrogen energy system. In the second scenario, $90 \%$ of hydrogen is produced by natural gas reformation process and the rest $10 \%$ is produced through solar-hydrogen is suggested. Clearly, the second scenario tends to be more favorable than the first one because less pollution would be generated in the overall hydrogen production scheme.

\section{Outlook on energy, environment and econom- ics}

The current analysis is conducted at many possibilities and suggested scenarios discussed in the previous section. The outlook consists of projected EU's energy demand in the next 20 years with $\mathrm{CO}_{2}$ emission consequences, GCC's role to fulfill the demand of supplying a clean energy and the associated economical benefits as a result of implementing such action.

\subsection{EU's Future Energy Demand and $\mathrm{CO}_{2}$ Emissions}

Irrespective of environmental damages and EU's commitment in Kyoto protocol, import conventional energy demand and $\mathrm{CO}_{2}$ emission could increase by $28 \%$ to reach 1190 million GJ and 85 MTC by 2025 if normal pace of $\mathrm{A}=1 \%$ (business as usual) took place as shown in Figure 1. However, these figures could be significantly reduced by at least 850 million GJ (30 MTC) of oil and natural gas if they are replaced by hydrogen energy at a growth rate of $\mathrm{B}=3 \%$. Moreover, $\mathrm{CO}_{2}$ emission could be reduced substantially to any desired level by substituting fossil fuels with hydrogen energy. In order to fulfill EU's commitment towards reduction of gas emission, EU should adapt a scheme where hydrogen is produced at a rate of $\mathrm{B}=10 \%$ if their energy demand growth rate remained at $\mathrm{A}=1 \%$. On the other hand, hydrogen should be supplied at a rate of approximately $\mathrm{B}=17 \%$ if EU's energy demand is increased to $\mathrm{A}=3 \%$ as a result of its enlargement and depletion of most of its natural resources. However, it should be stressed that the price change of fossil fuel in the future would be insignificant if EU's climate policy goals are well established [19]. 


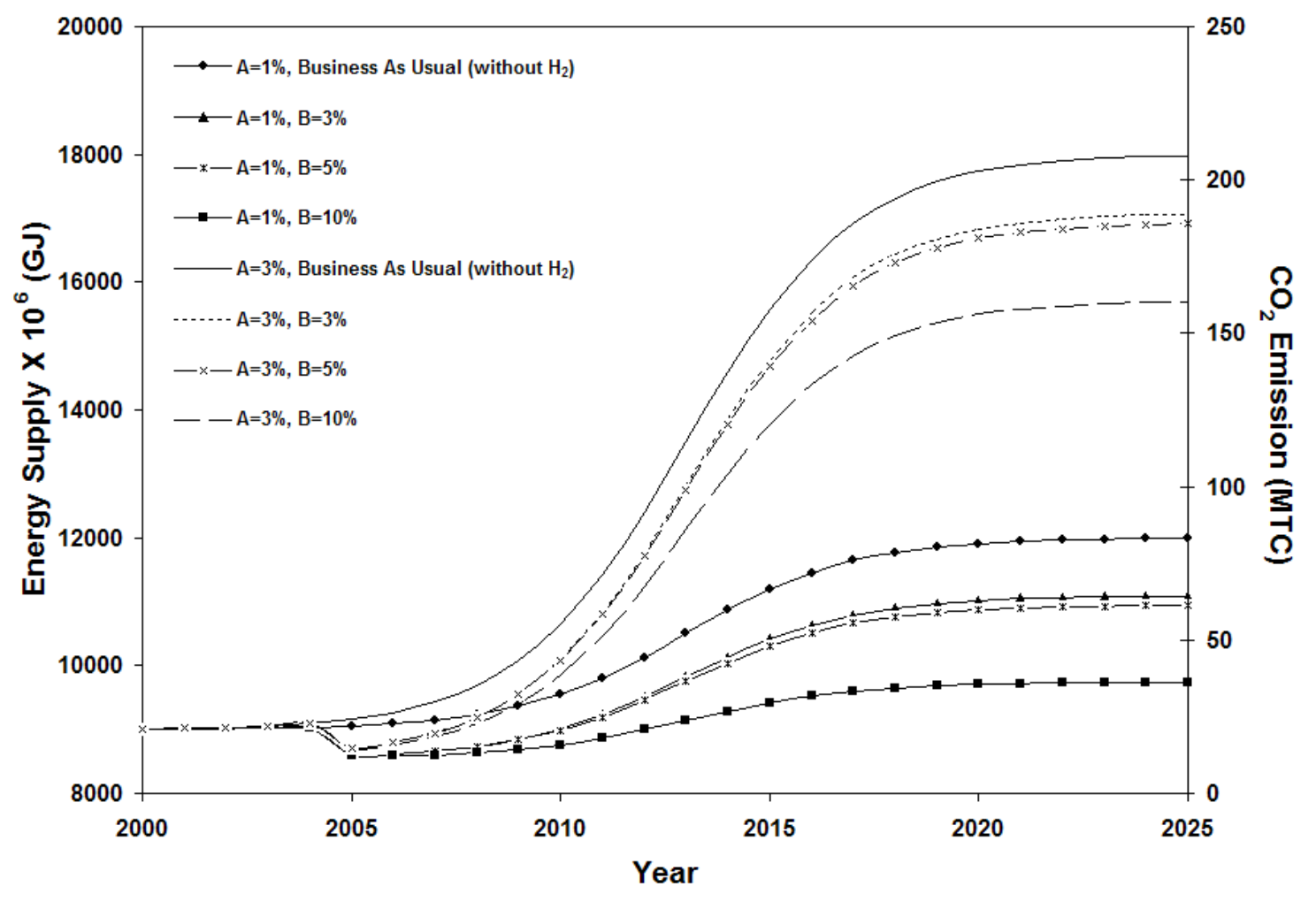

Figure 1. Current and future projected energy supply to EU countries

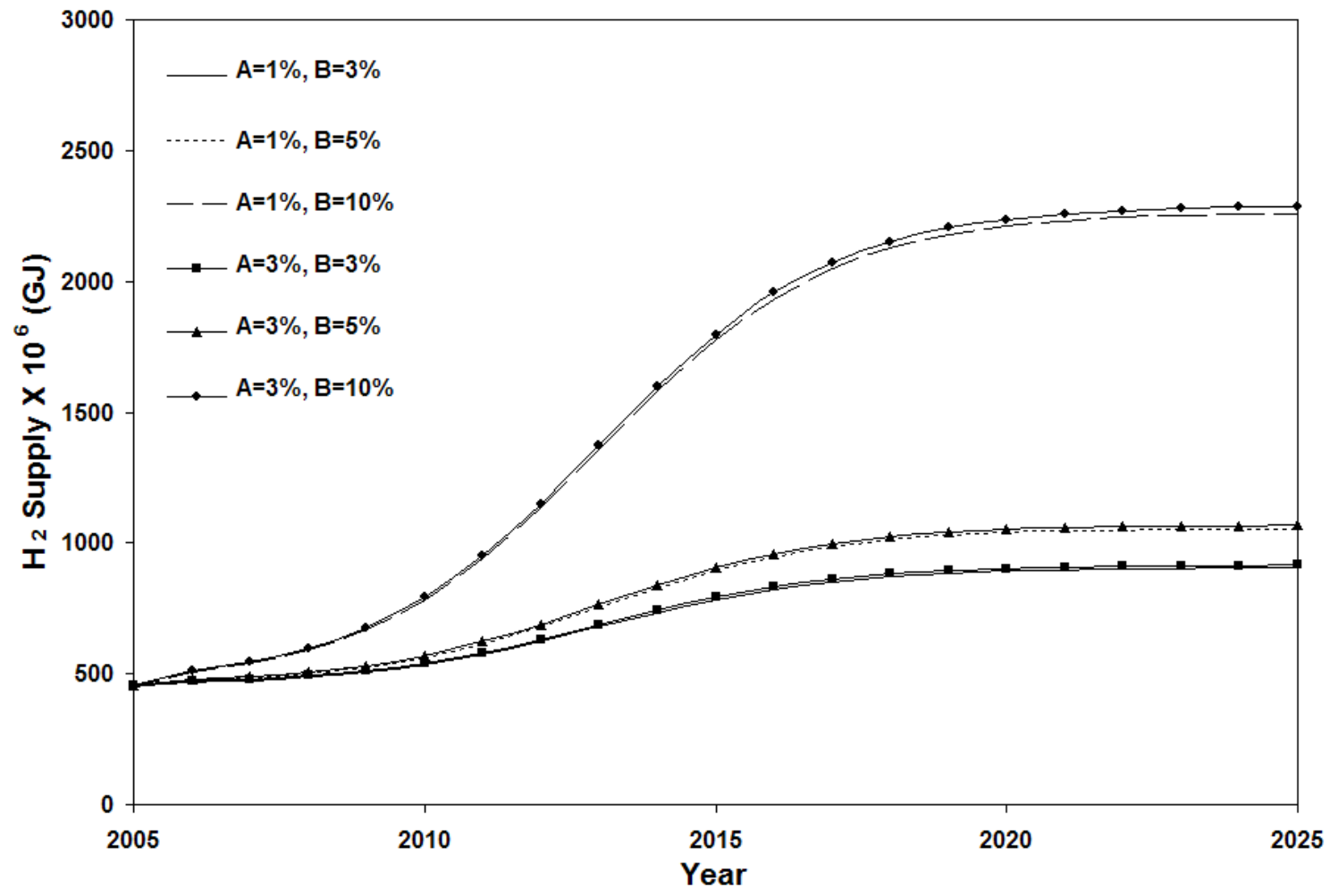

Figure 2. Hydrogen energy supply to EU at growth rates of $A=1 \%$ and $A=3 \%$ 


\subsection{GCC's Role in Supplying Hydrogen Energy}

Hydrogen is introduced in the overall energy supply picture in 2005 at approximately 485 million GJ ( $5 \%$ of total fossil fuel supplied to EU that year) as depicted in Figure 2. The growth rate of hydrogen supply B, can be adjusted depending on the pace at which GCC is welling to supply EU's demand of clean energy and cost of fossil fuels. For instance, at energy demand growth rate of $A=3 \%$ and hydrogen growth rate of $\mathrm{B}=5 \%$, hydrogen could be supplied at a rate of 1,000 million GJ by quarter of this century.

Approximately 5\%-10\% of hydrogen supplied to EU countries could be produced through solarhydrogen energy electrolysis process. Figures 3 and 4 present the required area of photovoltaic (PV) cells to produce hydrogen at $5 \%$ and $10 \%$ of solar-hydrogen systems and with various scenarios of energy demand rate A and hydrogen supply growth rate $\mathrm{B}$. Clearly, the higher the growth rates of A and $\mathrm{B}$, the greater $\mathrm{PV}$ cell area is needed. For instance at $\mathrm{A}=1 \%$ and $\mathrm{B}=10 \%$, hydrogen production could be doubled to 275 million GJ in 2025 if the supplied hydrogen is produced from the renewable source at a rate of $10 \%$ rather than $5 \%$. This will eventually lead to an increase in the PV cell area from $11,800 \times 10^{3} \mathrm{~m}^{2}$ to $23,600 \times 10^{3} \mathrm{~m}^{2}$, as shown in Figure 3 . Conversely, at $\mathrm{A}=3$ and $\mathrm{B}=5 \%$, approximately 90 million GJ of hydrogen could be produced in 2025 , and requiring $5,000 \times 10^{3} \mathrm{~m}^{2}$ of PV area if it is supplied at a rate of $5 \%$ rather than $10 \%$ as depicted in Figure 4.

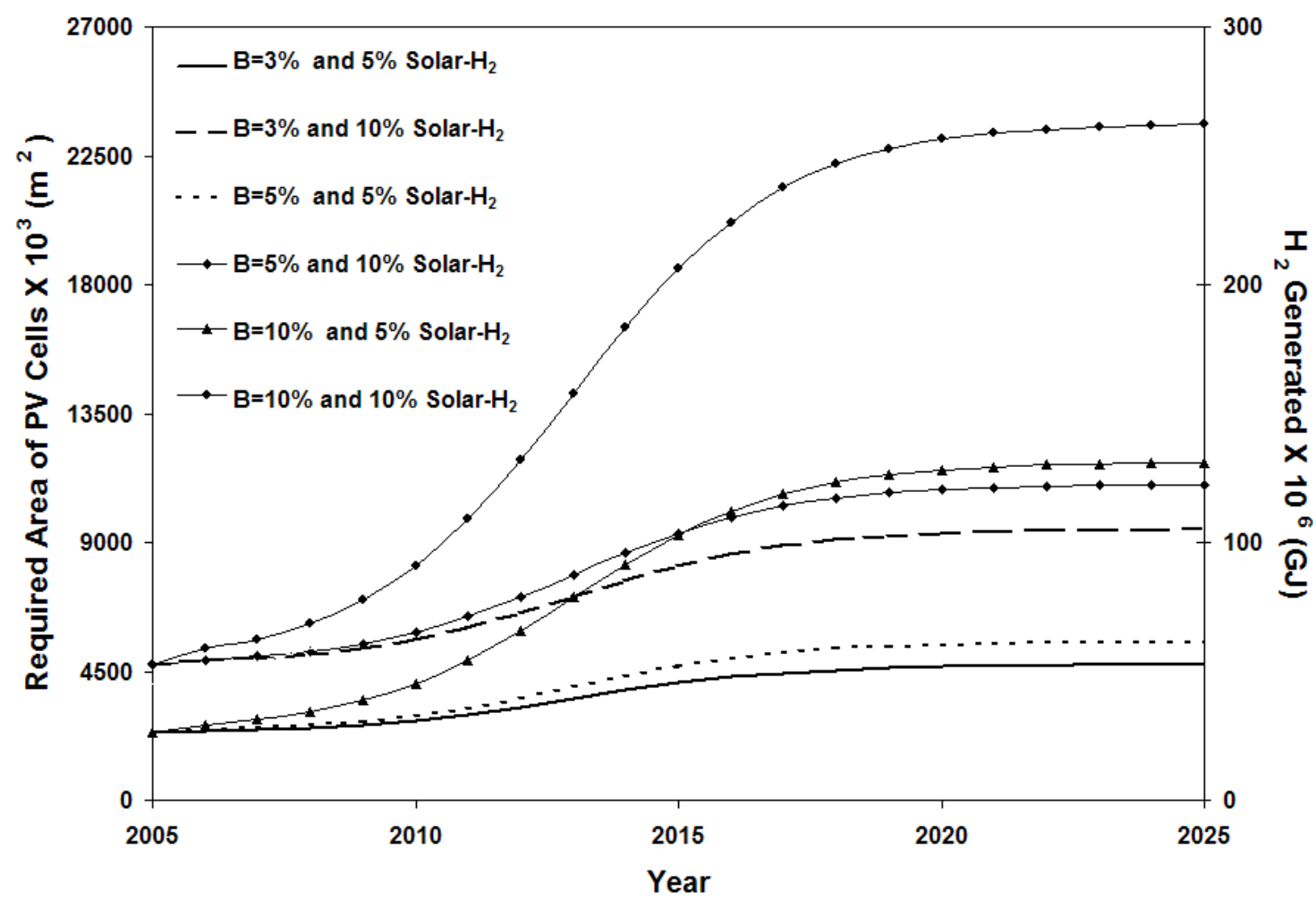

Figure 3. Required PV cell area and Hydrogen energy at a growth rates of $A=1 \%$ 


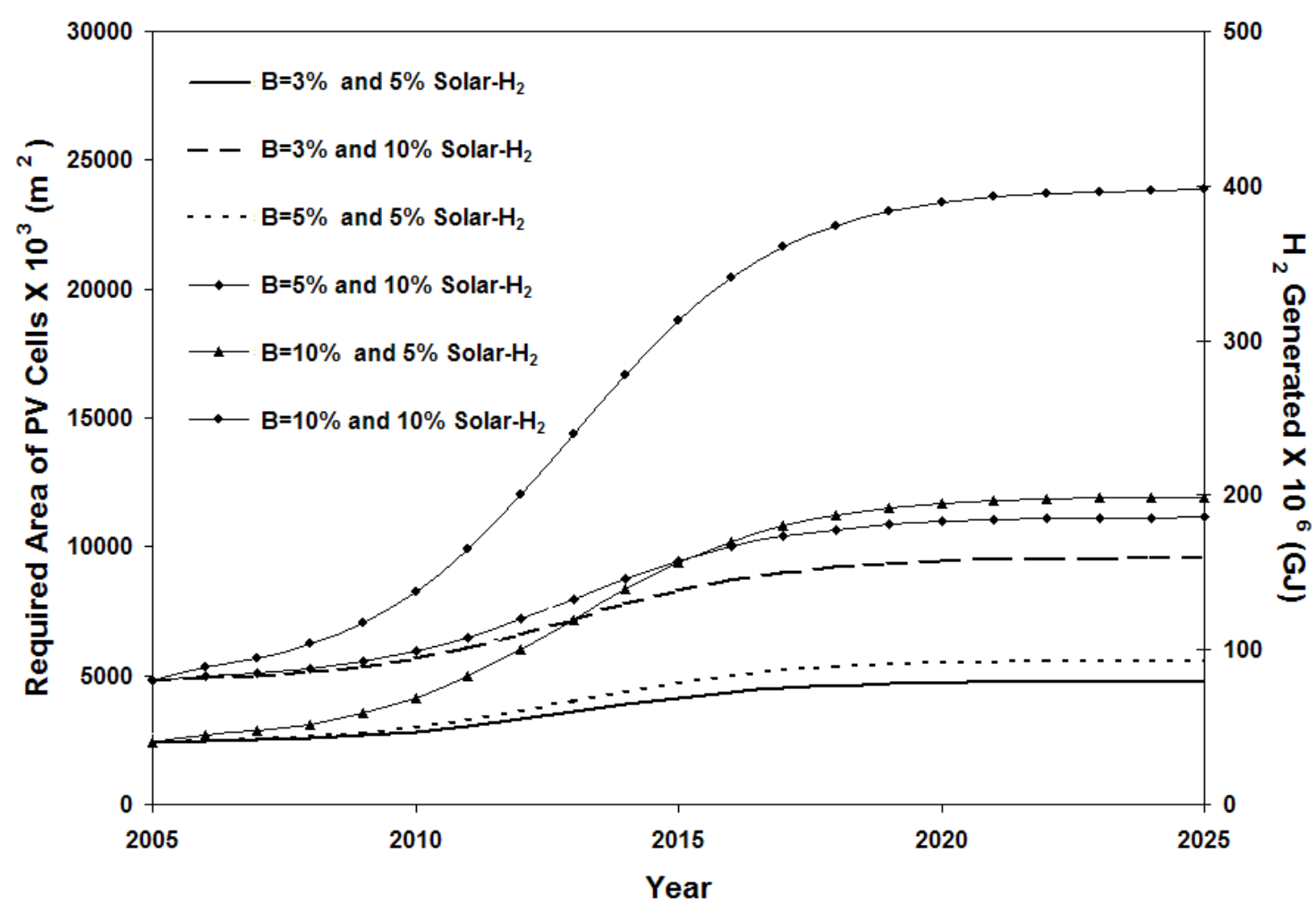

Figure 4. Required PV cell area and Hydrogen energy at a growth rates of $A=3 \%$

The initial photovoltaic cell area required to produce hydrogen energy in GCC countries in 2005, is considered to be reasonable. The area could be reduced if the efficiencies of the electrolyser and PV cells are increased above $90 \%$ and $18 \%$, respectively. At the present time, it would be difficult to acquire a PV cell with extremely high efficiency (greater than 20\%), but in the near future it could be probably feasible due to rapid advances in the PV cell technology [20].

A negligible carbon emission associated with solar-hydrogen energy system is anticipated since only solar energy is utilized to power the electrolyser specially PEM electrolyser, which produces hydrogen and oxygen with no carbon emission. On the other hand, a substantial amount of $\mathrm{CO}_{2}$ can be emitted from natural gas steam-reformation process to produce hydrogen. Figures 5 and 6 present $\mathrm{CO}_{2}$ emission associated with producing hydrogen at $95 \%$ and $90 \%$ of hydrogen production through steamreformation process and with various scenarios of energy demand rate $\mathrm{A}$ and hydrogen supply growth rate $\mathrm{B} . \mathrm{CO}_{2}$ emission starts from a constant value of 12 million tonne carbon (MTC) in 2005 and increases depending on the growth rates $\mathrm{A}$ and $\mathrm{B}$ and percentage of hydrogen produced by steamreformation. For instance in 2025 , at $\mathrm{A}=1$ and $\mathrm{B}=10 \%, \mathrm{CO}_{2}$ emission associated with $90 \%$ NGreformation is approximately $49 \mathrm{MTC}$, which is $5 \%$ less than $95 \%$ NG-reformation as illustrated in Figure 5. Without any doubt, a slight increase in the carbon emission of at most $5 \mathrm{MTC}$ could occur if the energy demand was increased from a growth rate of $A=1 \%$ to $A=3 \%$, as depicted in Figure 6 .

Experimentally, natural gas is considered to be the least polluting fossil fuel as opposed to oil and coal. Natural gas used in the reformation process contains mixture of various components such as methane $\left(\mathrm{CH}_{4}\right)$, ethane $\left(\mathrm{C}_{2} \mathrm{H}_{6}\right)$, propane $\left(\mathrm{C}_{3} \mathrm{H}_{8}\right)$ and other types of hydrocarbons, carbon dioxide $\left(\mathrm{CO}_{2}\right)$, etc., which results difficulty in predicting the performance of the plant [21]. Thus, hydrogen production through renewable energy would be more environmentally attractive as compared with natural gas reformation [22]. However, it should be pointed out that using technologies to capture $\mathrm{CO}_{2}$ for either safe, long-term storage or use as a commercial commodity or carbon sequestration technologies could effectively lower carbon emission. 


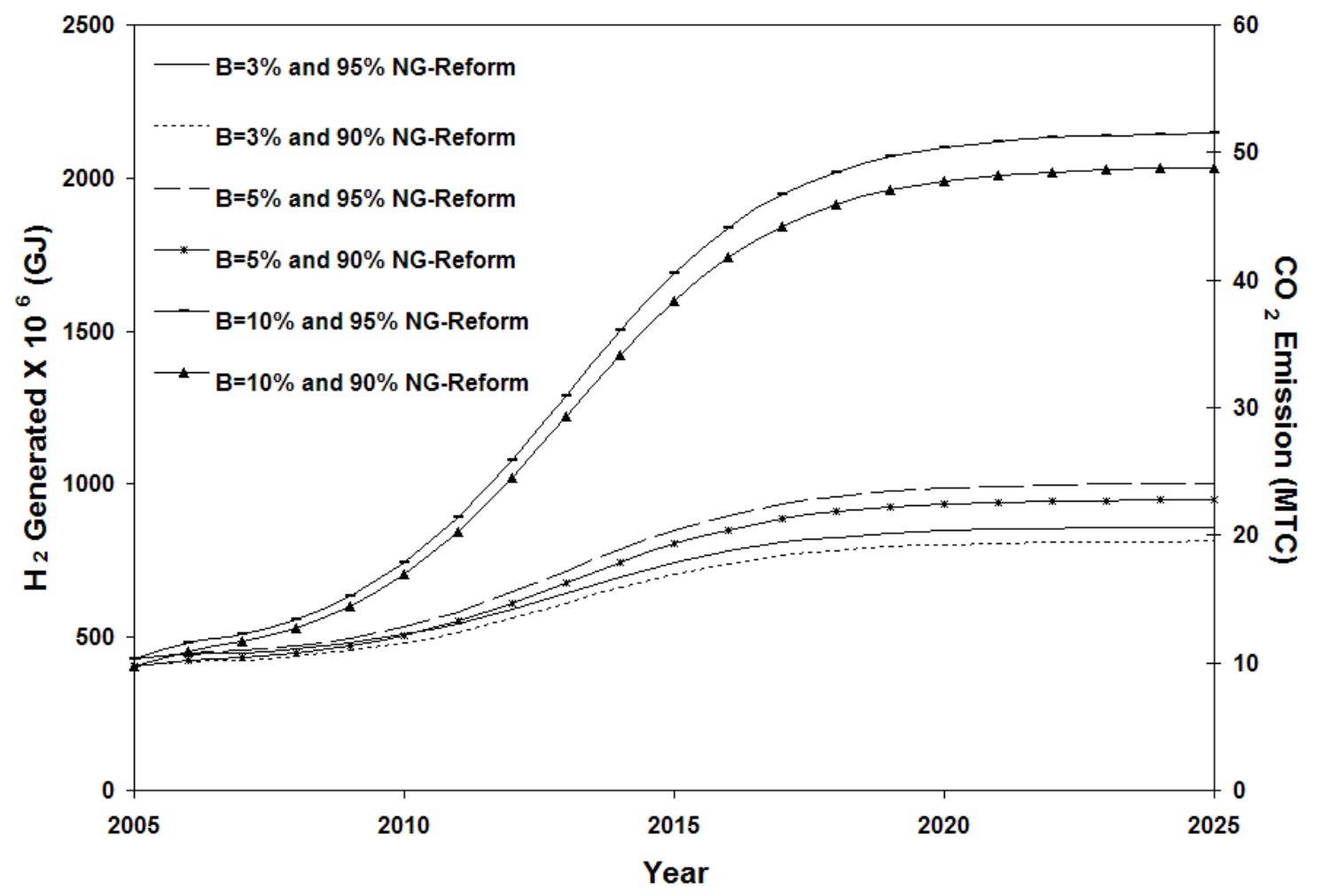

Figure 5. Hydrogen generation and $\mathrm{CO}_{2}$ emission by NG-steam reformation process at growth rate of $A=1 \%$

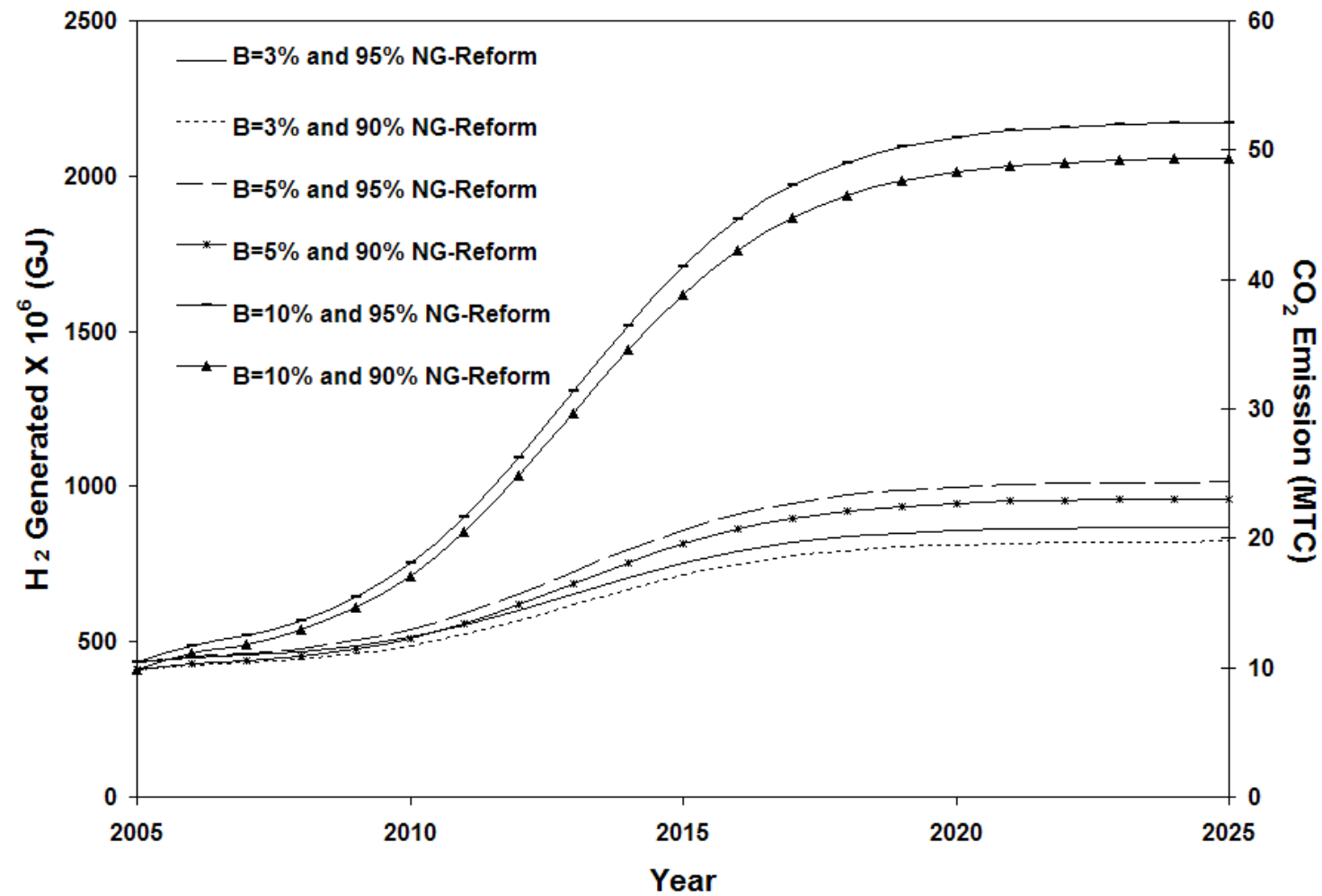

Figure 6. Hydrogen generation and $\mathrm{CO}_{2}$ emission by NG-steam reformation process at growth rate of $\mathrm{A}=3 \%$ 


\subsection{Economical Returns}

The current average gross domestic product (GDP) per capita of GCC countries is estimated to be around \$16,500/captita shown in Figure 7. However, it is anticipated that this rate will fall to less than $\$ 15,000 /$ capita in 2025 due to higher population growth rate (approximately $3 \%$ ) as compared with an average economic growth rate of approximately $2.5 \%$, inflation, future cost and high dependency of GCC countries on the revenues generated from sales of fossil fuels. Thus, GCC countries should seriously consider three important measures to achieve a sustainable economic growth. Firstly, optimum exploitation of natural conventional resources such as oil and natural gas to produce environmentally clean hydrogen energy to be supplied to developed countries particularly EU countries. Secondly, exploitation of their potential of renewable energy resources such as solar energy to produce hydrogen energy and to be supplied to developed countries. Thirdly, diversify their economy in order to be less dependent on oil and natural gas. By implementing these measures specially the first two measures, GCC countries could secure a healthy economic growth and supply EU countries a sustainable source of a clean energy.

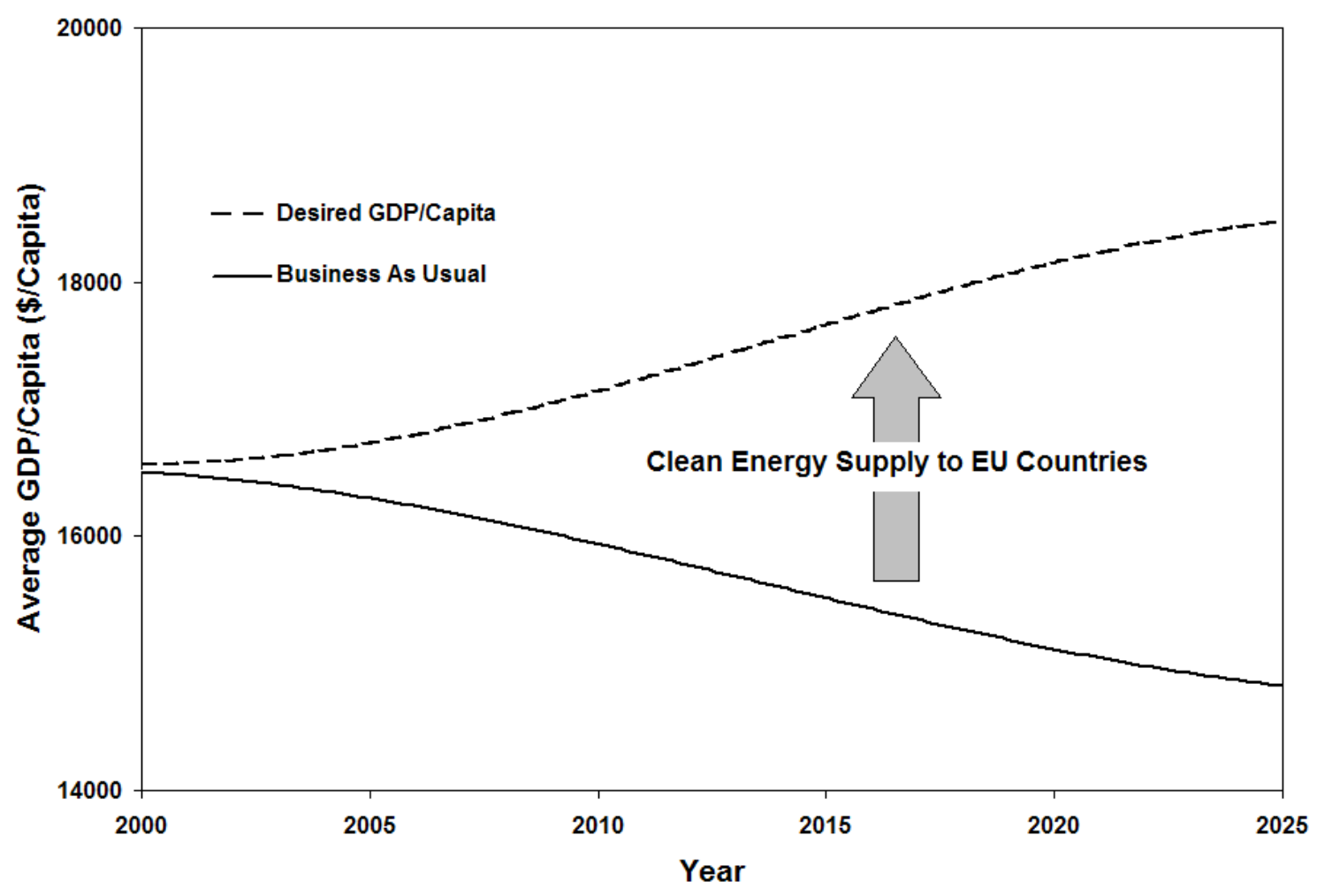

Figure 7. Projected average GDP/capita of GCC countries 


\section{Conclusions}

In this paper technical, environmental and economical aspects of hydrogen energy and its role to a sustainable development of EU and GCC countries were presented. The conclusions are summarized as follows:

- Energy supplied to EU countries would start at 9,000X10 $10^{6} \mathrm{GJ}$ in 2005 and increases depending on the growth rates $\mathrm{A}$ and $\mathrm{B}$.

- In order to secure a clean energy supply of hydrogen to fulfill its future demand and implement the Kyoto-protocol, hydrogen should be supplied to EU countries at a rate of $\mathrm{B}=10 \%$ if their energy demand stayed at $\mathrm{A}=1 \%$. However, we should keep in mind that a hydrogen production rate of $\mathrm{B}=17 \%$ is required to meet a suggested increase in the energy demand of $\mathrm{A}=3 \%$.

- Hydrogen is introduced in 2005 at a rate of approximately 485 million GJ (5\% of total fossil fuel supplied to EU) and its growth rate B, can be adjusted depending on the pace at which GCC are welling to supply EU's demand of clean energy and cost of fossil fuels.

- The initial photovoltaic cell area required to produce hydrogen energy in GCC countries in 2005, is considered to be reasonable. The area could be reduced if the efficiencies of the electrolyser and PV cells are increased above the suggested values of $90 \%$ and $18 \%$, respectively.

- $\mathrm{CO}_{2}$ emissions from natural gas steam-reformation would start at $12 \mathrm{MTC}$ in 2005 and increases depending on the growth rates $\mathrm{A}$ and $\mathrm{B}$ and percentage of hydrogen produced by steamreformation.

- It is anticipated that GDP/capita for GCC countries will fall to less than $\$ 15,000 /$ capita in 2025 if no serious measures were taken to achieve a sustainable economic growth.

\section{References}

[1] European Commission. Green Paper-Towards a European Strategy for the Security of Energy Supply, EUR-OP. 2001

[2] Department of energy, United States Energy Information Administration, Regional Indicators: European Union (EU). October 2002.

[3] A. Kazim and T.N. Veziroglu. Utilization of solar-hydrogen energy in the UAE to maintain its share in the world energy market for the $21^{\text {st }}$ century. Renewable Energy, 24, pp. 259-274, 2001.

[4] Knapp K. Exploring Energy Technology Substitution for Reducing Atmospheric Carbon Emissions. The Energy Journal, 20, pp. 121-143, 1999.

[5] Department of energy, United States Energy Information Administration, Kuwait, August, 2002.

[6] Department of energy, United States Energy Information Administration, Saudi Arabia, October, 2002.

[7] Department of energy, United States Energy Information Administration, Oman, September, 2002.

[8] Department of energy, United States Energy Information Administration, Qatar, October, 2002.

[9] Department of energy, United States Energy Information Administration, Bahrain, September, 2002.

[10] Department of energy, United States Energy Information Administration, United Arab Emirates, December, 2002.

[11] OPEC, OPEC Annual Statistical Bulletin, Organization of petroleum exporting countries, Austria, 2000.

[12] S. Valverde. Hydrogen as energy source to avoid environmental pollution, Geofisica Internacional, 41 (3), 223-228, 2002.

[13] Y. Yurum. Hydrogen Energy Systems- Production and Utilization of Hydrogen and Future Aspects, Kluwer Academic Publisher group, The Netherlands, 1995. 
[14] P. Spath and M. Mann. Life Cycle Assessment of Hydrogen Production via Natural Gas Steam Reforming, National Renewable Energy Laboratory, Technical Report, NREL/TP-570-27637, 2001.

[15] N. Lutfi and T.N. Veziroglu, A Clean and Permanent Energy Infrastructure for Pakistan: SolarHydrogen Energy System. Int. J. Hydrogen Energy, 16, pp. 169-200, 1991.

[16] M. Abdallah, S.S. Asfour and T.N. Veziroglu, Solar-Hydrogen Energy System for Egypt. Int. J. Hydrogen Energy, 1999;24(6):505-517.

[17] A. Canteras, J. Carpio, M. Molero and T.N. Veziroglu, Solar-Hydrogen: an Energy System for Sustainable Development in Spain. Proc. of $12^{\text {th }}$ World Hydrogen energy Conference, Buenos Aires, Argentina, 1998. pp.415-422.

[18] H.K. Abdel Aal and M.A. Al-Naafa. Prospects of Solar Hydrogen for Desert Development in the Arab World. Int. J. Hydrogen Energy, 23, pp. 83-88, 1998.

[19] M. Radetzki. What will happen to the producer prices for fossil fuels if Kyoto is implemented? Energy Policy, 30, pp.357-369, 2002.

[20] T. Johansson, H. Kelly, A. Reddy and R. Williams. Renewable energy- sources for fuels and electricity- Island Press- 1993.

[21] Chan S. and Wang H., Effect of NG Composition on Reforming $\mathrm{H}_{2}$ and $\mathrm{CO}$, Proceeding of the $13^{\text {th }}$ World Hydrogen Energy Conference, Beijing, China, pp. 200-206, 2000.

[22] Dunn S., Hydrogen futures: toward a sustainable energy system, Int. J. Hydrogen Energy, 27 (3), pp. 235-264, 2002. 


\section{Session 10: Biomass in the Transport Sector}

Chairman: Ulf Hansen, Universität Rostock, Germany 


\title{
Regionalized Global Energy Scenarios Meeting Stringent Climate Targets - cost effec- tive fuel choices in the transportation sector
}

\author{
Maria Grahn, Christian Azar and Kristian Lindgren \\ Department of Physical Resource Theory, \\ Chalmers University of Technology, Göteborg University, \\ 41296 Göteborg, Sweden. \\ E-mail: maria.grahn@,fy.chalmers.se
}

\begin{abstract}
The aim of this study is to analyze the world's future energy supply, in general, and costeffective fuel choices in the transportation sector, in particular, under stringent $\mathrm{CO}_{2}$ abatement targets. The analysis is carried out with the help of a global energy systems model GET-R 1.0, developed specifically for this project. It is a linear programming model and it has three end-use sectors: electricity, heat and transportation fuel. It is set up to generate the energy supply mix that would meet exogenously given energy demands at the lowest global energy system cost. We have chosen an upper limit on $\mathrm{CO}_{2}$ emissions corresponding to an atmospheric $\mathrm{CO}_{2}$ concentration target of $400 \mathrm{ppm}$, by the year 2100. We find that it is cost-effective to carry out the transition from gasoline/diesel in the middle of the century and that hydrogen becomes the most cost-efficient fuel in the long run. Within the electricity production sector all renewable energy sources show a pattern of increasing contributions during the century and solar produced hydrogen will dominate by year 2100. Biomass is the dominant fuel in the heat sector. Scenarios are also presented which show the effects of different way of regionalizing the model. Here significant changes may occur, in particular when it comes to the where solar hydrogen is being produced. Further, we compare our results with those generated using a globally aggregated version of the model. We find that the regionalization only marginally affects the general pattern.
\end{abstract}




\section{Introduction}

As the global population reaches $9-10$ billion, and living standards increase, energy requirements will increase dramatically. Currently, $80 \%$ of energy used is based on fossil fuels and unless alternatives are introduced, huge increases in atmospheric $\mathrm{CO}_{2}$ are to be expected. Substantial reductions of the global $\mathrm{CO}_{2}$ emissions are required in order to minimize risks of severe climatic changes, but this would involve considerable changes in the present energy system.

To stabilize the atmospheric $\mathrm{CO}_{2}$ at $400 \mathrm{ppm}$, which might be an acceptable level (see Azar and Rodhe, 1997), global $\mathrm{CO}_{2}$ emissions need to drop to around 2 Gton $\mathrm{C} / \mathrm{yr}$, by the year 2100 (IPCC, 1994). This corresponds to 0.2 ton $\mathrm{C}$ per capita per year, assuming a population of 10 billion people, which can be compared to the current 5.5 tonC/cap/year in the US and 0.3 ton C/cap/year in India. This study explores the possibility of combining increasing energy demand with strong reductions in $\mathrm{CO}_{2}$ emissions over the $21^{\text {st }}$ century.

The transportation sector has a negative impact on local air quality and is a major emitter of $\mathrm{CO}_{2}$. In 1990 , the transportation sector was responsible for some $25 \%$ of the world's energy use, and $22 \%$ of the global $\mathrm{CO}_{2}$ emissions (IPCC, 1994). Fuel cell vehicles are seen by many as a promising option or even solution to these problems. Emissions of local pollutants are reduced to near-zero levels, and $\mathrm{CO}_{2}$ emissions are lower or zero if renewable primary energy sources are used. However, it is still being discussed which fuel should be used in the long run, when there are stronger restrictions on $\mathrm{CO}_{2}$ emissions. The two main candidates are liquid biofuels and hydrogen (from renewables or fossil fuels with carbon sequestration).

The purpose with this study is to analyze cost-effective fuel choices in the transportation sector under stringent $\mathrm{CO}_{2}$ constraints and to investigate whether regional differences in energy supply potentials may result in differences in fuel choices. We do this by regionalizing a global energy systems model, designed to develop global energy scenarios. More specifically, we ask the following questions:

- when is it cost-effective to carry out the transition away from gasoline/diesel?

- to which fuel is it cost-effective to shift?

- will the cost-effective choice of fuel in the transportation sector be different if a globally aggregated model is used rather than a regionalized version?

- how will the method of regionalization affect transportation fuel choices and trade in energy carriers?

Model and scenario assumptions are presented in section 2 followed by global and some regional results presented in section 3 . The results are discussed and conclusion are drawn in section 4 followed by some ideas for future work in section 5 .

\section{Model and scenario assumptions}

\subsection{Model description}

A global energy systems model (GET 1.0) has been developed by Azar et al, 2000. The model was used to study fuel choices in the transportation sector (see Azar et al 2003). In this study, we have regionalized this earlier model into eleven different regions: North America, Latin America, Western Europe, Eastern Europe, Former Soviet Union, OECD countries in the Pacific Ocean, Middle East and North Africa, Africa, Centrally Planned Asia, South Asia and Other Pacific Asia. These new scenarios will show how each region can meet its energy demand, and thereby give a better understanding of the prospects for changes in the global energy system than a global aggregate model. 
The regionalized energy system model (GET-R 1.0) is a linear optimization model designed to choose primary energy sources, conversion technologies, energy carriers and transportation technologies that meet the energy demands of each region, at the lowest aggregate costs subject to a carbon constraint (a tax or an emission cap). In this study, the only environmental concern is $\mathrm{CO}_{2}$ emissions. Energy supply potentials and the demand for electricity, heat and transportation fuel, are exogenously given. The transportation sector is disaggregated into cars, trains, buses, trucks, ships and air planes whereas the electricity and heat sectors is analyzed in aggregate. Primary energy supply options, the three energy demand sectors and fuel choices in the transportation sector, are presented in Figure 1.

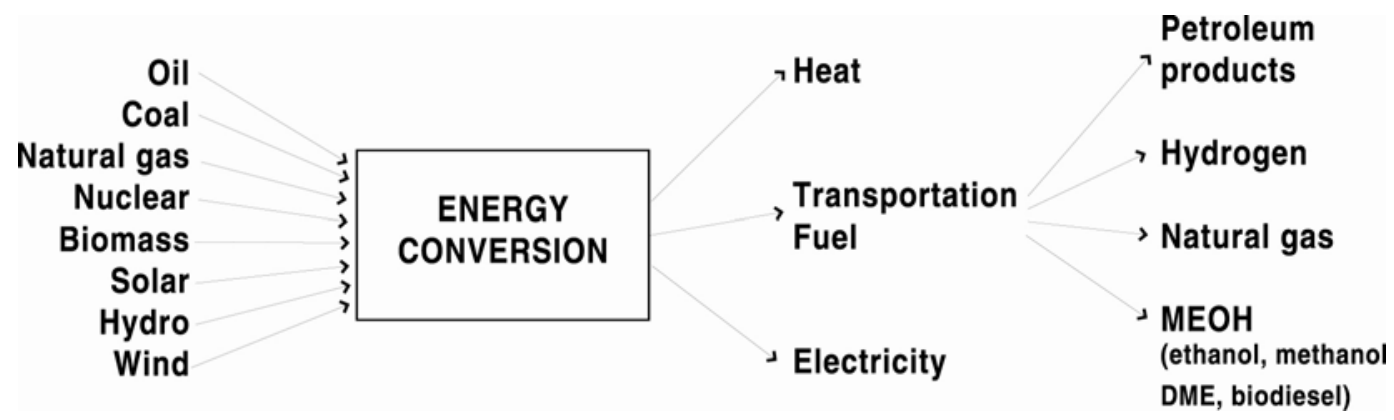

Figure 1: The basic flow chart of supply and fuel choices in the energy system model

\subsection{Scenario assumptions}

\section{Energy demand}

Regional population, heat and electricity demand are assumed to follow an "ecologically driven" scenario developed by International Institute for Applied Systems Analysis (IIASA) in Austria. In this scenario, titled "C1", it is assumed that technological development leads to energy efficiency improvements, so that per capita heat and electricity demands in industrialized countries are reduced. In some regions, strong economic development will increase the per capita demand even if efficiency improvements are taken into account (Nakicenovic et al, 1995).

In all regions, per capita income increases. The developments of $\mathrm{GDP}_{\mathrm{PPP}}$ per capita (GDP measured in purchasing power parities) are also taken from IIASA/WEC scenario C1. GDP ${ }_{\mathrm{PPp}}$ per capita in industrial regions will increase from about 20,000 USD/yr today to about 50,000 USD/yr by the end of the $21^{\text {st }}$ century. Developing regions will reach the level at which Western Europe is today. Increased income is followed by an increased demand for heat, electricity and transportation fuel.

Transportation scenarios are developed separately for passenger transportation and freight transportation. The energy requirement is derived from scenarios of transportation activities measured as person kilometer, pkm, and ton kilometer, tkm, combined with scenarios for the energy intensities measured as $\mathrm{MJ} / \mathrm{pkm}$ and $\mathrm{MJ} / \mathrm{tkm}$ (Azar et al, 2000).

Public use of aviation will increase rapidly and by the end of the century an American will travel $40,000 \mathrm{~km} /$ year by air compared to $4,300 \mathrm{~km} /$ year currently. Domestic motor vehicle use is also assumed to strongly increase, especially in the developing countries. The average citizen of India drives about $150 \mathrm{~km}$ per year, which will increase to $10,000 \mathrm{~km}$ per year by the end of this century. Assuming a population of 10 billion, a total of 5 billion cars will exist by the year 2100 . The global density of cars will be 0.5 cars/capita, which is the current car density in Germany.

From 1990 to 2100 total passenger transportation is assumed to increase ten fold. Passenger rail increases by a factor three, bus by a factor of five, car by a factor of eight and passenger aviation by a factor of 40 in the scenarios. Freight transport will increase by about a factor of four. Intercontinental ocean transport dominates, although road transport will have the highest relative growth rate. Road 
transport will grow by a factor of six, air and ocean transport by a factor of four and continental water and rail approximately doubles. More details are given in Azar et al, 2000.

\section{Energy availability}

Regional oil and gas supply potentials and the annual hydro and biomass supply are assumed to follow Johansson et al, (1993). The regional coal maximum supply potentials are assumed to follow Rogner, (1997). The potential for solar energy is huge and therefore has not been assigned an upper limit. This model allows carbon capture and storage technologies when applied to fossil fuels for heat, electricity and hydrogen production. Biomass is limited upwards to around $200 \mathrm{EJ} / \mathrm{yr}$ (Johansson et al, 1993). This constraint has important implications since the total energy demand is much larger. Thus, the model chooses to use biomass in the sector where it is most competitive.

Efficiency of energy conversions, cost of industrial plants, vehicle engines and fuel infrastructure are discussed in detail in the paper presenting the global model GET 1.0 (Azar et al, 2000). The same values have been used in all regions. Regionalized load factors for solar energy technologies give some advantages to the regions Africa, Middle East and North Africa, Latin America and North America.

\subsection{Maximum expansion rate}

In reality, it takes time to make profound changes in the energy system of the world. This inertia is sometimes difficult to capture in energy system models. In our model, inertia is introduced in several ways. First, it takes time before the capital stock is replaced and therefore it becomes more expensive to introduce new technologies. Second, we have also introduced exogenous constraints on how fast new technologies might enter. When the total supply from a specific technology is set, then the maximum level of supply in the following decade is set so that a complete transformation of the energy system would take at least 50 years.

The maximum expansion rate can be set as a global or as a regional constraint. If a global maximum expansion rate is chosen, the model will choose to expand technologies in regions where it is most cost-efficient, and this means that solar will expand at a faster rate in sunnier regions than what happens if regional expansion rate constraints are chosen. In this study we use the global maximum expansion rate as our base case, but we will also present some interesting differences to the base case using the other method of a regionalized maximum expansion constraint.

\section{Results}

\subsection{Global results}

Due to space limitations, it is only possible to present a short summary of our results here. A more complete description can be found in (Grahn et al, 2003).

\section{Primary Energy Supply}

In order to stabilize atmospheric $\mathrm{CO}_{2}$ concentrations at $400 \mathrm{ppm}$, approximately 500 Gton $\mathrm{C}$ may be emitted over the period 1990-2100, (IPCC, 1994). This means that emissions may on average be around half of current levels (if we include the contribution from deforestation). In turn, this means that the emissions may increase perhaps a decade, but that they would then have to decline over the next couple of decades. Figure 2 displays a scenario in which this happens in a cost-effective manner. 


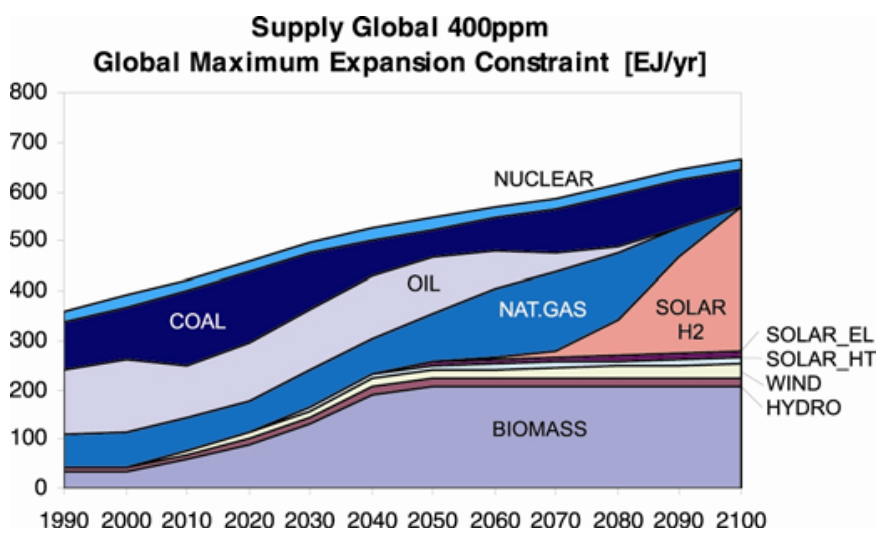

Figure 2. Primary energy sources required to supply the world's energy system, if atmospheric $\mathrm{CO}_{2}$ concentrations are stabilized at 400 ppm. The eleven regional results have been added to produce this global figure

Over the next fifty years, the model suggests that a rapidly increasing supply for biomass is a costeffective way of meeting ambitious climate targets. The use of oil and gas remains roughly constant until they become exhausted. The use of coal remains possible since carbon capture and storage technologies are used on a larger scale, from the middle of the century and onwards. Of the three solar energy technologies in this model, solar energy for electricity production and solar energy for heat production remain at about the same level as wind and hydro, but solar energy for hydrogen production increases rapidly during the second half of the century.

\section{Transportation}

The scenario describing the cost-effective fuel choices in the transportation sector is presented in Figure 3.

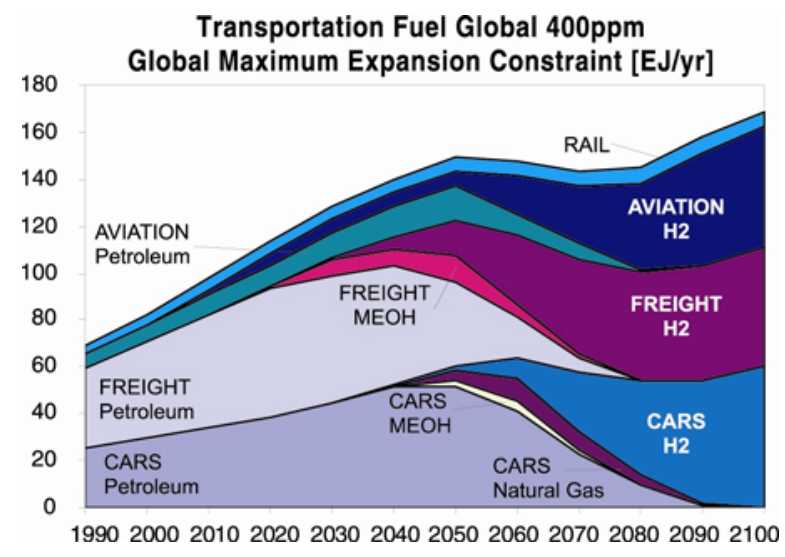

Figure 3. Projected transportation fuels requirements, if atmospheric $\mathrm{CO}_{2}$ concentrations are stabilized at 400 ppm. Note that regional results are added to give a global figure

In cars and freight sectors there is a transition from petroleum-based fuels in internal combustion engines to hydrogen used in fuel cell engines. Some methanol in internal combustion engines will be used in the transition period in both sectors. The model also present natural gas as a cost-effective transition fuel in the sector cars. In airplanes, there is a transition from fuels based on oil towards liquefied hydrogen. 


\section{Heat and Electricity Production}

The end-use sector heat is defined as the heat required domestically as well as process heat in industries, e.g. pulp and paper production. The regional results, showing the scenarios for heat and electricity production, are added to give the global figures presented in Figure 4.
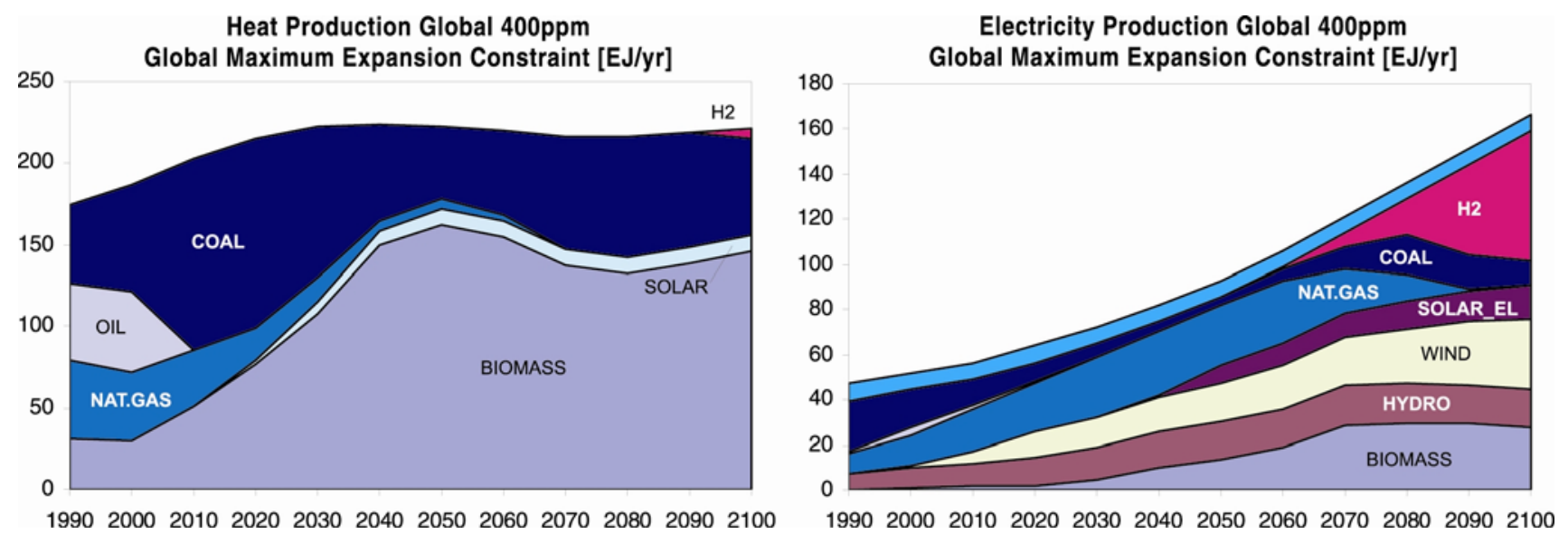

Figure 4. Primary energy sources used to supply households and industries global demand for heat as well as primary energy sources to supply the world's demand of electricity, given that atmospheric $\mathrm{CO}_{2}$ concentrations are stabilized at $400 \mathrm{ppm}$. These graphs are produced using the global maximum expansion constraint and regional results are added together

Biomass and coal dominate as primary energy source for heat production. For electricity production oil is phased out early and by the end of the century coal increases due to the fact that decarbonization techniques become cost-effective and used on a larger scale. When solar based hydrogen is introduced by the middle of the century it will rapidly increase its share and dominate as a primary energy source in year 2100. Biomass, as well as the other renewable energy sources, displays an increasing pattern throughout the century. Wind and hydro power are used to their exogenously set maximum level. The decline in gas use, by the end of the century, is caused by lack of availability.

\subsection{The impact of different ways of setting the maximum expan- sion rates}

When it comes to fuel choices in the transportation sector, the difference between the two ways of setting maximum expansion rates are minor. We will compare our two results with the figure generated using a globally aggregated version of the model, in section 3.3

The major impact of different ways of setting the maximum expansion rates is where solar hydrogen is being produced. Using a global maximum expansion rate, the region Middle East and North Africa (MEA) will extract almost $200 \mathrm{EJ} / \mathrm{yr}$ of solar produced hydrogen, in year 2100 , out of which $160 \mathrm{EJ} / \mathrm{yr}$ will be exported to other regions. Using a regionally set maximum expansion rate MEA will only produce solar hydrogen for its own need. The differences in primary extraction for MEA due to choice of expansion constraint, are illustrated in Figure 5. The Asian regions Centrally Planned Asia dominated by China (CPA), South Asia dominated by India (SAS) and Other Pacific Asia (PAS) are examples of regions which import hydrogen in the case of a global maximum expansion constraint and produce their own solar hydrogen in the other case, as illustrated in Figure 6. 


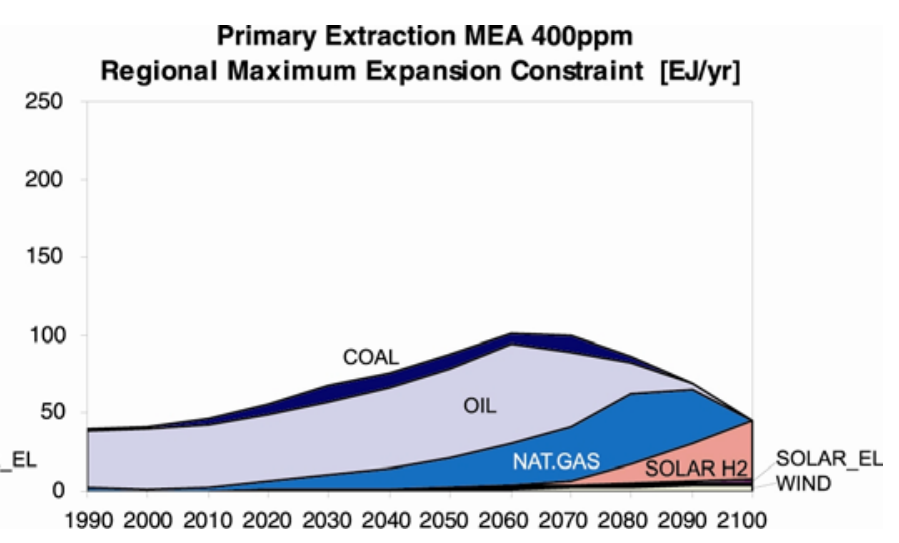

Figure 5. Primary energy extracted in region Middle East and North Africa, MEA. Solar produced hydrogen will be exported in the case of a global maximum expansion rate
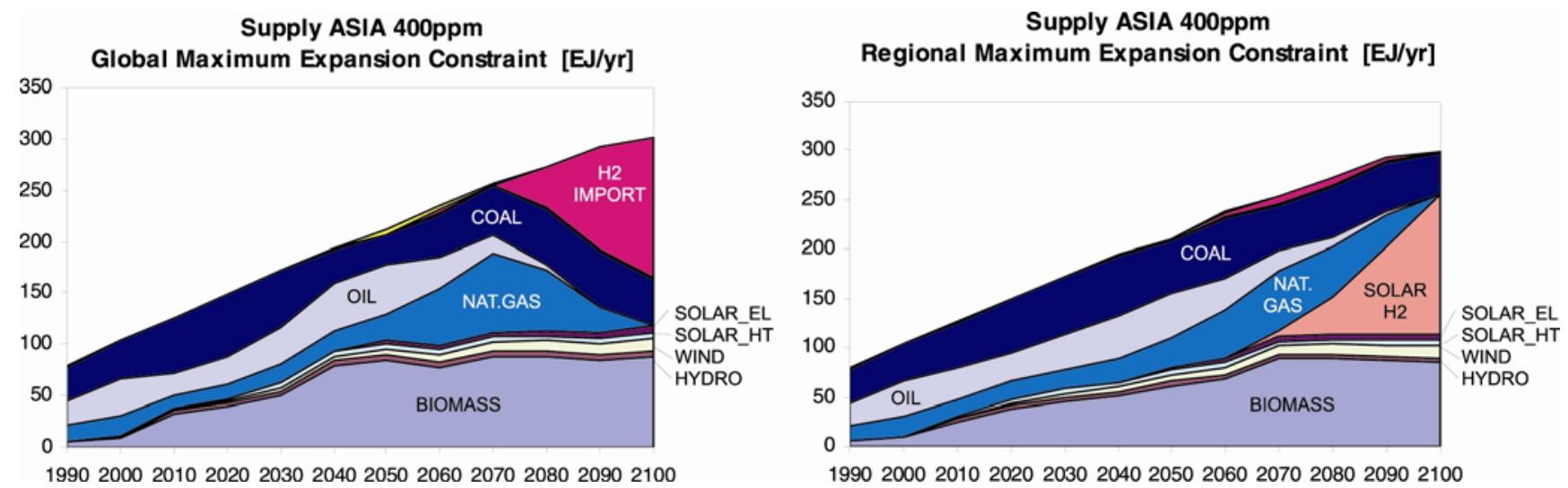

Figure 6. Primary energy sources to supply the energy demand in the Asian regions. No solar produced hydrogen will be developed in the case of a global maximum expansion rate. Instead hydrogen will be imported mainly from MEA. In the case of a regional maximum expansion rate the Asian regions will produce their own solar hydrogen

\subsection{The difference between a globally aggregated model and a global regionalized model}

To explore if the cost-effective choice of fuel in the transportation sector will be different if a globally aggregated model is used rather than a regionalized version, we will produce two more figures as a comparison to Figure 3. A globally aggregated model, of this version of the energy system model, as well as the run with regional maximum expansion constraint, are presented in Figure 7 . These two figures are very similar to Figure 3, shown in section 3.1 

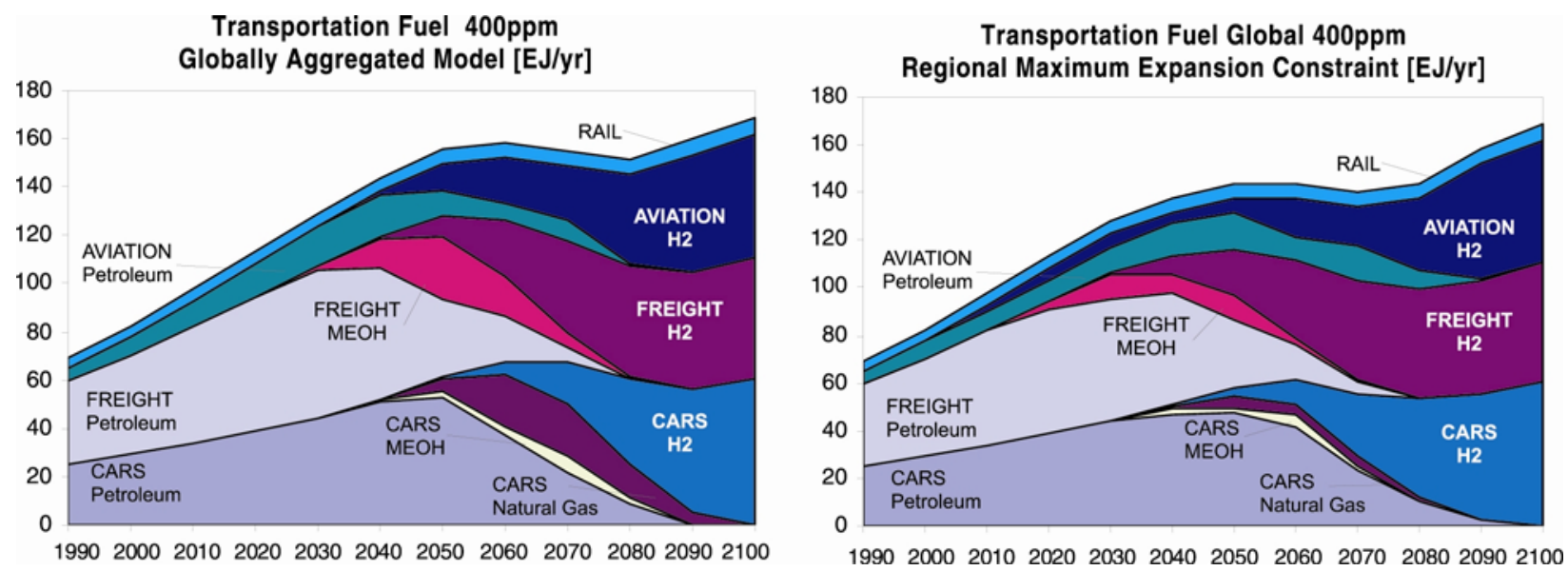

Figure 7. Fuel choices in the transportation sector will show the same over all pattern no matter global or regionalized model

\section{Discussion and Conclusions}

In this paper, we asked the following questions: When is it cost-effective to carry out the transition away from gasoline/diesel? To which fuel is it cost-effective to shift? Will the cost-effective choice of fuel in the transportation sector be different if a globally aggregated model is used rather than a regionalized version? How will the method of regionalization affect transportation fuel choices and trade in energy carriers? Below, we summarize our results and offer some explanations for them.

\subsection{Oil remains dominant in the transportation sector for sev- eral decades despite stringent climate targets}

A perhaps somewhat surprising result from our modeling exercise is that oil remains dominant in the transportation sector several decades ahead. A physical explanation for that is that known oil and natural gas reserves, contain about $200 \mathrm{Gton} \mathrm{C}$ (and we have assumed that the ultimately recoverable oil and natural gas resources are twice the current reserves). It is thus possible to release more $\mathrm{CO}_{2}$ emissions than what exist in the total reserves of oil and natural gas, and still stabilize the atmospheric $\mathrm{CO}_{2}$ concentration at $400 \mathrm{ppm}$. The most cost-effective use for oil is in the transportation sector (the advantages of using oil in the transportation sector is larger than using oil for heat or electricity production).

One tempting interpretation may be that no new technologies would need to be developed until the middle of the $21^{\text {st }}$ century, but other elements ensure that this is not the case. The transition to hydrogen in the transportation sector will start around 2030 - 2050, and to make this possible, hydrogen should be used in vehicles before 2030. It is only by $2030-2050$ that the carbon constraint becomes stringent enough to make hydrogen and fuel cell engines in cars and trucks competitive with gasoline and diesel.

\subsection{Hydrogen and not biofuels become the dominant transporta- tion fuel in our model}

Hydrogen becomes the dominant fuel in the transportation sector, as it is more cost-efficient to use biomass for heat production. Using biomass to produce methanol would imply that the heat demand would have to be satisfied from other $\mathrm{CO}_{2}$-neutral sources (hydrogen from solar or fossil fuels with decarbonization), which would increase the overall cost of the model. The reason why biomass can not 
be used for both heat and transportation is that the overall supply is limited upwards due to availability constraints.

\subsection{A global but regionalized model versus a globally aggregated model}

As shown in Figure 3 and in Figure 7, cost-effective choice of fuel in the transportation sector will, more or less, not be different if a globally aggregated model is used rather than a regionalized version. In fact many fuel choices are very close to each other in costs, and the transition fuels is not an effect by regionalization, but an effect due to development of the model.

\subsection{Affects of the two methods of regionalization}

The two methods of regionalization will not affect the over all pattern of transportation fuel choices, but will affect the trade in energy carriers. The major impact of different ways of setting the maximum expansion rates is where solar hydrogen is being produced, as illustrated in Figure 5 and 6, in section 3.2 .

\subsection{Model results are not a prediction of the future}

The purpose of this study is not to predict the future. This model illustrates which fuels are most costefficient, based on presented assumptions. It is of course possible to use this study as an indication of which fuels and technologies are most cost effective, but even if assumptions in this model are reasonable by current standards, a great deal can occur within the next few decades, which may change the input data and produce different results. Also, since the model is an LP model, the less costly solution will always be chosen completely no matter how small the difference in cost is to the closest competing option. In reality, many options may be chosen simultaneously if the difference in cost is minor, but this cannot happen in our model.

One general result from our study that is less dependent on the actual parameter choices is that it is possible to combine ambitious climatic goals with an increased demand for energy services.

\section{Future Work}

The development of hybrid cars (electricity and internal combustion engine) has come to a point when its energy efficiency is close to what is expected for a fuel cell car. This is an important issue to follow up and include as an option in the model. In the current version of our model, we have not included hybrid cars.

Further it could be of interest to look more into biomass supply and conversion options. In this study biomass is a collective name for forest biomass, energy crops and biomass residues. The end-use sector heat is a collective name for industrial process heat and residential heating (including district heating and pellets production). If the model had more supply and end-use options, it could maybe give a more balanced picture of the most cost-efficient use for biomass. The use of biomass for electricity and transportation fuel becomes more interesting, the higher the cost of using biomass for heat production.

The model could also be further developed by study the effect of more combined energy options. The model includes co-generated electricity and heat production, but as a future work options as for example co-generated production of methanol and heat, could be of interest to study.

Finally, the results presented here assumes that there is a carbon constraint applied to all regions of the world. It could be interesting to analyze fuel choices in the transportation sector under the more 
realistic assumption that developing countries will adopt abatement policies perhaps a decade or two after the industrialized countries.

\section{Acknowledgement}

We would like to acknowledge Per Kågeson for his valuable comments. Financial support from Swedish Agency for Innovation Systems, Vinnova, and Swedish Energy Agency is gratefully acknowledged.

\section{References}

Azar C, Lindgren K, Andersson B.A. (2003), Global energy scenarios meeting stringent $\mathrm{CO}_{2}$ Constraints - cost-effective fuel choices in the transportation sector, Energy Policy, Volume 31, August 2003, p. 961-976

Azar C, Lindgren K, Andersson B.A. (2000), Hydrogen or Methanol in the Transportation. Sector, Dept. of Physical Resource Theory, Chalmers University of Technology, Göteborg, Sweden, Report.

Azar C, Rodhe H (1997), Targets for Stabilization of Atmospheric $\mathrm{CO}_{2}$, Science, 276, p. 1818-1819, 1997.

Grahn M, Azar C, Lindgren K (2003), Regionalised Global Energy Scenarios Meeting Stringent Climate Targets - cost effective fuel choices in the transportation sector, Department of Physical Resource Theory.

IPCC (1994), Climate Change 1994 - Mitigation, Contribution of working group III to the third assessment report of the Intergovernmental Panel on Climate Change, Cambridge University Press, UK

Johansson T. B., Kelly H., Reddy A. K. N. (1993), Williams R.H., Renewable Energy - Sources for Fuels and Electricity, Island Press, California.

Nakicenovic et al. (1995),, IIASA/WEC Global Energy Perspectives to 2050 and beyond, World Energy Council, London, 1995. Tables from the report are also presented on http://www.iiasa.ac.at/cgi-bin/ecs/book_dyn/bookent.py, June 2001

Rogner H. H.(1997), An Assessment of World Hydrocarbon Resources, Annual Review of Energy and the Environment, vol 22, p. 248, 1997. 


\section{Session 11: Electricity and Gas Markets and Liberalisation}

Chairman: John M. Christensen, Risø National Laboratory 


\title{
Analysis of a liberalised Lithuanian/Baltic Electricity market
}

\author{
Thomas Engberg Pedersen ${ }^{a}$, Jens Hauch ${ }^{a}$, Hans Ravn ${ }^{b}$ \\ a: COWI A/S, Parallelvej 2, DK-2800 Lyngby, Denmark \\ b: Elkraft System, Lautruphøj 7, DK-2750 Ballerup, Denmark
}

\begin{abstract}
The electricity sectors in the Baltic countries are presently undergoing reform processes in order to meet the requirements of the EU directives regarding deregulation of electricity sectors. At the same time, EU is putting a pressure upon Lithuania to close the largest electricity producer in the Baltic countries, the Ignalina Nuclear Power Plant. The purpose of the paper is to establish a common background for evaluating the future perspectives of the Lithuanian and Baltic electricity market. The results of the paper deal with the possibilities of creating a competitive market and with the economic and technical consequences of different future settings. The market concentration at a liberalised electricity market in Lithuania and the Baltic region may be high because of relatively few and large production units. The joint problem of liberalisation, high market concentration and nuclear phase out has been analysed. The future electricity and district heating markets are simulated using the Balmorel model. The focus of the analyses is the economic consequences of different market openings, different producer supply behaviour and different closure speeds of INPP. With focus on Lithuania, it is shown that if competition arises in the electricity market, the prices will become low due to a large excess capacity in the system. The consumers and the society as a whole will gain significantly from competition, but most power plants will have difficulties in making positive earnings. It is furthermore concluded that there is a high risk of lack of competition in a closed Lithuanian electricity market due to the high market concentration. Even a minor lack of competition will imply significant gains to producers, but losses to consumers and the society as a whole. The establishment of a common Baltic electricity market instead of national electricity markets may help reducing the competition problem.
\end{abstract}




\section{Power market situation}

The power systems differ considerably in the three Baltic countries. The Lithuanian system is dominated by nuclear and thermal production; the Latvian system is based on hydro and thermal production, and the Estonian system is purely thermal. The differences in the production systems create potential benefits to be gained from international electricity trade between the countries - just as in the Nordic countries.

The Lithuanian power system consists of the Ignalina nuclear power plant (INPP), the large thermal Lithuanian Power Plant (LPP) and a few combined heat and power plants. The Lithuanian power system also includes hydro power plants and a large hydro pump storage plant which in particular is useful in combination with the nuclear production that can not be regulated in line with the demand variation.

INPP commenced production in the eighties to meet the regional electricity demand in the former Soviet Union. The total installed power capacity in Lithuania is more than 6,000 MW, and of this 2,600 MW is in INPP. Compared to the present maximum need for power in Lithuanian which is about 2,000 MW, the installed capacity allows Lithuania to have a large electricity export. But it also leaves Lithuania with high fixed operation and maintenance costs.

An overview of the production system in the Baltic countries is given in Table 1.

Table 1. Installed power capacity in 2000, MW.

\begin{tabular}{|l|r|r|r|r|}
\hline & Lithuania & Latvia & \multicolumn{1}{c|}{ Estonia } & \multicolumn{1}{c|}{ Total } \\
\hline Nuclear power & 2,600 & 0 & 0 & 2,600 \\
\hline Thermal power & & & & \\
- condensing & 1,800 & 0 & 2,730 & 4,530 \\
- CHP & 843 & 575 & 247 & 1,665 \\
\hline Hydro power & 113 & 1,529 & 0 & 1,642 \\
\hline Wind power & 0 & 1 & 0 & 1 \\
\hline Hydro pump storage & 800 & 0 & 0 & 800 \\
\hline Total & 6,156 & 2,105 & 2,977 & 11,238 \\
\hline
\end{tabular}

The fact that the Lithuanian electricity market is dominated by relatively few large production units implies that competition in a closed liberalised Lithuanian electricity market is not presently realistic without regulation. Even with regulation there will be a large risk of competition limitations.

If the Lithuanian production concentration on power plants in 2000 is measured using a HirschmanHerfindahl index, a concentration of 5,572 is found, see Lietuvos Energija 2000 for production data1. The U.S. Federal Trade Commission and the Department of Justice (1992) divides the spectrum of market concentration as measured by the HHI into three regions, which can be broadly characterised as unconcentrated (HHI below 1,000) moderately concentrated (HHI between 1,000 and 1,800) and highly concentrated (HHI above 1,800).

A separation of production companies to smaller units than power plants is not realistic. The 2000 concentration of 5,572 therefore indicates that even if the production is separated into single power plants, an extremely high concentration is likely.

The new Lithuanian electricity law imposes a regulation upon INPP. This will reduce INPP's possibilities of utilising its market power. If INPP is separated from the market and regulated, the concentration on the remaining market will be 1,904. This shows that INPP is the main contributor to the potential competition problems, but a regulation of INPP is not sufficient to solve the potential competition problems as also 1,904 is a high concentration.

\footnotetext{
${ }^{1}$ In 2000, the production was carried out under regulated monopoly. The distribution of production is not necessarily the same in a future electricity market.
} 
A solution to the Lithuanian electricity market problem is to ensure external competition at least from the other Baltic States, but preferably also from other countries. The transmission capacities between the Baltic States are quite strong, and with free trade they will probably be sufficient to ensure free internal Baltic electricity trade most of the time.

Transmission connections out of the Baltic region only exist to Russia, Kaliningrad and Belarus. However, the electricity markets in these countries are not yet liberalised. New transmission connections between Lithuania and Poland and between Estonia and Finland might offer additional possibilities of creating competition. Another possibility of external competition could be usage of Russian or Belarusian grid as transit to the liberalised Western European electricity markets.

\section{Methodology used in the analysis}

\subsection{Type of model}

The modelling tool used for the analyses is the partial bottom up equilibrium model Balmorel that simulates the electricity and district heating markets, see Elkraft System et al. (2002) and Elkraft System et al. (2001) for a comprehensive description. A graphical presentation of the model is given in Figure 1.

The input to the Balmorel model comprises a technical and economic description of the electricity and district heating production technologies, including endogenous determination of investments. The demand side is on one hand modelled roughly through an aggregated demand function, but on the other hand a detailed day/night variation, weekly variation and seasonal variation are included. The basic version of the model covers the countries around the Baltic Sea. The presented analyses cover only the three Baltic countries, Lithuania, Estonia and Latvia, in order to have a well documented and consistent data set. Being a partial model, Balmorel does not take into account general equilibrium or macro effects of different electricity market policies, but allows on the other hand more details. The choice of Balmorel therefore represents a choice in the trade off between technology details and macro effects.

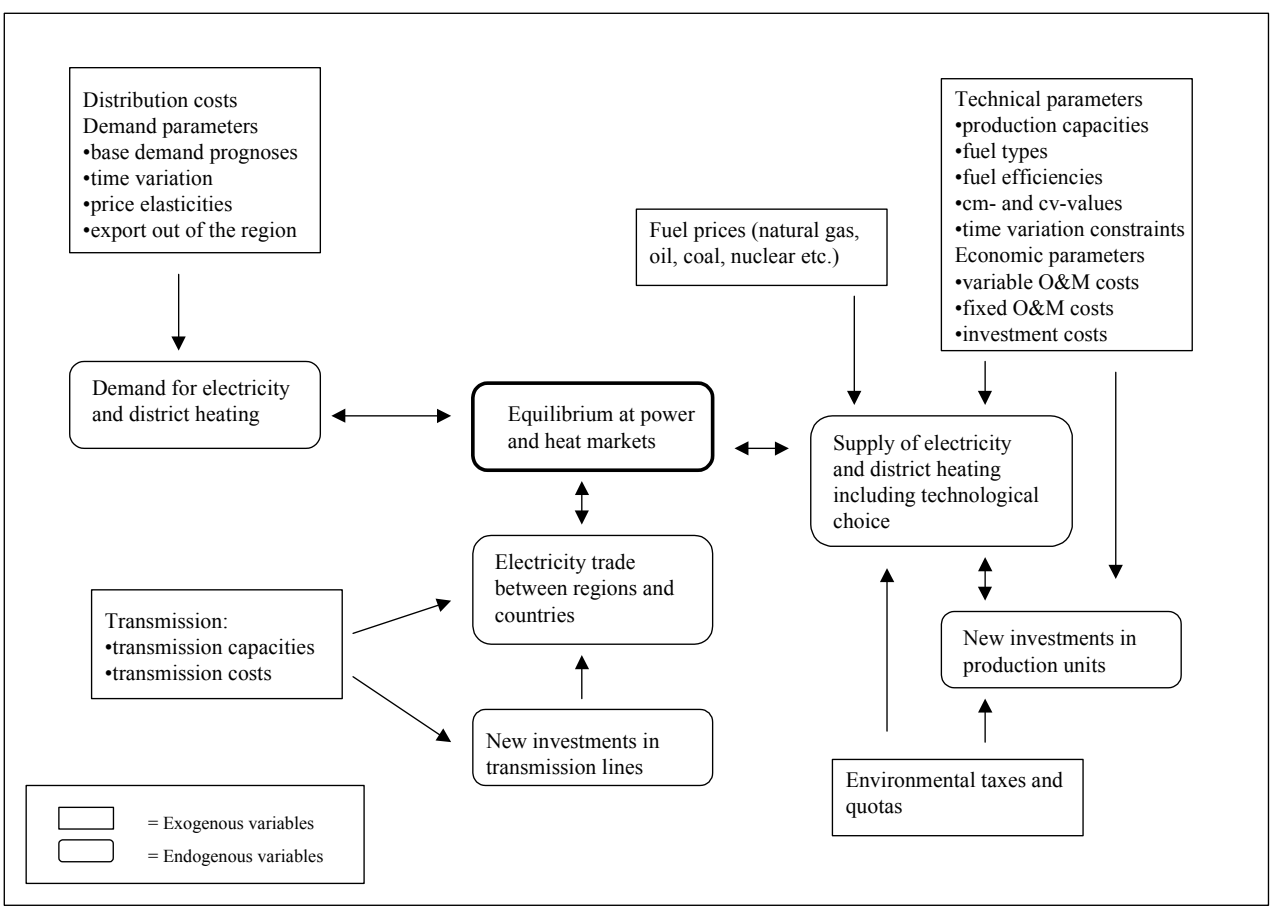

Figure 1. Graphical presentation of the Balmorel model 


\subsection{Assumptions about competition}

The analyses are carried out for three different competition situations resulting in three different sets of market prices.

The perfect competition price is the price that appears assuming that there is perfect competition in the electricity market.

The mark-up price is defined as the price that will result if producers do not supply electricity at a price equal to own marginal costs, but equal to the marginal costs of the "next" unit in the system if units are ordered with increasing marginal costs (i.e. the cheapest non-producing unit). If producers know the market well, this will in many cases be the price that can be charged without running a risk of losing market shares as the "next" unit will never supply below its marginal costs.

The long-run price covers all costs of new capacity including production and annualised investment costs over the expected lifetime. It is therefore the lowest price that new producers should achieve to make a positive profit. It can be viewed as the highest price which existing producers can charge without running a risk of new competitors entering the market. The long-run price will in the long run equal the competition price when new investments are necessary to satisfy the demand.

The analysed prices are examples of how the market could develop assuming only moderate lack of competition.

\section{Results of analyses}

To illustrate the consequences of different future development options, a range of quantitative analyses has been carried out. The analyses have been carried out for two different overall market situations, a common Baltic electricity market and a closed Lithuanian market. Furthermore, different analyses have been carried out illustrating for instance the consequences of not having full competition in the electricity market and for different closure speeds of INPP.

In the common Baltic electricity market situation, it is assumed that free electricity trade between the Baltic countries is possible. In the closed national markets situation, no international electricity trade is possible.

The analysed period is 2002 to 2021. In the baseline situation it is assumed that the first unit of INPP will be closed by the end of 2004, and the second unit will be closed by the end of 2010 .

A fixed annual export of electricity from Lithuania to countries outside the Baltic region of $2 \mathrm{TWh}$ is assumed as long as both units at INPP are in operation.

The electricity demand, heat demand, and the fuel prices increase during the period. For simplicity, the price elasticities are assumed to equal zero meaning that the electricity and heat demands equals the input projections.

The results are in general uncertain due to e.g. the future levels of several parameters. The results should therefore mainly be viewed as indications based upon the best available data and model today rather that certain projections.

\subsection{Production patterns and market prices}

An overview of the electricity production that has been simulated in the baseline situation is presented in Figure 2, Figure 3 and Figure 4.

As long INPP is in operation, Lithuania is a net exporter of electricity and INPP is the main electricity producer. When both units at INPP have been closed by the end of 2010, Lithuania turns to be a net importer of electricity, and in a longer run Lithuania becomes a net exporter again.

Figure 5 shows the development in the annual average electricity prices in Lithuania. These prices can be interpreted as the prices that would occur on a Baltic spot market similar to the Nordic spot market Nord Pool. 


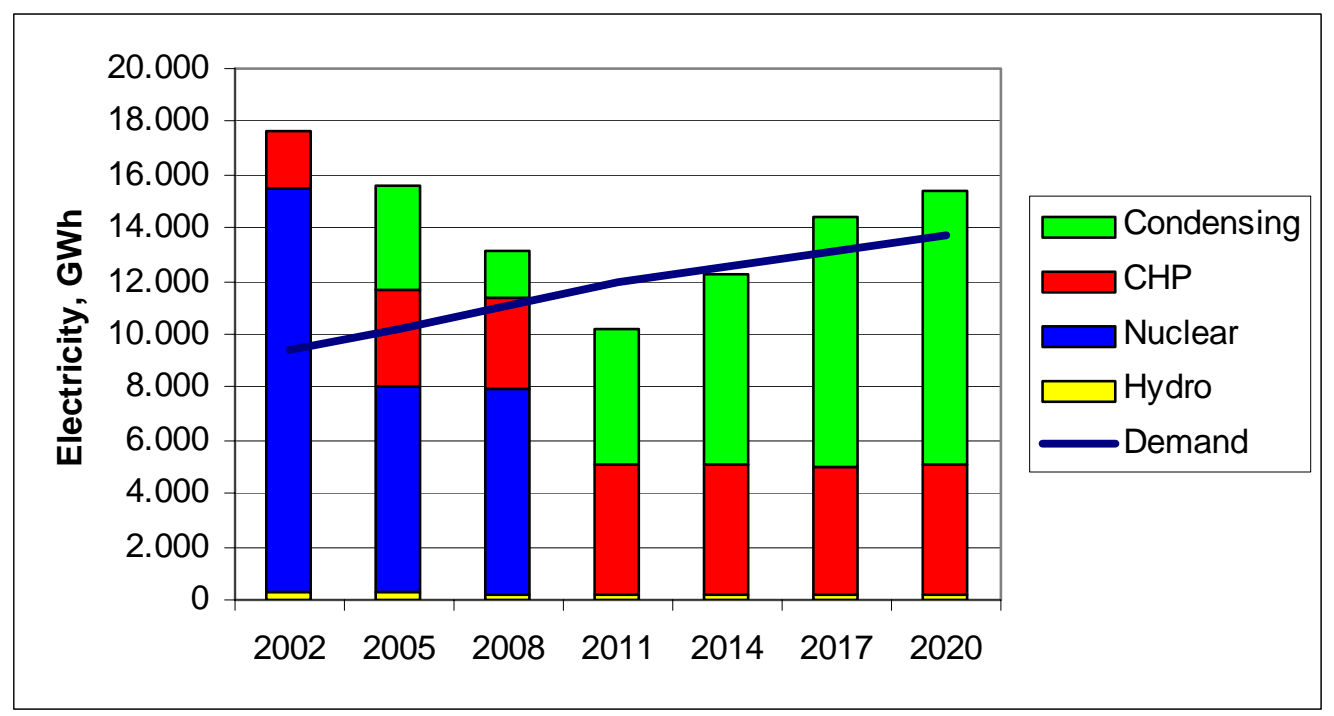

Source: Own calculations using Balmorel.

Figure 2. Electricity production in Lithuania assuming a common Baltic electricity market and a phased closure of INPP (baseline situation)

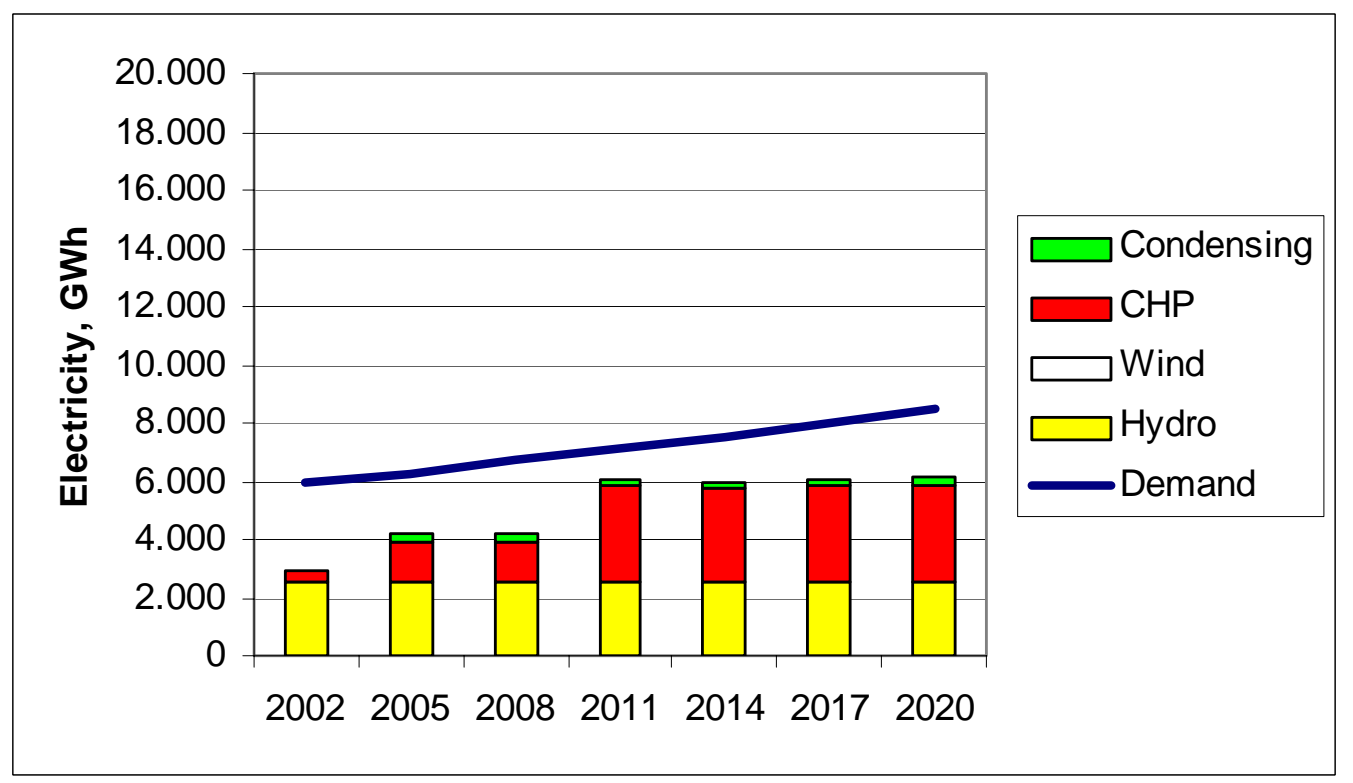

Source: Own calculations using Balmorel.

Figure 3. Electricity production in Latvia assuming a common Baltic electricity market and a phased closure of INPP (baseline situation) 


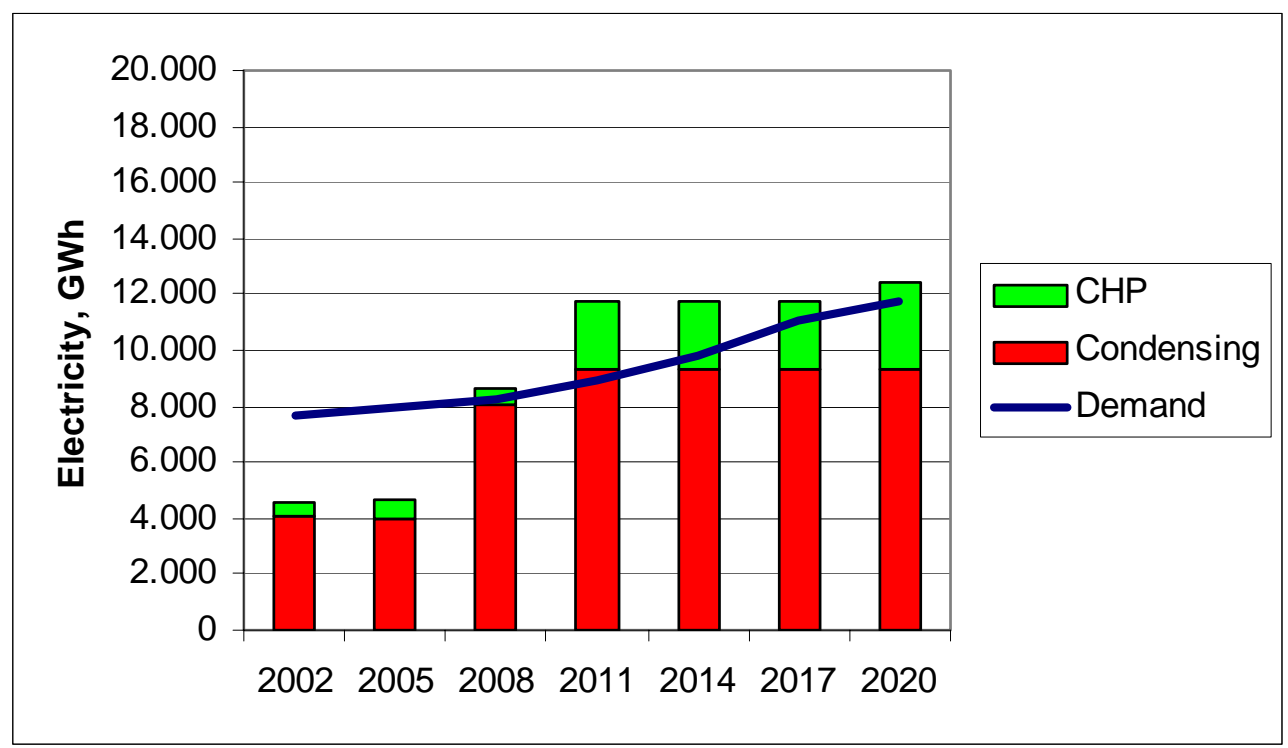

Source: Own calculations using Balmorel.

Figure 4. Electricity production in Estonia assuming a common Baltic electricity market and a phased closure of INPP (baseline situation)

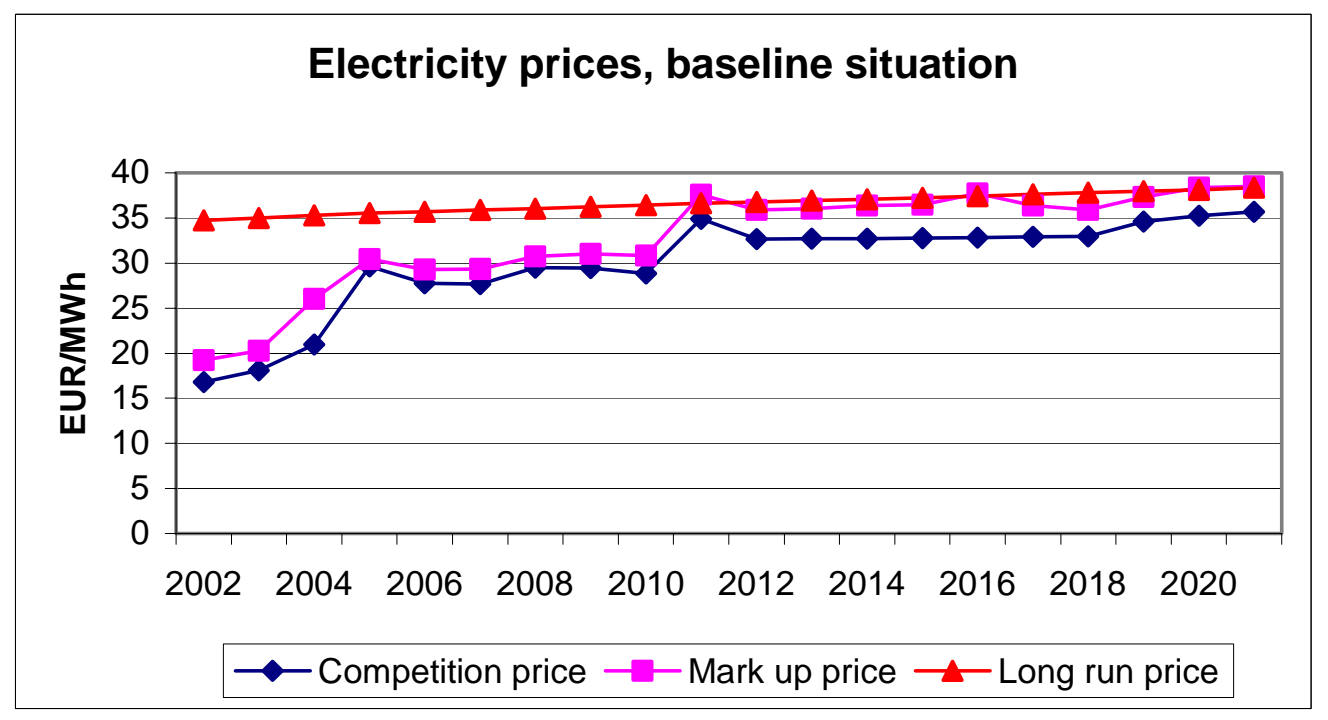

Source: Own calculations using Balmorel.

Figure 5. Electricity prices in Lithuania in the baseline situation

The perfect competition price is low in the beginning of the period as the excess capacity implies equilibrium prices below long-run equilibrium prices. In a longer term, when INPP has been closed, new investments will be necessary, and the perfect competition price will increase. By the end of the period, the perfect competition price is close to the long-run price. In an even longer term, when all existing units have been closed down, these two prices will be equal.

The increase of the long-run price during the period is caused by increased fuel prices.

As expected, the mark-up price is always above the perfect competition price. In the long run, it is close to the long-run price. In the short term, the mark-up price is mainly determined by the marginal production cost at CHP plants. It is not much above the perfect competition price indicating that producers can only obtain limited excess profit using this strategy. 
The market prices in Estonia and Latvia are slightly higher than in Lithuania as also transmission costs for these countries must be added to the Lithuanian export price.

Assuming a closed Lithuanian electricity market, the excess capacity will be relatively higher than when assuming a common Baltic market and INPP will generate a relatively higher proportion of the electricity production. This means that more expensive production can be avoided. Assuming a closed Lithuanian market, the average perfect competition price will be as low as $11 \mathrm{EUR} / \mathrm{MWh}$ in 2002 instead of 17 EUR/MWh.

\subsection{Future situation for power plants}

The future situation for the individual power plants is evaluated on the basis of the "value" of each power plant. This is calculated as the net present value of all future earnings (income minus expenses) during a twenty-year period, i.e. 2002-2021. The earnings are discounted to 2002 using a discount rate of $6 \%$ p.a.

The income is defined as the total income from sale of electricity and district heating. The expenses include variable costs and fixed costs, but not payment of loans related to the original investment costs of the power plants as these costs are viewed as sunk and a part of the companies' financial assets.

If a power plant does only produce a small amount of electricity (and district heating), the income will be close to zero, and therefore the earnings may be negative due to the fixed costs.

If a closed Lithuanian market was established instead of a common Baltic market, the Lithuanian production units would in general produce less, and the perfect competition prices would be lower. Both these circumstances lead to lower contribution margins and thus to lower values of the power plants.

The calculated values of production units are presented in Table 2 .

Table 2. Discounted value of Lithuanian power plants, million EUR.

\begin{tabular}{|l|rr|rr|rr|}
\hline & \multicolumn{2}{|c|}{ Perfect competition } & \multicolumn{2}{c|}{ Mark-up price } & \multicolumn{2}{c|}{ Long-run price } \\
& Baltic & LT & Baltic & LT & Baltic & LT \\
market & market & market & market & market & \multicolumn{1}{c|}{ market } \\
\hline Ignalina NPP & 896 & $-1,233$ & 1,546 & -598 & 4,371 & 3,341 \\
Lithuanian PP & -86 & -220 & 406 & 20 & 608 & 66 \\
Vilnius CHP & 91 & -131 & 308 & -6 & 759 & 521 \\
Kaunas CHP & -53 & -96 & 20 & -70 & 101 & 28 \\
Mazeikiai CHP & -373 & -375 & -341 & -360 & -110 & -267 \\
Klaipeda CHP & -1 & -1 & -1 & -1 & -1 & -1 \\
Kaunas & 365 & 301 & 404 & 335 & 514 & 477 \\
\hline Total & 841 & $-1,756$ & 2,340 & -671 & 6,242 & 4,165 \\
\hline
\end{tabular}

\subsection{Welfare economic analyses}

Table 3 shows the welfare economic consequences to Lithuania if mark-up prices or long-run prices appear on a common Baltic electricity market instead of perfect competition prices.

Table 3. Welfare economic consequences for Lithuania assuming long-run prices instead of perfect competition prices assuming a common Baltic electricity market, million EUR.

\begin{tabular}{|l|l|c|c|c|}
\hline & $\begin{array}{l}\text { Increased tax } \\
\text { revenue }\end{array}$ & $\begin{array}{l}\text { Increased profit } \\
\text { of production } \\
\text { sector }\end{array}$ & $\begin{array}{l}\text { Increased con- } \\
\text { sumer welfare }\end{array}$ & $\begin{array}{l}\text { Total welfare } \\
\text { economic con- } \\
\text { sequence }\end{array}$ \\
\hline Mark-up prices & 0 & 472 & -368 & 104 \\
\hline Long-run prices & 0 & 1,645 & $-1,001$ & 644 \\
\hline
\end{tabular}


With increased market prices, the production sector's profit increases, and the consumer welfare decreases. The total welfare in Lithuania increases also because Lithuania is found as a net exporter of electricity, and thus Lithuania gains by higher electricity prices. The increment of the total welfare in Lithuania is, however, counterbalanced by a loss in the neighbouring countries.

Assuming the price elasticity of zero (i.e. no price elasticity), the loss in the neighbouring countries corresponds exactly to the gain in Lithuania. If there was assumed a price elasticity, the demand would decrease as a result of higher market prices, and the loss in the neighbouring countries would be even higher than the welfare gain in Lithuania. This is probably not acceptable to Estonia and Latvia and will be a political obstacle towards an integrated market. Lithuania should therefore not in reality expect a gain from competition failures.

Table 4 shows the welfare economic consequences for Lithuania of different INPP closure scenarios assuming a common Baltic electricity market.

Table 4. Welfare economic consequences for Lithuania of different INNP closure scenarios assuming a common Baltic electricity market, million EUR.

\begin{tabular}{|l|c|c|c|c|}
\hline & $\begin{array}{l}\text { Increased tax } \\
\text { revenue }\end{array}$ & $\begin{array}{l}\text { Increased profit } \\
\text { of production } \\
\text { sector }\end{array}$ & $\begin{array}{l}\text { Increased con- } \\
\text { sumer welfare }\end{array}$ & $\begin{array}{l}\text { Total welfare } \\
\text { economic con- } \\
\text { sequence }\end{array}$ \\
\hline $\begin{array}{l}\text { Accelerated closure of } \\
\text { INPP }\end{array}$ & 6 & -250 & -94 & -337 \\
\hline $\begin{array}{l}\text { Continued operation of } \\
\text { INPP }\end{array}$ & -9 & 406 & 77 & 474 \\
\hline
\end{tabular}

In the accelerated closure situation, it is assumed that both INPP blocks are closed in 2004, while it is assumed in the continued closure situation that operation on block 2 is continued until 2021. None of these possibilities are politically very realistic, but they can be used for determining the Lithuanian costs of the decided steps of closure.

Compared to the baseline situation, the society looses 337 million EUR if both units are closed already by the end of 2004, and it wins 474 million EUR if one unit continues operating. The refurbishment cost that could be necessary to keep one INPP block in operation is not included in this calculation, nor is the change in the timing in the payment of decommissioning costs.

INPP operation requires large reserve capacity and flexible capacity elsewhere in the electricity system. These costly requirements are reduced when INPP is closed. The welfare cost of an early closure and the gains from continued operation are therefore most likely smaller than estimated in Table 4 . Nor are safety risks and the political value of earlier closure included in the estimated value. Inclusion of such considerations implies that the costs of earlier closure may be smaller than estimated. On the other hand, taking into account that the closure costs of INPP are not included in the analyses, the welfare loss of an early closure of INPP and the gains from continued operation could also be higher than estimated.

Table 5 shows the consequences to the three Baltic countries of having closed national markets instead of a common Baltic electricity market assuming competition prices.

Table 5. Welfare economic consequences for all three countries of having closed markets instead of a common Baltic electricity market assuming competition prices, million EUR.

\begin{tabular}{|l|c|c|c|c|}
\hline & $\begin{array}{l}\text { Increased tax } \\
\text { revenue }\end{array}$ & $\begin{array}{l}\text { Increased profit } \\
\text { of production } \\
\text { sector }\end{array}$ & $\begin{array}{l}\text { Increased con- } \\
\text { sumer welfare }\end{array}$ & $\begin{array}{l}\text { Total welfare } \\
\text { economic con- } \\
\text { sequence }\end{array}$ \\
\hline Lithuania & -6 & -750 & 497 & -259 \\
\hline Latvia & 3 & -171 & -193 & -360 \\
\hline Estonia & -4 & -381 & -9 & -394 \\
\hline
\end{tabular}


A common Baltic market will give benefits to all three Baltic countries, as would be expected from basic theory of international economics. If national markets are created instead, Latvia will lose around 360 million EUR while Estonia will lose around 390 million EUR compared with a Baltic market. In Lithuania, producers will be the main losers from closed markets but in Latvia and Estonia also consumers lose because of the lacking possibilities of importing electricity. Still Lithuania will lose almost 260 million EUR if only closed national markets are created.

\section{Conclusion}

The Lithuanian electricity market is dominated by very few and large production units. Because of this, there will be a considerable risk of lack of competition if a closed Lithuanian electricity market is established. If competition is not fully achieved, the production companies will gain because of their ability to manipulate market prices. But on the other hand, consumers and the Lithuanian society as a whole will lose.

The establishment of a common electricity market covering a larger area than Lithuania will help reducing the competition problem. Therefore, it is recommended to establish a common Baltic electricity market. The establishment of a common Baltic market does not guarantee strong competition, because the market is still characterised by relatively few and large power producers. It will, however, be an important step towards competition in the sector.

The specific analyses carried out have estimated the values of production units and the welfare economic consequences for Lithuania under different future market conditions. These analyses rest upon parameters and assumptions regarding the future that are highly uncertain. The results should therefore not be interpreted as facts but only consistent expectations based upon the best information available to the authors.

Assuming perfect competition prices, the electricity prices become low, and many production units can not cover their fixed costs. Because of this, many production units come up with negative values. Assuming mark-up prices or long-run prices, most units come up with positive values which indicate that the plant values are highly sensitive towards changes in the electricity price.

An early closure of INPP in a Baltic market costs Lithuania around 350 million EUR, while continued operation of one unit until 2021 gives a gain of around 500 million EUR. It should, however, be noted that safety risks and the political value of an earlier closure are not taken into account. INPP operation also requires large reserve capacity and flexible supplementary capacity, which is not taken into account in the estimated welfare costs. These concerns suggest that the welfare loss of an early closure most likely is lower than the estimated 350 million EUR. Also the potential gain from continued operation is most likely lower than the estimated 500 million EUR. On the other hand, costs of INPP closure which are not taken into account either have an opposite effect.

By establishing closed national electricity markets in the Baltic countries instead of a common Baltic electricity market, there will be a total welfare economic loss in all three countries.

\section{References}

Elkraft System et. al. 2001. Bamorel: A Model for Analyses of the Electricity and CHP Markets in the Baltic Sea Region. Balmorel Project, 2001. ISBN 87-986969-3-9. Available at www.balmorel.com.

Elkraft System et. al. 2002. Economic analyses in the Electricity Sector in Lithuania. April 2002.

Lietuvos Energija 2000. 2000 Annual Report. Lietuvos Energija, April 2001.

U.S. Department of Justice and U.S. Federal Trade Commission 1992. Horizontal Merger Guidelines. Washington D.C. www.usdoj.gov/atr/public/guidelines/merger.txt. 


\title{
The European green electricity markets in 2010
}

\author{
Peter Meibom \\ Klaus Skytte \\ Systems Analysis Department \\ Risø National Laboratory \\ DK - 4000 Roskilde \\ peter.meibom@risoe.dk \\ klaus.skytte@risoe.dk
}

\begin{abstract}
The market shares of different electricity producing renewable energy technologies in the green electricity markets in EU, and the size and prices obtained on these markets depends strongly on the market designs and support policies governing the development of these markets. These issues have been analysed with the use of the ADMIRE REBUS model. Costs data for all significant electricity producing renewable energy technologies and data on the sizes of the renewable energy resources in EU are combined with different national development of the support policies for green electricity in the different EU countries towards a common EU market in 2010. The model simulates the operation of each green electricity market in EU and the interaction between the markets. This enables calculations of which technologies that are competitive on the markets. Model results show that in a harmonized EU wide tradable green certificate system starting from 2010, i.e. in a system without technology-specific support, wind power will be the most competitive technology, but power plants using different types of biomass will also gain a large share of the market. To reach the indicative EU targets for RES-E production in 2010 a TGC price of 5.6 eurocents is necessary in addition to a physical power price of 2.2 eurocents.
\end{abstract}




\section{RES-E Policies within EU}

At present the existing support policies to electricity from renewable energy sources (RES-E) differs between the Member States within EU. The support to RES-E deployment can be generation-based or capacity-based. In addition, the support can be given at the supply side (technology push) or at the demand side (demand pull). This has yielded a large playing field for designing support policies within each Member State. Figure 1 below illustrates this.

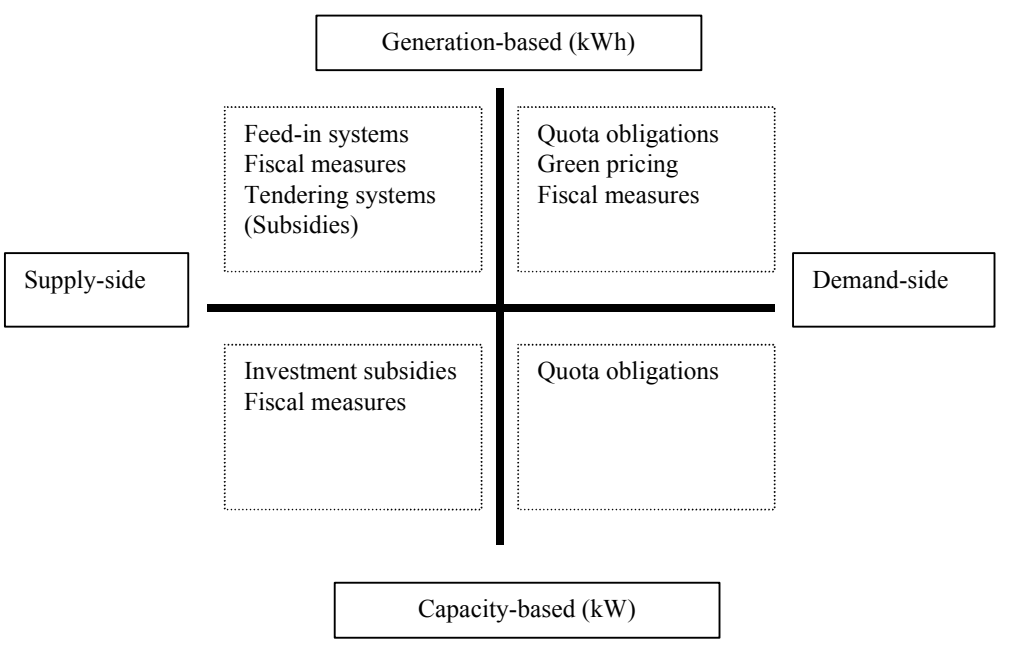

Figure 1. Classifying RES-E policy support mechanisms [5]

In addition to the wide spread of support policies also the national deployment ambitions have differed between the Member states due to difference policy reasons for deployment of RES-E, e.g. natural resources, security of supply, local employment, emission reduction, etc. These differences have for many years implied that it has been difficult to agree on a common scheme [4]. However, in line with creation of a common EU market for electricity also common RES-E ambitions have been agreed upon.

The EU-directive, on promotion of RES-E in the internal market ([2] and [3]), is the main legislation for deployment targets of RES-E within the EU 15. Within this directive indicative deployments targets have been decided for each Member States. The RES-E targets are measured as percentages of the total gross electricity consumption. The overall target for EU is $22.1 \%$ in 2010 compared with a RESE share of $14 \%$ in 1997. The indicative targets per Member State differ according to Figure 2 below. 


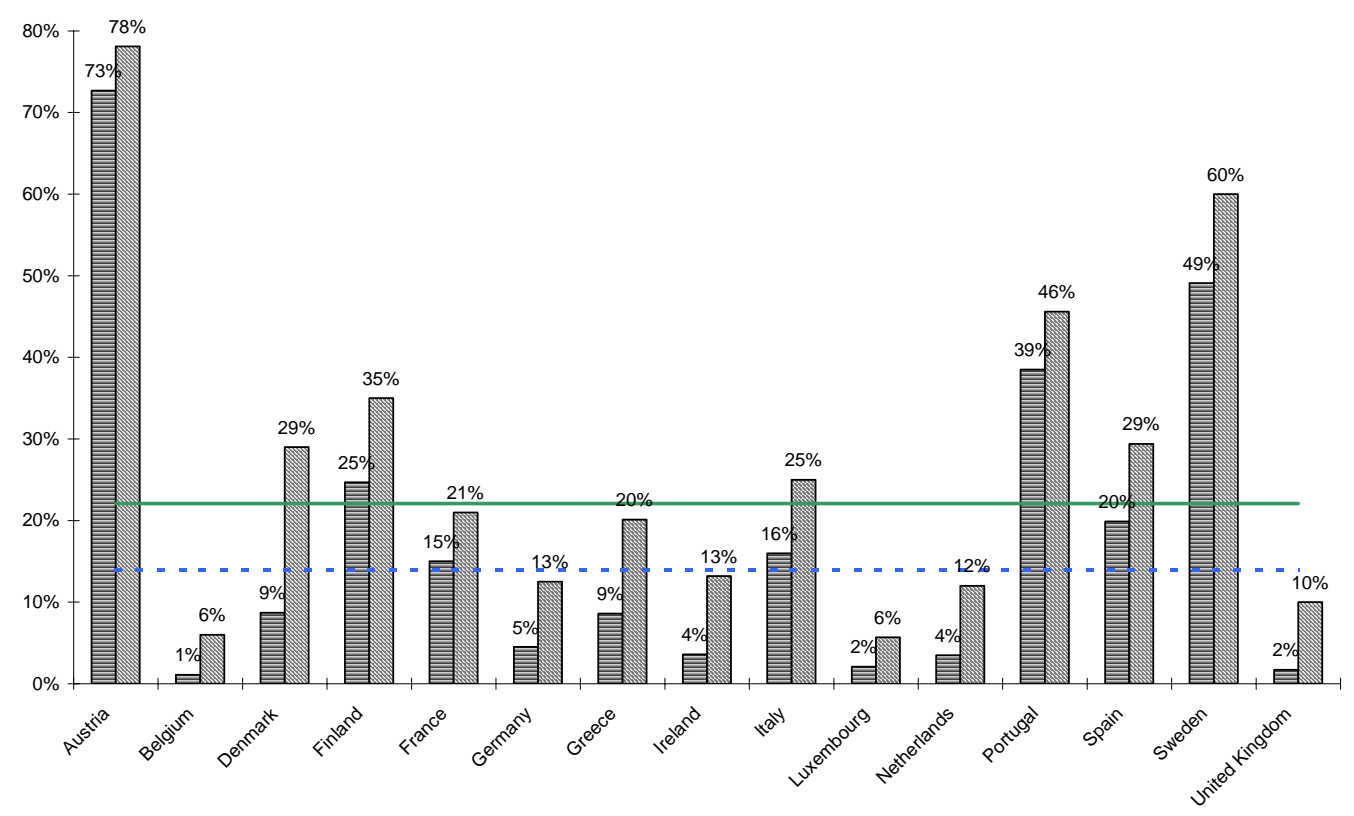

Figure 2. EU targets for RES-E

The broken line and the left pillars in Figure 2 indicate 1997 data for EU and the solid line and right pillars indicate the 2010 targets. For example Denmark has promised to increase its share of RES-E from $9 \%$ in 1997 to $29 \%$ in the year 2010 .

The RES-E directive [2] requires a certification of RES-E. This green certification provides an accounting system to register production, authenticate the source of electricity, and verify whether the quota obligation has been met.

When the certificates are tradable, they are denoted tradable green certificates (TGC). The main benefit of making them tradable is to facilitate trade and, thereby, stimulate deployment of renewable energy based technologies in the most efficient areas and countries, i.e. it provides a cost-effective means of achieving a target for generation or consumption of renewable electricity across country borders.

The EU-directive for RES-E does not introduce a mandatory, common TGC system at present. However, in 2005 the Commission will publish a report on the experiences gained with coexistence and application of the different support mechanisms within the EU. If this report concludes that there are good reasons to make a common trading system, e.g. a TGC system, it is reasonable to believe that the Commission will to decide by 2007 if a common system has to be implemented.

Until now, the effects of having different RES-E support systems in connection to a common liberalised power market have not been analysed. In this paper we use a model, ADMIRE-REBUS that do take into account the differences in policy schemes and thereby show these effects. The model also allows for making a common TGC market, i.e. going from national markets and support schemes to a common support scheme. The paper gives a short description of the model. A case study is described and the model results of this case study are presented.

\section{ADMIRE-REBUS model}

The ADMIRE-REBUS model is based on an extensive dataset for the potentials and costs of RES-E technologies in EU-15. The model enables representation of current and expected renewable electricity policies of all Member States in different policy scenarios. This representation is based on a survey 
of existing and planned RES-E support schemes in EU-15 countries that has been carried out as part of the ADMIRE-REBUS project ([1] \& [5]). An overview of the model is given in figure 3 .

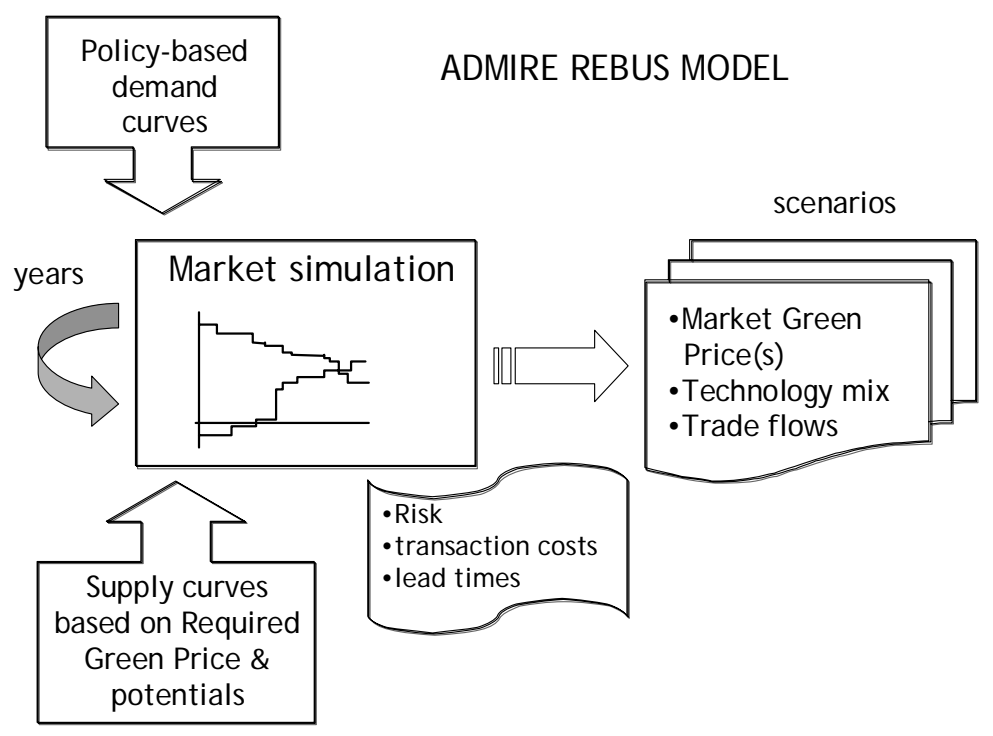

Figure 3. Schematic overview of the ADMIRE REBUS model [5]

By doing a dynamic year-for-year market simulation in which national RES-E supply curves are matched with policy-based demand curves, the market green price, the location of the most costefficient generation sites, and the type (and cost) of technologies deployed are calculated. The market green price is the price at which the supply curve for renewable electricity and the demand curve meet (see figure 3), i.e. the trading price of the marginal supply option. It can be interpreted as an estimate of the production support necessary to reach a given level of RES-E production.

For a given year a supply curve consists of the available RES-E production potentials in a given country ordered according to the required green price (see below) of each production potential. The production potentials are calculated with a consistent methodology taking all restrictions on the exploitation of renewable energy sources for electricity production into account except the economic ones, which are taken into account in the model runs. A technology type can be divided into technology bands thereby taking the variation in production costs according to the location of the technology into account. The number of full load hours of each RES-E technology band is an exogenously parameter in the model used in the calculation of the size of each production potential given as the potential yearly production from a given RES-E technology band.

The 'required green price' is the average minimal green price that the investor has to obtain from the green electricity markets over the lifetime of the production capacity in order to make the construction of additional green capacity (or the production with existing capacity) attractive. It is calculated endogenously using a net present value calculation where the revenue from physical delivery of electricity on the "normal' (grey) electricity market as well as up-front investment support are included such that the required green price indicates the additional production support required to make the investment attractive.

By using the realised production in previous years in the construction of the supply curves for a given year learning effects and technology development are taken into account. Furthermore constraints on deployment growth due to planning procedures and industry growth limits are included in the model.

Methodologies for translating different types of production support schemes into a demand size and a bid price have been devised thereby enabling construction of national demand curves. For a more thorough description see [5].

The results are calculated in a way that takes into account the discriminative characteristics of some policies, and the ability of producers to choose whether they produce for the domestic market or wish 
to trade their production. When several national support schemes having different levels and conditions are in operation different sub markets emerge with local equilibria (market green prices). Likewise a EU wide tradable green certificate market gives a single market equilibrium for the EU.

\section{Case study - Harmonisation in 2010}

As a case study we assume that it is decided in 2007 to introduce a EU-wide TGC system that can be functional from 2010 for all new RES-E capacity. Thereby the indicative targets mentioned in the RES-E directives (see Figure 2) will become mandatory targets.

Until 2010, all Member States will continue their current national support schemes. However, after 2007 there will not be implemented any new policies when these deviate from the harmonised, common TGC system.

The fast shift to a TGC system is mainly for new capacity by 2010. For existing capacity, we assume a transition period of 7 years, unless currently available policy data indicates a longer operational period, e.g. feed-in tariffs that are guaranteed for 10 years.

\section{Results}

Model runs show that the existing support policies in some Member States are more than sufficient to reach the national targets for 2010 which where set as indicative targets within the Directive for RESE. Whereas for other Member States there are gaps between the actual deployments and the national targets. This is illustrated in Figure 4 for Germany and Spain.

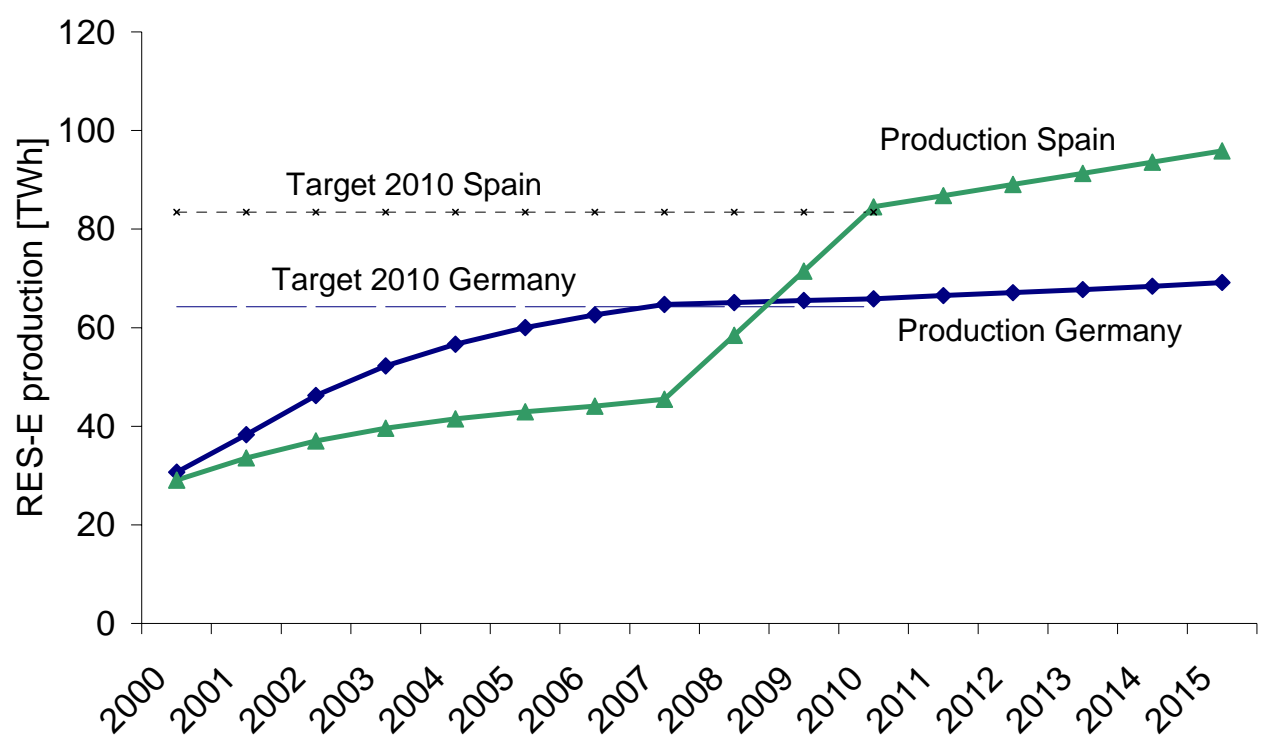

Figure 4. Actual production under existing policies until 2007 and a common EU wide TGC system after 2010 for Germany and Spain

It is seen that with the existing support policies Germany will reach its 2010 target already in 2007 whereas Spain only has achieved approximately $50 \%$ of the target in 2007. Therefore Spain will have 
to speed up its deployment of RES-E as a result of EU decision in 2007 to make the targets mandatory three years after in 2010.

The same situation applies on a total EU level that also experiences a gap between the 2010 target and the RES-E production in 2010 if no new initiatives aimed at supporting RES-E are put into operation as a supplement to the existing support schemes. The introduction of mandatory targets and a EU wide TGC fully functioning in 2010 will therefore generate a large deployment of RES-E in the period 2007-2010 in order to reach the targets. As a result the TGC price on the EU wide TGC market starts at a relatively high level in order to stimulate this deployment. In the years to come, the additional increase in the target will follow the increase in the power demand, i.e. a more moderate relative increase. This implies a TGC price pattern as shown in Figure 5 where the TGC price go down for a while and ends at a level of 4.15 Euro cent $/ \mathrm{kWh}$.

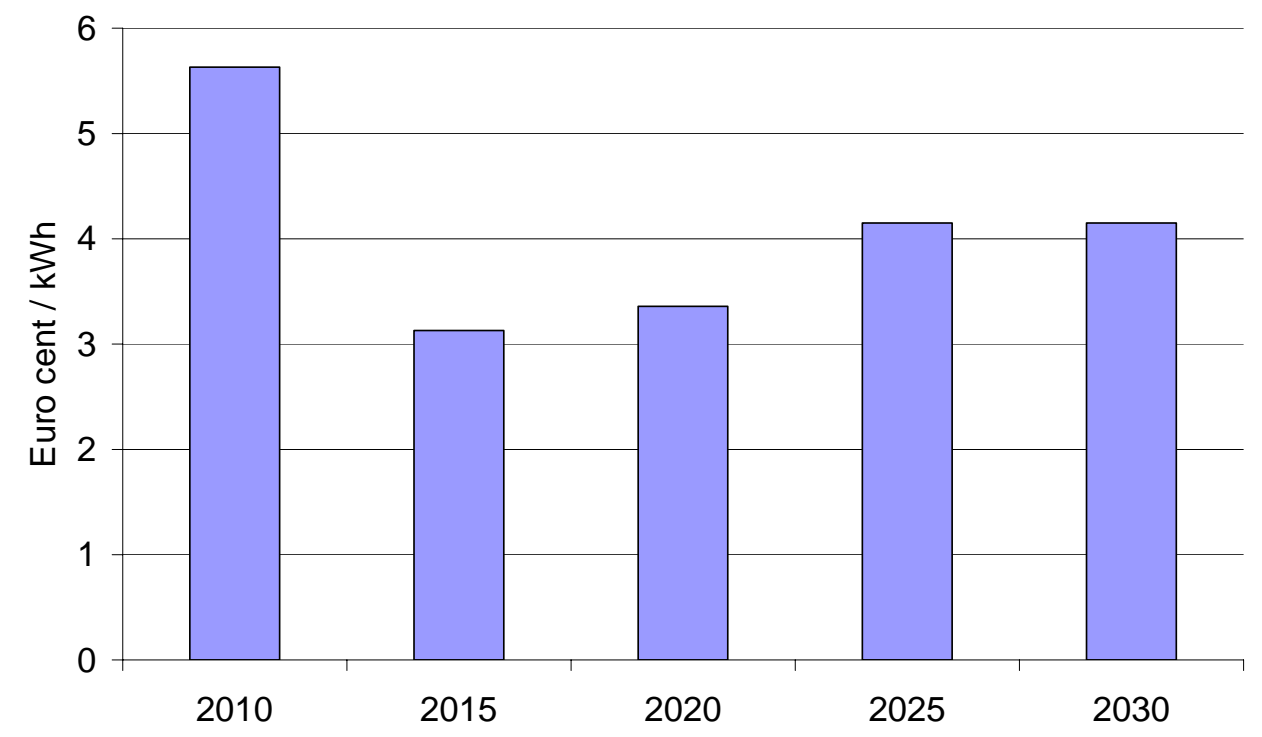

Figure 5. EU wide TGC prices in different years. In addition to the TGC price the RES-E producers achieve a power price of 2.2 Euro cent / $k W h$

Figure 6 illustrates the RES-E production divided by technology types. As expected a significant increase in the deployment of RES-E technologies is taking place driven by the EU targets for RES-E production. As a single technology wind power onshore will have the largest share of the new deployments, but the group of technologies using biomass will also have a large share of the new deployment and will produce almost $25 \%$ of the total RES-E production in 2030. Large-scale hydropower is a mature technology with few remaining sites available for exploitation due to environmental considerations. This situation is reflected in the model results where the production from large hydropower (>10 MW) is nearly constant until 2030. 


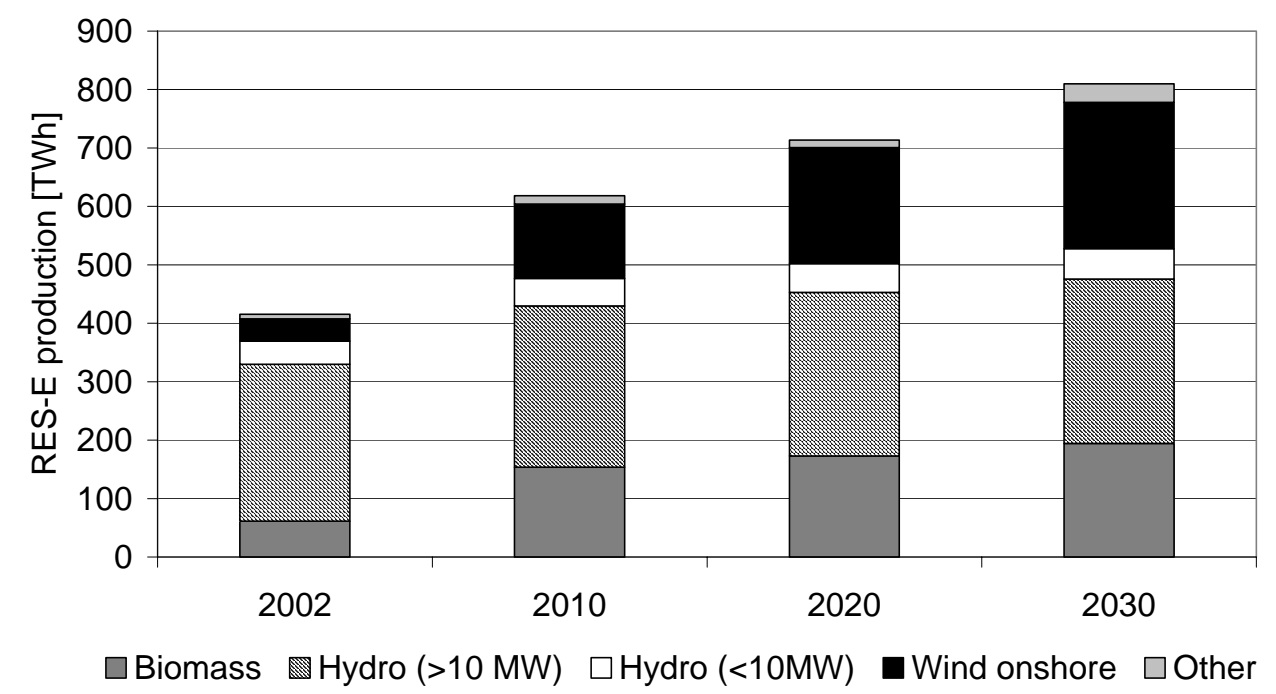

Figure 6. The total RES-E production in EU divided on technology groups ${ }^{1}$ for selected years

Onshore wind power has an additional (average) yearly deployment of $20 \%$ under the existing support schemes between 2002 and 2007. Under the TGC system and with more moderate additional increases in the targets offshore wind power has an additional, average yearly deployment of $7 \%$ between 2010 and 2017. This implies a tripling of the amount of RES-E from onshore wind turbines between 2002 and 2010 and more than five times more onshore wind power in 2020 than in 2002.

Even though wind onshore is going to have the largest increase in deployment within the EU this does not implies that all Member States are going to deploy large amounts of wind power onshore. The TGC system implies that the deployment takes place where it is most cost effective. In addition, the model takes into account the amount of realisable potentials for wind power in each Member States. In a country like Denmark the realisable potentials for additional wind power onshore will be more or less exhausted in 2010. Whereas other Member States still have large realisable potentials for additional wind power onshore.

This is reflected in the deployment of onshore wind power through time illustrated in Figure 7 showing the onshore wind power production in selected countries.

\footnotetext{
${ }^{1}$ In the grouping of RES-E within Figure 5 the group Other consists of wind offshore, photovoltaics, geothermal electricity and tidal power. The group Biomass consists of all technologies utilising biomass resources to produce electricity, where waste is included as a biomass resource.
} 


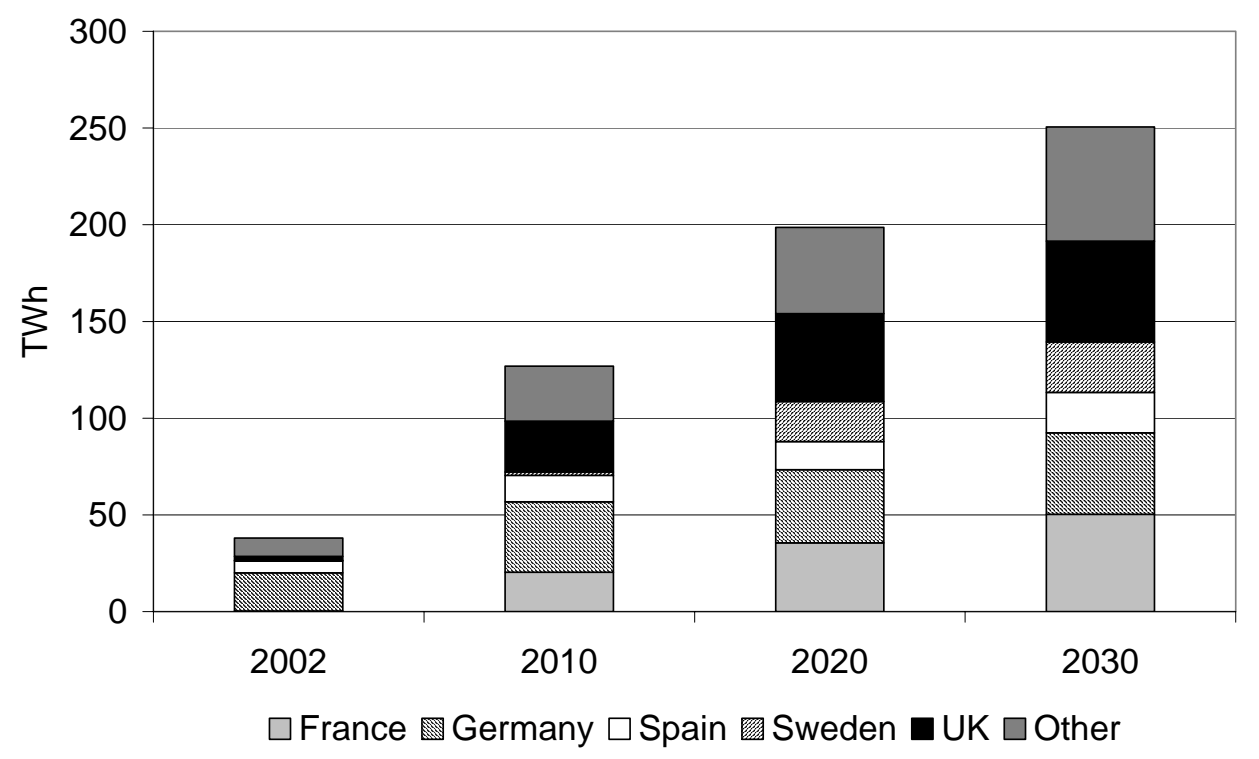

Figure 7. Production from onshore wind power in different countries in selected years. "Other" consists of the remaining countries in EU-15

France, Sweden and the UK will become large onshore wind power producing countries with a significant increase in installed capacity also taking place after 2010. This means that cost effective potentials for onshore wind power are available in these countries and they will be used when the EU wide TGC market starts operating in 2010. In contrast to this Germany and Spain will already have exploited much of their national cost effective potential for onshore wind power until 2010 due to the existing relatively favourable support policies for onshore wind power in these countries.

In other words, the introduction of a EU wide TGC system increase the deployment speed in some Member States (e.g. France, Sweden and the UK) and damps further deployment in other Member States according to where the most cost effective potentials exist.

\section{Conclusions}

The model simulation made by the Admire-Rebus model and described is this paper shows that the existing support policies for RES-E are not sufficient in order to reach the overall target for EU of $22.1 \%$ in 2010 compared with a RES-E share of $14 \%$ in 1997.

In order to reach the target the EU Commission can make mandatory targets for the Member States by 2010. In addition the Commission may agree on a common TGC market starting in 2010 in order to make the deployment where it is most cost effective, i.e. at the lowest costs. If this is done the model results in this paper show that the EU TGC price in 2010 will be $5.6 € \mathrm{ct} / \mathrm{kWh}$ and the long-run TGC prices will be between 3.1 and $4.15 € \mathrm{ct} / \mathrm{kWh}$ assuming a reference power price at $2.2 € \mathrm{ct} / \mathrm{kWh}$.

With respect to the amount of additional deployment of the different RES-E technologies, wind power is still the main technology. The amount of RES-E from onshore wind power is tripled between 2002 and 2010 and more than five times more onshore wind power is produced in 2020 relatively to 2002.

This large deployment of onshore wind turbines will mainly take place in France, Germany, Spain, Sweden and the UK. 


\section{Acknowledgement}

This paper has been written as a working paper under the Admire-Rebus project. EU funded this project under the ALTENER programme, for which the authors are grateful. This project is partly an extension of experiences gained in previous projects ([6] \& [7]).

\section{References}

[1] Admire-REBUS homepage 2003, http://www.admire-rebus.net

[2] European Commission, Directive of the European Parliament and of the Council on the promotion of electricity from renewable energy sources in the internal electricity market, $\operatorname{COM}(2000) 0884$ final, Brussels, Belgium, 2001.

[3] European Commission, Directive on Electricity Production from Renewable Energy Sources, (COM 2001/77/EC), Brussels, Belgium, 2001.

[4] Skytte, K., Market imperfections on the power markets in Northern Europe. A survey paper. Energy Policy (1999) Vol. 27 p. 25-32, 1999.

[5] Uyterlinde, M.A. et al., ADMIRE-REBUS - Assessment and Dissemination of Major Investment Opportunities for Renewable Electricity in Europe using the REBUS Tool - Interim report, 2003, available from M.A. Uyterlinde from ECN, the Netherlands.

[6] Voogt, Uyterlinde, Skytte, Nielsen et al., Renewable Energy Burden Sharing - REBUS. Effects of burden sharing and certificate trade on the renewable electricity market in Europe. ECN-report no. C--01-030, NL, June 2001.

[7] Voogt, M.H., Uyterlinde, M.A., Cost effects of international trade in meeting EU renewable electricity targets. Working paper, ECN, NL, 2002 


\title{
On the effectiveness of Regulatory vs Voluntary vs Strategies for Increasing the Share of Re- newables in Electricity Generation
}

\author{
Reinhard Haas, Claus Huber, Gustav Resch, Thomas Faber \\ Energy Economics Group, Vienna University of Technology, Gusshausstrasse 27-29/373-2, \\ A-1040 Vienna, AUSTRIA, Fax. ++43-1-58801-37397, Web \\ **Tel. ++43-1-58801-37352, E-mail: Reinhard.Haas@tuwien.ac.at,
}

\begin{abstract}
The promotion of electricity generation from Renewable Energy Sources (RES-E) has a high priority in the energy policy strategies of many countries world-wide. To meeting this objective in recent years a wide variety of deployment strategies and dissemination programmes for RES-E has been launched by quite different organizations and institutions. The core focus of this paper is to extract under which conditions various strategies are effective for substantially boosting RES in the future. Moreover, it is analysed what are the most important regulatory conditions for implementing voluntary (Green Pricing, voluntary green electricity trade) and regulatory (TGC-based quotas, bidding feed-in tariffs) promotion strategies for RES-E. The most important results and conclusions of this analysis are:
\end{abstract}

- Regardless which instrument is chosen the careful design of a strategy is of paramount importance.

- Focus on new capacities: It is of paramount importance that a promotional system does not mix existing (at least fully depreciated) and new capacities. Hence, Green Pricing strategies as well as regulatory approaches should have a strong focus on new capacity!

- Credibility: To provide confidence among the industry and investors it must be guaranteed by highly credible sources that a strategy survives a certain planning horizon

- Feed-in tariffs are an effective instrument if a policy is introduced on a national level and if the rates are optimally designed e.g. using a stepped feed-in tariff

- Of high relevance for quotas based on tradable certificates is that the penalty for not purchasing a certificate is higher than the worst case of investment

- With respect to voluntary strategies - e.g. Green Power Marketing - the minimum requirement for a label is that it guarantees at least that the proportional increase in total electricity demand is provided by new capacities!

- With respect to international trading of Green electricity at least one of the following conditions must be fullfilled:

$\rightarrow$ Either reciprocity (That is to say, to allow imports only from compatible markets with the same rules of competition) or

$\rightarrow$ guarantee that the electricity traded is generated from new RES-E power plants!

Key words: Renewables, voluntary strategies, regulatory strategies. 


\section{Introduction}

The promotion of electricity generation from Renewable Energy Sources (RES-E) has a high priority in the energy policy strategies of many countries world-wide. In Europe the White Paper on Renewable Sources of Energy and the Directive on the promotion of electricity from RES, published by the European Commission, set challenging goals to double the share of renewables in the energy mix of EU countries.

In the history of RES-E world-wide a large variety of dissemination strategies has been launched. In the age of regulated electricity generators and regulated electricity markets mainly regulatory promotion strategies were implemented. Dissemination strategies for commercial electricity from RES have included rebate programmes as major incentives, whereby purchasers of renewable energy generating plants could claim back (i.e. be rebated for) part of the costs by a government grant. The most influential rebate programmes in Europe were (a) the wind promotion programme in Denmark (1978-1985) and (b) the German "1000 Roofs Programme" for promoting photovoltaic (PV) power.

In the mid-1990s, in various European countries, promotional programmes based on regulated tariff rates for the purchase of electricity from specified renewable sources became common: The most important models in this context were enhanced feed-in tariffs as for all RES generators at fixed values in Denmark, Germany, Italy and Spain, and against competitive tendering in the UK and France.

Table 1. Promotion strategies for RES-E in European countries (Source: Haas (2001), Haas (2002)).

\begin{tabular}{|c|c|c|c|c|}
\hline Year & Country & Type of strategy & Programme name & Technologies adressed \\
\hline $1978-1985$ & DK & Rebate & & Wind \\
\hline $1989-1993$ & $\mathrm{DE}$ & Rebate & "1000-Dächer-Programm" & PV \\
\hline 1990-1999 & UK & Bidding & $\begin{array}{l}\text { Non-fossil fuel obligation } \\
\text { (NFFO) }\end{array}$ & Selected technologies \\
\hline $1990-2000$ & $\mathrm{DE}$ & Regulated Rates & "Einspeisetarif 1" & $\begin{array}{l}\text { PV, Wind, Biomass, Small } \\
\text { hydro }\end{array}$ \\
\hline $1991-2000$ & $\mathrm{CH}$ & $\begin{array}{l}\text { Voluntary target } \\
\text { programme }\end{array}$ & "ENERGIE 2000" & PV and others \\
\hline 1991-present & $\mathrm{SE}$ & $\begin{array}{l}\text { Labelled "Green } \\
\text { Electricity" }\end{array}$ & "Bra Miljöval" & PV, Wind, Biomass \\
\hline 1992-1994 & $\mathrm{AT}$ & Rebate & 200 kW PV-Program & PV \\
\hline $1992-2000$ & IT & Regulated Rates & "CIP 6/92" & All technologies \\
\hline $1991-1996$ & SE & Rebates/Tax relief & & Wind, Solar, Biomass \\
\hline 1992-1999 & DK & Tax relief & & Wind, Biomass \\
\hline 1992-1999 & $\begin{array}{l}\text { DE, CH, } \\
\text { AT }\end{array}$ & Regulated Rates & $\begin{array}{l}\text { "Kostendeckende Vergü- } \\
\text { tung" }\end{array}$ & PV \\
\hline 1994-1999 & GR & Rebates & $\begin{array}{l}\text { "Operational Programme for } \\
\text { Energy" }\end{array}$ & $\mathrm{r}_{\mathrm{PV}}$, Wind, Biomass, Small hydro \\
\hline 1994-present & ES & Regulated Rates & $\begin{array}{l}\text { "Royal Decree 2366/ 1994" } \\
\text { and "2818/1998" }\end{array}$ & $\begin{array}{l}\text { All technologies (except Large } \\
\text { hydro) }\end{array}$ \\
\hline 1996-present & $\begin{array}{l}\text { DE, CH, } \\
\text { NL, UK }\end{array}$ & Green tariffs & Various brands & Selected technologies \\
\hline 1996-present & $\mathrm{CH}$ & $\begin{array}{l}\text { Bidding, Trading, } \\
\text { Green tariffs }\end{array}$ & "Solarstrombörse" & PV \\
\hline 1998-present & $\mathrm{DE}$ & $\begin{array}{l}\text { Labelled "Green } \\
\text { Electricity" }\end{array}$ & $\begin{array}{l}\text { TÜV, Grüner Strom-label } \\
\text { e.V., Öko-Institut }\end{array}$ & $\begin{array}{l}\text { PV, Wind, Biomass, Small } \\
\text { hydro }\end{array}$ \\
\hline 1999-present & $\mathrm{DE}$ & Soft loans & $\begin{array}{l}\text { "100,000 Dächer- } \\
\text { Programm" }\end{array}$ & PV \\
\hline $1999-2000$ & NL & $\begin{array}{l}\text { Voluntary trade of } \\
\text { Green certificates }\end{array}$ & & $\begin{array}{l}\text { All technologies (excpt mu- } \\
\text { nicipal solid waste) }\end{array}$ \\
\hline 2000-present & $\mathrm{DE}$ & Regulated Rates & "'Einspeisetarif 2" & Selected technologies \\
\hline
\end{tabular}


With the spread of the idea of liberalization an increasing number of voluntary strategies emerged. Firstly, in markets with no full liberalization various types of so-called green tariff programmes launched by the incumbent utilities became popular. Within these programmes, traditional supply companies and utilities offer RES-E for tariffs at an enhanced price or charge a premium to cover higher generation costs. By giving customers the opportunity to choose the "brand" of electricity according to their willingness to pay, no public funds are necessary to increase the use of renewables. Secondly, after the full liberalization in some countries, in addition, or as an alternative Green utilities or Green electricity suppliers emerged.

Table 1 provides an overview of the historically most important programmes and dissemination strategies for RES-E within Europe.

The core focus of this paper is to extract the criteria for the effectiveness of the most important regulatory and voluntary promotion strategies for RES-E. These investigations are based mainly on the results of the project ELGREEN funded by the EC see e.g. Huber et al (2001).

\section{The Basic Principle of Static Cost Curves for Assessing Promotion Strategies for Res-E}

The analyses in the model ElGreen as well as in this paper are based on so-called static cost curves. A static cost curve provides for a point-of-time a relationship between (categories of) technical potentials (of e.g. wind energy, hydro, biogas..) and the corresponding (full) costs of utilisation of this potential at this point-of-time (Note, no learning effects are included in static cost curves!).

It is important to differ between (theoretically existing) continuous cost curves, see Fig. $2 \mathrm{a}$ and (in real life used ) stepped (discrete) cost curves, see Fig. 2b.

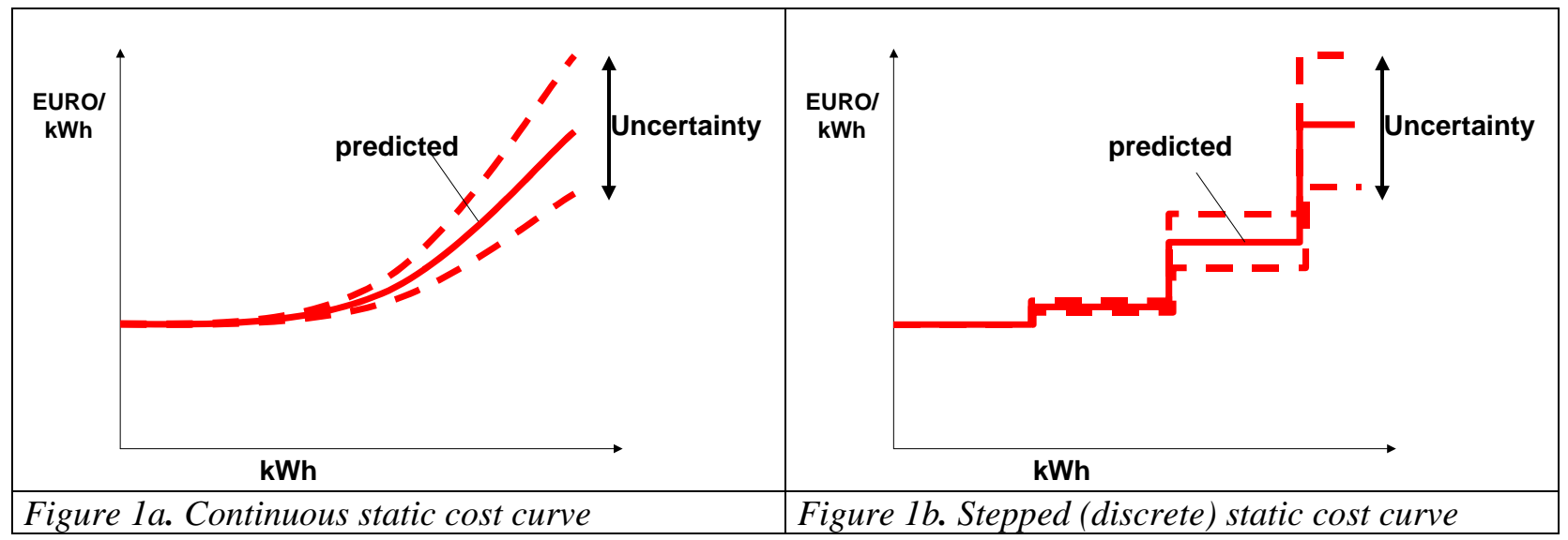

Figure 1a depicts the theoretically ideal continous static cost curve taking into account that every location is slightly different from each other and, hence, looking at all locations e.g. for wind energy in a certain geographic area a continous curve emerges after these potentials have been classified and sorted in a least cost way. Fig. $1 \mathrm{~b}$ takes into account that in real life this accuracy is impossible. Different sites are put into certain categories and then a stepped curve emerges.

Moreover, as Fig. 1 depicts these cost curves are associated with uncertainties. These uncertainties are the higher the more right we move in the diagram. 


\section{Fundamental Requirements to Successful De- ployment Strategies}

In recent years a wide variety of dissemination strategies have been implemented in various OECD countries. In the following the major objectives of and the requirements to dissemination strategies are described.

The major objective of/requirement to a deployment strategy for RES-E is of course to increase the capacity installed and the amount of electricity generated from RES-E to enjoy the corresponding environmental benefits.

This leads straightforward to the following core requirements to a strategy:

- effectiveness with respect to deploying a substantial amount of RES-E capacities;

- economic efficiency: the deployed capacities should be provided at prices which correspond to prices in a competitive market;

- Minimise costs for the public and

- enhance social acceptance.

Derived from these fundamental aspects related targets of strategies are:

- to increase public awareness with respect to renewable energy;

- to reduce costs per $\mathrm{kWh}$ generated;

- to improve technical reliability, technical performance and standardization;

- to remove obstacles with respect to grid-connection;

- to strive for low administration costs, low transaction costs and to minimise public financial support to reach a certain amount of RES-E capacity installed;

- to exhaust customers WTP;

- to ensure sustainable growth of the RES-E industry.

\section{Survey on Regulatory and Voluntary De- ployment Strategies}

Next, a survey on which types of promotion exist in principle and how these strategies can be classified systematically is provided. Table 2 provides an overview. Of course, a specific programme put into practice may consist of a mix of different strategies. In this context the following questions are of interest:

- Who launches a strategy? Governments? NGO's? Commercial companies, e.g. "Green" utilities?

- Is it a voluntary strategy or based on regulation?

- Are financial incentives provided or not?

- Is the investment influenced, e.g. subsidized or the $\mathrm{kWh}$ generated by a RES-E system?

- Who is addressed by the strategy? RES-E generators? Green electricity customers? Or a specific target group? E.g. architects, teachers, schools, building construction companies?

\subsection{Regulatory capacity-driven strategies}

In this case the strategy is based on a government decision on the desired level of generation or market penetration of electricity from different RES. The price is in principle set through competition between generators. 
Non-tradable quotas

Tendering/bidding, quotas, Renewable Portfolio Standards

Tradable quotas

Electricity or $\mathrm{CO}_{2}$ based certificates

Table 2. Categories of strategies: Voluntary vs regulatory, capacity targets vs financial incentives, investment focused vs generation-based.

\begin{tabular}{|c|c|c|c|}
\hline & & Regulatory & Voluntary \\
\hline \multirow{2}{*}{$\begin{array}{l}\text { Capacity-driven } \\
\text { strategies }\end{array}$} & Generation-based & \begin{tabular}{|ll} 
- & RPS \\
- & Quota-based TGCs \\
\end{tabular} & $\begin{array}{l}\text { - National generation tar- } \\
\text { gets }\end{array}$ \\
\hline & Investment focused & - $\quad$ Bidding/Tendering & $\begin{array}{l}\text { National installment or } \\
\text { capacity targets }\end{array}$ \\
\hline \multirow[b]{2}{*}{$\begin{array}{l}\text { Price-driven } \\
\text { strategies }\end{array}$} & Generation-based & $\begin{array}{ll}\text { - } & \text { feed-in tariffs, } \\
\text { - } & \text { rate-based incentives } \\
& \text { Net metering }\end{array}$ & $\begin{array}{ll}\text { - } & \text { Green Power Marketing } \\
\text { - } & \text { Green tariffs } \\
\text { - } & \text { Solar stock exchange } \\
\end{array}$ \\
\hline & Investment focused & $\begin{array}{ll}- & \text { Rebates } \\
\text { - } & \text { Soft loans } \\
\text { - } & \text { Tax incentives } \\
\end{array}$ & $\begin{array}{ll}\text { - } & \text { Contracting } \\
\text { - } & \text { Shareholder progr. } \\
\text { - } & \text { Contribution } \\
\text { - } & \text { Bidding } \\
\end{array}$ \\
\hline \multicolumn{2}{|l|}{ Other } & - & $\begin{array}{ll}\text { - } & \text { NGO-marketing } \\
\text { - } & \text { Selling green buildings } \\
\text { - } & \text { Retailer progr. } \\
\text { - } & \text { Financing } \\
\text { - } & \text { Public building prog. } \\
\end{array}$ \\
\hline
\end{tabular}

\subsection{Regulatory Price-driven strategies}

Generators of electricity from RES receive financial support in terms of a subsidy per kWp capacity installed or a payment per $\mathrm{kWh}$ produced and sold.

Investment focused:

Rebates, income tax incentives, soft loans

Generation based:

This type of strategy is typically based on regulated rates. Examples are:_Net metering, enhanced feedin tariffs, rate-based incentives (= "Kostendeckende Vergütung" for PV in Germany, Austria and Switzerland); Environmental pricing.

\subsection{Voluntary capacity-driven strategies:}

In this case the strategy is based on a government decision on the desired level of generation or market penetration of electricity from different RES. Non-mandatory national targets with respect generation or capacity_or number of systems installed (e.g. the Swiss ENERGIE 2000 initiative or the American President's Million Solar Roofs Initiative) are typical for this category of strategies.

\subsection{Voluntary price-driven strategies:}

This type of strategy is mainly based on the WTP (Willingness to pay) of different categories of customers. The strategy is usually launched by an electric utility. The financial incentive is provided by the electricity user with a corresponding WTP. This type of strategy can be split into two categories: 


\section{Investment focused:}

shareholder programmes, contribution programmes, voluntary bidding/tendering.

\section{Generation based}

Green tariffs, w/ or w/o labelling, "Solarstrombörse", Green power marketing by Green utilities in liberalised electricity markets

\subsection{Other strategies}

Other programmes encompass marketing programmes by NGO's or by commercial companies (e.g. selling Green buildings), retailer programmes (e.g. franchising, guaranteed yield), programmes for public buildings (schools, townhalls, churches), and voluntary financing programmes by private companies (general information campaigns and education programmes, programmes for specific target groups e.g. architects?)

\section{Success Criteria for Regulatory Strategies}

In this section it is explained

- how different types of regulatory strategies work in principle and

- how and under which conditions they meet the above stated requirements.

Furthermore, with respect to the optimal design and choice of the optimal type of instrument under specific conditions the most important issues are described in this chapter.

\subsection{Feed-in tariffs}

A promotion strategy, which has attracted attention since the late 1980s especially in Denmark, Germany, Italy and, in the 1990s, in Spain are feed-in tariffs (FITs). A FIT is the guaranteed price per unit of electricity that a utility has to pay to a private RES-E generator, if his form of generation meets certain criteria. Thus, a federal (or provincial) government regulates the tariff rate. The output due to FITs is uncertain due to the uncertainties in the cost curve, see Fig. 3. The FIT attracts new capacity, as long as the unit price is sufficiently high (see e.g. the substantial growth of wind power in Denmark, Germany and Spain in recent years in Fig. 4). Currently the highest FITs in Europe are in force in Italy, Germany and Spain, see Haas (2001). 


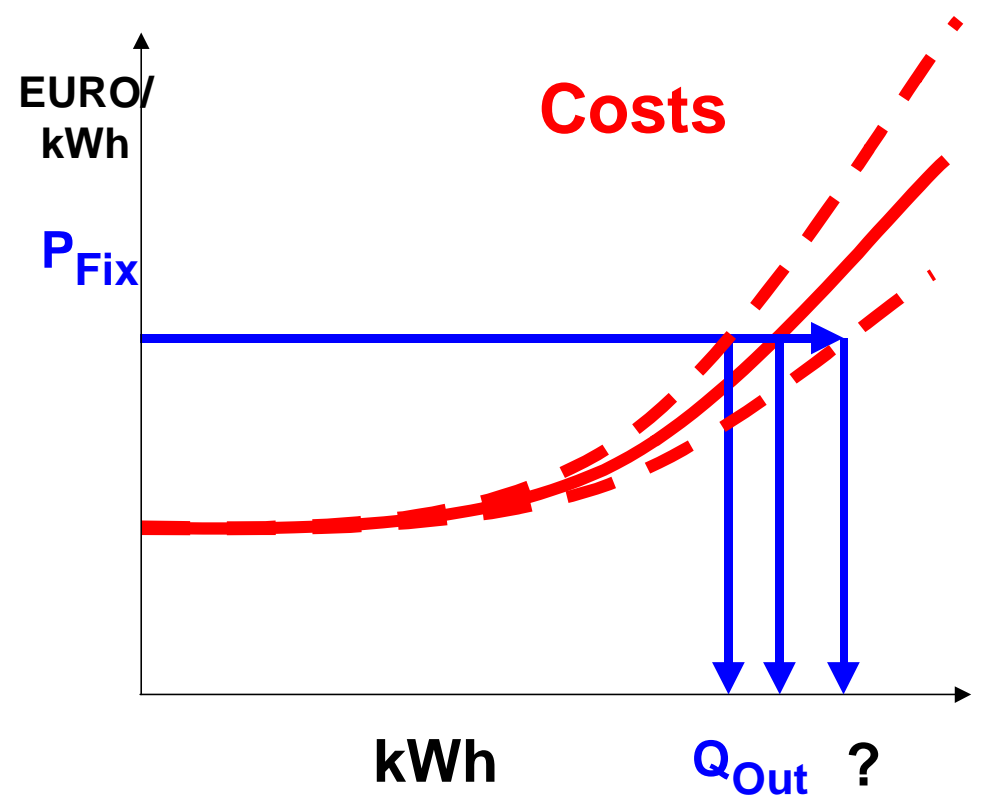

Figure 3. How a FIT works

The major advantages of FITs are:

- They have been effective so far in the sense that they trigger substantial installations of new RES-

E plants in all countries where they have been introduced properly;

- They ensure technically efficient operation of the plant;

- They provide an assured aspect of business plans for new investment;

- They allow small co-operative groups and companies to participate;

- FITs are flexible, fast and easy to establish (and to revise or to abandon if there are difficulties);

- Stepped FIT as currently implemented in Germany turned out to be effective from the dissemination point-of-view as well as efficient from the economic point-of-view.

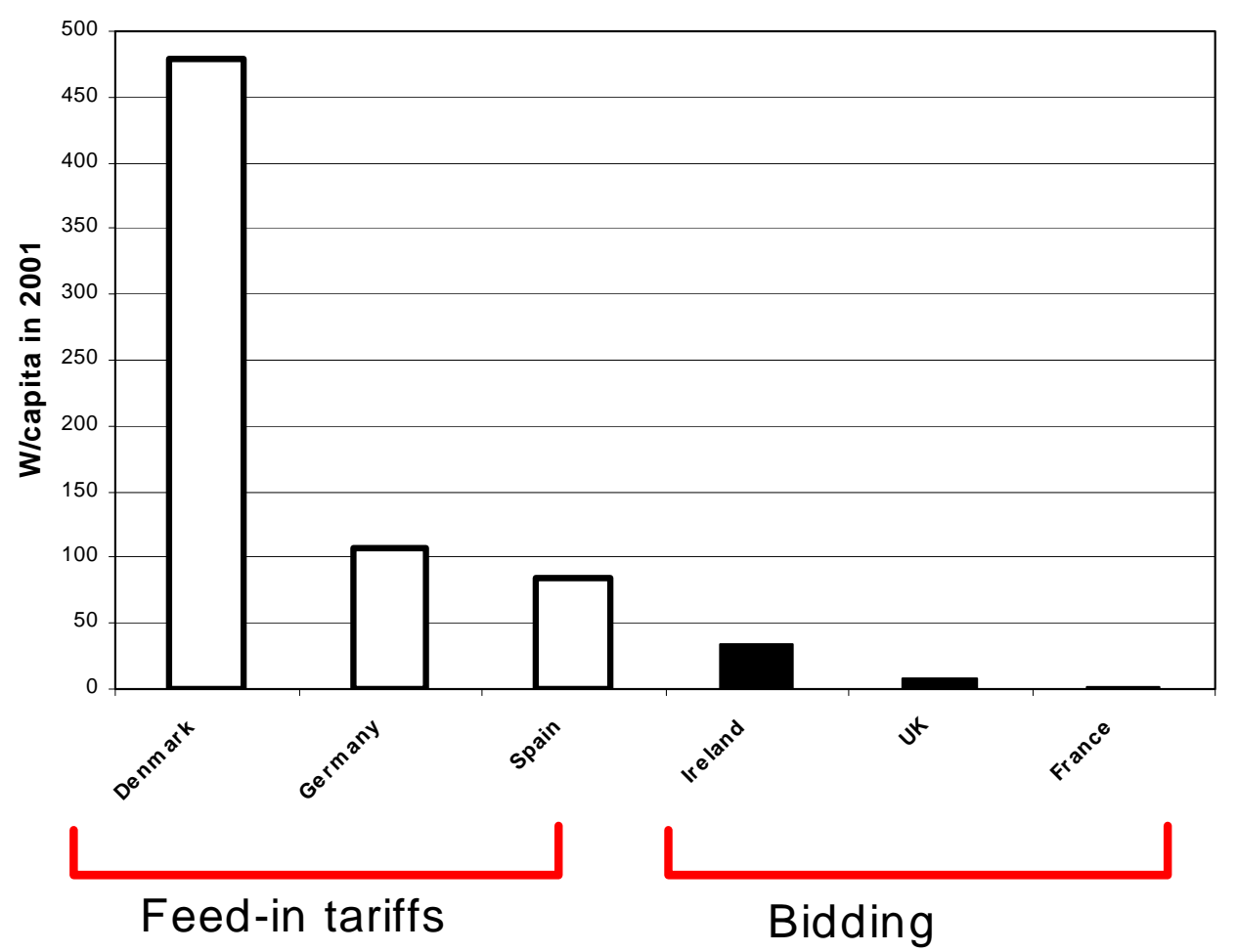

Figure 4. The success of feed-in tariffs and bidding strategies for promoting Wind energy 
The major points of criticism with respect to feed-in tariffs are:

- They provide subsidies;

- They do not encourage competition between generators and do not force reductions in unit electricity price. However competition may not be, in itself, a policy objective. The policy objective might rather relate to the dissemination and enlargement of RES-E in a beneficial and acceptable manner.

An important result of our analysis is that feed-in tariffs are especially an economically effective dissemination instrument, if:

- the feed-in tariff rates decrease over time, as experience is gained and in line with the expected learning curve giving investment cost reductions. This means that feed-in tariffs for new facilities and, hence, new contracts, should be adopted every year according to the technological progress.;

- The time a producer receives a guaranteed feed-in tariff is limited to a predefined period of e.g. 10 years;

- a stepped feed-in tariff is used, so the guaranteed feed-in tariff rate is decreased as installed capacity increases. The decline in the guaranteed price, however, must be less than the total revenue that can be gained if an efficient plant and location are chosen, otherwise investors have no incentive to implement the most efficient technologies and locations. This means that profits must be higher at cost efficient locations compared to less efficient ones. ${ }^{1}$ The principle of this scheme is depicted in the lower part of Fig. 5.

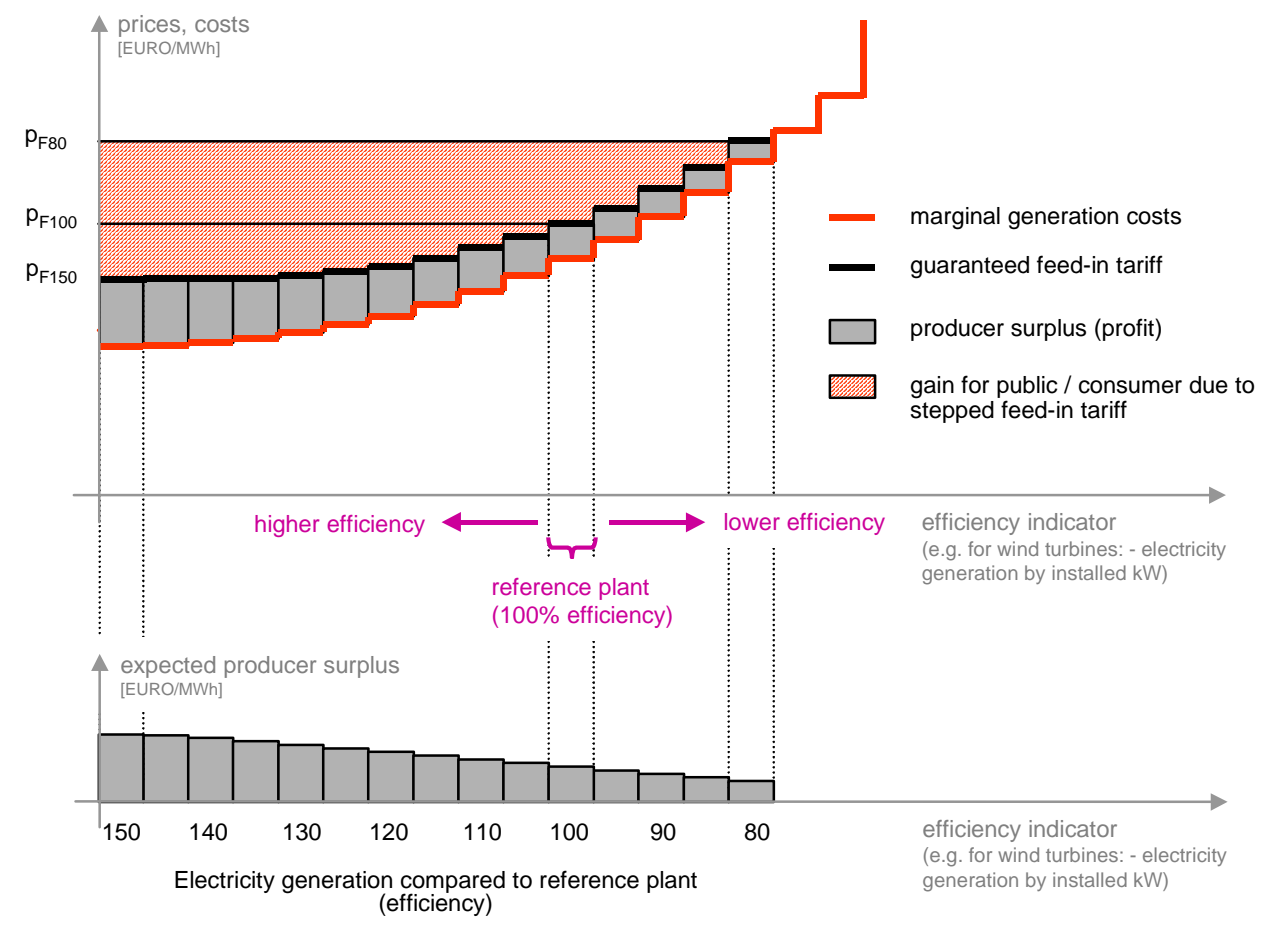

Figure 5. Optimal incentive-compatible design of a stepped feed-in tariff

Note: lower part of figure - producer surplus according to standardised baseline; upper part transfer of the incentive-compatible contract to the feed-in tariff scheme.

\footnotetext{
${ }^{1}$ E.g. wind energy: $20 \%$ expected profit for locations with 2400 full-load hours and $14 \%$ for locations with 1800 expected full-load hours. In the new German feed-in tariff scheme ('Erneuerbare Energien-Gesetz') the incentive compatibility constraint is fulfilled for the case of wind energy.
} 


\subsection{Tradable Green Certificate (TGC)-based quotas}

TGC-based quotas work as follows (see Fig. 6): A quota (= certain percentage of electricity to be guaranteed from renewable energy sources) is set by a government. The generators (producers), wholesalers, retailer or consumers (depending who is obligated in the electricity supply chain) are obligated to supply / consume a certain percentage of electricity from renewable energy sources. At the date of settlement, they have to submit the required number of certificates to demonstrate compliance. Those obligated obtain certificates in three ways:

- they can own their own renewable energy generation, and each defined amount of energy (e.g. $10,000 \mathrm{kWh}$ in the Dutch system) produced by these facilities would represent one certificate;

- they can purchase electricity and associated certificates from another renewable energy generator.

- they can purchase certificates without purchasing the actual power from a generator or broker, i.e. purchasing certificates that have been traded independently of the power itself.

Due to competition on the supply side, this system of tradable certificates leads, under the assumption of perfect market conditions (perfect price signal), to minimal generation costs from renewable energy sources. Of course, this happens only if there is a surplus of renewables generation above the demand for certificates. Regarding TGC it has to be stated that so far to less experience is available to provide an in-depth evaluation.

The major arguments in favour of TGC are:

- High economic efficiency;

- A market for best-practice in the environment is created;

- No market distortion due to fixed subsidies;

- The market determines the magnitude of the subsidy.

- Possible setbacks are:

- Uncertainty about actual investment;

- Unpredictable (volatile) revenues

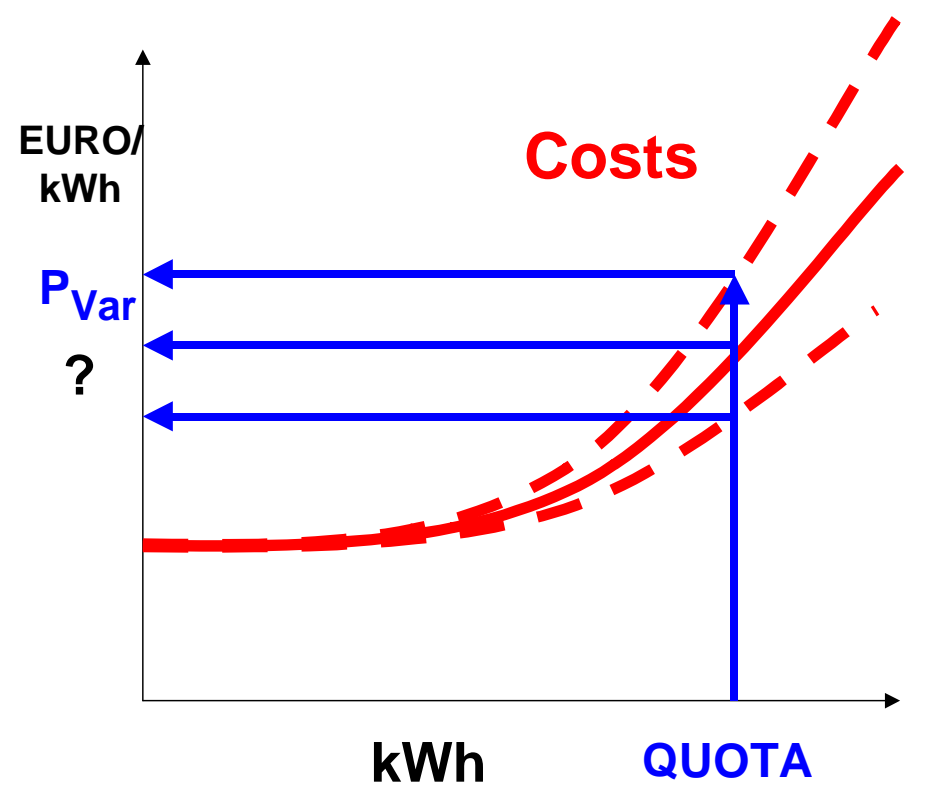

Figure 6. Regulatory capacity driven strategies: fixed quota for RES-E and high penalty

The most important conclusions with respect to the correct design of quota-based TGCs for promoting RES-E derived from the project ELGREEN are:

- High penalty for not purchasing a certificate: It has to be guaranteed more or less by fundamental/reasonable-law that the penalty for not purchasing a certificate is significantly higher than the 
expected market price for TGCs. Otherwise there is no incentive to fulfil the quota! This means that if different countries participate the lowest penalty must exceed the expected marginal generation costs (minus market price for electricity) within the system. This fact is depicted in Figure 7. The case on the left-hand-side is characterised by no 'wrong' penalties. The penalties for all countries $\mathrm{A}, \mathrm{B}$, and $\mathrm{C}$ are higher than the additional marginal costs and hence the market price for TGCs. Under this assumptions the quota for all countries A, B, and C will be reached. The impact of a 'wrong' penalty setting is depicted on the right-hand-side of Figure 7. As the penalty in country $\mathrm{C}$ is lower than the additional marginal costs for providing TGCs, total demand will be less than obligated. In this case only country A and B have an incentive to reach their quota. For actors in country $\mathrm{C}$ it is rational to pay the penalty $\mathrm{C}$ rather than fulfil the quota at the given market price $\mathrm{p}_{\mathrm{TGC}}$. In this case the quota $\mathrm{Q}_{\mathrm{A}+\mathrm{B}+\mathrm{C}}$ will not be reached.
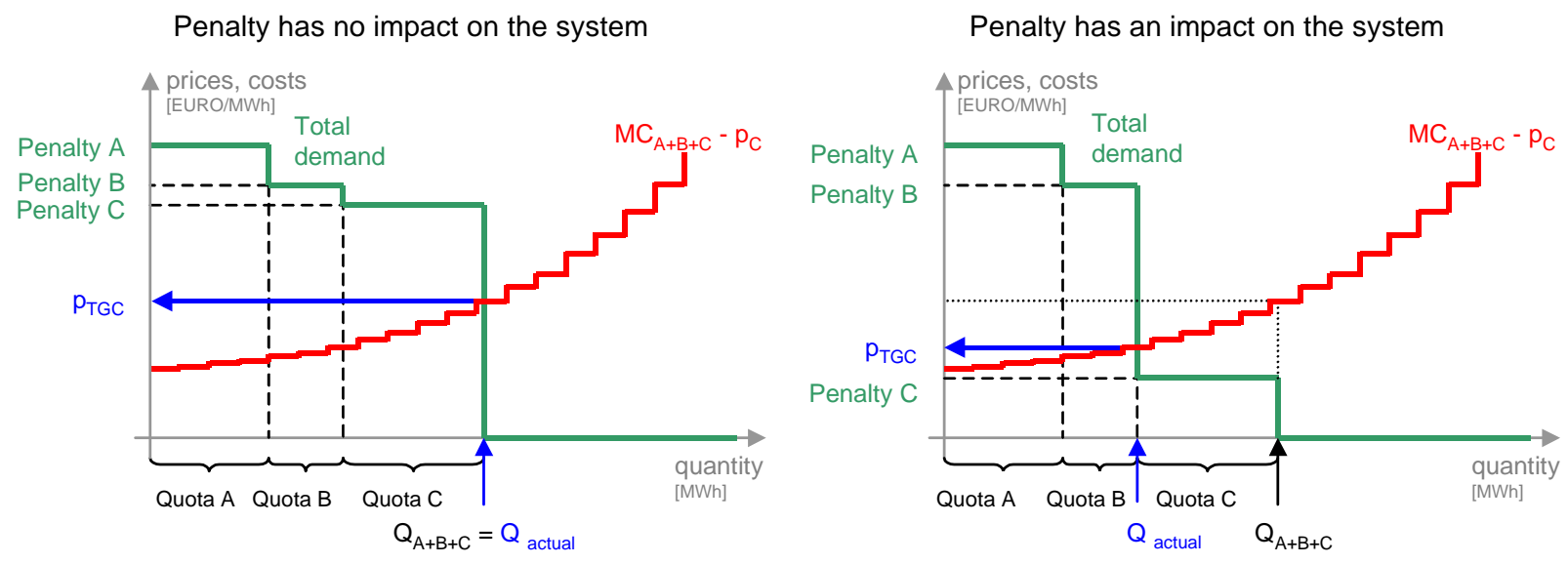

Figure 7. Influence of the penalty on the electricity generation: sufficiently high penalty (left) and to low penalty (right)

- Another important issues is a long-term planning horizon with planning certainty. It has to be guaranteed by highly credible authorities that a TGC system will exist for a specified and sufficient planning horizon. Otherwise the uncertainty for potential investors is to high and it is likely that no investments at all take place (see current situation in Denmark).

- A quota-based TGC system has to focus mainly on new RES-E capacity. If a large share of the required capacity to meet a quota already exists, TGCs lead to windfall profits for the owners of existing plants, see Fig. 8. Hence, it is counter-productive to include old depreciated facilities into a trading system especially if the marginal cost of new capacity is high; If existing capacity is low, it is less relevant to exclude existing plants from a (national) Quota / TGC system; 


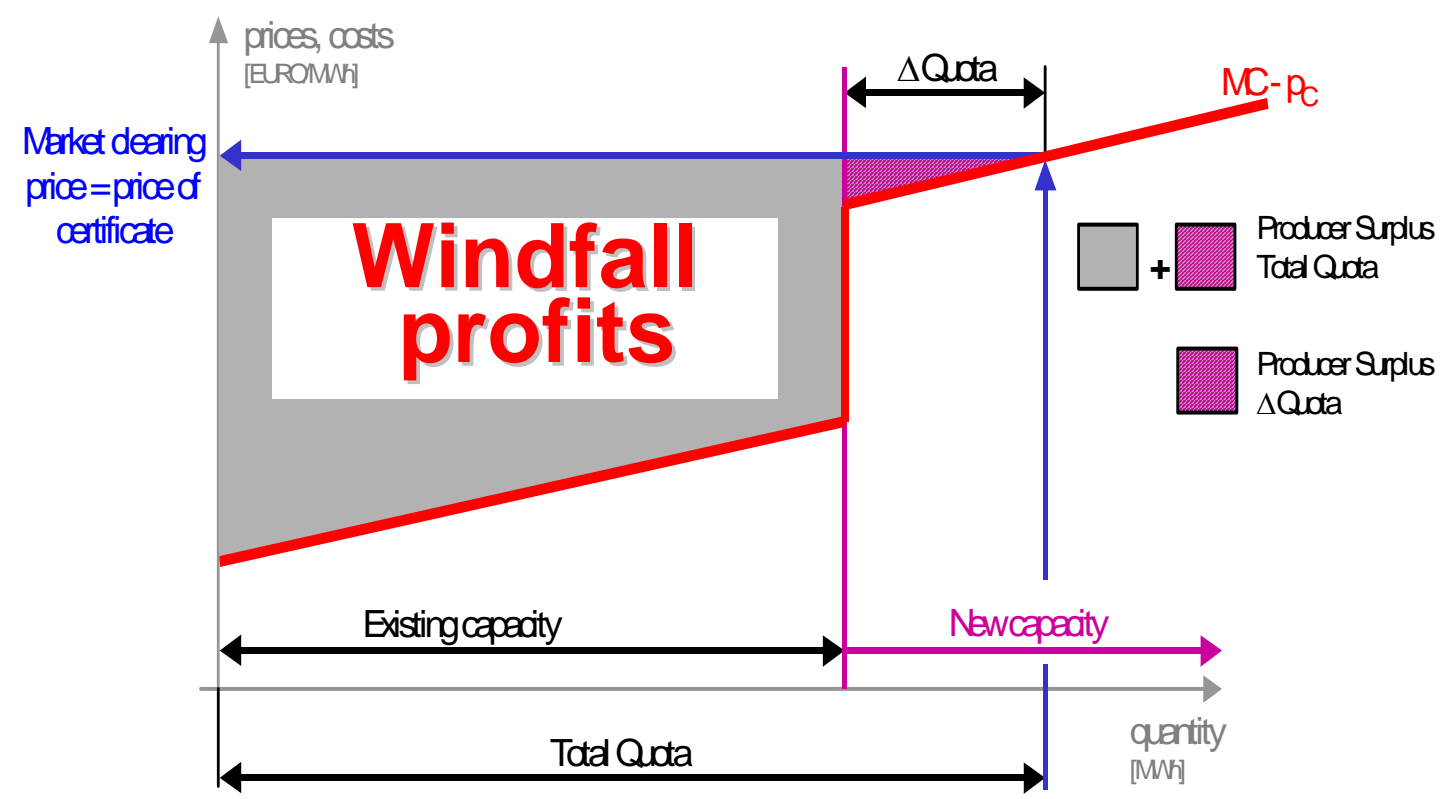

Figure 8. Comparison of producer surplus if existing capacity is included or not (-> "Windfall profits!")

- Hence, from the public's point-of-view, TGCs qualifying for a quota should only be issued over a pre-defined period of time. More precisely, no existing or at least no fully depreciated plant should be included in a quota system, otherwise substantial windfall profits occur. A rolling redemption may provide a proper solution;

- If TGC's are traded on a small short term spot market this system will not work in the sense that new capacities are constructed: Short term competition works only for existing capacities! Hence, quotas based on TGC's work, if the owners are allowed to sign long-term contracts!

Finally, it has to be stated that with respect to a TGC-based quota for RES-E the situation is ambiguous. Despite experiences from other fields being promising, e.g. pollution abatement, as yet there has been no successful example in electricity supply.

\subsection{Bidding/Tendering}

Tendering systems used to promote RES have been used in France (for wind energy only), Ireland and the UK. The most well known of these promotion strategies is the NFFO in England and Wales. Similar schemes have been set up for Scotland (Scottish Renewables Order - SRO) and Northern Ireland (NI-NFFO). The UK strategy has recently been changed and renamed so as to increase the amount of renewables capacity.

The most important conclusions from bidding systems so far are:

- A long administrative process which discourages many investors and the industry;

- If the conditions for the evaluation of projects are to restrictive only very few systems will be achieved;

- The transaction costs are very high for both, administrators and potential investors;

- Another important perception of past bidding systems is a low acceptance because of concentration on few excellent sites!

- Furthermore, in England and France bidding systems did not provide a sound base for an emerging industry while in Germany and Denmark a competitive wind industry emerged due to FITS

- A solution can be that a flour price is introduced, guaranteeing that all bidders who accept this flour price will get immediate approval for construction. 


\subsection{Rebate programs}

Reabtes work in principle similar to FIT with one exemption: they do not necessarily encourage operators to generate as much as possible electricity in their plant. Rebates are in general an effective tool to enhance the market penetration of a RES-E technology in a nascent market. Moreover, rebates are an important instrument to ensure a maximum of own use of decentralised electricity. Some lessons learned from rebate programmes so far are

- Different subsidy strategies led to different effects of cost reduction. In the German 1000 roofs programme (1991-1995) subsidies were a constant share of the investment costs (about 70\%). This led to almost no cost reduction within the duration of the program. After the programme was terminated investment costs dropped. The most advanced strategy so far was pursued in Japan. Over the period 1994 till 2000 the rebates (in 1994 about 50\% of the overall investment costs) are cut every year by about $10-15 \%$. This type of dynamic strategy led to considerable cost reductions in the first years and to some stagnation in the last years;

- The rebates in virtually all programmes where too high. This can be seen from the fact that in all of these (limited) programs there were far more applications than approvals. This was true in the German, the Austrian and the Japanese programme.

- That is to say, the ignorance of consumers' W T P led to a smaller total capacity installed than what would have been possible to be achieved with the same amount of money. A recent example is the Australian NGO programme for PV that has been revised substantially because otherwise the budget foreseen would have been exhausted too fast;

- Rebates as percentage of total cost are the wrong incentives because they do not provide a sufficient incentive for the customer to look for the cheapest or most efficient system; E.g. if the rebate share is $50 \%$ or higher deals between customer and the PV retailer may take place so that the objective is to maximise the amount of the rebate and not to look for the best system.

- Rebates have to decline continuously over time. Otherwise the suppliers (retailers) would not reduce the system costs to the same extent but rather earn an extra profit;

\section{Success Criteria for Voluntary Green Power Marketing (GPM) Strategies}

In the following it is described how "pure" voluntary GPM strategies work and what are the conditions to make them successful in the sense that they meet the four generally important requirements defined in Section 4. Voluntary strategies are based on a high consumers' willingness to pay for "green electricity". The amount of green electricity provided results from the intersection of the WTP curve with the supply curve, see Fig. 9. 


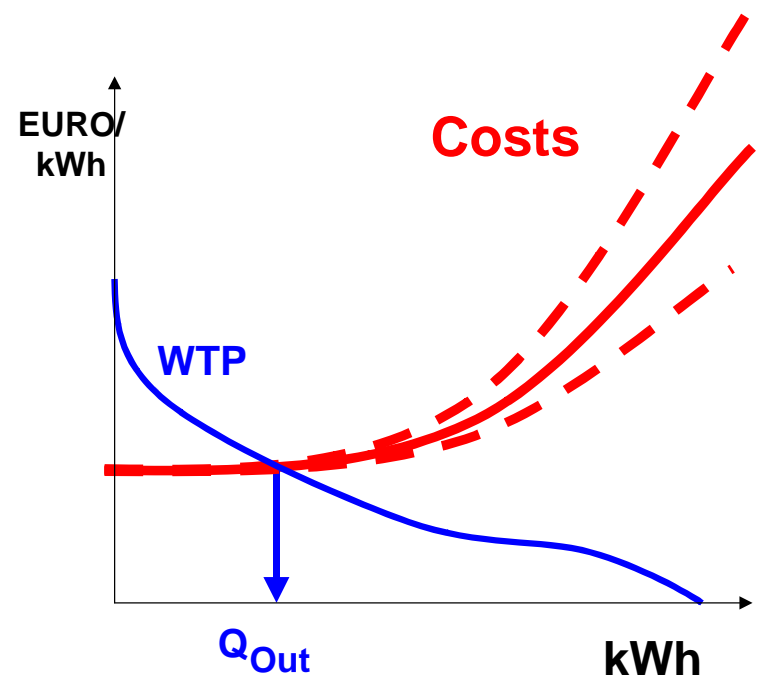

Figure 9. Voluntary approach: focus on customers WTP

Hence, effective GPM programmes have to exhaust electricity consumers' willingness to pay for "green electricity" as far as possible. To meeting this objective it is important to investigate what things customers worry about and what are potential RES-E customers willing to pay for.

These issues have been investigated in various WTP studies. The most important studies with respect to the WTP for RES-E have been conducted by Farhar B. and Roper A. (USA) (1998), Farhar B. and Houston (1996), INFAS (1997), Haas et al (1998), Fouquet (1999), ISMA in Austria (2000) and Datamonitor, see Petrovic (2000). Of special interest is the work by Farhar because she summarises various utility studies in the U.S.

Surprisingly (or: Fortunately) the results of these different studies are very similar. All studies come to the conclusion that the vast majority of the population in different countries - between 55 and $75 \%$ - state that they would in principle be ready to pay a higher price for electricity if it would be generated by environmentally benign sources. In detail upt to $10 \%$ of residential customers are very willing to pay a higher price (20\% premium and more). The majority of 40 to $50 \%$ are fairly willing to pay a higher price ( 10 to $15 \%$ premium) and only 10 to $25 \%$ are not at all willing to pay a higher price, see Fig. 9. Of course, the results of these studies refer to customers reported WTP. Given that there is a difference between stated and demonstrated WTP the actual demand for Green electricity might be substantially lower.

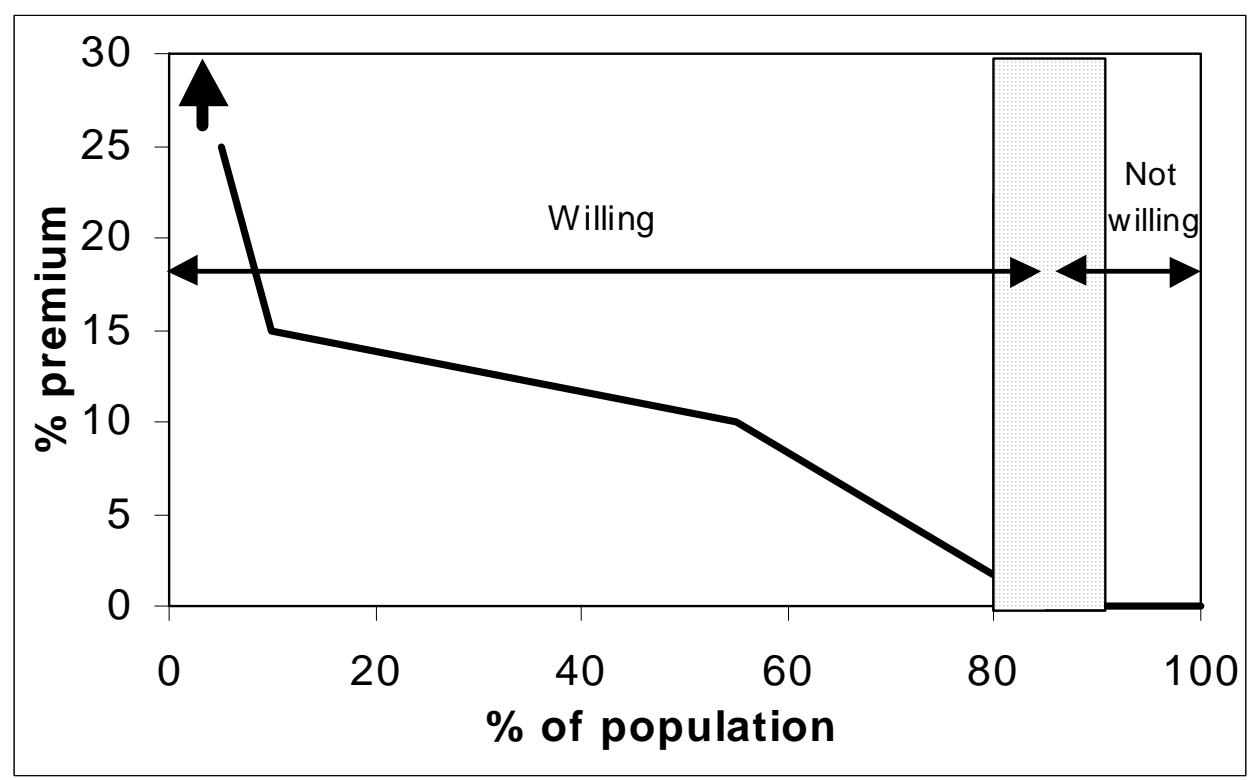

Figure 9. Willingness-to-pay for Green electricity due to different surveys 
There are (at least) four fundamentally different approaches of marketing Green Power, which depend very strongly on the degree of the liberalisation of an electricity market:

1. Green tariff by incumbent utilities

2. Solar stock exchanges by incumbent utilities

3. Voluntary capacity-based programmes by incumbent utilities

4. Green Power Marketing by Green utilities

Green Power Marketing by Green Utilities is a new strategy in a liberalised market. That is to say, under Green Power Marketing a private or commercial or industrial customer may change their supplier and switch to a company which provides a certain brand of Green electricity. In different mixes a certain amount of $\mathrm{PV}$ is required.

\subsection{The role of labels}

One of the main problems with respect to a voluntary system concerns the confidence of the consumer. If the market for green electricity tariffs is to increase, consumers must have confidence that their demand results in additional installed RES-E capacity. Therefore several third-party organisations have established quality labels. Currently about 16 different labels for green electricity exist in Europe, each with its own set of criteria. Table A-1 in the Annex 1 provides details of some of the labels being promoted in Europe. There is, unfortunately, little consensus between labelling bodies on what constitutes a genuinely 'green' electricity tariff. ${ }^{2}$

Harmonisation among different label systems is not perhaps strictly necessary, however some basic principles for green electricity labelling will help to overcome these barriers. The most important are:

- An important recommendation for participants in GPM of incumbent utilities as well as for customers of Green Power companies is that they should not accept their supplier to include noncompeting green electricity in a label!

- The absolute minimum requirement for a label is that it guarantees at least that the proportional increase in total electricity demand is provided by new capacities!

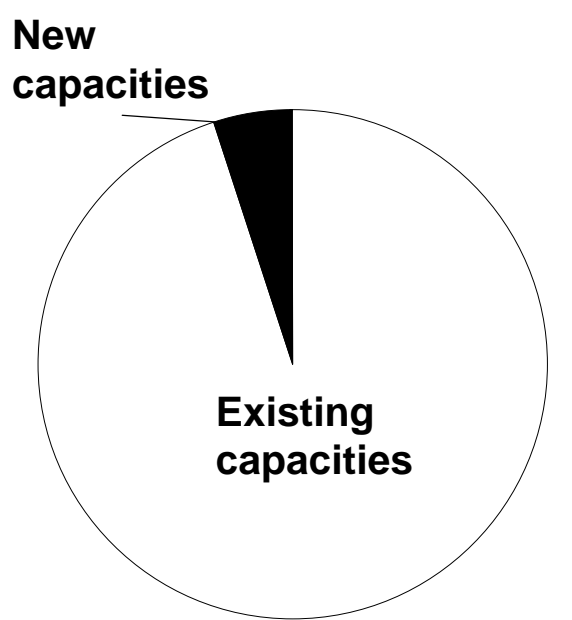

Capacity mix

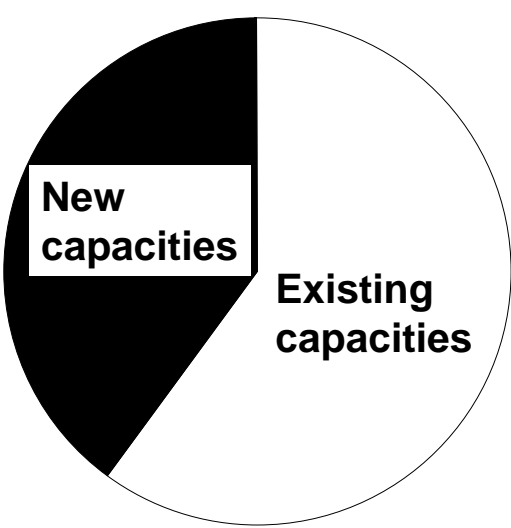

Cost mix

Figure 14. The share of various RES-E sources in a label and the shares of costs

\footnotetext{
2 For more details see Green et. al. (2001).
} 
Of course, the premium for an electricity label which contains new RES-E capacities will be proportional to the share of costs and represent the average costs of existing and new capacities.

Based on these principles it would be advantageous to harmonise the labelling for common recognition across Europe. Such a framework would facilitate market transparency, which should lead to enhanced consumer demand. Moreover, there are increasing proposals for disclosure of information to customers concerning the emissions from all forms of electricity generation. Thus labelling would be a common requirement for all forms of generation. At present, renewable energy generators are presently being burdened with the additional cost of accreditation to prove their benign environmental impact, whereas generators using conventional energy technologies are not so required.

Hence, successful GPM would furthermore be supported by the introduction of a general "Power content label" to distinguish all sources of electricity (see e.g. Green, 2001).

\subsection{Marketing Green electricity: From existing or from new power plants?}

One of the most crucial questions with respect to succesfully deploying RES-E by Green Pricing and/or trading approaches is whether Green electricity from existing vs Green electricity from new to constructed power plants is promoted. This has also been one of the most important issues analysed in the project ELGREEN. In the following it is analysed how the RES-E capacity develops with and without mandatory new installations in a label for Green electricity.

First, it is analysed what happens, if only electricity from existing capacity is traded. As can be seen from Fig. 15 as long as demand does not exceed existing RES-E generation prices remain relatively low and no new capacities are built. Fig. 15 depicts supply of and demand for green electricity at different points of time if the label does not require the inclusion of new capacity. The corresponding development of total electricity demand and supply of and demand for green electricity is depicted in Fig. 16. As can be seen new RES-E capacities are only built at that point of time when consumers WTP exceeds the marginal costs for new RES-E capacities.

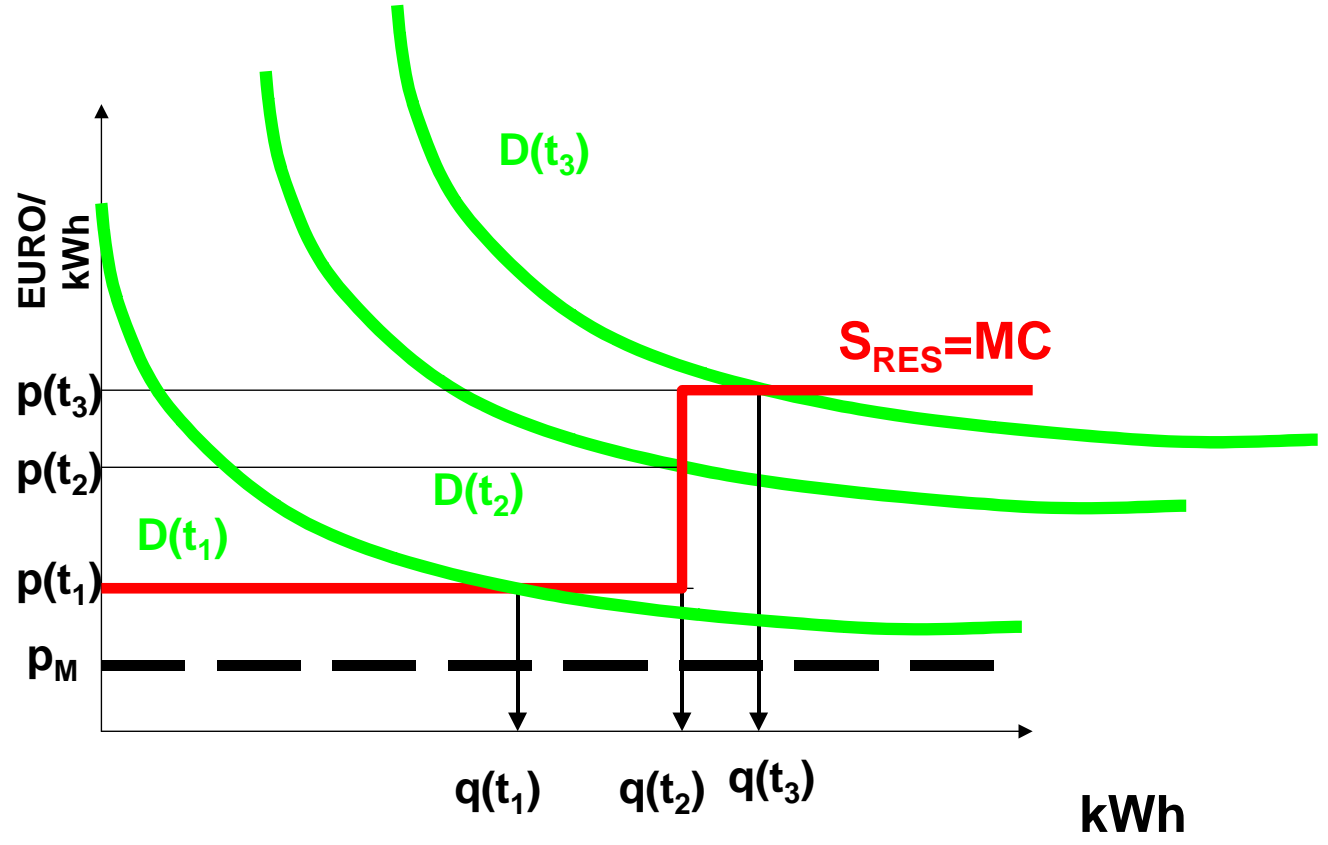

Figure 15. Supply and Demand for green electricity if the label does not require the inclusion of new capacity

Next, it is investigated what happens, if a certain share of electricity from new capacity is mandatory in a label. traded. As can be seen from Fig. 17 initial total demand for Green electricity is lower due to the higher price which results from the average costs of existing and new to built capacities. The corresponding development of total electricity demand and supply of and demand for green electricity is 
depicted in Fig. 18. As can be seen new RES-E capacities are immediately built and increase continuously reducing the need for constructing new plants generating electricity from non-renewable energy carriers.

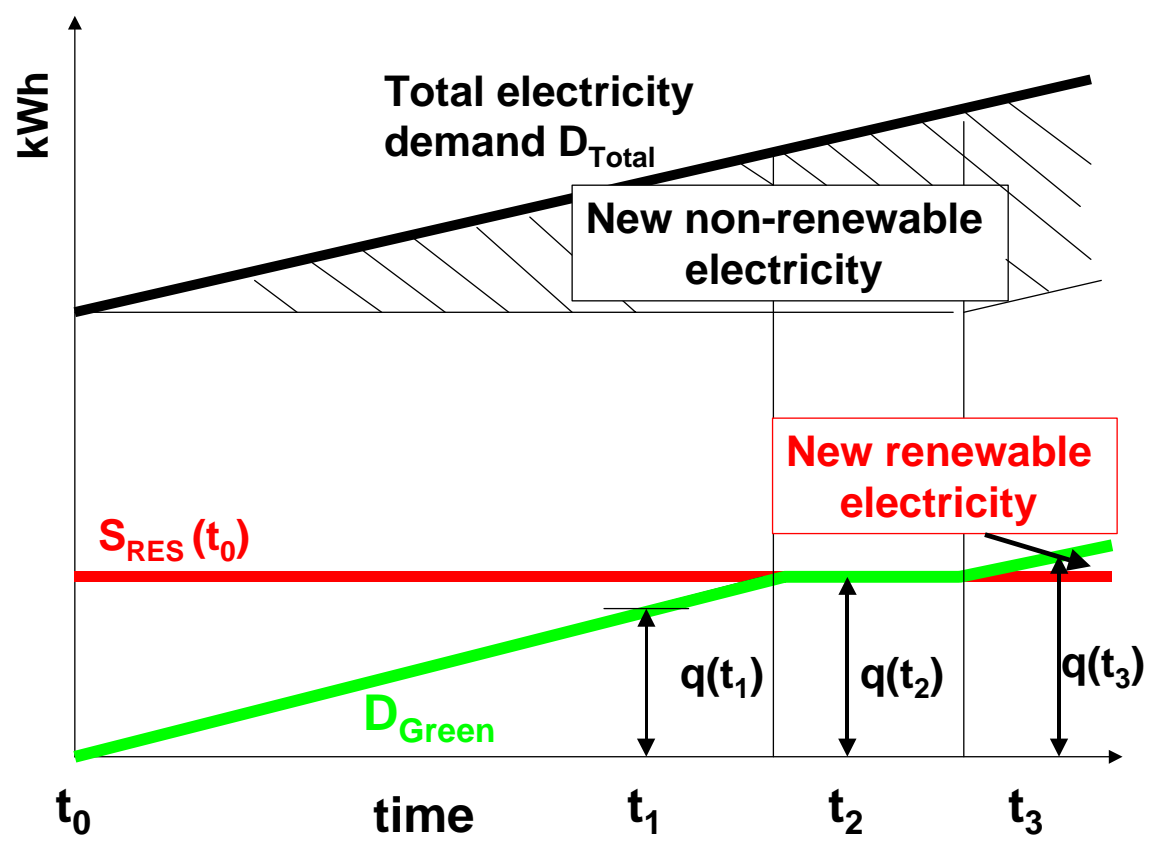

Figure 16. Development of Supply and Demand for green electricity over time if the label does not require the inclusion of new capacity

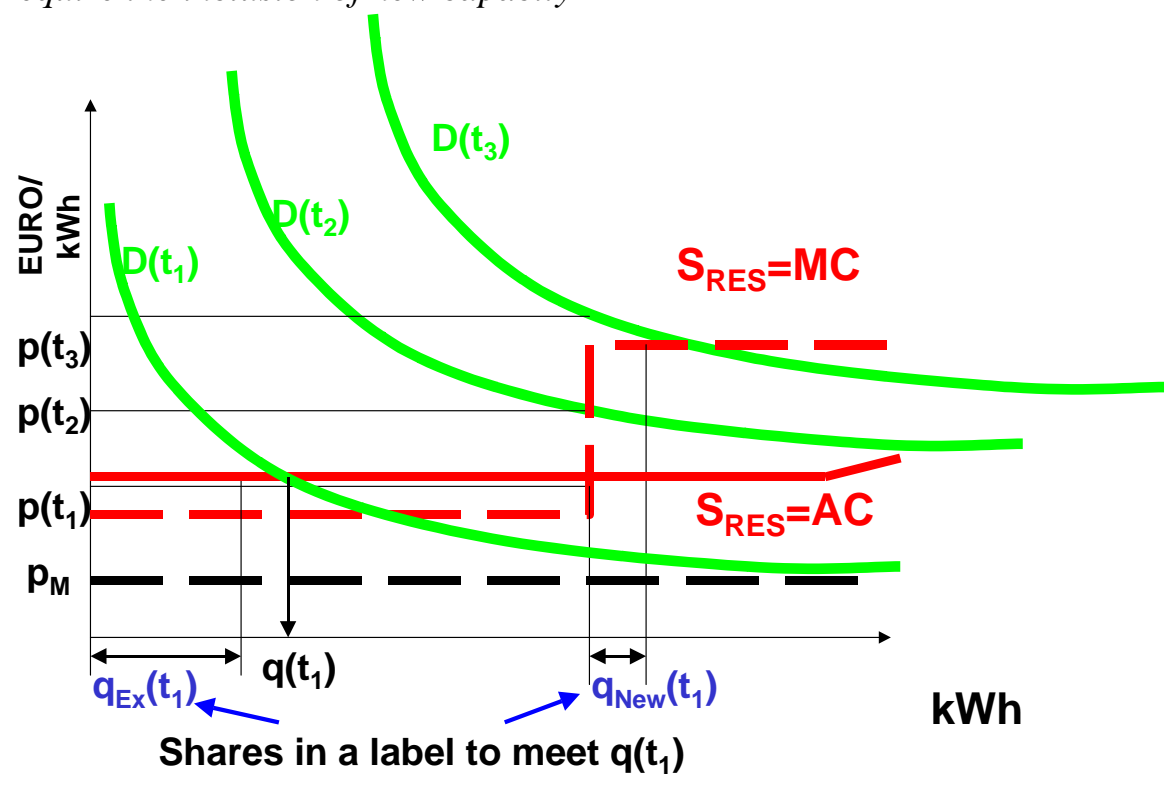

Figure 17. Supply and demand for green electricity if the label requires a certain share of new Green electricity

Fig. 19 depicts the development of the price for green electricity over time with and without a label that requires the inclusion of new capacity. it can be seen that without a RES-New-Label the price is lower as long as no new capacity is built. Then the price increases sharply to meet the marginal costs (MC) of additionally installed RES-E. On contrary, if a RES-New-Label exists prices refelect the average costs of generation of existing and new capacity. They remain constant as long as the demand 
for existing capacity is not exceeded by the label shares. Then the prices increase continously because the share of new capacities in the label must of cours increase.

Fig. 20 compares the development of supply and demand for green electricity over time with and without a label that requires the inclusion of new capacity. It can be seen that without a RES-NewLabel demand is first higher. Yet, from the point-of-time on when all existing RES-E electricity is demanded on the market the demand is higher if the label exists.

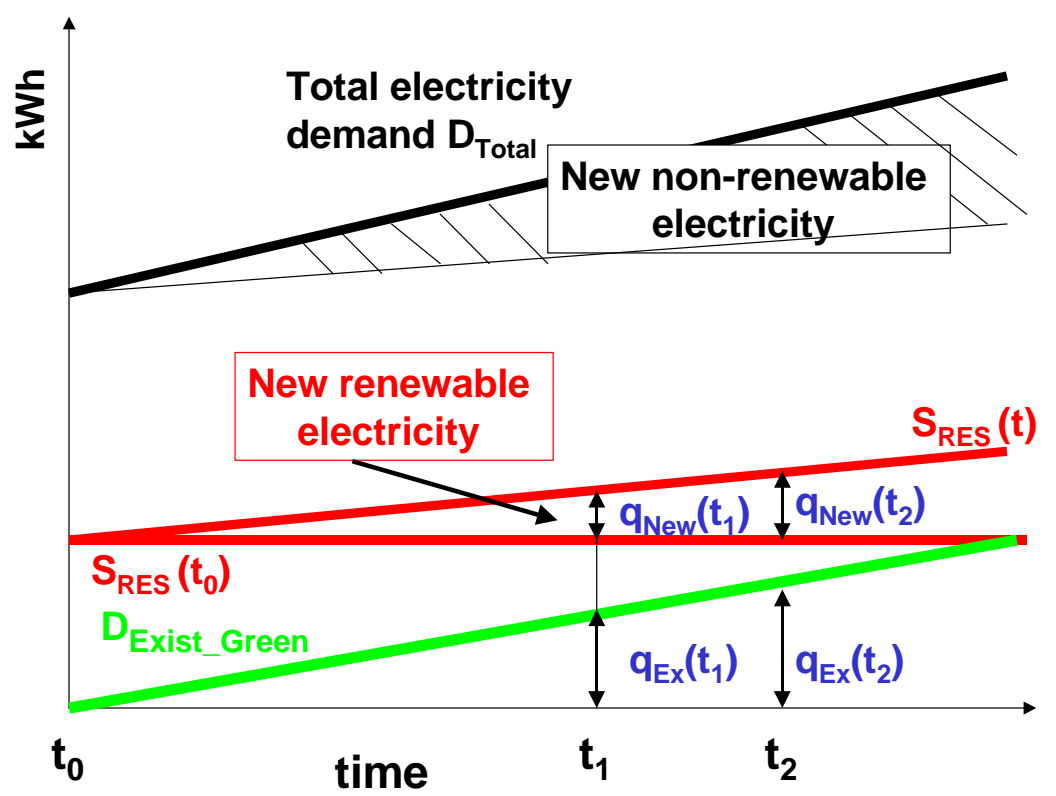

Figure 18. Development of supply and demand for green electricity over time if the label requires a certain share of new Green electricity

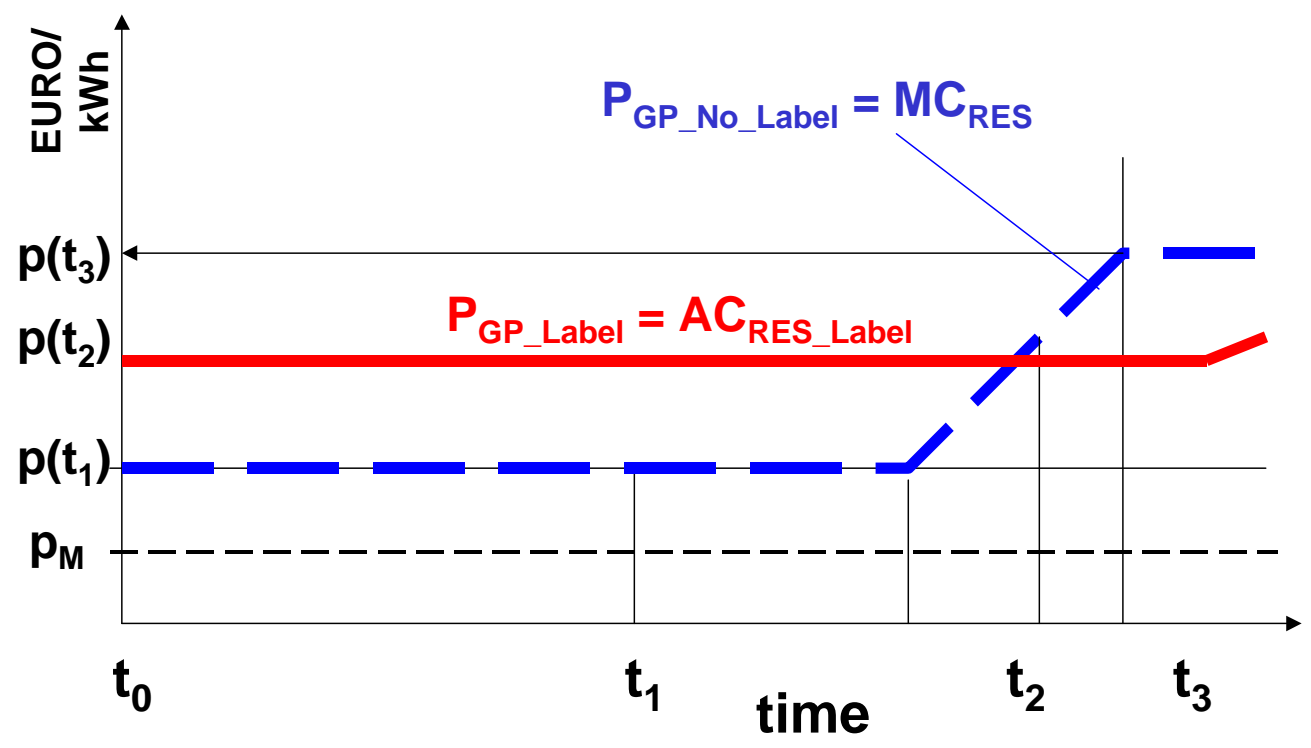

Figure 19. The development of the price for green electricity over time with and without a label that requires the inclusion of new capacity 


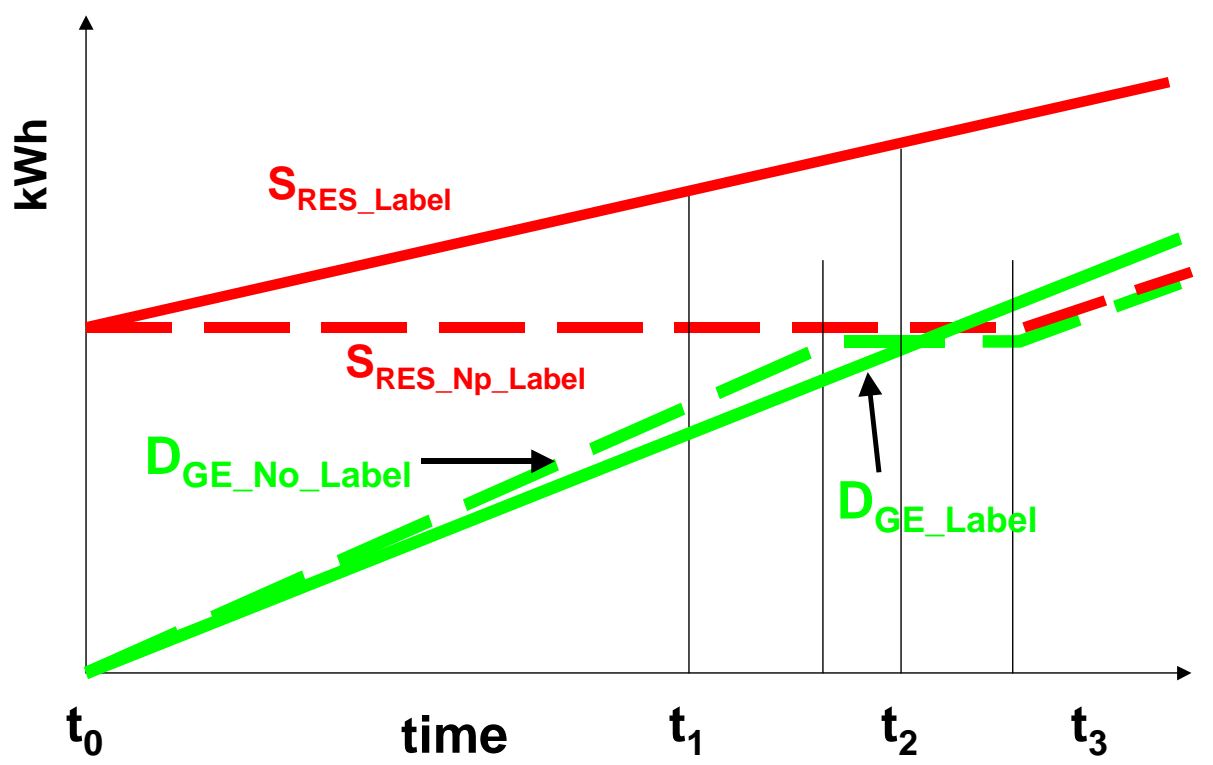

Figure 20. Supply and demand for green electricity over time with and without a label

If a trading or GPM system is started based mainly on existing capacity without any commitments to the installation of new capacity it leads to the following effects:

It takes a long lead-time until the existing WTP is exhausted and demand has caught up with existing generation;

$\rightarrow$ Moreover, the lack of credibility of such a system questions whether demand will ever increase to that level

Hence, it is of paramount relevance that new RES-E capacities are part of every trading/GPM strategy!

\section{Conclusions}

The most important general conditions to ensure the effectiveness of a strategy are ${ }^{3}$ :

- Regardless which instrument is chosen the careful design of a strategy is of paramount importance. A poorly designed system is worse than no promotional system at all because it discredits the idea;

- Focus on new capacities: It is important that a promotional system makes the proper distinctions between existing (at least fully depreciated) and new capacities. Hence, Green Pricing strategies as well as regulatory approaches should have a strong focus on new capacity!

- Credibility of the system: It must be guaranteed with high credibility that the promotional strategy, regardless of which instrument is implemented, survives for a specified planning horizon to provide confidence among investors and the industry;

- The support mechanism of any instrument should be restricted to a certain time frame e.g.10 years.

\footnotetext{
${ }^{3}$ These major conclusions are based mainly on the results of the project ELGREEN supported by the EC.
} 
- All selective barriers for new RES-E generators should be rigorously removed, e.g. fees for connection to the grid, extraordinary transmission fees.

With respect to different types of strategies the following criteria are most important:

- Feed-in tariffs are an effective instrument if a policy is introduced on a national level and if the rates are optimally designed e.g. using a stepped feed-in tariff

- Of high relevance for quotas based on tradable certificates is that the penalty for not purchasing a certificate is higher than the worst case of investment

- A TGC system is only preferable to feed-in tariffs if it is introduced as a transboundary system on a European-wide scale; Currently, however, it is very unlikely that such a harmonised strategy will be implemented soon. Therefore, promotional schemes based on stepped feed-in tariffs are the best strategy until international trading scheme can be implemented;

- With respect to voluntary strategies - e.g. Green Power Marketing - the minimum requirement for a label is that it guarantees at least that the proportional increase in total electricity demand is provided by new capacities!

- With respect to international trading of Green electricity at least one of the following conditions must be fullfilled:

$\rightarrow$ Either reciprocity (That is to say, to allow imports only from compatible markets with the same rules of competition) or

$\rightarrow$ guarantee that the electricity traded is generated from new RES-E power plants!

\section{References}

Bird Lori, Rolf Wüstenhagen, Jörn Aabakken: "Green Power Marketing Abroad: Recent Experience and Trends" NREL, Golden, 2002.

Farhar, Barbara C. and Ashley H. Houston: " Willingness to Pay for Electricity from Renewable energy" Proc. 1996 ACEEE Summer Study on Energy Efficiency in Buildings, ACEEE 1996.

Farhar, Barbara C., Roper, M.: "Understanding Residential Grid-tied PV Customers and Their Willingness to Pay Today's Costs: A Qualitative" Proc. 1998 ACEEE Summer Study on Energy Efficiency in Buildings, ACEEE 1998.

Green John, J. Plastow (2001): "Options of labelling Green Electricity in Europe" - Report of the project ELGREEN co-financed under the 5th framework programme of the European Commission, IT Power, United Kingdom.

Haas R., T. Faber, J. Green, M. Gual, C. Huber, G. Resch, J. Twidell (2001): "Promotion Strategies for Electricity from Renewable Energy Sources in EU Countries", Review Report, compiled within the cluster "Green Electricity" co-financed under the 5th framework programme of the European Commission, 2001.

Haas Reinhard, Claus Huber (EEG, Vienna University of Technology), Wolfgang Eichhammer (ISI), Ole Langniss (Lund University), Arturo Lorenzoni (IEFE), Reinhard Madlener (CEPE), Philippe Menanteau (IEPE), Poul-Erik Morthorst (RISÖ), Alvaro Martins (CEEETA), Anna Oniszk (EC BREC) Adrian Smith (SPRU), Emiel van Sambeek (ECN), Zoltan Vass (EnergiaClub), Aviel Verbruggen (University of Antwerp, STEM): "How To Promote Renewable Energy Systems Successfully And Effectively", in Proceedings ENER Forum 3 (forthcoming). 2002.

Huber Claus, R. Haas T. Faber, G. Resch J. Green, J. Twidell, W. Ruijgrok, T. Erge: "Action plan for a green European electricity market", - Report of the project ELGREEN co-financed under the 5th framework programme of the European Commission, Energy Economics Group, Vienna University of Technology, 2001b.

Langniß Ole, Markard Jochen: Grüner Strom und staatliche Förderung: Eine Analyse der Wechselwirkungen, Zeitschrift für Energiewirtschaft 4/1999, 275-284. 
Morthorst P.E. (2000): "The development of a green certificate market", System Analysos Department, Risoe National Laboratory, Energy Policy 28(2000).

Petrovic L. (2000): “The greener option", Power Engineering International.

Schaeffer G.J., M.G. Boots, T. Anderson, C. Mitchell, C. Timpe, M. Cames (1999): "The Implications of tradable Green Certificates for the deployment of renewable electricity", ECN.

Swezey Blair and Lori Bird: "Green Power Marketing in the U.S.: A status report", NREL, Golden 2001. 


\title{
Small Scale CHP: Alternative Integration Forms in the Danish Energy System
}

\author{
Rasmus Bøg, Ramunas Gatautis, Thomas Engberg Pedersen, Rune Schmidt, Hans F. Ravn
}

Corresponding author:

Rasmus Bøg, Elkraft System, Lautruphøj 7, DK-2750 Ballerup, Denmark, rab@elkraft.dk.

\section{Introduction}

In Denmark, introduction of small scale combined heat and power (CHP) plants were part of the energy policy during the 1990's. Thus, the installed electricity capacity on this type of units multiplied approximately ten times during this decade, to constitute more than $2000 \mathrm{MW}$ in 2000 , or around $20 \%$ of total installed electricity capacity. The motivation for this development was mainly energy savings due to the relatively high thermal efficiency in combined production, and the associated reduction of emissions. The remuneration for the electricity delivered to the electrical network was in part based on a feed in tariff. The construction of the tariff reflected estimated benefits to the electrical system.

With the liberalisation of the electricity markets this arrangement has been questioned, and it has been suggested that the differentiated payment to local CHP should be based on electricity market prising. For Denmark this would imply that the local CHP should trade the electricity on the Nordpool electricity spot market.

This paper analyses parts of these two alternative ways of economic arrangement in relation to small scale CHP. First it described the development and status till now. Then it analyses the production patterns and associated immediate economic consequences of a change from the tariff based system to a market system.

\section{Development of CHP in Denmark}

While the primary energy consumption in Denmark almost doubled from 1960 to 1970, it has been virtually constant since then at a level around $800 \mathrm{PJ}$ annually. On of the reasons for the stagnation in primary energy consumption has been that energy use has become more efficient, in part due to increased application of combined heat and power production.

Today more than 400 district heating companies supply more than half of the total heat consumption in Denmark. Most of them have CHP units. Local CHP has experienced a rapid development during the 1990's, see Figure 1, such that installed local CHP capacity now is almost 2200 MW electricity and 3900 MW heat. Of this, about two thirds are located in Western Demark and one third in Eastern Denmark. Natural gas is the dominant fuel type. The total efficiency in the country's electricity and district heating sector has increased from around $50 \%$ in 1980 to around $70 \%$ in 2000 . This is to a large extent due to the introduction of CHP; half of the electricity production and $80 \%$ of heat comes from CHP. Other contributions to increase of efficiency are made by wind power where the installed capacity constitutes $20 \%$ of total electricity generation capacity. 


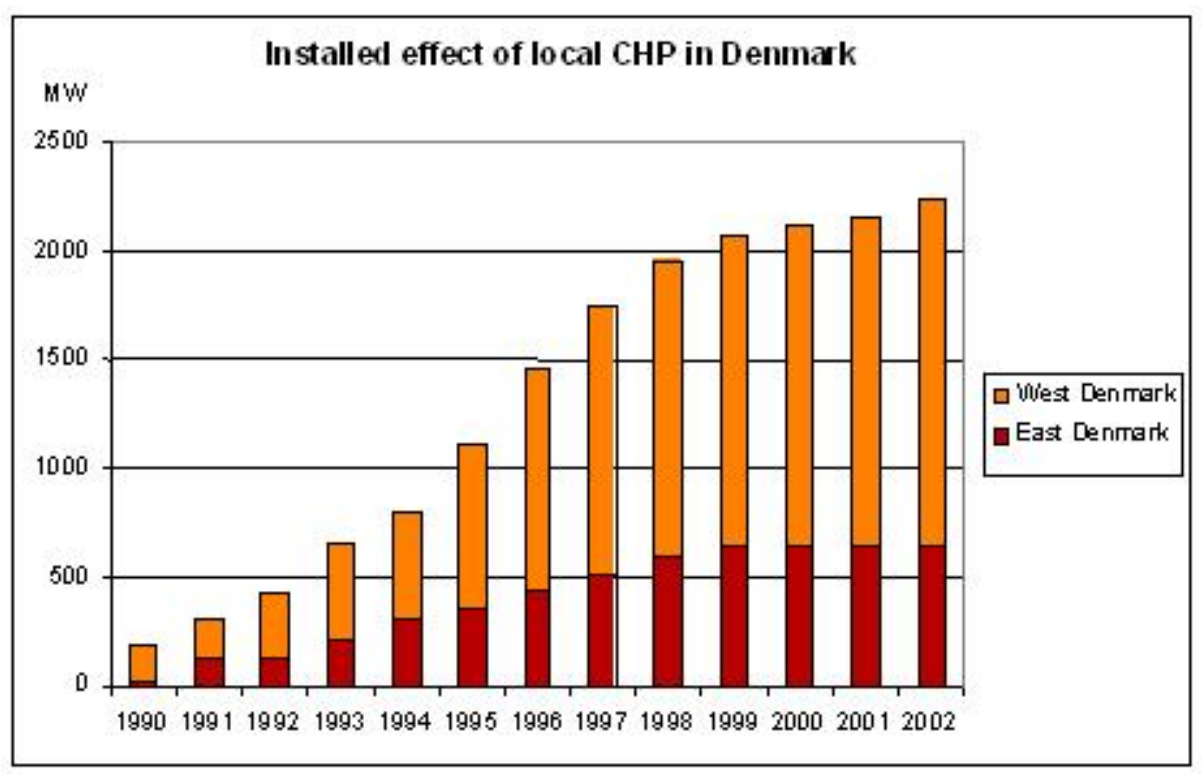

Figure 1.

The growth of small scale CHP has been supported by various measures, see below. In the strategy document on liberalisation of the energy markets [1] from September 2002 the government proposed that the conditions for the small scale CHP should be changed towards operation on marked conditions. Various possible ways of doing this are discussed in that document, central issues being the consequences for the heat prices and for the public support.

\section{CHP regulation}

The legal and taxation framework has supported the development of CHP. For instance it has been prohibited to use electric heating in new residential buildings, and there have been legal measures to ensure that all buildings in a district heating area could be connected to the heat network. The most important taxes in relation to electricity and heat production relate to $\mathrm{CO}_{2}$ emission and energy consumption.

The $\mathrm{CO}_{2}$ tax, introduced in 1996 , is $100 \mathrm{DKK}$ per ton emitted $\mathrm{CO}_{2}(100 \mathrm{DKK}$ is approximately 13 Euro). The effects of this differ between the fuels due to the different quantities of $\mathrm{CO}_{2}$ emitted per GJ fuel. Approximate numbers are 5.60 DKK/GJ for natural gas, $9.60 \mathrm{DKK} / \mathrm{GJ}$ for coal, $7.90 \mathrm{DKK} / \mathrm{GJ}$ heavy fuel oil, 7.40 DKK/GJ for light fuel oil. Waste, straw and other forms of bio mass are exempted for $\mathrm{CO}_{2}$ tax. CHP units are exempted for $\mathrm{CO}_{2}$ tax on that part of the fuel which is used for production of electricity. For heat produced on industrial CHP units the tax may be less than $100 \mathrm{DKK} /$ ton $\mathrm{CO}_{2}$. For space heating full tax is used, while process heat has a lower tax. If an agreement concerning energy savings is made between an industrial company and the authorities the tax may be further decreased.

In local CHP units the allocation of fuel used for electricity and heat production, respectively, is done administratively. Presently the owners of such unit may choose between four formulas. In one, the fuel for heat production is calculated as: ((total fuel) - (electricity production)/0.65). In a second formula, the fuel for heat production is calculated as: ((heat production)/1.25); however, for this formula at most ((electricity production)/0.35) can be allocated to electricity production. A third formula distributes the fuel according to the proportions of heat and electricity produced. The fourth calculates the fuel consumption for electricity using an efficiency of 0.9 for electricity production while the remaining fuel is assumed used for heat production. 
An important condition related to the operation of local CHP is that heat and electricity must be produced together whenever technically feasible. In particular, heat may only be on the boiler if the heat production capacity on the CHP unit is insufficient to cover heat demand.

Local CHP units are given a remuneration for the electricity produced. Until mid 2002 the main rule was that units having less than $3 \mathrm{MW}$ electricity capacity were given $100 \mathrm{DKK} / \mathrm{MWh}$ while the bigger units were given $70 \mathrm{DKK} / \mathrm{MWh}$. From mid 2002 all natural gas fuelled units below $25 \mathrm{MW}$ electricity capacity are given $80 \mathrm{DKK} / \mathrm{MWh}$, but limited to 8000 hours full load per year. Further differentiations exist, however, they will not be specified here. Income from sale of electricity is described next.

\section{Sale of Electricity}

Local CHP are paid for the electricity produced according to a feed in tariff. The tariff depends on the time of the day, the day of the week and the voltage level at which the unit is connected to the electricity network. The tariff is regulated (slightly) every third month. Table 1 illustrates the levels, and the division of the day into low, high and peak hours is illustrated in Figure 2.

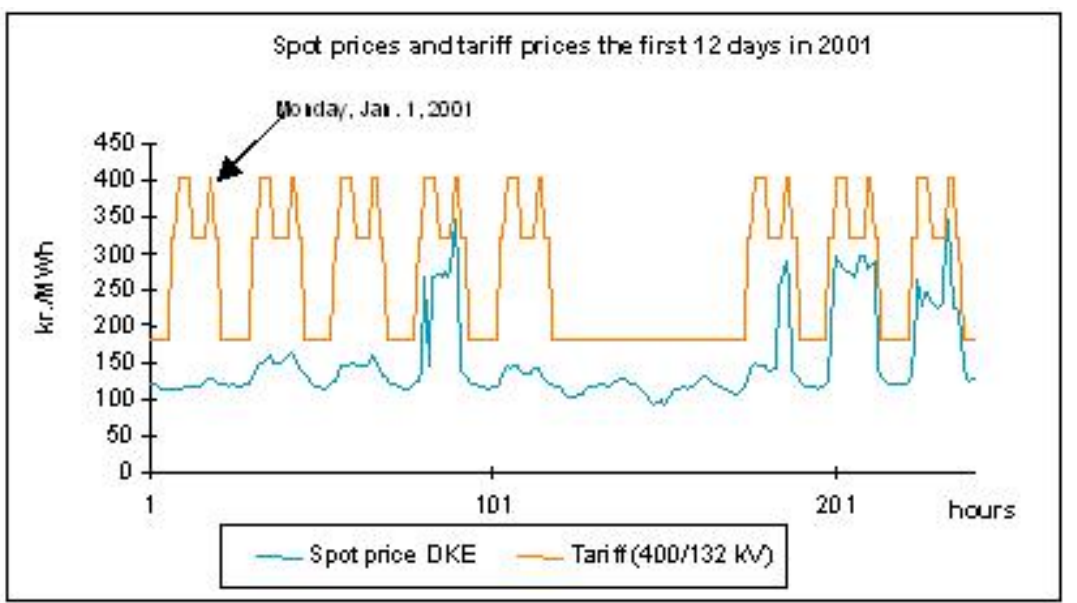

Figure 2.

Table 1. Feed in tariff for local CHP, Eastern Denmark, last quarter of 2002, DKK/MWh.

\begin{tabular}{|l|c|c|c|c|}
\hline Voltage level & Low & High & Peak & Approx. average \\
\hline $400 / 132 \mathrm{kV}$ & 178 & 321 & 409 & 267 \\
\hline $132 / 50 \mathrm{kV}$ & 183 & 374 & 491 & 302 \\
\hline $50 / 10 \mathrm{kV}$ & 187 & 399 & 530 & 319 \\
\hline $100 / 0.4 \mathrm{kV}$ & 190 & 417 & 560 & 332 \\
\hline $0.4 \mathrm{kV}$ & 195 & 446 & 613 & 354 \\
\hline
\end{tabular}

In the future, probably from 2004, the local CHP may be expected to sell their electricity at market conditions. This in particular could be through bilateral contracts or at the spot market. The spot market is the Nordpool market [2].

The main uncertainty related to sale on the spot market is the spot price itself. Figure 2 illustrates that there is uncertainty related to the short term phenomena. In Figure 3 the spot prices for the years 2000-2002 are shown. It is observed from this that there is also uncertainty related to the longer terms. In particular the high levels at the end of 2002 are due to low levels of hydro inflow in Norway and Sweden in the autumn of 2002. 
Further possible elements related to income include financial contracts to reduce risks, and possibly sale of services like provision of regulating power and voltage stability.

By comparing the feed in tariff with the spot prices it is obvious that the operation of the local CHP cannot be completely in accordance with the hour-by-hour economics of the total electricity system. Figure 4 illustrates the same period as Figure 2. It is seen that although most of the time the local CHP production is in accordance with the price signals given by the spot prices, there are some hours where better correspondence might be imagined.

In the following some immediate consequences of changing the operation of small scale CHP form being based on tariffs to being based on spot prices will be analysed.

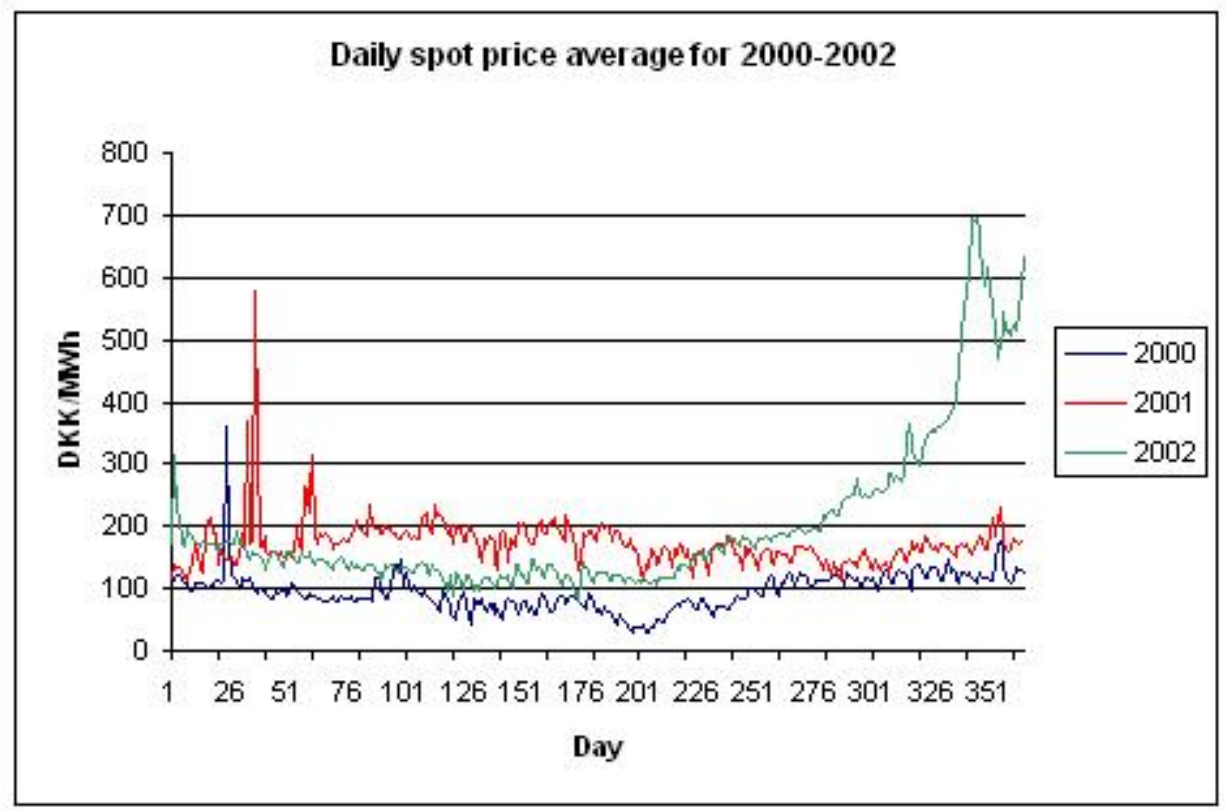

Figure 3.

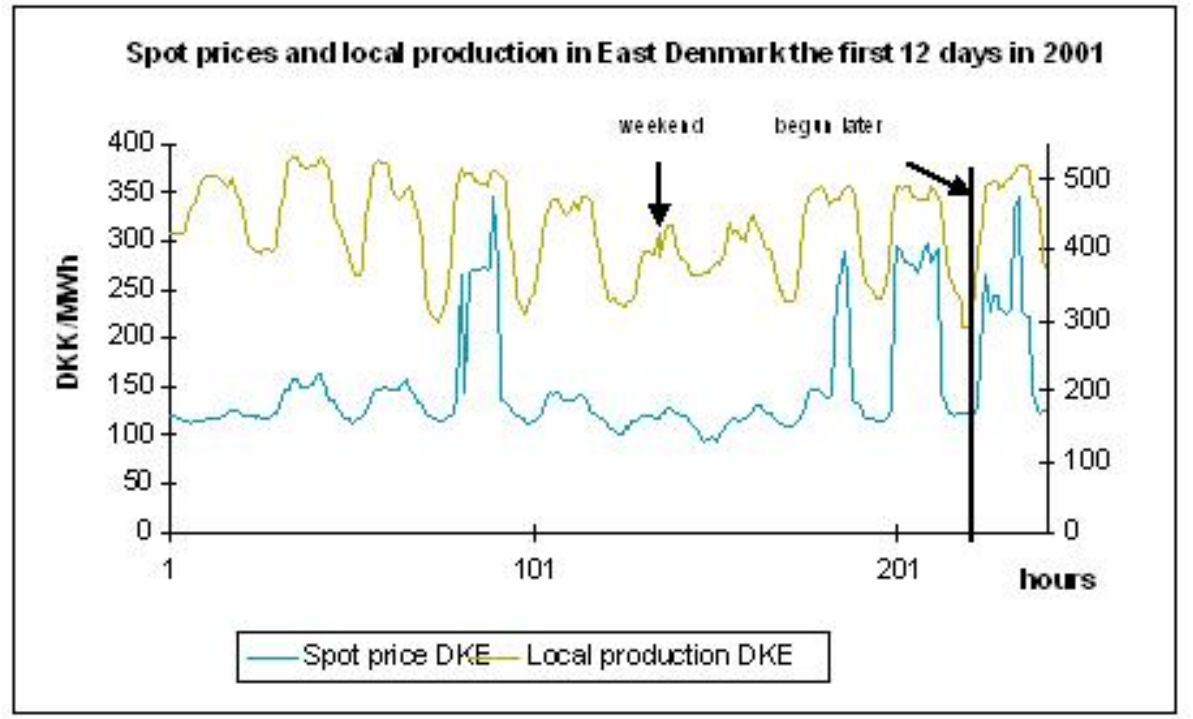

Figure 4. 


\section{Analyses}

The effect of operating the local CHP according to the signals given by the spot market has been analysed [3] - [4]. The analyses presented concern local CHP in Eastern Denmark for the year 2001. Since there is not access to detailed data for the units, a number of assumptions have been introduced concerning in particular the details of the technical configuration of the production units, their heat supply conditions and their cost structure. Figure 5 shows the average daily production patterns for the four seasons of the year. This pattern is based on the feed in tariff previously described.

To get an idea of the potential in operating the units according to the spot prices a number of analyses were made. The analyses were undertaken assuming that heat may be stored during the 24 hours of the day, that there are no start-up costs, that the maximal production within any hour of any day cannot exceed the maximal production observed in 2001 for any hour during the same day. It is noted that the last assumption implies that many units will not reach their rated maximum hourly production.

Figure 5 indicates the daily production pattern as it was in 2001, and Figure 6 shows the pattern as found using the above mentioned assumptions. As seen, the profile has changed somewhat towards a more distinct shape.

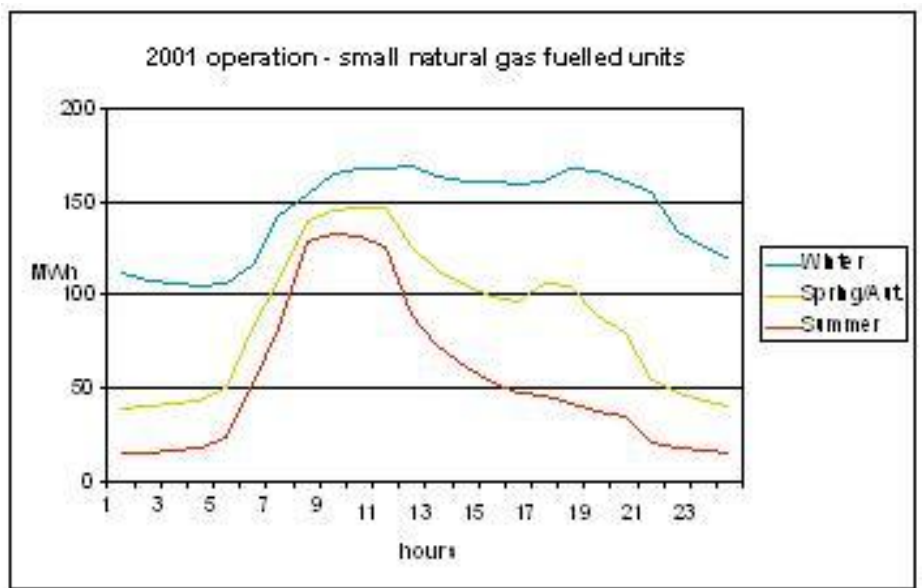

Figure 5.

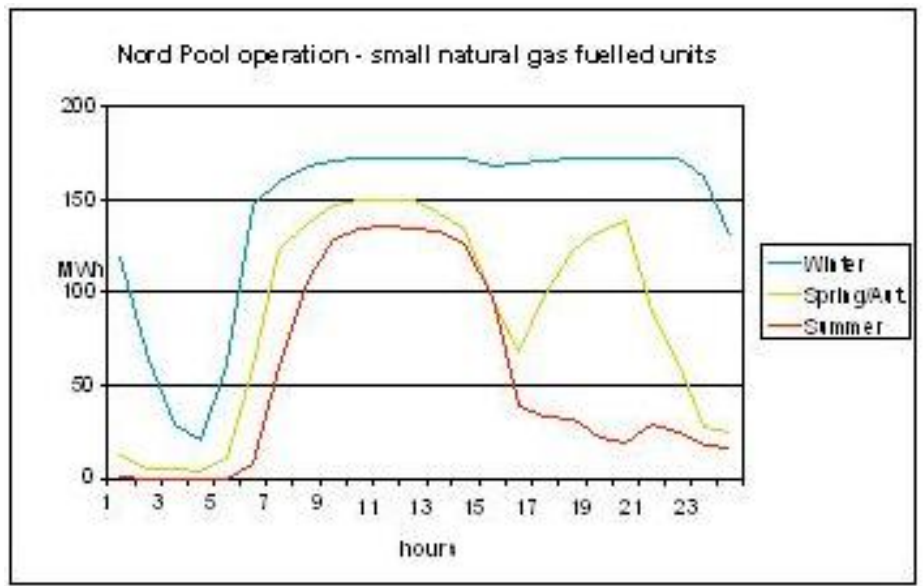

Figure 6.

Now assume that the production during 2001 had actually been remunerated according to the spot price. Then from the historical production pattern as indicated in Figure 5, it would be possible to calculate the income from sale of electricity. Similarly it is possible to calculate the income according to the production pattern shown in Figure 6. The latter should be higher since this pattern reflects the optimal adaption to the price pattern on the spot market. The calculations have been made and the result 
is that by adjusting the production pattern to the spot prices the income can be increased by 10.5 mio DKK for 2001; of this, the natural gas fuelled units account for 6 mio.

A major condition related to the operation of local CHP is that heat and electricity must be produced together whenever technically feasible. In a situation with sale at spot prices this would imply that even when electricity prices are very low electricity must be produced, and even when electricity prices are very high no more electricity may be produced than corresponding to the demand for the associated heat produced.

Figure 7 shows results of a simulation where this condition is abolished. Comparing with Figure 6 it is seen that the patterns are not all that different, however on Figure 7 there are more hours during the night and first parts of the day where production is less.

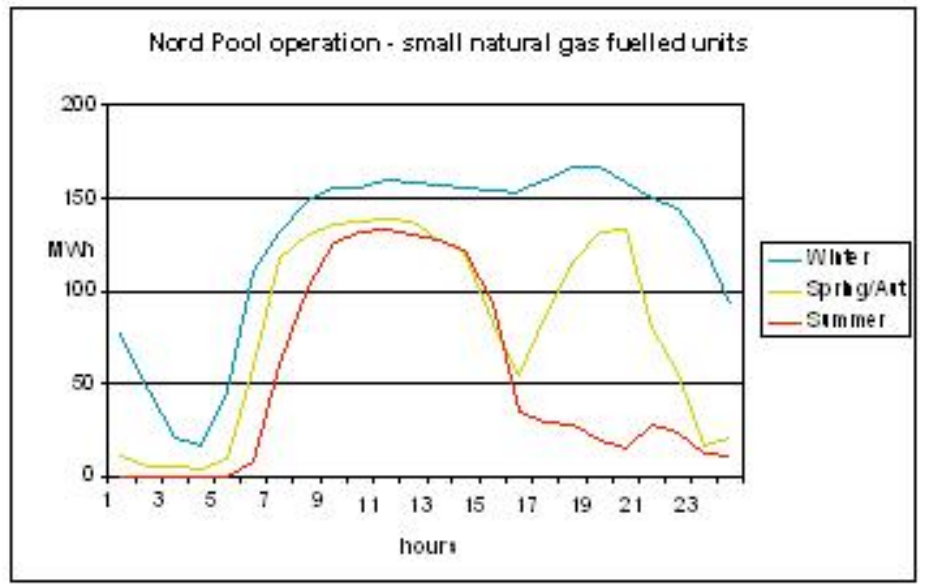

Figure 7.

In order to calculate the economic consequences of this change in production pattern it is necessary to specify the assumptions concerning cost of production on the various types of units. For a natural gas fuelled local CHP station consisting of a CHP unit and a boiler the assumptions are the following. The CHP unit gives 35 units of electricity output and 55 units of heat output for 100 units of fuel input, i.e. a total efficiency of $90 \%$. The boiler has an efficiency of $95 \%$. The price of natural gas is assumed to be $30 \mathrm{DKK} / \mathrm{GJ}$, reflecting the short term social marginal cost. Cost of $\mathrm{CO}_{2}$ emission is assumed to be $100 \mathrm{DKK} / \mathrm{ton}$. The CHP unit has a $\mathrm{CO}_{2}$ emission of $260 \mathrm{~kg} / \mathrm{MWh}$. The marginal emission for the electricity system is assumed to be $600 \mathrm{~kg} / \mathrm{MWh}$, thus each MWh electricity produced on the CHP unit is assumed to imply a net $\mathrm{CO}_{2}$ reduction of $340 \mathrm{~kg}$.

The social cost for each MWh electricity produced on the CHP unit may therefore be calculated as follows:

- Cost of natural gas: $30 * 3.6 / 0.35=309 \mathrm{kr} / \mathrm{MWh}$

- Saved cost of heat production: $30 * 3.6 / 0.95 * 0.55 / 0.35=-179 \mathrm{kr} / \mathrm{MWh}$

- Operation and maintenance: $50 \mathrm{kr} / \mathrm{MWh}$

- $\mathrm{CO}_{2}$ emission: $26 \mathrm{kr} / \mathrm{MWh}$

- $\mathrm{CO}_{2}$ reduction: $-60 \mathrm{kr} / \mathrm{MWh}$

Total social cost of electricity production is then: $146 \mathrm{kr} / \mathrm{MWh}$.

With these assumptions the increase in income by changing the production pattern from the historical one indicated in Figure 5 to that indicated in Figure 7 is 18 mio DKK, of which the natural gas fuelled units account for 10 mio.

These results are sensitive to the assumptions. The range $25-35 \mathrm{DKK} / \mathrm{GJ}$ for the marginal social cost of natural gas combined with the range $85-95 \%$ for total fuel efficiency on the CHP unit implies the approximate range $100-200 \mathrm{DKK} / \mathrm{MWh}$ for the social cost of electricity production.

Figure 8 shows the result of using the range $100-200 \mathrm{DKK} / \mathrm{MWh}$ for the social cost of electricity production to the same calculation as illustrated in Figure 7. The figure shows the increase in income (calculated as for Figure 7) and the resulting full load hours during 2001. The figure shows these result 
for natural gas and for bio mass. For natural gas units the result from Figure 7 (10 mio DKK) is recognised on Figure 8.

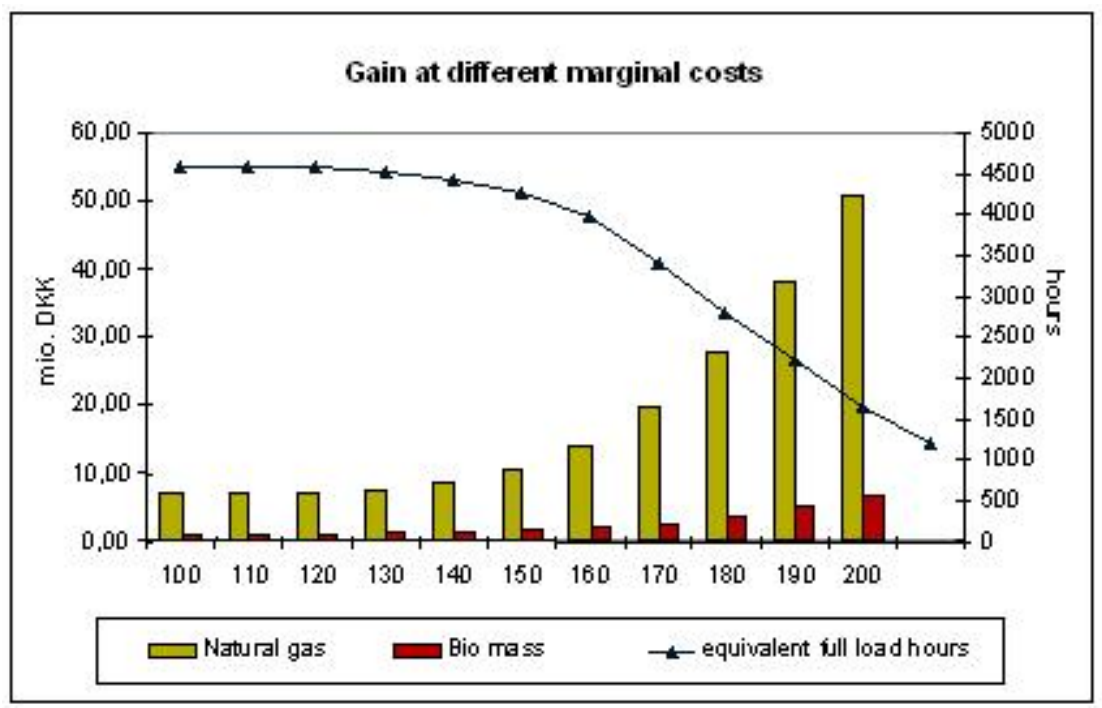

Figure 8.

As seen, for the social cost of electricity production rising above approximately $150 \mathrm{kr} / \mathrm{MWh}$ the increase in income rises markedly due to reduction of the production on CHP (as indicated by the annual full load hours).

Some further analyses have been done using the Balmorel model [5]. For these analyses the local CHP units have been allocated into six groups according to the characteristics (e.g. fuel type, district heating/industrial). For each group a heat demand has been modelled based on 2001 historical production and the assumption that $90 \%$ of the heat demand is covered from CHP. A standard profile for heat demand over the hours of the year has been used. Total efficiency of CHP units is assumed to be $90 \%$, for boilers the assumptions are $95 \%$ for natural gas fuelled and $90 \%$ for oil fuelled units. Natural gas is assumed used in all areas where the CHP units is natural gas fuelled, otherwise oil is assumed. Fuel prices are: natural gas: $30 \mathrm{DKK} / \mathrm{GJ}$, light oil: $40 \mathrm{DKK} / \mathrm{GJ}$, waste: $0 \mathrm{DKK} / \mathrm{GJ}$, wood and straw: 30 $\mathrm{DKK} / \mathrm{GJ}$; for central units the price of coal is $11.7 \mathrm{DKK} / \mathrm{GJ}$ and the price of orimulsion is 10.7 DKK/GJ. All groups are assumed to have a heat accumulator with a size equivalent to eight hours of full CHP heat production.

The heat price in each area is assumed to be given such that the total production costs are covered by income from sale of electricity and heat. Thus, if the electricity price is high, the heat price is low, and vice versa.

The time resolution used in the model has 12 months each subdivided into 12 time sub-segments.

Table 2 shows a comparison between the electricity production as observed in 2001 and the electricity production calculated in the model. The numbers are reasonably similar. The differences are in part due to the simpler time structure in the model, and it has been observed that boilers have been used more extensively in reality than in the model simulations.

Table 2. Comparison of electricity production, 2001 history and model calculation, GWh.

\begin{tabular}{|l|c|c|}
\hline & 2001 history & Model calculations \\
\hline Small natural gas & 869 & 937 \\
\hline Large natural gas & 800 & 842 \\
\hline Waste & 538 & 538 \\
\hline Biomass & 211 & 236 \\
\hline Industrial & 111 & 121 \\
\hline Other & 127 & 141 \\
\hline Total & 2657 & 2817 \\
\hline
\end{tabular}


Assuming now that the units were operated according to the spot price signals, rather than according to the feed in tariff, the difference in earnings have been calculated as shown in Table 3. As seen, the difference is 10 mio DKK. This calculation assumes that there is no obligation to produce heat and electricity simultaneously whenever possible (the same assumption as in relation to Figure 7). The value of the electricity produced is in both calculations assumed to be equal to the spot price. If the obligation to produce heat and electricity simultaneously is preserved (the same assumption as in relation to Figure 6), the difference has been calculated to 3 mio DKK.

Table 3. Comparison of net heat annual costs with production pattern according to tariff or spot price, respectively.

\begin{tabular}{|l|c|c|c|}
\hline & Tariff operation & Spot price operation & Difference \\
\hline Production cost & 894 & 825 & -69 \\
\hline El. quantity (GWh) & 2867 & 2471 & -396 \\
El. Sale (mio DKK) & 583 & 524 & -59 \\
\hline Net heat cost (mio DKK) & 310 & 300 & -10 \\
\hline
\end{tabular}

The results are sensitive to the assumptions, as previously observed. Table 4 confirms this with respect to assumptions in the spot prices and in the price of natural gas.

Table 4. Electricity production and changes (between calculations based on tariff operation and spot price operation) in net cost of heat as a function of changes (relative to 'Ref' which is the 2001 spot price and a social cost natural gas price of $30 \mathrm{DKK} / \mathrm{MWh}$ in the spot price and the natural gas price.

\begin{tabular}{|l|r|r|r|r|r|r|}
\hline & Tariff & Ref & $-25 \%$ spot & $\begin{array}{r}+25 \% \\
\text { spot }\end{array}$ & $-25 \%$ gas & $\begin{array}{c}+25 \% \\
\text { gas }\end{array}$ \\
\hline El., GWh & 2866 & 2471 & 1811 & 2806 & 2731 & 2241 \\
\hline Change, mio DKK & - & 10 & 41 & 4 & 5 & 13 \\
\hline
\end{tabular}

\section{Conclusions}

This paper has described alternative ways of economic arrangement in relation to small scale CHP and analysed the production patterns and associated immediate economic consequences of a change from the tariff based system to a market based system.

It has been demonstrated how the change of conditions for sale of electricity will influence the production pattern. It has also been concluded that some rationalisation will be achieved in the form of lower net cost of heat production. However, the difference in net production costs - and hence the change in net cost of heat production - have been found to be relatively small compared to the total costs.

Seen form the perspective of the total electricity system, small scale CHP may provide a number of useful services, for instance in relation to supply of regulating power, voltage stability, reserves and otherwise. This has not been analysed here, however. If the potential benefits to the electricity system from other services provided by small scale CHP shall remain an option then a necessary precondition is that the economic basis for continued operation of those units are attractive.

If the potential for rationalisation shall be realised in practice, at number of conditions must be fulfilled, and in particular:

- That the total income for local CHP is sufficient to motivate continued operation.

- That the marginal cost experienced by the local CHP company (i.e. including fuel prices, taxes and environmental regulation) reflect the social cost. 
- That the operation according to spot prices is practically feasible, i.e., that effective bidding to the spot market is possible.

\section{References}

[1] Liberalisering af energimarkederne. Available at www.oem.dk.

[2] www.Nordpool.no.

[3] Decentral kraftvarme i Østdanmark. Bilagsrapport til temarapporter om elpris, forsyningssikkerhed og beredskab, Elkraft System 2002. Available at www.elkraft-system.dk.

[4] Decentral kraftvarme i Danmark. Baggrundsrapport - Systemplan 2002. Cowi. Available at www.elkraft-system.dk.

[5] Balmorel see: www.Balmorel.com. 


\section{Session 12: Solar Energy Technologies, PV and Thermal}

Chairman: Klaus Bechgaard, Risø National Laboratory 


\title{
Solar Cells Beyond Silicon
}

\author{
Keld West, The Danish Polymer Centre, Risø National Laboratory, DK-4000 Roskilde, Denmark
}

\section{Introduction}

All renewable energy sources (apart from tidal and geothermal energy) are powered by a steady flux of energy from the sun. The total flux amounts to approximately $1.7 * 10^{17} \mathrm{~W}(0.2 \mathrm{EW})$, which is more than 50 thousand times the rate at which energy ${ }^{1}$ is produced and consumed by mankind. Systems with a large energy throughput are generally known to resist the thermodynamic drive towards even distribution of energy. Such non-equilibrium systems often show a partitioning of energy between different modes, each with its own characteristic spatial and temporal variations. It is these different modes that are tapped when renewable energy is harvested.

This paper is concerned with direct conversion of the energy from sunlight into electric energy. This is obviously the most direct way of utilising solar energy, but this direct energy transfer does not involve the elements of focusing or concentration that are important in e.g. wind and wave energy schemes, or the element of integration as e.g. utilisation of energy from biomass. The energy intensity in sunlight it thus relatively low compared to other renewable energy sources, and it continues to be a technological challenge to extract exergy directly from solar energy in a way that is economically competitive, also in regions where other energy sources are readily available.

\section{Sunlight}

The intensity of sunlight just outside the atmosphere is $1366 \mathrm{~W} / \mathrm{m}^{2}$ (the solar constant). On the way down the atmosphere some of the radiation is reflected back into space and a part of the energy is absorbed in clouds and the air mass. The absorbed energy drives the dynamics of the atmosphere from which energy can be tapped as wind or wave energy. The amount of solar irradiation that reaches the ground amounts to $160 \mathrm{~W} / \mathrm{m}^{2}$, averaged over time and the surface of the earth. This number is put into perspective by the following citations from an essay by Denis Hayes [1]:

"The sunlight that fell on the roads in the US last year contained roughly as much energy as in all the fossil fuel consumed last year in the world"

"No country uses as much energy as is contained in the sunlight that strikes its buildings"

These quotations underlines that solar power is an abundant resource that has the potential for playing a major role in the world's energy supply. As it is furthermore universally available (although to a varying extent), it may also play a key role in bringing electric power to areas where an electric grid has not yet been established.

\footnotetext{
${ }^{1}$ Throughout this paper the term "energy" is used instead of the more correct terms "exergy" or "free energy".
} 


\section{Photovoltaics}

Conversion of light directly into electric energy involves the photovoltaic effect where photon energy is used to excite an electron from its ground state to an excited state, see Figure 1 [2]. A functional photovoltaic scheme should implement at least the following three steps:

1. Light harvesting: photons are absorbed and their energy used to excite electrons.

2. Charge separation: the excited electrons are separated spatially from the ground state to avoid recombination.

3. Selective charge transport/extraction: electrons and holes are transported to the terminals of the device, where the high-energy electrons are selectively extracted at one terminal while the holes selectively are replenished from the other terminal.

Ideally, there should be a one-to-one relationship between light and electric current: Each photon that strikes the device deliver its energy to an electron, which in turn transports the energy to an electrical load connected to the terminals of the device. Here the energy can be released in the form of work.

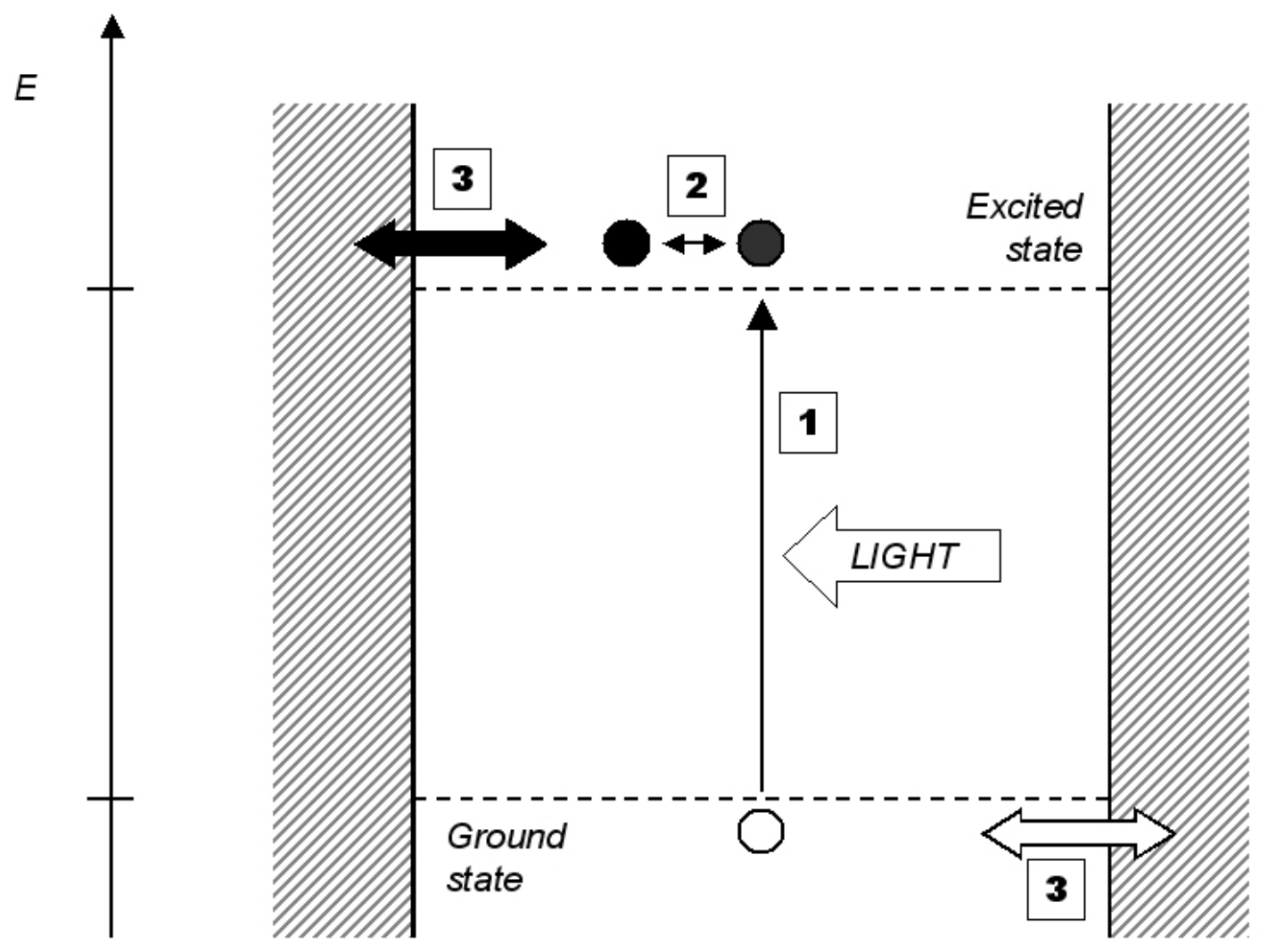

Figure 1. Diagram of photovoltaic principle showing the elemental steps: 1) light harvesting; 2) charge separation; and 3) charge transport

A number of devices based on these principles (photovoltaics or PV's) have been developed, and they share a number of common characteristics: PV devices are inherently modular. There is no great increase in efficiency on going from $\mu \mathrm{W}$ or $\mathrm{mW}$ devices to $\mathrm{kW}$ or MW installations. PV devices can be used in densely populated areas, as they are free of emissions of noise and fumes; but PV devices are also well suited for use in remote areas without infrastructure because they require only a minimum of maintenance. The major drawback is the price! PV produced electric power - even in areas of good insolation (received solar radiation) - costs nearly an order of magnitude more than electricity gener- 
ated from fossil fuels. Because PV constitutes a clean energy source that can aid in reduction of the consumption of fossil fuels there is, however, a major incentive for developing this technology to a state where PV power generation can deliver a significant contribution to the worlds energy supply.

Despite the higher current cost, PV power generated at small scales where and when it is needed is under certain circumstances already a competitive alternative to central-station power. Small PV systems can be sited near users on rooftops or building façades. Furthermore, distributed power generation can improve overall power supply reliability by reducing loads on the grid, and gives consumers more control over their future energy costs.

Because of these advantages, solar photovoltaics are by now the second fastest growing energy source surpassed only by wind energy. The total shipment of PV modules reached 390 peak MW $\left(\mathrm{MW}_{\mathrm{p}}\right)$ in 2001, with an increase in the averaged annual growth rate from $10 \%$ to $35 \%$ over the last decade - see Figure 2. At the same time the price of PV is decreasing. The effect that learning through market experience has on the cost of a particular technology can be captured in experience curves. An analysis of historic price data shows that the learning rate (i.e. the decrease in price for each doubling of the cumulative production) for photovoltaic modules has increased from $20.2 \%$ to $22.6 \%$ in the last decade [3].

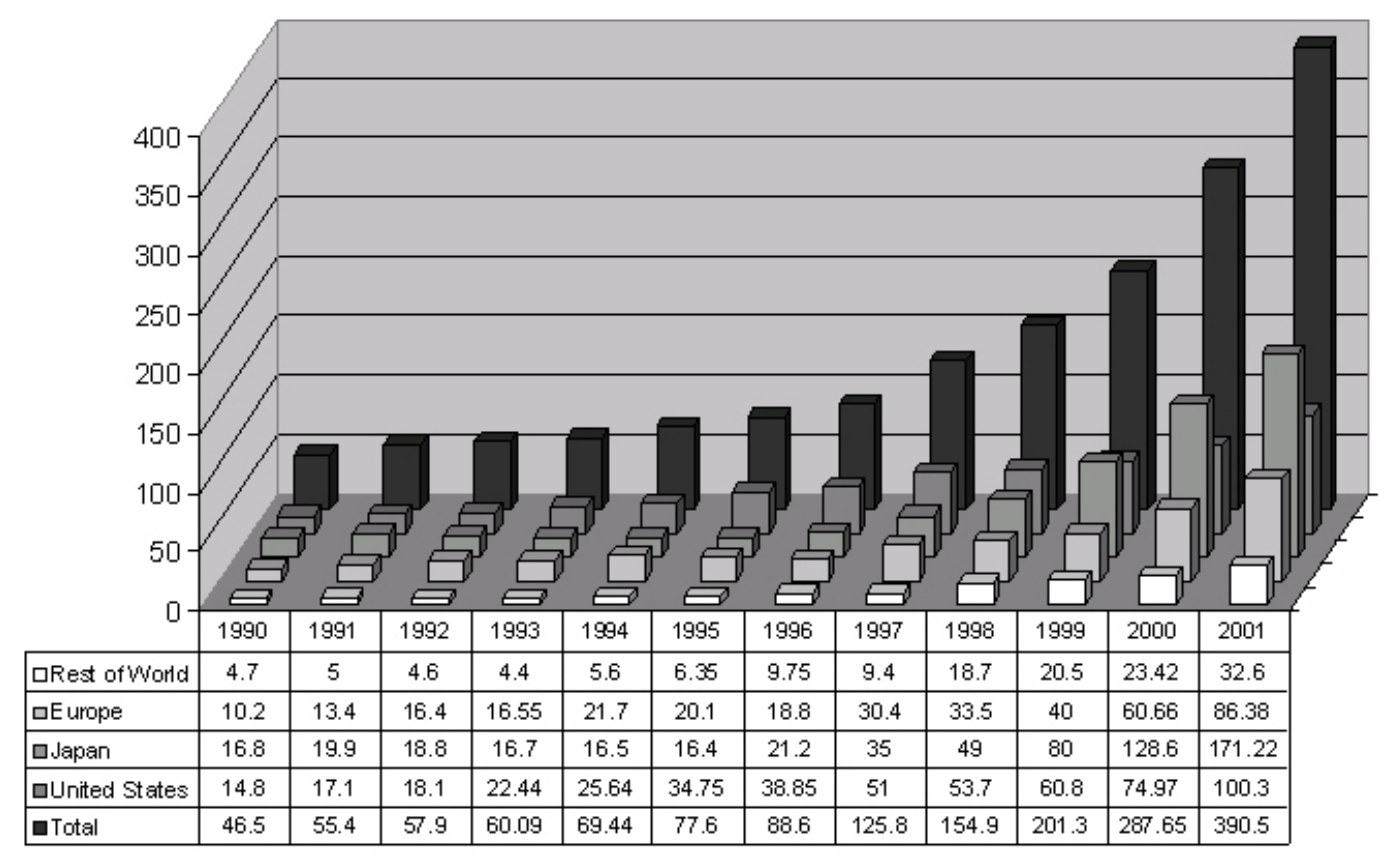

Figure 2. Worldwide PV market (data from PV News, ed. Paul Maycock)

Both the growth rate and the price reduction through learning are very respectable, but unfortunately they fall short of bringing us PV power at a price that on its own can compete with power produced from fossil fuels in the near or medium term.

In the following, the major PV technologies are outlined with emphasis on issues that impedes a rapid cost reduction. Two emerging technologies that may constitute alternative routes to low-cost PV are also outlined. 


\section{$41^{\text {st }}$ generation photovoltaic devices}

The PV scheme of Figure 1 is implemented elegantly in the classical semiconductor solar cell. In these PV's all the steps necessary for conversion of light to electric energy are provided by the cleverly manipulated band structure of a single semiconductor crystal Figure 3 shows the band structure of such a semiconductor $p-n$-junction. An excited electron-hole pair will - provided that its lifetime is sufficiently long - diffuse to the junction region where the charge carriers are separated. The activated electron is carried through the $n$-doped region to the negative terminal while the hole is replenished through the $p$-doped region from the cells positive terminal. Because impurities and grain boundaries acts as recombination centres, these devices should preferably be produced from high purity single- or multi-crystalline semiconductor material.

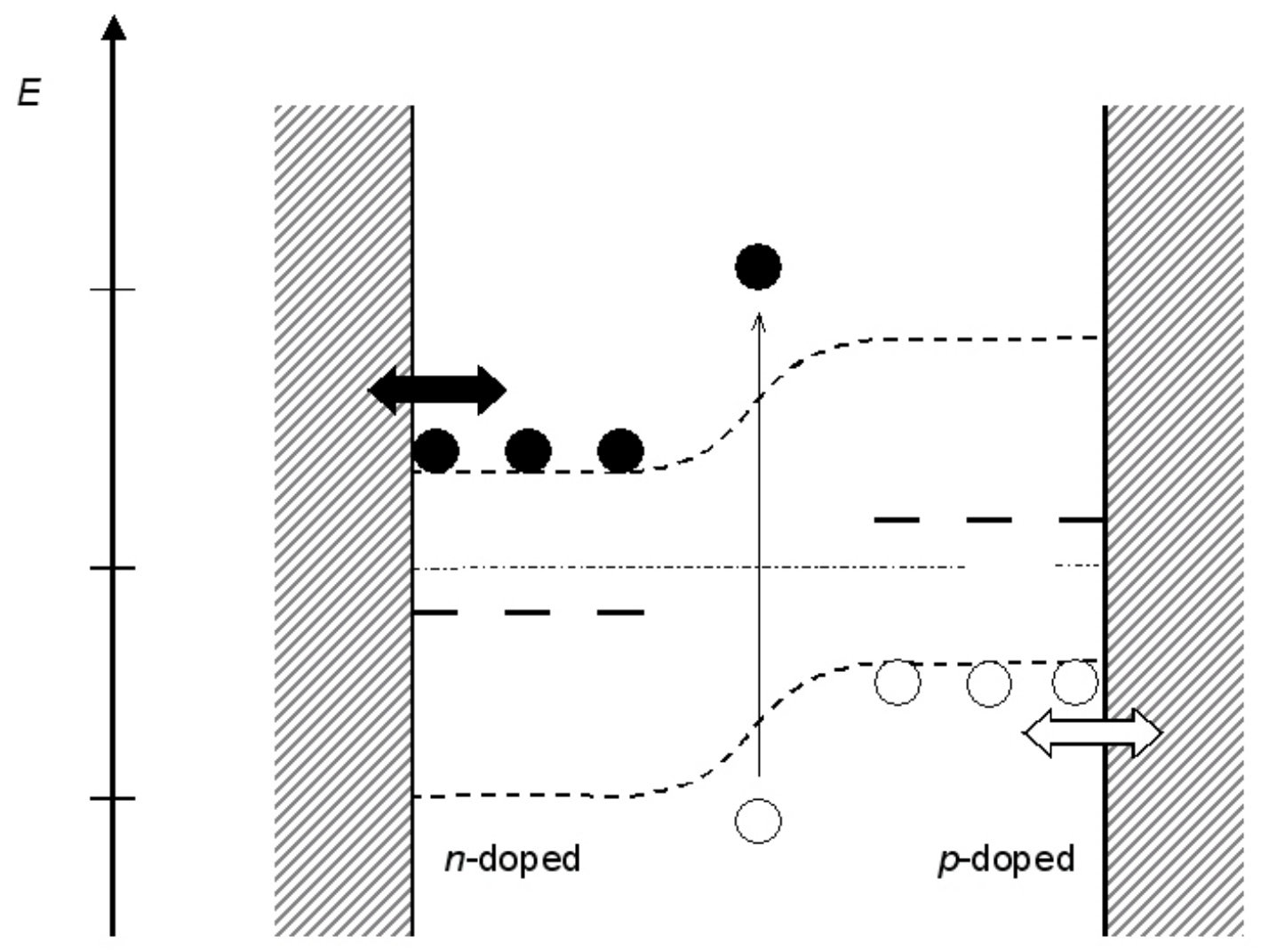

Figure 3. Principle of photovoltaic device based on a semiconductor junction

Approximately $90 \%$ of the PV units produced today are made from crystalline silicon. In 2000 the equivalent of $103 \mathrm{MW}_{\mathrm{p}}$ was produced from monocrystalline silicon and $104 \mathrm{MW}_{\mathrm{p}}$ from polycrystalline silicon [4]. A small amount was also made from ribbon or sheet silicon.

The primary advantage of crystalline silicon is that highly efficient and rugged devices can be made with this technology. Laboratory devices with efficiencies close to $25 \%$ have been demonstrated, and the best commercial cells have now reached efficiencies of $17 \%-18 \%$. When production quantities of higher quality float zone silicon become available, $20 \%$ efficiencies in commercial modules are expected.

Because silicon is an "indirect band" semiconductor, a relatively thick active layer of silicon is required to absorb the full solar spectrum, and the wafers used to produce these cells are typically several hundred $\mu \mathrm{m}$ thick. They are machined from ingots produced in high-temperature, energy-intensive metallurgical processes, and substantial amounts of material are lost during processing. Solar cell quality silicon is thus expensive to produce. The price of the wafers accounts for around $40 \%$ of the 
final module cost, and as a large part of this price is energy cost, several years of operation are required to recoup the energy used to manufacture the cells. The large amount of high quality silicon and thereby the high amount of energy that goes into the production of $1^{\text {st }}$ generation photovoltaics will ultimately set an upper limit to the level to which the price of this technology can be reduced.

Alternatives to silicon are III-V semiconductors like gallium arsenide, from which highly efficient $(>25 \%)$ photovoltaics have also been made.

\section{$52^{\text {nd }}$ generation photovoltaic devices}

In order to reduce the high materials cost intrinsic to $1^{\text {st }}$ generation PV technology, several thin-film technologies are being pursued to enable higher volumes to be produced at a lower cost.

Thin-film devices based on amorphous silicon are less efficient than devices based on crystalline silicon, but as this technology is well suited for mass production they can potentially achieve a better price to performance ratio. With ongoing development in performance and production technology, thin-film PV's are becoming increasingly competitive with crystalline silicon, and their production volume is now $30 \mathrm{MW}_{\mathrm{p}} /$ year.

Amorphous silicon is a direct-band semiconductor characterised by a high absorption coefficient in the visible spectrum. Only a thin film $(<1 \mu \mathrm{m})$ is needed to absorb the sunlight, but even thinner layers are typically used in order to minimise recombination losses.

Thin-film cells can be deposited in a continuous process (plasma-enhanced chemical vapour deposition, PECVD) onto a flexible steel or plastic substrate, and a stacked-cell approach has been developed in which multiple thin cells of different band gaps are stacked on top of each other. This has the advantage of using the solar spectrum more efficiently [5]. Another approach is deposition onto a textured, reflecting substrate. The light reflected from the back contact undergoes multiple internal reflections within the device, allowing weakly absorbed light to pass through the cell many times.

The major drawback of amorphous silicon is its low efficiency, caused by recombination at unsaturated bonds in the amorphous material. Exposure to light increases the number of these defects, so the efficiency of the device decreases to a lower but stable value during the first 1000 or so hours of illumination (the Stäbler-Wronski effect).

Alternatives to amorphous silicon are copper indium diselenide (CIS) and copper indium gallium diselenide (CIGS). These systems are not prone to light-induced degradation, and the very high efficiency of $16.6 \%$ has been obtained for thin-film solar modules based on CIGS. The technology for producing these modules is now close to commercialisation [6].

\section{$63^{\text {rd }}$ generation photovoltaic devices}

Even though the materials costs of thin film PV devices can be reduced to a very low level, it may still be difficult to bring down the overall production cost to the level where solar power becomes economically competitive to power produced from fossil fuels. This is mainly because of the vacuum processes involved in the production. Despite a substantial effort, it has proven to be an obstinate problem to bring up the deposition rates to a level where the high cost of production equipment is balanced by an equally high production volume. It is thus interesting that alternative PV schemes presently are being researched and developed. The two schemes outlined below show the promise of low materials cost combined with facile, low cost manufacture. If conversion efficiency and device durability can be engineered to meet the requirements for volume applications, these technologies may in the future be instrumental in bringing up the proportion of power generated by direct conversion from sunlight. 

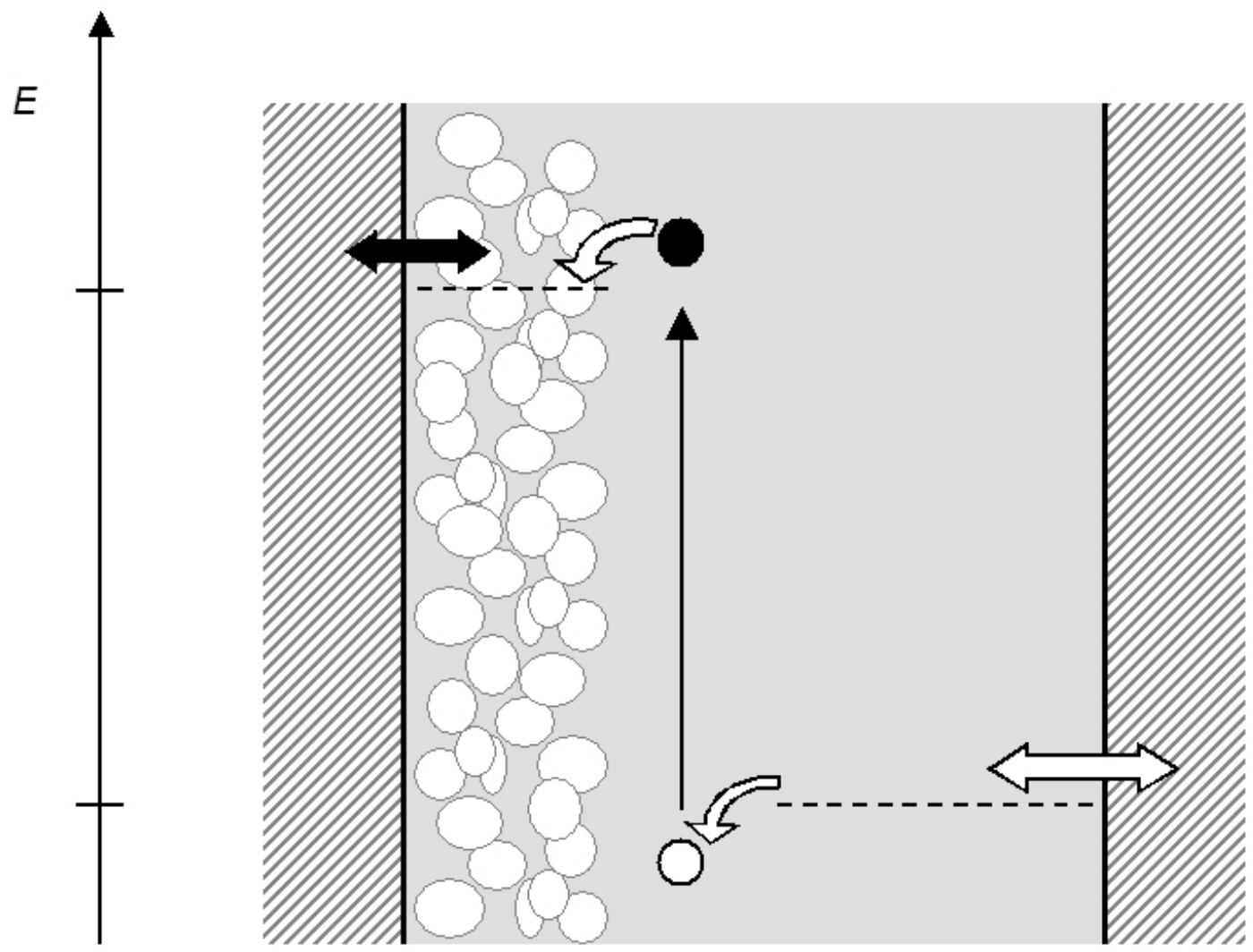

Figure 4. Principle of photoelectrochemical (PEC) cell

Photo-electrochemical (PEC) or Grätzel cells [7]. These cells implement the photovoltaic principle differently from the semiconductor solar cells - see Figure 4. Light absorption occurs in a transition metal complex (dye) that is absorbed on the inner surface of a nano-particulate, porous layer of anatase (titanium dioxide, a white pigment used in paints and tooth paste). The excited electron is immediately transferred to the conduction band of the anatase, and the remaining electron vacancy is replenished from a liquid or solid redox electrolyte. In this way the three steps in the photovoltaic process are carried out by different parts of the cell. The light is absorbed in a dye, which can be tailored with respect to spectral sensitivity. Charge separation occurs at the dye/semiconductor interface, which can be manipulated to reduce the recombination rate and to tailor the optical properties of the cell. Charge transport occur selectively in two different phases, and these materials can in principle be chosen among a series of different alternatives, although Grätzel's original proposal is still the most efficient combination known. Solar cells of this type can be produced using relatively simple techniques, and they are particular well suited for building integration. With proper engineering the price of glass encapsulated PEC cells is expected to be brought down to a level comparable with the prize of high quality double-glazing. 


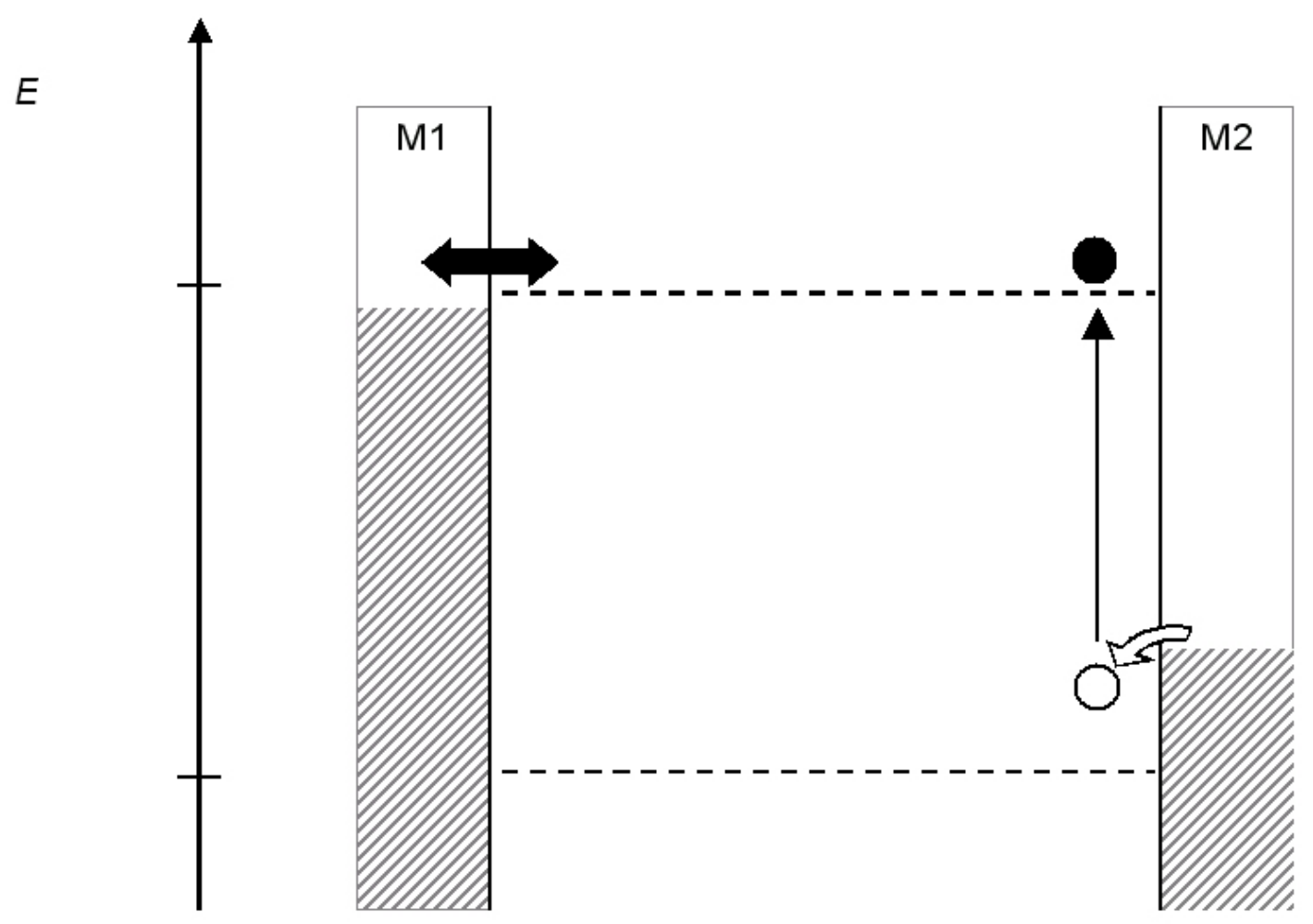

Figure 5. Principle of simple single-layer organic $P V$ with charge separation at one of the interfaces

Organic-Based Photovoltaics. Recently, substantial advances have [8] been achieved in the conversion efficiencies of PV's based on molecular (organic) semiconductors and on conducting polymers. In these organic-based PV's, excitons play an important role. Excitons are mobile, electrically neutral, optically excited states, which exist because they do not have enough energy to separate into an electron and a hole - in other words: the optical band gap is smaller than the electrical band gap. In organic materials this is often because charge separation involves a conformation change and thus requires a relatively large energy. One way to produce charge carriers from excitons involves dissociation at interfaces. This is illustrated on Figure 5 showing an organic semiconductor sandwiched between electrodes made of metals with different work functions. In the example the exciton dissociates at the high work function electrode whereby an electron is released to the conduction band. Schemes like this are not very efficient because of a high recombination rate, but as the field evolves, more complex schemes like single- or multi-junction devices and dye sensitised devices are emerging. The great promise of organic PV's is that they can be produced at low cost in large volumes using wellestablished polymer coating technologies.

\section{Conclusion}

Figure 6 illustrates the present state of the development of different PV technologies. The figure reports the highest conversion efficiencies demonstrated in single cells and modules, and it can be seen that $1^{\text {st }}$ generation devices based on single- and multi crystalline silicon now can be considered a mature technology with efficiencies approaching the theoretical maximum, which for silicon is less than $30 \%$. 


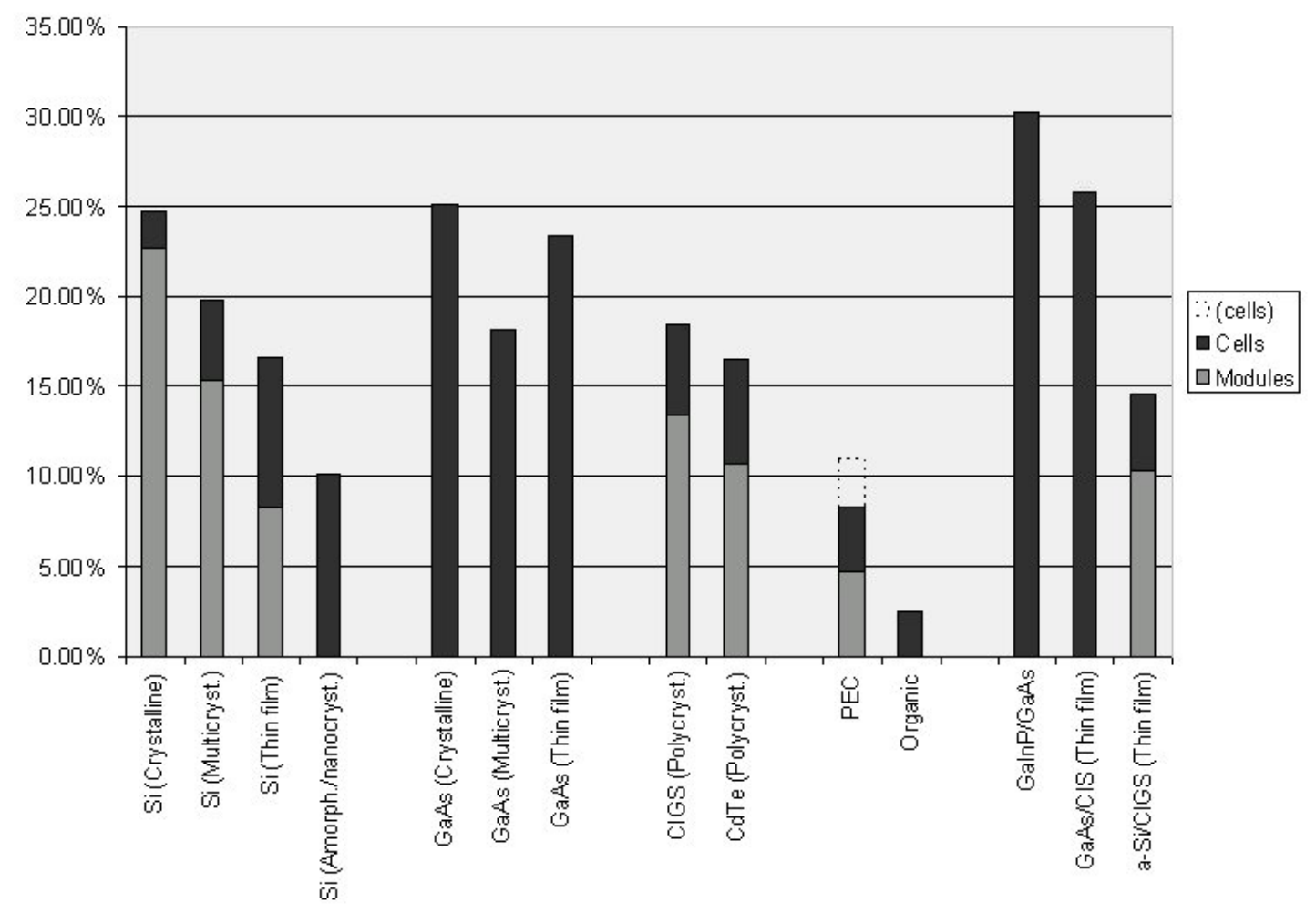

Figure 6. Record (Jan. 2003) conversion efficiencies for different PV technologies (data from [8])

Unless PV's are utilised as integral part of buildings or devices, the space that the solar cells take up may be considered a substantial part of the investment. It is thus essential to bring up the conversion efficiency to increase the power output per unit area. As can be seen from the figure, some of the tandem or multi-junction cells are beginning to improve their efficiencies above the theoretical limit for single junction cells. This development is expected to continue, and it is not unlikely that the future will bring PV devices with efficiencies approaching $50 \%$.

In this presentation, PV technologies that are not rooted in silicon semiconductor technology have rather presumptuously - been classified as $3^{\text {rd }}$ generation PV's. The examples mentioned have the inherent advantage of facile production, but on the other hand they do not benefit from developmental advantages gained in a cutting edge technology like the semiconductor technology. From the figure it can be seen that the conversion efficiencies demonstrated so far by these technologies are not by them selves impressive. The present implementation of the PEC principle has the potential of module efficiencies around $10 \%$, which is sufficient for making integration into building elements interesting. Intelligent building elements powered with PEC cells may aid in the thermal management of buildings and thereby reduce the amount of power that now is consumed for this purpose. With an improved combination of materials both a higher voltage and a reduction in the internal recombination may be achiever, which will increase the conversion efficiency further.

Organic-based solar cell technology is still in its infancy, but respectable conversion efficiencies have already been achieved. The key potential of this technology is the very high degree of freedom that can be attained by molecular engineering. Because organic molecules are not restrained to those configuration of elements that minimises the global free energy - as is inorganic semiconductors made in high-temperature processes - the variability in properties like band gap and conductivity that can be accessed is continuous rather than discrete, which gives a much better condition for device optimisation. The main obstacle is the durability of these inherently unstable materials under the exposure to light and a hostile environment. At the same time, the physics of these materials is still not well explored and much of the present research is guided by classical semiconductor physics that has proven inadequate to fully describe the localised excitations in organic semiconductors. There is however rea- 
son to believe that these problems may be - at least partially - overcome, and that low-cost organic solar cells eventually will find their market.

For reasons stated above, it is fair to assume that new PV technologies in the future will contest the total dominance of silicon-based devices on the PV market. As these alternative devices have different performance-price profiles they may pave the way for utilisation of solar power in new application areas, and thereby help to increase the share of power produced from sunlight.

\section{References}

1. Denis Hayes, 'Sunpower' www.energyfoundation.com (2000).

2. M.A. Green, Physica E 1411 (2002).

3. V. Parente, J. Goldemberg, and R. Zilles, Prog. Photovolt: Res. Appl. 20571 (2002).

4. T.M. Bruton, Solar Energy Materials \& Solar Cells 723 (2002).b

5. A. Goetzberger, J. Luther, and G. Willeke, Solar Energy Materials \& Solar Cells 741 (2003).

6. J. Wennerberg, J. Kessler, J. Hedstrom, L. Stolt, B. Karlsson, M. Ronnelid, Solar Energy 69241 (2001).

7. A. Hagfeldt and M. Grätzel, Acc. Chem. Res. 33269 (2000).

8. S.E. Shaheen, C.J. Brabec, N.S. Sariciftci, F. Padinger, T. Fromherz, J.C. Hummelen, Appl.Phys.Lett. 78841 (2002).

9. M.A. Green, K. Emery, D.L. King,S. Igari, W. Warta,, Prog. Photovolt: Res. Appl. 1139 (2003). 


\title{
Solar PV Rural Electrification Lessons from South Africa and Zimbabwe
}

\author{
Yaw Afrane-Okese \& Maxwell Mapako \\ Energy and Development Research Centre \\ University of Cape Town \\ South Africa \\ yaw@energetic.uct.ac.za \& mpkmax001@mail.uct.ac.za
}

\begin{abstract}
This paper draws lessons from field observations and interviews of solar energy service providers and customers in South Africa and Zimbabwe as well as analysed data from household energy surveys in rural areas where solar photovoltaic (PV) electrification has been implemented. It deals with many issues involved in the dissemination of solar PVs such as impacts on poverty alleviation, provision of energy needs of the poor, energy service flexibility, and environmental benefits. The paper also analyses stakeholder satisfaction issues and concerns like subsidy requirement, maintenance provision, service and installation fees, ownership and payment methods, service levels, financial viability, high operating costs, income generation activities, de-installation, etc. The lessons from these issues would be useful for the consideration of solar PVs in the implementation of the Clean Development Mechanism under the Kyoto Protocol.
\end{abstract}




\section{Introduction and Background}

The provision of universal access to electricity has been one of the main policy objectives of new democratic governments in Africa due to the huge expectations that emanate from transition from oppressive regimes to representative governance. However, this becomes extremely challenging when it gets to remote rural areas with dispersed settlements and low population densities. In Zimbabwe, whilst urban electrification has risen relatively high, over $90 \%$ in Bulawayo and over $80 \%$ in Harare, only about $5 \%$ of rural households are connected to the electricity grid. In South Africa, the massive electrification programme that followed the democratic transition in 1994 led to over $80 \%$ electrification of urban households by 1999 but rural households' electrification remained below 50\%.

Thus, off-grid solar electrification with photovoltaic (PV) panels has become an attractive option in both South Africa and Zimbabwe, as well as many African countries, for reducing the unit cost of providing basic electricity services to remote areas. Although the upfront cost of this technology is still very high, the justification for this attraction is buttressed by its international acclamation for reducing carbon dioxide $\left(\mathrm{CO}_{2}\right)$ emissions under the Kyoto protocol. The Department of Energy in Zimbabwe has vigorously promoted, supported and disseminated renewable energy technologies, especially, solar PVs for most of the post-independence era. However, it has become increasingly clear that, despite the considerable efforts to disseminate solar PVs for over two decades now, the impact is hardly noticeable. Taking a cue from past failures in the dissemination of solar PVs in rural areas, the South African government, in consultation with various stakeholders, has adopted the concessionaire fee-for-service model as the delivery mechanism for its massive off-grid solar programme in poorer remote communities since the beginning of 1999. The efforts continue but are unlikely to be more successful unless lessons are drawn from the past failures to inform future efforts.

The business model adopted by the South African Government for its off-grid solar programme is fee for service through public-private partnership with utility service providers or energy service companies (ESCOs). A detailed understanding of the institutional arrangements has been documented by Afrane-Okese \& Thom (2001). Five service providers are currently involved in the programme. For the South African situation, this paper mainly analyses the impacts of the operations of the EskomShell Joint Venture (JV) since it is the only one utility (or concessionaire as they are called) that has made significant impact so far. Its installation of solar home systems (SHS) started in February 1999 and by March 2000, about 6000 SHS had been installed in rural households in mostly the Eastern Cape Province.

In Zimbabwe, it has been estimated that 85000 solar PV systems have been installed (ESMAP 2000). The Global Environment Facility (GEF) Solar Project had three delivery modes, commercial, utility and NGO and ran from 1993 to 1998. A total of 12000 45watt equivalent systems were installed countrywide. The Japan International Cooperation Agency (JICA) ECSO Solar Project which started in 1997 installed two 50 system clusters in Kadoma and Kwekwe districts, and is still ongoing. The Chinese donation project installed 110 SHS complete with televisions, plus a PV water pump at Nzvimbo in Mazowe district in 1999. By far the largest number of systems, over 70000 were installed through private sector dissemination, which includes do-it-yourself (DIY) systems built up gradually by the owners. This has been active since the late 1970s.

\section{Research Objectives}

The main objectives of this paper are: 1) to examine the extent to which solar PV electrification supports the alleviation or the deepening of poverty, 2) to probe into the different ways solar PV provides means of meeting household priority energy needs, 3) to enquire about what flexibility exists in the energy service provision through solar PV, 4) to verify the acclaimed environmental benefits of solar PV and 5) to identify the factors that make the key stakeholders of solar PV dissemination dissatisfied and what concerns urgently need to be addressed to ensure successful implementation. 


\section{Research Methodology}

The information for the analysis in this paper is largely drawn from two recent rural household surveys - one in the Eskom-Shell JV area of operation in the Eastern Cape Province of South Africa and the other in three rural areas of Zimbabwe. The households surveyed in South Africa comprised 232 solarelectrified, 51 grid electrified and 65 non-electrified households. 135 households were surveyed in Zimbabwe in the remote rural areas of Sanyati, Nzvimbo and Makosa. The sample distribution of the Zimbabwean survey was 60 solar-electrified, 30 automotive battery-electrified, 30 non-electrified and 15 grid electrified households. Besides the analysis of the data from the two rural surveys, the paper also draws on extensive field experiences in the surveyed areas and a literature survey. The Zimbabwe case looks at the four different means of disseminating solar PVs in Zimbabwe described in Section 2 above.

\section{Research Findings}

\subsection{Solar PV Electrification and Poverty Alleviation}

One of the main drivers of the South African off-grid electrification programme was to ensure equity in accordance with the government's policy goal of universal access to electricity (DME 1998). Most of the poor people in South Africa live in the remote rural areas of the country. To avoid discriminating against the poor in the rural areas, off-grid electrification, which was perceived as becoming costeffective in remote rural areas, was integrated into the national electrification programme. Thus, after the first phase of the mass electrification programme in 1999, the government decided to ensure transparency and accountability in the allocation and management of subsidies to grid and off-grid electrification. Since grid electrification was already heavily subsidised, it was decided to provide a similar level of subsidy for off-grid electrification in order to speed up electrification access to rural poor areas, as well as support the promotion of renewable energy. Due to the deep level of poverty and remoteness of the former Transkei area in the Eastern Cape Province, the area became the obvious first choice for implementation of the off-grid electrification programme.

It is therefore interesting to examine the income distribution amongst households who have access to solar home systems through the implementation of the off-grid electrification programme in the Eastern Cape, compared with those with access to grid electricity, and those with no electrification. Figure 1 below shows the quintiles of household incomes amongst solar-electrified, grid electrified and nonelectrified households in the Eastern Cape off-grid concession area of the Eskom-Shell Joint Venture (JV). Although there are limitations in the assessment of the household incomes in this study, efforts were made to include many informal sources of income like remittances, pension, child grants, casual jobs (widely known as piece jobs in South Africa), informal selling, household businesses, etc. 


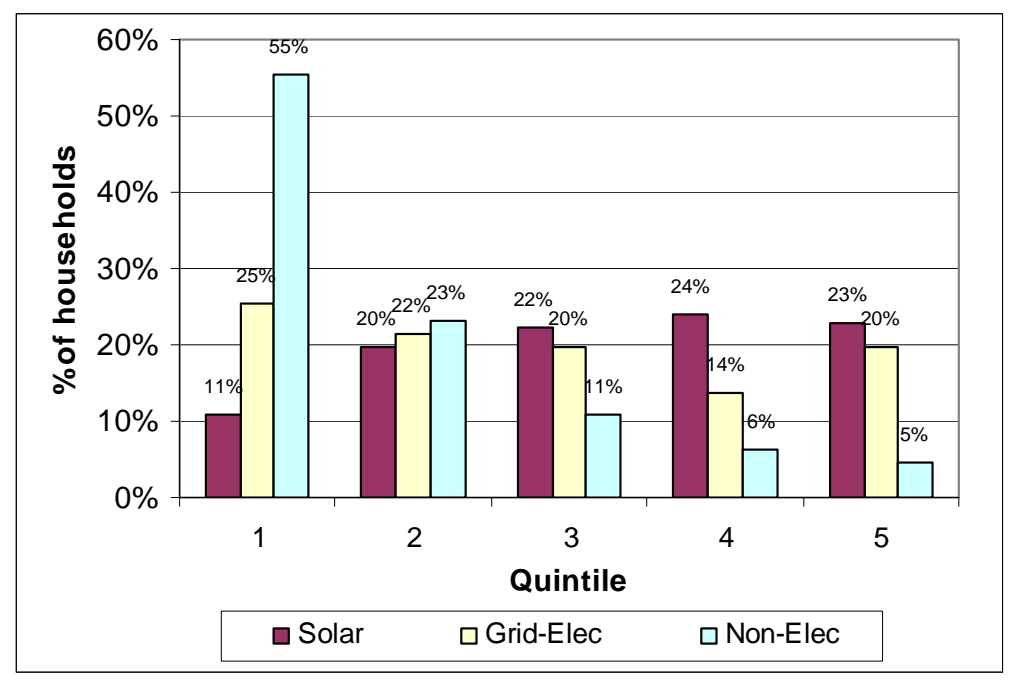

Figure 1. Income quintiles of rural solar-, grid and non-electrified households in the Eastern Cape, South Africa

Figure 1 clearly shows that solar-electrified households are the wealthiest in terms of household income. Whilst the solar-electrified households have about $31 \%$ in the lowest 2 quintiles and about $47 \%$ in the highest 2 quintiles, the grid electrified households have about $47 \%$ in the lowest 2 quintiles and about $34 \%$ in the highest 2 quintiles. The non-electrified households are clearly the poorest with almost $80 \%$ in the lowest 2 quintiles. Although not intended by the off-grid programme, the figure shows that the ultimate outcome seems to be a clear exclusion of the poor in this rural area from access to both grid and off-grid electrification. There are two obvious reasons for this observation. The first is that both grid and off-grid electrification require an upfront payment of a connection/installation fee of similar magnitude (R110). Even though this is a substantially subsidised amount, most of the non-electrified households cannot afford it due to extreme poverty. The second reason is that the approach of the off-grid electrification requires a monthly service fee of R58, which most households cannot afford. Thus, only the better off amongst rural households are able to meet the screening by the off-grid utility, Eskom-Shell JV, for households with regular sources of income. These households are mainly the ones with personal small businesses, pensioners, and civil servants like teachers, foresters, etc.

It is widely documented that women-headed households form the bulk of poorer households in the rural areas of South Africa (May et al 1998). Thus, if the off-grid electrification were to support poverty alleviation, one would expect it to support greater access by women-headed households. However, as shown in Figure 2 below, women-headed households have less access to solar electrification than men-headed households. Whilst women-headed households are in the majority amongst grid and non-electrified households, only $40 \%$ of the solar-electrified households are women-headed. It is clear from this that not much has been done to improve access to this modern energy service by womenheaded households in order to address poverty alleviation. Since the service is heavily subsidised from public resources, there is a concern that those who need support most are being left out and that the government subsidy is mostly going to the relatively rich. This could inadvertently deepen poverty instead of alleviating it in support of sustainable development. 


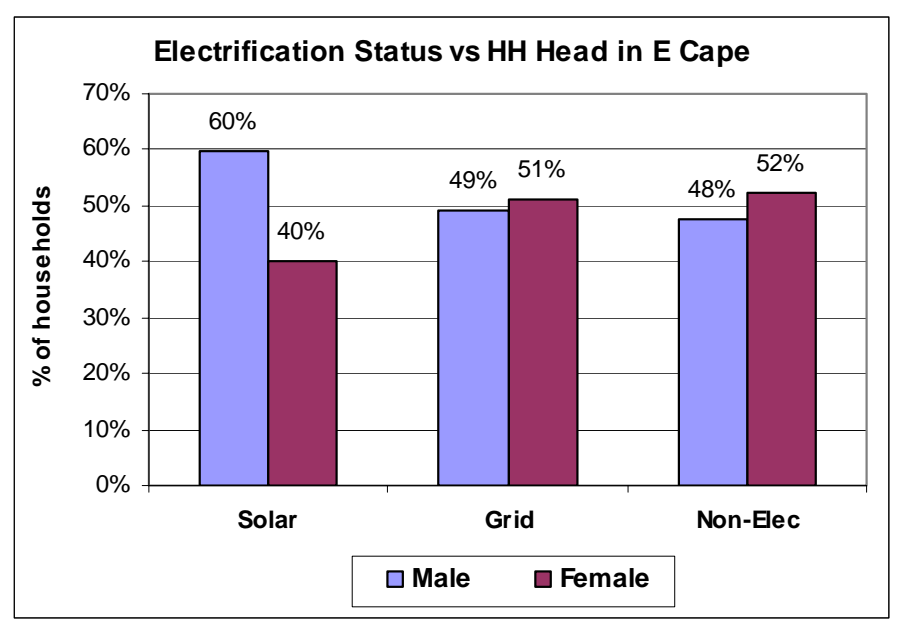

Figure 2. Disaggregation of solar-, grid and non-electrified households according the gender of the household head

The recent mini-survey of 135 households in three areas of Zimbabwe (Mapako 2003) confirms the common research findings in many developing countries (Afrane-Okese 2001) that low income households bear the highest burden in terms of their energy expenditure. Figure 3 shows that the percentage of the total household expenditure spent on energy drops dramatically in a curve to an insignificant horizontal as household income increases. Whilst households with monthly incomes below Z\$20 000 spend significant percentages of their expenditures on energy, households with monthly incomes above Z $\$ 20000$ spend not more than $3 \%$ on energy. Thus any dissemination of SHS that is purposed to support poverty alleviation should focus on making the energy service affordable to the low-income households.

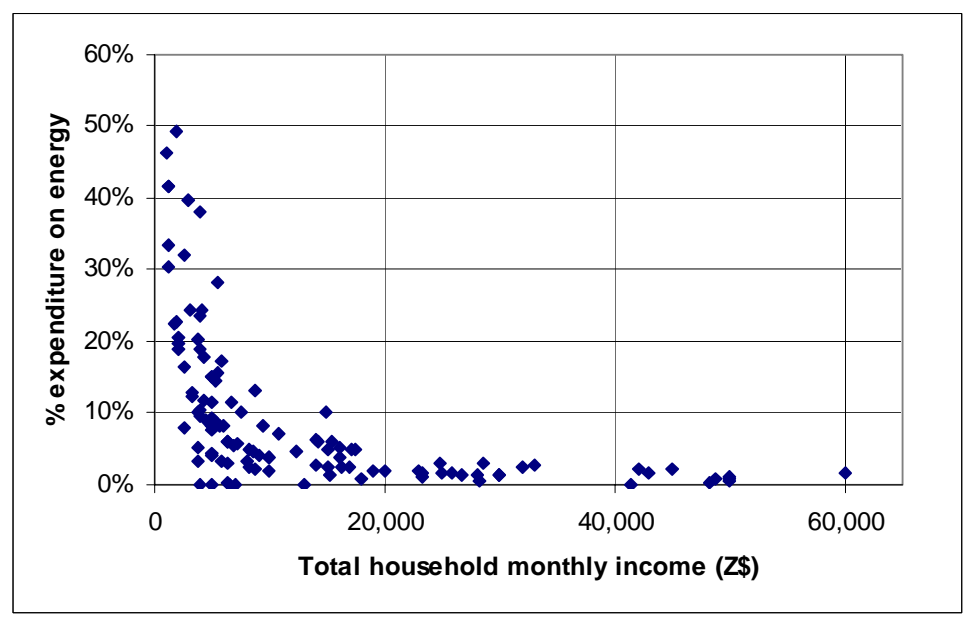

Figure 3. Variation of the percentage of household expenditure on energy with total household monthly income (Zimbabwe dollars)

However, the Zimbabwe household survey showed that the low income households tend not to have solar home systems due to their unaffordability. As shown in Figure 4, the percentage of households with access to grid or solar electrification generally increases with income whilst that of nonelectrified households and households depending only on automotive batteries for their electricity decreases with income. The main difference between the South Africa and Zimbabwe electrification patterns (Figures 1 and 4) is that most of the grid electrified households in rural Zimbabwe are in the highest income group whilst in South Africa majority of solar-electrified households are in higher income groups, although to a lesser extent. Thus grid electrification is mainly accessible to the higher income households in rural Zimbabwe. This is because, unlike in South Africa where most rural electrification is subsidised, in Zimbabwe most rural electrification specifically targets rural service cen- 
tres, not households. Therefore rural households far away from the service centres who insist on getting connected to the grid have to pay a high connection fee which the poor cannot generally afford.

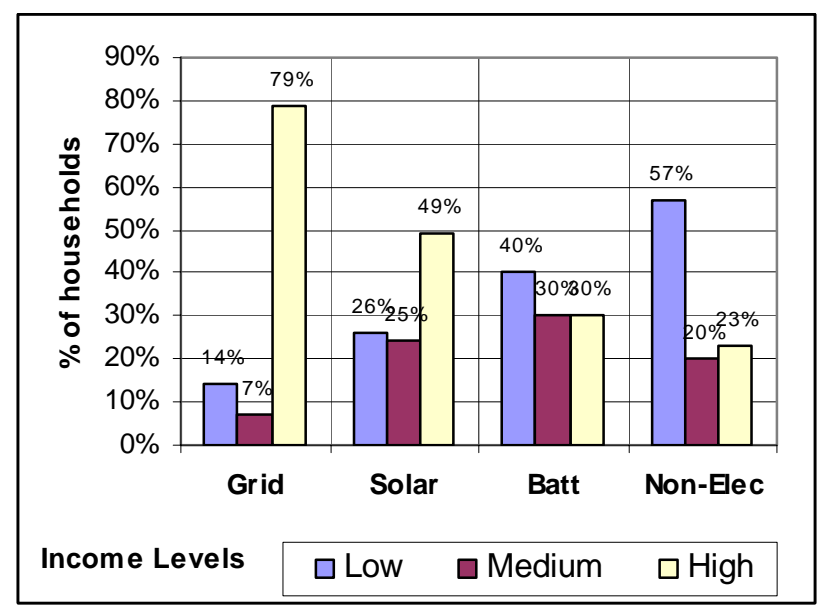

Figure 4. Income distribution amongst grid, solar-, battery and non-electrified households in Zimbabwe

This marginalisation of the poor is also confirmed by the different means of SHS dissemination. A clear example is the GEF Solar Project in Zimbabwe which offered commercial concessional loans and a waiver of taxation on the importation of solar equipment under the project and yet the majority of clients in the project were rural-based civil servants who are better off in terms of income (GEF PMU 1998). Figure 5 shows that the highest income group forms the majority of those owning SHS through private means and those through the commercial concessional loan arrangements of the GEF Solar Project. This shows that where households have to purchase their own systems either privately or through special commercial arrangements with certain companies, it is mostly the rich who gain access to the systems. In the special Chinese donor project in Nzvimbo, Zimbabwe, where no payment was required in terms of installation and service fees, there is no particular income pattern amongst the beneficiary households in Figure 5. The JICA Project which required a monthly service fee but no initial installation fee seemed more appealing to the medium income group. In this case, the lowest income group probably found the monthly service fee not affordable. It is worth noting that although the JICA Project was targeted at communities that were generally better off, the service level of $25 \mathrm{Wp}$ initially provided was so low that it was only attractive to a small percentage of the high income group.

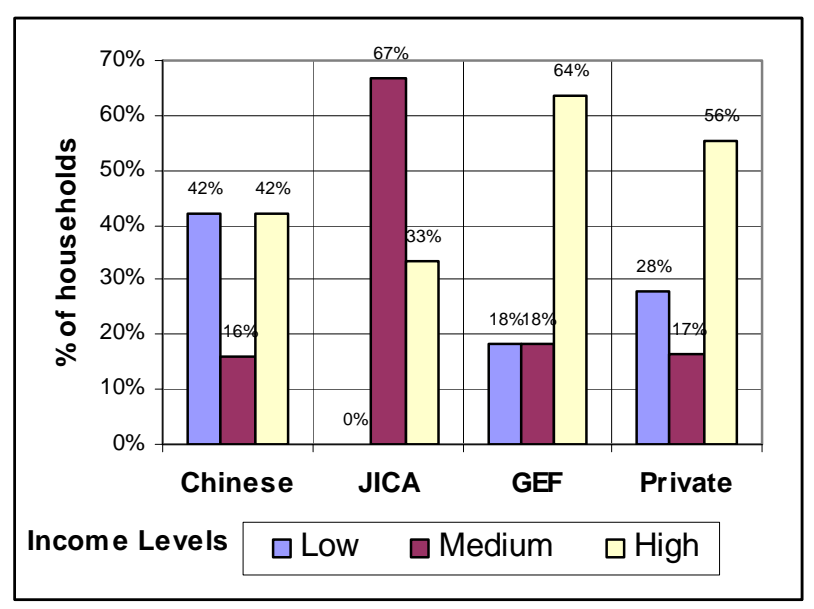

Figure 5. Income distribution amongst different dissemination modes of PV modules in Zimbabwe 


\subsection{Meeting Household Energy Needs through Solar PV Electri- fication}

Solar PV electrification has been making some impacts in the lives of rural households in both South Africa and Zimbabwe in terms of improving the quality of lighting for general household use, enhancing children's studies at home and improving security around the house at night. It has also improved the welfare of households in terms of the provision of entertainment, information and education through media applications by powering radios and black and white televisions. However, due to the low power output of solar PVs compared to its cost, the technology is still incompatible with most critical applications that would have made a real difference in the lives of households (Karekezi and Kithyoma 2002). The approach of solar PV electrification has in many cases not dealt effectively with the energy poverty plight of the 2 billion people mentioned in the Millennium Development Goals (DFID 2002).

The major energy needs that keep entrapping households in poverty are largely thermal (World Bank 1996). Unfortunately solar PVs have not been disseminated in a way that would provide the thermal needs of households that are often met through the burning of wood and dung. It has been widely documented that the household energy burden is mostly on women and children in the gathering and fuelwood and sometimes dung. Fuelwood gathering is full of drudgery and it takes time - time that could be devoted to more productive activities such as farming. Aside from the economic hardship associated with gathering and cooking with fuelwood and dung, the indoor pollution created by such fuels is a health hazard, particularly to women and children. In addition, the ecological damage to forests, woodlands and farmlands due to the use of fuelwood is well known. Thermal energy sources could provide opportunities for productive activities for the poor especially women. Thus the need to disseminate solar PV in an integrated manner with modern fuels like liquefied petroleum gas (LPG) which is about ten times more efficient than wood in producing energy.

The South African off-grid programme included this integrated approach popularly called "energisation" in its contracts with service providers, but the daunting nature of the implementation difficulties faced by the pioneering utility, Eskom-Shell JV, has led to less emphasis currently being placed on this requirement. For the over four years of its operation, Eskom-Shell JV has not yet managed to include the supply of LPG and paraffin for thermal applications in its services as initially required since it wants to finish dealing with its teething problems with the solar energy service before taking on more management challenges. The operational challenges facing the utility, including high levels of non-payment for services, frequent system technical failures, unexpected high operational costs, and overwhelming field management have been documented by Afrane-Okese et al (2001). It must be mentioned that one other utility operating in the north-east of KwaZulu-Natal Province of South Africa is making frantic effort to include the supply of LPG in its services, and it will be interesting to observe its customers' response, and the impact on its profitability.

Figure 6 below indicates the main cooking energy sources amongst the three categories of households in the rural Eastern Cape Province of South Africa. The obvious observation from the figure is that grid and non-electrified households are dependent on paraffin and fuelwood for cooking more than the other energy sources whilst the solar-electrified households are more dependent on paraffin and LPG for cooking. The higher use of LPG by solar-electrified households more than gridelectrified households is not an indication of its improved access to solar-electrified households since grid electrified households are generally more accessible by roads for the supply of LPG. However, the levels of LPG use are an indication of poverty levels since LPG is known to be expensive in rural areas due to its limited availability. The figure does not show any indication of general improvement in the access to LPG by all households through the implementation of the off-grid programme but it rather confirms its marginalisation of the poor and their continued dependence on fuelwood. 


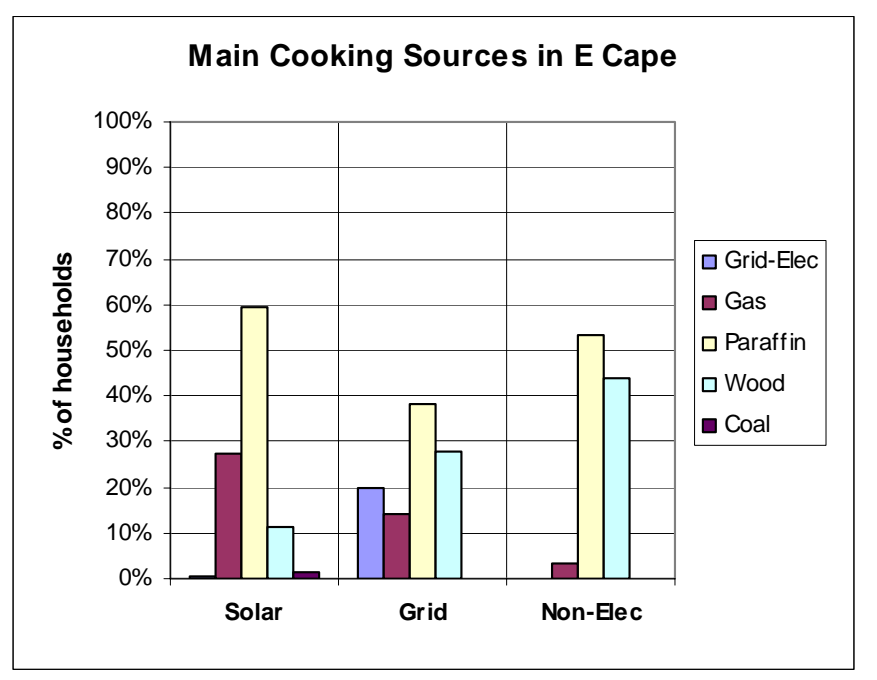

Figure 6. Percentage of households using energy source as main cooking energy amongst solar-, grid and non-electrified rural households in the Eastern Cape, South Africa

Another observation from Figure 6 is that electricity use as the main cooking fuel amongst rural dwellers is fairly low (about $20 \%$ in this case). This seems to confirm the generally accepted assertion in South Africa that SHS should suffice for the needs of rural households since electrified rural households hardly use electricity for thermal applications due to its cost. However, a closer examination of the average monthly electricity expenditure of R30, which translates into about $78 \mathrm{kWh}$, shows that the consumption is significant enough and it is above the qualified consumption rate approved for the poverty tariff (50kWh) (UCT 2002). Apart from the secondary use of grid electricity for cooking and water heating, it is also conveniently used for almost all refrigeration, colour TV and sound/music system (Hi-Fi) which is impossible for 50Wp PV systems.

In Zimbabwe, however, the situation is different. Almost all households with no access to the electricity grid depend on fuelwood mainly for their cooking energy as shown in Figure 7 below. On the other hand, grid electrified households use electricity mainly for their cooking since they mostly happen to be in the high income group. Paraffin is not used as a main cooking fuel in rural Zimbabwe households.

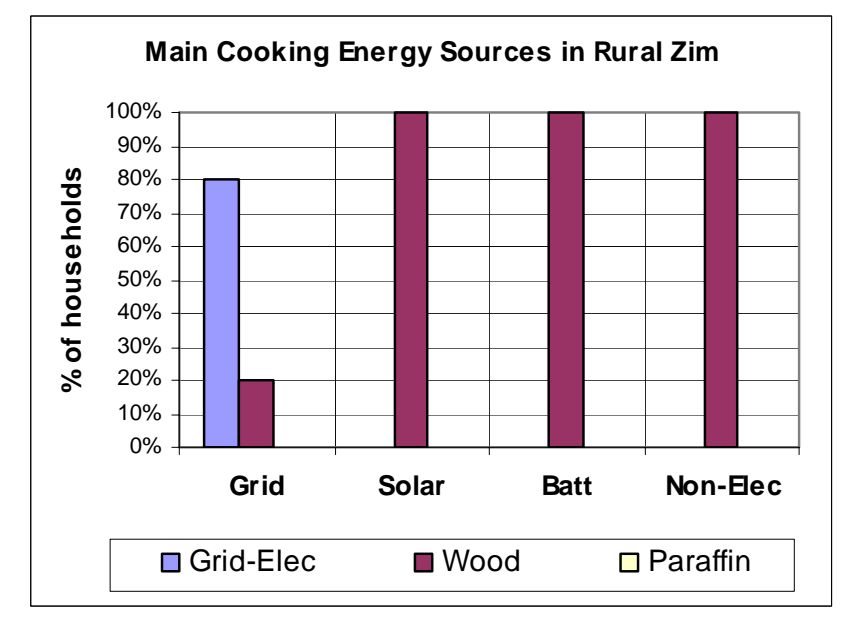

Figure 7. Percentage of households using energy source as main cooking energy amongst grid, solar-, battery and non-electrified rural households in Zimbabwe 


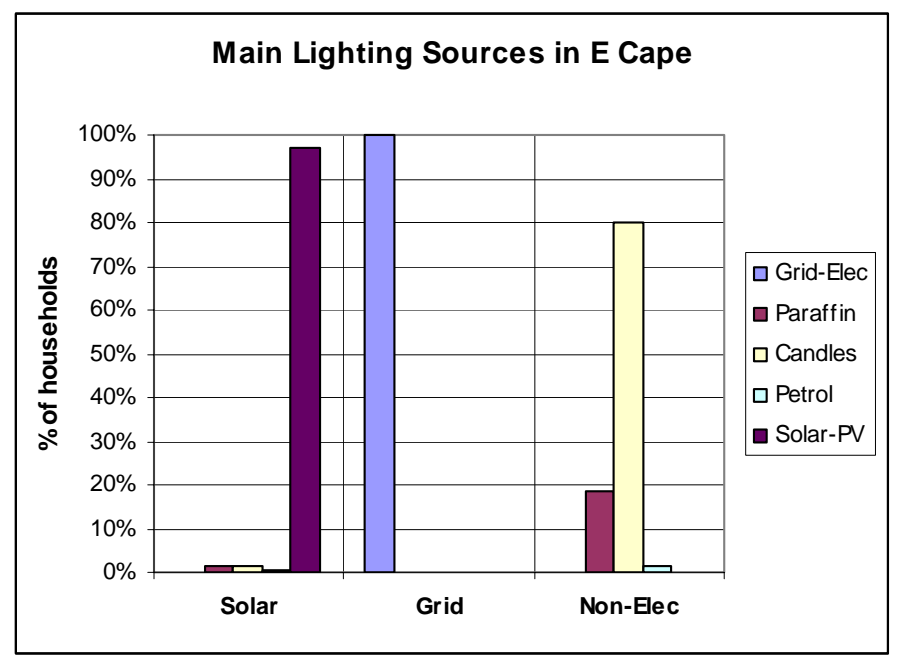

Figure 8. Percentage of households using energy source as main lighting energy amongst solar-, grid and non-electrified rural households in the Eastern Cape, South Africa

The main impact of SHS is lighting as shown in Figure 8. Comparing the lighting sources of non-grid and non-electrified households in the figure above, it is clear that solar lighting mainly replaces candle use in the Eastern Cape rural solar electrification in South Africa. As many as $80 \%$ of the nonelectrified rural households in the Eastern Cape mainly depend on candles for their lighting. In fact, in the north-eastern KwaZulu Natal in South Africa, candle use for the main lighting need of rural households is over $90 \%$. This is a clear indication of major improvement in the lighting quality of rural households in South Africa when they are solar-electrified. On the other hand, it also shows that solar lighting has insignificant benefits in terms of $\mathrm{CO}_{2}$ emissions reduction in South Africa since the shift is mainly from candles with insignificant emissions.

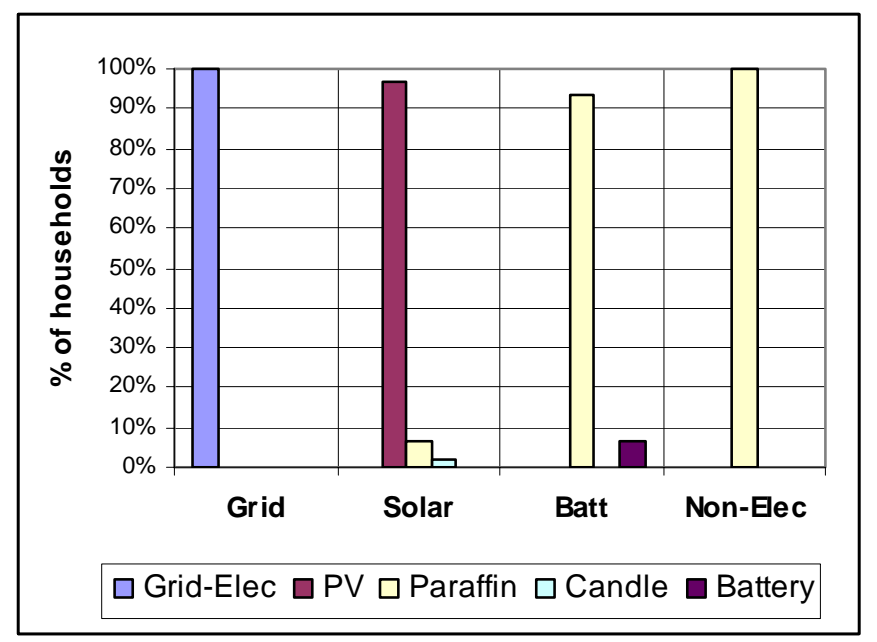

Figure 9. Percentage of households using energy source as main lighting energy amongst grid, solar-, battery- and non-electrified rural households in Zimbabwe

In Zimbabwe too solar PV has made a significant impact as the main lighting source in rural households as shown in Figure 9, although the shift is from paraffin instead of candles. Non-electrified rural households in Zimbabwe can afford to use paraffin for lighting instead of candles which are largely used in South Africa because paraffin is more subsidised in Zimbabwe compared to South Africa. Although the $\mathrm{CO}_{2}$ emission reduction is still insignificant, it is more than in the South African situation since the fuel shift is from paraffin and not candles.

This positive picture of fuel-shifting to solar PV as the main lighting fuel becomes less convincing when one takes a closer look at the secondary sources of lighting in the rural households. What do 
households really mean when they say solar PV is the main lighting fuel? Do they switch completely from the other fuels or the switch is partial? In most cases it is partial fuel-switch. Some of them mean that it is the main lighting fuel when it is working. Others mean it is the main lighting fuel for the rooms mostly used but for the other rooms candles or paraffin are the fuels used. For some others, candles and paraffin are the fuels for the period of the night when solar lighting is not available. Figure 10 shows that over $70 \%$ of solar-electrified households in the Eastern Cape still use candles for some lighting.

Figure 11 gives an indication of the level of satisfaction with solar lighting amongst rural households in the Eastern Cape. In spite of the high improvement in the quality of lighting compared with candle lighting, most solar-electrified households prefer to shift to grid electric lighting if they could get the opportunity. Only a few of those who have not tasted solar/electric lighting (non-elec) still think it is better than nothing. This raises a fundamental question concerning the sustainability of the solar energy service. The dissatisfaction with the solar lighting is due to many factors like the unreliability of the service, the inconvenience of a limited time of use, the high cost of the service, the impossibility of moving the lamp from one to the other like candles and paraffin lamps, etc.

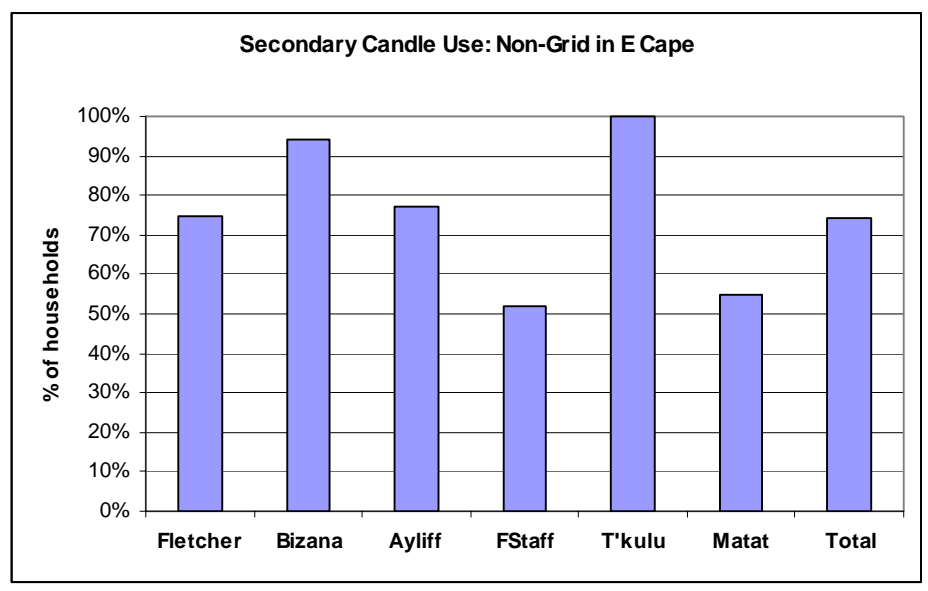

Figure 10. Percentage of households using candles for some amount of lighting in solar-electrified households in different areas in the Eastern Cape, South Africa

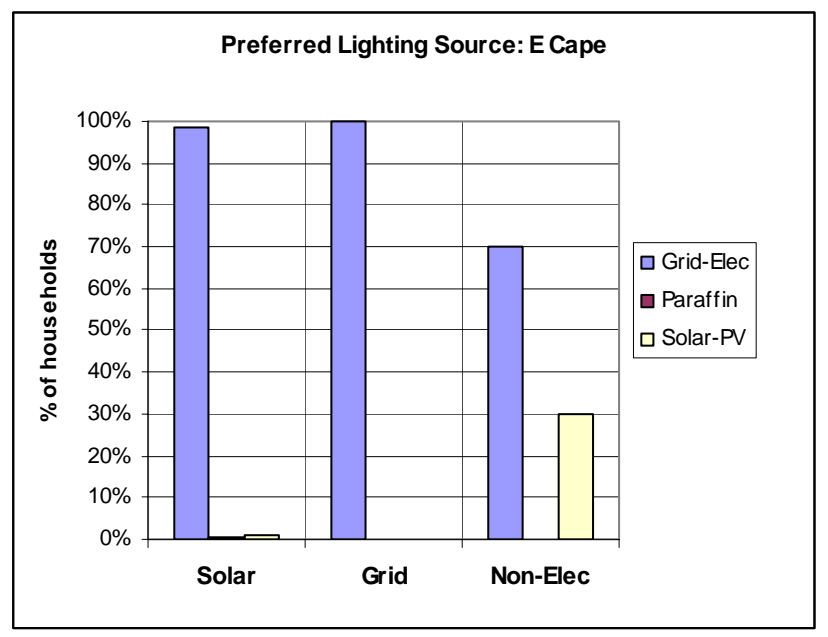

Figure 11. Percentage of households preferring a particular energy source for lighting amongst solar-, grid and non-electrified rural households in the Eastern Cape, South Africa 


\subsection{Flexibility in solar energy service provision}

The main lesson on the flexibility of solar energy service provision is that the PV dissemination approach that prescribes one size of module for all recipients runs a very high risk of incurring deep customer dissatisfaction that may consequently lead to non-payment and the attendant high cost of deinstallation of systems. Where the prescribed system size is too small in comparison with the lighting and radio/TV power demand of the clients, public pressure can be brought to bear on the project as it happened in the Zimbabwe JICA project. The most satisfaction seems to be where clients were free to select systems that suited their needs. Satisfaction with such systems obviously depends on the client receiving good advice on systems sizing, something not always possible where company sales persons are keen to make a sale. It is interesting to note that regardless of system size, clients end up wanting more power than solar home systems can provide.

In the survey of 232 solar-electrified households in the Eastern Cape, at least $8 \%$ of the households indicated that they had more than one SHS even though it was not allowed under the South African off-grid electrification programme. A third of the households with multiple systems had 3 or more systems while two-third had 2 systems. The main intention of most of these households was to be able to power their colour TV which was not possible with the prescribed 50Wp systems. Even though multiple systems would still not provide the power required for the colour TVs, the agents of the utility failed to advise them against that possibly due to the zeal for more sales. Eventually, these households have become very dissatisfied with the service. Figure 12 below indicates the number of unused appliances amongst solar- and non-electrified households in the Eastern Cape. The TV shown in the figure is not the black and white type but the colour type which cannot be powered by the 50Wp systems. SHS clients complain a lot about their inability to use their colour TVs and refrigerators, and they cannot understand why they should not be allowed to pay more to get what they want. Over $50 \%$ of them have some electric appliances they cannot use due to lack of the required power.

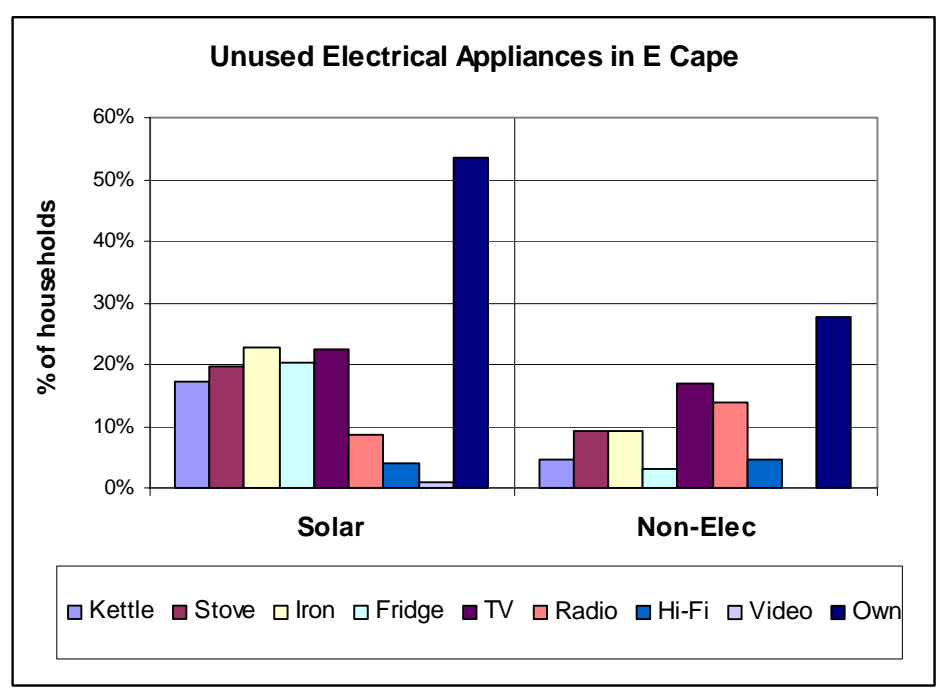

Figure 12. Percentage of households having unused appliances amongst solar- and non-electrified rural households in Eastern Cape, South Africa

In the Private Sales and DIY dissemination of SHS in Zimbabwe, the client is free to purchase a solar home system, constrained only by availability of components, and cost. Selection seems to be dictated more by cost of each component and the ability to afford at the time of purchase. Costly components not regarded by clients as critical, which in most cases are the charge/discharge controllers, are often left out. The outcome in practice is that many of these solar home systems are not optimally configured and installed. The mismatched systems may perform poorly due to weak links, bringing down the overall level of service delivered to the owner.

In the GEF Solar Project in Zimbabwe, flexibility of the level of service delivery was more reasonable. The main constraint was that the project equipment warehouse did not always have the full range of component sizes. Companies were at times forced to substitute the ideal size of module or battery 
with the nearest available in stock. Figure 13 shows the prevalence of different sizes of modules installed by the GEF Solar Project which is an indication of the satisfaction of wider range of needs. Ability to afford was the other obvious constraint for clients in this project, though the resultant compromise of mismatched systems was unlikely in this case, since all key components had to be included to ensure approval of the installation by the Project Management Unit.

The JICA Solar Project in Zimbabwe (1997 to date) initially took a rigid approach whereby all systems had to be small to ensure inclusion of poorer households. The irony was that the areas selected for the installations were however relatively affluent. The $25 \mathrm{Wp}$ systems limited for powering 2 lights, or one light and a power point for a radio therefore fell far short of the power needs of households who needed to power radios, lights, and televisions. The project was forced by popular pressure to relent and offer an expansion option to $56 \mathrm{Wp}$ with three lights and a power point for a black and white TV or a radio. This bigger option had been taken up by half of all clients by late 2002 .

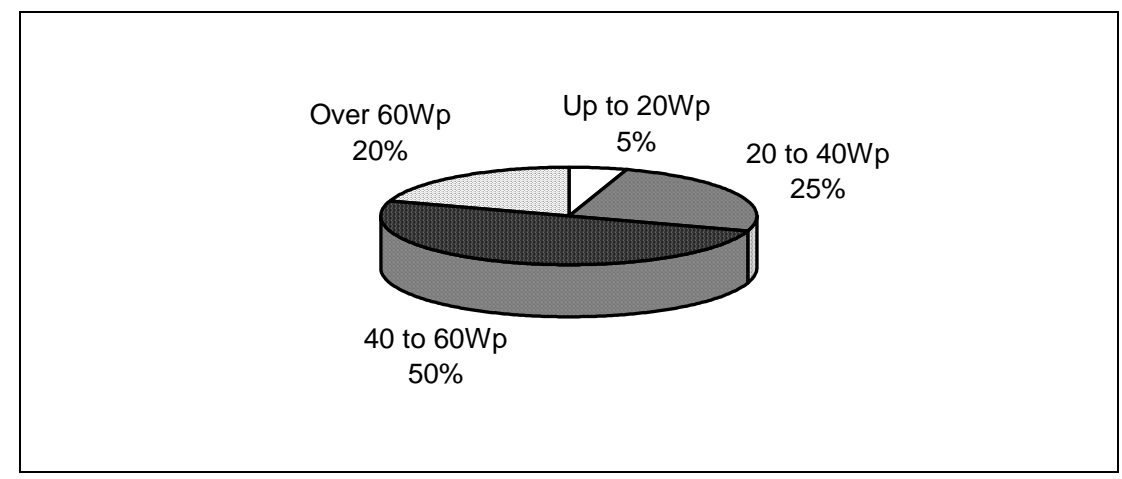

Figure 13. Sizes of modules disseminated in the GEF Solar Project

(Source: GEF PMU, 1998)

Only one $70 \mathrm{Wp}$ four-light option was offered in the Chinese donation project. No clamour for larger systems was seen after installation of the solar home systems. Expectations were still unrealistic, with households wishing to power stoves and other high power appliances with solar PV systems. This could be an issue or low awareness, or could indicate general discontent with the power level of solar home systems, even if the $70 \mathrm{Wp}$ systems are at the upper end of the available power range in Zimbabwe.

\subsection{Environmental and Health Benefits of Solar Electrification}

The most attractive thing about the use of SHS is the fact that it does not lead to emission of $\mathrm{CO}_{2}$ into the atmosphere like other fuels, and it does not cause indoor air pollution. Thus, in spite of its high upfront cost for developing countries, it is unquestionably justified amongst many experts for reducing $\mathrm{CO}_{2}$ emissions under the Kyoto Protocol. Its attraction is mainly for the Clean Development Mechanism (CDM) with the double potential benefits of improving the quality of life (development) as well as reducing $\mathrm{CO}_{2}$ emissions. Thus it is becoming fashionable to promote so-called innovative delivery mechanisms that would increase the market share of solar energy without paying much attention to the environmental impact of the means of achieving this. Little have many questioned whether the increased market share of solar energy through the fee-for-service approach which is evolving has also got the same positive effect on the environmental impacts.

Research conducted in the Eastern Cape Eskom-Shell JV project shows that $\mathrm{CO}_{2}$ emissions through operational motoring could be far exceeding the assumed emission reductions from SHS dissemination. Combining this with the carbon emissions associated with the manufacturing of the solar PV cells probably makes the SHS service compound the global problem of carbon emissions, instead of helping to curtail it. This is where climate change advocates must be cautious in their promotion and support 
for climate-friendly energy services without critically analysing well the whole cycle of the service delivery.

As a rough indication of the magnitude of carbon emissions in disseminating SHS through the utility route, it is worth considering the motoring requirements of the Eskom-Shell JV operational staff. During field visits to the company about a year ago, the General Manager and the Operational Manager were driving about 6000-8000 km/month each while each of the 6 Area Managers were making not less than $6000 \mathrm{~km} /$ month. Almost all the cars used are 4-wheel drives and considering the fact that larger portions of these journeys are made at a very slow pace in the difficult hilly terrain areas, their fuel consumption levels could be very high and so also are their carbon emission levels. The mileage covered by the operational staff could even be more now since they have been doing a lot of deinstallation in order to stimulate service fee payment. Despite all these, Eskom-Shell JV has already collected international prices for its "environmentally-correct" business practice. The challenge is to mobilise and re-direct all the climate change monies "flying around" into supporting the operations of SHS dissemination so that their operational costs (of which motoring costs form a significant portion) could be drastically re-organised and reduced, and hence effectively reduce some $\mathrm{CO}_{2}$ emissions.

There is a need to reduce the unjustifiably high premium placed on the environmental benefits of SHS so that policy makers in developing countries are allowed a free hand to realistically separate cost-reflective options from mere environmental activism. The unquestioned high expectations placed on solar energy projects are what have led to many implementation failures. As shown in this paper in analysing both the South African and Zimbabwean lessons, the environmental benefits of solar PV dissemination should be measured based on some of the following questions:

- How many of the solar systems went to the real poor people who would have been walking miles to cut trees and cooking for hours in an indoor air polluted environment?

- How many solar systems got installed compared to the investment in the project? Could other options not have provided a more long-term reliable access with less or similar investment?

- How many light points are produced the installed solar system per unit cost besides the improved quality of light?

- What percentage of households has managed to switch completely from using candles and paraffin for lighting? What are the candle or paraffin consumption levels of those who have switched partially? The tendency for most environmental calculations is to use fully switch assumptions.

- What is the average downtime of the solar systems, because whenever the systems are not working the users would revert to their paraffin or candles?

- For those systems working, what percentage is working fully and partially?

- How are old batteries disposed of or recycled?

\subsection{Stakeholders Dissatisfaction and Concerns}

The general concerns and dissatisfaction with the benefits or impacts of solar PV dissemination to the relevant stakeholders involved should be of paramount importance if the impacts are to remain sustainable. Although there are many stakeholders involved in the dissemination of solar PVs, these are simplified and grouped in this paper into three main classes namely, the customers, the service providers and the government or donors.

\section{Customers}

The customer stakeholder group includes individual households having SHS in their homes and communities benefiting from solar-electrified facilities like water pumps, schools, clinics, public telephones, etc. Some of the main positive benefits were alluded to in Section 5.2 of this paper. This section deals with the negative aspects of solar PVs that require urgent attention. These sources of dissatisfaction and concerns of customers include the following:

Lower service level compared to the high service fees and system costs, as well as the subsidies from government and donors. Although customers are grateful for the difference solar PV is making in their lives, they are also concerned whether it is good value for the money they pay. Comparing with 
their grid electrified neighbours; they express shock at how little their solar PV can do for them in spite of all the costs involved. For example, the R58 monthly fee paid by customers in the rural Eastern Cape, South Africa, for their $50 \mathrm{Wp}$ systems produces about $6 \mathrm{kWh}$ of electricity monthly. On the other hand, the average monthly electricity expenditure of R30 by their grid-electrified counterparts gives them about $78 \mathrm{kWh}$ monthly. In Zimbabwe, the monthly Z $\$ 75$ paid for the $25 \mathrm{Wp}$ systems of the JICA ESCO Solar Project in 1997 could produce energy service of about 3.4kWh compared with the $225 \mathrm{kWh}$ that their grid electrified counterparts were enjoying from the same amount. This issue of paying more for less service does not go down well with many customers. Only few customers are able to appreciate the fact that solar PV electricity is produced in a remote area where the grid would not be for some years and therefore higher fees are required for the sacrifices made.

Cumbersome payment arrangements unsuitable for remote rural communities. Often the monthly payment arrangements for either service fees or loan instalments do not coincide with the annual or semi-annual times of farm harvests when most poor rural people receive their incomes. The frequency of travelling to make monthly payments is also of major concern due to the poor transportation infrastructure and services in rural areas.

Difficulties with the payment requirements of fee-for service projects. In both Zimbabwe and South Africa, most rural customers continue to find it difficult to understand the fee-for-service concept which requires a mandatory payment of monthly service fee whether the household uses the energy service or not. The unpopularity of the concept mainly stems from the fact that the income sources of most rural communities are usually erratic, and annual or semi-annual, instead of the required monthly income sources.

Unacceptable ownership arrangements in fee-for service projects. Customers have difficulty with the ownership arrangements in the fee-for-service ESCO approach. They find it difficult to accept that they would own nothing in the end, in spite of their installation and regular monthly payments.

The inconvenience of frequent maintenance and poor system reliability associated with both privately- and ESCO-owned systems. This is even worse when the ESCO systems include sophisticated anti-tampering and prepayment devices, as in the case of Eskom-Shell JV.

Lack of integration of higher priority needs in the dissemination of solar PV projects. These include thermal energy needs, energy needs of community facilities, and energy for income generating activities. It is even shocking that lighting and media applications powered by solar PVs are often not priority needs of rural communities - they only accept them because they cannot afford to let free government subsidies or donations pass them by. Usually the priority needs are not even energy; cleaner water and improved roads may have higher priority.

The fear of de-installation when customers are unable to afford either the monthly service fee or the loan instalments. Sometimes the constraints are genuine, and communities feel they deserve a sympathetic hearing instead of automatic disconnection.

Lack of a broader range of energy services from which customers could choose to satisfy their priority needs.

Lack of upfront transparency around the community obligations required for the implementation of donated systems. These include payment for the maintenance and administration of donated SHS and community facilities like solar water pumps, solar-electrified schools, clinics, telephones, etc.

The difficult problem of battery replacement that arises in the aftermath of solar PV projects. This happens in projects that lead to private ownership of systems. Often during the projects, imported batteries are introduced into a country where the same type of battery is not locally available, or would be prohibitively expensive if available. Replacement batteries inevitably become the local automotive batteries. The difficulty arises because the setting of charge/discharge controllers must match the type of battery connected to the systems in question. Fluorescent lights pose similar problems in countries where the capacity to manufacture and repair them does not exist, and where continued availability of the tubes is not assured.

The lack of education on the choices and use of solar PVs and the powerlessness of not being able to even identify or fix minor problems of a system that sits in one's own dwelling. 
The service providers include fee-for-service utilities (ESCOs) who own the systems and only offer energy services for a fee. They also include solar companies who sell systems to customers for cash, or credit, or hire purchase, or through special commercial arrangements supported by donors or by government. NGOs like the Biomass Users Network (BUN) of Zimbabwe who undertake fee collection for the ESCOs also form part of this group of stakeholders.

Financial viability of the solar energy market remains one of the more difficult problems facing the dissemination of solar home systems in rural areas especially when it involves a lot of subsidies. The financial viability of the off-grid utilities in South Africa is heavily dependent on government subsidy for both capital and operational costs. R3500 out of a system capital cost of about R 4000 is paid for by the government as a subsidy, and recently, R40 out of the R58 monthly service fee is being paid by the government as part of the poverty tariff policy. The sustainability of this heavy dependence on subsidies is questionable and there are also concerns of other players in the market place whether this is not wiping out all the competition and stimulation that the solar energy market urgently needs. In the GEF Solar Project in Zimbabwe, special concessions were negotiated for equipment imported for the project. The concessions were exemption from import duty and surtax for the duration of the project (GEF PMU, 1998). Only 15\% sales tax was still payable on equipment sold by the project. In addition, the interest rate on loans taken out by clients buying solar home systems under the project was reduced to $15 \%$ compared to the bank rate which was about $23 \%$ at the time the project started in 1993 . The above concessions were restricted to the project and private sales did not benefit from this. In the aftermath of the project when these concessions were removed, many of the installing companies that had sprung up fell victim to the harsher operating climate and eventually collapsed (SEIAZ, 2001), leaving their clients without maintenance backup. The JICA Solar Project in Zimbabwe too did not attempt to fully simulate a commercial trial in that the ESCO was contracted to run systems that were already installed and operational. The Chinese-donated solar home systems and communal water pumps in Zimbabwe were given away free to households without clear assessment of the ability and willingness of recipients to pay for maintenance and spares. The value of these types of subsidy, which cannot be sustained beyond the project, is not clear. It may be more sustainable to target the available subsidies or donation toward the development of specific aspects of the market and its associated social issues as done in the Energy Services Delivery Project in Sri Lanka (Negandran 2001). The normal commercial lending approach has proved to be financially viable in Zimbabwe as indicated by over $85 \%$ of solar home systems in the country being installed by the private sector. However, this has been at the expense of the poor who fail to meet the loan conditions. The credit schemes run by commercial lending agencies require collateral, which is difficult for rural households to provide because they have no title deeds to their land, and often have limited assets.

The NGO approach in Zimbabwe allows the use of local knowledge of communities in which they are active to decide on eligibility for loans. This has been shown to be viable like in Sri Lanka, especially with the clustering of installations and facilitation of payment through the use of local agents who collect and bank instalments or service payments from clients for a commission.

In Zimbabwe the ESCO approach has shown that it was not possible to cover operating costs from the maintenance fees collected from clients. The ECN report that reviewed worldwide experience on solar PVs found this to be a global problem (Niewenhout et al 2000). Having larger clusters of solar home systems per technician, or having the ESCO closer to the cluster sites are some ways to reduce costs. In the Eskom-Shell JV project in South Africa, the need for harsh measures of de-installation in order to stimulate payment has led to unprofitably high levels of operational costs. According to information sourced from the company, it managed to increase fee payment levels of a paltry $50 \%$ or so in 2001 , to about $80 \%$ in 2002 . However, this was achieved at the cost of de-installing over 1200 systems. Apart from the negative impacts this has on their customers, de-installation also costs the company a great deal in terms of removing the systems, transporting and refurbishing them, storage, transportation and re-installation of the systems for new customers. In fact, de-installation is currently their highest operational cost.

The full ownership of the systems by ESCOs in South Africa has resulted in the utilities resorting to expensive electronic money collection and anti-tampering devices to protect their systems against theft, vandalism and non-payment. Apart from the additional capital costs associated with these de- 
vices, their frequent maintenance requirement in these remote rural areas also puts substantial operational costs burden on the utilities. If the ownership debate could be revisited as suggested by AfraneOkese et al (2001) and ownership transferred to the customers, it is likely that the threat of theft, tampering and vandalism would reduce drastically and the administration of payment, which is another significant operational cost would no longer be a burden on the service providers. This would in effect release the service providers to concentrate on the delivery of more quality service.

\section{Government or Donors}

For more effective off grid electrification programme governments and donors are, or should be, concerned about the following at least:

- The high failure rate of most donation and government subsidised projects. A clear example is the solar electrification of schools under the Reconstruction and Development Programme (RDP) funded by the South African and the Dutch governments. For the 1400 systems installed between 1996 and 1998 only about 6\% were found partly operational when researchers visited in 2000 (Oldach et al 2000). For a similar a school project in South Africa funded by the European Union (EU) that was aiming at installing 1000 systems, $40 \%$ of the systems were not operating properly within a year of installation when the same researchers visited the systems in 2000. The situation in the Chinese donated solar water pumping system in Nzvimbo in Zimbabwe is no different. There is a need for proper responsibility and accountability of such projects.

- The subsidy or donation requirements for solar PV projects are so high that their replication is always a problem.

- The impact of off-grid electrification has remained insignificant in spite of all the government and donor support. For example, the South African off-gird programme was planned to deliver at least 250000 systems in five years but the number of systems installed within over four years of implementation is still less than 10000 .

- The continuous dissatisfaction with solar energy services should be of great concern to governments and donors since it creates a bad image for government programmes and renewable energy.

- The disappointment that solar PV has not delivered much in terms of income generating activities to improve the quality of life and enhance individual independence.

\subsection{Concluding Lessons}

The poor do not generally benefit from SHS projects because the projects generally strive to operate viably and must screen potential customers for ability to pay. The poor are therefore either excluded from the outset, or get disconnected because they struggle to pay their instalments or service fees. What is even worse is that most solar PV projects are subsidised and since the subsidies generally go to the rich, the gap between the poor and the rich is exacerbated. Even if the poor get SHSs, these systems will not enhance their income-generating activities, instead they are likely to be a drain on already meagre finances. While donations may be a sure way to get SHSs to the poor, such projects must have criteria to ensure correct targeting. If ability to pay maintenance and component replacement costs becomes part of the criteria for getting a donated SHS, then the poor are also likely to be excluded. The question of whether the poor can access SHSs and operate them sustainably therefore still remains.

Although SHSs contribute to the improvement of quality of life in terms of improved lighting quality and access to media applications, the critical energy needs of households involving the drudgery many poor people endure through fuelwood collection, wood cooking and indoor air pollution are not integrated into the way SHSs are generally disseminated. Solar lighting, although important clearly meets a relatively low priority energy need. The complex pattern of use of the different lighting devices in the changing circumstances faced by households is probably not yet well understood, and switching claims need to be treated with some caution.

The provision of a wide range of systems size options to potential customers who are not sufficiently empowered to make informed choices is self-defeating. For flexibility to make sense, effective user 
information, and a wide choice that encompasses the known load range must be provided together. The information needs to be packaged in a form that the target customers can understand, including some form of size coding to facilitate component matchings for DIY systems. Given the evident desire to get ever-larger module sizes among households with SHSs, it is probably true that SHSs will never be able to satisfy their owners. This is chiefly because they fail to meet all thermal and cooling needs, and generally cannot meet the requirements of larger electronic appliances such as colour TVs and videocassette recorders.

The assessment of $\mathrm{CO}_{2}$ emissions saved by the replacement of paraffin and candles must be set against the additional emissions by motor fuels in project administration support activities especially in operational activities of ESCOs. Given the limited displacement of paraffin and candles, and the use of secondary lighting sources, caution needs to be exercised in making claims about the environmental benefits of SHS projects. The extent of displacement of candles and paraffin partly depends on the operational status of SHSs, and how adequately they cover the total lighting needs at each installation. If there is no battery recycling mechanism in place, it may be necessary to enforce a policy of some form of battery recycling on any projects that disseminate batteries.

The three main stakeholders in solar PV dissemination are the customer, off-grid utilities and government together with donors. For the customer, it is necessary to address dissatisfaction arising from the comparatively limited service level, coupled with poor value for money and unsuitable payment and administrative schemes that solar PV projects usually impose. Inexperienced off grid utilities who fail to consult widely often struggle to reduce operating costs, and some may easily overreact by adopting rigid automatic disconnections which can easily lead to a downward spiral. Governments and donors seem to have poured donations and subsidies into PV projects without pausing to take stock of lessons, or examining their motives vis-à-vis the needs of the target, often claimed to be the poor.

\subsection{References}

Afrane-Okese, Y and Thom, C 1979. Understanding the South African Off-Grid Electrification Programme, in ISES 2001 Solar World Congress, Adelaide, Australia, 25-30 November, 2001.

ESMAP 2000. Zimbabwe rural electrification study. Report 228/00. The World Bank. Washington.

Global Environment Facility/Project Management Unit (GEF/PMU) 1998. Progress report of the GEF Solar Project, 1997. Harare.

(Japan International Cooperation Agency (JICA) 1999. Final report of the study phase of the Zimbabwe electrification master plan study. JICA. Tokyo.

Karekezi S \& Kithyoma W 2002. Renewable energy strategies for rural Africa. Is a PV-led renewable energy strategy the right approach for providing modern energy to the rural poor of sub-Saharan Africa? In Energy Policy Special Issue, Volume 30 Numbers 11-12. Pages 1071-1086.

Mapako MC 2003. Survey of Sanyati, Nzvimbo, and Makosa.. Unpublished survey results.

Solar Energy Industry Association of Zimbabwe (SEIAZ) 2001. Renewable Energy News, JanuaryMarch 2001. SEIAZ. Harare.

Department of Minerals and Energy [DME] (1998), White Paper on Energy Policy for Republic of South Africa, DME, Pretoria.

May, J, Govender, J, Budlender, D, Mokate, R, Rogerson, C \& Stavrou, A 1998. Poverty and inequality in South Africa. Report prepared for the Office of the Executive Deputy President \& InterMinisterial Committee for Poverty and Inequality. Pretoria.

Afrane-Okese Y 2001. Socio-economic assessment of the energy burden on low-income households in urban Botswana. In Proceedings of the Domestic Use of Energy Conference, 10-12 April, 2001. Cape Town. Pages 1-7.

World Bank 1996. Rural energy and development: Improving energy supplies of two billion people. Development in practice series. Washington, DC.

Afrane-Okese Y, Mohlakoana N, dos Santos RR 2001. Operational challenges of large scale off-grid PV rural electrification programme in South Africa. Paper presented at the ISES 2001 Solar World Congress. Adelaide, Australia, 2001. 
University of Cape Town (UCT) 2002. Options for a basic electricity support tariff: analysis, issues and recommendations. A report for Eskom and the South African Department of Minerals and Energy, Research project 40093, Cape Town, February.

Department for International Development (DFID) 2000.Improving the success rate of photovoltaics. DFID Energy Research Newsletter, Issue 15, December, Oxfordshire.

Oldach R, Louineau J-P, Purcell C, Taylor S \& Montwedi M 2001. Economics and project management interventions in a large scale EU funded PV project in South Africa. $17^{\text {th }}$ European Photovoltaic solar energy conference, Munich, 22-26 October.

Negandran J 2001. Sri Lankan Energy Services Delivery Project Credit Programme: A Case Study. http://www.gefweb.org/ResultsandImpact/Experience_and_Lessons/GEF_Sri_Lanka_case.pdf, DFCC Bank, Colombo, May.

Niewenhout FDJ, van Dijk A, van Dijk VAP, Hirsch D, Lasschuit PE, van Roekel G, Arriaza H, Hankins M, Sharma BD \& Wade H 2000. Monitoring and evaluation of solar home systems: experiences with applications of solar PV for households in developing countries. ECN funded report, Utrecht. 


\section{Session 13: Technology and Policy Options}

Chairman: Hanns-Joachim Neef, IEA, France 


\title{
Considerations in Promoting Markets for Sustainable Energy Technologies in Developing Countries
}

\author{
Mark Radka \\ Division of Technology, Industry and Economics \\ United Nations Environment Programme \\ mark.radka@unep.fr \\ Sami Kamel \\ UNEP Risø Centre for Energy, Climate Change and Sustainable Development \\ Risø National Laboratory, Denmark \\ sami.kamel@risoe.dk
}

\begin{abstract}
The growth in demand for energy in both developed and developing countries is expected to continue an upward trend for many years, with a large portion of the increase projected to occur in developing countries. As these countries undertake various economic development initiatives and programmes it is important from a global environmental perspective that they increase the proportion of efficient, low carbon emitting energy technologies in the energy mix. This paper identifies a number of ways of improving markets that foster increased adoption of clean energy technologies in developing countries. The paper concludes that a holistic approach is needed if new technology promotion efforts are to succeed. Ensuring the appropriateness of the technology, and hence its sustainability, requires proper attention to social, economic and political criteria as well as the fundamental technical characteristics.
\end{abstract}




\section{Introduction}

The International Energy Agency (IEA) estimates that more than 60 percent of the increase in world primary energy demand projected to occur between 2000 and 2030 will come from developing countries (IEA, 2003). This is understandable considering both the rapid population growth and the increased per capita energy needs of these countries. At present there are approximately two billion people with no or very poor access to commercial energy in the world today, most of them living in rural areas of countries in sub-Saharan Africa and South Asia. Providing these people with the energy that makes economic growth possible - and doing so in an environmentally sound manner - is one of the principle challenges of our times, and an essential element in the quest for sustainable development.

Increased adoption of better energy technologies will require concerted and simultaneous efforts on many fronts, efforts that must be undertaken by a variety of institutions in both developed and developing countries. The purpose of this paper is to present some approaches that experience has shown help in deploying new energy technologies, principally those that help develop or strengthen markets that favor investments in renewable energy technologies. Although most of these approaches apply equally well to technology market development in either developing or developed countries, the focus here is on the particular challenges regarding renewable energy market development in developing countries. The main conclusion is that no one approach is usually adequate by itself to create markets and that a package of different but complementary approaches must be implemented together - or in a coordinated sequence - in order to create a conducive market environment for new energy technologies.

\section{The Goal: Market Transformation}

The objective by governments or the private sector when either introduces a new energy technology is to 'transform' the market in some manner. IEA defines market transformation as "a significant or even radical change in the distribution of products in a given market, in which the most efficient products substantially displace the least efficient ones" (IEA 2003).

IEA outlines three strategic considerations necessary for the success of programmes that aim to further the commercial deployment of energy technologies. First, the cost of technology must be reduced to a level where it matches the ability of potential customers or consumers to pay. This could be achieved, for example, through R\&D efforts that support the design and testing of new technologies and so bring down costs. Second, obstacles that may curb the smooth deployment of energy technologies should be identified so that effective means of overcoming these can be undertaken. Third, successful market creation requires that policy makers listen to concerns of the private sector and other market actors and shapers and not act in isolation.

Experience from developed countries has shown that the commercial viability of a clean energy technology is necessary but not always sufficient for that technology to be picked up by the market. Government support programs and initiatives can help new technologies gain a foothold at the early stages after their introduction. IEA (2003) states that "deployment policies and programmes are critical for the rapid development of cleaner, more sustainable energy technologies and markets." As new products increasingly manage to penetrate the market their performance tends to improve because more investment is injected into further development, experience is gained in their use, and the services they provide to users become clearer. A virtuous circle develops in which increased market penetration leads to technological improvement and reduced costs, making new technologies even more attractive to customers. So-called "viable business models" can have a powerful demonstration effect as well; that businesses built around new technologies are visibly profitable is a powerful attractant to new market entrants (Martinot et al., 2000). 


\section{Barriers to Market Transformation}

Numerous barriers can prevent markets for new energy technologies from developing despite the inherent attractiveness of the technologies. Often these barriers are specific to the technology and the country and so vary greatly from one context to another. Generalizations are possible, however, and Table 1 summarizes the most common market barriers to energy technology deployment according to the IEA (2003).

Table 1. Types of market barriers and remedial measures.

\begin{tabular}{|c|c|c|}
\hline Barrier & Key Characteristics & Typical Measures \\
\hline Non-competitive market price & $\begin{array}{l}\text { Scale economies and learning bene- } \\
\text { fits have not yet been realized }\end{array}$ & $\begin{array}{ll} & \text { Learning investments } \\
- & \text { Additional technical development }\end{array}$ \\
\hline Price distortion & $\begin{array}{l}\text { Costs associated with incumbent } \\
\text { technologies may not be included } \\
\text { in their prices; incumbent tech- } \\
\text { nologies may be subsidized }\end{array}$ & \begin{tabular}{|ll} 
& (Re)regulation to internalize "ex- \\
& ternalities" or remove subsidies \\
- & Special offsetting taxes or levies \\
- & Removal of subsidies
\end{tabular} \\
\hline Lack of information & $\begin{array}{l}\text { Availability and nature of a new } \\
\text { product must be understood at the } \\
\text { time of investment }\end{array}$ & \begin{tabular}{|ll}
- & Standardization \\
- & Labeling \\
- & Provision of reliable independent \\
& information
\end{tabular} \\
\hline High transaction costs & $\begin{array}{l}\text { Higher than normal costs of reach- } \\
\text { ing a decision to purchase and use } \\
\text { new equipment }\end{array}$ & $\begin{array}{l}\text { - Convenient and transparent calcula- } \\
\text { tion methods for decision making }\end{array}$ \\
\hline Risk perceptions of buyers & $\begin{array}{ll}- & \text { Perception of risk may differ } \\
\text { from actual risk (e.g., a "pay- } \\
\text { back gap") } \\
\text { - } \\
\text { Difficulty in forecasting over an } \\
\text { appropriate time period }\end{array}$ & $\begin{array}{ll}- & \text { Demonstration projects } \\
- & \text { Routines to make life-cycle cost } \\
& \text { calculations easy } \\
- & \text { Performance insurance or guaran- } \\
& \text { tees }\end{array}$ \\
\hline Finance & $\begin{array}{ll} & \text { Initial cost may set a high } \\
\text { threshold } \\
\text { - Imperfections in market access } \\
\text { to funds }\end{array}$ & $\begin{array}{ll}\text { - } & \text { Third party financing options } \\
\text { - } & \text { Special funding vehicles } \\
\text { - } & \text { Adjusted financial structure }\end{array}$ \\
\hline $\begin{array}{l}\text { Inefficient market organization in } \\
\text { relation to new technologies }\end{array}$ & $\begin{array}{ll}\text { - } & \text { Incentives inappropriately split } \\
\text { - owner/designer/user not the } \\
\text { same } \\
\text { - } \quad \text { Traditional business boundaries } \\
\text { may be inappropriate } \\
\text { - } \quad \text { Established companies may } \\
\text { have market power to guard } \\
\text { their positions } \\
\text { - Lack of sales, distribution, and } \\
\text { service networks }\end{array}$ & $\begin{array}{ll}- & \text { Restructured markets } \\
- & \text { Market liberalization that forces } \\
& \text { market participants to find new so- } \\
& \text { lutions }\end{array}$ \\
\hline $\begin{array}{l}\text { Excessive or inefficient regula- } \\
\text { tion }\end{array}$ & $\begin{array}{l}\text { Regulation based on industry tradi- } \\
\text { tion laid down in outdated stan- } \\
\text { dards and codes }\end{array}$ & \begin{tabular}{|ll}
- & Regulatory reform \\
- & Performance based regulation \\
\end{tabular} \\
\hline Low capital stock turnover rates & $\begin{array}{l}\text { Sunk costs, tax rules that require } \\
\text { long depreciation; inertia }\end{array}$ & \begin{tabular}{|ll}
- & Adjusted tax rules \\
- & Capital subsidies \\
\end{tabular} \\
\hline Technology-specific barriers & $\begin{array}{l}\text { Often related to existing infrastruc- } \\
\text { tures in regard to hardware and the } \\
\text { institutional skill to handle changes }\end{array}$ & $\begin{array}{ll}- & \text { Focus on system aspects in use of } \\
\text { technology } \\
-\quad\end{array}$ \\
\hline
\end{tabular}

Source: IEA, 2003 (modified) 
Martinot et al. (2000) have singled out high transaction costs as a serious market barrier in developing countries as being particularly troublesome. They state that "long distances, poor infrastructure, impassable roads during monsoons, low literacy rates (making educating customers difficult), and cashand-barter based transaction" all contribute to the high costs of technology deployment and adoption in developing countries. Furthermore, for technology markets to function efficiently, conditions of competition and free entry should exist (World Bank, 2000), and there should be free flow of information among market players including vendors, customers and regulators. Conditions in developing countries are rarely so favorable.

Through fieldwork in North Africa, UNEP has recently had a chance to survey the renewable energy sector in Egypt and identify various market barriers in that country as part of an effort to improve the market for clean energy technologies in North Africa (Table 2). Market barriers identified in two other project countries - Morocco and Tunisia - are similar to those in Egypt. 
Table 2. Market Barriers to RET Market Development in Egypt.

\begin{tabular}{|c|c|}
\hline General Type of Barrier & Description \\
\hline Awareness and Information & $\begin{array}{l}\text { Lack of awareness and information about RE technologies among } \\
\text { policy makers, energy planners, financing sources, and potential } \\
\text { users of the technology } \\
\text { - Misconceptions about RETs, including O\&M costs } \\
\text { - Levelized Cost of Energy (LCOE), carbon emissions, and life cycle } \\
\text { cost are seldom, if at all, considered by local energy planners while } \\
\text { designing off-grid power supply solutions; the main power system } \\
\text { design decision criterion is minimization of initial capital cost }\end{array}$ \\
\hline Financial & $\begin{array}{l}\text { Banks refusal to commit their own funds in RET projects due to } \\
\text { lack of knowledge about project evaluation techniques }\end{array}$ \\
\hline Energy Pricing \& Taxation & $\begin{array}{l}\text { Economics of some RETs (e.g., PV water pumping and PV home } \\
\text { systems) are in an unfavorable competitive position due to large } \\
\text { energy subsides, specifically those for diesel fuel and electricity } \\
\text { - High import tariffs on components of RET (e.g. ,50\% import tariff } \\
\text { on batteries for PV systems, and 30\% on integrated PV systems, } \\
\text { and 10\% import tariff on PV cells) }\end{array}$ \\
\hline Institutional & $\begin{array}{l}\text { National economic development plan does not incorporate renew- } \\
\text { able energy as a target sector that should be given priority } \\
\text { - National Renewable Energy Agency is not directly involved with } \\
\text { local energy planners in the evaluation of technology options for } \\
\text { off-grid power supply systems; its role is confined to R\&D and } \\
\text { does not extend to technology deployment } \\
\text { - No financial/non-financial incentives or regulations that would in- } \\
\text { crease the adoption of RETs }\end{array}$ \\
\hline Regulatory & $\begin{array}{l}\text { - Newly modified BOOT regulations stipulating that PPA should be } \\
\text { in local currency rather than foreign currency even when the IPP is } \\
\text { a foreign company }\end{array}$ \\
\hline Business size & $\begin{array}{l}\text { RE companies in Egypt are relatively small which makes them un- } \\
\text { able to influence policies or regulations set by the government } \\
\text { - No strong or active specialized trade association that could convey } \\
\text { demands or concerns of small businesses }\end{array}$ \\
\hline Reputation & $\begin{array}{l}\text { Poor reputation for certain RETs due to bad experiences with the } \\
\text { technology as a result of lack of clear technical standards. Exam- } \\
\text { ples include solar water heaters installed with no technical supervi- } \\
\text { sion of quality of equipment used }\end{array}$ \\
\hline Lack of skilled human resource base & $\begin{array}{l}\text { - No specialized consultancy firms that provide consultancy services } \\
\text { in the area of RE } \\
\text { - Curriculum in local engineering universities pays limited attention } \\
\text { to RETs } \\
\text { - Majority of managers in RE companies lack business development } \\
\text { training and skills }\end{array}$ \\
\hline Competing Resources & $\begin{array}{l}\text { Large discoveries of natural gas in recent years continue to shift the } \\
\text { government's attention away from developing the renewable en- } \\
\text { ergy sector and markets. }\end{array}$ \\
\hline
\end{tabular}

Source: Kamel, 2003

As the list of market barriers presented above makes clear, the success of technology deployment and market creation programs and initiatives depends on many criteria, of which political will and commitment are arguably the most important. The importance of political will stems from the fact that it is governments who do most to establish the underlying market 'framework' and provide financial and non-financial incentive programs and other measures that help establish markets for new technologies; if governments fail to show strong support then deployment efforts by the private sector are hobbled (IEA 2001). If the regulatory environment is not conducive to the introduction of new energy technologies efforts exerted at the R\&D and capacity building levels will have little effect in bringing about the hoped for market transformation. The general weakness of government institutions in devel- 
oping countries makes aid programmes important in efforts to develop markets for improved technologies.

\section{Subsidies for New Energy Technologies}

Although subsidies can overcome some of the challenges of financing new technologies they remain controversial in energy deployment programmes in both developed and developing countries. The main cause for controversy is that by their very nature subsidies change markets, distorting them and often causing inefficiencies in unintended and unforeseen ways. Part of the problem is that subsidies too often do not reach the intended target group and instead end up benefiting other, more politically influential groups. Put in place, they are stubborn and difficult to remove. As a result, economists often speak about applying "smart subsidies".

Barnes et al. (2000) outline typical shortcomings associated with the way energy subsidies are designed in developing countries, flaws that eventually render many subsidy schemes ineffective with respect to their original objectives. These design shortcomings make subsides: a) implicit, such as when nonpayment of electricity bills is overlooked; b) untargeted, as when the subsidy is given to everyone; c) indiscriminate, as when the subsidy is for levels of energy consumed well above those needed by poor or rural populations; d) complex and difficult to administer; and e) overly restrictive with respect to the end use or technology, thereby depriving users of choice. Ideally, a smart subsidy avoids these design pitfalls. Table 3 presents additional views on how energy subsidies should be introduced and utilized, categorizing these into situations where RD\&D, market transformation, and removal of market barriers are the primary objectives (IEA, 2003).

Table 3. Different Types of Technology Deployment Subsidy.

\begin{tabular}{|c|c|}
\hline Perspective & Function of the Subsidy \\
\hline $\begin{array}{l}\text { Research, Development and Deploy- } \\
\text { ment }\end{array}$ & $\begin{array}{l}\text { The subsidy should be used for investments in learning. The focus is } \\
\text { on new products, technology characteristics and manufacturers that } \\
\text { can move the process along. The subsidy is viewed as creating future } \\
\text { return in forms that cannot be predicted now. Success will be } \\
\text { achieved when the market accepts the product on its own merits, } \\
\text { taking account of both price and performance. }\end{array}$ \\
\hline Market Transformation & $\begin{array}{l}\text { The subsidy should be used to attain interest from certain groups that } \\
\text { could move the market. These groups are assumed to set trends and } \\
\text { act as proponents for the improved products. The return from the } \\
\text { subsidy is expected to come from the establishment of new prefer- } \\
\text { ences on the part of buyers and more interest on the part of suppliers } \\
\text { in the business opportunities that can be created by exploiting a new } \\
\text { technology. }\end{array}$ \\
\hline Overcoming Market Barriers & $\begin{array}{l}\text { The subsidy should be used to overcome a reluctance to buy new } \\
\text { products that are superior to currently favored products in ways that } \\
\text { are not recognized by consumers, perhaps because they tend to over- } \\
\text { estimate the risks involved in using the new product or because some } \\
\text { of the benefits accrue to third parties. All customers are addressed } \\
\text { equally. The money is spent in the public interest as viewed by the } \\
\text { present value calculations of the current buyers. }\end{array}$ \\
\hline
\end{tabular}

Source: IEA, 2003. 


\section{The transfer of new energy technologies to developing countries}

In its special report entitled Methodological and Technological Issues in Technology Transfer (2000), the Intergovernmental Panel on Climate Change (IPCC) defines technology transfer as "a broad set of processes covering the flows of know-how, experience and equipment for mitigating and adapting to climate change amongst different stakeholders such as governments, private sector entities, financial institutions, NGOs and research/education institutions." Bedrous et al. (1999) point out, however, that this broad definition has not often been used in technology transfer efforts.

More commonly, energy technology ends up being treated as an imported commodity rather than an "acquired ability" to adapt the underlying technological concepts in an effort to make them more appropriate for local conditions. Bedrous et al. recommend that developing countries approach the imported technology as a concept to be modified or adapted as doing so would increase the technology's ability to penetrate the market, in part due to higher levels of social acceptability. In a similar vein, Kline et al. (2003) partially attribute lack of social acceptability of new technologies in developing countries to local stakeholders' inability to alter or modify imported technology so as to make it match the "socio-institutional context" of the importing country.

A 2003 report by TERI adds other necessary elements to successful technology transfer efforts, including sound policy for incoming foreign direct investment (FDI), standardization of testing and certification procedures, and protection of intellectual property rights (TERI, 2003). Martinot et al. (2000) have also noted the importance of establishing clear technical standards and specifications in order to avoid malfunctioning devices that give a technology a poor reputation, which once established can prove difficult to overcome.

For the transfer process to be effective, careful surveying and analysis of the energy services sector in the target country is necessary. Understanding that the energy consumers are not interested in energy itself as a commodity but rather in the services they can get from energy is vital, and points to the need for accurate energy services needs assessments (IEA, 2003). In this respect, there is usually an opportunity for local institutions as they often have a much better knowledge of energy service needs and of customers than do outsiders.

Finally Greenpeace International (2001) has stressed on the importance of supporting local manufacturing and assembly capabilities in poor countries as such efforts "reduces poor countries' dependence on costly imports and is good for the economies of local communities." In addition to the poverty alleviation benefits from jobs created in local manufacturing, the new technology is likely to be more social and economically sustainable when it is designed and manufactured with the local conditions in mind.

The typical flow of energy technology is from North to South but there are success stories of South to South transfer of technologies. Shared R\&D efforts between Southern countries can be an effective means of designing and developing appropriate technologies. UNEP's AREED project is supporting various small-scale rural energy businesses in Africa, some of which are adopting and marketing sustainable energy technologies originally invented in Latin America. A small business venture in Zambia, for example, is producing charcoal from eucalyptus trees using semi-spherical brick kilns, a technology originally developed by Argentinean farmers. Another AREED business is manufacturing and marketing efficient charcoal stoves in Zambia based on a design from Kenya that itself had origins in Thailand. 


\section{Conclusion}

Successful technology market creation programmes are inherently holistic. Numerous policy and technology approaches for deployment and transfer of sustainable energy technologies exist (and have been tried), yet none by itself is sufficient to fulfill the objective of promoting markets that foster faster adoption of superior technologies in developing countries. Good support by governments, appropriate framework conditions, proper involvement of local groups, and the existence (or creation) of business opportunities in market or near-market conditions are all important elements of successful efforts. When these ingredients are present, better energy technologies can both gain a foothold and thrive in developing countries, where great opportunities lie for expanding access to energy in a way that brings benefits to the global environment.

The authors would like to thank Gordon McKenzie of the UNEP Risø Centre for insightful comments and suggestions on an early draft of this paper.

\section{References}

Barnes, Douglas and Jonathan Halpern. "The Role of Energy Subsidies", in Energy Services for the World's Poor. World Bank publications. April 2000.

Bedrous, Maher et al. "Re-appraisal for Energy Technology Sustaining Development In Developing Countries: Egypt Case". Energy and Environment, vol. 10, No. 4. 1999.

Greenpeace International. "Power to Tackle Poverty: Getting Renewable Energy to the World's Poor". www.greenpeace.org. June, 2001.

Intergovernmental Panel on Climate Change. Special Report: Methodological and Technological Issues in Technology Transfer. 2000.

International Energy Agency and United Nations Environment Programme. Technology Without Borders. 2001.

International Energy Agency. Creating Markets for Energy Technologies. 2003.

Kamel, S. Baseline Survey of Renewable Energy Sector in Egypt. (unpublished). UNEP Collaborating Center on Energy and Environment. April 2003.

Kline, David. et al. "Clean Energy Technology Transfer: A Review of Programs under the UNFCCC". (Forthcoming) Mitigation and Adaptation Strategies for Global Change, Kluwer Academic Press. 2003.

Martinot, Eric et al. The GEF Solar PV Portfolio: Emerging Experience and Lessons. World Bank working paper. August 2000.

TERI. "Enabling Environments for Technology Transfer". March 2003.

World Bank. Energy Services for the World's Poor. 2000. 


\title{
Sustainable Energy Use and Energy Supply - From Vision to Reality?
}

\author{
Hake, J.-Fr.; Eich, $R$. \\ Research Centre Jülich, Systems Analysis and Technology Evaluation (STE), \\ D-52425 Jülich, Germany
}

\section{Global Issues}

The term Sustainable Development refers to a "development that meets the needs of the present without compromising the ability of future generations to meet their own needs." ${ }^{\text {"l }}$ Since publication of the Brundtland Report in 1989, Sustainable Development represents an important element in the political debate on future environmental, economic and societal development (see Fig. 1), i.e. searching for a balance between these different dimensions represents a major task. ${ }^{2}$

The work of the Brundtland Commission lead directly to the United Nations Conference on Environment and Development held in Rio de Janeiro in 1992. The Rio Declaration and Agenda 21 represent the main results of this important conference. Chapter 38 of Agenda 21 called for the creation of a Commission on Sustainable Development (CSD). In 1992, the UNGA set out the CSD's terms of reference, composition, guidelines for NGO participation, organisation of work, relationship with other UN bodies, and Secretariat arrangements. It is the task of this commission to keep the Rio process moving and to stimulate it furthermore.

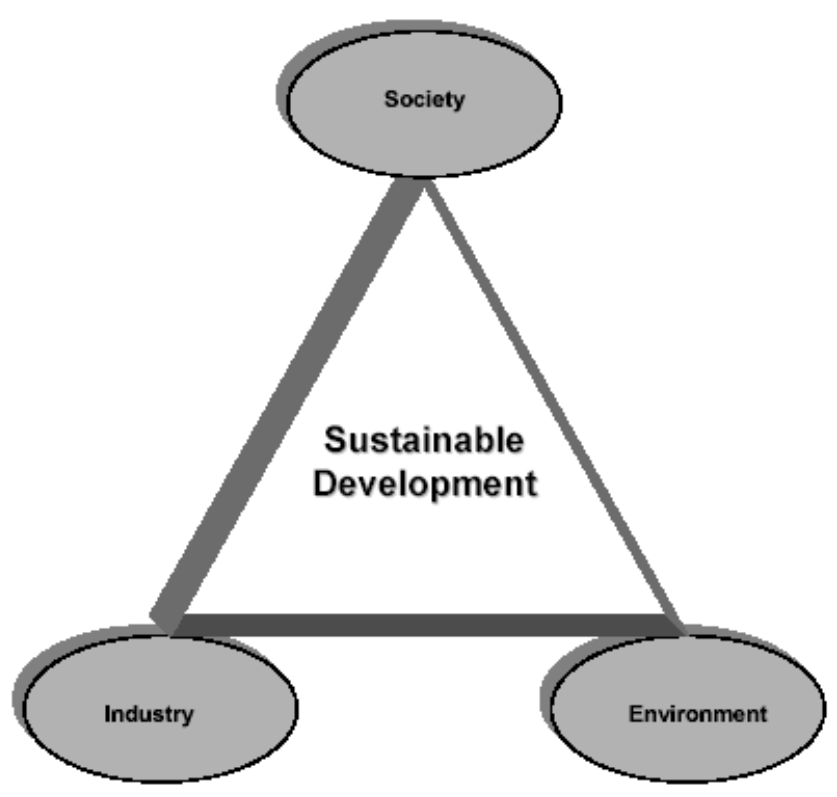

Figure 1. Three dimension of sustainable development.

\footnotetext{
${ }^{1}$ World Commission on Environment and Development: Our Common Future. Oxford, New York 1987. s. S. 43.

${ }^{2}$ Gro Harlem Brundtland was chairperson of the World Commission on Environment and Development. 3 IISD: Earth Negotiations Bulletin 22, 51. www.iisd.ca/linkages/2002/w ssd
} 
Conventions, e.g. the UN Framework Convention on Climate Change (UNFCCC) and the Convention on Biodiversity, play an important role in the Rio process in order to work out more 2 detailed conceptions for Sustainable Development, i.e. to specify goals, to derive indicator sets and to implement verification procedures.

In 1997 at the conference Rio+5 in New York, the progress of the Rio process so far achieved was evaluated. The results from this evaluation were not very promising. The speed of the Rio process was lower than expected and limited by the lack of financial resources.

With increasing duration of the Rio process, issues of financing are more and more given priority. Thus, great significance was attached to the international conference "Financing for Development" which took place in Monterrey/Mexico in March 2002 as a prelude to the world summit. The conference was concerned with the total range of topics concerning the mobilisation of private and public, local and external financial resources for Sustainable Development. ${ }^{4}$

The World Summit on Sustainable Development (WSSD) held at Johannesburg in 2002 aimed at (re)focussing the Rio process on the most relevant topics and to accelerate the overall process. Five key thematic areas have been identified: Water, Energy, Health, Agriculture and Biodiversity (WEHAB). ${ }^{5}$ The Johannesburg Plan of Implementation and the Johannesburg Declaration represent the most important results of the World Summit. The Plan of Implementation addresses the following topics: ${ }^{6}$

- Poverty Eradication;

- Changing Unsustainable Patterns of Consumption and Production;

- Protecting and Managing the Natural Resource Base of Economic and Social Development;

- Sustainable Development in a Globalizing World;

- Health and Sustainable Development;

- Sustainable Developments of Small Island States;

- Sustainable Development for Africa;

- Means of Implementation and

- Institutional Framework for Sustainable Development.

This list shows a multilevel approach. At the first level specific problems are addressed (topics $1-5$ ). Another level addresses regional issues (topics 6 and 7). Topics 8 and 9 are devoted to implementation and a corresponding institutional framework.

The Summit reaffirmed Sustainable Development as a central element of the global agenda and was implemented a new impetus to global action to fight poverty and to protect the environment. The summit enabled a broadening of the understanding between the environment and the use of natural resources. In this context the summit confirmed in the Johannesburg Declaration on Sustainable Development the importance of the three pillars of sustainable development - economy, society and environment - at the local, national and global level.

The post Johannesburg process focuses on the five core elements of the WEHAB on the agenda. The WSSD has detected the fundamental changes in the way societies produce and consume are indispensable for achieving global sustainable development. Therefore, all countries should promote sustainable consumption and production patterns.

The WSSD concluded that a critical challenge in the future would be to ensure the necessary internal conditions for mobilizing, domestic savings, sustaining an adequate level of productive investment and increasing human capacity.

\footnotetext{
${ }^{4}$ United Nations - General Assembly: Report of the Secretary-General to the Preparatory Committee for the High-level Intergovernmental Event on Financing for Development. New York, 18 December 2000. (A/AC.257/12.)

${ }^{5}$ WEHAB initiative proposed by UN Secretary-General Kofi Annan as a contribution to the preparations for the World Summit on Sustainable Development (WSSD). 3

${ }^{6}$ United Nations: Report of the World Summit on Sustainable Development. Johannesburg, South Africa. 26 . August -4. September 2002. New. York 2002.
} 


\subsection{Substainable Development in Germany}

Germany takes an active role in participating in the Rio process, adopting it to national conceptions and to support other countries on their path to Sustainable Development. Milestones of the German Rio Process are the commitment to the goals and actions of the Rio Declaration and the Agenda 21 as well as signatures to the corresponding UN conventions, e.g. UNFCCC etc.

During the past five years German Federal Government took several actions:

- In summer 2000 the Federal Cabinet adopted a bill according to which a Council for Sustainable Development (Nachhaltigkeitsrat) was to be instituted by the Federal Government at the beginning of the following year. Its task should be to participate in the development and formulation of a sustainability strategy for the Federal Republic of Germany. For this purpose, highranking representatives of different social groups in the Federal Republic of Germany - such as representatives of the two Christian churches, the consumer associations, the local authorities as well as industry and science - were appointed to this panel by the Federal Chancellor.

- Moreover, the red-green Federal Government agreed on the institution of a State Secretary Committee for Sustainable Development. In this committee, which is called the "Green Cabinet" following the appointment of so-called "Green Ministers" in the United Kingdom, the State Secretaries from ten of the in total 14 federal ministries meet. The Committee is chaired by the State Secretary of the Federal Chancellery. Its task also consists in developing a national sustainability strategy on behalf of the Federal Government. Moreover, it has to define concrete projects for the implementation of the sustainability strategy. In addition, the State Secretary Committee was granted the right to charge both the Council for Sustainable Development and the individual bodies of the Bundesrat with developing contributions to a federal German sustainability strategy. Moreover, it is entrusted with the task of informing the Federal Cabinet - as the competent decision-making body - about the results obtained.

Both the "Green Cabinet" and the Council for Sustainable Development took up work in the course of 2001. The first concrete results have been presented to the public in spring 2002.

At present, the Council for Sustainable Development is in an intensive deliberation phase. In this connection, various events and hearings were organised with experts from science, research, politics and society. The activities of the Council for Sustainable Development concentrate on the three topics of agriculture - environment - nutrition - health, mobility, and climate protection - energy. ${ }^{7}$

The "Green Cabinet" published its first considerations on Sustainable Development in late 2001 in the form of a first draft of a national sustainability strategy for Germany. The "Green Cabinet" selected a form of presentation comprising four target levels with associated lower-level indicators. These four target levels comprise the topics of generation justice, quality of life, social bonds and international responsibility. 4

As a result of this work, in preparation of the conference in Johannesburg, and to fulfil obligations resulting from Agenda 21 German Government presented a report to WSSD on the national strategy for Sustainable Development comprising the same key areas:

- Generation Justice;

- Quality of Life;

- Social Co-operation and

- International Responsibility.

Progress in these areas is measured by 21 indicators referring to corresponding goals (see Tab. 1). ${ }^{8}$ It is striking to note that the focus is on the social dimension.

\footnotetext{
${ }^{7}$ Nachhaltigkeitsrat der Bundesrepublik Deutschland: Ziele zur Nachhaltigen Entwicklung in Deutschland - Schwerpunktthemen. Dialogpapier des Nachhaltigkeitsrates. Berlin 2001.

${ }^{8}$ Die Bundesregierung: Perspektiven für Deutschland - Unsere Strategie für eine nachhaltige Entwicklung. Berlin, April 2002.
} 
Table 1. The targets and target indicators of the "Green Cabinet".

\begin{tabular}{|l|l|l|l|}
\hline Generation Justice & Quality of Life & Social Bonds & International Responsibility \\
\hline conservation of resources & economic prosperity & employment & development cooperation \\
$\begin{array}{l}\text { renewable energies } \\
\text { land use }\end{array}$ & $\begin{array}{l}\text { mobility } \\
\text { air quality } \\
\text { prospects for } \\
\text { families } \\
\text { equal rights } \\
\text { integration of for- } \\
\text { eign citizens }\end{array}$ & opening markets \\
$\begin{array}{l}\text { biodiversity } \\
\text { national indebtedness } \\
\text { economic precautions for } \\
\text { innovation } \\
\text { education }\end{array}$ & $\begin{array}{l}\text { crime } \\
\text { health }\end{array}$ & & \\
\hline
\end{tabular}

German Parliament also contributed to the national strategy on Sustainable Development. Over the past legislative periods Study Commissions actively analysed the options for sustainable development with respect to individual fields, e.g. materials flows, mitigation of climate change, and energy supply. The Study Commissions first laid a basis for the political formulation of emission reduction goals. Subsequently, a Study Commission dealt with the topic of "Sustainable Energy Supply in View of Globalisation and Liberalisation". ${ }^{9}$

Moreover, Germany participated in an OECD study to evaluate the information resulting from the implementation of such a detailed indicator set describing (sustainable) development in individual countries. ${ }^{10}$

In all studies the importance of the energy dimension to Sustainable Development is stressed because the energy dimension is regarded as cross-cutting to the environmental, economic and social dimensions.

\section{The Energy Dimension of Sustainable Devel- opment}

\subsection{Global Issues}

Management of energy supply according to guiding principles (e.g. safe, efficient and environmental acceptable) has always been in the tradition of the energy economy. Again, a solution with respect to multiple criteria is required (Fig. 2).

\footnotetext{
${ }^{9}$ Deutscher Bundestag: Erster Bericht der Enquete-Kommission Nachhaltige Energieversorgung unter den Bedingungen der Globalisierung und der Liberalisierung. Drucksache 14/7509, Berlin 2001 and Deutscher Bundestag: Zweiter Bericht der Enquete-Kommission Nachhaltige Energieversorgung unter den Bedingungen der Globalisierung und der Liberalisierung. Drucksache 14/9400, Berlin 2002. See further information: http://www.bundestag.de

${ }^{10}$ Bundesministerium für Umwelt, Naturschutz und Reaktorsicherheit: Erprobung der CSD-Nach-haltigkeitsindikatoren in Deutschland - Bericht der Bundesregierung. Berlin, April 2000.
} 


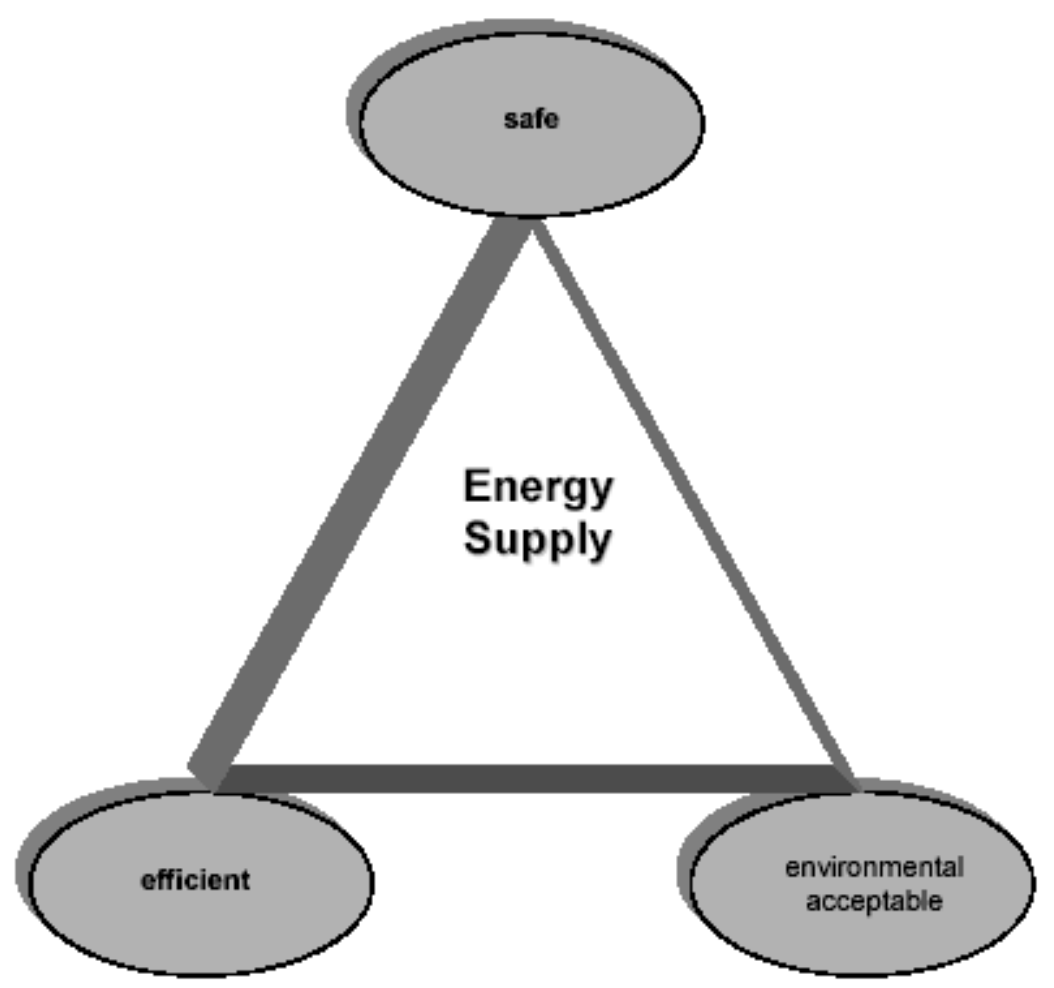

Figure 2. Three-pillar concept of energy supply

\section{Brundtland-Commission}

In the seventh chapter of its final report "Our Common Future", the Brundtland Commission dealt at great length with the topic of energy. The introductory formulations there read as follows: "Energy is necessary for daily survival. Future development crucially depends on its long-term availability in increasing quantities from sources that are dependable, safe, and environmentally sound. At present, no single source or mix of sources is at hand to meet this future need."11

The central question is how to ensure a globally permanent and reliable energy supply in the future. The commission arrives at the following conclusions here: present-day energy supply is based to a major extent on fossil fuels such as oil, coal and natural gas. Abandoning the use of these energy carriers on a larger scale does not seem possible. At all levels, however, there are great potentials for a more efficient use than in the past. The Brundtland Commission derives the following claims for a Sustainable Development in the energy sector:

- expansion of energy supply to meet the demand for energy services to a sufficient extent world wide,

- measures to improve efficient energy use,

- reduction of health risks associated with energy use,

- measures for the protection of the biosphere and prevention of the increase of local environmental pollution.

The recommendations derived by the Brundtland Commission can be subsumed under the following keywords:

\footnotetext{
${ }^{11}$ World Commission on Environment and Development: Our Common Future. Oxford, New York, 1987, p. 168.
} 
- lowering specific per-capita energy consumption,

- expanding the investments for the development of technologies and mechanisms resulting in a reduction of energy consumption and

- $\quad$ reducing the provision of energy from non-renewable resources.

In order to achieve these goals also in practice, the Brundtland Commission considers fundamental political and institutional adaptations in the energy sector to be necessary. At the same time, it underlines that a specific reduction in energy consumption can only be achieved by an optimum use of the currently available energy sources. Optimum use is understood by the commission to be the consumption of the least expensive environment-friendly energy source. ${ }^{12}$

The industrialised countries are under a particular obligation because one quarter of the world population (and this primarily in the industrialised countries) consumes roughly 75 percent of the globally used primary energy. ${ }^{13}$ The Brundtland Commission supports a more effective and efficient use of the energy sources available to date. At the same time, however, it is also a concern of the commission to develop plans and programmes for the long-term generation and use of renewable energy carriers. The Brundtland Commission regards the energy price as an important element for promoting the use of renewable resources.

\section{UN-Summit in Rio de Janeiro}

The 9th chapter "Protection of the Atmosphere" of the Agenda 21 summarises the demands and suggestions concerning a sustainable energy use and energy supply, i.e. "Energy is essential to economic and social development and improved quality of life. Much of the world's energy, however, is currently produced and consumed in ways that could not be sustained if technology were to remain constant and if overall quantities were to increase substantially." 14

The basic and ultimate objective of the energy topic in the Agenda 21 is to reduce adverse effects on the atmosphere from the energy sector by promoting policies or programmes, as appropriate, to increase the contribution of environmentally sound and cost-effective energy systems, particularly new and renewable ones, through less polluting and more efficient energy production, transmission, distribution and use. This objective should reflect the need for equity, adequate energy supplies and increasing energy consumption in developing countries, and should take into consideration the situations of countries that are highly dependent on income generated from the production, processing and export, and consumption of fossil fuels and associated energy-intensive products or the use of fossil fuels for which countries have serious difficulties in switching to alternatives, and the situations of countries highly vulnerable to adverse effects of climate change.

The following concrete measures and their implementations are proposed in the Agenda $21^{15}$ :

- Cooperation in identifying and developing economically viable, environmentally sound energy sources to promote the availability of increased energy supplies to support sustainable development efforts, in particular in developing countries;

- Promoting the development at the national level of appropriate methodologies for making integrated energy, environment and economic policy decisions for sustainable development through environmental impact assessments;

- Promoting the research, development, transfer and use of improved energy-efficient technologies and practices, including endogenous technologies in all relevant sectors, giving special attention to the rehabilitation and modernization of power systems, with particular attention to developing countries;

\footnotetext{
${ }^{12}$ World Commission on Environment and Development: Our Common Future. Oxford/New York, 1987, p. 196.

${ }^{13}$ ibid.

${ }^{14}$ United Nations Division for Sustainable Development: Agenda 21. Chapter 9. New York 1992.

${ }^{15}$ United Nations Division for Sustainable Development: Agenda 21. Chapter 9. New York 1992.
} 
- Promote the research, development, transfer and use of technologies and practices for environmentally sound energy systems, including new and renewable energy systems, with particular attention to developing countries;

- Promote the development of institutional, scientific, planning and management capacities, particularly in developing countries, to develop, produce and use increasingly efficient and less polluting forms of energy;

- Review of current energy supply mixes to determine how the contribution of environmentally sound energy systems as a whole, particularly new and renewable energy systems, could be increased in an economically efficient manner, taking into account respective countries unique social, physical, economic and political characteristics, and examining and implementing, where appropriate, measures to overcome any barriers to their development and use;

- Coordination of energy plans regionally and subregionally, where applicable, and study the feasibility of efficient distribution of environmentally sound energy from new and renewable energy sources;

- in accordance with national socio-economic development and environment priorities, evaluate and, as appropriate, promote cost-effective policies or programmes, including administrative, social and economic measures, in order to improve energy efficiency;

- Build capacity for energy planning and programme management in energy efficiency, as well as for the development, introduction, and promotion of new and renewable sources of energy;

- Promote appropriate energy efficiency and emission standards or recommendations at the national level, aimed at the development and use of technologies that minimize adverse impacts on the environment;

- Encourage education and awareness-raising programmes at the local, national, subregional and regional levels concerning energy efficiency and environmentally sound energy systems;

- Establish or enhance, as appropriate, in cooperation with the private sector, labelling programmes for products to provide decision makers and consumers with information on opportunities for energy efficiency.

These topics do not present solutions but outline the fundamental challenges of Sustainable Development with respect to the energy question.

\section{UN-Summit in Johannesburg}

Since the adoption of Agenda 21 the energy issue has been at the centre of the Rio process - either directly, if aspects of supply for humans are concerned, or indirectly, if the anthropogenic greenhouse effect is dealt with. At the special session of the United Nations General Assembly in 1997 ("Rio plus 5") the interdependence of Sustainable Development and the production, distribution and use of energy was emphasised once again. The General Assembly declared this topic to be a priority of work of the United Nations Commission on Sustainable Development (CSD-9) in 2001. In preparation of the debate the United Nations Development Programme (UNDP), the United Nations Department of Economic and Social Affairs (UNDESA) and the World Energy Council (WEC) had a "World Energy Assessment" carried out. The results have been available since the year $2000 .{ }^{16}$ The associated report constitutes a comprehensive review of the social, economic and ecological aspects of energy supply and its use and of issues of supply assurance, but the report hardly addresses the structural change in the energy sector currently taking place at company level.

\footnotetext{
${ }^{16}$ UNDP - UNDESA - WEC: World Energy Assessment - Energy and the Challenge of Sustainability. New York 2000.
} 
Table 2. Energy - Frameworks for Action. ${ }^{17}$

\begin{tabular}{|c|c|}
\hline Key Issue & Action Areas \\
\hline $\begin{array}{l}\text { 1. Access to } \\
\text { energy and modern } \\
\text { energy services }\end{array}$ & $\begin{array}{l}\text { - Reduce poverty by providing access to modern energy services in rural and } \\
\text { peri-urban areas. } \\
\text { - Improve health and reduce environmental impacts of traditional fuels and } \\
\text { cooking devices } \\
\text { - Improve access to affordable and diversified energy sources in Africa }\end{array}$ \\
\hline $\begin{array}{l}\text { 2. Energy } \\
\text { efficiency }\end{array}$ & $\begin{array}{l}\text { - Reduce poverty by providing access to modern energy services in rural and } \\
\text { peri-urban areas. } \\
\text { - Improve energy efficiency in all sectors using established practices on } \\
\text { standards and labelling techniques. } \\
\text { - Improve efficiency in power generation }\end{array}$ \\
\hline $\begin{array}{l}\text { 3. Renewable } \\
\text { energy }\end{array}$ & $\begin{array}{l}\text { - Progressively increase contribution of renewable energy mix of all countries } \\
\text { - Improve access to basic health care and education for poor people through } \\
\text { the provision of renewable energy systems in primary health care centres } \\
\text { and schools. } \\
\text { - Promote the use of renewable energy in vaccine and immunisation } \\
\text { programmes. } \\
\text { - Provide the use of renewable energy to facilitate access to safe drinking } \\
\text { water. }\end{array}$ \\
\hline $\begin{array}{l}\text { 4. Advanced } \\
\text { fossil-fuel } \\
\text { technologies }\end{array}$ & $\begin{array}{l}\text { - Increase the use of advanced fossil fuel technologies for energy generation. } \\
\text { - Promote the use of clean coal technologies in countries using coal. } \\
\text { - Reduce atmospheric pollution from energy generating systems. } \\
\text { - Enhance productivity through advanced fossil fuel technologies. }\end{array}$ \\
\hline $\begin{array}{l}\text { 5. Energy and } \\
\text { transport }\end{array}$ & $\begin{array}{l}\text { - Improve air quality and public health through the introduction of cleaner } \\
\text { vehicular fuels. } \\
\text { - Implement better transportation practices and systems in mega-cities. } \\
\text { - Promote new technologies for transport. }\end{array}$ \\
\hline
\end{tabular}

For the range of energy use and energy supply in the apron of the summit in Johannesburg five outstanding characteristics were identified (Tab. 2).

At the world summit on Sustainable Development in Johannesburg, the energy issue has been on the agenda again in a prominent position under the heading "Access to Energy and Energy Efficiency". The focus in the energy sector during the Johannesburg-Summit was concentrated on the pre-work established by the WEHAB working group and was mainly summarized in four major topics: renewable energy, access to energy, energy markets and energy efficiency.

The Johannesburg Summit was terminated with the aim to diversify the energy supply by a substantial increase of the share of renewable energy to the total energy supply. The WSSD also pointed out the necessity to improve the access to reliable, affordable, economically viable, socially acceptable and environmentally sound energy services and resources. This also includes the removal of market distortions including the restructuring of taxes and the phasing out of harmful subsidies and support efforts to improve the functioning, transparency and information about energy markets with respect to both supply and demand. The aim was to achieve greater stability and to ensure consumer access to energy services. This includes efforts to improve the energy efficiency and the promotion of research and development.

\footnotetext{
${ }^{17}$ WEHAB Working Group: A Framework for Action on Energy. World Summit on Sustainable Development, Johannesburg 2002.
} 


\subsection{Germany}

The focus of the German Green Cabinet is also on the energy sector. The main goal consists of decoupling the demand for energy and other natural resources from economic growth. Specific action should take place in the following fields:

- reduction of primary energy demand by increased efficiency and rational use of energy,

- improvements in energy services, and

- emphasis on renewable energy and reduced usage of fossil and nuclear energy.

The Green Cabinet also recommends the implementation of specific national goals and measures such as reduction of greenhouse gas emissions by $21 \%$ from 1990 to 2012, the reduction of $\mathrm{CO}_{2}$ emissions by $25 \%$ up to 2005 , a doubling of the share of renewable energy until 2010 with respect to the year 2000 , and combined heat and power production. Moreover, pilot studies and projects have been initiated to increase energy efficiency in all sectors of the economy. ${ }^{18}$

A Study Commission of German Parliament dealt with the topic of "Sustainable Energy Supply in View of Globalisation and Liberalisation". ${ }^{19}$ Preliminary results from this commission have been presented to CSD 9 at New York. The outcome of this commission is a set of 71 indicators for the energy sector (see Tab. 3), a set of scenarios reflecting the fundamental options for future development of the energy sector up to 2050. The report concludes with a detailed discussion of instruments and measures suitable to direct the energy sector towards the desired goals. A final chapter is devoted to implementation of the strategy.

\footnotetext{
${ }^{18}$ Secretary of State Committee for Sustainable Development: Perspectives for Germany. Our strategy for Sustainable Development. Draft of the national Sustainable Development Strategy. Berlin, in December 2001. Page 132 to 143.

${ }^{19}$ See for further information: http://www.bundestag.de
} 
Table 3. Core indicators of the study commission "Sustainable Energy"

\begin{tabular}{|ll|}
\hline Ecological Dimension & Emissions of GHG \\
& Emissions of air pollutants \\
& Acidification \\
& Settlement area \\
& Area consumption \\
& Non-toxical and non-nuclear waste \\
& Toxical waste \\
& Nuclear waste \\
& Nuclear inventory \\
& Labour \\
& Employment rate \\
& Household expenses for energy consumption \\
& Total primary energy supply \\
Economic Dimension Dimension & Renewable energy \\
& Nuclear energy \\
& Fossil fuels \\
& Biomass \\
& Primary energy supply per GDP \\
& Energy consumption and demand of transportation \\
& Energy consumption and demand of households \\
& Share of fossil fuels and REN for power generation \\
& Range of coverage of different energy sources \\
Total costs of energy supply and energy use & Import quota of energy sources \\
Innovative Dimension & R\&D-Expenses for energy supply and energy use \\
& R\&D-Expenses for fossil fuels \\
& R\&D-Expenses for nuclear fuels \\
& R\&D-Expenses for REN \\
& Coverage of development aid \\
&
\end{tabular}

The indicators favoured by the Study Commission refer to an indicator set developed by the OECD. ${ }^{20}$ But there exist differences because the commission looks at the energy sector from different perspective. Hence, there still exists the need for unification and comprehension.

The members of this commission did not agree on the overall future strategy for the German energy sector. Issues of controversy have been detected particularly in the following fields:

- $\quad$ perception of the risks resulting from climate change (i.e. starting from the worst case scenario published by IPCC?)

- $\quad$ attitude towards the impact of globalisation on the energy sector (i.e. catastrophe with respect to the social dimension of Sustainable Development?)

- role and precision of goals and instruments to direct structural change in the energy sector (i.e. how much regulation?)

- at the technical level: different opinions about the future role of nuclear energy (phase out?) and about renewable energy (how much and which subsidies?).

\footnotetext{
${ }^{20}$ OECD: Framework to measure Sustainable Development. Paris 2000.
} 
Besides the differences the commission emphasised the central role of education, science and research in the context of Sustainable Development. ${ }^{21}$

For energy research the European Commission decided to set priorities and a perspective with respect to Sustainable Development in the 6th Framework Programme: ${ }^{22}$

1. Research Activities having an Impact in the Short and Medium Term:

a. Clean energy, in particular renewable energy sources and their integration in the energy system, including storage, distribution and use.

b. Energy savings and energy efficiency, including those to be achieved through the use of renewable raw materials.

1. Research Activities Having an Impact in the Medium and Longer Term:

a. Fuel cells, including their application.

b. New technologies for energy carriers/transport and storage, in particular hydrogen.

c. New and advanced concepts in renewable energy technologies.

d. Capture and sequestration of $\mathrm{CO}_{2}$, associated with cleaner fossil fuel plants.

e. Socio-economic tools and concepts for energy strategy.

This structure shows three important elements. First, time plays a crucial role; i.e. development of technological alternatives as required and desired for Sustainable Development in the energy sector represents a time consuming process which can only be accelerated to a certain extent. Second, the range covered by research should start from basic research and must end with commercially competitive products. Third, great importance is attached to the future role of renewable energy.

\section{Conclusions}

Sustainable Development represents an open process with respect to decisions of present and future generations. Societal and political decision making has to reflect that the understanding of the corresponding natural and social systems is not yet complete. For this reason, goals have to be specified with regard to this uncertainty. Hence, the processes of decision making should be transparent to a maximum degree. The assessment of the initiated developments and the possibility to correct misjudgements should represent standard features in the process of Sustainable Development.

Several institutes have started to evaluate existing and to formulate new goals with respect to Sustainable Development, to specify indicator sets which yet are not consistent and complete to describe the journey towards Sustainable Development. But progress can be observed at the global and national levels.

For the energy sector, the approach to Sustainable Development starts in many cases from the supply side of energy assuming that new and advanced technology will suffice to full-fill demand. The assessment of existing energy technologies does not yet show a consistent picture. This one-side approach focussing on efficiency will probably not be sufficient as many experts already have pointed out. Increased efficiency has to be complemented by rational use of energy including all aspects up to questioning consumption patterns particular in the industrialised countries.

The international treatment of model problems like climate change already indicates the difficulties to achieve international concerted action. The appropriate treatment of these model problems seems absolutely necessary with respect to Sustainable Development. But huge investments are required, particular in the least and less developed countries. How could science and research contribute to speed up? Hence, the gap between vision and reality can only be closed by intensified science and research.

\footnotetext{
${ }^{21}$ Study Commission „Sustainable Energy Supplies in View of Globalization and Liberalization". Sustainable Power Supply on the liberalized and globalized markets: Stocktaking and starting points. Berlin 2001. Page 39 and 40.

${ }^{22}$ European Commission: The 6th Framework Programme. Brussels, December 2002.
} 


\title{
Energy Saving Policy and Emission Decreasing: Latvian Experience
}

\author{
Dr. A. Davis, M. oec. E. Zeberga, Prof. V. Zebergs and Prof. N. Zeltins \\ Institute of Physical Energetics, Latvian Academy of Sciences \\ 21 Aizkraukles Street, Riga, LV 1006, Latvia
}

\section{Introduction}

The objective of studying these problems is to promote the fast progress of the Latvian energy sector and create a sustainable system of energy supply. At the same time, considerably reducing the energy consumption and improving to the most possible degree the efficiency of energy use are necessary. Such an efficient use of energy would give us an opportunity to reduce considerably the energy intensity as well as costs for energy and solving ecological problems.

It is evident from Table 1 that the consumption of primary energy resources during the last 10 years $(1990-2000)$ has decreased more than 2 times. This is generally due to the crucial changes in the structure of the branches of national economy (decreased specific weight of industry) in the transition from the planned economy to a market economy after 1990. Improvement of the structure of the useful primary energy resources, too, (increased ratio of highly efficient gaseous fuel) allows raising the efficiency of the fuel consumption and the economy of energy resources as well.

Table1. Primary energy consumption in Latvia.

\begin{tabular}{|l|l|c|c|c|c|}
\hline \multirow{2}{*}{ Nr. } & & \multicolumn{2}{|c|}{1990} & \multicolumn{2}{c|}{2000} \\
\cline { 3 - 6 } & & Mtoe & $\%$ & Mtoe & $\%$ \\
\hline 1 & Heavy fuel oil (HFO) & 2,08 & 22,98 & 0,28 & 7,57 \\
\hline 2 & Natural gas & 2,63 & 29,06 & 1,14 & 30,81 \\
\hline 3 & Light oil product & 2,54 & 28,07 & 0,91 & 24,59 \\
\hline 4 & Coal & 0,63 & 6,96 & 0,07 & 1,89 \\
\hline 5 & Wood, peat e.tc. & 0,45 & 4,97 & 0,91 & 24,59 \\
\hline 6 & Others & 0,72 & 7,96 & 0,39 & 10,54 \\
\hline & Total & 9,05 & 100 & 3,70 & 100 \\
\hline
\end{tabular}

Table 2 shows a diminished amount of harmful emissions in atmosphere corresponding to the decrease in the consumption of primary energy resources in Latvia. According to experts' estimation, the amount of emissions during this time has decreased 2-3 times. To a great extent this is also due to the perfection of the structure of energy resources (diminished HFO-content from 23 to $8 \%$ and the ratio of the renewable local energy resources from 5 to $25 \%$ ).

This inspires a hope to fulfil successfully the condition provided by the Kyoto documents to decrease (to maintain) the harmful emissions at the level of the year 1990 till 2008-2012 even at a significant rate of development of industry and energetics, and their increased ratio in Latvia. In addition 
to it, a certain gain for the trade in the emissions quotas with foreign countries may make the advancement of the Latvian energy sector if such develops.

Comparatively favourable energetic and ecological conditions in Latvia during the last 10 years do not alleviate the energy efficiency raising problems in the future. Up to now Latvia imports more than $70 \%$ of primary energy resources, mainly from Russia, and also up to $50 \%$ electricity from different neighbour countries (clean electricity imports promote low atmosphere pollution in Latvia). There fore there are lot of development problems of Latvian energy sector and energy saving.

Table 2. Formation of pollutants at fuel combustion (kt/year).

\begin{tabular}{|c|l|r|r|r|r|r|}
\hline \multirow{2}{*}{ Nr. } & \multirow{2}{*}{ Kind of fuel } & \multicolumn{5}{|c|}{1990} \\
\cline { 3 - 7 } & & $\mathrm{CO}_{2}$ & $\mathrm{SO}_{2}$ & $\mathrm{CO}$ & $\mathrm{NO}_{\mathrm{x}}$ & \multirow{2}{*}{ Solid particles } \\
\hline 1 & Heavy fuel oil & 5453 & 101.10 & 1.32 & 2.36 & 4.93 \\
\hline 2 & Natural gas & 5860 & - & 0.53 & 3.75 & - \\
\hline 3 & Light oil products & 8051 & 2.60 & 558.86 & 77.52 & 7.21 \\
\hline 4 & Coal & 2413 & 68.70 & 6.30 & 0.19 & 45.36 \\
\hline 5 & Wood, peat e.tc. & 132 & 0.10 & 5.04 & 0.25 & 2.75 \\
\hline & Total & 21909 & 172.50 & 572.05 & 84.07 & 60.25 \\
\hline
\end{tabular}

\begin{tabular}{|c|l|r|r|r|r|r|}
\cline { 3 - 7 } \multicolumn{2}{c|}{} & \multicolumn{5}{c|}{2000} \\
\hline 1 & Heavy fuel oil & 736 & 13.70 & 0.18 & 0.32 & 0.67 \\
\hline 2 & Natural gas & 2555 & - & 0.23 & 1.64 & - \\
\hline 3 & Light oil products & 3136 & 1.00 & 219.52 & 30.46 & 2.83 \\
\hline 4 & Coal & 268 & 7.60 & 0.70 & 0.02 & 5.04 \\
\hline 5 & Wood, peat e.tc. & 264 & 1.30 & 9.90 & 0.50 & 5.49 \\
\hline & Total & 6959 & 23.60 & 230.53 & 32.94 & 14.03 \\
\hline
\end{tabular}

\section{Modelling the prognoses for raising energy ef- ficiency}

By means of the macroeconomic model of analysis for raising energy efficiency it is possible to evaluate the economy gained from various kinds of energy having a wide range of input data concerning the perspective GDP and prognoses for the increase in the consumption of energy resources.

Prognoses for raising the economic efficiency of energy utilisation are of great importance for the development of a perspective national energy balance and prognostication of energy consumption. On the other hand, in the cases when the energy consumption prognoses have been worked out, it is necessary to evaluate the extent of the required energy economy and the potential of this economy. To a great degree prognostication is connected with the assessment of uncertainties and possible variants. The methods of the analysis of the energy efficiency development should enable to discuss a wide range of input data, which can be ensured by forming corresponding computer models. 
Usually the prognoses of the electric energy consumption are studied rather well, and there are several variants of prognoses worked out in Latvia for the period till the year of 2020 and a further perspective. Under such conditions it is significant to determine the required extent of electric energy economy for different variants of the Gross domestic product (GDP) increase. The results obtained can be analysed by mathematical methods or using the methods of expert appraisal. In any case this will give a possibility to evaluate the necessary extent of electric energy saving (the increase in the energy utilisation efficiency rate) or to make a correction of the electric energy consumption prognoses at a more rapid GDP increase (for limited possibilities of electric energy economy because of technical or economic reasons).

Electro intensity $(\boldsymbol{e})$ of the $\boldsymbol{G D P}$ is that indicator of macroeconomics, which conveys the relation of the annual consumption of electric energy $(\boldsymbol{E})$ to the respective GDP value. For the $\boldsymbol{i}-$ th year it can be written as:

$$
e_{i}=E_{i} / G D P_{i}
$$

The prognosis of the GDP changes is usually expressed by coefficients $\left\{\boldsymbol{a}_{1}, \boldsymbol{a}_{2}, \ldots \boldsymbol{a}_{\boldsymbol{n}}\right\}$, which characterise the GDP increase or decrease. The GDP for the limits of an $\boldsymbol{n}$-year period is:

$$
\underset{G D P_{n}=G D P_{0} \prod\left(1+a_{i}\right),}{i=1}
$$

where: $\boldsymbol{i}=1,2, \ldots \mathrm{n}-$ year numbers,

$\boldsymbol{a}_{\boldsymbol{i}}$ - the coefficients of the GDP increase/decrease in the $\boldsymbol{i}$ - the year;

$\boldsymbol{G D P}_{0}, \boldsymbol{G D P}_{\boldsymbol{n}}$ - the GDP values at the beginning and end of the period.

At $\boldsymbol{a}_{1}, \boldsymbol{a}_{2}, \ldots \boldsymbol{a}_{\boldsymbol{n}}=\boldsymbol{a}_{\boldsymbol{n}}$ formula (2) is simplified:

$$
G D P_{n}=G D P_{0}(1+a)^{n}
$$

In principle, the relation $\boldsymbol{E}=\mathbf{f}(\mathbf{G D P})$ is expressed, as a rule, in the form of the Cobb-Douglas function, yet successful application of this function requires a wider scope of macroeconomic indices.

If sets of values $\left\{\boldsymbol{G D} \boldsymbol{P}_{\boldsymbol{i}}\right\},\left\{\boldsymbol{E}_{i}\right\}$ and $\left\{\boldsymbol{e}_{\boldsymbol{i}}\right\}$ are obtained, a respective economy of electric energy $\left(\boldsymbol{E} \boldsymbol{E}_{\boldsymbol{i}}\right)$ for each $\boldsymbol{i}$ - th period can be calculated:

$$
E E_{i}=1-e_{i} / e_{0}
$$

where $\boldsymbol{e}_{0}$ - electro intensity at the beginning of the period.

The variable $\boldsymbol{E} \boldsymbol{E}$ is a macroeconomic indicator that can be purposefully changed in conformity with the demands of the target programme for the correction of the rate of economic development. The use of the set of corrected $\left\{\boldsymbol{E} \boldsymbol{E}_{i}^{*}\right\}$ values may allow to solve a reverse task, i.e. at the previous set of the $\{G D P\}$ values it is possible to find $\left\{\boldsymbol{E}_{i}^{*}\right\}$ and $\left\{\boldsymbol{e}_{i}^{*}\right\}$. Thus, as a result of a reverse calculation, one can find out a new, corrected prognosis of the electricity consumption and the GDP electro intensity:

$$
\begin{aligned}
& E_{i}^{*}=e_{i}^{*} G D P_{i} \\
& E_{i}^{*}=e\left(1-E E_{i}^{*}\right)
\end{aligned}
$$

Below, Table 3 presents an algorithm for the estimation of the GDP electro intensity and the correction of electricity consumption at a changed GDP electro intensity for the period from 2000 to 2020 , which is being realised as the EXCEL packet in the WINDOWS files. 
Table 3. Algorithm for the correction of electro intensity and consumption of electricity (a medium optimistic variant).

\begin{tabular}{|l|l|l|l|l|l|l|}
\hline & & \multicolumn{1}{|c|}{2000} & \multicolumn{1}{|c|}{2005} & \multicolumn{1}{|c|}{2010} & \multicolumn{1}{|c|}{2015} & \multicolumn{1}{|c|}{2020} \\
\hline 1 & GDP grows (\% per year) & 5 & 6 & 7 & 6 & 5 \\
\hline 2 & GDP (bill. LVL) & 4.32 & 5.781 & 8.108 & 10.85 & 13.85 \\
\hline 3 & Electricity consumption $\boldsymbol{E}(\mathrm{TWh})$ & 5.9 & 6.698 & 7.401 & 8.278 & 8.964 \\
\hline 4 & Electro intensity $\boldsymbol{e}(\mathrm{kWh} / \mathrm{LVL})$ & 1.366 & 1.159 & 0.913 & 0.763 & 0.647 \\
\hline 5 & Electricity saving (\%) & 0 & 15.16 & 33.16 & 44.14 & 52.61 \\
\hline 6 & Corrected $\boldsymbol{E}^{*}(\%)$ & 0 & 16 & 35 & 48 & 50 \\
\hline 7 & Corrected $\boldsymbol{e}^{*}(\mathrm{kWh} / \mathrm{LVL})$ & 1.366 & 1.147 & 0.888 & 0.71 & 0.574 \\
\hline 8 & Corrected $\boldsymbol{E}^{*}(\mathrm{TWh})$ & 5.9 & 6.634 & 7.199 & 7.708 & 7.945 \\
\hline
\end{tabular}

In Table 3 the variations in GDP increase are used as output data (Line 1), as well as the corrected electro intensity (Line 6) in accordance with the development programmes of national economy. The other data of the table are calculated in an automatic mode according to the algorithm. The results of calculations can be reflected in a graphic way.

The analytical method and model of energy efficiency enables to estimate the necessary amount of the electric energy economy so that it could ensure a consumption of electricity, adequate to the increase of the GDP. If such an economy cannot be ensured due to limited investments, or suchlike, the consumption of electricity and electro intensity should be corrected, as shown in Table 1 (Line 6).

The method of macro-economical analysis of energy efficiency mentioned above forms the basis for the research of energetic, economical and ecological analysis of various technologies designed to raise energy efficiency.

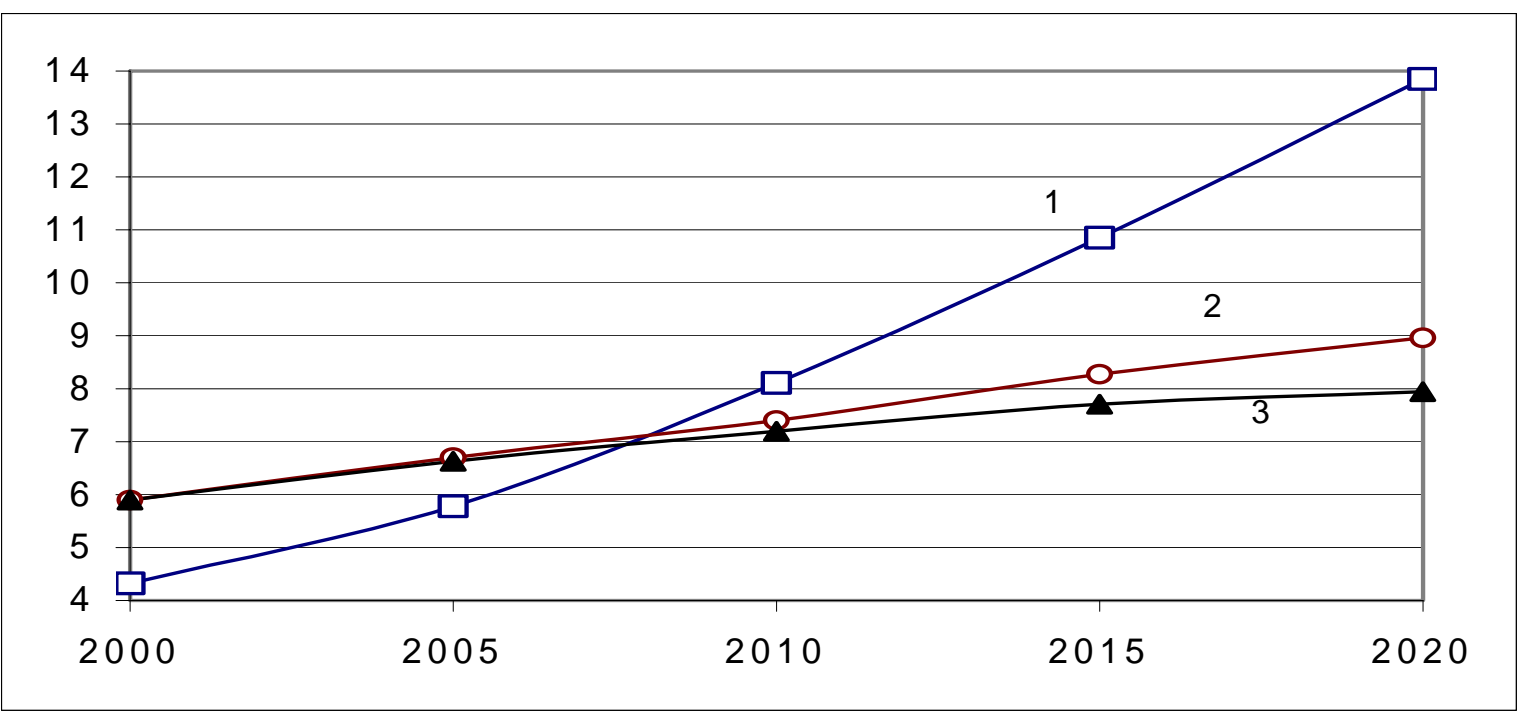

Figure 1. Prognostic calculation (a medium optimistic variant)

1 - GDP (bill. LVL)

2 - electricity consumption (TWh)

3 - electricity consumption after correction (TWh) 


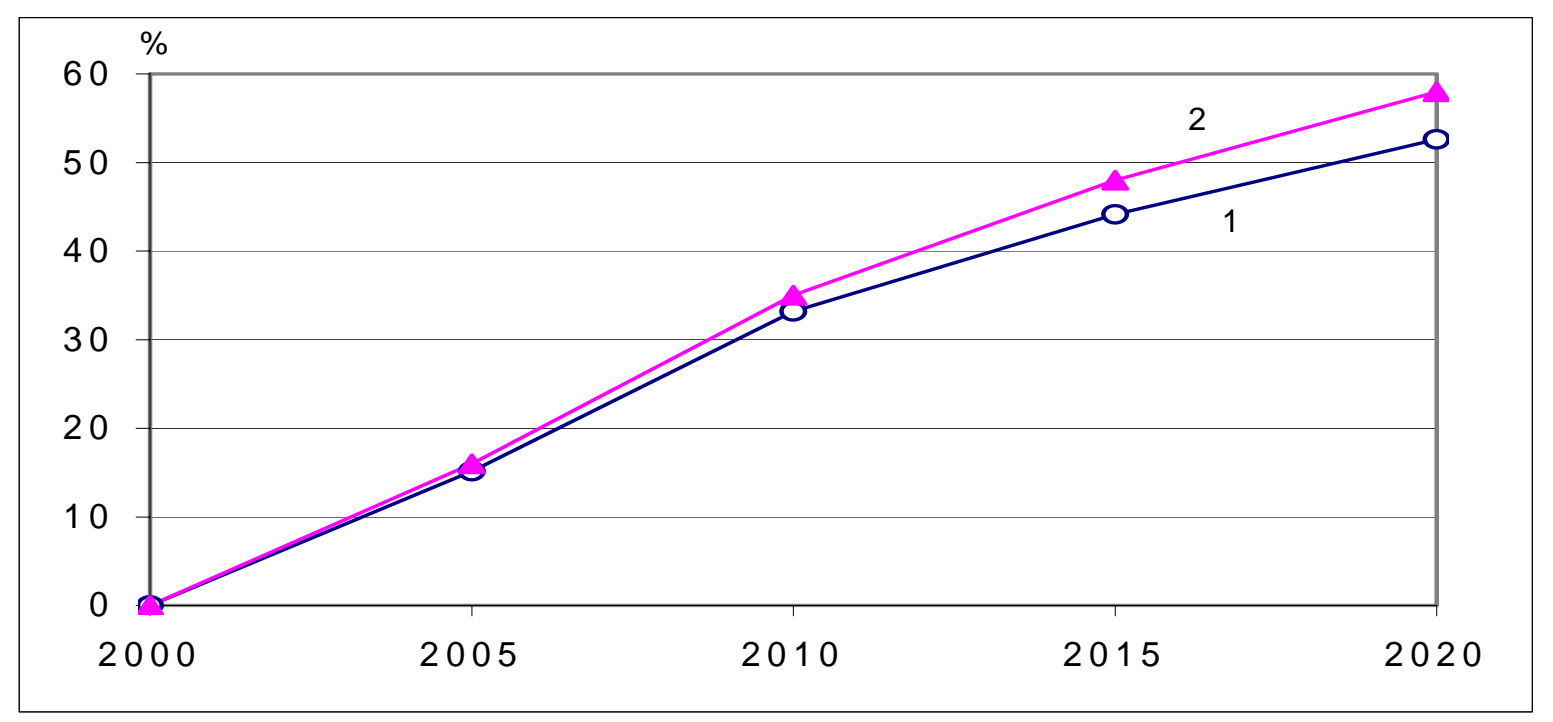

Figure 2. Electricity saving

1 - before correction of electro intensity

2 - after correction of electro intensity

\section{Methods of managing the energy efficiency in the industrial sector}

The goal of energy efficiency management system is to achieve economy in energy consumption through better management. The present strategy of EC is integration of energy management systems in environmental management systems. All management systems are formed to ensure sustainable development.

Target of the increasing energy efficiency in industrial sector are connecting with rational use of optimal energy (electricity, heat, gas, oil products and so on) in every production process, adopting use of secondary energy, increasing it potential, realizing regeneration and recuperation, using low potential energy and involving environmental heat.

The management methods for raising energy efficiency are different in every branch of national economy, which has its own specificity; therefore it is necessary to develop respective management system methods. The choice of the management method depends on how the problem of the institutional and financial support to this system is solved. It is the interaction between the component parts of this management system that may give an optimum foundation for the management system, which can be illustrated in a simplified way by means of Figure 3.

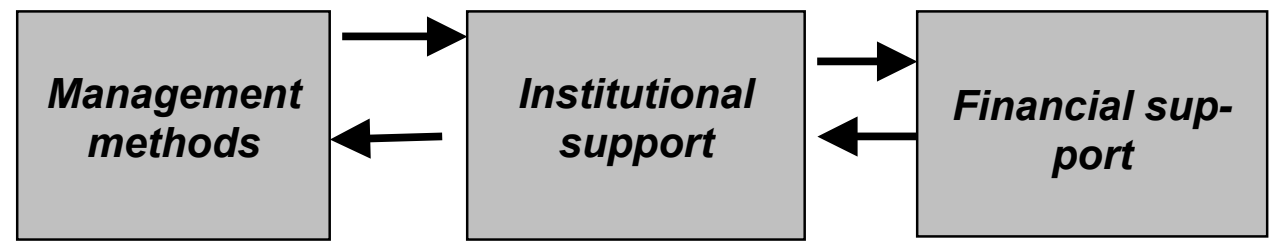

Figure 3. Interaction of the component parts of the management system

In the present situation of the economic development of Latvia the choice of the management method most of all can be affected by the financial support and its possibilities although the implementation of the management system of state and private institutions may have an impact by the choice of the man- 
agement method and the method of the whole system as well. At the present moment and also in the future the most acceptable method of energy efficiency management in industry could be "Benchmarking". This method allows creating conditions ensuring deliberate interest of the managers of industrial enterprises in decreasing energy efficiency and its significance in the reduction of production costs.

In principle, within the framework of energy efficiency management one should take into consideration the support for long-term training of the managers' and specialists' of industrial enterprises under Latvian conditions, as well as the necessary information (visual aids) because no attention was paid to this process. Unlike the advanced countries, it is, to some extent, a new phenomenon.

Due to the little specific weight of heavy industry in Latvia, the reduction of energy consumption in the industrial sector will depend to a great extent on the improvement of the heating and ventilation systems of industrial buildings, as well as their thermal insulation, which considerably fall back the thermo technical parameters of Western buildings.

As for raising energy efficiency in the technological processes of production, one should note the great difference at the enterprises of even the same branch. In a somewhat simplified manner it is possible to generalise the processes of raising energy efficiency at the milk processing enterprises. There not only technological improvements take place but also the perfection of the production processes by applying modern Western biological and chemical premixes.

In order make use of "Benchmarking" as an energy efficiency management method, first of all, it is necessary to sum up the required and necessary information about the work of the enterprise, to make calculations; only then one can visualize the situation of each enterprise in comparison with the other enterprises of the same branch by means of a diagram and a table (see Fig.4), revealing the "weak" spots.

In addition to that confidentiality of the information provided by each enterprise should be ensured, where a number is given to each enterprise, which is unique and known only to this enterprise. So this "Benchmarking" is a sort of database, allowing the plant to compare its energy efficiency data with the data from the other enterprise of the same branch (energy efficiency index - production energy intensity).

In order to implement the Benchmarking management method (see Fig.4), energy efficiency networks are being set up as an institutional support of the energy efficiency management. Now there is also a project for the development of such a network in Latvia and which have already been operating successfully for a comparatively long time in Canada, Norway and elsewhere. Enterprises can volunteer such networks and anonymous (confidential) comparison of the heat efficiency indices is carried out there by the branches. The enterprise which, due to its sufficiently high index in comparison with the other enterprise of the same branch, reveals a potential ability to raise it carries out an energy audit already described in this report setting the priorities of heat efficiency raising measures and increasing the value of the index of its enterprise. After a repeated audit the first index-improvement cycle may be followed by the next index-improvement cycle aimed at further rising of efficiency.

At present such a sort of networks performing Benchmarking have been created in many countries of the world. For instance, in Norway by means of this network a national programme is being implemented in the field of energy efficiency. 


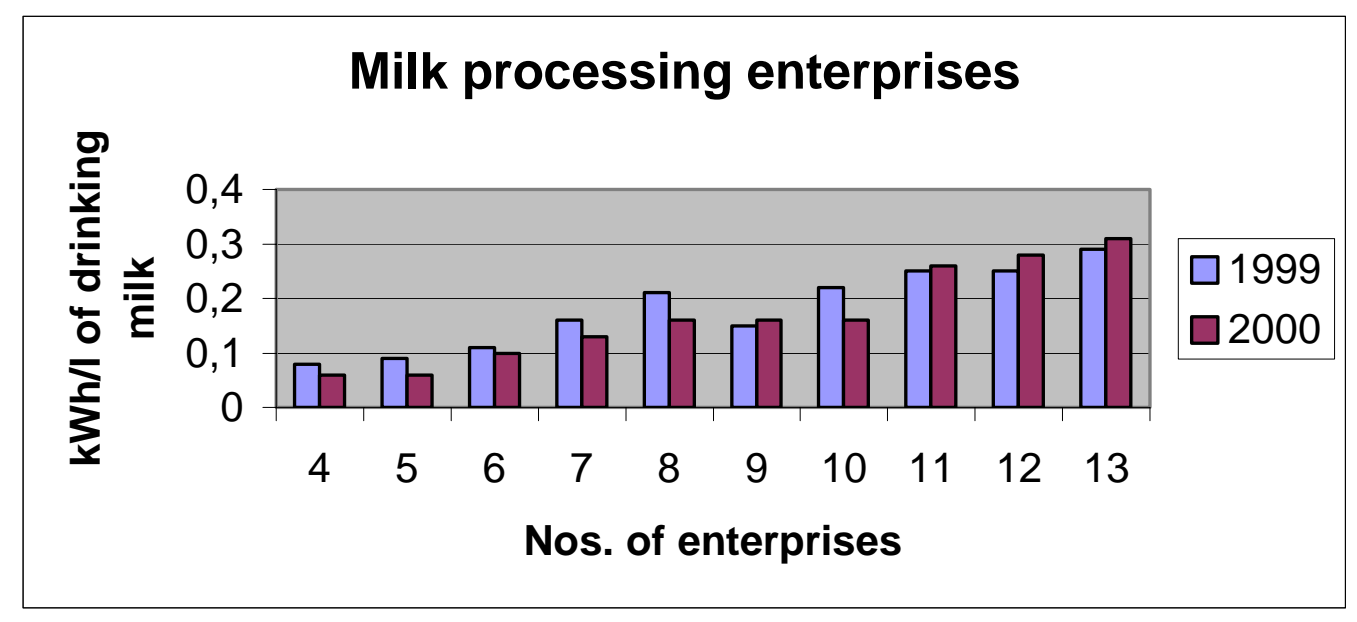

Figure 4. Benchmarking of some milk processing enterprises

As mentioned above, in Latvia, too, it is intended to develop such an energy efficiency network. The financial support for the application of the Benchmarking method (see Fig. 4) could be settled only after the improvement of the economical situation in industry and the managers' increased interest in energy economy. Under such conditions the interested enterprises could support the energy efficiency network with small deposits (in Norway the network is financed from the state budget), which is unlikely but debatable in Latvia.

In Latvia a network is being organized at the present moment. It will exist as an experiment and a sort of a pilot research to prove that the creation of such a network is very pressing and will be necessary in the future for the Latvian industry and economy, on the whole. There the managers' main motivation for saving energy certainly is the cost reduction; however, at the same time, it is quite clear that this is not a principal matter for the people who are practically engaged in the implementation of energy efficiency measures at their enterprise.

\section{Methods of managing the energy efficiency in the residential building sector}

Analysing energy consumption reduction programmes in different countries and specific measures that since 1975 resulted in reduction by $30-50 \%$ of building heat consumption it was found that changes in calculation of building normative heat loss made till now do not correspond to the international practices and there is no reliable data on building real heat consumption in Latvia.

The process of raising energy efficiency in Latvia can be considered as successful. There are also objective reasons for that connected with the incomplete privatisation, lack of organization in the management of buildings and the low purchasing capacity of the population. It is essential under such conditions to form public opinion in order to change its attitude to energy as valuable merchandise. The time factor is also important to make the introduction of energy saving as soon as possible because every day when energy is wasted brings great losses.

Economy of electric energy in the residential sector is connected with the introduction of modern electric appliances. Their labelling is a positive factor since it allows the population to choose the most energy saving devices. Meanwhile, with the rise in the people's well being, more devices will be introduced for their comfort irrespective of how much electricity they consume, as well as a greater variety of electric appliances. Therefore the consumption of the electric energy is growing.

There is a great potential in Latvia for saving thermal energy. Most of the total heat consumption in Latvia comes to the heating of buildings. The greatest part of all the 4 consumer groups given in Table 4 is related to heating. As the experience of the advanced countries shows, there are great possibilities 
to reduce heat consumption in heating the buildings, which are the aim of heat management and the respective reduction of harmful environmental effects.

Table 4. The consumption structure of thermal energy in Latvia.

\begin{tabular}{|l|c|}
\hline Consumer group & Ratio, \% \\
\hline Industry & 6 \\
\hline Residential sector & 76 \\
\hline Other consumers & 18 \\
\hline Total & 100 \\
\hline
\end{tabular}

There are no complete data in Latvia about heat consumption in dwelling houses because heat meters are widely installed only in the recent years. The results of the heat consumption analysis in several hundred dwelling houses in the City of Riga are presented in Table 5. from which it is evident that almost $1 / 3$ of the houses consume more than $250 \mathrm{kWh} / \mathrm{m}^{2}$ a year.

Table 5. Annual heat consumption in the dwelling houses in Latvia.

\begin{tabular}{|c|c|c|}
\hline \multicolumn{3}{|c|}{ Heat consumption $\left(\mathrm{kWh} / \mathrm{m}^{2}\right.$ year) in percentage of the } \\
total number of the analysed houses \\
\hline More than 200 & $200-250$ & More than 250 \\
\hline 5 & 65 & 30 \\
\hline
\end{tabular}

Great success in the reduction of heat consumption have been gained in Scandinavian countries (see Table 6)

Table 6. Dynamics of the annual specific heat consumption in Finland.

\begin{tabular}{|l|r|r|r|r|r|r|}
\hline Gads & 1970 & 1975 & 1980 & 1985 & 1990 & 1996 \\
\hline $\mathrm{kWh} / \mathrm{m}^{3}$ & 72 & 65 & 57 & 52 & 50 & 45 \\
\hline $\mathrm{kWh} / \mathrm{m}^{2}$ & 216 & 195 & 171 & 156 & 150 & 135 \\
\hline
\end{tabular}

The data from Table 6 illustrate well the potential possibilities of heat economy in Latvia. It is important to work out an optimal management method for raising energy efficiency with its institutional and financial support (see Fig.4), which is complicated by Latvia's economic situation.

A particularly important factor is the financial support of energy efficiency raising measures. One should note that the EU Directive 93/76/EEC provides that in financing the energy saving measures particular attention should be paid to the development of the third party financing.

The third party financing is a technical and financial instrument ensuring the most appropriate technical solution of an energy efficiency project and the required financial means.

A third-party financer is the Energy Service Enterprise (ESE). Its responsibilities generally include:

- $\quad$ audit of the customer's energy consumption;

- selection of the technical solutions for the reduction of energy consumption;

- economical assessment of the project;

- implementation of the project.

After the realisation of the energy efficiency improvement measures the ESE, which is also responsible for all the expenditure of this period, ensures maintenance: the fuel costs, maintenance and repair costs. The user of the object pays for energy a little less, or, at worst, exactly as much as he would have paid if the realisation of the project had not taken place. Such an order of maintenance is envisaged for the number of years according to the agreement, which is calculated so that after the end of this period the ESE would regain the invested sum with a definite profit rate.

In such a way the ESE takes part for the period envisaged by the agreement after which the equipment becomes the user's property. 
During the validity period of the agreement the equipment is insured. The insurance costs are included into the maintenance costs covered by the side, which is responsible for maintenance. Therefore neither side suffers damage because of the potential technical faults.

The payback agreement states the maximum payback time. Any sums not paid after the set period are revoked and should be paid to the third-party investment enterprise. If the user wishes, a sooner payback of the investments is allowed.

The third party financing gives the user a series of technical and economical privileges.

The above variant of financial support for the improvement of energy efficiency illustrates well the impact of the financial and institutional support given in Fig. 4 upon the choice of the management method. In this case the institutional support is connected with the establishment of enterprises as the ESE.

The third party financing as a method of raising energy efficiency with a corresponding institutional and financial support has not found application in Latvia as yet.

In cases when the owners of a factory or a building (in a residential or public sector) have their own sufficient financial coverage and the payback time of energy saving measures is not long, and it can give good profit, the implementation of the respective project is simple. So, as a rather widespread heat economy measure in Latvia is the replacement of the old windows by modern glass package windows where the investment payback time is not long.

In the present economic situation in Latvia it will be necessary to continue, for the greatest part, the research of new methods of financial and institutional support in order to implement the energy efficiency improvement projects.

\section{References}

Davis A., Ekmanis Yu., Zebergs V., Zeltinsh N. The Efficiency of DHS with Decentralised CHP and the Low Temperature Network for Latvia // $17^{\text {th }}$ Congress of the World Energy Council, Division 2, Houston, Texas, USA, 1998: 483 - 491.

Davis A., Freibergs G., Zebergs V., Zeltinsh N. Technological Progress and Development of Heat Energy Market // IAEE 1999 European energy conference " Technological progress and the energy challenges", Concurrent sessions proceeding. Paris, France 1999: $132-140$.

Davis A., Zebergs V. and Zeltins N. Latvian Energy Sector in Transition to Free Energy Market // Regional WEC European Energy Forum KYIV-2000 "Market transformation in the energy industries. Perspectives for the beginning of the third millennium", Proceedings 2, Kiev, Ukraine, 2000: 45-50.

Blazevich J., Davis A., Mikelsons K., Zebergs V., Zeltins N. (2001) Development of Baltic Energy Sector in Central Europe Energy Market $/ / 18^{\text {th }}$ World Energy Congress, Buenos Aires, Argentina, CD - Technical Papers: 16 p.

Michna Jerzy, Frormann Detlef, Bartoš Jaroslav, Gnedoy Mikola, Kaleta Piotr, Kapała Jan, Krawczyński Francizek, Mészáros Géza, Miškinis Vaclovas, Rousek Jan, Rouytcheva Maria,Rudi Ülo, Ruginá Vasile, Viksna Ints, Zeltiņš Namejs (2001) Energy conservation policy //Polish Acadamy of sciences, Institute of environmental engeneering. Zeszyt Nr 1/2001: 226 p.(in English, German and Russian).

Zeltiňš Namejs, Rubīna Maija, Kanders Uldis (2001) Energy Production and Greenhouse Gases Pollution Load to the Environment on the Latvian Scale. // II Pasaules latviešu zinātnieku kongress, Tēžu krājums, Rīga: 539.

Kapala J., Michna J., Ekmanis Y. and Zeltinsh N. (2001) Still transition or a new situation in energy conservation policy in Central and Eastern European countries? // International Journal of Global energy Issues, Energy conservation policy in Central and Eastern European countries, UNESCO, Volume 16, Nos. 1/2/3: 242-251.

Sitenko L. Zebergs V. Zeltins N. Zeberga E. (2002) Macro economical analysis methods of energy efficiency // Post REHVA $45^{\text {th }}$ General Assembly Conference proceedings, Latvian Academy of Science, Riga: 152-155. 
Michna Jerzy, Frormann Detlef, Zeltins Namejs and Kaleta Piotr (2002) Present and future energy and envairolmental policy problems in central and eastern European countries //International centre for energy and environmental policy, Bulletin No. 1/2002:24. 


\section{Session 14: Climate Change, Emission Reduc- tions and Permit Trading}

Chairman: F.D. Yamba, Centre for Energy, Environment and Engineering, Zambia 


\title{
The Clean Development Mechanism and Power Sector Reforms in Developing Countries
}

\author{
Romeo Pacudan, Jorge Rogat and Wilson Wasike \\ UNEP Collaborating Centre on Energy and Environment, Risoe National Laboratory, Denmark \\ April, 2003
}

\begin{abstract}
The commitment period of the Kyoto Protocol is expected to result in a large role for the Clean Development Mechanism (CDM) in electric power projects, including grid-based renewable energy generation. This paper contributes to the discussion on reforms in developing country electricity sectors and on how they affect CDM investment potential in overcoming barriers to enhancing deployment of renewables. It reviews implications of power sector reforms for grid-based CDM renewable energy projects in Chile, Kenya and the Philippines, as examples of economies with high potential subject to removal of market entry barriers.
\end{abstract}

Author Keywords: Kyoto Protocol, CDM, Power sector; Renewable energy 


\section{Introduction}

There is a widespread optimism that the Kyoto Protocol may enter into force soon ${ }^{1}$. Its entry into force will put into practice the much debated and awaited Clean Development Mechanism (CDM), the only mechanism in the Protocol that requires involvement of developing countries in combating climate change. Broadly speaking, CDM allows entities of Annex I countries (developed countries with emission reduction commitments) to invest in developing countries on sustainable development activities that reduce greenhouse gas emissions (GHG). These entities, in return, will receive emission reduction credits for their investments, which will be used to offset their emission reduction targets.

While CDM principle appears to be simple and straightforward, it requires functioning institutions, markets, technical methodologies, etc. at the international level and within national boundaries of participating countries. In developing countries, the power supply industry is one of the most attractive markets for CDM project development. CDM projects being developed in many developing countries are mostly renewable energy power generation projects. The power industry in many developing countries however had been reformed or is currently undergoing reforms. Reforms include unbundling and privatisation of the industry. Unbundling involves breaking down the industry into generation, transmission, distribution and supply functions. Privatisation is the transfer of ownership from public to private sector.

The reforms are reported to threaten renewable energy project development. The paper reviews implications of CDM on renewable energy development under the new power sector environment in developing countries. Three developing countries are being analysed: Chile in Latin America where electricity industry reforms had been undertaken two decades ago; the Philippines in Southeast Asia which is currently implementing competitive wholesale electricity market; and Kenya in Africa which has just unbundled the electricity supply industry.

\section{The Kyoto Protocol and the CDM}

\section{Kyoto Protocol}

The United Nations Convention on Climate Change (UNFCCC), which was initiated in 1991, is an international treaty for the mitigation of global climate change. The Convention divided countries into Annex I countries, industrialised countries that historically contributed most of GHG emissions, and non-Annex I countries, mainly developing countries. The Kyoto Protocol of the UNFCCC, adopted in 1997 by the third session of the Conference of the Parties (COP 3), sets binding quantified reduction commitments for a basket of six greenhouse gases, that is, $\mathrm{CO}_{2}, \mathrm{CH}_{4}, \mathrm{~N}_{2} \mathrm{O}, \mathrm{SF}$, PFCs, and HFCs, for the Annex I Parties during the period 2008-2012. Each Annex I Party has its own reduction target ranging from $8 \%$ reduction to $10 \%$ increase from the 1990 base year. The average reduction commitment is 5.2\% for all Annex I Parties (Article 3). Non-Annex I countries are however required to submit national communications, which provide details of their climate change policies and programs, and greenhouse gas emissions inventories.

The Kyoto Protocol also defines three international cooperation mechanisms to help Annex I Parties to achieve part of their reduction commitments at lower costs: joint implementation (JI) in Article 6, and the clean development mechanism (CDM) in Article 12, and international emissions trading (ET) in Article 17. ET allows countries to transfer part of their allowed emissions; JI permits countries to claim credits for emission reductions that arise from investments in other developed countries; and the

\footnotetext{
${ }^{1}$ As of end of March 2003, there are 103 Annex I and non-Annex I countries that have ratified, accepted, acceded and approved accounting for $43.9 \%$ of the total emissions. The rules for entry into force requires 55 Parties to ratify (or accept, accede or approve) the Kyoto Protocol accounting 55\% of Annex I Parties' 1990 greenhouse gas emissions level.
} 
CDM allows Annex I countries to invest and claim credits on emission reduction projects that support sustainable development in non-Annex I countries.

\section{Clean Development Mechanism}

The main objectives of CDM are to assist Annex 1 countries to meet their emission reduction targets at lower costs, and promote sustainable development in non-Annex 1 countries. CDM projects must lead to sustainable development and result in real, measurable and long-term climate change benefits. The emission reductions must be additional to any that would have occurred without the project. CDM participation is voluntary. In order for developing countries to take advantage of the investments from Annex 1 countries, they must ratify or accede to the Kyoto Protocol and establish a national authority or focal contact point for companies wishing to engage in CDM projects.

Eligible CDM projects include: end-use and supply-side energy efficiency improvement, renewable energy, fuel switching, agriculture (reduction of methane and nitrous oxide), industrial processes, and sink projects (aforestation and reforestation). In the Marrakech Accords, small-scale projects are fasttracked with simpler modalities and procedures in order to be competitive with large-scale projects. Fast-tracked projects include renewables up to $15 \mathrm{MW}$ capacity, energy efficiency with the reduction of consumption (either on the supply or demand-side) up to $15 \mathrm{GWh}$ per year, and other projects that both reduce emissions and emit less than 15 kilotons of carbon dioxide equivalent.

CDM can assist developing countries in various ways and this include the following: i) attract capital for projects, ii) encourage and permit active participation of both private and public sectors, iii) provide a tool for technology transfer, and vi) help define investment priorities that meet sustainable goals. At the national level, benefits that could be derived from CDM include the following: i) transfer of technology and financial resources, ii) sustainable ways of energy production, iii) increase in energy efficiency and conservation, iv) poverty alleviation through income and employment generation, and v) local environmental benefits.

\section{Power Sector Reforms and the CDM}

As mentioned earlier, CDM eligible energy projects include energy efficiency, renewable energy and fuel switching. This paper however focuses on grid-based CDM renewable energy projects.

\section{Power Sector Reforms in Developing Countries}

Power sector reforms in developing countries consist of restructuring and privatisation. Restructuring is mainly the unbundling of the vertically integrated electricity supply industry into four main industry functions: generation, transmission, distribution and supply. Transmission and distribution are considered monopolistic functions while generation and supply are potentially competitive functions. Privatisation is the transfer of ownership from the public to private sector. The role of the government has been changed from utility operator to regulator (monopolistic segments). The government also introduces competition and levels the playing field for industry players.

The level of reforms undertaken in developing countries varies from region to region. Reforms in Latin America are the most advanced, followed by Asia and Africa. Similarly, the justifications for reforms are relatively different among regions. Ideological arguments on the role of government are common in Latin America. Free market had become the dominant philosophy in the 1970s replacing the interventionist approach that had been embraced by many countries since the 1940s. In Asia, the 'necessity' argument to reform the market is dominant rather than developmental philosophies. Electricity demand outstrips capacities and governments are facing difficulties in raising investments for future supply expansions. Though the above arguments are also relevant in Africa, they are only secondary. The World Bank has been instrumental in pushing reforms in the region. Despite these differences, common objectives of the electricity reforms include: stimulating private sector financing, increasing operational and managerial efficiencies and lowering electricity tariffs. 
Power sector reforms could potentially threaten renewable energy (RE) investments but the reform process also offers opportunities for developing country governments to develop policies and regulatory frameworks promoting RE development.

Renewable energy projects in general are disadvantaged compared with conventional fuels for electricity generation. Renewable energy has high resource and technology risks, which result in higher financing costs. Moreover, the RE industry size is small, and also RE projects are small compared with conventional energy projects. Transaction costs per megawatt for smaller projects are much higher because the same project development process is followed regardless of project size. Lastly, RE project economics in many cases is influenced by government policies, and these policies are often unpredictable and change frequently. Thus private investors are reluctant to invest on RE projects.

The introduction of competitive electricity markets could increase investment risks on RE. In precompetitive electricity markets, long-term contracts provide steady stream of revenue and shield project developers from financial risks. With competitive electricity markets, long-terms contracts will become scarce resulting in larger financing requirements for renewables. Bilateral contracts and hedging mechanisms however exist to insulate generators from price variability in competitive electricity markets but these are often short to medium term contracts. Moreover, electricity generation from RE are more costly than competing fuel sources. With this, project developers often have difficulties in attracting project financing from lenders. Also, many RE project developers are not sufficiently capitalized to undertake corporate financing on large RE projects.

To address these reform threats, several countries that established competitive electricity markets have also introduced regulatory mechanisms and programs that promote RE development. Common approaches include the following: i) public benefit charges to support RE development programs, ii) renewable portfolio standards which requires electricity suppliers to source a percentage of their electricity product from renewables, iii) green marketing programs which takes advantage of customer's willingness to pay for products that provide a range of public environmental benefits, iv) other direct mechanisms that reduce RE financing costs such as low interest loans, project loan guarantees, and project aggregation.

\section{CDM, Renewable Energy and Power Sector Reforms}

CDM provides additional stream of revenues to RE projects through the sale of certified emission credits (CERs) generated by the project. The most obvious impact of additional revenue stream is to alter the project risk profile, and project returns are improved. For example, a wind power and biomass power plant projects in India, the sale of CERs at a price of 4 Euros per ton of $\mathrm{CO}_{2}$ improves the project internal rate of return (IRR) by $10 \%$ and $14 \%$ respectively (Heer, 2003).

CDM projects however entail additional transaction costs. These costs include pre-operational (emission reduction feasibility assessment, monitoring and verification plan, registration, validation, and legal work) and operational costs (sale of emission reduction credits, risk mitigation, and monitoring and verification). Project developers expect the up-front cost to be below 5-7\% of the net present value of the revenue. Some studies however show that these costs range from 1.2\%-1.9\% (Harmelink. and Soffe 2001). This means that transaction costs are tenable by CDM projects.

For countries without incentives or programs supporting renewable energy, the revenues from carbon credit sales represent additional financial incentives for RE development. Those countries that adopted policies, this stream of revenues would make investments in RE projects extremely attractive. These financial benefits are however relatively small compared to the total project costs. Thus the sale of electricity generated from the project remains an important source of revenue for the project. The main attraction of CDM RE project therefore is the purchase agreements of the energy generated by the project. The emission reduction revenues are just icing on the cake.

In developing countries, the most attractive market for RE is the power supply industry. CDM project developers ensure that there are long-term buyers of electricity generated by the project. This possibility is facilitated by power sector reforms. In the pre-reform situation in many developing countries, generation is a state monopoly and, except in special conditions, private generators are not 
permitted in the market. With reforms, market rules as well as grid-connection rules are being defined thus market entry of CDM renewable energy project developers are being facilitated.

\section{Chile}

\section{Power Sector Reforms}

Chile was the first country in Latin America to restructure its energy sector. The main drivers of energy reform in Chile were high energy prices, and the need to improve efficiency in the energy sector and thereby, meet the country's increasing electricity demand. Prior to the reform, the electricity sector was mainly state-owned and the government controlled about $90 \%$ of the generation, $100 \%$ of the transmission and $80 \%$ of the distribution (Gagler Bailly Services, Inc., 1997).

The power sector reform was formulated and implemented by the National Energy Commission (CNE) established in 1978. CNE depends on the Ministry of Foreign Affairs and Energy, and has since its creation performed the regulatory and policy making functions of the entire energy sector. The Superintendence of Electricity and Fuel (SEC), is the agency that oversees the technical, operating and financial performance of the existing energy utilities of the country (CNE, 2003).

The electricity law of 1982, opened the sector to private ownership and set the rules for sector structure, operations, market and pricing at the various level of activities. At present, the energy sector is almost entirely vertically and horizontally unbundled. The legal framework created different segments for generation, transmission and distribution. As a result of reforms, The Chilean electricity industry currently consists of 72 fully privatised companies (CNE, 2003).

The generation segment is constituted by 31 companies, where Empresa Nacional de Electricidad S.A. (ENDESA), Compañía de Generación Electrica SA (Chilinger), and Colbum Machicura S.A., are the three largest companies. The transmission segment is composed of 5 companies. However, since transmission is considered to be a natural monopoly, it is subjected to government regulation. The distribution segment has 36 companies, of which two major companies serve most of the customers. The largest one is Enersis, which is a holding company owning $17 \%$ of ENDESA and $73 \%$ of Distribuidora Chilena Metropolitana (CHILECTRA). The second largest company is Chilquinta. The electricity generation is concentrated among four interconnected systems, namely, SING (Great Northern Interconnected System), SIC (Central Interconnected System), Aysen and Magallanes. SING covers the electricity demand of the northern part of the country and has approximately $35 \%$ of the total installed capacity in the country. SIC covers the demand of the central region of the country and represents $64 \%$ of the total installed capacity. Aysen and Magallanes covers the demand of the southern region and represents $1 \%$ of the total installed capacity.

\section{Reforms, Renewable Energy and CDM}

Chile's total installed capacity for electricity power is around 10,500 MW (CNE, 2003). The main source of power generation for electricity is hydropower $(51 \%)$ followed by gas-fired combine cycles (31\%) and thermo generation (18\%) INE, 2003.

Chile has been considered as one of the leading energy reformers in the world. The country has been however, less known as a supporter of RE, which is clearly reflected in the absence of an explicit energy policy that promotes the use of renewable resources. This has undoubtedly not only created disincentives to RE use, but also, it has given rise to the existence of strong lobby groups, such as electrical companies that have indirectly opposed to RE applications. In addition to this, the use of natural gas has been enormously promoted in the country. Relatively cheap natural gas and the fact of knowing that natural gas can be found in abundance in the neighbouring countries Argentina and Bolivia, have made investors reluctant to invest in more capital intensive renewable energy projects.

Lower energy prices as a result of the energy sector reform implemented in the country, may be another likely explanation to the lack of incentives for the increased use of RE. 
Nevertheless, this view has been changing during the last years, and the government is now more open to RE use. This has already allowed the initiation of a number of RE projects. One example is the result of an agreement signed few years ago between the United States and the Government of Chile. The agreement will bring solar, photovoltaic and hydropower pilot projects to two remotes areas in South Chile, Talca and Temuco. The projects will allow electricity from RE to provide residents with lighting, communications and other services, such as water pumping, refrigeration for vaccines and electricity for television and radio (Gray, Tom, August 1995). Another example is the import of 30 commercial wind pumps supported by the United Nations Development Programme (UNDP), of which eight of them are functioning. The government's revised view in favour of the use of renewable energy, is also being reflected in the implementation of a project aimed at providing electricity services for rural and isolated areas of Chile. This materialised in a five-year project that will provide power to around 10,000 households, and to lay the ground for electrification of another 100,000 homes with renewable energy by 2020 (Newton-Small, J., 2001).

The government's new vision in favour of an increased use of RE, and the increased influx of foreign investment as a consequence of the energy sector reform, are likely factors that will pave the way for the development and implementation of new CDM projects in Chile. To this, the increasing interest that international donor agencies are having in implementing CDM projects in Chile, has to be added. Chile has significant potential for solar energy in the north, for hydro and biomass energy in the south, and for wind power along the coastline in the far south of the country. Efforts are being made to exploit these renewable resources through the CDM. One example is the $26 \mathrm{MW}$ CDM hydropower project being currently implemented in Chacabuco, 100 kilometres north Santiago. The project will facilitate through the construction of a hydropower plant, the substitution of coal thermal power generation (UNEP Collaborating Centre on Energy and Environment, 2002).

Chile is a signatory and ratified the Kyoto Protocol in August 2002. The fact that an institutional framework for the development of CDM projects has been created, may further contribute to the development and implementation of such projects.

\section{Philippines}

\section{Power Sector Reforms}

Prior to the reforms, the Philippines electric power sector was characterized by vertical integration in generation and transmission. Currently, a monopolistic structure characterized the generation segment and monopsony in the procurement of electricity and customer sales. Power generation is undertaken by the National Power Corporation (NPC), a state-owned corporation, which serves as the sole supplier of electricity at the wholesale level. Power generation was also carried out by independent power producers (IPPs) through energy conversion agreements with NPC (though in some cases IPPs are allowed to enter agreements with some power utilities and industries). Bulk power transmission is a monopoly of NPC, which owns the nationwide extra-high and high voltage transmission grid and medium-voltage sub-transmission networks. Seven separate grids are serving the nine major islands, which contain $95 \%$ of the population. Distribution of electric power lies entirely with electric utilities and member-owned rural electric cooperatives located within their respective franchise areas.

The enactment of Republic Act 9136, also known as the Electric Power Industry Reform Act (EIRA) on June 8, 2001 enabled the restructuring of the Philippine electricity industry. Two major reforms are embodied in EIRA, namely, the restructuring of the electricity supply industry and the privatisation of NPC. The restructuring of the electricity industry entailed the separation of the different components of the power sector namely, generation, transmission, distribution and supply, and the introduction of the wholesale electricity spot market (WESM). On the other hand, the privatisation of NPC involves the sale of the state-owned power firm's generation and transmission assets (e.g., power plants and transmission facilities) to private investors. These two reforms are aimed at encouraging greater competition and at attracting more private-sector investments in the power industry. A more competitive 
power industry will in turn result in lower power rates and a more efficient delivery of electricity supply to end-users.

The legislation essentially requires the state-owned NPC to prepare for eventual privatisation and unbundle or break up its integrated assets to provide a competitive environment in the generation, transmission, distribution and supply sectors. The NPC will be split into several viable generation companies (GENCOs) that will promote profitability, ensure economic efficiency, encourage competition and foster reasonable power rates. To carry out its high voltage transmission and subtransmission functions, the National Transmission Company (TRANSCO) was created. Distribution utilities will retain their functions and will provide open and non-discriminatory access to users of distribution wires and charge wheeling rates to be determined by the Energy Regulatory Commission (ERC). Electric Cooperatives (ECs) will adopt a corporate structure that will increase accountability to consumers and private sector investment.

Reforms also open up the electricity supply industry not only to domestic investors but also to foreign investors. The government however classifies the whole electricity supply industry as a utility. The foreign investment law limits a maximum foreign participation in utility projects to $40 \%$.

\section{Renewable Energy Policies, Reforms and CDM}

The country's installed generation capacity reached 13,264 MW at the end 2000. Oil-based plants contributed the biggest share of $39.2 \%$, coal-fired ranks second with $28.8 \%$, and followed by hydro and geothermal with shares of $17.4 \%$ and $14.4 \%$ respectively. Virtually, no new and RE generation capacities were connected to the grid until 2000. The country's RE potential is estimated to be significant. Wind energy potential is estimated at 70,000 MW, hydro at 13,000 MW, geothermal resource at 4,537 MW, and around $130 \mathrm{MW}$ of biomass resources (bagasse - 90 MW and rice hulls - $40 \mathrm{MW}$ ) could be connected to the grid.

Renewable energy development has been an important component of government's national energy policy. The current policy thrust of the government include i) provision of conducive RE policy environment to help attain national energy self-sufficiency and support poverty alleviation efforts, ii) nurture RE market through the establishment of various credit programs, and information and training programs, and provision of legal and regulatory framework, and iii) redefine government role in the new and RE market. Moreover, the national government issued the Executive Order 232 in 1997, which allows private sector participation in the exploration, development and utilization and commercialisation of ocean, solar and wind energy resources for power generation and other uses.

At present, there exist entry barriers to grid-based renewable electricity generation. Power utility regulations are not favourable to RE development. There is a lack of standardized power purchase agreement (PPA) and power purchase prices are relatively low. Moreover, it is difficult to obtain permit from rural electric cooperatives (RECs) to set up RE projects by the private sector in areas under REC franchise.

The power sector structural reforms will remove several market entry barriers to small RE-based power generators. Small power producers are able to participate in the market at minimum cost, are not required to secure a national franchise nor subject to price regulation. The only requirement is a certification from the Energy Regulatory Commission (ERC). Moreover, small RE power generators can sell electricity either to the power pool or bilateral trade. In the power pool they can be classified as non-scheduled generating units meaning, available capacity can be dispatch anytime. In bilateral trade, the small renewable energy power generators can sell electricity to the distributors, electricity aggregators or even to large electricity consumers. In the rural areas where franchised distributors are unable to deliver their service, small power generators can sell electricity to the isolated villages. At present, however the government has yet to define and elaborate technical and financial requirements as well as other market rules for grid connection of renewable energy power generators.

As presented earlier, one of the main objectives in the Philippines power reforms is to bring electricity tariffs down. With wholesale competition, electricity prices are set based on the wholesale electricity market, which approaches the short-run marginal costs. These prices are expected to be lower than the current prices, which are based on rate-of-return regulation (in the long-run, short-run marginal costs approach long-run marginal costs). Government simulation studies show that the long-run mar- 
ginal costs are lower than the current average prices. Lower wholesale prices could have negative impact on private sector renewable energy investments for power generation.

Power sector reforms therefore open up the electricity supply industry to foreign investments, and facilitate market entry of CDM-type RE projects. At present, several project developers are investigating wind, biomass-based cogeneration and some small-hydro projects. The progress and timing of the implementation of the competitive electricity market would be crucial in the development of CDM projects. The possible decline of electricity prices in competitive markets could however negatively affect CDM renewable energy investments.

On the other hand, though the Philippine government is signatory, it has yet to ratify the Kyoto Protocol. Country ratification of the Protocol is one of the main requirements in participating CDM. Moreover, the country has also to establish national institutional framework and capacities to facilitate the development of CDM-type projects.

\section{Kenya}

\section{Power Sector Reforms}

While reform drivers such as government commitment to privatisation, growing demand and constraints to power supply, and limited availability of traditional financing sources, were important to the reform process in Kenya, they appeared to be largely of a secondary nature (Karekezi and Mutiso, 2000; Nyoike, 2002). The primary impetus clearly emanated from the World Bank which was - and continues to be - the champion of power sector reform in the country. Many of the reform initiatives in Kenya's electricity industry have been started by the World Bank's Power Development Projects.

Major legal and regulatory revisions in Kenya's power sector are relatively recent with the bulk of the changes taking place between 1995 and 1998. The key changes in the power sector institutions and laws in Kenya are contained in a new electricity law, the Electric Power Act (EPA), Number 11 of 1997. In principle, the liberalization of the sector allows for both local and foreign equity participation.

Vertical unbundling of Kenya Power and Lighting Company (KPLC), a de facto vertically integrated power utility, was implemented in 1997. KPLC's generation assets were separated from its distribution and transmission facilities. Its power generation assets and those of other main power companies in Kenya were transferred to a newly formed Kenya Electricity Generating Company (KenGen), ahead of its privatisation. KenGen together with independent power producers (IPPs) are now in charge of power generation and sale to KPLC while KPLC's function is confined to transmission and distribution.

Under these reforms, the roles of key players in the power sector have been restructured. KPLC, which owns all transmission and distribution assets, buys electricity in bulk from generating companies for transmission, distribution and retail to customers. KenGen manages and develops all former public power electricity generating facilities ${ }^{2}$. Independent Power Producers (IPPs) build, own and operate power stations and sell the power in bulk to KPLC. Liberalisation of electric power generation has now seen market entry by four IPPs most of which supply thermal power emanating from diesel

\footnotetext{
${ }^{2}$ Prior to 1997, electric power assets were under Kenya Power Company (KPC) and several other organisations. Since its incorporation, KenGen took stewardship of the assets of KPC and Tana River Development Company (TRDC), another fully government owned body that developed Kindaruma, Gitaru and Kamburu Power Stations. Other generating facilities now under KenGen are: Kipevu Gas Diesel and Thermal Power Stations, small hydro stations in upper Tana, Masinga and Kiambere power stations formerly owned by Tana and Athi Rivers Development Authority (TARDA), Turkwel Power Station formerly owned by Kerio Valley Development Authority (KVDA), Nairobi Gas turbine, and Garissa and Lamu diesel power stations. KenGen is currently generating approximately 90 percent of the total capacity available in the country. IPPs generate the rest. A small percentage is still being imported from Uganda.
} 
generating sets to the grid ${ }^{3 .}$ Two of these became operational in 1997 with a combined capacity of $87 \mathrm{MW}$. A third IPP has an operating capacity of $12 \mathrm{MW}$ and hopes to increase it to $64 \mathrm{MW}$ by July 2003 and the fourth had its 74MW medium speed diesel plant operational in August 2001. Electricity Regulatory Board (ERB) reviews electricity tariffs and enforces safety and environmental regulations in the power sector as well as safeguarding the interests of electricity consumers (Nyoike, 2002). Lastly, the Ministry of Energy formulates public policy on the energy sector, in addition to administering the Rural Electrification Scheme.

\section{Renewable Energy Policies, Reforms and CDM}

The current installed capacity for electric power in Kenya is about 810MW (Karekezi and Mutiso, $2000)$. The sources of electricity include hydro (75\% share), thermal/diesel $(20 \%)$ and geothermal (approximately 5\%). Development of renewable energy is a key plank in Kenya's economic reforms as it responds to government policy to diversify sources of energy using indigenous resources. While traditional biomass provides over $70 \%$ of the primary energy requirements for Kenya, the government in liberalizing the energy sector sets up policies for increasing energy security through an increased role of modern, new supply technologies based on solar, wind, biomass, geothermal, and small hydropower. Adoption of RE technologies such as solar home systems, improved biomass stoves (specially the Kenya ceramic jiko) and biogas units) has been largely successful in Kenya. This has been mainly due to efforts by donor programmes and private dealers in developing local capacities in component assembly and in installation, repair and maintenance. As in other developing economies, however, the key threats to the success are the unrealistic political promises or plans for rural electric grid extension and subsidies on kerosene.

The potential for increased grid-based renewable electric power generation is high. For instance, it is estimated that the country's total installed capacity of geothermal-based electricity could increase from the current level of $45 \mathrm{MW}$ at the Ol-Karia plant to about 320MW by the year 2015 (Karekezi and Mutiso, 2000: p. 86). Wind energy is used on a limited scale, but given the recent KPLC tests of wind turbines for on-grid generation and hybrid wind/diesel systems.

The EPA legislation provides a regulatory framework that allows IPPs and KenGen to generate and sell power to KPLC. So, in terms of grid-power generation from RE, the Kenyan electricity sector reforms offer potential for increased supply from agro-based biomass power (from sugar and tea processing industries), small hydropower for rural areas and geothermal power from the Rift Valley region of Olkaria. However, this potential may not be realised as the country has not developed detailed policies for grid-connected RE power generation (e.g., power transmission "wheeling", "banking" and direct power sells).

Kenya, perhaps more than any other country in the East Africa region, has the economic and financial infrastructure to seize CDM opportunities and operationalise them (Mazzoni, 2000). The finance sector (banks, credit societies, other financial institutions, insurance companies) is relatively robust and Kenyan industry is dynamic with strong links to the international business community. In addition, Kenyan industries seriously need investment in the areas that are particularly suited to CDM fuel-switching (particularly in the agro-processing sector), energy efficiency and power generation.

\footnotetext{
${ }^{3}$ The IPPs include IberAfrica in Nairobi, Westmont in Mombasa and Ormat Power at Olkaria.
} 
So far, several potential CDM projects in Kenya have been proposed and analysed. These include: solar home systems for rural electrification, installation of new geothermal generating capacity, and development of bagasse co-generation systems. Lastly, wind power for CDM could readily fit into two categories: first, as grid connected wind farms in high wind potential areas ${ }^{4}$ and also as wind-diesel hybrids for off-grid towns.

Lack of transparency in contract awards, cumbersome regulatory procedures and KPLC's potential to stifle competition are examples of outstanding and potential flaws in the Kenya's electricity sector reform structure and process. As noted by several analysts, IPP awards have been particularly controversial. Several international contractors have questioned the transparency of the awards (EIU, 1997). The method used in awarding the contracts has been a bone of contention between GoK and the IMF, with the latter arguing that the seven-year supply period was too short and the unit cost was on the higher side. On the crucial issue of competition, independent legal analysis of the Electric Power Bill indicates that substantial barriers to new entrants remain in the power market and that the licensing procedures are cumbersome. Furthermore, there are indications that power reforms in Kenya will result in the dominant utility, KPLC, retaining overall control of the transmission and dispatch centre. This is likely to stifle competition and substantially reduce the perceived benefits of power sector reforms in general and to grid-based renewable electric power generation.

Kenya ratified the UNFCCC on 30th August 1994, but is yet ratify the Kyoto Protocol. In terms of institutional infrastructure for CDM projects, the country has already established a National CDM Clearinghouse $(\mathrm{NCCH})$ within the Ministry of Environment and Natural Resources. The NCCH evolved out of the office that was set up for Activities Implemented Jointly (AIJ). Unfortunately, during the AIJ pilot phase no projects were put forward for approval and an opportunity for gaining valuable experience of the procedures for project implementation was lost. This time, however, there is considerable determination to seize the opportunity for attracting foreign investment in the country. It is intended that the Clearinghouse will (a) serve as the executive arm of all CDM activities in the country; and (b) be responsible for carrying out the first project appraisal to check that the projects reflect the Kenyan development priorities and contribute to the country's sustainable development priorities and goals.

\section{Conclusion}

The clean development mechanism of the Kyoto Protocol provides additional incentives to grid-based renewable energy project development in developing countries. Though the electricity sale to the grid remains the principal source of project revenues, the sale of emission reduction credits is an additional revenue stream for renewable-based power projects.

\footnotetext{
${ }^{4}$ Two grid-connected pilot wind systems totaling $650 \mathrm{~kW}$ are in place. In 1988, the Belgium Government provided the Ministry of Energy (MoE) with 3 Windmaster turbines for demonstration purposes: grid-connected in Ngong Hills outside Nairobi $(2 \times 200 \mathrm{~kW})$, and an isolated diesel grid in Marsabet (150 kW in conjunction with 100/200 kVA gensets). An appraisal of output of both demonstration unit installations by the Ministry of Energy and KPLC shows that the performance of the wind turbines was successful in both Ngong and Marsabet. The Ngong wind generators recovered their investment costs (based on electrical output) within 6 years whilst the units in Marsabet recovered costs in terms of saved diesel. Due to the success of these pilots and interest in wind power investment by potential IPPs, the government has invested substantial resources in preparation of a national wind map.

${ }^{5}$ KenGen and KPLC operate small $(<1 \mathrm{MW})$ independent off-grid thermal power stations in remote District administrative headquarters. The costs of purchasing and transporting fuel, and of operating and maintaining these diesel units is more than US $\notin 30$ per $\mathrm{kWh}$, and is presently cross-subsidised by urban electricity consumers through a "fuel levy". Since most of the above sites are in the high-wind areas of the country, and since the demonstration wind generator in Marsabet proved financially viable, installation of wind generators in combination with the diesel sets would be attractive in consideration of both financial benefits and reduced carbon emissions.
} 
The structure of the power industry affects the development of grid-based renewable energy projects. In countries with pre-competitive electricity markets such as Kenya and the Philippines, there exist significant market entry barriers to private sector renewable energy projects. The on-going reforms in these countries partly address entry barriers though technical and market rules are yet to be elaborated and defined in these countries. In Chile where wholesale competition has been introduced for more than a decade, entry barriers have been significantly reduced leading to the development of grid-based CDM renewable energy projects. 


\section{References}

CNE, 2003. http://www.cne.cl

EIU (1997). Country Report - Kenya: $1^{\text {st }}$ Quarter, Economist Intelligence Unit, London, UK.

Gagler Bailly Services, Inc., 1997. "Case Studies of the Effects pf Power Sector Reform on Energy Efficiency". Prepared for: USAID/Office of Energy, Environment and Technology. Arlington, Virginia.

Gray, Tom (1995) Remote renewables in Chile. http://ibrary.wustl.edu/^listmgr/devel-1/Aug 1995/0109.html

Gutiérez, L. E. (1996). "How do Sub-Saharan African Utilities Compare". In Proceedings of Symposium on Power Sector Reform and Efficiency Improvement in SubSaharan Africa, World Bank, Washington DC, USA.

Harmelink, M. and Soffe, P. 2001. Financing and Financing Mechanisms for Joint Implementation Projects in the Electricity Sector, Ecosecurities and Ecofys, UK and the Netherlands.

Heer, L. 2003. Factor's Experience with CERUPT Projects in India. Presentation materials presented in the second regional workshop of the ASEM-ASEAN Green IPP Network, Roskilde, Denmark, March 2003.

INE, 2003. http://www.ine.cl

Karekezi, S. and Mutiso, D. (2000). "Power Sector Reform: A Kenyan Case Study", in J.K. Turkson (ed.) Power Sector Reform in SubSaharan Africa. MacMillan Press Ltd, Basingstoke, UK, p. 83120.

Mazzoni, O. (September 2000), "The Clean Development Mechanism: Harmonising the potential of business with sustainable development requirements of Kenya", Imperial College of Science and Technology, University of London

Newton-Small, Jay (2001) Chile joins the renewable energy bandwagon. The Earth Times. http://www.climateark.org/articles/2001/4th/chjoinsr.htm

Nyoike, P. (2002). Is the Kenyan electricity regulatory board autonomous? Energy Policy 30 (11/12): 987-997

Republic of Kenya (1997). Kenya Gazette Supplement No. 61: The Electric Power Bill, Government Printer, Nairobi, Kenya, 25 August.

UNEP Collaborating Centre on Energy and Environment, 2002. "The Clean Development Mechanism (CDM)". ISBN: 87 -550-386-6

World Bank (1997). Energy Sector Reform and Power Development Project, Staff Appraisal Report Kenya, World Bank, Eastern and Southern Africa Department. 21 May. 


\title{
Allocation of emission rights - economic incen- tives for emission reductions of $\mathrm{CO}_{2}$ in developing regions
}

\author{
Tobias A. Persson and Christian Azar \\ Department of Physical Resource Theory, \\ Chalmers University of Technology and Göteborg University, \\ SE-412 96 Göteborg, Sweden; \\ E-mail: frttp@fy.chalmers.se
}

\begin{abstract}
The economic impacts on developing regions following three allocation approaches are estimated through the use of an energy-economy systems model. Both an equal per capita allocation and a contraction allocation with convergence of the per capita emissions by 2050 is shown to give an economic incentive for developing countries to accept binding emissions target under a $450 \mathrm{ppm}$ carbon dioxide stabilization scenario. The revenues from emissions trading are estimated to be higher than the cost for changing the energy system. A contraction allocation with convergence of the per capita emissions by the end of this century, on the other hand, is estimated to generate net social loss for most developing countries.
\end{abstract}




\section{Introduction}

International negotiations on the control of greenhouse gas emissions have so far, not reached consensus on the issue of commitments beyond the first period (2008-2012). The allocation of emission rights for subsequent commitment periods must be acceptable for most countries, both developed and developing, and encourage US-re-engagement. A proposal must thus deal with issues such as: equity, environmental effectiveness, and economic efficiency. Several allocation principles have been suggested and analyzed in the literature (see for example by Beckerman and Pasek, 1995; Harvey, 1995; Gupta and Bhandari, 1999; Azar, 2000; Baer et al. 2000; Meyer, 2000; Neumayer, 2000; Philibert, 2000; Torvanger and Ringius, 2000; Berk and den Elzen, 2001).

Representatives, especially from developing countries, have argued that given the high past emissions, the developed countries have the responsibility for the climate change problem and should therefore bear the brunt of emission reductions. On the other hand, the senate in US adopted a resolution (S.RES. 98) in 1997 stating that the US would not accept any binding reduction targets under the UN framework convention on climate change, in the absence of meaningful developing country participation. The unilateral focus on industrialized countries was also one of the prime reasons that George W. Bush invoked when stating that the US would withdraw from the Kyoto Protocol.

Stringent absolute targets are probably not acceptable for developing countries in the near term due to the expected effects on economic development. The emission rights allocated to developing countries must, hence, be generous enough so as to provide financial incentives for these countries to join. The drawback with this is that too lax targets for developing counties could lead to the introduction of large amounts of tropical hot air into the international trading regime.

We have evaluated quantitative allocation approaches leading to a stabilization of the atmospheric concentration of carbon dioxide at $450 \mathrm{ppm}$. The allocation approaches evaluated are the following:

- Equal per capita - emission rights are proportional to population.

- Contraction and convergence 2050 - emission rights are allocated on the basis of a convergence of per capita emissions in year 2050 under a contracting global emission profile.

- Contraction and convergence 2100 - emission rights are allocated on the basis of a convergence of per capita emissions in year 2100 under a contracting global emission profile.

\section{The need for developing country participation}

Figure 1 shows the $\mathrm{CO}_{2}$ emissions from North (industrialised countries) and South (developing countries). The $\mathrm{CO}_{2}$ emissions in North are assumed to be reduced by one percent per year after the first commitment period (2010). Until 2050, the emissions are, thus, reduced by 45 percent compared to today (the emissions in 2010 are 5 percent lower than in 2000). The $\mathrm{CO}_{2}$ emissions in South are assumed to follow the EIA reference scenario until 2020 (EIA, 2002), thereafter the emissions are assumed to grow by 3 percent per year (the emissions in the EIA reference scenario grows by $3-3.5$ percent per year between year 2000 and 2020). The figure also shows the emission trajectory leading to atmospheric stabilization at $450 \mathrm{ppm}$ (derived as the average of the WRE and SRES $450 \mathrm{ppm}$ scenarios) and the total emissions from North and South including deforestation.

In Figure 1, one can see that the $\mathrm{CO}_{2}$ emissions in South surpass those of North rather soon, around 2010. The emissions from only developing countries are actually estimated to pass the emission profile for the $450 \mathrm{ppm}$ stabilization target by 2035. Thus, to stabilize the atmospheric carbon dioxide concentration at $450 \mathrm{ppm}$, some developing countries have to begin to abate their emissions the coming decades.

On a per capita basis, global emissions have to drop from around 1.1 tonC capita ${ }^{-1} \mathrm{yr}^{-1}$ today, to approximately 0.8 tonC capita ${ }^{-1} \mathrm{yr}^{-1}$ by 2050 under a $450 \mathrm{ppm}$ stabilization profile. For the EU, this 
means that the per capita emissions in a contraction and convergence 2050 regime has to be reduced from around 2.2 tonC capita ${ }^{-1} \mathrm{yr}^{-1}$ to 0.8 tonC capita ${ }^{-1} \mathrm{yr}^{-1}$ by 2050 to be domestically in compliance with an equal per capita allocation scheme in that year. In the same scheme, the emissions in the South are allowed to increase from 0.5 to 0.8 tonC capita $\mathrm{yr}^{-1}$. On the other hand, if trade in emission rights take place between South and North, one might expect higher emissions in the North and lower emissions in the South.

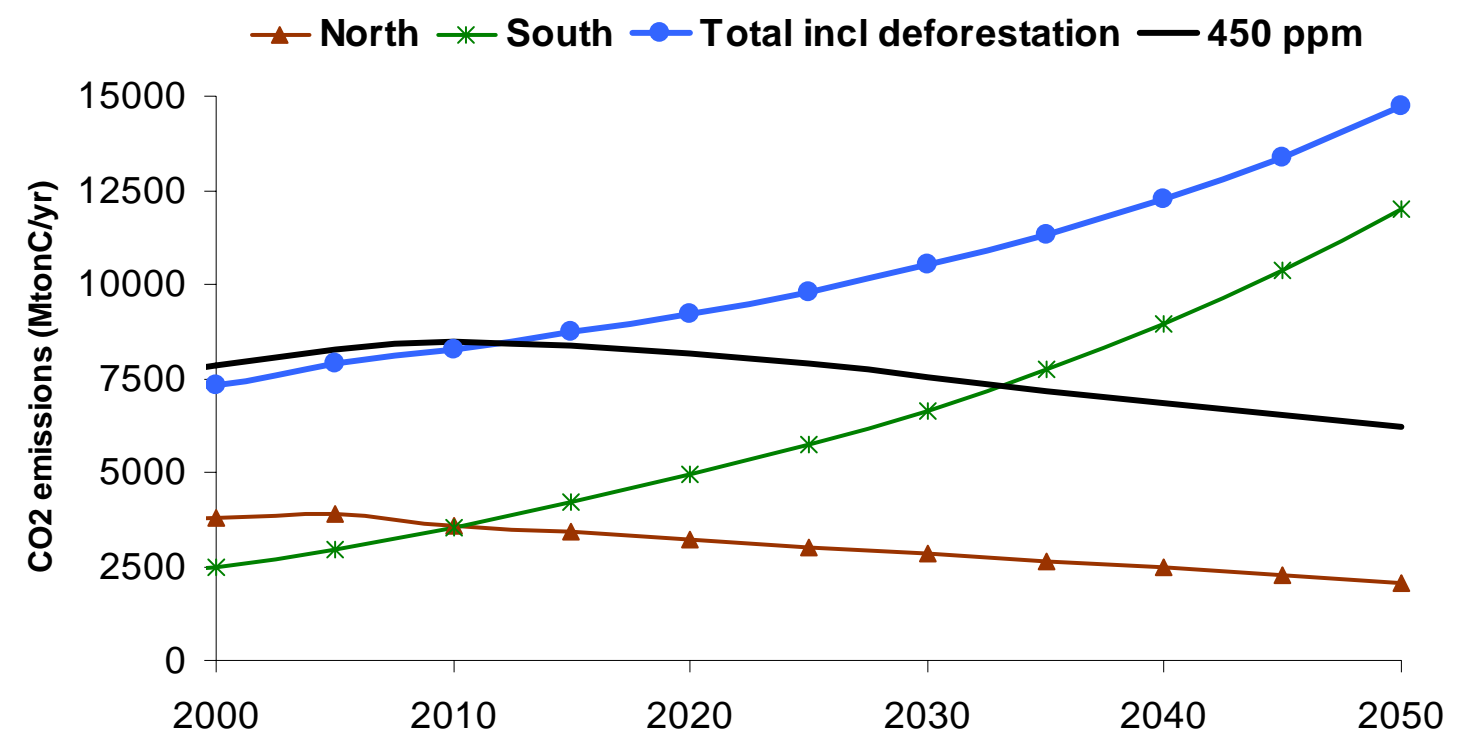

Figure 1. Total emissions including deforestation compared to a $450 \mathrm{ppm}$ stabilization profile (derived as the average of the WRE and SRES 450 ppm scenarios). The carbon dioxide emissions in North (the industrialised countries) are assumed to be reduced by 1 percent per year (on a linear basis), while the emissions in South follows the EIA reference scenario until 2020 and grows by 3 percent per year thereafter

\section{Methodology}

\subsection{Allocation of emission permits}

In this paper, three long-term allocation approaches are evaluated for industrialised and developing regions: (i) equal per capita, (ii) contraction and convergence in 2050, and (iii) contraction and convergence in 2100. The global climate regime is assumed to begin in year 2020. Before that the $\mathrm{CO}_{2}$ emissions in Annex B countries follow the commitments in the Kyoto Protocol while non-Annex B emissions follow a reference scenario.

Two different convergence years are compared, 2050 (see Figure 2) and 2100 (see Figure 3), respectively. The per capita emission rights are assumed to follow linear trends from the regions' per capita emission level by 2010 towards an equal per capita allocation by the convergence year. The per capita emission rights are then assumed to follow the equal per capita emission profile towards the atmospheric stabilization target assumed in this paper: $450 \mathrm{ppm}$. However, linear trends do not exactly generate the allowed emission profile leading to the stabilization targets of $450 \mathrm{ppm}$. The emission rights that correspond to the difference between the linear trends and real emission profile are equally distributed to the regions on a per capita basis. Only carbon dioxide from the energy system is considered in the analyses. 


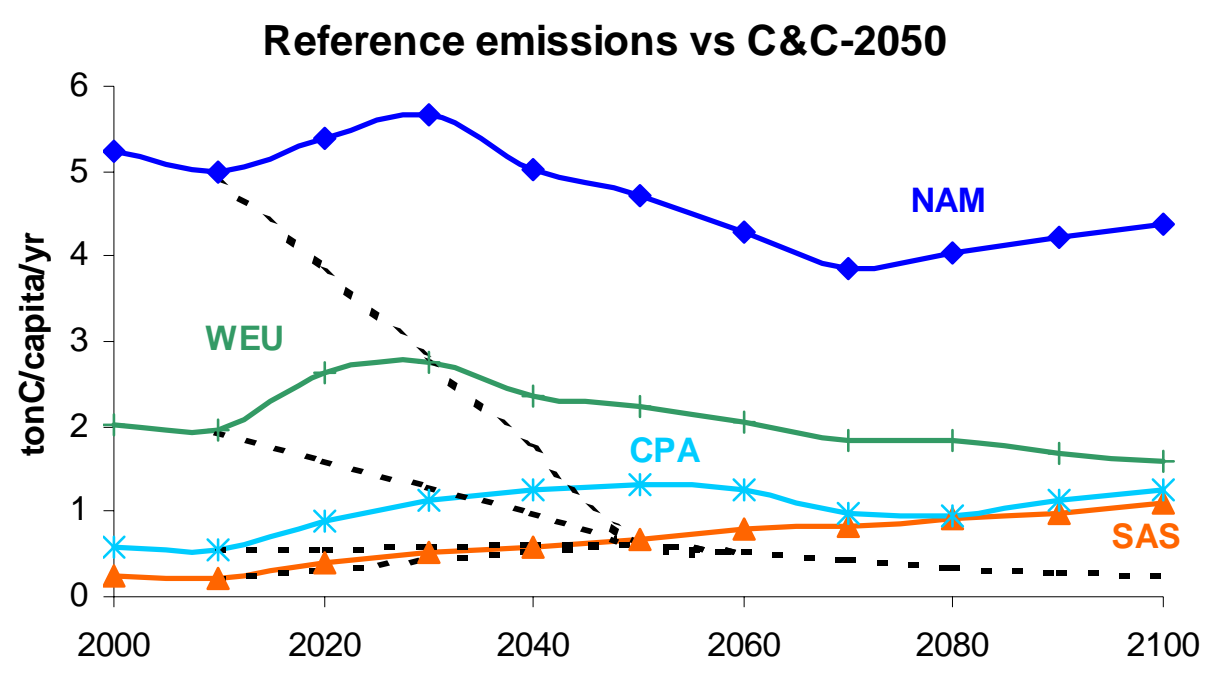

Figure 2. Carbon emissions on a per capita basis from the combustion of fossil fuels. The dashed line is an example of contraction and convergence $(C \& C)$ allocation with convergence of the per capita emissions in year 2050 under the assumption that the atmospheric $\mathrm{CO}_{2}$ concentration is stabilized at $450 \mathrm{ppm}$. This allocation is compared to the reference scenario emissions from our energy system model GET-R 2.0 for four regions North America (NAM), Western Europe (WEU), Centrally Planned Asia (CPA) and South Asia (SAS)

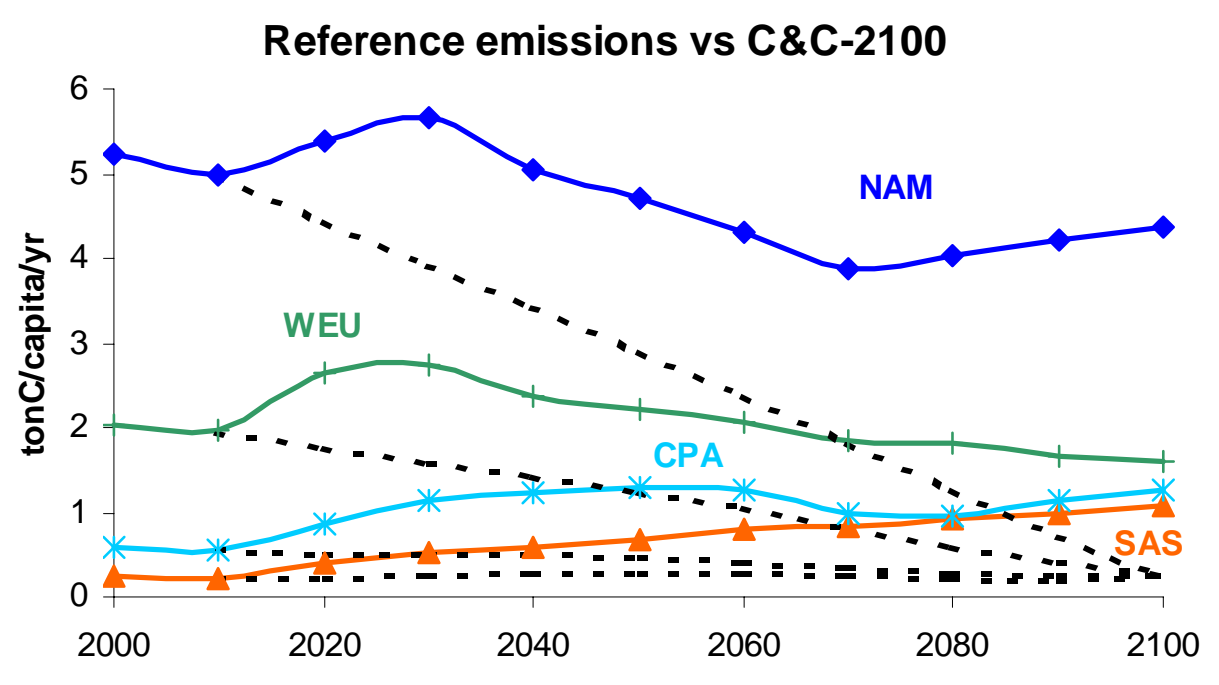

Figure 3. Carbon emissions on a per capita basis from the combustion of fossil fuels. The dashed line is an example of contraction and convergence $(C \& C)$ allocation with convergence of the per capita emissions in year 2100 under the assumption that the atmospheric $\mathrm{CO}_{2}$ concentration is stabilized at $450 \mathrm{ppm}$. This allocation is compared to the reference scenario emissions from our energy system model GET-R 2.0 for four regions North America (NAM), Western Europe (WEU), Centrally Planned Asia (CPA) and South Asia (SAS)

\subsection{The energy economy model}

GET-R 2.0, a global energy-economic model, is a non-linear version of the GET-R 1.0 model (see Grahn, 2002, and Azar et al., 2003, for details) with eleven regions: North America (NAM), Western Europe (WEU), Pacific OECD (PAO), Former Soviet Union (FSU), Central and Eastern Europe 
(EEU), Africa (AFR), Other Pacific Asia (PAS), Latin America (LAM), Centrally Planned Asia including China (CPA), and South Asia (SAS). The model is a LP model with elastic energy demand and with perfect foresight. The energy demand is endogenous for three end-use sectors - transportation fuel, electricity and direct fuel.

In GET_R 2.0, $\mathrm{CO}_{2}$ emissions can be reduced by reducing the energy demand, by carbon capture and storage and by fuel switching, i.e., by either expanding the production of non carbon emitting energy sources such as wind, biomass and hydro, or shifting from fuels with high carbon-to-energy ratios (such as coal) to fossil fuels with lower carbon-to-energy ratios (such as natural gas).

\section{Results: Trade in carbon permits and costs}

In this section, we present results from our analysis of the equal per capita and contraction and convergence allocation approaches. The atmospheric concentration of $\mathrm{CO}_{2}$ is assumed to be stabilized at $450 \mathrm{ppm}$. The target is met in a cost-effective manner, i.e., the carbon price is the same in all regions. This determines how much abatement takes place in each region and thus the demand and supply of permits.

In the beginning of the trading regime, a huge carbon surplus is generated in almost all developing regions when the emission rights are allocated on an equal per capita basis (Figure 4), especially in regions with presently low per capita emissions like South Asia (SAS) and Africa (AFR). The industrialised regions are the buyer of these emission rights.

In a contraction and convergence approach, the amount of carbon surplus in developing regions is reduced (Figure $5 \& 6$ ). For example, the number of emission rights SAS receives in an Equal per Capita allocation with the long-term stabilization target $450 \mathrm{ppm}$ is almost $1500 \mathrm{MtC}$ in 2020 which could be compared to 560 and 385 in our C\&C-2050 and C\&C-2100 allocation schemes, respectively.

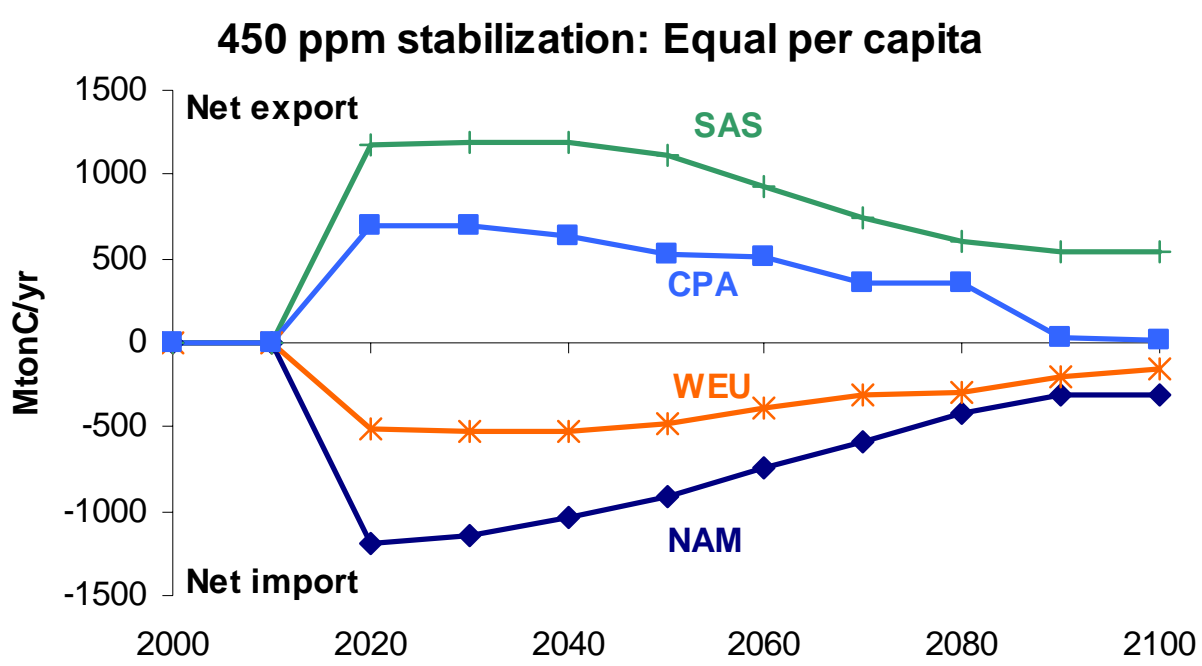

Figure 4. Trade in permits in an equal per capita allocation regime stabilizing the $\mathrm{CO}_{2}$ concentration at 450 ppm. Four regions are shown: Centrally Planned Asia (CPA), South Asia (SAS), Northern America (NAM) and Western Europe (WEU) 


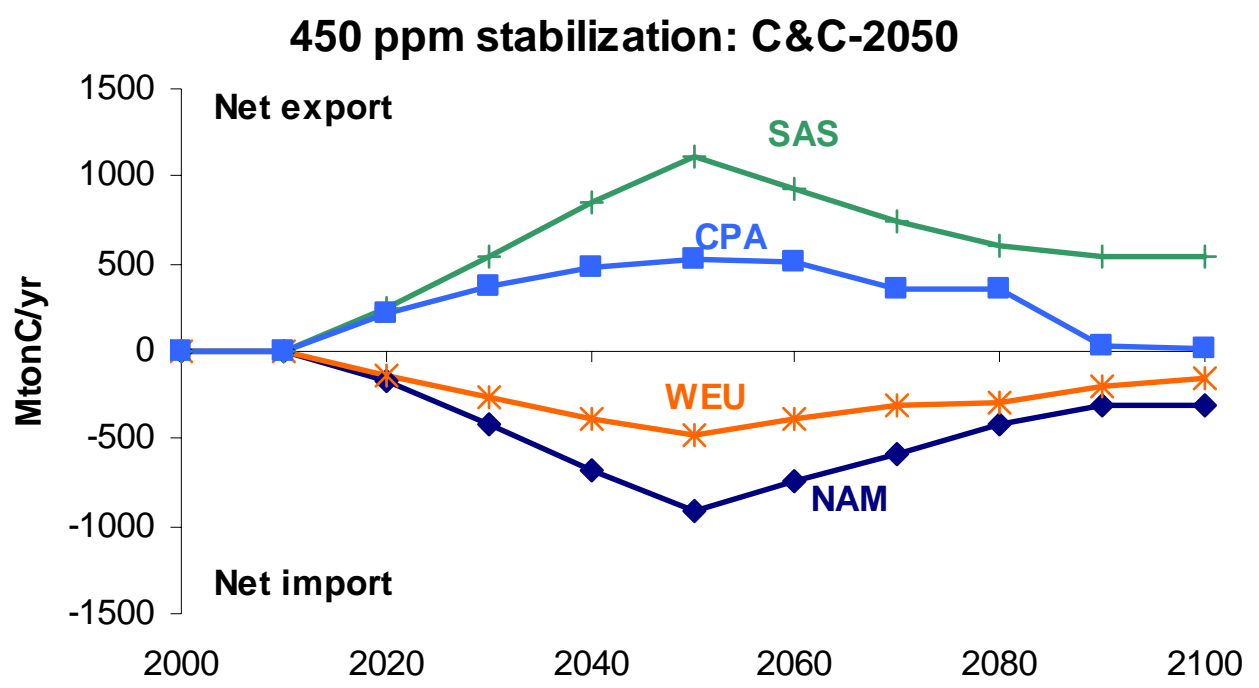

Figure 5. Trade in permits in a Contraction and Convergence allocation regime with convergence by 2050 (C\&C-2050) stabilizing the $\mathrm{CO}_{2}$ concentration at 450 ppm. Four regions are shown: Centrally Planned Asia (CPA), South Asia (SAS), Northern America (NAM) and Western Europe (WEU)

\section{0 ppm stabilization: C\&C-2100}

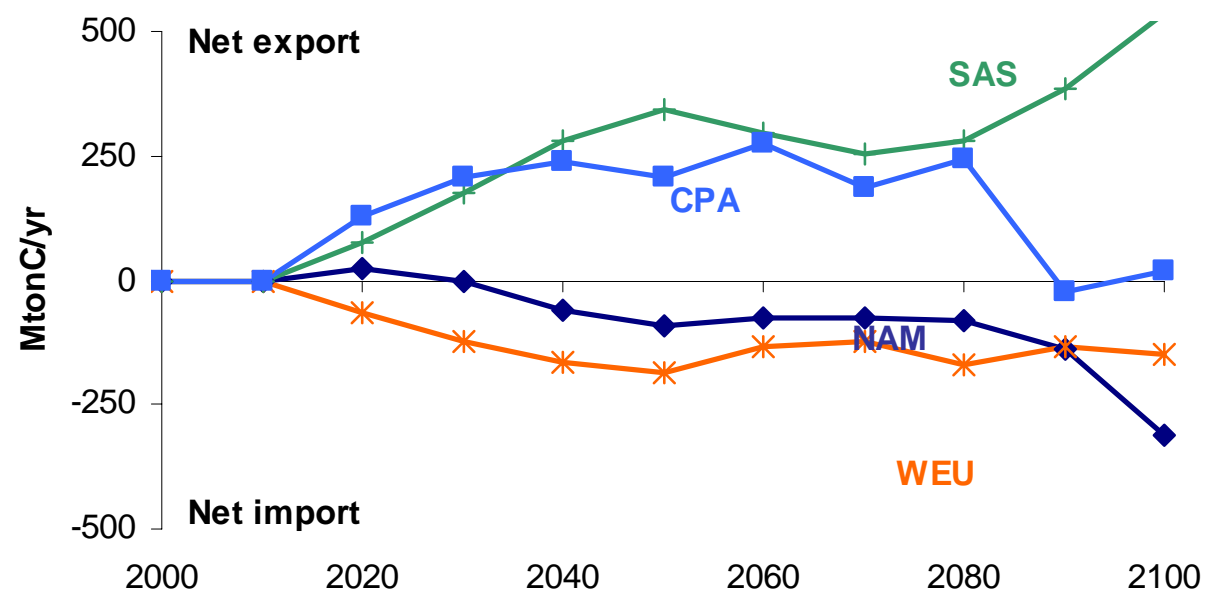

Figure 6. Trade in permits in a Contraction and Convergence allocation regime with convergence by 2100 (C\&C-2100) stabilizing the $\mathrm{CO}_{2}$ concentration at 450 ppm. Four regions are shown: Centrally Planned Asia (CPA), South Asia (SAS), Northern America (NAM) and Western Europe (WEU)

Whether the developing regions will gain or not from trading of permits, depends on how the emission rights are allocated. The carbon permit price is assumed to grow by 3 percent per year from roughly 60

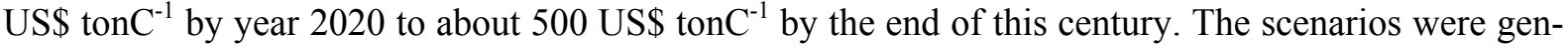
erated under the assumption that the atmospheric $\mathrm{CO}_{2}$ stabilization target ( $450 \mathrm{ppm}$ in our analysis) should be met while the net social payoff was maximized, calculated as net present value costs discounted with a discount rate of 5 percent $\mathrm{yr}^{-1}$.

The revenues to developing countries from the trade of carbon dioxide emission rights, to the price mentioned above, increases up to a few percent of the expected GDP during the middle of this century. In absolute numbers the financial flow is highest around 2070-2090, when the number of traded emission rights is still substantial and the permit price is higher than during the first decades. 
On the other hand, lower carbon emissions will entail costs since more expensive energy technologies are required, which results in a reduction of the consumers' and producers' surpluses. The total present value of future abatement costs is estimated to be around 2500 billion US\$ for reaching the $450 \mathrm{ppm}$ target, (this value is comparable to other estimates, see chapter 8 of Working Group III of latest IPCC assessment, IPCC, 2001).

The net social loss, including costs or benefits from emissions trading, to stabilize the atmospheric $\mathrm{CO}_{2}$ concentration at $450 \mathrm{ppm}$ as a fraction of expected GDP levels is shown in Figure 7, 8 and 9. During the first decades, the revenues from the sales of emission permits are higher than the carbon mitigation costs for almost all developing regions (especially for the less developed countries) under an equal per capita or a contraction and 2050 convergence allocation approach. This indicates that these two allocation approaches could offer significant economic incentives for the developing countries to join the regime.

A contraction regime with convergence by the end of this century, on the other hand, is estimated to generate a net social loss for all developing regions. If the developing regions will be sellers in our contraction and convergence 2100 regime that stabilize the atmospheric $\mathrm{CO}_{2}$ concentration at 450 ppm, the regions emissions on a per capita basis have to decrease compared to present levels ${ }^{1}$. The revenues from emissions trading are smaller than in the two other more generous allocation schemes. The mitigation costs are, often, higher than the revenues from the emissions trading.

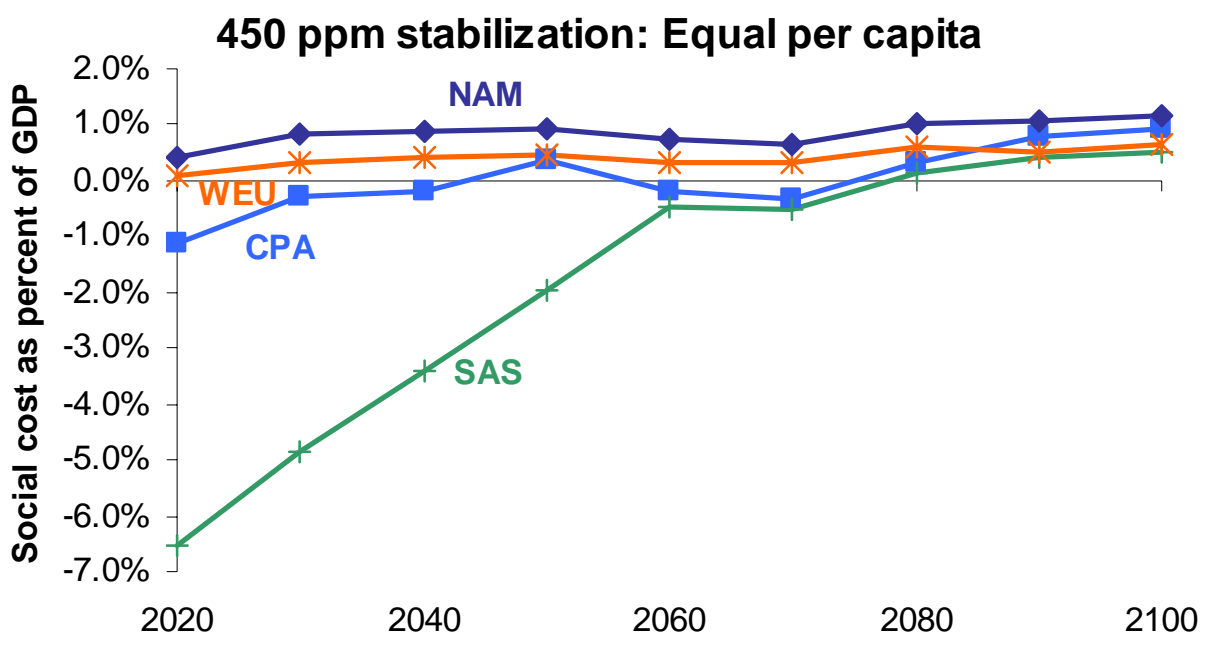

Figure 7. Net social cost (including costs for emissions trading) in an equal per capita allocation regime stabilizing the $\mathrm{CO}_{2}$ concentration at $450 \mathrm{ppm}$. Four regions are shown: Centrally Planned Asia (CPA), South Asia (SAS), Northern America (NAM) and Western Europe (WEU)

\footnotetext{
${ }^{1}$ This is only true for the region as a whole. There are some developing countries, especially in Africa that is allowed to increase the per capita emissions in the contraction and convergence 2100 regime.
} 


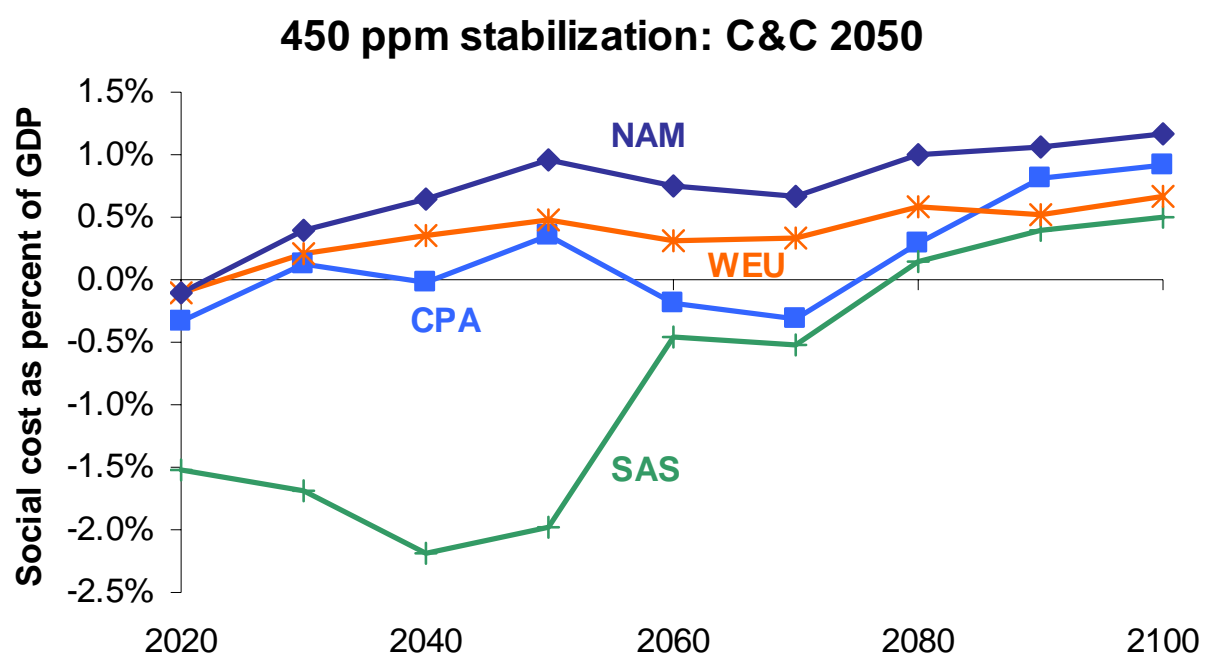

Figure 8. Net social cost (including costs for emissions trading) in a Contraction and Convergence allocation regime with convergence by 2050 (C\&C-2050) stabilizing the $\mathrm{CO}_{2}$ concentration at 450 ppm. Four regions are shown: Centrally Planned Asia (CPA), South Asia (SAS), Northern America (NAM) and Western Europe (WEU)

450 ppm stabilization: C\&C 2100

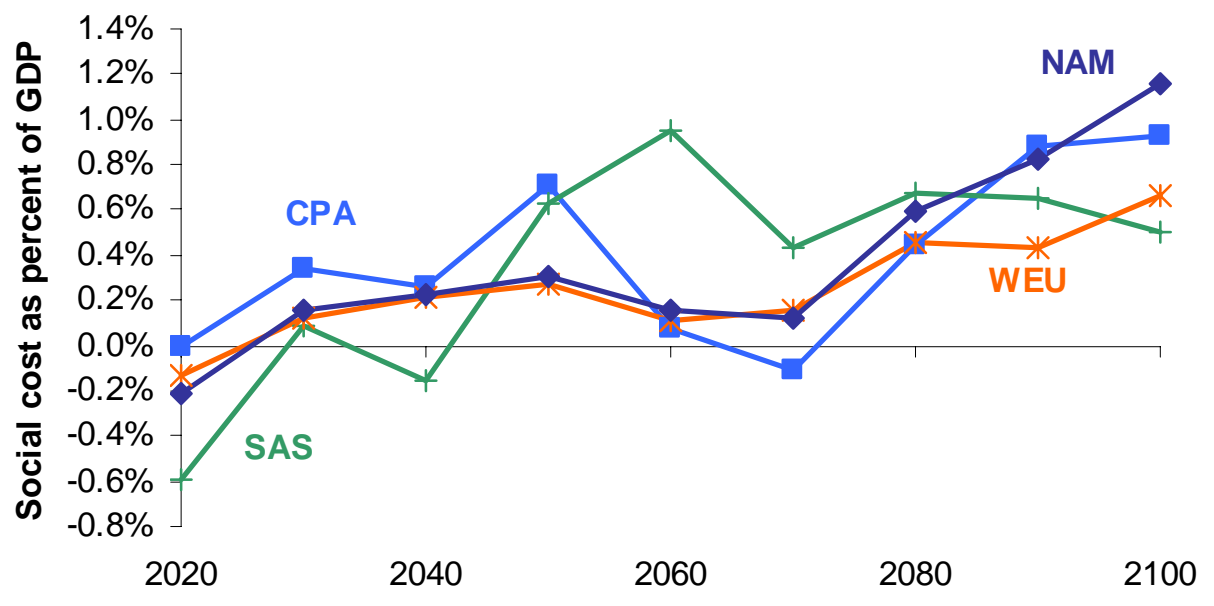

Figure 9. Net social cost (including costs for emissions trading) in a Contraction and Convergence allocation regime with convergence by $2100\left(C \& C\right.$-2100) stabilizing the $\mathrm{CO}_{2}$ concentration at 450 ppm. Four regions are shown: Centrally Planned Asia (CPA), South Asia (SAS), Northern America (NAM) and Western Europe (WEU)

\section{Discussion and conclusions}

Economic analyzes, show that the economic cost of stabilizing the atmospheric concentration of $\mathrm{CO}_{2}$ will be lower if developing countries adopted abatement targets under the United Nations Framework Convention on Climate Change already from the beginning. However, since it is the developed countries that have caused most of the emissions so far, they should bear the main costs, at least in the ini- 
tial phase. This could be done by offering a generous allocation of emissions rights to developing countries for the coming decades, maybe along the lines sketched in this paper.

In this paper, the equal per capita and the contraction and convergence allocation approaches have been evaluated for a $450 \mathrm{ppm}$ stabilization of the atmospheric $\mathrm{CO}_{2}$ concentration. The developing countries are assumed to have commitments from 2020.

An equal per capita allocation would generate a huge flow of money to the developing countries. A contraction and convergence approach may also be used as an economic incentive for developing countries to accept quantitative commitments. However, it depends on the convergence year and how the emission rights are allocated until the convergence year. Emission rights allocated with linear trends from the regions' per capita emission level by 2010 towards the convergence in 2050 could offer economic incentives for most developing countries to accept quantified commitments. The revenues from trading of permits are higher than the mitigation costs for several developing regions. On the other hand, with convergence by the end of this century, the cost of changing the energy system is higher than the revenues from emissions trading.

The results presented in this paper are part of an ongoing research project. In the near future, it will be extended with more extensive sensitivity analysis.

\section{Acknowledgements}

Maria Grahn and Kristian Lindgren are gratefully acknowledged for their development and regionalisation of the GET model. Financial support from the Swedish Energy Agency is gratefully acknowledged. Dean Abrahamson is acknowledged for comments on early manuscripts.

\section{References}

Azar C. (2000) Economics and distribution in the greenhouse, Climatic Change, 47, 233-238.

Azar C., K. Lindgren and B.A. Andersson (2003) Global energy scenarios meeting stringent $\mathrm{CO}_{2}$ constraints - cost-effective fuel choices in the transportation sector, Energy Policy, 31, 961-976.

Baer P., J. Harte, B. Haya, A.V. Herzog, J. Holdren, N.E. Hultman, D.M. Kammen, R.B. Norgaard and L. Raymond (2000) Equality and greenhouse gas responsibility, Science, 289, 2287.

Berk M.M. and G.J. den Elzen (2001) Options for differentiation of future commitments in climate policy: how to realise timely participation to meet stringent climate goals? Climate Policy, 1, 465480.

Beckerman W. and J. Pasek (1995) The equitable international allocation of tradable carbon emission permits, Global Environmental Change, 5, 405-413.

EIA (2002) International Energy Outlook, Energy Information Administration, DOE/EIA-0484(2002), Washington, DC, USA.

Grahn M. (2002) Global Energy Scenarios Meeting Stringent Climate Targets - A comparison between the Global Energy System Model GET 1.0 and the Regionalised Model GET-R 1.0, Master Thesis, Department of Physical Resource Theory, Chalmers University of Gothenburg and Göteborg University, Sweden.

Grübler A. and N. Nakićenović (1994) International burden sharing in greenhouse gas reduction, IIASA, Austria.

Gupta S. and P.M. Bhandari (1999) An effective allocation criterion for $\mathrm{CO}_{2}$ emissions, Energy Policy, 27, 727-736.

Harvey L.D.D. (1995) Creating a global warming implementation regime, Global Environmental Change, 5, 415-432. 
IPCC (2001) Climate change 2001 - Mitigation, Contribution of Working group III to the Third Assessment Report of the Intergovernmental Panel on Climate Change, Cambridge University Press, UK.

Meyer A. (2000) Contraction and convergence: The global solution to climate change. Schumacher Briefing No. 5, Greenbooks for the Schumacher Society, Bristol, USA.

Neumayer E. (2000) In defence of historical accountability for greenhouse gas emissions, Ecological Economics, 33, 185-192.

Philibert C. (2000) How could emissions trading benefit developing countries. Energy Policy, 28, $947-$ 956.

Torvanger A. and L. Ringius (2000) Burden differentiation: criteria for evaluation and development of burden sharing rules. The joint CICERO-ECN Project on Sharing of Burden of Greenhouse Gas Reduction Among Countries. CICERO working paper 2000:1, Oslo, Norway. 


\title{
The Role of the Clean Development Mechanism in Facilitating the Application of Biomass Re- newable Energy Technologies in Malaysia
}

\author{
Wong Hwee Kheng ${ }^{1}$ \& Jorgen Hvid ${ }^{2}$ \\ ${ }^{1}$ Pusat Tenaga Malaysia (Malaysia Energy Centre) \\ Level 8, Sapura@Mines \\ 7 Jalan Tasik, The Mines Resort City \\ 43300 Seri Kembangan, Selangor, MALYSIA \\ Tel: 603-89434300; Fax: 603-8941 1121 \\ ${ }^{2} R A M B O L L$ \\ Teknikerbyen 31, DK-2830 Virum, DENMARK \\ Tel: 454598 6000; Fax: 4545988515
}

\begin{abstract}
The Malaysian Government's move to ratify the Kyoto Protocol in September 2002 reaffirms the country's support to combat global climate change. Although Malaysia is not bound by any commitments to reduce its greenhouse gas emissions, the opportunities that exist through the Clean Development Mechanism (CDM) could be two-fold: to contribute to the country's sustainable development objectives and to improve the energy supply security through the application of clean energy technologies such as renewable energy technologies.

Malaysia is very dependent on fossil fuel based technologies for electricity generation and energy production. In 2001 almost $90 \%$ of the total energy input to power stations was derived from fossil fuels. Although the energy mix will continue to be predominantly based on fossil fuels, indigenous renewable energy resources may come to play it's a noticeable role in complementing the depleting fossil fuels.

This paper focuses on how best to utilize the oil palm residues for electricity generation and energy production as these residues are the 'low hanging fruits' that are readily available. It compares the use of two different technological uses of the residues: distributed power generation and co-firing with coal in large-scale power plants. The paper analyses the financial, economic and environmental impacts of these technologies, and it discusses the relative benefits of the technologies. In addition, the paper looks into the barriers associated with each of the technologies, and it suggests possible policy interventions to be adopted in order to promote a viable and environmentally efficient use of the limited biomass resources.
\end{abstract}




\section{Introduction}

Over the last two decades, pragmatic energy policies introduced by the Government have facilitated a more environment-friendly energy development path. The four-fuel strategy adopted in the early 1980s has accelerated the transition from oil to natural gas in the electricity generation sector. As a result natural gas has made dramatic inroads as the preferred fuel in the electricity industry, rising from $1.2 \%$ of the total fuel mix in 1980 to $72 \%$ in 2001 (Figure 1). While the general energy policy thrust for the next ten years remains unchanged, concerted efforts will be made to usher the energy sector development on a greener path. Since domestic fossil fuel resources (oil, gas and coal) are depletable, efforts to promote renewable energy will be intensified in the period (2001-2005). In addition, the Government has set a target that $5 \%$ of the total fuel mix or 600 MW (Koh \& Hoi, 2002) should be derived from renewable energy sources by 2005. In this regard, the Government has identified oil palm residues as the biggest source of renewable energy that can be easily developed.

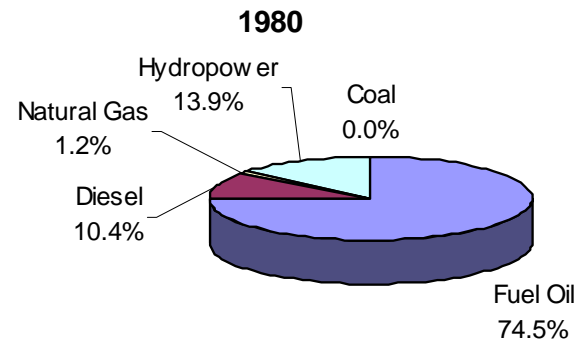

Total: 2,762 ktoe

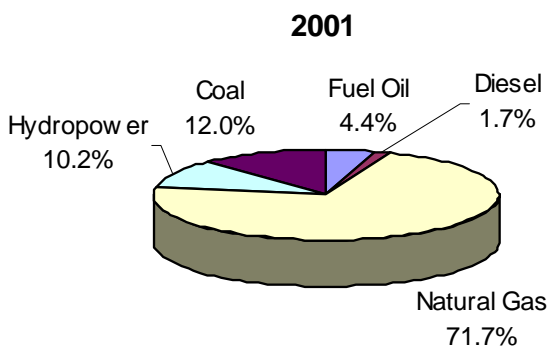

Total: 16,611 ktoe

Source: Ministry of Energy, Communications and Multimedia, Malaysia (1980 and 2001)

\section{Figure 1. Fuel Mix in Power Stations in Malaysia}

The Malaysian palm oil industry generates abundant and readily available amounts of residues during the harvesting (fronds), replanting (trunks and fronds) and milling processes (fruit fibres, shells and empty fruit bunches). After the oil has been extracted from the fresh fruit bunches (FFB) in the mills, significant amounts of residues are generated. These residues are either recycled back to the field as fertilizer, burned as fuel to generate steam and electricity for the mill's own use, disposed or sold to entrepreneurs who convert the residues into value-added products. During replanting of oil palms and harvesting of fresh fruit bunches, huge amount of biomass residues such as fronds and trunks are generated. These resources have not been tapped as fuel because the mills currently have more than sufficient biomass residues to generate electricity for their own use.

Based on the growing energy demand and Government policies to promote and encourage the utilisation of renewable energy resources, there will be opportunities to apply the Clean Development Mechanism (CDM) in the Malaysian energy sector. The explicit purpose of the CDM is to assist developing countries with achieving sustainable development. This is in line with the national plan to ensure sustainable development of energy resources in meeting the energy demand of the economy (EPU, 2001). Furthermore, the transfer of environmentally safe technologies will be the central aspect in achieving sustainable development goals of the country.

In 2000, the total $\mathrm{CO}_{2}$ emissions in Malaysia were about 126 million tonnes (IEEJ, 2003). Malaysia's First Initial Communication (MOSTE, 2000) shows that approximately $68 \%$ or 97.8 million tonnes of the total greenhouse gas (GHG) emissions in 1994 were the result from energy development activities. Carbon dioxide emissions from the energy sector represented $86 \%$ of the total $\mathrm{CO}_{2}(97.7$ million tonnes) emitted in 1994.These figures clearly show that the energy sector is the single largest contributor to the country's greenhouse gas emissions. Hence, any policies and strategies to reduce the country's $\mathrm{CO}_{2}$ emissions should begin by considering mitigation options in the energy sector. Reduc- 
tion in $\mathrm{CO}_{2}$ emissions implies shifting the major technological and fossil fuel biases. New technologies such as gasification and pyrolysis have higher efficiencies and lower emissions (Gallagher, 2001). Moreover, global environmental concerns over emissions of $\mathrm{CO}_{2}$ have stimulated the growth of more environmentally benign technologies and cleaner fuels in electricity generation.

More efficient and sustainable practices in the energy sector will not only mitigate GHG emissions but will also contribute to economic development and environmental protection. Nevertheless, the high cost of new technologies would always be a major source of contention in developing countries, as the financial viability of applying such technologies would have to be justified.

\section{Objectives}

The aim of this paper is to assess the role of the CDM in facilitating the application of state-of-the-art renewable energy technologies with higher efficiencies. As Malaysia continues to advocate the promotion and utilisation of renewable energy there will definitely be a bigger scope to increase the share of renewable energy for heat and power generation. However, a number of barriers related to the implementation of renewable energy projects need to be overcome before renewable energy is attractive enough to gain a bigger market share. These barriers include among others, financial, technology and policy barriers.

With the ratification of the Kyoto Protocol by the Government, the Clean Development Mechanism (CDM) has now become a possible market-based instrument to improve the project viability of renewable energy projects in Malaysia. Although the impact of the CDM on project viability remains to be seen, there is anticipation that perhaps the CDM could, to a certain extent, help facilitate the application of renewable energy technologies in Malaysia.

Currently, the uptake of state-of-the art renewable energy technologies in the energy sector has been quite slow. Although the palm oil millers have been utilising oil palm residues for heat and power generation, these are carried out only on small-scale with rather low efficiency levels of about $3 \%$. Therefore, this paper aims to assess the role of the CDM in facilitating the application of renewable energy technologies with higher efficiencies. In addition, the environmental aspects of applying such technologies would also be discussed.

\section{Methodology}

The COMPEED (Comparative Techno-Economic Assessment of Energy Supply, Energy Demand and DSM Options) model is a cost-benefit analytical tool used to perform energy project analysis for various technology options (www.energianalyse.dk). This model was introduced as part of the 'Capacity Building in Integrated Resource Planning' Project in 2000, under the Malaysian-Danish Cooperation. In this Study, COMPEED is used to compare the economic costs of generation from a renewable energy plant with economic costs of a power system that is avoided. For example, the avoided cost could be from the central grid system, if the renewable energy plant is grid connected or from a stand-lone power system if the renewable energy plant is not connected to the electricity grid.

In the COMPEED model, economic, financial and environmental costs and benefits are aggregated over a particular planning period and discounted to arrive at a present value. This net present value (NPV) discounts any biases that may arise in comparing different projects as all future payments and incomes are discounted to present day value. The economic calculation involves the calculation of the cost that can be avoided if a renewable energy power plant replaces a conventional power plant in terms of capacity (MW) or energy (MWh). The economic analysis in COMPEED provides insights into the economic benefit of specific type of energy projects to the society. If the energy project is viable from an economic viewpoint, it could be argued that it should be also financially viable in order 
to make the project attractive. On the other hand, the financial analysis in COMPEED provides insight into the financial viability of the project from the perspective of the project developer. Externalities are not included in the analysis.

\subsection{Description of Case Studies}

A. Grid-connected Biomass Power Plant

This case study is based on a feasibility study of a small power producer whose core activity is to generate power for sale to the national grid. This power plant will apply a biomass technology at an efficiency of $21 \%$. A $5.2 \mathrm{MW}$ of firm capacity will be supplied to the national grid. A combination of shells and empty fruit bunches is used as fuel for power generation.

B. Co-firing of Biomass and Coal

This case study looks at the introduction of a co-firing technology at an existing $600 \mathrm{MW}$ coalfired power plant. Assuming an increase of heat rate of 15 percent on the biomass share by firing $10 \%$ of shells and empty fruit bunches, the overall thermal efficiency of the existing coal-fired power plant will be reduced from $34.5 \%$ to $34 \%$.

\section{Results}

\subsection{A. Grid-connected Biomass Power Plant}

The power plant is briefly described by the characteristics listed in Table 1 .

Table 1. Key Characteristics of the Grid-connected Biomass Power Plant.

\begin{tabular}{|l|l|}
\hline Gross power capacity & $6.0 \mathrm{MW}$ \\
\hline $\begin{array}{l}\text { Net power capacity (excludes internal } \\
\text { consumption) }\end{array}$ & $5.2 \mathrm{MW}$ \\
\hline Electrical efficiency & $21 \%$ \\
\hline Fuel & Oil palm residues - mostly empty fruit bunches \\
\hline Operation hours per year & 7,008 \\
\hline Investment cost & $7,100,000 \mathrm{US} \$$ \\
\hline Financing & $30 \%$ equity, $70 \%$ financing at $6 \%$ interest over 10 years \\
\hline Fuel costs & $3.2 \mathrm{US} \$$ /tonne \\
\hline Fuel calorific value & $1,750 \mathrm{kWh} /$ tonne \\
\hline
\end{tabular}

The results of the analysis show that the financial internal rate of return (FIRR) of the biomass-based power plant is $8.3 \%$ in real terms. The financial payback period for the power plant is 6.8 years. The return on the developer's investment - return on equity (ROE) is $12.1 \%$. This ROE would be considered insufficient to attract investors even if project risks - such as those associated with fuel supply security, technological reliability are deemed not high by investors. As long as the issue associated with fuel supply security remains, investors may still be hesitant to invest in this type of project even if the ROE is about $20 \%$.

Based on the electricity selling price of 4.4 US cents/kWh (fixed for 20years), the levelised selling price (adjusting the fixed price for inflation by 3\% per annum and NPV the revenue and amount of electricity sold during the 20 years by using a discount rate of $10 \%$ ) is 3.6 US cents $/ \mathrm{kWh}$. COMPEED analysis shows that the levelised avoided production cost to the utility system in 2004 is 3.5 US cents 
$/ \mathrm{kWh}$. This value includes the avoided capacity costs, energy costs and transmission and distribution losses. As the levelised selling price is about the same as the levelised avoided production cost, the fixed selling price of $4.4 \mathrm{US}$ cents $/ \mathrm{kWh}$ offered to the small plant developer could be considered as fair from the power utility's perspective.

The amount of Certified Emission Reductions (CERs) which a CDM project earns is determined from the quantity of $\mathrm{CO}_{2}$ emissions, which would otherwise be emitted if the CDM project were not implemented. The impact of the carbon credits generated through the CDM is analysed. Table 2 shows the effects of the electricity selling price following prices of CERs at the selected levels.

Table 2. Impact of the Carbon Credit Value on the Electricity Selling Price in Malaysia.

\begin{tabular}{|c|c|}
\hline Price of CER (US\$/tonne of $\left.\mathrm{CO}_{2}\right)$ & Power Sales Adder (US cents $/ \mathrm{kWh})$ \\
\hline 3 & 0.30 \\
\hline 5 & 0.50 \\
\hline 10 & 1.0 \\
\hline
\end{tabular}

The environmental analysis in the COMPEED Model calculates the amount of $\mathrm{CO}_{2}$ emissions that can be avoided when a renewable energy plant replaces the energy and capacity from a coal-fired plant in the central power generation system. It is assumed that power generation utilising renewable biomass resources produces a net $\mathrm{CO}_{2}$ emissions of zero.

If an externality adder in the form of CER under the CDM is added, the impact of the CDM on project viability can be calculated. The current market price for CER is between 3-5 US\$/ tonne of $\mathrm{CO}_{2}$ equivalent. Assuming that the value of CER is $5 \mathrm{US} \$ /$ tonne of $\mathrm{CO}_{2}$ and using of coal fired plants as the baseline, the ROE will increase from $12.1 \%$ to $17.6 \%$, a rise of $5.5 \%$, as shown in Table 3 . If the FIRR threshold is $15 \%$, the price of 10 US\$ /tonne of $\mathrm{CO}_{2}$ will not improve the project financially viability to the acceptable FIRR. However, the ROE will improve to above $20 \%$, which may be sufficient for an investor.

Table 3. Sensitivity Analyses Based on Different Prices of CERs

\begin{tabular}{|c|c|c|}
\hline $\begin{array}{c}\text { Price of CER } \\
\text { (US\$/tonne of } \mathbf{C O}_{\mathbf{2}} \text { ) }\end{array}$ & $\begin{array}{c}\text { Financial IRR } \\
\mathbf{( \% )}\end{array}$ & $\begin{array}{c}\text { Return on Equity } \\
\mathbf{( \% )}\end{array}$ \\
\hline 0 (base case) & 8.3 & 12.1 \\
\hline 3 & 10.1 & 15.5 \\
\hline 5 & 11.2 & 17.6 \\
\hline 10 & 13.8 & 22.9 \\
\hline
\end{tabular}

\subsection{B. Co-firing of Biomass and Coal}

A case study based on co-firing of empty fruit bunches from oil palms together with coal in centralised coal fired plant was investigated. The case involves installation of fuel storage, fuel treatment and feeding systems for the biomass to be fired together with the coal.

So far no cases of co-firing exist in South-East Asia, and therefore data of efficiencies and costs have been obtained from a review of United States cases (Hughes, 1998). The costs have been found to vary considerably in the United States from case to case. Furthermore, it is uncertain to what extent US price levels would apply in Malaysia. As a base case, the investment costs are assumed to be 180,000 US\$/MW of input fuel capacity.

It is assumed that an additional transportation cost of $3.4 \mathrm{US \$} /$ tonne is incurred due to the anticipated longer average transportation distances as compared to the small-scale power plant above.

The key characteristics for the co-firing power plant are shown in Table 4. 
Table 4. Key Characteristics of Co-Firing System.

\begin{tabular}{|l|l|}
\hline Total plant electricity generation capacity & $600 \mathrm{MW}$ \\
\hline Biomass share of input fuel & $10 \%$ \\
\hline Efficiency of power plant when using coal alone & $34.5 \%$ \\
\hline Efficiency of co-firing with biomass & $34.0 \%$ \\
\hline Co-firing fuel & Empty fruit bunches from palm oil production \\
\hline Fuel cost & $6.6 \mathrm{US} \$ /$ tonne \\
\hline Combustion value & $1,750 \mathrm{kWh} /$ tonne \\
\hline Investment costs for co-firing add-in & $180,000 \mathrm{US} \$ \mathrm{MW}$ of biomass input \\
\hline Annual operation hours & 6,570 \\
\hline Financing & $100 \%$ equity \\
\hline
\end{tabular}

The analysis shows that at the investment cost of 180,000 US\$/MW of biomass fuel input, the financial IRR is $5.4 \%$, while the ROE is $9.2 \%$ (Table 5).

A sensitivity analysis of the FIRR and ROE based on various investment costs is shown below.

Table 5. Financial IRR and ROE at Varying Investment Costs and CER Prices.

\begin{tabular}{|l|c|c|c|c|}
\hline & \multicolumn{4}{|c|}{ Investment Costs (US\$/MW of biomass input energy) } \\
\hline & 180,000 & 130,000 & 150,000 & 200,000 \\
\hline Without CER (base) & & & & \\
\hline FIRR & 5.4 & 9.2 & 7.4 & 4.3 \\
\hline ROE & 9.2 & 12.7 & 11.0 & 8.3 \\
\hline CER: 3 US\$/tonne & & & & 12.4 \\
\hline FIRR & 9.9 & 14.6 & 16.4 & 12.3 \\
\hline ROE & 13.6 & 18.9 & & \\
\hline CER: 5 US\$/tonne & & & 15.5 & 11.1 \\
\hline FIRR & 12.6 & 18.1 & 19.9 & 14.9 \\
\hline ROE & 16.6 & 22.9 & & \\
\hline CER: 10 US\$/tonne & & & 23 & 17.1 \\
\hline FIRR & 19.1 & 26.5 & 28.7 & 21.5 \\
\hline ROE & 23.9 & 33.1 & &
\end{tabular}

Table 5 shows that carbon credits could have a very significant impact on the project viability. At an investment cost of US\$180,000/MW and a credit value of $5 \mathrm{US} \$$ tonne of $\mathrm{CO}_{2}$, the FIRR increases from 5.4 to $12.6 \%$, - by approximately $7 \%$ - and the ROE increases from 9.2 to $16.6 \%$, also about $7 \%$. However, if investment costs are above US\$180,000/MW it is likely that credit value of US\$5/tonne is not sufficient to make the project viable. 


\section{Discussions}

\subsection{The Impact of Carbon Credits on the Promotion of Tech- nologies}

It appears from the above cases that CER revenue earned from the CDM could have a significant impact on the viability of biomass power projects being somewhat financially unviable on their own terms.

Results show that the co-firing case is more sensitive to the credit value than the grid-connected biomass power plant case. A main reason for this is to be found in the fact that the electricity conversion efficiency of the co-firing plant is $34 \%$ while that of the distributed generation plant is $21 \%$. An increase in the value of the power produced is therefore having a comparatively higher impact on the co-firing system.

There is reason to believe, therefore, that - all being equal - carbon credits would favour the more electricity efficient technologies as compared to more traditional low-efficient technologies.

\subsection{Economic Comparison of the Projects}

The economic analysis of the above projects show, that the economic IRR of the grid-connected biomass power plant is $10.7 \%$ in real terms. The unofficial national threshold for economic viability of public and power sector investments is $10 \%$, and the project is therefore viable even without including the environmental and other societal benefits of the project. It must be noted, however, that the viability is strongly depending on the fuel price. If in future the fuel price increases by $50 \%$ the economic IRR drops to $8.3 \%$.

The co-firing base case economic IRR is found to be $5.4 \%$, which is below the $10 \%$ threshold. Even at an investment cost of US $\$ 130,000 / \mathrm{MW}$ the IRR is $9.1 \%$ only.

\subsection{Non-financial barriers}

The successful uptake of renewable energy technologies depends on a number non-financial barrier that need to be overcome. One of these barriers is the negative perception on renewable energy associated with biomass combustion. This can be traced back from the practice in the existing oil palm mills where oil palm residues are burned inefficiently with the purpose of getting rid of as much oil palm residues as possible. Hence, combustion of biomass renewable energy often connotes a dirty and primitive practice (Koh \& Hoi, 2001).

One of the main barriers referred to by the developers as well as the financing institutions is the uncertainty related to biomass fuel supply and the future market price of the biomass fuel. It has been observed in many other countries that once a demand for biomass residues develops the market price of the fuel tend to increase. Demand can be generated from increased use of biomass for energy as well as industrial demand for the resource for non-energy purposes.

In the case of Malaysia a slow but steady growth in the demand for fibre from wood as well as from oil palm residues has been observed, and there is a concern in the industry that the market price may go up.

It has been observed that financing institutions tend to respond to this risk by requiring the existence of a long-term fuel supply contract. This has proven to be a major obstacle in several cases. In particular, the small players are supposed to be vulnerable to this risk since - in the absence of a developed market for biomass energy - they would have to depend on local supplies from a comparatively small number of suppliers.

There are also non-financial barriers related to the lack of local equipment suppliers and technical support services (Koh \& Hoi, 2001). Although the implementation of conventional technologies such as coal-fired and gas-fired power plants has led to a wealth of experience in this part of the power in- 
dustry, this is not true for companies in the renewable energy industry. There are insufficient support services for the users of renewable energy technology. In addition, Malaysia still relies on foreign equipment suppliers, as local suppliers of such technologies are not able to meet the needs of local customers. This increases the cost of project thus making renewable energy projects not feasible when compared to the larger power projects undertaken by Independent Power Producers and the incumbent national utility.

\subsection{Environmental Comparison of the Projects}

In view of the fact that the biomass resource is limited in Malaysia as well as in most other countries it should be a concern how to maximise the environmental benefits of using biomass resources.

The two case studies are both considered base load power plants. According to the Malaysian power development plans, future base load capacity will be mostly coal based (EPU, 2001). Therefore, both in both cases, coal could be substituted by biomass.

In the case of grid-connected biomass power plant, $\mathrm{CO}_{2}$ abatement amounts to $0.17 \mathrm{~kg} \mathrm{CO}_{2} / \mathrm{kWh}$ of biomass energy. In the co-firing case the $\mathrm{CO}_{2}$ abatement amounts to $0.30 \mathrm{~kg}$ of $\mathrm{CO}_{2} / \mathrm{kWh}$ of biomass energy. The difference comes as a result of the differences in conversion efficiency. The co-firing plant will provide an additional $40 \%$ of electricity per unit of biomass energy as compared to the gridconnected biomass power plant. Co-firing would also reduce $\mathrm{SO}_{\mathrm{x}}$ emission levels as biomass fuels contain much less sulphur than coal. $\mathrm{NO}_{\mathrm{x}}$ emissions would depend on the nitrogen content of the fuel (Coombes, 2002).

\section{Conclusion}

The CDM mechanism may be an important market-based instrument to promote the use of biomass energy in Malaysia, where the existing electricity pricing mechanisms are not conducive for a largescale use of biomass for power generation. Under a favourable environment such as the right pricing of CERs and support from the Government, CDM could support the uptake of renewable energy technologies. In addition, the revenue from the sales of CERs would favour more efficient technologies, as shown in this Study.

Efficient utilisation of indigenous renewable energy resources would assist the country in achieving sustainable energy development goals. Furthermore, there would be savings in foreign exchange as the country will be able to reduce its dependence on imported fossil fuels. There will also be reductions in local environmental problems such as those related to inefficient combustion of oil palm residues and their disposal problems.

The CDM mechanism tends to promote higher electricity conversion efficiencies, which may lead to a more effective use of the limited biomass resources.

However, non-financial barriers, which exist may hamper the uptake of biomass energy. This includes the lack of a secure supply of biomass fuel. Although fiscal measure such as tax incentives for utilisation of biomass has been introduced since 2001, there is generally still lack of interest and response from local companies. This calls for additional policy measures to be taken by the national government such as legislative, financial and administrative measures. 


\section{Acknowledgement}

This study was undertaken as one of the study components in the Malaysia-Danish Cooperation on 'Capacity Building in Integrated Resource Planning (IRP) at Government and Related Agencies', based at Pusat Tenaga Malaysia. The support of the IRP Supply Working Group members and Mr. Morten Blarke is gratefully acknowledged.

\section{References}

Blarke, M. (2001). Information on COMEED XL. http://www.energianalyse.dk

Coombes, P. (2002). Renewables and coal: Co-firing for greater efficiency. $8^{\text {th }}$ APEC Coal Flow Seminar, Kuala Lumpur.

Economic Planning Unit (EPU), Prime Minister's Department (2001). Eighth Malaysia Plan (20012005). Putrajaya, p 305-336.

Gallagher, G. (2001). Biomass for electricity generation. The Chemical Engineer November 2001. United Kingdom.

Hughes, E.E (1998). Utility coal-biomass cofiring test. Electric Power Research Institute (EPRI). United States. http://www.netl.doe.gov/publications/proceedings/98

Institute of Energy Economics Japan (IEEJ) (2003). Handbook of energy and economics statistics in Japan. The Energy Conservation Center, Japan. Tokyo.

Koh, M.P. and Hoi, W.K. (2002). Renewable energy in Malaysia: a policy analysis. Energy for Sustainable Development Volume VI No. 3 September 2002. The Journal for the International Energy Initiative. India, p 31-39.

Ministry of Energy, Communications and Multimedia, Malaysia (1980). National energy balance. Kuala Lumpur.

Ministry of Energy, Communications and Multimedia, Malaysia (2001). National energy balance. Kuala Lumpur.

Ministry of Science, Technology and the Environment (MOSTE), Malaysia (2000). Malaysia Initial National Communication. Kuala Lumpur, p 21-33. 


\title{
List of participians
}

\author{
$\underline{\text { Participants at }}$
}

\section{Last name}

\section{Afrane-Okese}

Andersen

Arndt

Basualdo

Bechgaard

Beck

Bøg

Boot

Borup

Bugge

Bünger

Busch

Christensen

Christensen

Diamantaras

Eisenbeiss

Engell

Engsig

Eriksen

Feidenhans'1

Fischer

Fonnesbech

Gaudernack

Giebel

Grahl-Madsen

Grahn

Haas

Hake

Hansen

Hansen

Heinesen

Heller

Hindsberger

Høstgaard-Jensen

Hvid

Jansdorf

Jensen

Jensen

Johansson

Jørgensen

Jørgensen

Kamel

Kara

Karottki

Kazim

Kjems

Knill

Koch

Kossmann

Kristensen

\section{First name}

Yaw

Per Dannemand

Mogens

Santiago

Klaus

Aksel

Rasmus

P.A.

Mads

Jørgen

Jan

Niels

John

Niels Peter

Komninos

Gerd

Thomas

Torben

Åge Bredahl

Robert

Joachim

Bjarke

Bjørn

Gregor

Laila

Maria

Reinhard

Jurgen-Friedrich

Lars

Ulf

Signar

Alfred

Magnus

Peter

Jørgen

Henrik

Bjarne Henning

Søren Højgaard

Mogens

Birte Holst

Martin

Sami

Mikko

Rene

Ayoub

Jørgen

Timothy

Hans Jørgen

Jens

Per Gravers

\section{Company}

University of Cape Town

Risø National Laboratory

ENERGI E2 A/S

Technical University of Denmark

Risø National Laboratory

Danish Energy Authority

Elkraft System a.m.b.a

Ministerie van Economische Zaken

Risø National Laboratory

Tech-wise

Danish Energy Authority

Busch \& Partners

UNEP Risø Centre

Geological Survey of Denmark and Greenland

European Commission

Forschungszentrum Jülich $\mathrm{GmbH}$

Carl Bro International A/S

Siemens A/S

Vitus Bering CVU

Risø National Laboratory

Institut for Energetik und Umwelt

The Society of Danish Engineers

Hydrogen Energi AS

Risø National Laboratory

IRD Fuel Cell A/S

Chalmers University of Technology

Technical University of Vienna

Forschungszentrum Juelich Gmb

Dansk Energi

Rostock University

Data Quality

Technical University of Denmark

ECON

Elsam A/S

RAMBØLL

Danisco A/S

Elsam A/S

Risø National Laboratory

Dansk Energi Analyse A/S

Risø National Laboratory

Siemens A/S

UNEP Risø Centre

VTT Processes

Ministry of Foreign Affairs

UAE University

Risø National Laboratory

Technical University of Denmark

Ministry of Economic and Buisness Affairs

Risø National Laboratory

Danish Gas Technology Centre

\section{Country}

South Africa

Denmark

Danmark

Denmark

Denmark

Denmark

Denmark

The Netherlands

Denmark

Danmark

Denmark

Denmark

Denmark

Denmark

Belgium

Germany

Denmark

Danmark

Denmark

Denmark

Germany

Denmark

Norway

Denmark

Denmark

Sweden

Austria

Germany

Denmark

Germany

Faroe Islands

Denmark

Danmark

Denmark

Denmark

Denmark

Denmark

Denmark

Danmark

Denmark

Danmark

Denmark

Finland

Denmark

United Arab

Emirates

Denmark

Denmark

Denmark

Denmark

Denmark 


\begin{tabular}{|c|c|c|c|}
\hline Lagerstedt & Kent & COWI & Denmark \\
\hline Larsen & Hans & Risø National Laboratory & Denmark \\
\hline Lemming & Jørgen & Danish Energy Authority & Denmark \\
\hline Lilholt & Hans & Risø National Laboratory & Denmark \\
\hline Linderoth & Søren & Risø National Laboratory & Denmark \\
\hline Lundsager & Per & Risø National Laboratory & Denmark \\
\hline Luxhøi & Fritz & Eltra & Danmark \\
\hline Lynov & Jens-Peter & Risø National Laboratory & Denmark \\
\hline Mackenzie & Gordon & UNEP Risø Centre & Denmark \\
\hline Madsen & Peter & Risø National Laboratory & Denmark \\
\hline Magtengaard & Jesper & DONG VE A/S & Denmark \\
\hline Majborn & Benny & Risø National Laboratory & Denmark \\
\hline Mathiesen & Jens & BankInvest & Denmark \\
\hline McDonald & Alan & IAEA & Austria \\
\hline Meibom & Peter & Risø National Laboratory & Denmark \\
\hline Meyer & Niels & Energitilsynet & Denmark \\
\hline Mogensen & Mogens Bjerg & Risø National Laboratory & Denmark \\
\hline Morishita & Masao & Tokyo Electric Power Co. & Japan \\
\hline Mortensgaard & Aksel & Danish Energy Authority & Denmark \\
\hline Morthorst & Poul Erik & Risø National Laboratory & Denmark \\
\hline Nakicenovic & Nebojsa & IIASA and VUT & Austria \\
\hline Neef & Hanns-Joachim & International Energy Agency & France \\
\hline Noppenau & Henrik & ENERGI E2 A/S & Denmark \\
\hline Nymark & Vivi & Risø National Laboratory & Denmark \\
\hline Olsen & Ole & Roskilde University & Denmark \\
\hline Øster & Flemming & Risø National Laboratory & Denmark \\
\hline Østergaard & Jacob & DEFU & Denmark \\
\hline Painuly & Jyoti Prasad & UNEP Risø Centre & Denmark \\
\hline Pålsson & Jens & Haldor Topsøe A/S & Denmark \\
\hline Pardo & Daniel & Technical University of Denmark & Denmark \\
\hline Pascual Alonso & José Luis & CIEMAT & Spain \\
\hline Pedersen & Aksel Hauge & DONG & Denmark \\
\hline Pedersen & Allan Schrøder & Risø National Laboratory & Denmark \\
\hline Pedersen & Thomas Engberg & COWI A/S & Denmark \\
\hline Perrette & Lionel & INERIS & France \\
\hline Persson & Tobias & Department of Physical Resource Theory & Sweden \\
\hline Petersen & Erik & Risø National Laboratory & Denmark \\
\hline Petersen & Jon Wulff & Risø National Laboratory & Denmark \\
\hline Petersen & Leif & Risø National Laboratory & Denmark \\
\hline Poireau & Michel & European Commission & Belgium \\
\hline Qvale & Björn & Dept. of Mech. Engineering & Denmark \\
\hline Radka & Mark & UNEP & France \\
\hline Raghavan & Madhan & Goa University & India \\
\hline Rasmusen & Hans Jørgen & DONG & Denmark \\
\hline Rasmussen & Flemming & Risø National Laboratory & Denmark \\
\hline Reijnders & Jos & NOVEM & The Netherlands \\
\hline Rise & Søren & Dansih Standards Association & Denmark \\
\hline Rogat & Jorge & UNEP Risø Centre & Denmark \\
\hline Rosendahl & Lis & Risø National Laboratory & Denmark \\
\hline Rosenfeldt Jakobsen & Klaus & Elkraft System a.m.b.a. & Danmark \\
\hline Sathaye & Jayant & Lawrence Berkeley National Lab. & USA \\
\hline Siddiqi & Dr. & Global Environment \& Energy in the 21st Century & yUSA \\
\hline Skytte & Klaus & Risø National Laboratory & Denmark \\
\hline Stærkind & Kaj & Danish Energy Authority & Danmark \\
\hline Steck & Cecilia & Risø National Laboratory & Denmark \\
\hline Thomsen & Anne Belinda & Risø National Laboratory & Denmark \\
\hline Töpfer & Executive Director & UNEP & Kenya \\
\hline Van Kuik & Gijs & Delft University of Technology & The Netherlands \\
\hline Wamukonya & Njeri & UNEP Risø Centre & Denmark \\
\hline West & Keld & Risø National Laboratory & Denmark \\
\hline
\end{tabular}


Yamba

Zacchi

Zeltins
Francis D.

Guido

Namejs
Centre for Energy

Lund University

Institute of Physical Energetics LAS
Zambia

Sweden

Latvia 
Title and authors

Energy Technologies for Post Kyoto Targets in the Medium Term

Proceedings

Risø International Energy Conference

Risø National Laboratory 19 - 21 May 2003

Edited by Leif Sønderberg Petersen and Hans Larsen

\begin{tabular}{ll}
\hline ISBN ISSN & ISN
\end{tabular}

$87-550-3203-6$

0106-2840

87-550-3205-2 (Internet)

\begin{tabular}{lc}
\hline Department or group & Date
\end{tabular}

Risø National Laboratory $\quad$ September 2003

\begin{tabular}{ll}
\hline Groups own reg. number(s) & Project/contract No(s)
\end{tabular}

Sponsorship

\begin{tabular}{llll}
\hline Pages & Tables & Illustrations & References
\end{tabular}

419

Abstract (max. 2000 characters)

The Risø International Energy Conference took place 19 - 21 May 2003 and the aim was to present and discuss new developments and trends in energy technologies which may become main contributors to the energy scene in 15 to 20 years. The conference addressed R\&D related to the individual technologies as well as system integration.

The proceedings are prepared from papers presented at the conference and received with corrections, if any, until the final deadline on 25 June 2003.

Descriptors INIS/EDB

BIOMASS; COGENERATION; ELECTRIC POWER; ENERGY SOURCE DEVELOPMENT;

ENERGY SYSTEMS; ENVIRONMENTAL IMPACTS; FORECASTING; FOSSIL FUELS;

FUEL CELLS; HYDROGEN-BASED ECONOMY; MARKET; MEETINGS;

SOLAR ENERGY; TECHNOLOGY UTILIZATION; WIND POWER 